\title{
INTEGRACIÓN DE LA MODELACIÓN DE LA CALIDAD DEL AGUA EN UN SISTEMA DE AYUDA A LA DECISIÓN PARA LA GESTIÓN DE RECURSOS HÍDRICOS.
}

\author{
Doctorando: \\ Javier Paredes Arquiola \\ Directores: \\ Joaquín Andreu Álvarez \\ Miguel Martín Monerris \\ UNIVERSIDAD POLITÉCNICA DE VALENCIA \\ Escuela Técnica Superior de Ingenieros de Caminos Canales y Puertos \\ Departamento de Ingeniería Hidráulica y Medio Ambiente
}

Octubre de 2004 

A mi mujer María y a mis hijos Inés y Álvaro. 



\section{AGRADECIMIENTOS}

A mis tutores D. Joaquín Andreu Álvarez y D. Miguel Martín Monerris por su dedicación y trabajo que han posibilitado el desarrollo de esta tesis doctoral. Me gustaría mostrar un especial agradecimiento a D. Joaquín Andreu Álvarez por todo el esfuerzo, medios y ánimo que ha puesto, en los últimos años, en mi formación y desarrollo como profesional.

A la Comission of the European Communities por su financiación a través del proyecto "Water resources Management Under Drought Conditions, WAM-ME", contrato ICA3.1999.00014 (Directorate General XII Science, Research \& Development); y del proyecto "SEDEMED - Sécheresse et Desertification dans les bassins méditerranées", ref. 2002-02-4.4-1084 (INTERREG III B-Mediterranée Occidentale).

Al Ministerio de Educación y Cultura de España por su financiación a través de la Comisión Interministerial de Ciencia y Tecnología, CICYT mediante el proyecto "Desarrollo de Elementos de un Sistema Soporte de Decisión para la Gestión de Recursos Hídricos", contrato HID1999-0656 y el proyecto "Sistema de apoyo a la decisión para la gestión cuantitativa, cualitativa y ambiental de cuencas hidrográficas", referencia REN2002/03192.

A mis compañeros del Grupo de Ingeniería de Recursos Hídricos del Instituto de Ingeniería del Agua y Medio Ambiente de la Universidad Politécnica de Valencia por la colaboración prestada.

A todo el personal técnico de la Confederación Hidrográfica del Júcar por la información y los datos proporcionados que han hecho posible la elaboración de esta tesis doctoral.

Por último agradecer a mi familia, a mis padres y hermanos, la comprensión que han mostrado frente a mi trabajo y dedicación. Quiero agradecer a mi mujer la comprensión, ayuda y animo que me ha dado, sin ella mi trabajo no tendría sentido. 



\section{RESUMEN}

La calidad del agua en los sistemas naturales y en particular en las aguas continentales influye en la salud de los ecosistemas acuáticos así como en los diferentes posibles usos del recurso hídrico. Por otro lado una adecuada gestión de los recursos hídricos es uno de los factores principales para el uso eficiente del agua y, en consecuencia, para alcanzar un desarrollo sostenible que proporcione un equilibrio entre el hombre y el medio ambiente.

Históricamente ambos conceptos, la calidad y la gestión del agua, han sido tratados científica y administrativamente de forma separada. Pocos son los desarrollos sobre simulación y optimización de sistemas de recursos hídricos que tienen en cuenta la calidad del agua. En la gestión de los recursos tan solo en momentos en que la calidad del agua supone un serio limitante en la utilización del recurso se considera su importancia y normalmente como una reducción de la misma.

En los últimos años existe un aumento de la importancia de los aspectos ambientales en la conciencia social y en la legislación, como refleja la última directiva europea sobre política de aguas (UE, 2000). Esto tiene como consecuencia que la gestión y la planificación de los recursos hídricos se tenga que realizar, en un futuro próximo, bajo los objetivos de eficiencia y protección del entorno. Para ello, ambas materias deben ser entendidas como una sola e inseparable.

En esta tesis doctoral se ha desarrollado un módulo o herramienta para la modelación de la calidad de sistemas de recursos hídricos. Esta herramienta funciona en coordinación con el Sistema Soporte de Decisión (SSD) AQUATOOL, desarrollado previamente por el DIHMA de la Universidad Politécnica de Valencia, para la planificación y gestión de sistemas de recursos hídricos.

El programa GESCAL permite la modelación de la mayor parte de los constituyentes convencionales como son la temperatura, el oxígeno disuelto, el ciclo del nitrógeno, el fósforo en sus distintas formas, el fitoplancton y otros contaminantes arbitrarios definidos por el usuario. Con ello el usuario puede abarcar muchos de los problemas actuales de la calidad del agua. La modelación de la calidad se realiza tanto en tramos de río como en embalses, pero se considera también la influencia del resto de elementos del sistema en los que no se considera la modelación. Con ello se tiene una herramienta que permite modelar de forma conjunta la gestión y la calidad de sistemas de recursos hídricos.

La validez y utilidad del desarrollo han sido demostradas mediante su aplicación a la cuenca del río Júcar. La simulación de diferentes alternativas del modelo realizado ha permitido, entre otras cosas, evaluar la evolución de la calidad en todo el sistema frente a distintos escenarios de distribución del recurso en la cuenca, analizar el efecto sobre la calidad del sistema de futuras infraestructuras de depuración y estimar caudales de dilución para la mejora medioambiental en los puntos críticos de la cuenca. 



\section{RESUM}

La qualitat de l'aigua en els sistemes naturals i en particular en les aigües continentals influïx en la salut dels ecosistemes aquàtics així com en els diferents possibles usos del recurs hídric. Per un altre costat una adequada gestió dels recursos hídrics és un dels factors principals per a l'ús eficient de l'aigua $i$, en conseqüència, per a aconseguir un desenvolupament sostenible que proporcione un equilibri entre l'home i el medi ambient.

Històricament ambdós conceptes, la qualitat i la gestió de l'aigua, han sigut tractats científica i administrativament de forma separada. Pocs són els desenvolupaments sobre simulació i optimització de sistemes de recursos hídrics que tenen en compte la qualitat de l'aigua. En la gestió dels recursos tan sol en moments en què la qualitat de l'aigua suposa un seriós llimitant en la utilització del recurs es considera la seua importància i normalment com una reducció del mateix.

En els últims anys hi ha un augment de la importància dels aspectes ambientals en la consciència social i en la legislació, com a reflexa l'última directiva europea sobre política d'aigües (UE, 2000). Açò té com a consequiència que la gestió i la planificació dels recursos hídrics s'haja de realitzar, en un futur pròxim, davall els objectius d'eficiència i protecció de l'entorn. Per a això ambdós matèries han de ser enteses com una sola i inseparable.

En esta tesi doctoral s'ha desenvolupat un mòdul o ferramenta per a la modelació de la qualitat de sistemes de recursos hídrics. Esta ferramenta funciona en coordinació amb el Sistema Suport de Decisió (SSD) AQUATOOL, desenvolupat prèviament pel DIHMA de la Universitat Politècnica de València, per a la planificació i gestió de sistemes de recursos hídrics.

El programa GESCAL permet la modelació de la major part dels constituents convencionals com són la temperatura, l'oxigen dissolt, el cicle del nitrogen, el fòsfor en les seues distintes formes, el fitoplàncton i altres contaminants arbitraris definits per l'usuari. Amb això l'usuari pot comprendre molts dels problemes actuals de la qualitat de l'aigua. La modelació de la qualitat es realitza tant en trams de riu com en embassaments però es considera també la influència de la resta d'elements del sistema en els quals no es consideran la modelació. Amb això es té una ferramenta que permet modelar de forma conjunta h gestió i la qualitat de sistemes de recursos hídrics.

La validesa i utilitat del desenvolupament han sigut demostrades per mitjà de la seua aplicació a la conca del riu Xúquer. La simulació de diferents alternatives del model realitzat ha permés, entre altres coses, avaluar l'evolució de la qualitat en tot el sistema enfront de distints escenaris de distribució del recurs en la conca, analitzar l'efecte sobre la qualitat del sistema de futures infraestructures de depuració i estimar cabals de dilució per a la millora mediambiental en els punts crítics de la conca. 



\begin{abstract}
Water quality in natural systems and, specially, inland water systems influences on the health of water ecosystems and on the different possible uses. An appropriate management of water resources is one of the main factors for the efficient use of the water, and as consequence, for the sustainable development that allows the equilibrium between human life and the environment.
\end{abstract}

Historically, both concepts, water quality and the management of water resources, have been considered scientifically and legally separately. Few developments have been done over simulation and optimization of the water resources systems taking into account the quality aspect. Only when the quality of the water is a limitation for the use it is considered in the management of the resource, and usually as a reduction of the available resource.

In the last years, a growth of environmental aspects on the social conscience and the legislation has been developed, as it reflects the European Water Framework Directive (UE, 2000). Consequently the planning and management of the water resources will be done, in the immediately future, under efficiency and environmental protection goals. For this, both fields must be understand as one and inseparable.

In this thesis a module for modeling the quality of water resources systems has been developed. This tool works coordinately with the Decision Support System (DSS) AQUATOOL, developed previously by the DIHMA of the Polytechnic University of Valencia, for the planning and management of the water resources systems.

The program GESCAL allows to model the grand majority of the conventional constituents such as: temperature, dissolved oxygen, nitrogen cycle, different forms of phosphorous, phytoplankton, and several arbitrary contaminants defined by the user. The user can deal with much of the current water quality problems. The program allows to model water quality in rivers and reservoirs but considers, also, the influence of the other elements of the system, which water quality is not modeled. GESCAL is a module for modeling conjunctively the management and the quality of water resources systems.

The utility of the module has been demonstrated with the application to the Jucar river basin. The simulation of different alternatives of the developed model has allowed, among others, to evaluate the evolution of the water quality in all the system facing different scenarios of the use of the resource in the basin, to analyze the effect on the water quality of the future water treatment facilities, and to estimate additional flows for improving the quality of the water at critical points of the basin. 



\section{Índice General de la Tesis}

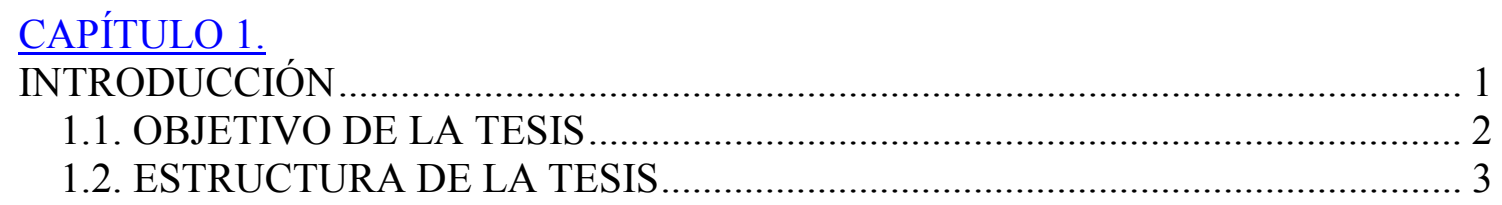

\section{CAPÍTULO 2.}

ESTADO DEL ARTE 5

2.1. HERRAMIENTAS DE MODELACIÓN DE SISTEMAS DE RECURSOS HÍDRICOS.

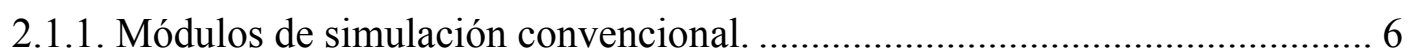

2.1.2. Módulos basados en redes de flujo................................................................. 6

2.2. EVOLUCIÓN DE LA MODELACIÓN DE LOS CONTAMINANTES

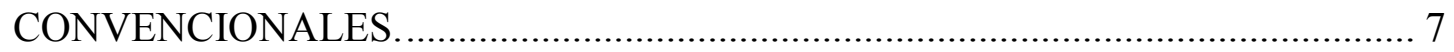

2.2.1. Modelación de la temperatura …………………………………………...... 7

2.2.2. La modelación del oxígeno disuelto y la eutrofización................................... 9

2.3. HERRAMIENTAS PARA LA MODELACIÓN DE LA CALIDAD DE LA

CALIDAD DEL AGUA................................................................................. 11

2.3.1. Herramientas para la modelación de la calidad del agua en ríos................... 12

2.3.2. Herramientas para la modelación de la calidad del agua en lagos y embalses.

2.3.3. Herramientas para la modelación de la calidad del agua en ríos y lagos. .... 17

2.3.4. Modelación tipo Caja. ............................................................................... 17

2.3.5. Modelación conjunta de cantidad y calidad del agua................................... 18

CAPÍTULO 3.

EL ENTORNO DE DESARROLLO AQUATOOL................................................... 23

3.1. DESCRIPCIÓN DE AQUATOOL. …………………....................................... 23

3.2. CONDICIONANTES DE SIMGES SOBRE EL MÓDULO DE MODELACIÓN

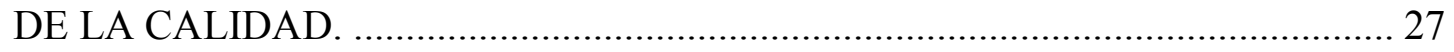

CAPÍTULO 4.

FORMULACIÓN Y DESARROLLO DE LA HERRAMIENTA DE MODELACIÓN.

4.1. INTRODUCCIÓN

4. 2. SUBRUTINAS Y ESTRUCTURA DEL PROGRAMA. ……………………..... 31

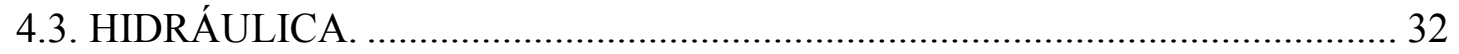

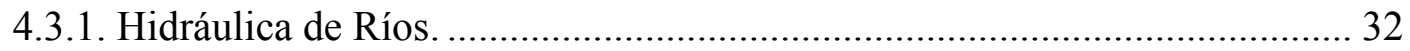

4.3.2. Hidráulica de Embalses ............................................................................ 34

4.4. CONSTITUYENTES, REACCIONES Y RELACIONES................................. 36

4.4.1. Modelación de la calidad en tramos de río ................................................... 36

4.4.2. Modelación de la calidad en embalses. ..................................................... 46

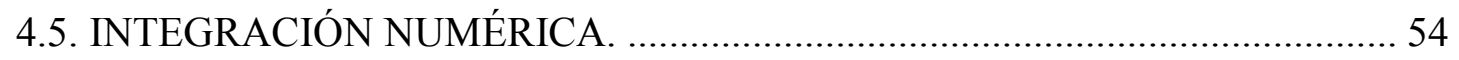

4.5.1. Resolución de las ecuaciones planteadas para los tramos de ríos. ................ 54

4.5.2. Resolución de las ecuaciones planteadas para los embalses. ......................... 60

4.6. LA CALIDAD DEL AGUA EN EL RESTO DE ELEMENTOS DEL SISTEMA.

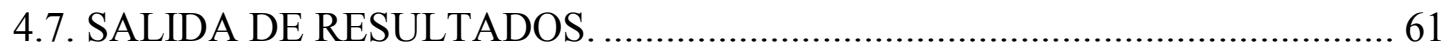

4.8. UNIDADES. 
CAPÍTULO 5.

APLICACIÓN DEL MÓDULO GESCAL A LA CUENCA DEL RÍO JÚCAR ........... 67

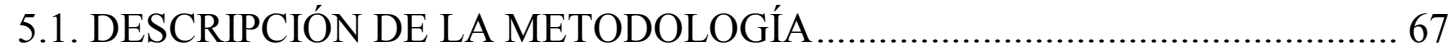

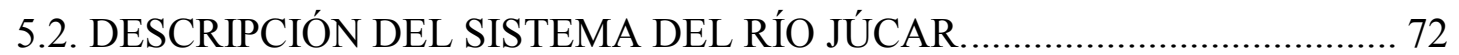

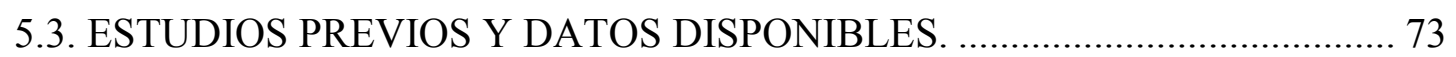

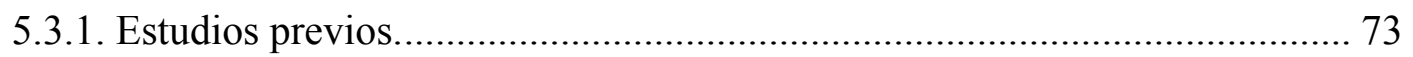

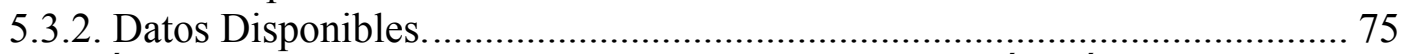

5.4. ANÁLISIS DE LA CALIDAD DE LA CUENCA DEL RÍO JÚCAR ................ 77

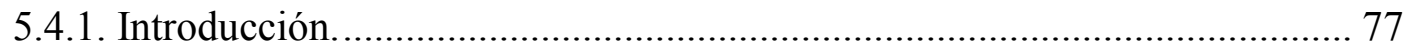

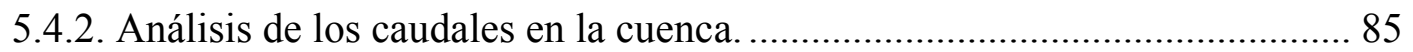

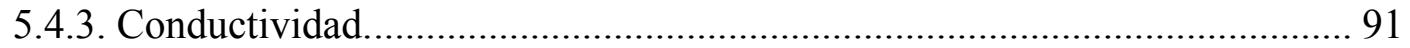

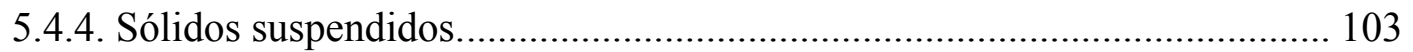

5.4.5. Oxígeno Disuelto y Demanda Biológica de Oxígeno. ................................ 111

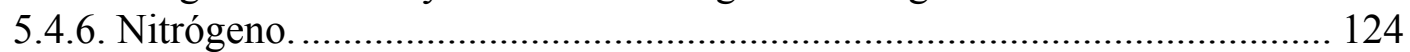

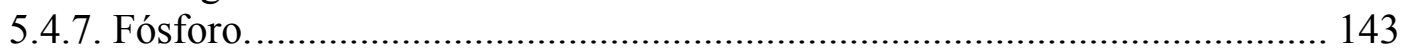

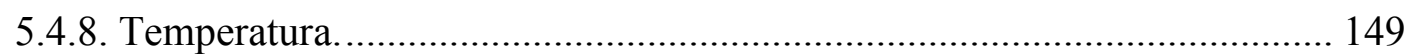

5.4.9. Procesos de eutrofización en la cuenca. .................................................. 154

5.4.10. Mejoras en la red ICA para la modelación de la calidad del agua. ........... 158

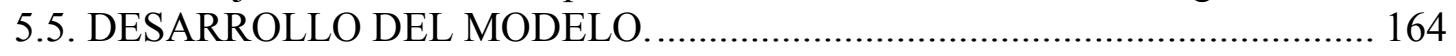

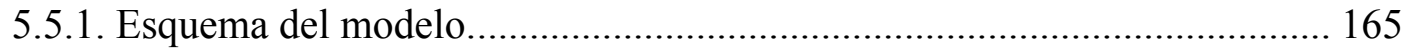

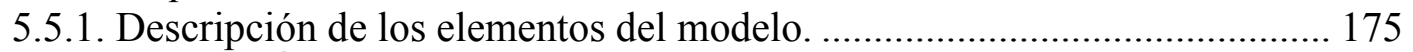

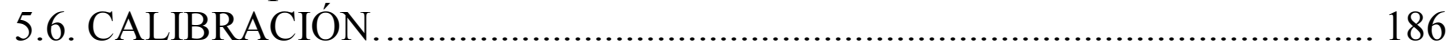

5.6.1. Descripción de la herramienta desarrollada para la calibración. ................ 187

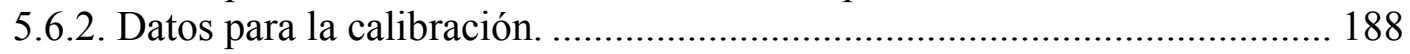

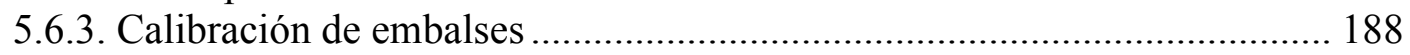

5.6.4. Calibración de conducciones aguas arriba de Tous................................... 191

5.6.5. Calibración de conducciones aguas abajo de Tous. ................................. 192

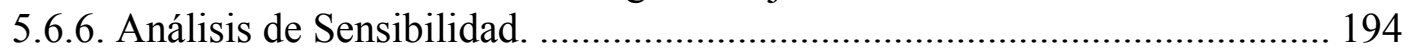

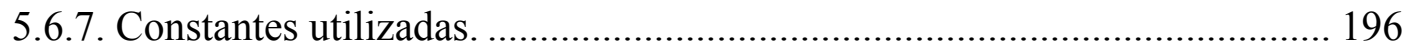

5.6.8. Otros Aspectos de la Calibración y la Modelación ................................... 196

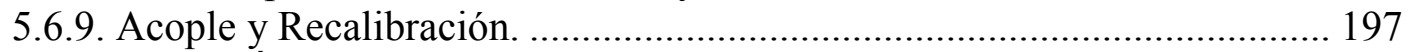

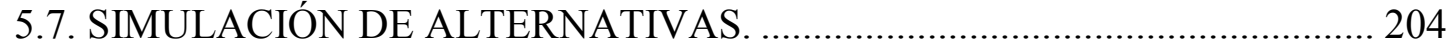

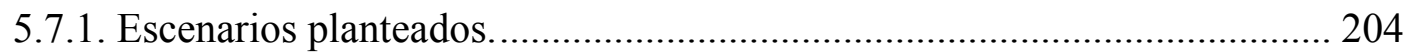

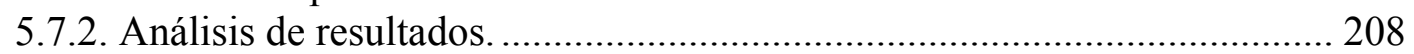

5.7.3. Conclusiones sobre la aplicación del módulo GESCAL al caso de la cuenca

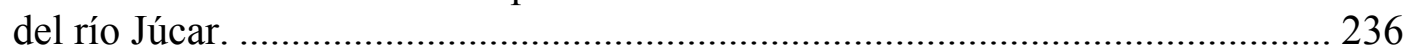

\section{CAPÍTULO 6.}

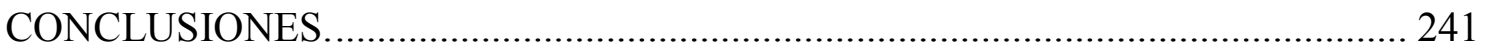

6.1. Conclusiones sobre el módulo GESCAL desarrollado. .................................. 241

6.2. CONCLUSIONES SOBRE LA APLICACIÓN DEL MÓDULO_................... 243

6.2.1. Conclusiones sobre el diagnóstico de la calidad. .................................... 243

6.2.2. Conclusiones obtenidas de la simulación................................................... 246

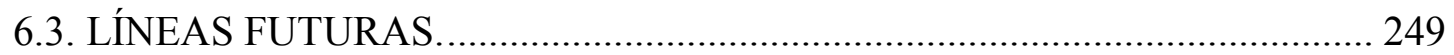

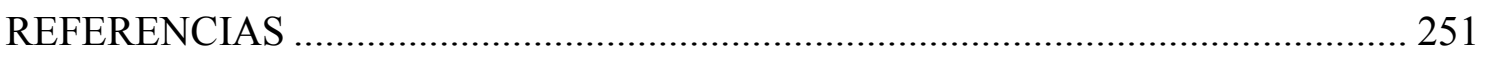




\section{Índice de Tablas}

Tabla 1. Estaciones ICA utilizadas para la obtención de perfiles medios de calidad. ... 81

Tabla 2. Resto de estaciones ICA utilizadas en el diagnóstico de la calidad. ................ 82

Tabla 3. Demandas consideradas en el modelo...................................................... 179

Tabla 4. Elementos conducción en los que se ha modelado la calidad del agua.......... 182

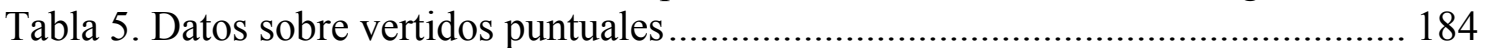

Tabla 6. Datos sobre los vertidos ficticios de Alarcón y Contreras. ............................. 185

Tabla 7. Datos de los elementos de contaminación difusa........................................... 186

Tabla 8. Parámetros obtenidos en la calibración de los embalses. ............................... 189

Tabla 9. Parámetros obtenidos en la calibración de las conducciones aguas arriba del embalse de Tous.

Tabla 10. Parámetros obtenidos en la calibración de las conducciones aguas abajo del

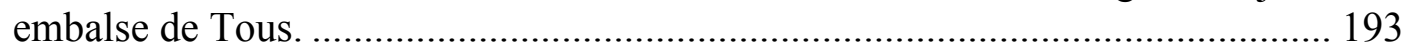

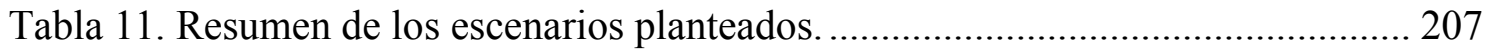

Tabla 12. Demandas utilizadas en los distintos escenarios. ......................................... 208

Tabla 13. Garantías obtenidas en las distintas simulaciones. ..................................... 210

Tabla 14. Caudales de dilución estimados para los diferentes escenarios..................... 214 

CAPITIJIOC I

\section{INTRODUCCIÓN}

La calidad del agua en los sistemas naturales depende de diversos factores naturales aunque el factor más importante suele ser el de las actividades humanas. La humanidad y el desarrollo de las civilizaciones han venido ligados desde antiguo a la disponibilidad del agua. El hombre ha utilizado las aguas continentales como fuente de recurso para multitud de funciones, así como medio receptor y depurador de parte de los residuos generados por los mismos.

A medida que la sociedad evoluciona, la presión sobre ríos y lagos cada vez es mayor. Por un lado debido al aumento de población y por otro al desarrollo de la industria y la agricultura, los cuales producen un incremento en la diversidad de las sustancias y en su complejidad que cada vez son más difíciles de degradar en el medio natural.

En la actualidad, en los países desarrollados se han realizado grandes esfuerzos para la depuración de vertidos y la disminución de la contaminación. Sin embargo sigue habiendo problemas en muchas zonas en donde se sigue sometiendo a grandes presiones a los medios naturales y en especial a los sistemas acuáticos.

El tratamiento de la calidad por parte de las administraciones se ha basado en tres tareas fundamentales: realizar un control de la calidad del agua mediante redes de medida, establecer estándares de calidad a cumplir según el objetivo deseado para la masa de agua y establecer y controlar normas de emisión para los vertidos.

Por otro lado en la gestión real de los recursos hídricos no se suele tener en cuenta la calidad del agua o, en su caso, sólo como una restricción en el momento en que la calidad supone un problema para el uso. La gestión de los sistemas de recursos hídricos ha ido de la mano del desarrollo de la teoría de optimización y de la creación de modelos de simulación y optimización sin que se realizasen grandes esfuerzos en considerar en los mismos aspectos relacionados con la calidad del recurso.

Existe una necesidad de conjugar la gestión de los sistemas de recursos con la calidad de los mismos siendo para ello imprescindible unir las herramientas que se están utilizado en la actualidad: los modelos de simulación de sistemas y los de modelación de la calidad.

La llamada Directiva Marco en Política de Aguas (UE-2000) marca la estrategia común a seguir en materia de política de aguas. En ella se enfoca como eje principal de la gestión del agua los aspectos ecológicos y de calidad de la misma. Así en el artículo 1 sobre el objetivo de la Directiva se puede leer: "Prevenir el deterioro adicional y 
mejorar el estado de los ecosistemas acuáticos" ... "Promover el uso sostenible del agua"... "Mayor protección y mejora del medio acuático". La Directiva, en su artículo 4, establece que todos los estados miembros deberán adoptar las medidas necesarias para prevenir el deterioro del estado de todas las masas de agua superficiales y alcanzar el "buen estado" de las aguas superficiales. El "buen estado" de las masas de agua se refiere al estado (valor) ecológico y químico de las aguas tomando como referente el estado de la masa del agua en su condición natural.

Esta directiva marca un punto de inflexión en el sistema tradicional de gestión y planificación de los recursos hídricos obligando a las autoridades gestoras a tener en cuenta aspectos tanto de calidad del agua como de ecología.

\subsection{OBJETIVO DE LA TESIS}

El objetivo principal de esta tesis es desarrollar una herramienta para la modelación de la calidad del agua a escala de cuenca. Se pretende implementar dicha herramienta sobre en un Sistema Soporte Decisión (SSD) previamente desarrollado. De este modo la aplicación conjunta permitirá, con una sola herramienta modelar la gestión y la calidad del agua del sistema.

El módulo ha desarrollar no debe intentar representar la evolución de la calidad del agua frente a eventos puntuales, sino por el contrario debe intentar reflejar la evolución espacio temporal de la calidad del agua en los sistemas modelados, fruto de las diferentes alternativas de gestión, depuración, contaminación y uso del recurso.

El módulo debe permitir la modelación de los constituyentes convencionales con un doble objetivo: por un lado se busca sencillez a la hora de modelar de una manera coherente con la escala de trabajo y por otro se intenta no perder representatividad ni capacidad de modelación. Todo ello en un entorno amigable que facilite su uso por parte de cualquier usuario.

El SSD escogido ha sido AQUATOOL, desarrollado por el DIHMA de la UPV. Esta elección se debe a la larga trayectoria de funcionamiento, aplicación y desarrollo que han tenido los módulos que lo forman.

Además la citada aplicación permitirá ayudar en el desarrollo de diferentes aspectos de aplicación de la Directiva Marco en política de aguas como son: el establecimiento de condiciones de referencia, programas de medidas, desarrollos de planes de demarcación hidrográfica, etc. 


\subsection{ESTRUCTURA DE LA TESIS}

La presente tesis se estructura de la siguiente forma:

En el capítulo segundo se realiza una revisión de antecedentes en cuanto a:

- Modelación de sistemas de recursos hídricos

- Modelación de la calidad por constituyentes: temperatura, oxígeno disuelto y eutrofización.

- Herramientas para la modelación de la calidad por sistemas naturales: ríos, lagos y embalses.

- Herramientas que permiten la modelación conjunta recurso - calidad.

En el capítulo tercero se realiza una breve descripción sobre el Sistema Soporte de Decisión SSD AQUATOOL y del modelo de gestión SIMGES. Además se recogen los principales condicionantes que impone el modelo de gestión sobre el de calidad.

El capítulo cuarto recoge la explicación sobre la formulación y el desarrollo del módulo de calidad. En él se explica qué constituyentes y cómo se pueden modelar, qué hipótesis se realizan tanto para los ríos como para los embalses y cómo se trata la calidad en el resto de elementos. Además, se explica la forma de integración de las ecuaciones diferenciales planteadas y la interfaz desarrollada.

En el capítulo quinto se realiza la aplicación de la herramienta desarrollada en el caso de la cuenca del Júcar. Este capítulo recoge:

- Descripción de la metodología general de trabajo.

- Descripción de la cuenca y de la información disponible.

- Análisis de la calidad del agua de la cuenca mediante el estudio de los datos históricos de la red de calidad ICA y otras fuentes.

- Creación del modelo a partir de toda la información disponible.

- Calibración del modelo, análisis de sensibilidad y acoplamiento del modelo.

- Simulaciones de diferentes escenarios en los que se incluyen aspectos de planificación, aspectos de infraestructura de depuración y de caudales de mejora ambiental.

- Finalmente se establecen las conclusiones del caso de aplicación.

En el capítulo sexto exponen las conclusiones de este trabajo así como las futuras líneas de investigación. 
Integración de la modelación de la calidad del agua en un sistema de ayuda a la decisión para la gestión de recursos hídricos. 


\section{CAPPI'TIJ!O 2}

\section{ESTADO DEL ARTE}

Históricamente los problemas de gestión y de calidad del agua han sido tratados por separado. La necesidad de considerar ambos aspectos en una estrategia común ha sido planteada por diversos autores como Loucks (1987), Arnold and Orlob (1989) y Strzepek and Chapra (1990). Aunque la gestión integral o conjunta de un sistema de recursos hídricos no ha sido aplicada en muchos casos, múltiples métodos han intentado considerar ambos aspectos para problemas específicos. Uno de los más estudiados ha sido la gestión de los embalses teniendo en cuenta aspectos de calidad del agua. Loftis et al. (1985) estudiaron diferentes métodos de análisis conjunto de cantidad y calidad de agua para la gestión de embalses.

Se denomina "modelo" al conjunto de conceptos y/o ecuaciones que nos permiten aproximarnos a la realidad de un fenómeno. Por otro lado, tanto en el análisis cuantitativo como de calidad existen aplicaciones informáticas que permiten la creación de modelos de formulaciones predefinidas sobre diferentes casos específicos. Aunque a estas herramientas de modelación en general también se les llama modelos en esta tesis doctoral se denominarán como "módulos" a las herramientas informáticas que permiten la modelación. La denominación de modelo se reserva para hacer referencia a un caso concreto.

Otro concepto que convendría diferenciar es "plataforma de modelación". En los últimos años debido a la gran cantidad de módulos disponibles para la modelación de la calidad del agua y a su idoneidad en función de diversos factores han surgido algunas herramientas informáticas que, en algunos casos implantadas sobre sistemas de información geográfica, realizan un preproceso de datos para posteriormente hacer llamadas a diferentes módulos de modelación.

A continuación se realiza una revisión de los diferentes módulos disponibles para la modelación de sistemas de recursos hídricos enfocados a la gestión de los mismos. Seguidamente se revisa el estado del arte de la modelación de la calidad de los contaminantes convencionales como son la temperatura, oxígeno disuelto, nutrientes y fitoplancton. En tercer lugar se realiza una revisión de los módulos disponibles para la modelación de la calidad. Finalmente se realiza una revisión de la modelación conjunta de la cantidad y calidad del agua. 


\subsection{HERRAMIENTAS DE MODELACIÓN DE SISTEMAS DE RECURSOS HÍDRICOS.}

Existen diversos módulos para la modelación de la gestión de sistemas de recursos hídricos. Solera (2004) realiza una revisión tanto de los modelos específicos como de los diferentes módulos de modelación para la simulación y optimización de recursos hídricos. Se puede diferenciar entre módulos de simulación convencional y los basados en redes de flujo. Los primeros no presentan ningún algoritmo de programación matemática para la resolución del problema de la asignación del agua. En estos módulos, el usuario debe indicar el modo de reparto de la misma entre los diferentes elementos. Por otro lado los módulos basados en redes de flujo incorporan algún algoritmo matemático para resolver el citado problema.

\subsubsection{Módulos de simulación convencional.}

Entre los primeros se pueden encontrar los siguientes: HEC-5 -Simulation of flood control and conservation systems- uno de los más utilizados permite la introducción de reglas de operación y la consideración de diferentes tipos de demandas. El módulo MITSIM (Strzepek and García, 1989) permite evaluar el rendimiento económico e hidrológico de una cuenca considerando diferentes tipos de demandas. IRIS -Interactive River System Simulation Program- (Loucks et al., 1990) está enfocado a sistemas de suministro y producción de energía hidroeléctrica. Otro módulo desarrollado es STELLA -system thinking experimental Learning Laboratory with animation- (Karpack y Palmer, 1992) es un módulo enfocado para la simulación de sistemas de embalses con un desarrollo informático de interfaz bastante completo. Finalmente Mike-Basin (DHI, 2000) es un modelo de simulación a escala diaria de la gestión de sistemas con múltiples embalses que dispone de una interfaz gráfica interactiva para la edición de los datos y resultados desarrollada en el entorno del GIS ArcView.

\subsubsection{Módulos basados en redes de flujo.}

Más utilizados que los anteriores, los módulos basados en redes de flujo, presentan algún algoritmo de optimización matemática para resolver el problema de la distribución de recurso. Entre los más antiguos destaca SIMLYD-II (Everson and Mosely, 1970) desarrollado por el Texas Water Development Board, que simula el almacenamiento y la transferencia de agua entre los embalses, ríos y conducciones de un sistema a escala mensual, con el fin de satisfacer un conjunto de demandas específicas según un orden de prioridad y unas reglas de operación dadas. Este módulo derivó en SIM-V (Martin, 1983) con una mayor complejidad y elementos para modelar. Un tercer módulo, muy relacionado con los dos anteriores, es MODSIM (Labadie, 
1992), cuyos fundamentos funcionales son prácticamente iguales a los de los dos módulos reseñados antes. Algunos de sus principales rasgos consisten en que: puede realizar simulaciones a escala mensual o semanal, la función objetivo está dada en términos de costos, y los repartos y almacenamientos de agua se hacen según una escala de prioridades dada por el modelador. Los modelos de optimización OPTIRED (Andreu, 1989), OPTIGES (Andreu, 1992) y de simulación SGC (Andreu y otros, 1989) y SIMGES (Andreu et al., 1992) desarrollados en el Departamento de Ingeniería Hidráulica y Medio Ambiente de la Universidad Politécnica de Valencia se enmarcan dentro de la misma filosofía de los modelos anteriormente descritos. Tanto SIMGES como OPTIGES están englobados en el Sistema Soporte de Decisión (SSD) AQUATOOL. En el capítulo tercero se realiza una descripción de AQUATOOL y su módulo SIMGES, debido a que es el módulo en el que se ha implantado la herramienta de modelación de la calidad del agua que se ha desarrollado con motivo de esta tesis doctoral.

\subsection{EVOLUCIÓN DE LA MODELACIÓN DE LOS CONTAMINANTES CONVENCIONALES.}

La concepción asociada a ciertos constituyentes como "convencionales" es debida a su consideración a lo largo de la historia de la modelación de la calidad. Entre estos se definen el oxígeno disuelto, la materia orgánica, coliformes, temperatura, salinidad y todos los relacionados con procesos de eutrofización como son el ciclo del nitrógeno, fósforo, biomasa de algas y otros. Además, casi todas las herramientas de modelación permiten considerar los denominados "contaminantes arbitrarios" que se modelan con un único proceso de transformación representado por una cinética de primer orden. Dentro de estos quedan también incluidos los denominados conservativos ya que pueden ser modelados considerando la constante de degradación nula. Tradicionalmente la modelación de los coliformes fecales se ha considerado como arbitrarios así como la salinidad de forma conservativa.

\subsubsection{Modelación de la temperatura}

Las primeras modelaciones de la temperatura del agua en sistemas naturales aparecieron en la década de los 60: Burt (1958); Delay and Seaders (1966); Raphael (1962). En general, la modelación de la temperatura del agua en sistemas naturales se realiza mediante el planteamiento del balance térmico. Las ecuaciones son las mismas 
que los balances de materia pero sustituyendo concentraciones $(\mathrm{mg} / \mathrm{l})$ por calor $\left(\mathrm{cal} / \mathrm{m}^{3}\right)$. Para un sistema natural el flujo, neto de energía se puede estimar de la siguiente forma:

$$
\phi_{\text {net }}=\phi_{s w}-\phi_{r s w}+\phi_{l w}-\phi_{r l w}-\phi_{\text {evap }}+\phi_{\text {emit }} \pm \phi_{\text {conv }}
$$

Donde:

- $\phi_{\text {net }}$ es el flujo neto de calor. $\left(\mathrm{Wm}^{-2}\right)$

- $\phi_{\text {sw }}$ la radiación de onda corta incidente. $\left(\mathrm{Wm}^{-2}\right)$

- $\phi_{\text {rsw }}$ la radiación de onda corta reflejada. $\left(\mathrm{Wm}^{-2}\right)$

- $\phi_{\mathrm{lw}}$ la radiación de onda larga incidente. $\left(\mathrm{Wm}^{-2}\right)$

- $\phi_{\text {rlw }}$ la radicación de onda larga reflejada. $\left(\mathrm{Wm}^{-2}\right)$

- $\phi$ evap representa la energía consumida en la evaporación. $\left(\mathrm{Wm}^{-2}\right)$

- $\phi$ emit la energía emitida por el volumen de agua. $\left(\mathrm{Wm}^{-2}\right)$

- $\phi_{\text {conv }}$ la energía transmitida por convección desde o hacia el volumen de agua. $\left(\mathrm{Wm}^{-2}\right)$

En general la información meteorológica necesaria para la modelación de la temperatura incluye: temperatura del aire, humedad, radiación solar, velocidad del viento y presión atmosférica. Diferentes estudios desarrollan la estimación de los términos anteriores, Ryan and Harleman (1973); Edinger et al. (1974); Chapra (1997); Bowie et al. (1985), aunque una de las más conocidas y utilizadas es la desarrollada por Wunderlich (TVA, 1972). Recientes aplicaciones de este método se encuentran en Cole and Buchak (1995) y Normandeu Associates (1999).

Para facilitar la integración analítica Edinger and Geyer (1965) plantearon el flujo de calor neto como una función del intercambio de calor total y la temperatura de equilibrio, del siguiente modo: $\phi_{\text {net }}=K_{e q}\left(T_{e q}-T\right)(2.2)$

Donde:

- $\mathrm{K}_{\mathrm{eq}}$ es el coeficiente de intercambio de calor $\left(\mathrm{Wm}^{-2 o} \mathrm{C}^{-1}\right)$.

- $\mathrm{T}_{\mathrm{eq}}$ es la temperatura de equilibrio $\left({ }^{\circ} \mathrm{C}\right)$.

La temperatura de equilibrio se define como la temperatura que alcanzaría la masa de agua si las condiciones meteorológicas se mantuviesen constantes. Se puede obtener por métodos iterativos haciendo cero el flujo neto de energía en la ecuación (2.1). Esta aproximación se suele usar, o tiene validez, para escalas temporales de medio y largo plazo. Diferentes autores, como Thomann (1987), y herramientas de 
modelación, como el HEC5-Q, han usado esta técnica. La ventaja que presenta este método es la linealidad de la ecuación.

Los modelos de calidad del agua en ríos tienen su origen en la simulación de procesos de contaminación aguas abajo de vertidos. El transporte de calor a lo largo del río es un problema similar, aunque el flujo de calor es una fuente distribuida.

Mayor complejidad presenta la modelación de la temperatura en lagos y embalses. Ello es debido a las variaciones diurnas y estacionales de la temperatura del agua en este tipo de masas de agua. Las variaciones térmicas anuales provocan el efecto denominado como estratificación térmica. Este efecto estacional se produce cuando, en los meses de verano, el calor de la radiación solar incidente crea una capa de agua caliente en la superficie. El viento y las corrientes internas son incapaces de mezclar dicha capa con el resto de la masa de agua. En otoño, cuando desciende la radiación atmosférica, se produce un enfriamiento de la superficie y la mezcla completa de todo el lago o embalse manteniéndose de esta forma hasta el verano siguiente.

Casi toda la radiación incidente es absorbida en los primeros metros de la columna de agua. Sólo la luz visible penetra hacia el interior. La radiación de onda corta que es la que pasa hacia la profundidad, se atenúa en la profundidad siguiendo la ley de Beer:

$q_{s z}=(1-\beta) q_{s w} e^{-\eta^{* z}}(2.3)$

Donde:

- $\beta$ es el ratio de radiación absorbida en la superficie.

- $\eta$ es el coeficiente principal de extinción.

Además, la temperatura en lagos y embalses está muy influenciada por el régimen hidrodinámico de los mismos.

\subsubsection{La modelación del oxígeno disuelto y la eutrofización.}

Se considera el trabajo de Streeter and Phleps (1925) como la base de la modelación de la calidad del agua. En él se modelaba el oxígeno disuelto en el río Ohio considerando el efecto del consumo de oxígeno disuelto por oxidación de la materia orgánica y el aporte del mismo en el proceso de reaireación. Tradicionalmente, el consumo de oxígeno disuelto, en sistemas naturales acuáticos, consecuencia de la degradación de la materia orgánica se considera mediante una cinética de primer orden. Algunos estudios propusieron, sin mucho acepción posterior, cinéticas de segundo orden: Young and Clarck (1965); Shastry (1973). Posteriormente, Thomas (1948) incorporó el efecto de la sedimentación de la materia orgánica y Camp (1960) el de la 
demanda de oxígeno por parte del sedimento. Los primeros modelos fueron sencillos debido a que se debían obtener las soluciones analíticas, al no disponer de capacidad computacional. Entre los modelos más completos de la época destacan los planteados por Dobbins (1962) y por O'Connor y Di Toro (1970). A partir de la década de los 70 la aparición de los ordenadores permitió plantear modelos más complejos incorporando en ciclo del nitrógeno y el fósforo. Así, el primer modelo de la familia QUAL el QUAL1 (TWDB, 1971) incorporaba el ciclo del nitrógeno.

Con la aparición de los procesos de eutrofización y su modelación, la consideración del oxígeno disuelto queda embebida en la modelación biológica en donde se consideran los nutrientes, la biomasa de algas, la materia orgánica y el oxígeno disuelto. La eutrofización fue definida por Vollenweider (1968) como un enriquecimiento de los nutrientes y el subsiguiente deterioro progresivo de su calidad principalmente en lagos debido a la proliferación vegetal con las repercusiones consiguientes en el metabolismo global de las aguas afectadas. Debido a que en la mayoría de los casos el fósforo es el nutriente limitante, los primeros modelos consistían en relaciones semiempíricas entre diferentes características hidráulicas de los embalses y el aporte de fósforo: Vollenweider (1968 y 1975); Larsen and Mercier (1976). Posteriormente surgieron las relaciones entre el contenido de fósforo y la concentración de clorofila-a, parámetro empleado como indicador de la población de fitopláncton. Entre estas destacan las propuestas por Dillon y Rigler (1974), Rast and Lee (1978) y Barstsch and Gakstatter (1975). También se plantearon modelos mecanicistas como el de Vollenweider (1976) y Chapra (1975). Gracias a las técnicas computacionales se pudieron plantear modelos de varios nutrientes en diversas formas y las algas, modeladas en la mayoría de los casos mediante clorofila-a. Así se incluyen el ciclo del nitrógeno, la materia orgánica y el oxígeno disuelto. Entre los modelos más tradicionales de eutrofización sobre lagos y estuarios destacan los realizados sobre el estuario Potomac (Jaworsky et al. 1971; Freudberg, 1985; Thonmann and Fitpatrick, 1982) y sobre los grandes Lagos (Thonmann, 1975; Thonmann et al., 1976; Thonmann et al., 1979; Di Toro and Connolly, 1980). Muchos de los estudios de eutrofización sobre lagos y en especial sobre estuarios, han sido la base de las herramientas de modelación actuales. Este es el caso de WASP, Water quality Analysis Simulation Program (Di Toro et al., 1983) o de HydroQual (Hydroqual, 1981) que tiene su origen en el estudio realizado sobre el delta Oeste y la bahía Suisun de los ríos Sacramento y San Joaquín en California.

Como se explica en Bowie et al. (1985), en la mayoría de modelos de calidad de aguas todas las transformaciones entre las diferentes formas abióticas de nutrientes son descritas mediante cinéticas de primer orden. Los modelos de nutrientes se diferencian principalmente en los nutrientes considerados y en las distintas formas utilizadas para 
considerar cada uno. Las diferentes formas presentes en un sistema acuático son: nutrientes disueltos orgánicos, disueltos inorgánicos, orgánicos particulados y bióticos (algas, plantas acuáticas, zooplancton, peces y organismos bénticos). Bowie et al. (1985) realizan una comparación sobre la forma de tratar los nutrientes, fitoplancton y zooplancton entre más de 20 modelos. En la siguiente figura se realiza una comparación del tratamiento que se realiza de la eutrofización en WASP5 y QUAL2E, dos de los módulos más utilizados en la modelación de la calidad del agua. Como se puede ver la consideración del proceso es muy parecida.

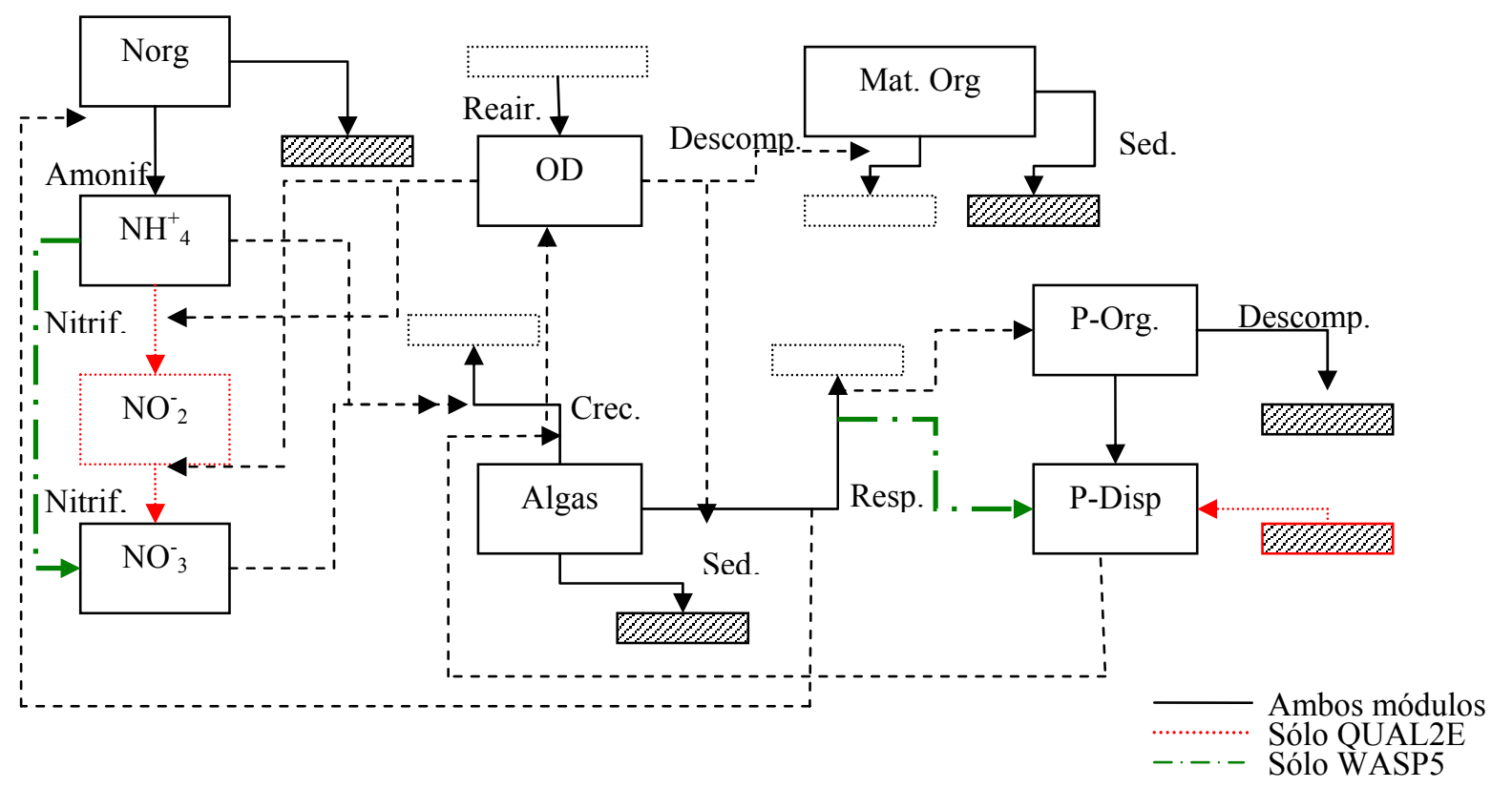

Figura 1. Esquema sobre los procesos considerados en los módulos QUAL2E y WASP5 para la modelación del fenómeno de eutrofización.

Los últimos modelos de eutrofización pasan por la consideración de nuevos estados de nutrientes, diferentes tipos de algas y nuevos tipos de organismos como bacterias o macrófitos (Chapra, 1997).

\subsection{HERRAMIENTAS PARA LA MODELACIÓN DE LA CALIDAD DE LA CALIDAD DEL AGUA.}

Existe una gran diversidad de módulos o herramientas de modelación de la calidad de las aguas superficiales. Diferentes recopilaciones de estos se pueden encontrar en Ambrose et al. (1996); Reichert et al. (2001); Deas and Lowney (2000). Además ciertas instituciones, como el US Geological Survey, han desarrollado portales en Internet en donde se recopilan módulos de calidad de aguas con acceso a 
documentación, referencias, a los modelos e incluso se permite la comparación entre los mismos.

En este intento de aclarar los módulos disponibles en general el criterio de clasificación más utilizado es el sistema natural para el que ha sido diseñado. Haciendo uso de este criterio podemos diferenciar entre varios casos: herramientas para zonas de mezcla; ríos, lagos, estuarios, zonas costeras, humedales, cuenca. Por otro lado hay que considerar la existencia de módulos tipo "elemento" o "caja" en donde el sistema natural se define mediante un conjunto de elementos o cajas relacionadas. Este tipo de herramientas han sido aplicadas a todo tipo de sistemas naturales aunque frente a sistemas naturales como ríos o embalses suelen aplicarse las diseñadas específicamente para los mismos.

Otros criterios utilizados en la clasificación de las herramientas de la modelación de la calidad son:

-Dimensionalidad.

- Dinámica temporal: estacionario, dinámicos o cuasi-estacionarios.

- Hidrodinámica: según tipo de sistema natural.

- Enfoque: empíricos o mecanicistas. Y dentro de estos últimos según los procesos físicos considerados: advección, dispersión, etc.

- Constituyentes y procesos considerados.

- Tipos de Datos: estocásticos o deterministas.

A continuación se desarrolla una revisión de los principales módulos disponibles para la modelación de la calidad del agua en función de los diferentes sistemas naturales. Esta clasificación se centra en ríos y lagos debido a que son los que se han tenido en cuenta a la hora de desarrollar el módulo de calidad objetivo de esta tesis doctoral.

\subsubsection{Herramientas para la modelación de la calidad del agua en ríos.}

El módulo QUAL2E-UNCAS (Brown and Barnell, 1987), desarrollado por la agencia de protección del medioambiente de Estados Unidos (EPA), es uno de las más conocidos y utilizados en la modelación de la calidad de ríos. Permite la modelación de contaminantes arbitrarios, temperatura, oxígeno disuelto (OD), Demanda Biológica de Oxígeno (DBO), nutrientes y fitoplancton. Asume hipótesis de unidimensionalidad y considera los procesos físicos de advección y dispersión. Aunque la hidráulica es 
estacionaria permite la modelación del efecto de la variación horaria de la radiación sobre la dinámica de los constituyentes. Otras de las características son:

- Posibilidad de calcular el incremento de caudal necesario para alcanzar un especificado nivel de oxígeno disuelto.

- Permite la incorporación de varios vertidos, afluentes o tomas de agua.

- Tiene incorporado un módulo para realizar análisis de sensibilidad e incertidumbre mediante el método de Monte Carlo.

Aunque ha sufrido pocas modificaciones desde la versión de 1987 sigue siendo una de las herramientas más utilizadas para la modelación de la calidad del agua en ríos. Algunas de sus limitaciones son:

- No permite la modelación de situaciones hidráulicas o de vertido dinámicas.

- No permite modelar tramos de ríos con gran influencia de macrófitos acuáticos.

- Los sedimentos se han considerado de forma excesivamente simplista.

- No tiene en cuenta la inhibición de degradación de materia orgánica en situaciones anóxicas.

Otra de los módulos más utilizados para la modelación de la calidad en ríos es CE-QUAL-RIV1 (Environmental Laboratory, 1990). Esta herramienta permite realizar una modelación hidráulica unidimensional, no estacionaria, y permite incluir diferentes elementos hidráulicos estructurales. La diferencia entre la modelación de constituyentes con respecto al QUAL2E es que esta incorpora el efecto de dos micronutrientes el hierro y el manganeso y que las algas no se consideran como constituyente sino sólo su efecto junto con el de los macrófitos.

Las tendencias de los módulos más modernos pasa por una mejora de la parte visual de la informática y entre los avances científicos se marcan las siguientes tendencias: incorporan el ciclo del sílice, consideran varias clases de algas, $\mathrm{pH}$ y metales. Además suelen mejorar la modelación de los sedimentos incluyendo los procesos en los mismos. Entre las últimas herramientas desarrolladas se pueden encontrar: ATV (ATV, 1996); ISIS (Wallingford 1996, 1997); Duflow (Aalderink et al. 1995); CE-QUAL-ICM (Cerco and Cole, 1995) y RWQM1 (Reichert et al, 2001).

Entre las herramientas más modernas destaca MIKE-11 (DHI, 1992) desarrollado por el Danish Hydrulic Institute. El origen de este módulo es hidráulico al que se le ha incorporado un potente modelo de calidad. El módulo hidráulico permite la modelación de ríos o canales bajo la hipótesis de unidimensionalidad en modo estacionario o transitorio. Para ello resuelve completamente las ecuaciones de St. Venant. Además admite diferentes tipos de elementos estructurales como compuertas, 
pasos inferiores, etc. El módulo de calidad permite modelar diferentes constituyentes como son el OD, DBO, fitoplancton, zooplancton, nitrógeno, temperatura, fósforo, coliformes, metales pesados y sedimentos cohesivos así como no cohesivos. En la modelación del OD se pueden establecer seis niveles de complejidad:

- El nivel uno permite la modelación de la DBO con un única cinética de primer orden y del OD con la afección de la degradación de la DBO y la reaireación.

- El segundo nivel permite adicionalmente considerar efecto de sedimentación y resuspensión de la DBO así como de la demanda de oxígeno disuelto por parte de los sedimentos.

- El siguiente nivel incluye el efecto sobre el OD de la nitrificación del amonio y los nitritos.

- El nivel cuarto, adicionalmente, considera la posible desnitrificación.

- El quinto nivel diferencia la parte suspendida y particulada de la DBO.

- Finalmente se puede incorporar la consideración de sedimentos cohesivos y no cohesivos.

Entre las desventajas de este módulo y gran parte de los módulos de última generación es la gran cantidad de datos necesarios para la modelación. La mayoría de ellos intentar evitar este problema mediante la modelación modular de procesos. El problema de la disponibilidad, se agudiza en el caso de modelar estados no estacionarios.

Por último el módulo RWQM1 (Reichert et al, 2001) presenta un enfoque diferente a los modelos tradicionales. Este módulo es una adaptación del módulo de calidad para la modelación de fangos activos denominado ASM1 (Henze et al. 1987). En ASM1 el planteamiento del modelo de calidad pasa por la modelación detallada de los procesos bacteriológicos. El módulo tiene como objetivo el paliar algunos problemas comunes a los tradicionales modelos de calidad de sistemas naturales, como son:

- La mayoría de modelos siguen basando sus formulaciones para la modelación del OD en la DBO como principal variable de estado, cuando realmente, la DBO no incluye toda la materia biodegradable.

- En general la mayor parte de los modelos no conciben, o lo hacen de una forma muy pobre, los flujos bénticos.

- Debido a todo esto, los modelos tradicionales no cierran los ciclos de balances de masas. 
El módulo desarrollado intenta paliar todas estas deficiencias considerando un mayor detalle entre la columna de agua y los sedimentos, así como intentando considerar todos los elementos de los ciclos de los compuestos como son el carbono, oxígeno, nitrógeno y fósforo. Para ello, el módulo se basa en la modelación de la composición elemental de los organismos y la estequiometría de los procesos bioquímicos. Con este fin se consideran 24 componentes y 23 procesos, algunos de los cuales se numeran a continuación:

- Crecimiento aeróbico de organismos heterótrofos.

- Respiración endógena aeróbica.

- Crecimiento anóxico de organismos heterótrofos.

- Respiración endógena anóxica de organismos heterótrofos.

- Crecimiento de nitrificadores de primera etapa.

- Crecimiento de nitrificadores de segunda etapa.

- Crecimiento de las algas.

- Muerte de las algas por depredadores.

- Crecimiento de depredadores.

- Hidrólisis.

- Equilibrio químico entre diferentes compuestos.

- Adsorción del fosfato.

- Desorción del fosfato.

Debido a la gran cantidad de procesos considerados y su complejidad los autores proponen una aplicación del módulo teniendo en cuenta sólo los mecanismos importantes dependiendo de la tipología del río y el objetivo a alcanzar. Entre las desventajas de este nuevo método se puede destacar:

- La complejidad del mismo y el alto grado de conocimiento de este tipo de procesos para el manejo del módulo.

- Su aplicación sólo está justificada en casos muy concretos en donde el sedimento tenga una gran influencia y se tenga una gran cantidad de datos de la columna de agua y del la capa de sedimento.

- El considerar tan bajo nivel de proceso supone que muchos de los parámetros de los modelos tradicionales son sustituidos por conjuntos de procesos en los que los parámetros son sustituidos por constantes conocidas. Sin embargo estas “constantes" en realidad como dicen los mismos autores (Reichert et al. 2001) 
están basadas en concentraciones "in-situ" del substrato y de luz. Por ello factores limitantes de luz deben desarrollarse con métodos empíricos. De lo anterior se deduce que la supuesta ventaja de plantear el modelo en procesos básicos, para tener un mayor conocimiento de los procesos que se están dando y las constantes que los rigen, no deja de ser un incremento de complejidad de los modelos ya que existen otros factores que obligan a "calibrar" términos perdiéndose, en muchos casos, la ventaja del método.

- Finalmente el conocimiento del proceso en el río depende del módulo hidráulico. Incrementar la complejidad de la parte de los procesos de calidad no implica un mayor conocimiento si el modelo hidráulico no tiene la misma escala de precisión.

\subsubsection{Herramientas para la modelación de la calidad del agua en lagos y embalses.}

La herramienta CEAQUAL-R1 (1986) permite la modelación de embalses representados como un conjunto de capas horizontales en donde la mezcla es completa en cada una de las capas. Este módulo permite la modelación de la temperatura y múltiples constituyentes como son: nutrientes, oxígeno disuelto, fitoplancton, zooplancton, $\mathrm{pH}$, detritus, alcalinidad, metales, etc. El reparto de las entradas al embalse en cada capa se hace en función la de densidad del agua. Las salidas del embalse pueden realizarse desde diferentes capas de forma especificada, o estimada por el modelo, en función de la temperatura de salida deseada.

Otra herramienta desarrollada, al igual que en el caso anterior, por el USACE (US Army Corps of Engineers) es CE-QUALW-2. Esta herramienta permite la modelación bidimensional de los embalses con lo que se puede modelar longitudinal y verticalmente todos los constituyentes. Además de la temperatura permite la modelación de la DBO, Oxígeno disuelto, nutrientes, algas y otros constituyentes como son: $\mathrm{pH}$, alcalinidad, sólidos suspendidos, hierro y coliformes. Debido a su capacidad, también ha sido utilizado para la modelación de ríos y estuarios. El modelo hidrodinámico permite la consideración de un régimen no estacionario.

BETTER Box Exchange Transport Temperatura Ecology Reservoir (Bender et al., 1990) es una herramienta que permite la modelación bidimensional en lagos de la temperatura, $\mathrm{OD}$, nutrientes, $\mathrm{pH}$ y la biomasa de algas. Este módulos permite tener en cuenta la estratificación térmica así como la influencia de los procesos de advección de entradas y salidas de caudal. 


\subsubsection{Herramientas para la modelación de la calidad del agua en ríos y lagos.}

Existen dos módulos destacables que permiten la modelación conjunta de ríos y lagos (o embalses). Estos son: HEC5Q (USACE-HEC. 1986a) y WQRRS (USACEHEC. 1986b). La herramienta HEC5 realiza la simulación de la gestión de sistemas de recursos hídricos por lo que se incluye y describe en el apartado de modelación conjunta.

La aplicación WQRRS (USACE-HEC, 1986) permite la modelación de la calidad en sistemas de recursos hídricos en tramos de ríos y hasta diez embalses. WQRRS permite una modelación de aspectos ecológicos ya que, entre los constituyentes a modelar se encuentran: la temperatura, tres tipos de peces, insectos acuáticos, animales bénticos, zooplancton, dos tipos de fitoplancton, algas bénticas, detritus, sedimentos orgánicos, nutrientes, etc.

Aunque los dos modelos son parecidos, el HEC5Q está más enfocado a cuestiones hidrodinámicas y de calidad convencional mientras que WQRRS permite el desarrollo de modelos más ecológicos.

\subsubsection{Modelación tipo Caja.}

Otro tipo de herramientas de la modelación de la calidad son aquellas enfocadas a la modelación de cualquier sistema natural acuático mediante su definición a base de "cajas" o elementos conectados. Aunque pueden ser aplicadas a cualquier sistema, suelen ser utilizadas en sistemas complejos como pueden ser los estuarios, lagos o ríos en donde interese estudiar la bidimesionalidad o tridimensionalidad del problema. Entre las más aplicadas destacan WASP (Ambrose et al., 1993 a y b; Wool et al., 2001) y EXAMSII (Burns, 1990).

El programa informático WASP (Water Quality Analysis Simulation Program) está basado en la modelación mediante elementos lo que permite analizar sistemas en una, dos o tres dimensiones. Cada elemento puede definirse como hipolimnion, epilimnion, capa béntica superior o inferior. El programa incluye dos submodelos EUTRO y TOXI5. EUTRO está diseñado para el análisis de la eutrofización y permite la modelación en varios niveles de complejidad para los nutrientes, fitoplanton, materia orgánica carbonosa y oxígeno disuelto. Por otra parte, TOXI5 permite la modelación de hasta tres compuestos químicos con relación o no entre ellos y procesos en los sedimentos. La parte hidráulica puede ser suministrada directamente como dato o modelada con el preprocesador DYNHYD5 (Ambrose et al., 1993c). Los constituyentes que pueden modelarse son: temperatura, salinidad, coliformes, nitrógeno, DBO, algas, 
fósforo, sílice, $\mathrm{OD}$, sedimentos cohesivos y no-cohesivos, arbitrarios, pesticidas y compuestos tóxicos.

Por otra parte EXAMSII, de menor aplicación, permite la modelación de compuestos sintéticos orgánicos incluyendo pesticidas, materiales industriales, etc. Puede realizar simulaciones tanto estacionarias como dinámicas de hasta tres dimensiones.

\subsubsection{Modelación conjunta de cantidad y calidad del agua.}

Mucho menor ha sido el desarrollo de herramientas para la modelación conjunta de gestión y calidad de sistemas de recursos hídricos. En algunos casos se ha incorporado un módulo de calidad sobre un módulo de gestión previamente desarrollado. En otros casos, se ha creado una aplicación informática para conectar un módulo de gestión con otro de calidad. Hasta el momento las aplicaciones desarrolladas con significativa aplicación han sido: HEC5Q, MODSIMQ y BASIN.

El módulo HEC-5 -Simulation of flood control and conservation systems- fue desarrollado en 1973, y ha sido uno de los módulos más ampliamente usados tradicionalmente en tareas de simulación de la planificación y la gestión de sistemas de embalses con las siguientes características (Solera 2004):

- Asigna el agua a las demandas mediante el balance hídrico de la cuenca, teniendo en cuenta las reglas de operación dadas por el usuario.

- Admite la consideración de múltiples propósitos como el abastecimiento de agua, la generación hidroeléctrica, la calidad del agua, y el impacto económico de los daños por avenidas.

- El módulo de simulación es del tipo convencional y el módulo de calidad permite la modelación de la misma de embalses y tramos de ríos.

Respecto a la parte de calidad los aspectos más remarcables son los siguientes:

- La modelación de la calidad se puede realizar en dos niveles de complejidad. El primero permite modelar la temperatura así como tres constituyentes conservativos y tres no conservativos. Entre estos últimos se puede incluir la DBO y así modelar también, el OD. El segundo nivel permite modelar la temperatura, sólidos totales disueltos, $\mathrm{DBO}, \mathrm{OD}$, amonio, nitratos, fosfatos, $\mathrm{y}$ fitoplanctón.

- La simulación se puede realizar en escala temporal horaria, diaria o mensual dependiendo de la escala de la simulación.

- Entre los datos necesarios se encuentran las características físicas de los embalses y los tramos de río así como series de datos meteorológicos. 
- La discretización de los embalses se realiza en capas horizontales en las que se considera mezcla completa de contaminantes. Los tramos de río se consideran unidimensionales y el cálculo hidráulico se realiza a partir de la fórmula de Manning.

- El programa permite estimar la combinación de aperturas de embalse para obtener la calidad del agua requerida aguas abajo.

- Además también se puede estimar los caudales de dilución necesarios para obtener una calidad requerida en un punto aguas abajo del embalse.

Entre sus aplicaciones destaca su uso en la modelación del río Klamath (Campbell et al., 2001) que posteriormente será comentada. Además, el módulo ha sido aplicado profusamente en diferentes sistemas de recursos hídricos del estado de California (EEUU) con especial énfasis en la modelación de la temperatura. Entre estas aplicaciones destaca la realizada sobre el sistema del Valle de Sacramento (USACEHEC, 1987) con la modelación de varios embalses y tramos de río, la modelación del río Yuba (Salmon et al., 1992) y la del el río Stanislaus (AD-CMRA 2002).

Aunque como se puede ver este módulo es uno de los que mejor trata la modelación conjunta presenta serios inconvenientes a la hora de su aplicación:

- La modelación de la temperatura es indispensable lo que requiere series de datos meteorológicos en diversos puntos de la cuenca. Esto suele ser un problema ya que, para cuencas medias o grandes no se suelen disponer de series de datos meteorológicos en todos los puntos necesarios.

- Por otra parte, la complejidad del modelo hidráulico y de calidad sin una base modular de la herramienta obliga a tener alta disponibilidad de datos como condición necesaria para su modelación.

- La introducción de los datos pasa por la modificación de archivos de texto sin que exista ninguna interfaz de ayuda. Este hecho junto a la cantidad de datos ha introducir, hace que el proceso de creación de un sistema sea muy laborioso, más si cabe en sistemas con numerosos elementos como son los sistemas de recursos hídricos.

- Finalmente, no se consideran, dentro de los elementos a modelar, los recursos subterráneos. Esto es un serio inconveniente debido a que, en muchos sistemas, son una gran parte de la totalidad del recurso además de afectar a la calidad de algunos tramos de río.

El módulo MODSIM previamente descrito fue diseñado para la planificación y gestión de sistemas de recursos hídricos incluyendo el uso conjunto de aguas superficiales y subterráneas. Este módulo incluye un algoritmo de optimización que, a 
diferencia del HEC5Q, no obliga al usuario a definir la asignación del recurso. MODISM ha sido aplicado en muchos casos entre los que se encuentran: la cuenca del río Grande (Graham et. al. 1986), la parte alta del río Colorado (Law and Brown 1989), la parte baja del río Nilo (El-Beshri and Labadie 1994) y la cuenca del río Gunnison (Weiss et al. 1997).

La herramienta MODSIMQ (de Azevedo, 1993) es una aplicación informática desarrollada para la conexión del modelo de simulación de recursos hídricos de redes de flujo MODSIM con el módulo de calidad para ríos QUAL2E. El desarrollo ha sido aplicado a la cuenca del río Piracicaba en Brasil (de Azevedo, 1993) y en el el río Arkansas Colorado-USA (Dai and Labadie 2001). Entre las características más interesantes se encuentra la posibilidad de modelar el movimiento de constituyentes en la zona no saturada utilizando el método desarrollado por Mackay and Riley (1993) . Además, la nueva variante permite la inclusión de limitaciones de calidad sobre el problema de optimización que se resuelve para estimar la distribución del recurso. De esta forma la calidad del agua, además de ser simulada, queda embebida en el proceso de optimización. El mayor inconveniente de esta aplicación es la imposibilidad de modelar la calidad del agua de los embalses y otros elementos del sistema de recursos hídricos.

Finalmente, el sencillo módulo MIKE-BASIN permite la modelación de la gestión del agua incluyendo embalses, tramos de río o canal, demandas, acuíferos (como depósitos), etc. Se ha aplicado en el río Montaro (Perú) para calcular las sueltas de embalses para producción hidroeléctrica. El módulo por sí mismo no incluye un algoritmo de optimización aunque, permite utilizar el desarrollo de la hoja de cálculo Microsoft Excell para plantear algún problema de optimización sin función objetivo previamente establecida. En cuanto a la modelación de la calidad del agua permite la modelación de: constituyentes arbitrarios, oxígeno disuelto junto con la DBO, el amonio $\mathrm{y}$ un término fijo que representa el efecto de las algas y del consumo de oxígeno por parte de los sedimentos. El módulo asume que los embalses y acuíferos se modelan como depósitos completamente mezclados. Los mayores inconvenientes que presenta la aplicación de este módulo es la excesiva simplicidad en que se consideran los elementos del sistema y la modelación de la calidad de algunos de los constituyentes. Debido a ello, no son muchos los casos de aplicación que incluyan la modelación de la calidad.

Entre las plataformas que consideran, conjuntamente aspectos de gestión como de calidad de aguas y medioambientales destaca un modelo específico para la cuenca del río Klamath (EEUU): System Impact Assessment Model (Flug et al. 1999; USGS2003). SIAM es una plataforma informática que conecta diferentes herramientas de modelación para una modelación integrada de la cantidad- calidad- ecología del recurso 
hídrico de la cuenca del río Klamath (Oregón). La aplicación utiliza el modelo de la cuenca realizado en MODSIM para la simulación del sistema de recursos hídricos. Una vez obtenidos los flujos en el sistema se realiza la simulación de la calidad con la herramienta HEC5-Q. Posteriormente se realiza la simulación del hábitat con la herramienta PHABSIM -Physical Habitat Simulation System (Milhous et al. 1989; USGS 2001). Esta herramienta modela la simulación hidráulica en los tramos de río y la implicación sobre los ecosistemas de la misma. Finalmente, los resultados de este último modelo son absorbidos por el modelo de producción de peces SALMOD (Williamson, et al. 1993; Bartholow et al., 1993). Todos los módulos utilizados son herramientas desarrolladas previamente mientras que la plataforma SIAM es una herramienta informática con dos objetivos: el traspaso de información entre los diferentes programas y la evaluación de la "salud del ecosistema" analizando los resultados de la simulación de la calidad y de la producción de biomasa piscícola. Aunque la herramienta es una de las pocas que presenta un tratamiento integral su mayor desventaja es que sólo puede ser aplicada sobre la cuenca del río Klamath. 
Integración de la modelación de la calidad del agua en un sistema de ayuda a la decisión para la gestión de recursos hídricos. 


\section{EL ENTORNO DE DESARROLLO AQUATOOL.}

En este capítulo se realiza una descripción del Sistema Soporte de Decisión (SSD) AQUATOOL elegido para la implantación del módulo de calidad GESCAL objetivo de esta tesis doctoral. Además, se explican los condicionantes del modelo de gestión sobre el de calidad.

\subsection{DESCRIPCIÓN DE AQUATOOL.}

El entorno de desarrollo o Sistema Soporte de Decisión Aquatool (en adelante "entorno Aquatool") es un sistema para la modelación de la gestión y planificación de sistemas de recursos hídricos. El paquete, denominado AQUATOOL, incluye básicamente un módulo de optimización de cuencas, un módulo de simulación de cuencas, un módulo de simulación de acuíferos y un módulo de Utilidades. El sistema no es específico para una cuenca determinada sino que esta previsto para uso general puesto que permite la representación de diferentes configuraciones de sistemas de recursos hidráulicos mediante el diseño gráfico y la entrada gráfica de datos. En los últimos años, se han desarrollado postprocesadores de los módulos principales entre los que se encuentran: un módulo de evolución y optimización económica y el resultado de la presente Tesis doctoral GESCAL que permite la simulación de la calidad en todo el sistema. En la siguiente figura se muestra un diagrama con los diferentes módulos incluidos en la herramienta soporte. 


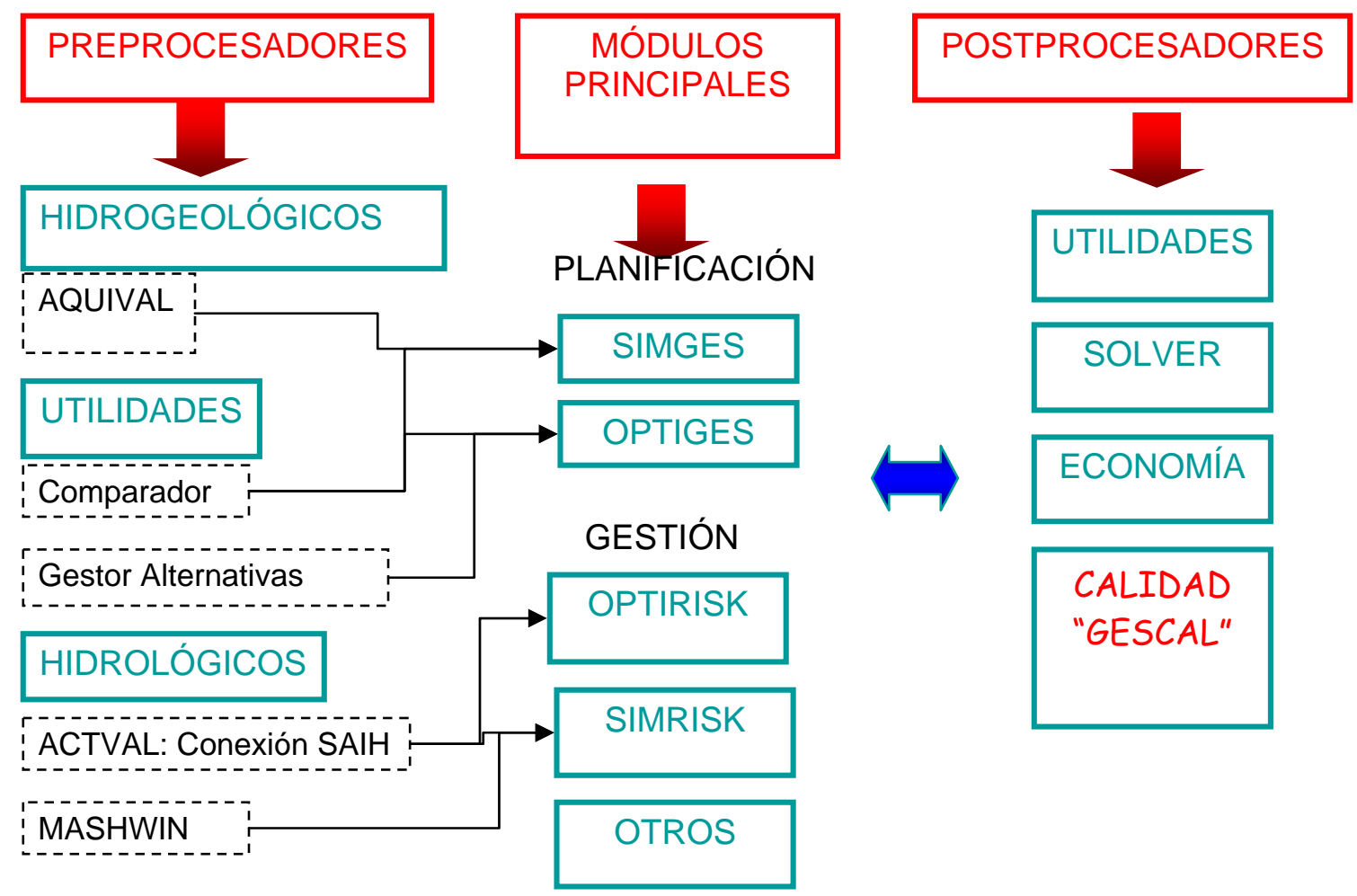

Figura 2. Componentes del Sistema Soporte de Decisión AQUATOOL

Los principales módulos son OPTIGES y SIMGES. El módulo OPTIGES permite la resolución generalizada del problema de la asignación del agua en sistemas mediante la generación de una red de flujo y el uso de algoritmos de programación lineal para el cálculo de la asignación óptima de recursos. Este módulo realiza la optimización de la gestión mensual para largos periodos de tiempo. Esto, junto con el análisis de los resultados, permite la deducción de reglas de operación óptimas para sistemas complejos de recursos hídricos. OPTIGES ha sido aplicado en diferentes casos como el río Ebro, los ríos Eugui, Estella y Guindano en Navarra (DOPTC, 1987), e Iregua en Logroño $(\mathrm{CR}, 1989)$ para el dimensionamiento de embalses y establecimiento de nuevas demandas. El módulo SIMGES de simulación incluye también la optimización de una red de flujo conservativa que, a diferencia del modelo de optimización, se formula para resolver la gestión en un sólo mes. Otra diferencia fundamental entre el módulo de simulación y el de optimización es que el módulo de simulación requiere la definición de las reglas de operación del sistema. Las reglas de operación incluidas son de los siguientes tipos:

- Curvas objetivo de volumen y zonas de embalses.

- Relaciones interembalses.

- Caudales mínimos objetivo por canales.

- Suministros objetivos.

- Caudales objetivo de turbinado para aprovechamientos hidroeléctricos. 
- Relaciones entre demandas.

- Relaciones entre canales.

- Relaciones entre elementos: bombeos, recargas artificiales.

Sobre ambos módulos existe un desarrollo informático que incluye diversas interfaces gráficas de usuario basadas en el sistema operativo Windows de Microsoft. Esta interfaz interactiva permite al usuario:

1.- Introducir y modificar, si es necesario, la configuración de un sistema de recursos hidráulicos; ya sea para optimización (módulo Optiwin) o para simulación (módulo Simwin). Esto incluye la posibilidad de obtener una copia en papel del diseño efectuado.

2.-Introducir y gestionar bases de datos que contienen las características físicas de los componentes de los esquemas, así como las características de gestión.

3.-Llevar a cabo una optimización de la gestión para una alternativa dada y un tiempo horizonte dado utilizando diferentes datos hidrológicos.

4.-Llevar a cabo una simulación de la gestión para una alternativa dada y un tiempo horizonte dado, usando diferentes datos hidrológicos y también diferentes reglas de gestión.

5.-Obtener los resultados de la optimización y de la simulación en forma de informe escrito, ya sea detallado para todo el tiempo horizonte o resumido como valores medios e indicadores de garantías.

6.-Obtener los resultados de la optimización y de la simulación en la forma de gráficos de series temporales, gráficos de valores medios y de valores para un año determinado.

7.-Obtener los resultados de la optimización y de la simulación almacenados en archivos que puedan ser utilizados como datos de entrada para cualquier tipo de postprocesador específico que no esté incluido en Aquatool.

Estas capacidades pueden ser utilizadas en un sistema de recursos hidráulicos para:

a.- Filtrar alternativas de diseño mediante el módulo de optimización.

b.-Filtrar alternativas de gestión mediante el uso del módulo de optimización obteniendo criterios de operación a partir del análisis de los resultados óptimos.

c.- Comprobar y refinar las alternativas filtradas mediante el uso del modelo de simulación. 
d.-Llevar a cabo análisis de sensibilidad comparando los resultados después de cambios en el diseño o en las reglas de operación.

e.- Llevar a cabo análisis de riesgo simulando y/u optimizando con diferentes series sintéticas hidrológicas.

f.- Ganar conocimiento del sistema en los aspectos físicos y de gestión. Y también ganar en el aspecto de organización de datos.

g.-Utilizar el modelo una vez que se implanta una alternativa como una ayuda en la operación del sistema de recursos hidráulicos (off-line), principalmente para reparto de recursos entre demandas conflictivas, y para estudiar impactos de cambios en el sistema.

Además, este sistema no es específico para una cuenca determinada sino que está previsto para uso general puesto que permite la representación de diferentes configuraciones de sistemas de recursos hidráulicos mediante el diseño gráfico y la entrada gráfica de datos.

Otro de los principales módulos es el denominado Aquival (Andreu y Capilla, 1996) el cual permite el preproceso y simulación de acuíferos por el método de los autovalores (Andreu y Sahuquillo, 1987). Este módulo permite la formulación de un modelo distribuido de simulación del flujo en un acuífero para su integración dentro de un modelo de simulación del uso conjunto desarrollado con SIMGES. Esto supone que en el módulo SIMGES se incluye también la formulación del modelo de simulación de acuíferos por el método de los autovalores. Más adelante también se desarrollan los módulos de control y edición gráfica de datos y resultados de la modelación de acuíferos.

Finalmente uno de los más modernos es el módulo de evaluación del riesgo "Simrisk". Los primeros usos del mismo se enfocaron al análisis de la gestión del Trasvase Tajo-Segura: Andreu (1994) y Solera (1997) y el sistema de recursos hídricos del río Segura (CHS, 1996). A diferencia de los módulos anteriores, que se aplican en la fase de planificación, este módulo está orientado a su uso en la fase de gestión. El estado de desarrollo de Aquatool en esta fase se describe en Andreu et al. (1996).

Entre los diferentes casos de aplicación del SSD se encuentran los siguientes:

- En 1993-94 se aplica al sistema del río Guadalquivir, como el objetivo de evaluar las garantías de suministro para usos agrícolas (CAPJA, 1984).

- A partir de 1996 el Entorno Aquatool es utilizado por el Centro de Estudios Hidrográficos del CEDEX para el análisis de la gestión del sistema unificado nacional, cuyos resultados son utilizados en la redacción del Libro Blanco del 
Agua en España (MMA, 1999) en los anejos sobre análisis de sistemas hidrológicos (MMA, 2001a) del Plan Hidrológico Nacional.

- En 1997 se comienza a utilizar el Entorno Aquatool en la Oficina de planificación de la Confederación Hidrográfica del Júcar $(\mathrm{CHJ})$, donde se modelan los subsistemas de los ríos Júcar, Turia (Pérez, 2000), Marina Baja (Gandia, 2001) y Mijares (Sopeña, 2002).

- Algunas oficinas de gestión de cuencas como la Confederación Hidrográfica del Guadiana, la Confederación Hidrográfica del Ebro, el Instituto Tecnológico Geominero de España, la Diputación de Alicante, la Diputación general de Aragón y la Agencia Catalana del Agua también han utilizado el Entorno Aquatool, aunque lo han hecho normalmente mediante la colaboración de empresas consultoras independientes sin ninguna intervención por parte del grupo de investigación del DIHMA (salvo el último caso).

El modelo GESCAL ha sido acoplado sobre el módulo SIMGES aunque su incorporación al módulo de optimización OTPIGES es inmediata ya que este módulo tiene un número menor de elementos y los archivos físicos y de resultados son muy similares.

\subsection{CONDICIONANTES DE SIMGES SOBRE EL MÓDULO DE MODELACIÓN DE LA CALIDAD.}

A continuación se describen los condicionantes que impone el módulo SIMGES sobre el módulo de simulación de la calidad desarrollado GESCAL:

- La escala de trabajo del módulo SIMGES, al igual que la mayoría de módulos de simulación de gestión de recursos hídricos, es mensual. Esto ha marcado las hipótesis y los objetivos del trabajo desde el principio.

- El segundo punto impuesto por el modelo de gestión son los elementos de modelación. Se ha trabajado con todos los elementos intentando tener en cuenta, en el nuevo módulo, el efecto de cada uno de ellos sobre la calidad del sistema. Además se ha tenido que añadir nuevos elementos propios de la modelación de la calidad como son los vertidos puntuales y la contaminación difusa.

- Respecto el punto anterior, hay que detallar que el elemento "aportación", el cual representa el aporte de recurso de una subcuenca, marca los límites del modelo tanto de simulación como el de calidad. En algún caso en que, la subcuenca aportante tenga algún proceso de calidad que sea interesante modelar, este aspecto puede ser una limitación. 
- Otro condicionante que se presenta es la posibilidad de calibración o validación del modelo. El objetivo de un modelo de simulación no es reproducir el pasado sino estimar el comportamiento del sistema actual frente a diferentes escenarios. Ello implica que aunque los datos de entrada al modelo sean las aportaciones históricas el resto de datos representa la actualidad del sistema y no su história. Los resultados ni intentan, ni van, a dar los caudales históricos circulantes. Esto conlleva una dificultad adicional para la calibración o validación del modelo completo. La solución a este problema se explica en el apartado de calibración del caso de aplicación.

- Finalmente el último condicionante, aunque no es propio del módulo SIMGES, es el tipo de modelación simplificada que suele hacerse para los modelos de simulación de la gestión. En los modelos de gestión, no importa que la distribución de caudales dentro del sistema sea la real siempre y cuando la disponibilidad del recurso, en los puntos de toma, sea lo más parecido a la realidad. Sin embargo, la circulación de caudales sí que influye en la modelación de la calidad. Debido a ello, a la hora de incorporar un modelo de calidad es normal que se deba realizar una labor de ampliación del detalle del modelo de gestión. 


\section{FORMULACIÓN Y DESARROLLO DE LA HERRAMIENTA DE MODELACIÓN.}

\subsection{INTRODUCCIÓN.}

La herramienta elaborada permite el desarrollo de modelos de calidad del agua sobre modelos de simulación de sistemas de recursos hídricos previamente desarrollados en el SSD AQUATOOL. Aunque la calidad de agua se ha considerado en todos los posibles elementos de la modelación de la simulación la modelación de los procesos físico - químicos y biológicos que afectan a la calidad se considera exclusivamente en los elementos de tramos de río (o canales) y embalses (o lagos). La característica fundamental, de esta herramienta, es la posibilidad de modelar tanto embalses como tramos de río con una misma herramienta y de una forma integrada con el resto de elementos del sistema. Así, de esta forma, la calidad en un tramo de río o en un embalse no sólo depende de los procesos que se producen sino también de la gestión del sistema y de la calidad de los diferentes elementos que tengan relación con el elemento en cuestión. Los constituyentes que se pueden modelar son los siguientes:

- Temperatura.

- Contaminantes arbitrarios

- Oxígeno disuelto y Materia Orgánica Carbonosa (MOC).

- Ciclo del nitrógeno: nitrógeno orgánico, amonio, nitritos y nitratos. Y su afección sobre el oxígeno disuelto.

- Eutrofización: ciclo del nitrógeno, fitoplancton, fósforo orgánico e inorgánico; y su afección sobre el oxígeno disuelto.

La modelación de la temperatura se realiza mediante el método propuesto por Edinger and Geyer (1965). Debido a la importancia de la temperatura en la mayoría de los procesos considerados y que, en algunos casos, no es posible obtener los datos para la modelación de la misma en toda una cuenca, la herramienta dispone de la opción de no modelar la temperatura pero incluir una curva de temperatura mensual para cada elemento modelado. Esta temperatura mensual se utiliza para la corrección de las diferentes constantes de la mayoría de los procesos.

Para los contaminantes arbitrarios se considera un proceso de descomposición modelado mediante una cinética de primer orden y un proceso de sedimentación de la parte particulada. 
Para la modelación del oxígeno disuelto se consideran tres posibles niveles incrementales de complejidad. La opción más sencilla tiene en cuenta la modelación de la MOC y el oxígeno disuelto. El segundo grado de complejidad considera adicionalmente el ciclo del nitrógeno. Las diferentes formas consideradas son nitrógeno orgánico, amonio, nitritos y nitratos. Finalmente el último nivel de complejidad permite la modelación de la MOC, el ciclo del nitrógeno, fitoplancton, el fósforo, sus relaciones y las afecciones sobre el oxígeno disuelto.

En el apartado 4.4. se describen los procesos considerados y las ecuaciones resultantes. La mayoría de los procesos se han considerado como cinéticas de primer orden. Otras características de la herramienta son las siguientes:

- En los ríos se considera las hipótesis de unidimensional y estado estacionario. Los procesos físicos considerados en los tramos de río han sido la dispersión y la advección. La modelación hidráulica puede realizarse por relaciones potenciales con el caudal o a través de la fórmula de Manning.

- Para los embalses se ha concebido la posibilidad de modelarlos en dos capas representando el epilimnion y el hipolimnion. También se pueden considerar como un sólo elemento de mezcla completa. Debido a la variabilidad del volumen de los embalses a lo largo del tiempo se realiza una estimación de la calidad de forma dinámica. En los embalses modelados con dos capas se considera la difusión entre las mismas.

- En los embalses se establece, de forma variable mensualmente, la cota de la termoclina y el reparto de entradas y salidas entre ambas capas. Además el programa, de forma automática, estima si el volumen no es suficiente para que se produzca la estratificación térmica y la elimina.

- Se permite la incorporación de vertidos puntuales en cualquier nudo o embalse del sistema lo que implica el inicio de los tramos de río. La incorporación de vertidos intermedios pasa por la fragmentación de los tramos. Además permite incorporar elementos de contaminación difusa sobre cualquier tramo de río.

- En la modelación de los tramos de río también se tiene en cuenta la posible relación hidráulica con los acuíferos ya sea por aporte de agua desde el acuífero o por filtración del río.

El programa ha sido desarrollado en lenguaje de programación Fortran y es utilizable en cualquier ordenador personal con sistema operativo Windows. Además se ha realizado una interfaz gráfica en la plataforma Visual Basic 6 para facilitar la modelación al usuario e integrar la herramienta en el SSD AQUATOOL. 


\section{2. SUBRUTINAS Y ESTRUCTURA DEL PROGRAMA.}

El programa está formado por diferentes módulos o subrutinas que se pueden dividir en tres tipos: lectura de datos, operaciones y salidas de resultados.

La entrada de datos, en primer lugar, está compuesta por la lectura de datos provenientes del modelo de gestión, estos son: datos físicos del modelo y datos de resultados de la simulación. Ambos se pueden obtener de dos archivos que genera el modelo de gestión SIMGES del SSD AQUATOOL. De estos archivos se obtiene toda la información necesaria sobre el sistema y sobre los flujos de caudal a través del mismo. Por otra parte, los datos expresamente recogidos para la modelación de la calidad se leen en tres archivos: un primer archivo que recoge toda la información de calidad sobre los elementos, la simulación, vertidos, etc. Un segundo archivo "Coeftes.cal" en el que se recogen todas las constantes que se utilizan en la modelación de la calidad, este archivo no suele tener modificaciones. Finalmente un tercer archivo en donde se recoge las series de calidad de las aportaciones del sistema.

Las subrutinas de operación son cuatro:

- La primera establece el orden de simulación de los elementos.

- La segunda monta la estructura de simulación de la calidad con bucles temporales y por elementos.

- Esta subrutina hace llamadas a las otras dos restantes una de simulación de conducciones y otra de simulación de embalses.

Una vez realizados todos los cálculos para la simulación de la calidad se realiza la llamada a una serie de módulos para la salida de resultados a archivo, ya sean a modo de informe o con formato importable desde una hoja de cálculo.

Debido a que gran parte de las variables son compartidas entre distintas subrutinas existen un conjunto de módulos de almacenamiento de variables.

Finalmente, un último módulo recoge un conjunto de funciones auxiliares como son las de cambio de unidades o la resolución de las ecuaciones diferenciales.

En la siguiente figura se muestra el diagrama de todos los módulos que componen el programa. 


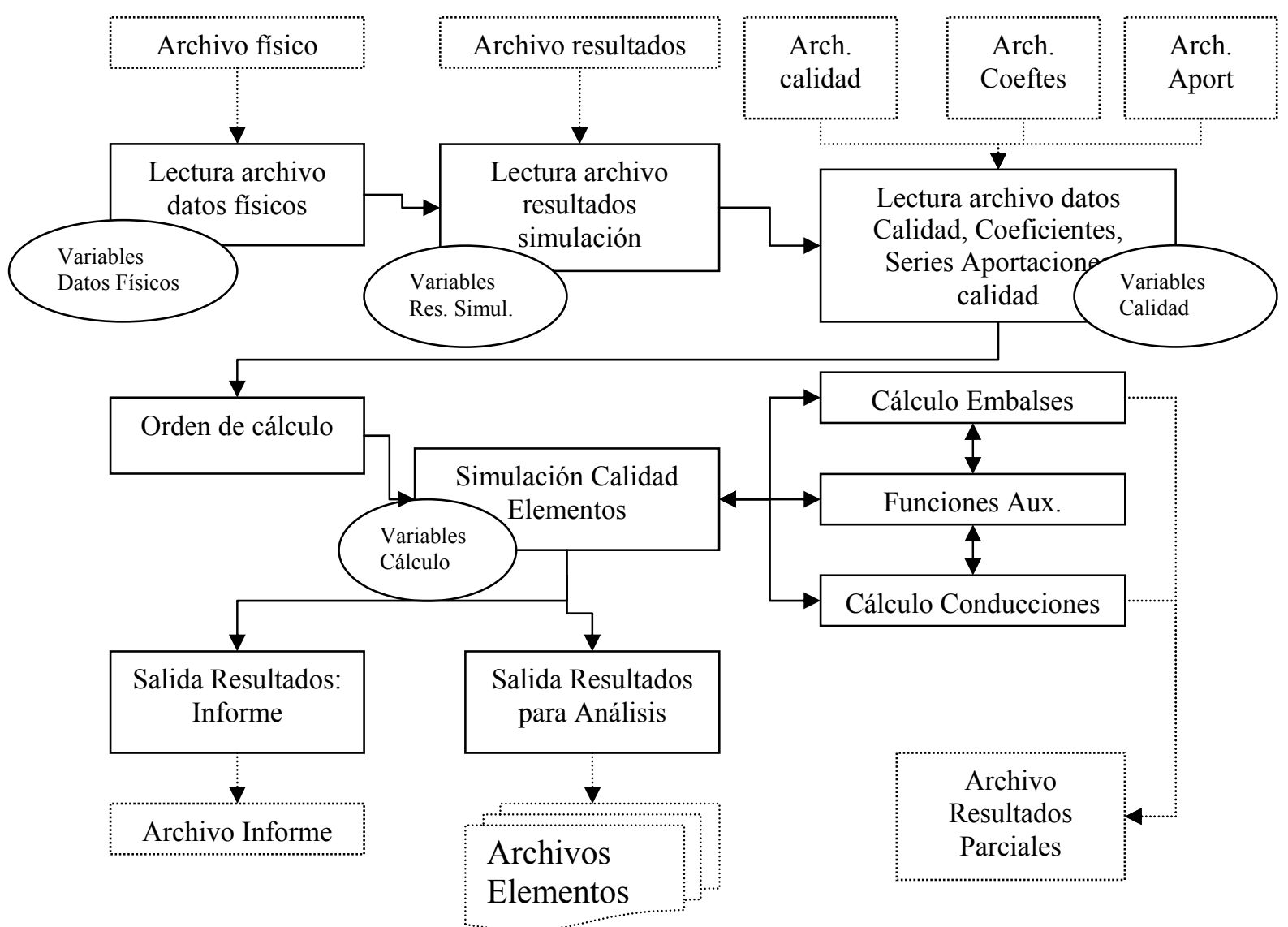

Figura 3. Estructura del Programa GESCAL

\subsection{HIDRÁULICA.}

\subsubsection{Hidráulica de Ríos.}

Bajo la hipótesis de unidimensionalidad en ríos es necesario establecer un modelo hidráulico que relacione los caudales circulantes con la velocidad del río, profundidad y ancho del mismo. Para el establecimiento de esta relación se dispone de dos métodos. El primero, desarrollado por Leopold and Maddock (1953) establece relaciones potenciales entre las distintas variables hidráulicas y el caudal:

$$
\begin{aligned}
& u=\alpha_{1} Q^{\beta_{1}} \\
& h=\alpha_{2} Q^{\beta_{2}} \\
& b=\alpha_{3} Q^{\beta_{3}}
\end{aligned}
$$

Donde:

- u representa la velocidad $\left(\mathrm{ms}^{-1}\right)$.

- $Q$ es el caudal circulante $\left(\mathrm{m}^{3} \mathrm{~s}^{-1}\right)$. 
- h es el calado (m).

- b el ancho del río (m).

- Los coeficientes $\alpha_{1}, \beta_{1}, \alpha_{2}, \beta_{2}, \alpha_{3}$ y $\beta_{3}$ son parámetros que se establecen de forma empírica y que por continuidad deben cumplir:

$$
\beta_{1+} \beta_{2+} \beta_{3}=1(4.4)
$$

$\mathrm{y}$

$\alpha_{1} \alpha_{2} \alpha_{3}=1(4.5)$

El segundo método implementado en el programa es el cálculo hidráulico por la fórmula de Manning:

$u=\frac{R_{h}^{2 / 3} I^{1 / 2}}{n}$

En donde:

- $R_{h}(m)$ representa el radio hidráulico que se obtienen como el cociente entre el área mojada y el perímetro mojado

- I ( $\mathrm{m} / \mathrm{m})$ representa la pendiente del canal y n es el número de Manning o de rugosidad. La velocidad se obtiene en $\mathrm{ms}^{-1}$.

Se considera una sección trapezoidal con lo que la ecuación anterior queda de la siguiente forma:

$$
u=\frac{\left(\frac{b_{o} y+s y^{2}}{b_{o}+2 y \sqrt{s^{2}+1}}\right)^{2 / 3} I^{1 / 2}}{n}
$$

Donde:

- $b_{o}$ representa el ancho de la solera del río $(\mathrm{m})$.

- $\mathrm{s}$ es la pendiente lateral $(\mathrm{m} / \mathrm{m})$.

- y representa el calado (m).

La resolución de la ecuación de Manning pasa por aplicar un método de resolución numérica por iteración.

Debido a las posibles relaciones de los tramos de río con los acuíferos, el caudal no tiene porque ser el mismo a lo largo del tramo. Por ello, asumiendo que las pérdidas o ganancias de caudal son uniformes a lo largo del tramo, las relaciones hidráulicas se 
resuelven para cada uno de los "segmentos" o diferenciales en los que se divide el tramo para el cálculo. Por otra parte, cabe destacar que la elección de un método u otro no es global para todos los tramos de río permitiendo aplicar un método u otro de forma discrecional sobre los tramos.

Los valores de dispersión longitudinal para cada tramo de río pueden ser introducidos directamente o calculados a través de la expresión establecida por Fischer et. al. (1979):

$$
E=0.011 \frac{u^{2} b^{2}}{h u^{*}}
$$

donde $\mathrm{u}^{*}$ es la velocidad gravitacional $\left(\mathrm{ms}^{-1}\right)$ calculada como:

$u^{*}=\sqrt{g h s}(4.9)$

donde g es la aceleración gravitacional $\left(\mathrm{ms}^{-2}\right)$.

La dispersión se calcula en cada uno de los segmentos de cada tramo de río.

Otra opción incluida en el programa es el cálculo de la dispersión para estuarios, una formula para obtener valores aproximados la define Thomman (1987):

$$
E=\frac{u L}{\ln \left(s_{2} / s_{1}\right)}
$$

Donde:

- L es la longitud del tramo (m).

- $\mathrm{s}_{2} \mathrm{y} \mathrm{s}_{1}$ la salinidad al final y al inicio del tramo.

\subsubsection{Hidráulica de Embalses}

Para la modelación de un embalse en dos capas que representan el epilimnion y el hipolimnion se necesita definir los siguientes datos:

- Tanto por ciento de entrada al epilimnion. Definido de forma variable para cada mes.

- Tanto por ciento de salidas desde el epilimnion. Definido de forma variable en cada mes.

- Cota de la termoclina. Definida de forma variable mes a mes.

El proceso hidráulico en los embalses consta de una serie de comprobaciones que define si la modelación se realiza como un tanque completamente mezclado o en dos capas. El proceso es el siguiente: 
- Cada mes si el dato de la cota de la termoclina es nulo el embalse se modelará como un único elemento completamente mezclado.

- Si por el contrario, la cota es superior a cero, la siguiente tarea es comprobar si hay suficiente volumen de agua para que se produzca esta estratificación. Cuando los volúmenes de embalse son muy bajos se rompe la estratificación debido a que las turbulencias inducidas por el viento, los aportes y el vaciado suelen influir en todo el volumen embalsado. Para tener en cuenta este efecto en el archivo de constantes se incluye un parámetro denominado "coeficiente de termoclina" que representa un tanto por ciento que se aplica a la altura actual del embalse. Si la cota de la termoclina es inferior a este tanto por cien entonces se considera que no hay suficiente volumen para la estratificación por lo que ese mes se modelará como mezcla completa. Si por el contrario hay suficiente volumen para que se dé la estratificación térmica, el siguiente paso es la estimación de los volúmenes iniciales y finales de las capas del embalse. Para ello, a partir de los datos introducidos en el modelo de simulación de la curva cota - superficie - volumen del embalse se estima la altura de la termoclina y los volúmenes del epilimnion e hipolimnion tanto a inicio como a final de mes.

- Finalmente se hace la comprobación de que ninguno de los volúmenes finales sean nulos. Si se da este caso se modelará como mezcla completa.

La siguiente figura muestra un diagrama del proceso:

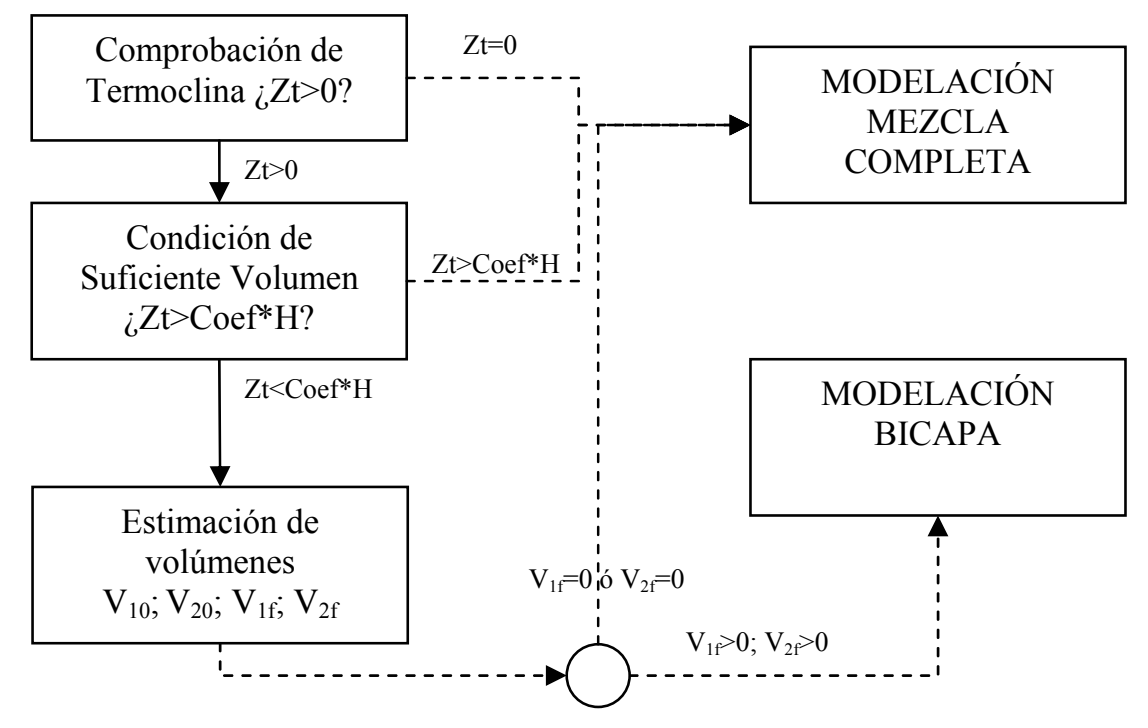

Figura 4. Estructura del cálculo hidráulico en los embalses considerada en GESCAL.

La modelación de la calidad dentro de cada mes se realiza resolviendo las ecuaciones planteadas para cada constituyentes en diferenciales de tiempo. El volumen 
de embalse en cada intervalo de tiempo se obtiene asumiendo una evolución lineal entre el volumen inicial y final de cada mes.

El valor de la difusión entre las dos capas puede ser estimado a través de la relación propuesta por Snodgrass (1974):

$$
E_{12}=7.07 * 10^{-4} H^{1.1505} \text { (4.11) }
$$

Donde $\mathrm{H}$ es la altura de la termoclina (m). Los coeficientes establecidos por Snodgrass pueden ser modificados en el archivo de constantes.

Mientras que la modelación de la calidad del agua de los embalses se realiza de forma dinámica, en los tramos de río se consideran condiciones estacionarias. Por ello, una vez estimada la evolución de la calidad del embalse en un mes, a los tramos de río de aguas abajo se les introduce un sólo valor, correspondiente a la media de todos los valores calculados para el embalse en ese mes.

\subsection{CONSTITUYENTES, REACCIONES Y RELACIONES.}

En este apartado se plantean las ecuaciones diferenciales a resolver que se obtienen de las diferentes hipótesis que se realizan para los tramos de ríos y los embalses y para cada uno de los constituyentes que la herramienta permite modelar. Para una mayor claridad, el apartado se divide primero por sistemas naturales y en subapartados por constituyentes. Seguidamente, un apartado muestra la forma de integración por métodos numéricos de las ecuaciones diferenciales planteadas.

\subsubsection{Modelación de la calidad en tramos de río.}

Como se ha comentado previamente para la modelación de los tramos de río se asumen las hipótesis de unidimensional y estacionario. Además se tienen en cuenta tanto procesos de dispersión como de advección a lo largo del eje longitudinal. Se permite la incorporación de carga difusa a lo largo de cualquier tramo, pero no de vertidos puntuales intermedios. Se ha considerado que los vertidos puntuales se ubican sobre los nudos del sistema y que en el mismo nudo se produce la mezcla instantánea.

Por otra parte se tiene que tener en cuenta las posibles filtraciones de un tramo de río o los posibles aportes del acuífero.

\subsubsection{Temperatura.}

Bajo las condiciones previamente mencionadas, se plantea la siguiente ecuación diferencial para la modelación de la temperatura en un tramo de río: 
$0=\frac{d}{d x}\left(E \frac{d T}{d x}\right)-\frac{d(u T)}{d x}+\frac{\phi A_{x y}}{\rho_{w} c_{s} V}+\frac{T_{d}+T_{e} q_{e}-T q_{s}}{V}$

En donde:

- E representa la dispersión $\left(\mathrm{m}^{2} \mathrm{dí}^{-1}\right)$.

- T la temperatura del tramo del río $\left({ }^{\circ} \mathrm{C}\right)$.

- x la distancia a lo largo del tramo de río (m).

- u la velocidad (mdía $\left.{ }^{-1}\right)$.

- $\phi$ es la energía incidente $\left(\mathrm{Wm}^{-2} \mathrm{dí}^{-1}\right)$.

- $\mathrm{A}_{\mathrm{xy}}$ representa el área de la lámina de agua $\left(\mathrm{m}^{2}\right)$.

- $\rho_{\mathrm{w}}$ es la densidad del agua $\left(\mathrm{grm}^{-3}\right)$.

- $\mathrm{c}_{\mathrm{s}}$ es el calor específico de la misma $\left(\mathrm{Wgr}^{-10} \mathrm{C}^{-1}\right)$.

- V el volumen de la masa de agua $\left(\mathrm{m}^{3}\right)$.

- $\mathrm{T}_{\mathrm{d}}$ es la posible contaminación térmica de forma difusa $\left({ }^{\circ} \mathrm{Cm}^{3} \mathrm{día}^{-1}\right)$.

- Te representa la temperatura del acuífero aportante $\left({ }^{\circ} \mathrm{C}\right)$.

- $\mathrm{q}_{\mathrm{e}}$ es el caudal que aporta el acuífero $\left(\mathrm{m}^{3} \mathrm{dí}^{-1}\right)$.

- $\mathrm{q}_{\mathrm{s}}$ el posible caudal filtrante al acuífero $\left(\mathrm{m}^{3} \mathrm{dí}^{-1}\right)$.

Aplicando la linearización propuesta por Edinger and Geyer (1965) explicada previamente en el capítulo 2 la ecuación anterior queda de la forma incluida en el módulo:

$0=-\frac{d(u T)}{d x}+\frac{d}{d x}\left(E \frac{d T}{d x}\right)+\frac{K_{e q}\left(T_{e q}-T\right) A_{x y}}{\rho_{w} c_{s} V}+\frac{T_{d}+T_{e} q_{e}-T q_{s}}{V}$

En donde:

- $\mathrm{K}_{\mathrm{eq}}$ es el coeficiente de intercambio de calor $\left(\mathrm{Wm}^{-2 o} \mathrm{C}^{-1}\right)$.

- $\mathrm{T}_{\text {eq }}$ es la temperatura de equilibrio $\left({ }^{\circ} \mathrm{C}\right)$.

\subsubsection{Contaminantes arbitrarios y conservativos.}

El programa permite la modelación de cuantos contaminantes arbitrarios se desee. Sobre los contaminantes arbitrarios se pueden considerar dos procesos que afectan a las concentraciones en los mismos: una descomposición siguiendo una cinética de primer orden y un perdida por sedimentación de la parte particulada. La ecuación diferencial a resolver queda de la siguiente forma: 


$$
0=\frac{d}{d x}\left(E \frac{d C}{d x}\right)-\frac{d(u C)}{d x}-K\left(\theta^{T-20}\right) C-\frac{V S}{h} C+\frac{S_{d}+C_{e} q_{e}-C q_{s}}{V}
$$

Donde:

- K representa la constante de descomposición a $20^{\circ} \mathrm{C}\left(\right.$ día $\left.^{-1}\right)$.

- $\theta$ es el coeficiente por corrección de temperatura.

- La sedimentación se considera mediante un parámetro VS que representa la velocidad de sedimentación del constituyente $\left(\right.$ mdía $\left.^{-1}\right)$.

- h es el calado del río (m).

- C representa la concentración del contaminante en el río $\left(\mathrm{mgl}^{-1}\right)$.

- $\mathrm{C}_{\mathrm{e}}$ es la concentración del acuífero $\left(\mathrm{mgl}^{-1}\right)$.

Para considerar un contaminante como conservativo basta con considerar nulos la constante de descomposición y la velocidad de sedimentación.

\subsubsection{Oxígeno Disuelto - Nitrógeno - Eutrofización.}

Por un lado la escala de trabajo mensual, que impone el modelo de gestión, y por otro la dependencia entre constituyentes como la materia orgánica, oxígeno disuelto y otros hace que en este módulo se haya considerado la búsqueda del estado estacionario. Para ello, se resuelven las ecuaciones planteadas de forma iterativa variando las concentraciones iniciales. Este aspecto se desarrolla más adelante.

Como se ha comentado previamente, la modelación del oxígeno disuelto y los procesos relacionados se puede realizar en tres niveles de complejidad.

El primer nivel realiza la simulación de la materia orgánica carbonosa (MOC) que queda por consumir en cada instante y del oxígeno disuelto. Para la modelación de la MOC se tiene en cuenta la degradación por microorganismos aeróbicos heterótrofos y la sedimentación de la parte particulada. Así la ecuación diferencial queda de la siguiente forma:

$$
0=\frac{d}{d x}\left(E \frac{d L}{d x}\right)-\frac{d(u L)}{d x}-K_{d} \theta_{d}^{T-20} L-\frac{V S_{L}}{h} L+\frac{S_{d L}+L_{e} q_{e}-L q_{s}}{V}
$$

En donde:

- L es la concentración de MOC en el río $\left(\mathrm{mgl}^{-1}\right)$.

- $\mathrm{K}_{\mathrm{d}}$ es la constante de degradación (día $\left.{ }^{-1}\right)$ 
- $\theta_{\mathrm{d}}$ es la constante por corrección de la temperatura de la constante $\mathrm{K}_{\mathrm{d}}$

- O es la concentración de oxígeno disuelto $\left(\mathrm{mgl}^{-1}\right)$.

- $\mathrm{VS}_{\mathrm{L}}$ es la velocidad de sedimentación $\left(\right.$ mdía $\left.^{-1}\right)$.

Como se puede ver, en la estimación de la constante de degradación de la MOC se tiene en cuenta la corrección por temperatura.

Por otra parte, hay que destacar que, como ya se comentará en el apartado de unidades, las entradas y salidas al programa de la MOC se realizan en forma de demanda bioquímica de oxígeno a cinco días $\left(\mathrm{DBO}_{5}\right)$. El programa internamente lo transforme a DBO límite como se explica más adelante.

Finalmente, cuando las concentraciones de oxígeno disuelto son bajas la degradación de materia orgánica se reduce ya que los microorganismos de oxidación de la misma son aeróbicos. Frente a esta situación se asume la hipótesis realizada por Gundelach y Castillo (1970) la cual mantiene que en condiciones anaerobias la degradación de materia orgánica es de orden cero. Bajo esta hipótesis la ecuación anterior queda de la siguiente forma:

$$
0=\frac{d}{d x}\left(E \frac{d L}{d x}\right)-\frac{d(u L)}{d x}-K_{a} \theta_{a}^{T-20} O_{s a t}-\frac{V S_{L}}{h} L+\frac{S_{d L}+L_{e} q_{e}-L q_{s}}{V}
$$

Donde

- Osat es la concentración de saturación de oxígeno disuelto $\left(\mathrm{mgl}^{-1}\right)$.

- $\mathrm{K}_{\mathrm{a}}$ es la constante de reaireación $\left(\right.$ día $\left.^{-1}\right)$.

- $\theta_{\text {a }}$ se factor de corrección por temperatura.

Para la modelación del oxígeno disuelto se tienen en cuenta el proceso de reaireación y el consumo del oxígeno debido a la degradación de la MOC. La ecuación diferencial queda de la siguiente forma:

$$
0=\frac{d}{d x}\left(E \frac{d O}{d x}\right)-\frac{d(u O)}{d x}+K_{a} \theta_{a}^{T-20}\left(O_{s a t}-O\right)-K_{d} \theta_{d}^{T-20} L+\frac{S_{o d}+O_{e} q_{e}-O q_{s}}{V}
$$

Donde:

- O es la concentración de oxígeno disuelto en el río $\left(\mathrm{mgl}^{-1}\right)$.

- Osat es la concentración de saturación de oxígeno disuelto $\left(\mathrm{mgl}^{-1}\right)$.

- $\mathrm{K}_{\mathrm{a}}$ es la constante de reaireación $\left(\right.$ día $\left.^{-1}\right)$.

- $\theta_{\mathrm{a}}$ se factor de corrección por temperatura. 
La saturación de oxígeno disuelto se estima a partir de la temperatura del tramo de río utilizando la ecuación propuesta en (APHA, 1992)

$$
\ln O_{\text {satpo }}=-139.34411+\frac{1.575701 \cdot 10^{5}}{T_{a}}-\frac{6.642308 \cdot 10^{7}}{T_{a}^{2}}+\frac{1.2438 \cdot 10^{10}}{T_{a}^{3}}-\frac{8.621949 \cdot 10^{11}}{T_{a}^{4}}
$$

Donde: $T_{a}$ es la temperatura del agua en grados Kelvin.

El valor de la saturación de oxígeno disuelto obtenido se corrige en función de la altitud media de la cuenca mediante la aproximación establecida por (Zison et al., 1998).

$$
O_{\text {sat }}=O_{\text {sapo }}\left(1-0.1148 Z_{e}\right)(4.19)
$$

Donde $Z_{\mathrm{e}}$ representa la elevación media de la cuenca sobre el nivel del mar en $\mathrm{km}$.

La constante de reaireación puede ser introducida como un dato u obtenerse mediante la expresión propuesta por O’Connor \& Dobbins (1956).

$$
K a=3.93 \frac{u^{0.5}}{h^{1.5}}
$$

En el segundo nivel de complejidad se tiene en cuenta el ciclo del nitrógeno y su efecto sobre el balance de oxígeno disuelto. En la modelación del ciclo del nitrógeno se tiene en cuenta el nitrógeno orgánico y las diferentes formas inorgánicas: amonio, nitritos y nitratos.

Para el nitrógeno orgánico se consideran los procesos de amonificación y sedimentación:

$$
0=\frac{d}{d x}\left(E \frac{d N_{o}}{d x}\right)-\frac{d\left(u N_{o}\right)}{d x}-K_{\text {Noa }} \theta_{\text {noa }}^{T-20} N_{o}-\frac{V S_{N_{0}}}{h} N_{o}+\frac{S_{d N_{o}}+N_{o e} q_{e}-N_{o} q_{s}}{V}
$$

Donde:

- $\mathrm{K}_{\text {noa }}$ representa la constante de amonificación ( día $\left.^{-1}\right)$.

- $\theta_{\text {noa }}$ representa el coeficiente de corrección de la constante anterior por temperatura.

- $\mathrm{N}_{\mathrm{o}}$ es la concentración de nitrógeno orgánico en el río $\left(\mathrm{mgl}^{-1}\right)$.

- $\mathrm{VS}_{\mathrm{NO}}$ velocidad de sedimentación del nitrógeno orgánico $\left(\right.$ mdía $\left.^{-1}\right)$.

- $\mathrm{N}_{\mathrm{oe}}$ concentración de nitrógeno orgánico del acuífero aportante $\left(\mathrm{mgl}^{-1}\right)$. 
Los procesos considerados sobre el amonio han sido el incremento de concentración por la amonificación del nitrógeno orgánico y la disminución de la misma por la nitrificación.

$0=\frac{d}{d x}\left(E \frac{d N_{a}}{d x}\right)-\frac{d\left(u N_{a}\right)}{d x}+K_{\text {Noa }} \theta_{K n o a}^{T-20} N_{o}-\left(K_{N a i} \theta_{n a i}^{T-20} \frac{O}{O+K_{n 1 / 2}}\right) N_{a}+\frac{S_{d N_{a}}+N_{a e} q_{e}-N_{a} q_{s}}{V}$

En donde:

- $\mathrm{N}_{\mathrm{a}}$ representa la concentración de amonio $\left(\mathrm{NH}_{4}{ }^{+}\right)$en el río $\left(\mathrm{mgl}^{-1}\right)$.

- $\mathrm{K}_{\mathrm{Nai}}$ es la constante de nitrificación de paso a nitritos (día $\left.{ }^{-1}\right)$.

- $\theta_{\text {nai }}$ es la corrección por temperatura de la constante de nitrificación

- $\mathrm{K}_{\mathrm{n} 1 / 2}$ es la constante de semisaturación del nitrógeno $\left(\mathrm{mgl}^{-1}\right)$.

El efecto de la reducción de nitrificación por condiciones anóxicas se ha considerado corrigiendo la constante con un factor dependiente de la concentración del oxígeno disuelto y una constante de semisaturación. Por otra parte, hay que mencionar, que esta ecuación se plantea en términos de concentración de nitrógeno. Como se explicará en el apartado de unidades las entradas y salidas del programa se realizan en términos de concentración de amonio $\left(\mathrm{NH}_{4}{ }^{+}\right)$e internamente se realiza el cambio de unidades. Esta característica también afecta a los nitritos y nitratos.

En el proceso de modelación de los nitritos se tiene en cuenta el efecto del incremento de concentración por la transformación de amonio y la disminución de los mismos por la transformación de los nitritos en nitratos.

$0=\frac{d}{d x}\left(E \frac{d N_{i}}{d x}\right)-\frac{d\left(u N_{i}\right)}{d x}+\left(\begin{array}{cc}K_{\text {Nai }} \theta_{\text {nai }}^{T-20} & O \\ O+K_{\text {nai } / 2}\end{array}\right) N_{a}-\left(\begin{array}{cc}K_{\text {nio }} \theta_{\text {nio }}^{T-20} & O \\ O+K_{n 1 / 2}\end{array}\right) N_{i}+\frac{S_{d N_{i}}+N_{i e} q_{e}-N_{i} q_{s}}{V}$

Donde:

- $\mathrm{N}_{\mathrm{i}}$ es la concentración de nitritos $\left(\mathrm{mgl}^{-1}-\mathrm{N}\right)$.

- $\mathrm{K}_{\text {nio }}$ representa la constante de nitrificación de nitritos a nitratos (día $\left.{ }^{-1}\right)$.

- $\theta_{\text {nio }}$ es el factor de corrección de temperatura para la constante anterior.

Como se puede ver en la ecuación, también se tiene en cuenta la afección de la concentración de oxígeno disuelto en la constante de transformación.

Finalmente, en la modelación de los nitratos se tiene en cuenta el incremento de concentraciones por la transformación de nitritos a nitratos y un proceso de eliminación que sigue una cinética de primer orden. Este proceso se ha considerado para poder modelar la eliminación de los mismos por actividad biológica pero sin que se tenga que 
modelar el fitoplancton, fósforo, etc. De esta forma la ecuación diferencial a resolver para los nitratos queda:

$0=\frac{d}{d x}\left(E \frac{d N_{o 3}}{d x}\right)-\frac{d\left(u N_{o 3}\right)}{d x}+\left(K_{n i o} \theta_{n i o}^{T-20} \frac{O}{O+K_{n 1 / 2}}\right) N_{i}-K_{\text {No3 }} \theta_{n 03}^{T-20} N_{o 3}+\frac{S_{d N_{i}}+N_{o 3 e} q_{e}-N_{o 3} q_{s}}{V}$

Donde:

- $\mathrm{N}_{\mathrm{o} 3}$ representa la concentración de nitratos en el río $\left(\mathrm{mgl}^{-1}-\mathrm{N}\right)$.

- $\mathrm{K}_{\mathrm{No} 3}$ es la constante de degradación de los mismos (día $\left.{ }^{-1}\right)$.

- $\theta_{\text {no3 }}$ es el factor corrector por temperatura.

Debido al consumo de oxígeno disuelto en el proceso de nitrificación la ecuación del oxígeno disuelto se modifica de la siguiente forma:

$$
\begin{aligned}
& 0=\frac{d}{d x}\left(E \frac{d O}{d x}\right)-\frac{d(u O)}{d x}+K_{a} \theta_{a}^{T-20}\left(O_{\text {sat }}-O\right)-K_{d} \theta_{d}^{T-20} L-r_{a}\left(K_{N a i} \theta_{n a i}^{T-20} \quad \begin{array}{l}
O+K_{n 1 / 2}
\end{array}\right) N_{a}- \\
& -r_{i}\left(K_{\text {nio }} \theta_{\text {nio }}^{T-20} \frac{O}{O+K_{n 1 / 2}}\right) N_{i}+\frac{S_{\text {od }}+O_{e} q_{e}-O q_{s}}{V}
\end{aligned}
$$

En donde:

- $r_{a}$ representa el consumo de oxígeno por oxidación de amonio $(3.43 \mathrm{mgO} / \mathrm{mgN})$.

- $\mathrm{r}_{\mathrm{i}}$ representa el consumo de oxígeno por oxidación de los nitritos $(1.14 \mathrm{mg} / \mathrm{O} / \mathrm{mgN})$.

La tercera opción consiste en considerar el fitoplancton y el fósforo y su relación con el nitrógeno y el oxígeno disuelto. Esta opción es conveniente para el caso de sistemas con problemas de eutrofización. La siguiente figura muestra un grafo con los procesos simulados y las relaciones entre elementos en este tercer nivel de complejidad. 


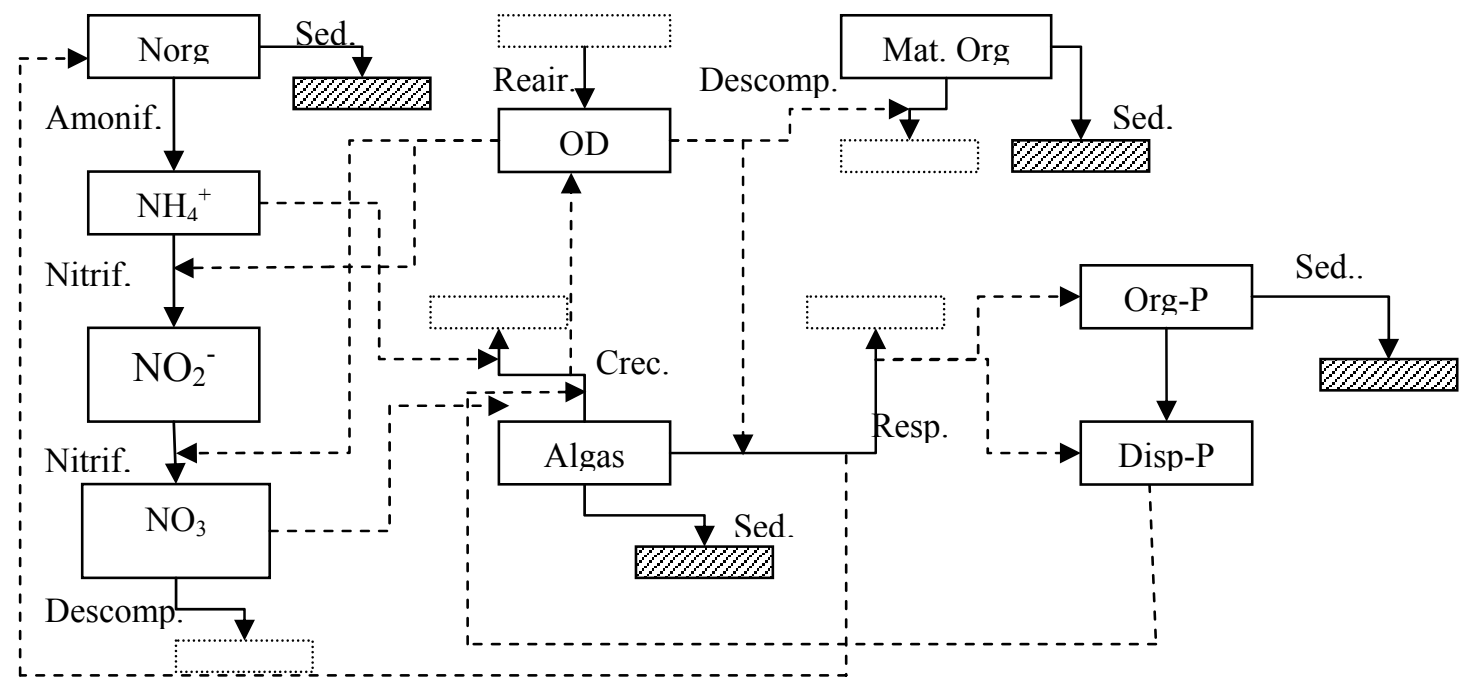

Figura 5. Grafo sobre los procesos modelables en la opción de eutrofización.

Para la modelación del fitoplancton se tienen en cuenta los procesos de crecimiento y respiración así como de sedimentación de las mismas. El crecimiento de las algas viene condicionado por la temperatura, el factor lumínico (variable de forma mensual) y la disponibilidad de nutrientes. Con ello se plantea la siguiente ecuación:

$$
\begin{aligned}
& 0=\frac{d}{d x}\left(E \frac{d A}{d x}\right)-\frac{d(u A)}{d x}+\left[\left(K_{g \max } \theta_{g}^{T-20} F_{l} \operatorname{Min}\left(\frac{N_{\text {aio } 3}}{N_{\text {aio } 3}+K_{N F 1 / 2}} ; P+K_{P 1 / 2}\right)\right)-K_{\text {resp }} \theta_{\text {resp }}^{T-20}\right] A- \\
& -\frac{V S_{A}}{h} A+\frac{S_{d A}+A_{e} q_{e}-A q_{s}}{V}(4.26)
\end{aligned}
$$

Donde:

- A es la concentración de clorofila-a en el tramo de río $\left(\mathrm{mgl}^{-1}\right)$.

- $\mathrm{K}_{\mathrm{gmax}}$ es la constante máxima de crecimiento de fitoplancton a 20 grados (día ${ }^{-1}$ ).

- $\theta_{\mathrm{g}}$ corrección por temperatura del crecimiento de fitoplancton.

- F $F_{1}$ es el factor de atenuación lumínica de variación mensual.

- $\mathrm{N}_{\text {aio3 }}$ representa la concentración de nitrógeno inorgánico $\left(\mathrm{mgl}^{-1}\right)$.

- $\mathrm{K}_{\mathrm{NF1} / 2}$ es la constante de semisaturación del nitrógeno.

- P es la concentración de fósforo disuelto en el tramo de río $\left(\mathrm{mgl}^{-1}\right)$.

- $\mathrm{K}_{\mathrm{p} 1 / 2}$ es la constante de semisaturación para el fósforo $\left(\mathrm{mgl}^{-1}\right)$.

- $K_{\text {resp }}$ representa la constante de respiración y muerte de las algas (día $\left.{ }^{-1}\right)$. 
- $\theta_{\text {resp }}$ es el coeficiente de corrección por temperatura.

- $\mathrm{VS}_{\mathrm{A}}$ es la velocidad de sedimentación de las algas (mdía $\left.{ }^{-1}\right)$.

El fósforo se ha modelado considerando sus formas orgánicas e inorgánico disuelto. Sobre el fósforo orgánico se considera el efecto de la respiración del fitoplancton, la mineralización del mismo a la forma inorgánica y la sedimentación. Con estas consideraciones la ecuación queda de la siguiente forma:

$0=\frac{d}{d x}\left(E \frac{d P_{o r}}{d x}\right)-\frac{d\left(u P_{o r}\right)}{d x}-K_{m p} \theta_{m p}^{T-20} P_{o r}+f_{p} r_{p a} K_{\text {resp }} \theta_{r e s p}^{T-20} A-\frac{V S_{o r}}{h} P_{o r}+\frac{S_{d P_{o r}}+P_{o r e} q_{e}-P_{o r} q_{s}}{V}$

Donde:

- $\mathrm{P}_{\text {or }}$ es la concentración de fósforo orgánico $\left(\mathrm{mgl}^{-1}\right)$.

- $\mathrm{K}_{\mathrm{mp}}$ representa la constante de mineralización del fósforo orgánico $\left(\right.$ día $\left.^{-1}\right)$.

- $\theta_{\mathrm{mp}}$ es el coeficiente de corrección por temperatura de la constante de mineralización.

- $\mathrm{r}_{\mathrm{pa}}$ es el coeficiente estequiométrico $(\mathrm{mgP} / \mathrm{mgA})$.

- VS $\left.\mathrm{or}_{\text {es la velocidad de sedimentación del fósforo orgánico (mdía }}{ }^{-1}\right)$.

- $\mathrm{f}_{\mathrm{p}}$ es la fracción de fósforo orgánico que se genera en la respiración del fitoplancton.

Sobre el fósforo inorgánico o disuelto se considera el efecto de mineralización de la forma orgánica y el del crecimiento del fitoplancton.

$$
\begin{aligned}
& 0=\frac{d}{d x}\left(E \frac{d P}{d x}\right)-\frac{d(u P)}{d x}+K_{m p} \theta_{m p}^{T-20} P_{o r}-r_{p a}\left[\left(K_{g \max } \theta_{g}^{T-20} F_{l} \operatorname{Min}\left(\frac{N_{a i 03}}{N_{\text {aio } 3}+K_{N F 1 / 2}} ; \frac{P}{P+K_{P 1 / 2}}\right)\right)\right] A+ \\
& +\left(1-f_{p}\right) r_{p a} K_{\text {resp }} \theta_{\text {resp }}^{T-20} A+\frac{S_{d P}+P_{e} q_{e}-P q_{s}}{V}(4.28)
\end{aligned}
$$

Donde:

- P representa la concentración de fósforo inorgánico en el río $\left(\mathrm{mgl}^{-1}\right)$.

La respiración y muerte de las algas produce un incremento de nitrógeno orgánico. Por ello la ecuación (4.21) que de la siguiente forma:

$0=\frac{d}{d x}\left(E \frac{d N_{o}}{d x}\right)-\frac{d\left(u N_{o}\right)}{d x}-K_{\text {Noa }} \theta_{\text {nоa }}^{T-20} N_{o}-\frac{V S_{\text {No }}}{h} N_{o}+\frac{S_{d N_{o}}+N_{o e} q_{e}-N_{o} q_{s}}{V}+r_{\text {na }} K_{\text {resp }} \theta_{\text {resp }}^{T-20} A$

Donde $r_{n a}$ representa el contenido de nitrógeno en la algas $(\mathrm{mgN} / \mathrm{mgA})$ 
La ecuación planteada para el amonio se modifica para considerar el consumo del mismo en el crecimiento del fitoplancton. La ecuación (4.22) queda de la siguiente forma:

$$
\begin{aligned}
& 0=\frac{d}{d x}\left(E \frac{d N_{a}}{d x}\right)-\frac{d\left(u N_{a}\right)}{d x}+K_{\text {Noa }} \theta_{\text {Knoa }}^{T-20} N_{o}-\left(K_{\text {Nai }} \theta_{n a i}^{T-20} \frac{O}{O+K_{n 1 / 2}}\right) N_{a}+ \\
& +\frac{S_{d N_{a}}+N_{a e} q_{e}-N_{a} q_{s}}{V}-r_{n a} F_{n}\left(K_{g \max } \theta_{g}^{T-20} F_{l} \operatorname{Min}\left(\frac{N_{a i 03}}{N_{a i o 3}+K_{N F 1 / 2}} ; \frac{P}{P+K_{P 1 / 2}}\right)\right) A
\end{aligned}
$$

Donde:

- $\mathrm{F}_{\mathrm{n}}$ representa el factor de preferencia por el amonio frente a los nitratos.

- $r_{\text {na }}$ es el coeficiente estequiométrico $(\mathrm{mgN} / \mathrm{mgA})$.

Además la ecuación (4.24) que planteaba el balance de masas para los nitratos se modifica por el mismo motivo:

$$
\begin{aligned}
& 0=\frac{d}{d x}\left(E \frac{d N_{o 3}}{d x}\right)-\frac{d\left(u N_{o 3}\right)}{d x}+\left(K_{n i o} \theta_{n i o}^{T-20} \frac{O}{O+K_{n 1 / 2}}\right) N_{i}-K_{N o 3} \theta_{n o 3}^{T-20} N_{o 3}+ \\
& +\frac{S_{d N_{i}}+N_{o 3 e} q_{e}-N q_{s 3}}{V}-r_{n a}\left(1-F_{n}\right)\left(K_{g \max } \theta_{g}^{T-20} F_{l} \operatorname{Min}\left(\frac{N_{a i o 3}}{N_{a i o 3}+K_{N F 1 / 2}} ; \frac{P}{P+K_{P 1 / 2}}\right)\right) A
\end{aligned}
$$

Finalmente la ecuación que representa el balance de masa del oxígeno disuelto debe ser modificada para tener en cuenta el consumo de oxígeno en la respiración del fitoplancton y la producción del mismo en el proceso de crecimiento mediante la fotosíntesis. La ecuación (4.25) queda de la siguiente forma:

$$
\begin{aligned}
& 0=\frac{d}{d x}\left(E \frac{d O}{d x}\right)-\frac{d(u O)}{d x}+K_{a} \theta_{K a}^{T-20}\left(O_{\text {sat }}-O\right)-K_{d} \theta_{d}^{T-20} L- \\
& -r_{a}\left(K_{N a i} \theta_{\text {nai }}^{T-20} \frac{O}{O+K_{n 1 / 2}}\right) N_{a}-r_{i}\left(K_{n i o} \theta_{\text {nio }}^{T-20} \frac{O}{O+K_{n 1 / 2}}\right) N_{i}+\frac{S_{\text {od }}+O_{e} q_{e}-O q_{s}}{V}+ \\
& +r_{\text {ocrec }}\left(K_{g \max } \theta_{g}^{T-20} F_{l} \operatorname{Min}\left(\frac{N_{\text {aio } 3}}{N_{\text {aio } 3}+K_{N F 1 / 2}} ; \frac{P}{P+K_{P 1 / 2}}\right)\right) A-r_{\text {oresp }} K_{\text {resp }} \theta_{\text {resp }}^{T-20} A
\end{aligned}
$$

En donde $\mathrm{r}_{\mathrm{ocrec}} \mathrm{y} \mathrm{r}_{\text {oresp }}$ representan el oxígeno producido y consumido por el crecimiento de las algas y la respiración. 


\subsubsection{Modelación de la calidad en embalses.}

Como se ha comentado previamente, la modelación de la calidad del agua en los embalses se puede realizar mediante un modelo bicapa representando el epilimnion y el hipolimnion o una sola capa totalmente mezclada. Dado que la estratificación térmica es un proceso estacional un mismo embalse puede ser modelado unos meses como un depósito de mezcla completa y otros como un modelo bicapa. El intercambio de materia entre las dos capas se considera mediante la difusión entre las mismas.

Dentro de cada capa se considera que la mezcla es instantánea, asumiendo que la concentración es la misma en cualquier punto de la misma. Para cada uno de los constituyentes que se pueden modelar se han considerado los mismos procesos que en los tramos de ríos.

Para definir la concentración de la salida del embalse en un mes dado se realiza un promedio de las concentraciones obtenidas para los diferentes intervalos de tiempo.

Paralelamente al diagrama presentado para modelar la hidráulica del embalse al inicio de cada mes, el modelo debe estimar las concentraciones iniciales de cada constituyente modelado. El proceso es el siguiente:

- Para el caso en que el mes se vaya a modelar de forma uni-capa la concentración es igual al del mes anterior si este se ha modelado de la misma forma o mediante un sencillo balance de masas si el mes anterior se modelaba como bicapa.

- Si el mes en cálculo mantiene una estratificación para el cálculo de la concentración inicial de cada capa hay tres posibilidades en función del mes anterior. Si el mes anterior se modelaba como una sola capa la concentración inicial de ambas capas es igual a la final del mes anterior. Si por el contrario el mes anterior ya se tenía una estratificación la concentración se estima teniendo en cuenta la concentración de cada capa más el incremento o pérdida que se produce en cada una por la nueva situación que se da en este mes. Así por ejemplo si entre el mes anterior y este hay un crecimiento de la termoclina la concentración inicial del epilimnion de este mes se obtendrá mediante un balance de masas entre la concentración y el volumen del epilimnion a final de mes y la parte del hipolimnion que se "calienta" y pasa a formar parte del epilimnion.

A continuación se plantean el sistema de ecuaciones diferenciales para cada uno de los constituyentes. Se plantea la opción de la modelación en dos capas ya que cuando se modela con una sola se trata simplemente de integrar exclusivamente la ecuación correspondiente al epilimnion sin tener en cuenta el término de difusión. 


\subsubsection{Temperatura.}

En la modelación de la temperatura se considera que toda la radiación es absorbida por el epilimnion. El sistema de ecuaciones diferenciales a resolver queda de la siguiente forma:

$$
\begin{aligned}
& V_{1} \frac{d T_{1}}{d t}+T_{1 / 2} \frac{d V}{d t}=Q_{1 e} T_{e}-Q_{1 s} T_{1}+E_{12}^{\prime}\left(T_{2}-T_{1}\right)+\frac{A_{s} \phi}{C_{s} \rho} \\
& V_{2} \frac{d T_{2}}{d t}-T_{1 / 2} \frac{d V}{d t}=Q_{2 e} T_{e}-Q_{25} T_{2}+E_{12}^{\prime}\left(T_{1}-T_{2}\right)
\end{aligned}
$$

Donde:

- El subíndice "1" representa el epilimnion o capa superior.

- El subíndice "2" el hipolimnion o capa inferior.

- $\mathrm{V}_{1}$ y $\mathrm{V}_{2}$ son los volúmenes de las capas $\left(\mathrm{m}^{3}\right)$.

- V es la ganancia o perdida (si es negativo) de volumen del epilimnion sobre el hipolimnion debido al calentamiento o enfriamiento a lo largo del mes $\left(\mathrm{m}^{3}\right)$.

- $\mathrm{T}_{1}$ y $\mathrm{T}_{2}$ son las temperaturas de las capas $\left({ }^{\circ} \mathrm{C}\right)$.

- $T_{1 / 2}$ representa la temperatura del epilimnion si el término de variación del volumen es positivo y la temperatura del hipolimnion si es negativo $\left({ }^{\circ} \mathrm{C}\right)$.

- $t$ representa la variable tiempo.

- $\mathrm{Q}_{1 \mathrm{e}} \mathrm{y} \mathrm{Q}_{2 \mathrm{e}}$ son las entradas de caudal en el intervalo de tiempo $\left(\mathrm{m}^{3} \mathrm{t}^{-1}\right)$.

- $\mathrm{T}_{\mathrm{e}}$ representa la temperatura del agua de entrada $\left({ }^{\circ} \mathrm{C}\right)$.

- Q1s y $Q_{2 s}$ son las salidas en el intervalo de tiempo $\left(\mathrm{m}^{3} \mathrm{t}^{-1}\right)$.

- E' ${ }_{12}^{\prime}$ representa el coeficiente de mezcla entre ambas capas $\left(\mathrm{m}^{3} \mathrm{t}^{-1}\right)$.

- $\mathrm{A}_{\mathrm{s}}$ es la superficie de la lámina de agua $\left(\mathrm{m}^{2}\right)$.

- $\phi$ es la radiación $\left(\mathrm{Wm}^{-2} \mathrm{t}^{-1}\right)$.

- Cs es el calor específico $\left(\mathrm{Wgr}^{-10} \mathrm{C}^{-1}\right)$.

- $\rho$ es la densidad del agua $\left(\mathrm{grm}^{-3}\right)$.

Como se ve en la ecuación debido a que el volumen de las capas no es el mismo al principio y fin de cada mes se debe tener en cuenta la variación de volumen en cada intervalo de tiempo modelado.

El coeficiente de mezcla se estima de la siguiente forma: 
$E_{12}^{\prime}=\frac{E_{12} A_{12}}{Z_{12}}$

Donde:

- $\mathrm{E}_{12}$ representa la difusión vertical $\left(\mathrm{m}^{2} \mathrm{t}^{-1}\right)$.

- $\mathrm{A}_{12}$ es el área entre las dos capas $\left(\mathrm{m}^{2}\right)$.

$-Z_{12}$ es la cota de la termoclina $(\mathrm{m})$.

Aplicando la linearización de Edinger and Geyer la ecuación (4.31) se transforma en la siguiente:

$$
\frac{d T_{1}}{d t} V_{1}+T_{1 / 2} \frac{d V_{1}}{d t}=Q_{1 e} * T_{e}-Q_{1 s}^{*} T_{1}+v_{12}^{\prime} * A_{t} *\left(T_{2}-T_{1}\right)+\frac{A_{s}^{*} K e *(T e-T)}{C_{s} * \rho}
$$

\subsubsection{Contaminantes arbitrarios.}

Los contaminantes arbitrarios se modelan mediante las siguientes ecuaciones:

$$
\begin{aligned}
& V_{1} \frac{d C_{1}}{d t}+C_{1 / 2} \frac{d V}{d t}=Q_{1 e} C_{e}-Q_{1 s} C_{1}+E_{12}^{\prime}\left(C_{2}-C_{1}\right)-V_{1} K \theta^{T_{1}-20} C_{1}-\frac{V S}{H_{1}} * C_{1} * V_{1} \\
& V_{2} \frac{d C_{2}}{d t}-C_{1 / 2} \frac{d V}{d t}=Q_{2 e} C_{e}-Q_{25} C_{2}+E_{12}^{\prime}\left(C_{1}-C_{2}\right)-V_{2} K \theta^{\left(T_{2}-20\right)} C_{2}-\frac{V S}{H_{2}} * C_{2} * V_{2}+\frac{V S}{H_{1}} * C_{1} * V_{1}
\end{aligned}
$$

Donde:

- $\mathrm{C}_{1} \mathrm{y} \mathrm{C}_{2}$ son las concentraciones de cada capa $\left(\mathrm{mgl}^{-1}\right)$.

- $\mathrm{C}_{1 / 2}$ es la concentración del hipolimnion si el incremento de volumen es negativo y del epilimnion si es positivo $\left(\mathrm{mgl}^{-1}\right)$.

- $\mathrm{C}_{\mathrm{e}}$ es la concentración del agua de entrada $\left(\mathrm{mgl}^{-1}\right)$.

- $\mathrm{K}$ representa la constante de degradación del contaminante a $20^{\circ} \mathrm{C}\left(\mathrm{t}^{-1}\right)$.

- $\theta$ es el factor por corrección de temperatura de la constante de degradación.

- VS es la velocidad de sedimentación $\left(\mathrm{mt}^{-1}\right)$.

- $\mathrm{H}_{1}$ y $\mathrm{H}_{2}$ son las alturas de las capas. 


\subsubsection{Oxígeno Disuelto - Nitrógeno - Eutrofización.}

En la modelación del oxígeno disuelto en embalses, al igual que en los tramos de río, se considera la posibilidad de tres niveles de complejidad de modelación. A continuación se expresa la opción más compleja. Las ecuaciones se simplifican al aplicar los diferentes niveles de sencillez de la misma forma que se explica en el apartado de ríos.

La nomenclatura es la misma que la definida en el apartado de ríos excepto que se diferencia entre epilimnion marcado con el subíndice "1" y el hipolimnión con el subíndice " 2 ".

Como se puede ver en las siguientes fórmulas en el caso de los embalses para tener en cuenta la afección de condiciones anaeróbicas sobre la degradación de la materia orgánica en este caso se ha optado por considerar un coeficiente corrector de la constantes de forma similar a lo realizado con el amonio y los nitritos. 
Para la modelación de la MOC se plantea el siguiente sistema de ecuaciones diferenciales:

$V_{1} \frac{d L_{1}}{d t}+L_{1 / 2} \frac{d V}{d t}=Q_{1 e} L_{e}-Q_{1 s} L_{1}+E_{12}^{\prime}\left(L_{2}-L_{1}\right)-V_{1}\left(K_{d} \theta_{d}^{T_{1}-20} \frac{O_{1}}{O_{1}+K_{d 1 / 2}}\right) L_{1}-\frac{V S_{L}}{H_{1}} L_{1} V_{1}$ (4.39)

$V_{2} \frac{d L_{2}}{d t}-L_{1 / 2} \frac{d V}{d t}=Q_{2 e} L_{e}-Q_{2 s} L_{2}+E_{12}^{\prime}\left(L_{1}-L_{2}\right)-V_{2}\left(K_{d} \theta_{d}^{T_{2}-20} \frac{O_{2}}{O_{2}+K_{d 1 / 2}}\right) L_{2}-\frac{V S_{L}}{H_{2}} L_{2} V_{2}+\frac{V S_{L}}{H_{1}} L_{1} V_{1}(4.40)$

Para el oxígeno disuelto:

$$
\begin{aligned}
& V_{1} \frac{d O_{1}}{d t}+O_{1 / 2} \frac{d V}{d t}=Q_{1 e} O_{e}-Q_{1 s} O_{1}+E_{12}^{\prime}\left(O_{2}-O_{1}\right)+K_{a} \theta_{a}^{T_{1}-20}\left(O_{s a t}-O_{1}\right) V_{1}-\left(K_{d} \theta_{d}^{T_{1}-20} \frac{O_{1}}{O_{1}+K_{d 1 / 2}}\right) V_{1} L_{1}-r_{a}\left(K_{N a i} \theta_{n a i}^{T-20} \frac{O}{O+K_{n 1 / 2}}\right) V_{1} N_{a 1}- \\
& -r_{i}\left(K_{\text {nio }} \theta_{\text {nio }}^{T_{1}-20} \frac{O_{1}}{O_{1}+K_{n 1 / 2}}\right) V_{1} N_{i 1}+r_{\text {ocrec }}\left(K_{g \max } \theta_{g}^{T_{1}-20} F_{l} \operatorname{Min}\left(\frac{N_{\text {aio } 3-1}}{N_{\text {aio } 3-1}+K_{N F 1 / 2}} ; \frac{P_{1}}{P_{1}+K_{P 1 / 2}}\right)\right) V_{1} A_{1}-r_{\text {oresp }} K_{\text {resp }} \theta_{\text {resp }}^{T_{1}-20} V A_{1} \text { (4.41) } \\
& V_{2} \frac{d O_{2}}{d t}-O_{1 / 2} \frac{d V}{d t}=Q_{2 e} O_{e}-Q_{2 s} O_{2}+E_{12}^{\prime}\left(O_{1}-O_{2}\right)-\left(K_{d} \theta_{d}^{T_{2}-20} \frac{O_{2}}{O_{2}+K_{d 1 / 2}}\right) V_{2} L_{2}-r_{a}\left(K_{N a i} \theta_{n a i}^{T_{2}-20} \frac{O_{2}}{O_{2}+K_{n 1 / 2}}\right) V_{2} N_{a 2}- \\
& -r_{i}\left(\begin{array}{cc}
K_{\text {nio }} \theta_{\text {nio }}^{T_{2}-20} & \mathrm{O}_{2} \\
\mathrm{O}_{2}+K_{n 1 / 2}
\end{array}\right) V_{2} N_{i 2}+r_{\text {ocrec }}\left(K_{g \text { max }} \theta_{g}^{T_{2}-20} F_{l} \operatorname{Min}\left(\begin{array}{c}
N_{\text {aio3-2 }} \\
N_{\text {aio } 3-2}+K_{N F 1 / 2}
\end{array} ; \begin{array}{c}
P_{2} \\
P_{2}+K_{P 1 / 2}
\end{array}\right)\right) V_{2} A_{2}-r_{\text {oresp }} K_{\text {resp }} \theta_{\text {resp }}^{T_{2}-20} V_{2} A_{2}(4.42)
\end{aligned}
$$


Para el nitrógeno orgánico:

$$
\begin{aligned}
& V_{1} \frac{d N_{o 1}}{d t}+N_{o 1 / 2} \frac{d V}{d t}=Q_{1 e} N_{o e}-Q_{1 s} N_{o 1}+E_{12}^{\prime}\left(N_{o 2}-N_{o 1}\right)-K_{N o a} \theta_{\text {noa }}^{T_{1}-20} V_{1} N_{o 1}-\frac{V S_{N o}}{H_{1}} V_{1} N_{o 1}+r_{\text {na }} K_{\text {resp }} \theta_{\text {resp }}^{T_{1}-20} V_{1} A_{1}(4.43) \\
& V_{2} \frac{d N_{o 2}}{d t}-N_{o 1 / 2} \frac{d V}{d t}=Q_{2 e} N_{o e}-Q_{2 s} N_{o 2}+E_{12}^{\prime}\left(N_{o 1}-N_{o 2}\right)-K_{N o a} \theta_{\text {noa }}^{T_{2}-20} V_{2} N_{o 2}-\frac{V S_{N o}}{H_{2}} V_{2} N_{o 2}+r_{n a} K_{\text {resp }} \theta_{\text {resp }}^{T_{2}-20} V_{2} A_{2}+\frac{V S_{N o}}{H_{1}} N_{o 1} V_{1}(4.44)
\end{aligned}
$$

Para el amonio:

$$
\begin{aligned}
& V_{1} \frac{d N_{a 1}}{d t}+N_{a 1 / 2} \frac{d V}{d t}=Q_{1 e} N_{a e}-Q_{1 s} N_{a 1}+E_{12}^{\prime}\left(N_{a 2}-N_{a 1}\right)+K_{\text {Noa }} \theta_{\text {noa }}^{T_{1}-20} V_{1} N_{o 1}-\left(K_{N a i} \theta_{n a i}^{T_{1}-20} \frac{O_{1}}{O_{1}+K_{n 1 / 2}}\right) V_{1} N_{a 1}-r_{n a} F_{n}\left(K_{g \max } \theta_{g}^{T_{1}-20} F_{l} \operatorname{Min}\left(\frac{N_{a i o 3-1}}{N_{a i o 3-1}+K_{N F 1 / 2}} ; \frac{P_{1}}{P_{1}+K_{P 1 / 2}}\right)\right) V_{1} A_{1}(4.45) \\
& V_{2} \frac{d N_{a 2}}{d t}-N_{a 1 / 2} \frac{d V}{d t}=Q_{2 e} N_{a e}-Q_{2 s} N_{a 2}+E_{12}^{\prime}\left(N_{a 1}-N_{a 2}\right)+K_{\mathrm{Noa}} \theta_{n o a}^{T_{2}-20} V_{2} N_{o 2}-\left(K_{\mathrm{Nai}} \theta_{n a i}^{T_{2}-20} \frac{O_{2}}{O_{2}+K_{n 1 / 2}}\right) V_{2} N_{a 2}- \\
& -r_{n a} F_{n}\left(K_{g \max } \theta_{g}^{T_{2}-20} F_{l} \operatorname{Min}\left(\frac{N_{\text {aio3-2 }}}{N_{\text {aio3-2 }}+K_{N F 1 / 2}} ; P_{2}+K_{P 1 / 2}\right)\right) V_{2} A_{2}
\end{aligned}
$$

Para los nitritos:

$$
\begin{aligned}
& V_{1} \frac{d N_{i 1}}{d t}+N_{i 1 / 2} \frac{d V}{d t}=Q_{1 e} N_{i e}-Q_{1 s} N_{i 1}+E_{12}^{\prime}\left(N_{i 2}-N_{i 1}\right)+\left(K_{N a i} \theta_{n a i}^{T_{1}-20} \frac{O_{1}}{O_{1}+K_{n a i 1 / 2}}\right) V_{1} N_{a 1}-\left(K_{n i o} \theta_{n i o}^{T_{1}-20} \frac{O_{1}}{O_{1}+K_{n 1 / 2}}\right) V_{1} N_{i 1}(4.47) \\
& V_{2} \frac{d N_{i 2}}{d t}-N_{i 1 / 2} \frac{d V}{d t}=Q_{2 e} N_{i e}-Q_{2 s} N_{i 1}+E_{12}^{\prime}\left(N_{i 1}-N_{i 2}\right)+\left(\begin{array}{cc}
K_{N a i} \theta_{n a i}^{T_{2}-20} & O_{2} \\
O_{2}+K_{n a i 1 / 2}
\end{array}\right) V_{2} N_{a 2}-\left(\begin{array}{cc}
K_{n i o} \theta_{n i o}^{T_{2}-20} & O_{2} \\
O_{2}+K_{n 1 / 2}
\end{array}\right) V_{2} N_{i 2}(4.48)
\end{aligned}
$$


Para los nitratos:

$$
\begin{aligned}
& V_{1} \frac{d N_{o 3-1}}{d t}+N_{o 31 / 2} \frac{d V}{d t}=Q_{1 e} N_{o 3 e}-Q_{1 s} N_{o 3-1}+E_{12}^{\prime}\left(N_{o 3-2}-N_{o 3-1}\right)+\left(K_{n i o} \theta_{n i o}^{T_{1}-20} \frac{O_{1}}{O_{1}+K_{n 1 / 2}}\right) V_{1} N_{i 1}-K_{\text {No3 }} \theta_{n o 3}^{T_{1}-20} V_{1} N_{o 3-1}- \\
& -r_{n a}\left(1-F_{n}\right)\left(K_{g \max } \theta_{g}^{T_{1}-20} F_{l} \operatorname{Min}\left(\frac{N_{a i 03-1}}{N_{\text {aio3-1 }}+K_{N F 1 / 2}} ; \frac{P_{1}}{P_{1}+K_{P 1 / 2}}\right)\right) V_{1} A_{1} \text { (4.49) } \\
& V_{2} \frac{d N_{o 3-2}}{d t}-N_{o 31 / 2} \frac{d V}{d t}=Q_{2 e} N_{o 3 e}-Q_{2 s} N_{o 3-2}+E_{12}^{\prime}\left(N_{o 3-1}-N_{o 3-2}\right)+\left(K_{n i o} \theta_{n i o}^{T_{2}-20} \frac{O_{2}}{O_{2}+K_{n 1 / 2}}\right) V_{2} N_{i 2}-K_{N 03} \theta_{n o 3}^{T_{2}-20} V_{2} N_{o 3-2}- \\
& -r_{n a}\left(1-F_{n}\right)\left(K_{g \max } \theta_{g}^{T_{2}-20} F_{l} \operatorname{Min}\left(\frac{N_{a i o 3-2}}{N_{a i o 3-2}+K_{N F 1 / 2}} ; \frac{P_{2}}{P_{2}+K_{P 1 / 2}}\right)\right) V_{2} A_{2}(4.50)
\end{aligned}
$$

Para el fitoplancton:

$V_{1} \frac{d A_{1}}{d t}+A_{1 / 2} \frac{d V}{d t}=Q_{1 e} A_{e}-Q_{1 s} A_{1}+E_{12}^{\prime}\left(A_{2}-A_{1}\right)+\left[\left(K_{g \max } \theta_{g}^{T_{1}-20} F_{l} \operatorname{Min}\left(\frac{N_{\text {aio } 3-1}}{N_{\text {aio } 3-1}+K_{N F 1 / 2}} ; \frac{P_{1}}{P_{1}+K_{P 1 / 2}}\right)\right)-K_{\text {resp }} \theta_{r e s p}^{T_{1}-20}\right] V_{1} A_{1}-\frac{V S a l g}{H_{1}} A_{1} V_{1}(4.51)$

$V_{2} \frac{d A_{2}}{d t}-A_{1 / 2} \frac{d V}{d t}=Q_{2 e} A_{e}-Q_{2 s} A_{2}+E_{12}^{\prime}\left(A_{1}-A_{2}\right)+\left[\left(K_{g \max } \theta_{g}^{T_{2}-20} F_{l} \operatorname{Min}\left(\frac{N_{\text {aio } 3-2}}{N_{\text {aio3 }-2}+K_{N F 1 / 2}} ; \frac{P_{2}}{P_{2}+K_{P 1 / 2}}\right)\right)-K_{\text {resp }} \theta_{\text {resp }}^{T_{2}-20}\right] V_{2} A_{2}-\frac{V S a \lg }{H_{2}} A_{2} V_{2}+\frac{V S a \lg }{H_{1}} A_{1} V_{1}$ 
Para el fósforo orgánico:

$$
\begin{aligned}
& V_{1} \frac{d P_{\text {org } 1}}{d t}+P_{\text {org } 1 / 2} \frac{d V}{d t}=Q_{1 e} P_{\text {orge }}-Q_{1 s} P_{\text {org } 1}+E_{12}^{\prime}\left(P_{\text {org } 2}-P_{\text {org } 1}\right)-K_{m p} \theta_{m p}^{T_{1}-20} V_{1} P_{\text {org } 1}+f_{p} r_{p a} K_{\text {resp }} \theta_{\text {resp }}^{T-20} V_{1} A_{1}-\frac{V S_{\text {org }}}{H_{1}} V_{1} P_{\text {org } 1}(4.53) \\
& V_{2} \frac{d P_{\text {org } 2}}{d t}-P_{\text {org } 1 / 2} \frac{d V}{d t}=Q_{2 e} P_{\text {orge }}-Q_{2 s} P_{\text {org } 1}+E_{12}^{\prime}\left(P_{\text {org } 1}-P_{\text {org } 2}\right)-K_{m p} \theta_{m p}^{T_{1}-20} V_{2} P_{\text {org } 2}+f_{p} r_{p a} K_{\text {resp }} \theta_{\text {resp }}^{T-20} V_{2} A_{2}+\frac{V S_{\text {org }}}{H_{1}} V_{1} P_{\text {org } 1}-\frac{V S_{\text {org }}}{H_{2}} V_{2} P_{\text {org } 2}
\end{aligned}
$$

Finalmente para el fósforo disuelto:

$$
\begin{aligned}
& V_{1} \frac{d P_{1}}{d t}+P_{1 / 2} \frac{d V}{d t}=Q_{1 e} P_{e}-Q_{1 s} P_{1}+E_{12}^{\prime}\left(P_{2}-P_{1}\right)+K_{m p} \theta_{m p}^{T_{1}-20} V_{1} P_{\text {org } 1}-r_{p a}\left[\left(K_{g \max } \theta_{g}^{T_{1}-20} F_{l} \operatorname{Min}\left(\frac{N_{\text {aio3-1 }}}{N_{\text {aio } 3-1}+K_{N F 1 / 2}} P_{1}+K_{P 1 / 2}\right)\right] V_{1} A_{1}+\right. \\
& +\left(1-f_{p}\right) r_{p a} K_{\text {resp }} \theta_{\text {resp }}^{T-20} V_{1} A_{1}(4.55) \\
& V_{2} \frac{d P_{2}}{d t}-P_{1 / 2} \frac{d V}{d t}=Q_{2 e} P_{e}-Q_{2 s} P_{2}+E_{12}^{\prime}\left(P_{1}-P_{2}\right)+K_{m p} \theta_{m p}^{T_{2}-20} V_{2} P_{\text {org } 2}-r_{p a}\left[\left(K_{g \max } \theta_{g}^{T_{2}-20} F_{l} M i n\left(\frac{N_{\text {aio } 3-2}}{N_{\text {aio } 3-2}+K_{N F 1 / 2}} P_{2}+K_{P 2 / 2}\right)\right] V_{2} A_{2}+\right. \\
& +\left(1-f_{p}\right) r_{\text {pa }} K_{\text {resp }} \theta_{\text {resp }}^{T-20} V_{2} A_{2}(4.56)
\end{aligned}
$$




\subsection{INTEGRACIÓN NUMÉRICA.}

A continuación se explica los métodos seguidos para la resolución de las ecuaciones diferenciales planteadas en el apartado anterior.

\subsubsection{Resolución de las ecuaciones planteadas para los tramos de ríos.}

Se ha optado por la resolución de las ecuaciones diferenciales planteadas para los tramos de ríos mediante el método de las diferencias finitas centrales. Para ello se realiza una descomposición de cada río o conducción en elementos diferenciales o segmentos. La siguiente figura muestra un esquema de los elementos que se consideran en un tramo de río.

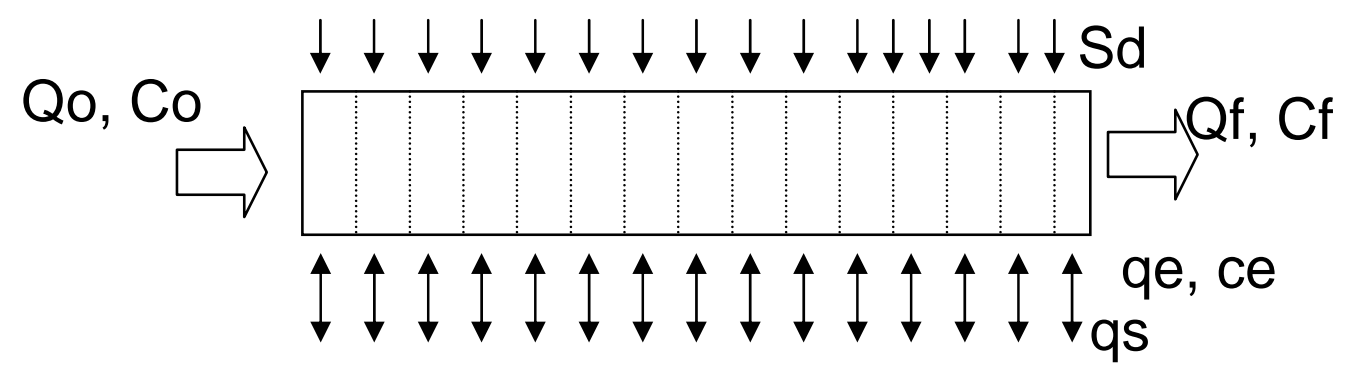

Figura 6. Esquema de los elementos que influyen sobre un tramo de río.

En la figura anterior:

- Qo y Co representan el caudal y la concentración de entrada al tramo de río.

- Qf y Cf son las mismas variables pero de salida de tramo.

- Sd representa la carga por contaminación difusa.

- qs son las posibles filtraciones.

- qe es el caudal aportante por un posible acuífero.

- ce la concentración del mismo.

Se ha realizado la hipótesis de que tanto la contaminación difusa como las filtraciones y los aportes subterráneos de caudal siguen una ley uniforme a lo largo del tramo. La figura siguiente muestra los elementos sobre un elemento diferencial aislado "i". 


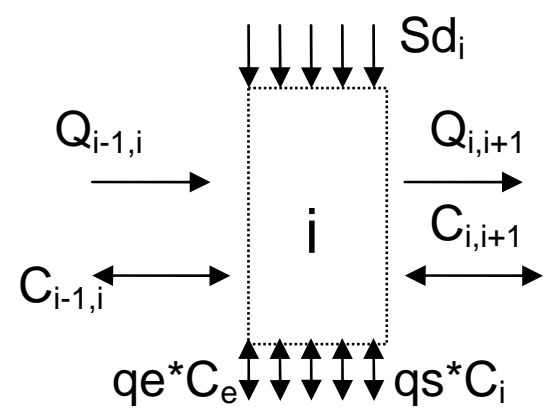

Figura 7. Esquema de los elementos que influyen sobre un elemento diferencial.

Planteando un balance de masas en un elemento diferencial para un constituyente arbitrario se obtiene:

$0=S d_{i}-q_{s} C_{i}+q_{e} C_{e}+Q_{i-1, i} C_{i-1, i}-Q_{i, i+1} C_{i, i+1}+E_{i-1, i}^{\prime}\left(C_{i-1}-C_{i}\right)+E_{i, i+1}^{\prime}\left(C_{i+1}-C_{i}\right)-K_{i} V_{i} C_{i}-\frac{V S}{H_{i}} V_{i} C_{i}$

Se considera cada elemento como un elemento en el que se produce una mezcla completa, como un depósito totalmente mezclado. Además se consideran flujo entrante y saliente de cada elemento así como difusión con los elementos adyacentes.

El coeficiente de difusión entre dos elementos diferenciales E’ se define como $E^{\prime}=\frac{E^{*} A}{\Delta x}(4.58)$

Además los términos qs y qe son caudales de salida y entrada en ese tramo que se obtienen como el caudal total dividido por la longitud total del río y multiplicado por la longitud del elemento diferencial.

La estimación de velocidades, calados y áreas se realiza para cada elemento diferencial.

Asumiendo diferencias finitas centrales:

$C_{i-1, i}=\frac{C_{i-1}+C_{i}}{2}$

$C_{i, i+1}=\frac{C_{i}+C_{i+1}}{2}$

Con lo que la ecuación (4.57) queda:

$$
\begin{aligned}
& 0=S d_{i}-q_{s} * C_{i}+q_{e} * C_{e}+Q_{i-1, i} * \frac{C_{i-1}+C_{i}}{2}-Q_{i, i+1} * \frac{C_{i}+C_{i+1}}{2}+E_{i-1, i}^{\prime} *\left(C_{i-1}-C_{i}\right)+ \\
& +E_{i, i+1}^{\prime} *\left(C_{i+1}-C_{i}\right)-K_{i} * V_{i} * C_{i}-\frac{V S}{H_{i}} * V_{i} * C_{i}(4.61)
\end{aligned}
$$


Reagrupando términos:

$$
\begin{aligned}
& C_{i} *\left(K_{i} * V_{i}+\frac{V S}{H_{i}} * V_{i}+q_{s}+\frac{Q_{i, i+1}}{2}-\frac{Q_{i-1, i}}{2}+E_{i-1, i}^{\prime}+E_{i, i+1}^{\prime}\right)+ \\
& +C_{i-1} *\left(-\frac{Q_{i-1, i}}{2}-E_{i-1, i}^{\prime}\right)+C_{i+1} *\left(\frac{Q_{i, i+1}}{2}-E_{i, i+1}^{\prime}\right)=S d_{i}+q_{e} * C_{e}
\end{aligned}
$$

La ecuación anterior se puede expresar de forma matricial para todos los elementos diferenciales del tramo:

$$
a_{i i} * C_{i}+a_{i-1, i} * C_{i-1}+a_{i, i+1} * C_{i+1}=W_{i}(4.63)
$$

Donde

$$
\begin{aligned}
& a_{i i}=\left(K_{i} * V_{i}+\frac{V S}{H_{i}} * V_{i}+q_{s}+\frac{Q_{i, i+1}}{2}-\frac{Q_{i-1, i}}{2}+E_{i-1, i}^{\prime}+E_{i, i+1}^{\prime}\right) \\
& a_{i-1, i}=-\frac{Q_{i-1, i}}{2}-E_{i-1, i}^{\prime}(4.65) \\
& a_{i, i+1}=\frac{Q_{i, i+1}}{2}-E_{i, i+1}^{\prime} \\
& W_{i}=S d_{i}+q_{e} * C_{e}
\end{aligned}
$$

Para el caso del primer elemento hay que tener en cuenta que no existe la celda "i-1" con lo que no hay difusión con esa celda. Además hay que considerar que el caudal entrante y la concentración son conocidas $\mathrm{Q}_{0} \mathrm{y} \mathrm{C}_{0}$.

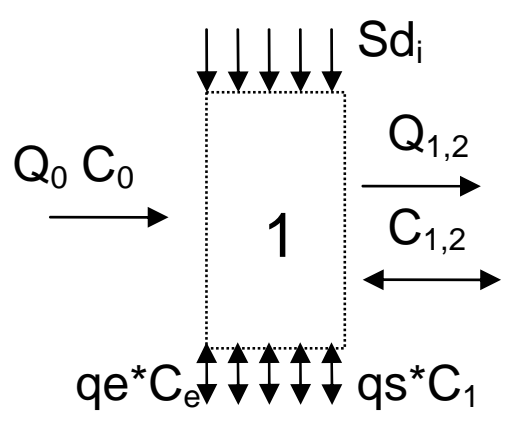

Figura 8. Elementos sobre el primer elemento diferencial

El balance de masas sobre el primer elemento diferencial del tramo de río queda:

$0=S d_{i}-q_{s} * C_{1}+q_{e} * C_{e}+Q_{0} * C_{0}-Q_{1,2} * \frac{C_{1}+C_{2}}{2}+E_{1,2}^{\prime} *\left(C_{i+1}-C_{i}\right)-K_{1} * V_{1} * C_{1}-\frac{V S}{H_{1}} * V_{1} * C_{1}$ 
Con lo que

$$
\begin{aligned}
& a_{11}=\left(K_{1} * V_{1}+\frac{V S}{H_{1}} * V_{1}+q_{s}+\frac{Q_{1,2}}{2}+E_{1,2}^{\prime}\right)(4.69) \\
& a_{1,2}=\frac{Q_{1,2}}{2}-E_{1,2}^{\prime}(4.70) \\
& W_{1}=S d_{1}+q_{e} * C_{e}+Q_{0} * C_{0}(4.71)
\end{aligned}
$$

Para el último elemento hay que tener en cuenta que no existe el elemento " $n+1$ "

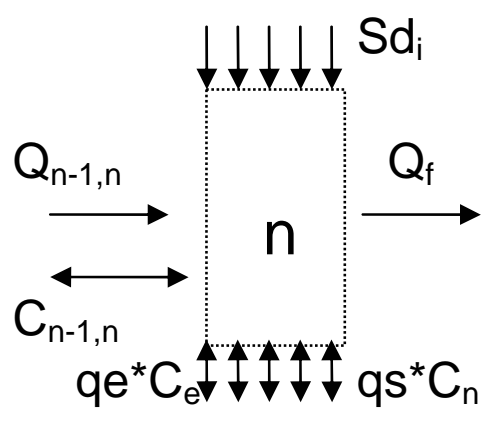

Figura 9. Balance de masas sobre el último elemento diferencial

Planteando el balance de masas en este elemento diferencial:

$$
0=S d_{n}-q_{s} * C_{n}+q_{e} * C_{e}+Q_{n-1, n} * C_{n-1, n}-Q_{f}^{*} C_{n}+E_{n-1, n}^{\prime} *\left(C_{n-1}-C_{n}\right)-K_{n} * V_{n} * C_{n}-\frac{V S}{H_{n}} * V_{n} * C_{n}
$$

Con lo que los términos quedan:

$$
\begin{aligned}
& a_{n n}=\left(K_{n} * V_{n}+\frac{V S}{H_{n}} * V_{n}+q_{s}+Q_{f}-\frac{Q_{n-1, n}}{2}+E_{n-1, n}^{\prime}\right) \\
& a_{n-1, n}=-\frac{Q_{n-1, n}}{2}-E_{1,2}^{\prime}(4.74) \\
& W_{n}=S d_{n}+q_{e} * C_{e}(4.75)
\end{aligned}
$$

Considerando todos los balances de masas para todos los elementos diferenciales de forma matricial se obtiene:

$$
(A) *(C)=(W)(4.76)
$$

La resolución de este sistema de ecuaciones puede abordarse por diferentes métodos. Para la elección del método óptimo en tiempo computacional es importante tener en cuenta que la matriz A es tridiagonal. Se ha desarrollado una subrutina específica para la resolución de este sistema. 
La metodología de resolución del problema para cada uno de los diferentes constituyentes es la misma. Las modificaciones de los términos anteriores para adaptar las diferentes ecuaciones pasa por lo siguiente:

-Los términos $\mathrm{a}_{\mathrm{ii}}$ deben modificarse para tener en cuenta todos aquellos procesos que son proporcionales a las concentraciones del constituyente que se está modelando. Así por ejemplo si un constituyente no se ha considerado la sedimentación se elimina el término de $(\mathrm{VS} / \mathrm{H}) * \mathrm{~V}$. Por el contrario en el caso de las algas habrá que sumar a ese término el efecto del crecimiento y la respiración de las mismas ya que depende de la concentración de la clorofila-a.

-Por otro lado, todos los términos que representen procesos que no sean proporcionales a la concentración de contaminante que se evalúa en ese momento deberán ser añadidos al término de $\mathrm{W}_{\mathrm{i}}$. Así, por ejemplo el incremento de concentración del amonio por amonificación del nitrógeno orgánico debe ser añadido a este término ya que depende de la concentración de nitrógeno orgánico.

\subsubsection{Positividad.}

El planteamiento de ecuaciones diferenciales en diferencias centrales trae consigo un problema de la positividad. En particular, en este caso para sistemas de componente básicamente advectivos pueden darse algunos valores de concentración negativos (Hall y Porsching, 1990). Este fenómeno se puede dar en los casos en que los términos de la diagonal superior sean positivos. Para ello

$$
\frac{Q_{i, i+1}}{2}-E_{i, i+1}^{\prime}>0
$$

Sustituyendo se obtiene que: $\Delta x<\frac{E}{0.5^{*} u}$

La ecuación anterior define la máxima longitud del diferencial para asegurar la postividad en todos los resultados. Sin embargo los casos normales en que la literatura muestra dicha posibilidad de negativos son casos de concentraciones de entrada bajas con una carga puntual bastante grande en la parte inicial del tramo. En el módulo GESCAL las cargas puntuales se realizan fuera de la modelación del tramo, en el nudo, por lo que este caso no se puede dar. Se han realizado pruebas sin que se hayan dado casos claros en donde suceda este efecto. Sin embargo el modelador debe, para cada elemento, realizar pruebas sobre el incremento diferencial a escoger porque influye en la precisión numérica de los resultados. 


\subsubsection{Estado estacionario.}

Como se ha comentado anteriormente se asume estado estacionario dentro de cada mes. En el planteamiento de las ecuaciones del oxígeno disuelto, los diferentes compuestos del ciclo del nitrógeno y del proceso de eutrofización existen interrelaciones entre los diferentes constituyentes. Debido a que cada constituyente se simula de forma independiente estas relaciones hay que tenerlas en cuenta. Por lo general los modelos de calidad del agua transitorios consideran estas interrelaciones utilizando los valores de las concentraciones del instante anterior. En este caso debido a que se realizan simulaciones estacionarias para cada mes asumir la hipótesis anterior se dependería en exceso de los valores del mes anterior cuando se asume que a lo largo del mes se mantienen las condiciones constantes. Por ello se opta por realizar para cada mes una estimación del estado estacionario final que tendría el tramo de río independientemente de las condiciones del mes anterior. Para ello se crea un bucle de simulación en donde se van modificando los valores de las variables que interrelacionan entre constituyentes hasta la convergencia. Los valores iniciales se consideran los valores de entrada a la conducción. A partir de estos valores se realiza la primera simulación y se van sustituyendo las concentraciones para cada diferencial y repitiendo el proceso hasta la convergencia. Por otra parte para la corrección por temperatura de las constantes de descomposición se simula primero la temperatura y a partir de los resultados obtenidos para el mismo mes se hacen las correcciones.

Se ha escogido como criterio de convergencia que diferencia, de la suma de las concentraciones de oxígeno disuelto de todos los diferenciales, de dos iteraciones consecutivas sea inferior a un umbral $(0.001 \mathrm{mg} / \mathrm{l})$. Se han analizado diferentes criterios obteniéndose el propuesto como el más adecuado.

Para las condiciones iniciales se han considerado dos posibilidades: utilizar las concentraciones finales del mes anterior o la concentración de entrada al tramo. Tras el análisis realizado se ha escogido la segunda opción por reducir significativamente el número de iteraciones.

Finalmente, otro problema analizado ha sido como considerar la afección de las condiciones anaeróbicas sobre la degradación de la materia orgánica y la oxidación del nitrógeno. La primera propuesta para todos ellos fue considerar un coeficiente corrector del parámetro de degradación obtenido mediante el cociente de la concentración de OD y la suma de este con un coeficiente de semisaturación. Esta opción ha sido utilizada por diferentes módulos como WASP5. Sin embargo, tras realizar diferentes análisis de diferentes casos se ha comprobado que este mecanismo puede producir una falta de convergencia para la degradación de la materia orgánica cuando se busca el estado 
estacionario de forma iterativa. Debido a ello para el caso de modelación de los tramos de río se asume que la degradación de la materia orgánica en zonas de anoxia sigue un proceso de descomposición de orden cero igual a la reaireación del sistema.

\subsubsection{Resolución de las ecuaciones planteadas para los embalses.}

En el caso de los embalses todas las ecuaciones planteadas para los diferentes constituyentes considerados pueden expresarse de la siguiente forma:

$$
\begin{aligned}
& \frac{d C_{1}}{d t}=A C_{1}+B C_{2}+D(4.79) \\
& \frac{d C_{2}}{d t}=E C_{2}+F C_{1}+G(4.80)
\end{aligned}
$$

Donde:

- $\mathrm{C}_{1}$ representa la concentración del epilimnion.

- $\mathrm{C}_{2}$ la concentración del hipolimnion.

- A, B, D, E, F y G son coeficientes que definen la ecuación diferencial.

En el archivo de datos se establece para cada embalse el intervalo de tiempo que se quiere utilizar para la resolución de las mismas. Cada mes se discretiza en un número de intervalos de tiempo y para cada intervalo se debe resolver el sistema de ecuaciones diferenciales anterior donde las condiciones iniciales son las concentraciones del intervalo de tiempo anterior. Para la resolución de este sistema de ecuaciones diferenciales de primer orden se utiliza el método de Runge-Kutta.

\subsection{LA CALIDAD DEL AGUA EN EL RESTO DE ELEMENTOS DEL SISTEMA.}

Para el resto de elementos considerados en el SSD AQUATOOL la calidad del agua se ha tenido en cuenta de la siguiente forma:

- En los nudos se hace la hipótesis de que se produce una mezcla instantánea del agua de todos los elementos que confluyen a ese nudo: aportaciones, conducciones, retornos, centrales, vertidos puntuales, etc.

- La calidad de las diferentes aportaciones es una entrada al modelo. Se introduce una serie de concentraciones por constituyente a modelar de longitud igual a las series de aportaciones modeladas en la gestión.

- La calidad del agua que llega a cada demanda se estima mediante la mezcla de la calidad del agua de salida de todas las tomas que suministran la demanda. 
- La calidad del agua de entrada a una toma se corresponde con la calidad del agua del nudo donde se realiza la toma. La calidad de salida puede ser la misma o se puede definir una calidad de salida constante por algún proceso de tratamiento o contaminación que se de en le misma.

- La misma posibilidad se tiene en los retornos. La calidad del agua retornada puede ser la misma que la de la demanda que retorna o una definida que representa algún proceso de variación de la calidad de la misma.

- Se asume que las centrales hidroeléctricas no realizan ningún cambio sobre la calidad del agua.

-Finalmente se asume que la calidad del agua de los acuíferos permanece constante y es definida como un dato para el modelo.

\subsection{SALIDA DE RESULTADOS.}

Debido a la gran cantidad de resultados que se genera con la modelación de la calidad se ha optado por un sistema de filtrado en la salida de los mismos. En el archivo de los datos de calidad se especifica cuales son los elementos de los que se quieren obtener resultados globales y parciales. Aunque la simulación se realiza para todos los elementos del sistema sólo los indicados se mostraran en los archivos de salida. En los resultados globales se muestra, para cada mes, la concentración inicial y final de cada tramo y la concentración final de cada embalse. Los resultados parciales representan la evolución de las concentraciones dentro del tramo escogido. Para los embalses se obtienen la evolución de las concentraciones en los diferentes intervalos de tiempo dentro de cada mes. En los resultados parciales se puede indicar si se quieren obtener salidas para las dos capas o sólo para el epilimnion.

Además de los resultados de las concentraciones la herramienta desarrollada permite la posibilidad de incorporar alarmas. En el archivo de datos de entrada de calidad se definen un valor de concentración de "alarma" para cada uno de los constituyentes. Cuando en cualquier tramo de río o embalse una concentración de un constituyente es inferior al valor alarma definido para ese constituyente el programa escribe en un archivo la fecha, el elemento, el constituyente y la concentración obtenida.

\subsection{UNIDADES.}

Debido a la gran cantidad de variables que se utilizan hay que tener en cuenta las unidades utilizadas en cada momento. Se destacan lo siguiente aspectos: 
- Las variables que se obtienen de los archivos de salida o datos del SSD AQUATOOL son, en su mayoría, variables de volumen y caudal. Las primeras se expresan en $\mathrm{hm}^{3}$ y las segundas en $\mathrm{hm}^{3} /$ mes. El programa de forma interna transforma estas unidades $\mathrm{a}^{3} \mathrm{y} \mathrm{m}^{3} /$ día.

- Dentro del archivo de calidad los volúmenes de los vertidos también deben definirse $\mathrm{en}^{3} /$ mes por coherencia con las variables anteriores.

- Las concentraciones de los contaminantes arbitrarios pueden introducirse en cualquier unidad de concentración pero siempre manteniendo coherencia con lo que se defina en el resto de elementos: vertidos puntuales, difusos, aportaciones, retornos y tomas.

- Las concentraciones de oxígeno disuelto deben definirse en $\mathrm{mg} / \mathrm{l}$.

- La MOC se introduce como mg/l de DBO5. El programa internamente estima la DBO límite (L) mediante la siguiente expresión:

$$
L=\frac{D B O_{5}}{1-e^{-k 5}}
$$

En donde se utilizan diferentes $\mathrm{k}$ en función si es agua del sistema natural $(\mathrm{k}=0.05)$ o es un vertido $(\mathrm{k}=0.35)$. Estas constantes pueden ser modificadas en el archivo de coeficientes. La salida de resultados se realiza en $\mathrm{DBO}_{5}$.

- Los datos de nitrógeno orgánico se introducen como mg/l de nitrógeno. Las formas de amonio, nitritos y nitratos se introducen como $\mathrm{mg} / \mathrm{l}$ de constituyente. El programa internamente, y utilizando los valores del archivo de coeficientes transforma todos los valores a $\mathrm{mg} / \mathrm{l}$ de Nitrógeno. Ello es debido a que los balances de masas de las distintas formas se realizan en $\mathrm{mg} / \mathrm{l}$ de nitrógeno. Los resultados se transforman a $\mathrm{mg} / \mathrm{l}$ del constituyente antes de escribirse en los diferentes archivos.

- El fitoplancton debe introducirse en $\mathrm{mg} / \mathrm{l}$ de clorofila-a.

- Los dos compuestos de fósforo se introducen en $\mathrm{mg} / \mathrm{l}$ de fósforo.

- Los valores de contaminación difusa se deben incluir en gr/día ya que no se realiza ningún cambio sobre el mismo. Son gramos totales en todo el tramo. En el programa se divide por la longitud para tener en cuenta cuantos gramos entran en cada segmento.

- Todas las constantes de descomposición deben introducirse en días ${ }^{-1}$.

Todos los cambios de unidades que se realizan internamente se deshacen al escribir los resultados con lo que las salidas tienen las mismas unidades que las entradas. 


\subsection{INTERFAZ GRÁFICA.}

Una de las características del SSD AQUATOOL es su interfaz gráfica que permite a cualquier persona con conocimientos en la materia utilizar los diferentes modelos de forma rápida. El postprocesador desarrollado forma parte de este SSD por lo que se ha desarrollado una interfaz gráfica que posibilita la entrada de datos de una forma cómoda y amigable para el usuario. La interfaz ha sido desarrollada en la plataforma Visual Basic 6 y está compuesta por diferentes pantallas que permiten de forma escalonada ir introduciendo todos los datos necesarios para crear el archivo de datos de calidad.

La siguiente figura muestra la pantalla inicial del programa. En ella el usuario especifica el nombre de los archivos de trabajo entre los que se encuentran:

- Archivo de datos de SIMGES.

- Archivo de resultados de SIMGES.

- Archivos de constantes y coeficientes de calidad.

-Archivo de datos de calidad del modelo.

- Archivo de resultados de calidad.

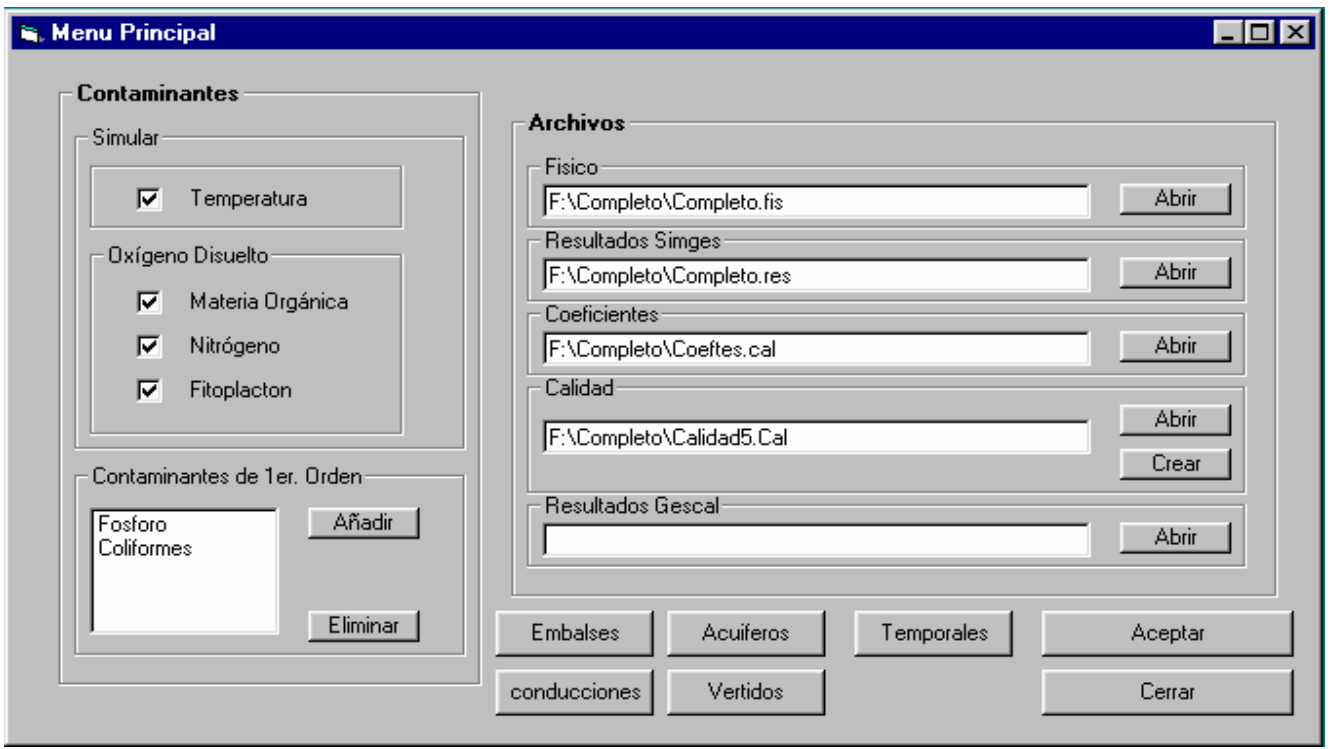

Figura 10. Pantalla principal del programa GESCAL.

Por otro lado en esta pantalla se especifica si se quiere modelar la temperatura y que nivel de complejidad de modelación se requiere para el oxígeno disuelto. Además permite añadir y eliminar contaminantes de primer orden sin límite alguno. Finalmente desde esta pantalla se accede al resto de pantallas que permiten introducir los datos necesarios para cada uno de los elementos. 
En la siguiente figura se muestra la pantalla de introducción de datos de calidad para los elementos embalses. En ella se introducen para todos los contaminantes las constantes de degradación. Además se introducen las características generales como el diferencial de cálculo.

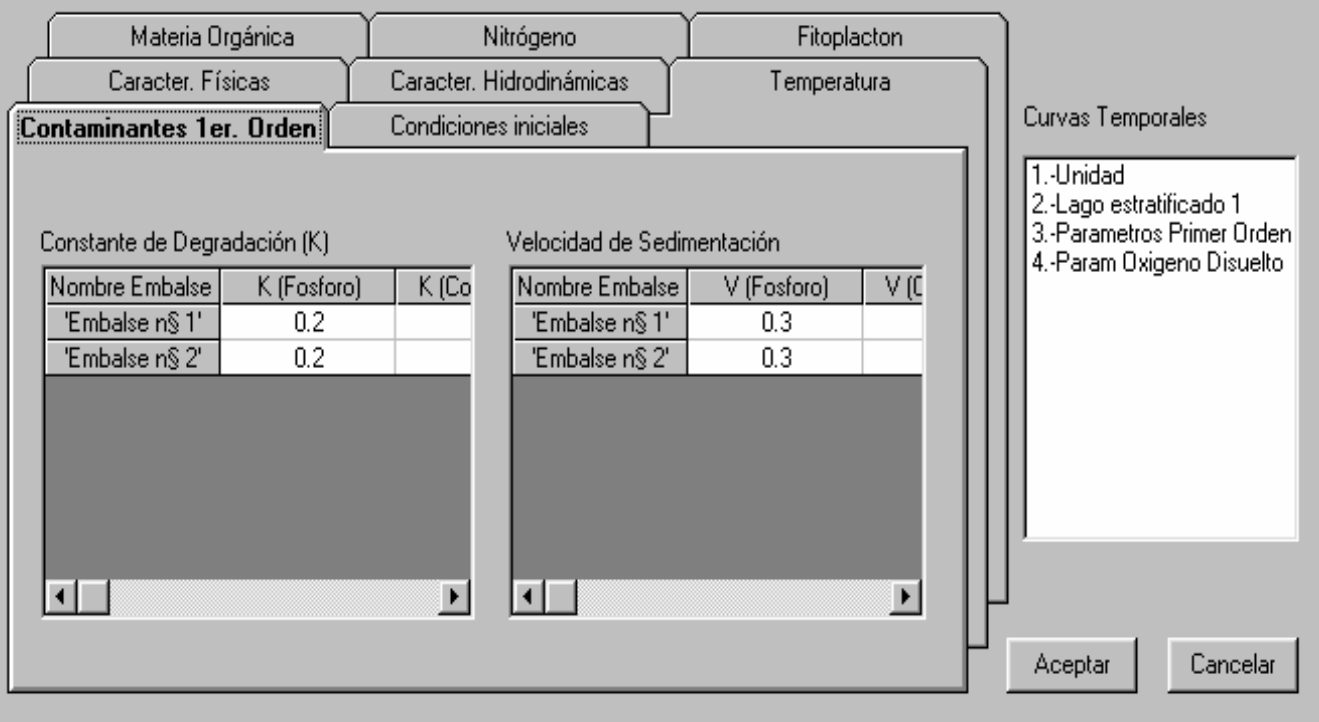

Figura 11. Interfaz para la introducción de los datos de calidad de embalses.

La siguiente pantalla ofrece las mismas posibilidades pero esta vez para las conducciones.

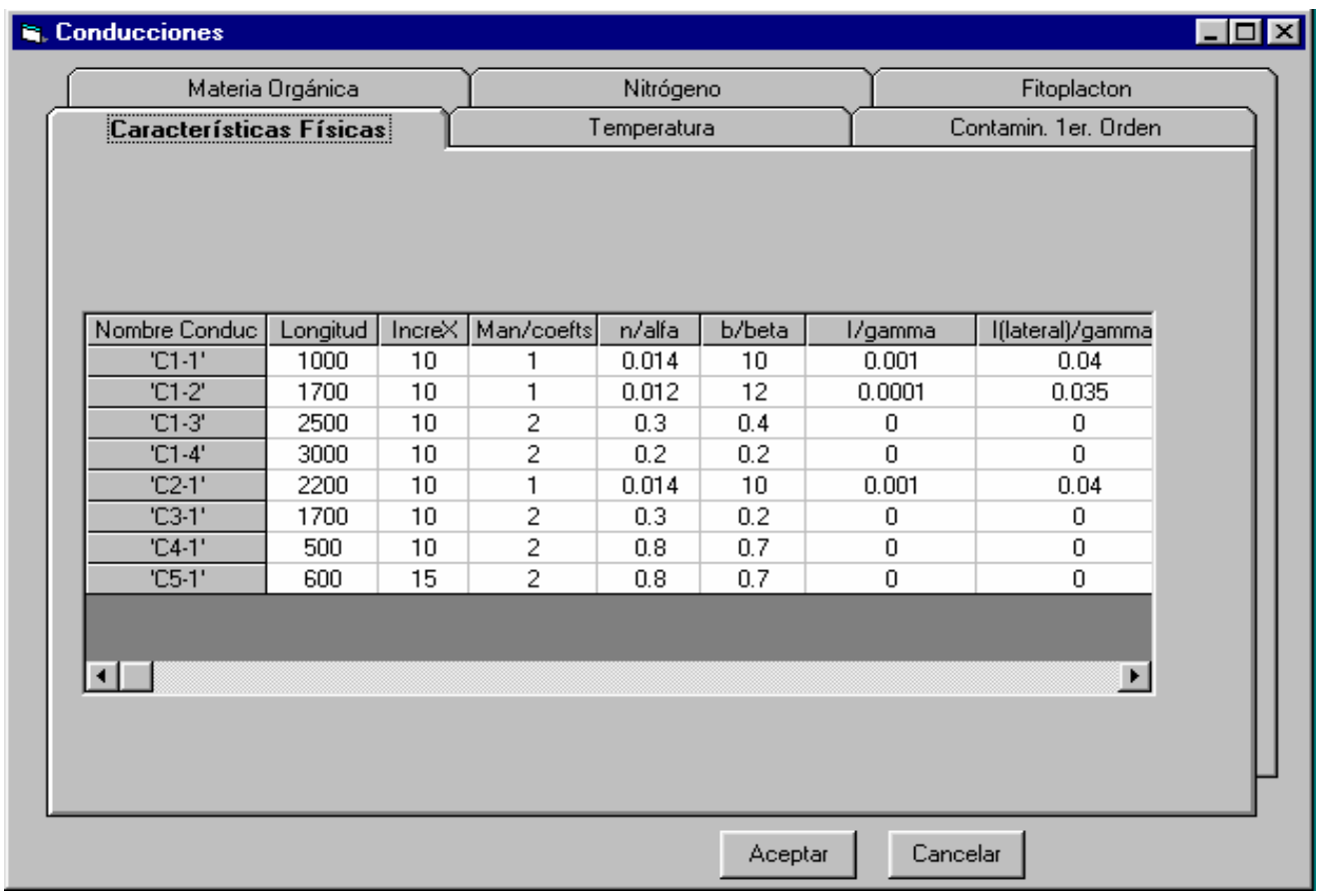

Figura 12. Interfaz para la introducción de los datos de calidad de las conducciones. 
La configuración mediante pestañas permite introducir la información de forma fácil y accesible.

La información sobre la temperatura de cada uno de los elementos, embalses o conducciones, se introduce mediante un solo valor y una curva asociada de variación temporal. Además a los vertidos puntuales se les puede asociar curvas de variación temporal. Para ello se ha desarrollado una interfaz que permite la creación de curvas temporales las cuales se almacenan de forma conjunta. Para introducir la temperatura de un elemento basta con indicar el valor constante y el número de curva que representa su variación temporal. La siguiente figura muestra la interfaz desarrollada para crear y visualizar estas curvas.

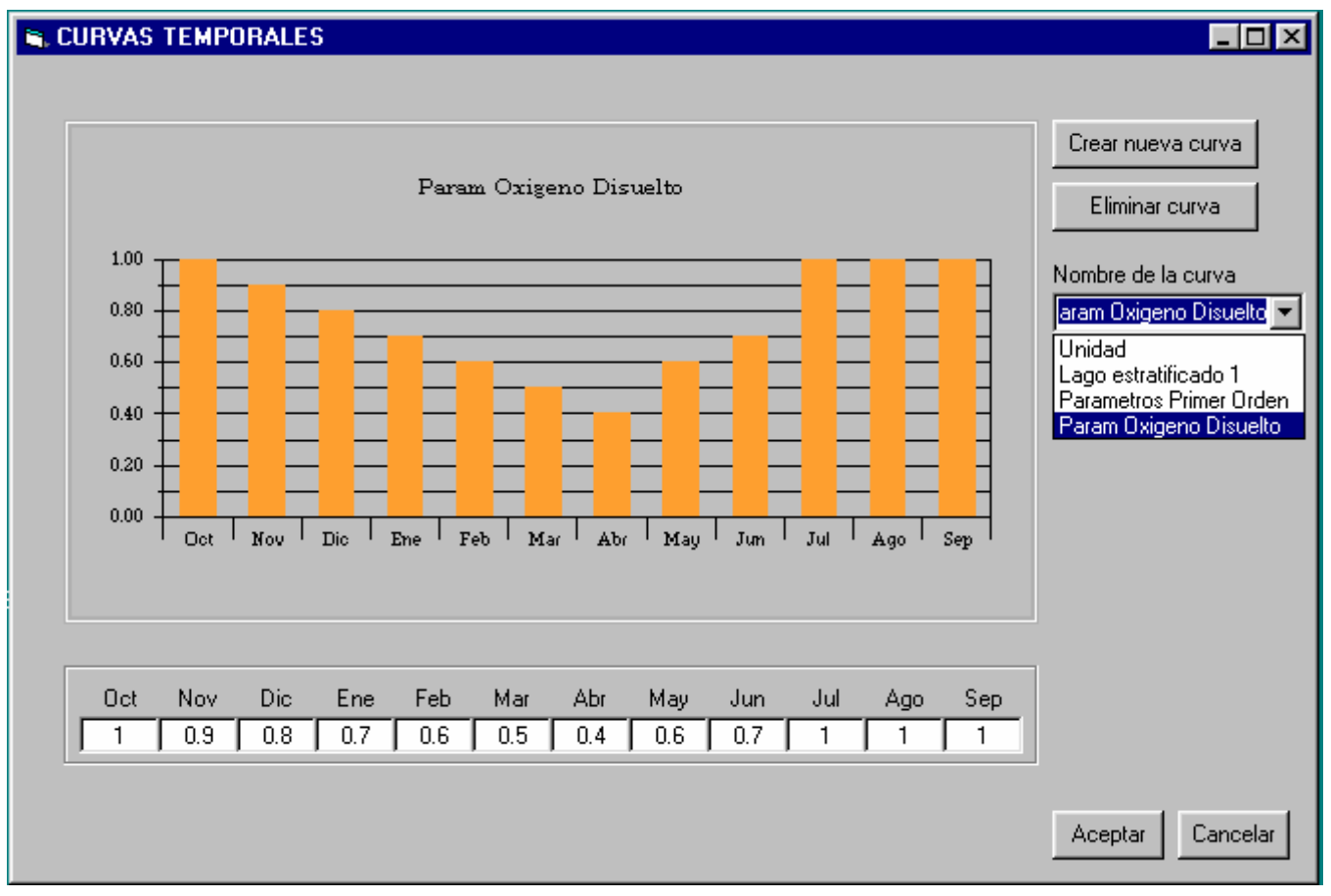

Figura 13. Interfaz para la creación de curvas temporales.

Para la introducción de las condiciones iniciales en los acuíferos se utiliza la pantalla siguiente. 


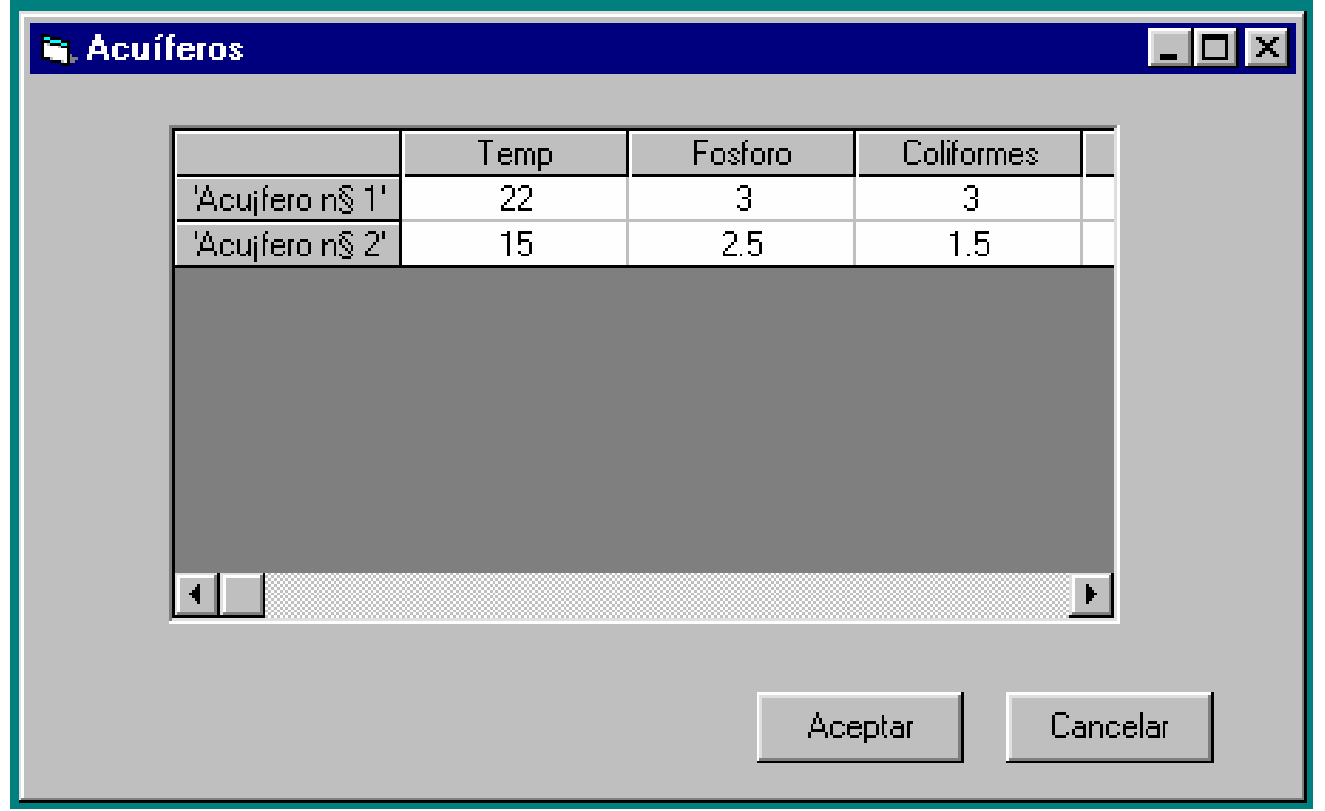

Figura 14. Interfaz para la introducción de las condiciones iniciales de calidad.

La última pantalla permite crear o eliminar los vertidos puntuales así como definir sus características.

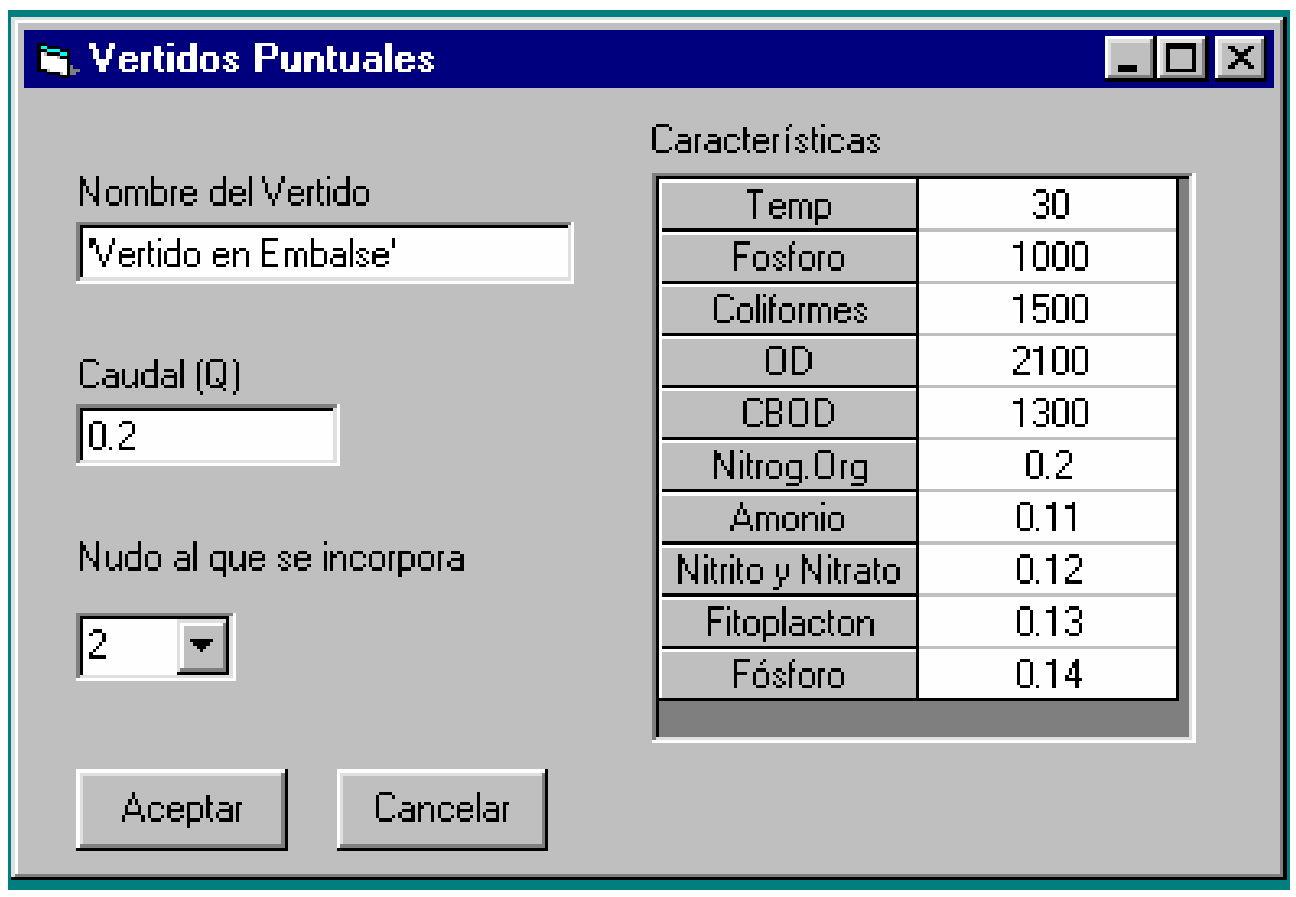

Figura 15. Interfaz para la introducción de los datos de vertidos.

El programa finaliza creando un archivo ASCII con toda la información introducida y ejecutando el programa de cálculo de la calidad GESCAL. 


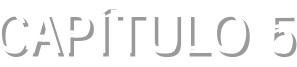

\section{APLICACIÓN DEL MÓDULO GESCAL A LA CUENCA DEL RÍO JÚCAR.}

En el presente capítulo se describe la aplicación de la herramienta desarrollada sobre un caso real, la cuenca del río Júcar. Con ello, por una parte se demuestra la utilidad de la aplicación y por otra se desarrolla una metodología de trabajo general para la aplicación de la herramienta a cualquier caso real. Este capítulo recoge:

- Descripción de la metodología.

- Descripción de la cuenca y de la información disponible.

- Análisis de la calidad del agua de la cuenca mediante el estudio de los datos históricos de la red de calidad ICA y otras fuentes.

- Creación del modelo a partir de toda la información disponible.

- Calibración del modelo, análisis de sensibilidad y acoplamiento del modelo.

- Simulaciones de diferentes escenarios en los que se incluyen aspectos de planificación, aspectos de infraestructura de depuración y de caudales de mejora ambiental.

- Finalmente se establecen las conclusiones del caso de aplicación.

\subsection{DESCRIPCIÓN DE LA METODOLOGÍA}

A continuación se explica el proceso realizado para la modelación conjunta de la gestión y la calidad de un caso real. La figura siguiente recoge una síntesis de los trabajos que componen la metodología de trabajo. 


\section{METODOLOGÍ A DE TRABAJ O}

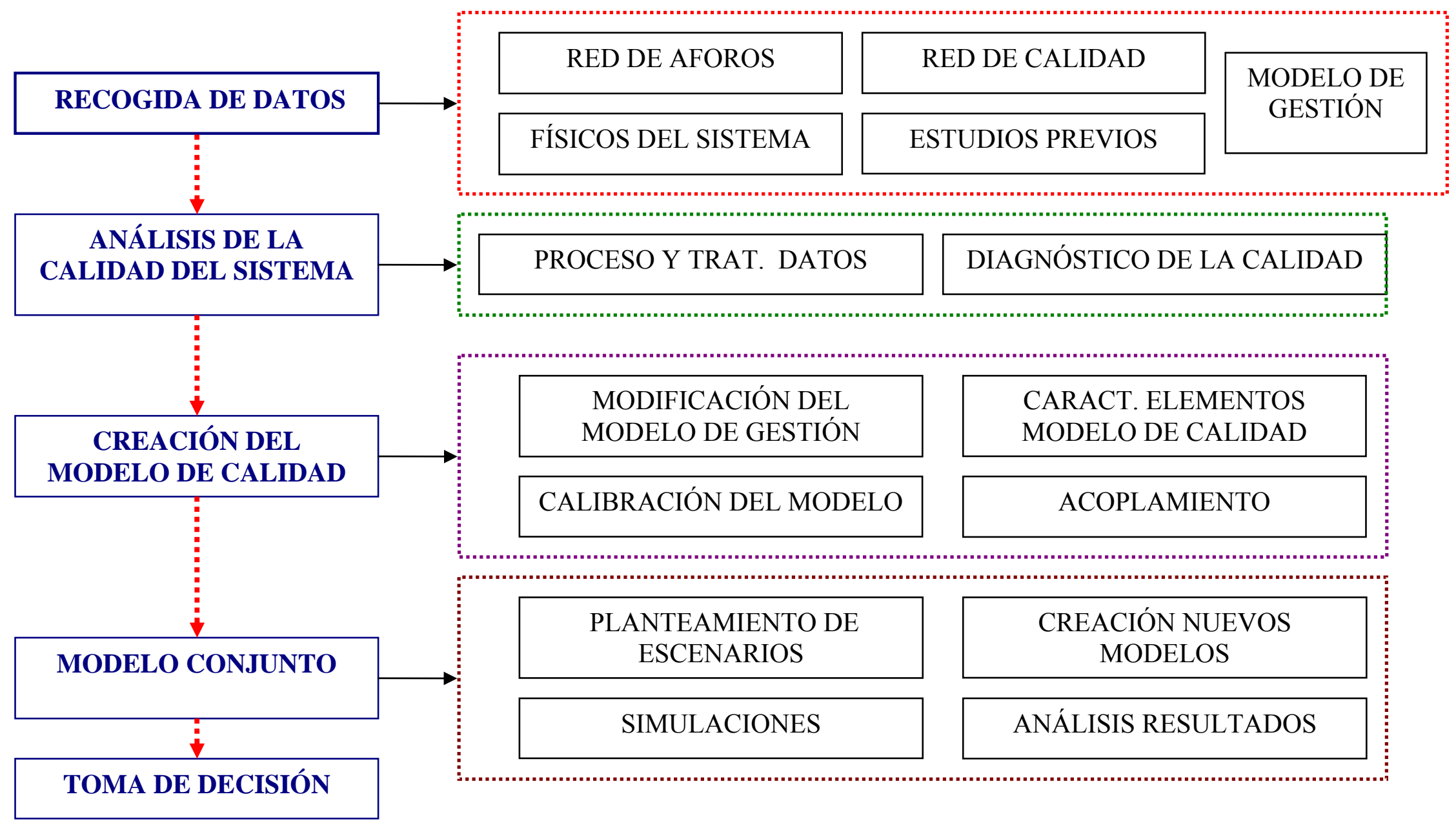

Figura 16. Metodología de trabajo propuesta. 
El primer trabajo consiste en la recopilación de todos los datos disponibles:

- Los datos físicos permiten la caracterización del sistema y sus elementos. Suelen ser necesarios datos sobre infraestructura, red hidrográfica, acuíferos, etc.

- Con los datos de aforo se analiza el régimen de caudales de las diferentes zonas de la cuenca.

- Los datos de la red de calidad permiten realizar el diagnóstico de la calidad en todo el sistema y calibrar el modelo conjunto.

- La recopilación y análisis de los estudios previos aporta nueva información para el conocimiento, caracterización y modelación del sistema.

- En la metodología propuesta se asume que se dispone de un modelo de gestión previo. Este modelo de gestión es la base para la creación del modelo conjunto, aunque, como se explica más adelante, es frecuente la modificación del mismo para obtener un modelo final adecuado. Junto que en este modelo de gestión se asume que se dispone de series históricas restituidas a régimen natural en varios puntos de la cuenca.

El segundo proceso, o etapa de esta metodología, consiste en realizar un análisis de la calidad de todo el sistema.

- Para ello, previamente se realiza un tratamiento, catalogación y validación de los datos de las estaciones del sistema.

- Partiendo de los datos validados se realiza un análisis de los mismos. Esta tarea es fundamental para entender la evolución espacio - temporal de la calidad en la cuenca y los factores principales que influyen sobre la misma. Las tareas a realizar son las siguientes:

- Comparación de datos entre estaciones consecutivas.

- Análisis temporal continuo y estacional de cada estación.

- Análisis espacial de zonas de la cuenca mediante perfiles longitudinales de calidad.

- Comprobación de hipótesis y procesos observados con la información física disponible del sistema.

Del análisis de los datos de calidad se puede obtener lo siguiente:

- Identificar las presiones y los impactos sobre el sistema.

- Definición de los elementos a modelar incluyendo los tramos en que se debe fragmentar el río. 
- Períodos de calibración de cada elemento.

- Constituyentes susceptibles de ser modelados con la información disponible.

- Estimación por balance de los focos de contaminación difusa.

- Definición de la calidad de diferentes elementos como son acuíferos, aportaciones y retornos.

- Mejoras sobre la red de calidad para su uso en la modelación de la calidad.

Un tercer paso consiste en la creación del modelo de conjunto de gestión y calidad. Para ello se realizan las siguientes fases:

- Modificación del modelo previo de gestión para incorporar nuevos elementos necesarios para una modelación adecuada de la calidad.

- Partiendo del análisis de calidad realizado se necesita, también, disponer o estimar la siguiente información:

- Datos del régimen térmico de cada elemento o datos meteorológicos si se va a realizar la modelación de la temperatura.

- Características hidráulicas y datos físicos de los tramos de río a modelar.

- Comportamiento hidráulico de los embalses e hipótesis de modelación.

- Vertidos puntuales con efecto significativo sobre la calidad del agua. Se debe disponer información sobre el volumen de vertido, su variación temporal y las concentraciones de vertido.

- Elementos de contaminación difusa definidos por su localización y la carga de contaminación aportante por unidad de tiempo.

- Calidad del resto de elementos de la modelación como son acuíferos, retornos y tomas.

- Es necesario la estimación de las series de calidad de las aportaciones.

- Con el modelo creado se debe realizar una calibración de los todas las constantes de cada uno de los constituyentes. La calibración se realiza por elementos de forma individualizada. Para ello la herramienta desarrollada, que se explica posteriormente, es de gran ayuda.

- Una vez calibrados todos los elementos el análisis de sensibilidad permite distinguir, para cada constituyente, las zonas en donde la calidad depende de factores externos y aquellas en las que se depende de los procesos internos. 
- El último paso, en la creación del modelo conjunto, es el acoplamiento de los elementos y modelos. Para ello se realiza una simulación del modelo completo para un período representativo. Los resultados se comparan con los valores históricos de calidad permitiendo comprobar por un lado que la calibración de ningún elemento este distorsionando los resultados aguas abajo del mismo, y por otro que la distribución de caudales proporcionada por el modelo de gestión es suficientemente realista para la modelación de la calidad. Tras estas comprobaciones y posibles ajustes en ambos modelos se obtiene finalmente un modelo conjunto que permite la modelación de la gestión y de la calidad del agua de forma integrada en un mismo sistema.

El último paso, una vez construido el modelo conjunto, consiste en la simulación de diferentes alternativas en función del objetivo que se persiga.

- Para ello, en primer lugar se deben definir los objetivos del estudio, estos deben traducirse en el planteamiento de diferentes escenarios o alternativas. Esta herramienta de modelación conjunta permite analizar, entre muchas otras cosas, el efecto sobre el sistema de lo siguiente:

- Creación de nueva infraestructura en el sistema.

- Modificación del uso actual del recurso.

- Creación de nueva infraestructura de depuración.

- Estimación de caudales de dilución en zonas críticas.

- Análisis de nuevos puntos de toma para demandas con problemas de calidad.

- Una vez planteados los diferentes escenarios se procede a su materialización mediante la modificación del modelo conjunto de tal forma que los nuevos modelos sean representativos de las situaciones a estudiar.

- Con los diferentes modelos planteados se realiza la simulación para un período representativo.

- Una vez realizadas las simulaciones se realiza un análisis de resultados comparativo y de él se extraen las conclusiones que permiten tomar decisiones sobre el sistema de recursos hídricos modelado.

La metodología aquí descrita, general para cualquier caso de estudio, se ha aplicado al caso de la cuenca del río Júcar. El resto del capítulo representa el detalle de dicha aplicación. 


\subsection{DESCRIPCIÓN DEL SISTEMA DEL RÍO JÚCAR.}

La cuenca del río Júcar se extiende por las comunidades autónomas de Castilla la Mancha y Valencia. Desde el punto de vista geomorfológico está delimitada al este por Serranía de cuenca, al norte por los Montes Universales, al sur con el sistema penibético y al este con el mar mediterráneo. En relación con otras cuencas fluviales limita al norte con la cuenca del río Turia, al este con las cuencas del río Tajo y del río Guadiana y al sur con la cuenca del río Segura y Vinalopó. Ocupa una extensión de cerca de $22,000 \mathrm{~km}^{2}$, y la longitud del cauce principal es de casi $500 \mathrm{~km}$.

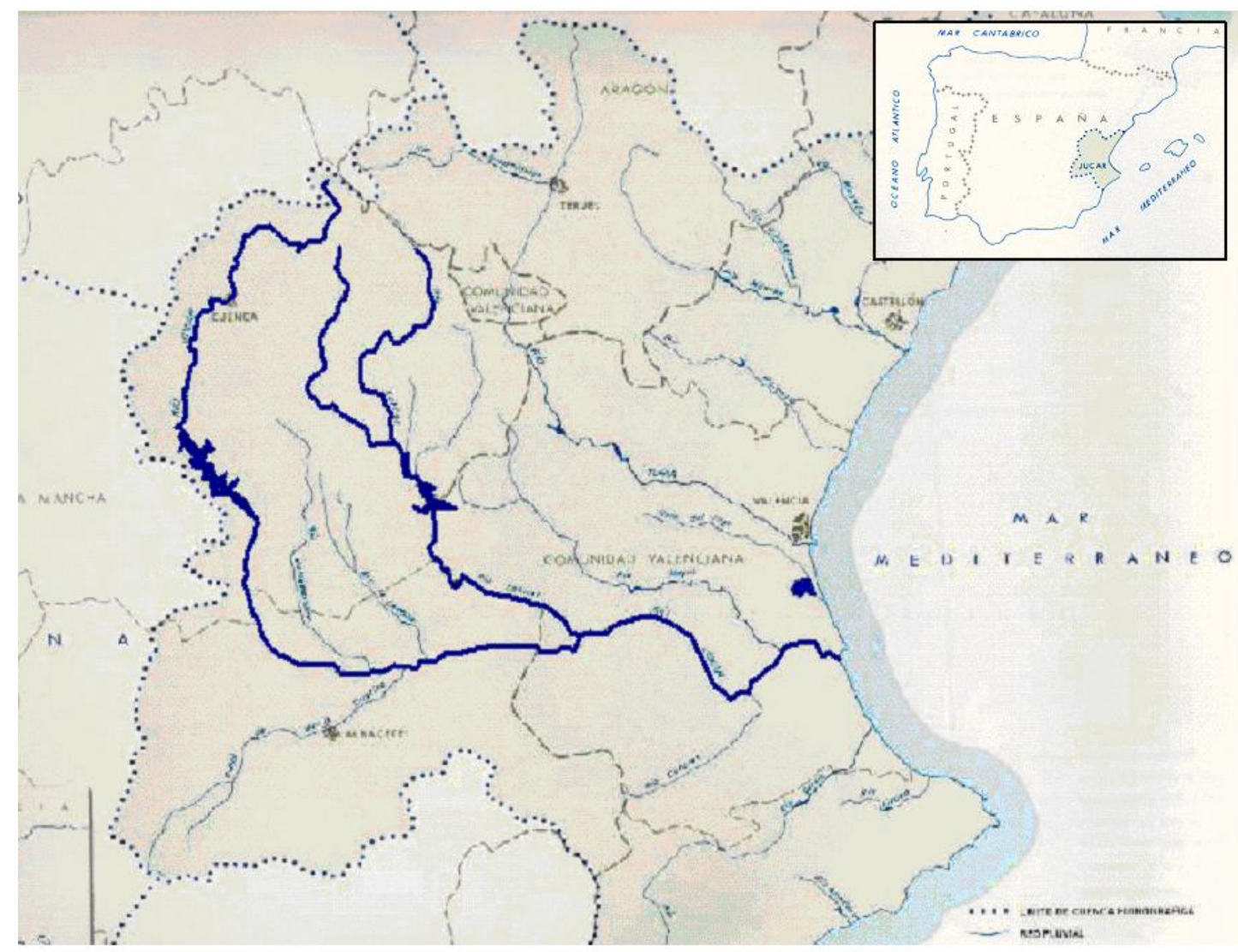

Figura 17. Localización de la cuenca del Júcar.

La precipitación total media en la cuenca del Júcar es de $510 \mathrm{~mm} / \mathrm{año}$. La aportación total media es de $1,450 \mathrm{hm}^{3} /$ año. Los recursos subterráneos renovables se estiman en un $80 \%$ del valor anterior.

Los suministros urbanos de la cuenca alcanzan los $150 \mathrm{hm}^{3} /$ año aproximadamente. El total de población abastecida en la cuenca es aproximadamente de 860,000 habitantes. La superficie de regadío 158,500 has que suponen unos 1,000 $\mathrm{hm}^{3} /$ año de suministro. Por último, el potencial hidroeléctrico instalado es del orden de 
1,300 MW, aunque el 40\% (540 MW) lo proporciona la central reversible de Cortes-La Muela.

La capacidad total de embalses construida es de unos 2,900 $\mathrm{hm}^{3}$. También se explotan del orden de $300 \mathrm{hm}^{3} /$ año de recursos subterráneos.

\subsection{ESTUDIOS PREVIOS Y DATOS DISPONIBLES.}

En el presente apartado se explica los estudios previos realizados en materia de planificación y gestión de recursos hídricos y calidad de aguas. Además se realiza una descripción de los datos utilizados para la realización del estudio.

\subsubsection{Estudios previos.}

Para el desarrollo de esta tesis doctoral se ha realizado una revisión tanto de los estudios relacionados con los recursos hídricos como de la calidad, y su modelación, de las aguas superficiales de la cuenca del río Júcar. En este apartado se realiza en primer lugar un análisis de los estudios sobre aspectos de evaluación y modelación de recursos hídricos y un segundo apartado recoge una explicación sobre los diferentes estudios previos en materia de calidad del agua.

\subsubsection{Estudios previos sobre modelación y evaluación del recurso hídrico en la cuenca del río Júcar.}

En materia de modelación de recursos hídricos el primer referente importante es el Plan Hidrológico de Cuenca (CHJ- 1998) en el cual se evalúan los recursos de la cuenca y se establece un modelo de simulación representativo del sistema. Posteriormente se han seguido realizando estudios de mejora tanto de la evaluación del recurso como de la modelación del sistema.

En cuanto a la evaluación del recurso destacar los dos estudios que en los últimos años han realizado un mayor aporte sobre la caracterización de los mismos son:

- El trabajo realizado por Albín (2001) en donde se realiza una evaluación de las aportaciones naturales conjuntas de los afluentes del Magro, Albaida, Sellent y Verde. Además esta evaluación tuvo como consecuencia una modificación del modelo de gestión en la parte baja de la cuenca con un mayor detalle y precisión.

- El segundo estudio, desarrollado por Herrero (2002), realiza una revisión y validación de todos los datos disponibles sobre caudales en la cuenca del río 
Júcar aguas arriba del embalse de Tous y mejora las series de aportaciones disponibles hasta ese momento.

En cuanto a los modelos de simulación disponibles desde el desarrollado para el PHJ ha habido varios en función del objetivo que se quería alcanzar. Uno de los últimos fue el desarrollado en el convenio de colaboración entre la CHJ y la UPV (2000) y que representa un modelo bastante completo en todas las zonas de la cuenca. En este marco de colaboración entre ambas entidades surgieron los dos estudios previamente citados sobre la evaluación del recurso. El último modelo disponible es el obtenido del estudio (MS-Ingenieros, 2002) de colaboración entre la CHJ, el DIHMA-UPV y la empresa MS-Ingenieros que presenta algunas mejoras sobre el anterior. Se escoge este último modelo como referencia para el presente trabajo.

\subsubsection{Estudios previos en materia de calidad de aguas.}

De los estudios sobre aspectos de calidad destacar por su proliferación los realizados en los años 1994 y 1995 debido a la sequía acaecida en la época. Los estudios de calidad especiales realizados para el control de la calidad en aquellos momentos fueron los siguientes:

- En el estudio realizado por TMConsult (1995) se realiza una campaña de medidas de variables limnológicas, en el verano de 1995, sobre diferentes embalses de la CHJ entre los que se encuentra el de Alarcón. La situación en que se encontraba el embalse en el momento de realizar el estudio era de volúmenes mínimos extremos debido a la sequía de la época. Ello repercute en que aunque se tomaron medidas a diferentes profundidades el embalse no estaba estratificado por el poco volumen almacenado. Del estudio se deduce que el $75 \%$ del aporte de fósforo sobre el embalse se debe a fuentes puntuales en especial de los vertidos de la ciudad de Cuenca. Las medidas realizadas de concentraciones de oxígeno disuelto varían entre 6 y $11 \mathrm{mg} / 1$ con un descenso de las mismas en el último metro de $3 \mathrm{mg} / \mathrm{l}$ por el efecto de los sedimentos. El fitoplancton medido osciló entre 4 y 8 (ind/ml). El diagnóstico final de la situación de embalse en esa campaña es de eutrófico.

- Otro estudio sobre el estado trófico de un embalse de la cuenca fue el realizado por el CEDEX (2000). En este caso entre los veintisiete embalses en estudio se encontraba el embalse de Tous. Se realizaron diferentes muestreos durante el año 1999 tanto de variables físico-químicas como biológicas para determinar el estado trófico del embalse. Con los datos disponibles se aprecia una estratificación del embalse en los meses de verano con un epilimnion de 5 
metros de profundidad a una temperatura media de $25^{\circ} \mathrm{C}$, el metalimnion situado entre cinco y quince metros con un descenso de temperatura de $1.1^{\circ} \mathrm{C}$ por metro y el hipolimnion hasta el fondo con una temperatura de $11.4^{\circ} \mathrm{C}$. La conclusión más interesante del estudio es el diagnóstico como oligotrófico con una calidad muy buena del agua y concentraciones muy bajas de todos los estados de oxidación del nitrógeno inorgánico así como del fósforo total.

Finalmente los dos estudios relacionados con los problemas de la calidad del agua y de mortandad de peces en los embalses en aquella época son:

- "Control analítico intensivo y despesque en embalses de abastecimiento por motivo de la sequía en la Confederación Hidrográfica del Júcar durante el verano de 1995".

- Actuaciones encaminadas a la recuperación y retirada de la zona piscícola de los embalses de Alarcón, Contreras, Benageber, y Loriguilla y del seguimiento intensivo de su calidad dada la prolongada sequía que afecta a los ríos Júcar y Turia (verano 1994) TMC Consult.

Como se puede ver el enfoque tradicional ha sido exclusivamente el control y el seguimiento de la calidad en el río pero no la modelación. De la documentación recabada no hay ningún modelo de calidad de algún tramo de río en la cuenca del río Júcar. Otro aspecto remarcable es que aunque existen informes periódicos, emitidos por comisaría de aguas, sobre la calidad del agua en la cuenca estos tienen un carácter puramente estadístico sobre cumplimiento de normativas. No se dispone de un estudio que realice el diagnóstico de la calidad del agua en la cuenca analizando las series de datos de calidad disponibles a partir de la red de calidad de la CHJ.

\subsubsection{Datos Disponibles.}

Para la realización del estudio tanto la Oficina de Planificación Hidrológica de la Confederación Hidrográfica del Júcar (OPH-CHJ) como Comisaría de Aguas (CA-CHJ) han aportado datos de dos tipos: datos numéricos de diversa índole e información georenferenciada para su uso mediante sistemas de información geográfica. Ambos tipos de información han sido esenciales para el buen desarrollo de este trabajo.

En cuanto a la información georenferenciada aportada por la OPH-CHJ destaca las siguientes capas en formato ARCVIEW:

- Modelo Digital del Terreno de toda la cuenca.

- Definición de límites de ámbito de la CHJ. 
- Usos del suelo (CORINE). Así como usos de suelo reclasificados para una mejor identificación de posibles presiones sobre el sistema hídrico.

- Geología del terreno y geología reclasificada que ha permitido comprobar los focos de aporte natural de sales del terreno.

- Embalses de la cuenca con sus características.

- Red hidrográfica de toda la cuenca y las subcuencas de cada tramo.

- Estaciones de la red ICA.

- Estaciones de la red biológica.

- Estaciones de la red de aforos.

- Vertidos urbanos industriales y otras actividades. Se ha tenido en cuenta el cauce o elemento receptor. De los vertidos se disponen datos de volumen de vertido pero no de concentraciones.

- Estaciones depuradoras de aguas residuales. Entre los datos que se disponen los más útiles son la fecha de inicio, tipo de tratamiento y tanto por ciento de tratamiento.

- Azudes existentes en el río y sus características.

- Información de las demandas agrarias del sistema.

Toda esta información ha sido utilizada para la caracterización de los diferentes tramos de estudio en el río así como para la obtención de las presiones de contaminación sobre cada tramo. Además de la localización de los elementos las capas permiten obtener distintas informaciones de gran valor para la modelación.

Además se dispone de los siguientes datos:

- Series de datos de las estaciones de aforos así como de explotación de embalses a escala mensual hasta la actualidad. No hay que olvidar los estudios previos como el de (Herrero, 2002) para tener en cuenta la validez de estos datos. De ellos se puede obtener la dinámica de flujo de caudales a en toda la cuenca.

- Comisaría de la CHJ aportó datos de la antigua red de calidad COCA, datos entre 1980 y 1994, así como las series trimestrales de mediciones de clorofila-a para los embalses de Alarcón, Contreras y Cortes II. Por otra parte también se ha tenido acceso a información sobre campañas especiales de análisis de calidad realizadas por el laboratorio de la $\mathrm{CHJ}$ en la parte final del río, así como a su base de datos de análisis de calidad. 
- Se dispone de los valores de las estaciones de calidad, de la red ICA, para todos los parámetros medidos desde 1994. Estos datos han sido la base fundamental del estudio ya que han servido para el diagnóstico de la calidad del río y para la calibración del modelo de calidad. Previamente se ha realizado una tarea de validación de los datos en todas las estaciones utilizadas.

\subsection{ANÁLISIS DE LA CALIDAD DE LA CUENCA DEL RÍO JÚCAR.}

\subsubsection{Introducción.}

En este apartado se realiza un análisis espacio temporal de la calidad del agua en el río Júcar y su afluente el Cabriel. Para ello se han utilizado datos de la red de calidad en activo en la Confederación Hidrográfica del Júcar (red ICA). El objetivo es caracterizar la calidad en la cuenca, su evolución espacial y temporal tanto estacional como a lo largo de los años. El estudio de la calidad del agua es fundamental para analizar la realidad del sistema, evaluar los focos contaminantes y el posterior desarrollo de modelos de calidad. Además el estudio de algunas variables ha permitido localizar más en detalle la procedencia y magnitud de ciertos flujos de agua. Así se demuestra que el uso de la información de la calidad del agua para la evaluación de los recursos hídricos, aunque no es una metodología comúnmente aplicada, es importante ya que permite corroborar hipótesis y descubrir nuevas opciones.

Por otra parte se debe destacar que, sorprendentemente, hasta la actualidad ningún estudio había realizado este análisis ni en lo que se refiere al tratamiento y depuración de los datos ni en cuanto al análisis de los mismos para la evaluación de calidad de forma espacio temporal.

La red Integrada de Calidad de Aguas diseñada en 1993 engloba diferentes redes de calidad de aguas anteriores como son la red de Control Oficial de la Calidad del Agua (COCA), la red de Control Oficial de Abastecimientos (COAS) y la red de control de la calidad de los tramos de río declarados como piscícolas (ICTIOFAUNA).

Debido a la escasez de datos en la parte final del río Júcar, entre Alcira y la desembocadura, para una mejor caracterización se han utilizado datos procedentes del Laboratorio de la Oficina de Comisaría de Aguas de la CHJ. Estos datos tienen su origen en campañas específicas para la zona y que consta de seis puntos de muestreo:

- Aguas abajo del vertido de Alcira.

- Confluencia con el río Magro. 
- Poliña del Júcar.

- Riola.

- Azud de Sueca.

- Azud de Cullera.

En la siguiente figura se puede ver la localización de las diferentes estaciones de calidad de la red ICA en el ámbito de estudio.

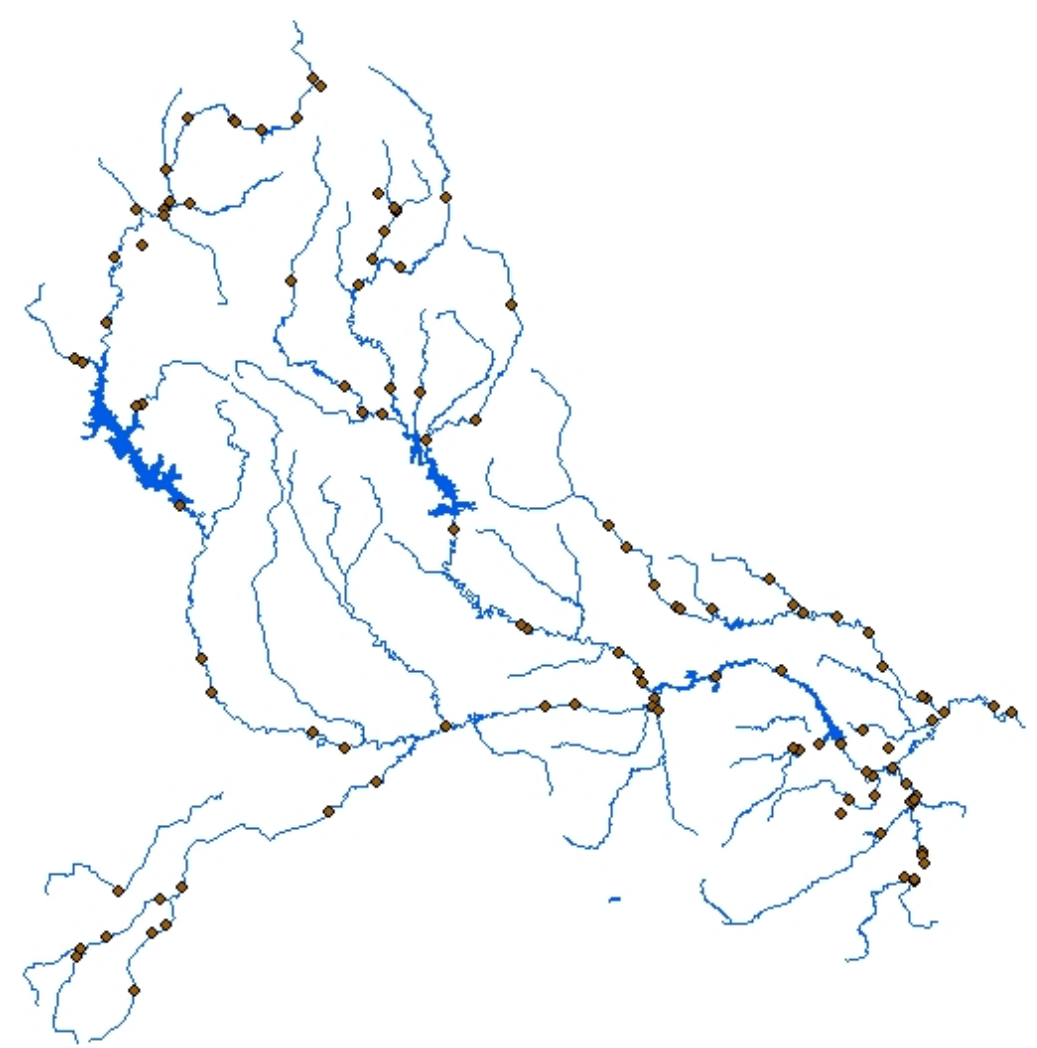

Figura 18. Ubicación de las estaciones ICA en la cuenca del río Júcar.

El período de datos disponibles de la red ICA comprende entre 1994 y la actualidad. La periodicidad de muestreo depende del parámetro y la importancia de la estación. Por lo general una estación de importancia realiza muestreos con periodicidad mensual de los constituyentes más importantes.

Para el diagnóstico de la calidad de la cuenca se han elegido diversos parámetros según su importancia como indicador de la calidad del sistema, la disponibilidad de los mismos y la posibilidad de su posterior modelación. Estos parámetros han sido:

- Conductividad

- Sólidos suspendidos 
$-\mathrm{DBO}_{5}$

- Oxígeno disuelto

- Formas de nitrógeno: amonio, nitritos, nitratos

- Formas de fósforo: fósforo total y fosfatos

- Temperatura

- Otras variables en principio estudiadas pero que no presentan gran disponibilidad de datos han sido los cloruros, sulfatos, DQO, $\mathrm{pH}$ y coliformes fecales.

Se ha tenido que realizar un gran esfuerzo en la depuración y validación de los datos. Se han eliminado concentraciones extremas obtenidas por fallo en la medición o por mediciones de algún evento particular que no refleja la situación normal de la calidad del agua en el río. Una vez validados los datos se realiza el análisis de calidad del sistema. Este análisis, como se comenta en la descripción de la metodología es fundamental para la caracterización y modelación de la calidad.

A continuación se realiza un análisis de la calidad por constituyentes. Se explica, en cada uno de ellos, la evolución espacial media a lo largo del río así como análisis más detallados de algunos puntos. Aunque en el análisis se han tenido en cuenta todos los datos disponibles, los perfiles longitudinales de calidad mostrados se refieren a los valores medios del período años 2000 y 2003. Esto es así porque es el período con mayor disponibilidad de datos, de forma homogénea en toda la cuenca, y representativo de la situación actual del sistema. En la siguiente figura se muestra las estaciones con una mayor disponibilidad de datos que permiten, actualmente, caracterizar la calidad del río con una disponibilidad de datos suficiente. En la tabla siguiente se aporta más información sobre las mismas. 


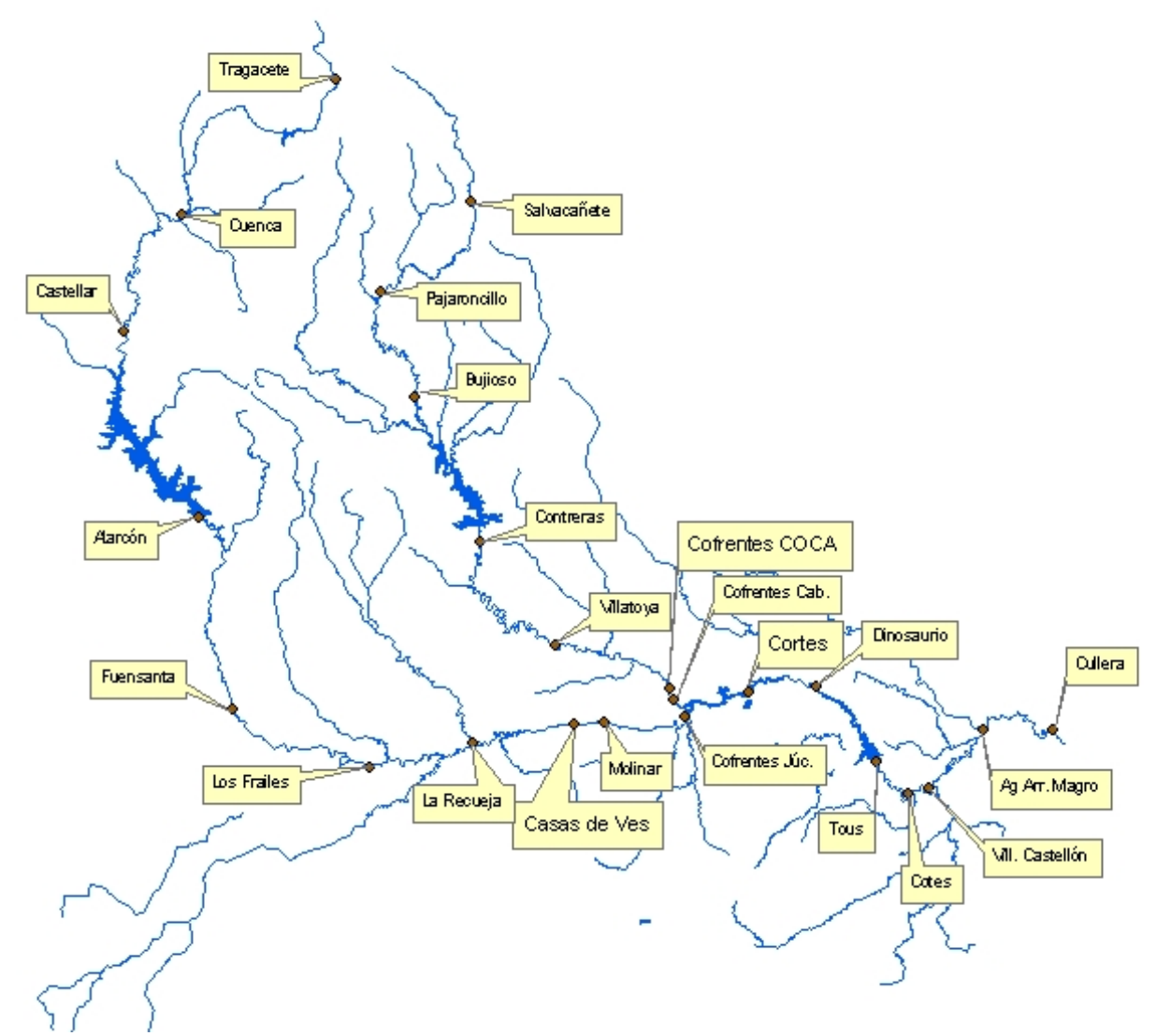

Figura 19. Estaciones ICA utilizadas para la obtención de perfiles medios de calidad. 
Capítulo 5. Aplicación del módulo GESCAL a la cuenca del río Júcar.

\begin{tabular}{|c|c|c|c|c|c|c|}
\hline Cod. Est. & Cod. ICA & X UTM & Y UTM & Nombre & Municipio & Cauce \\
\hline D204 & JU05880004 & $601,802.00$ & $4,461,686.00$ & Júcar-alto (Tragacete) & HUÉLAMO & R. Júcar \\
\hline E101 & JU06100001 & $573,187.00$ & $4,436,477.00$ & $\begin{array}{l}\text { Cuenca } \quad(\mathrm{COCA})- \\
\text { Estación Aforos } 032\end{array}$ & CUENCA & R. Júcar \\
\hline E305 & JU06120005 & $627,270.00$ & $4,438,800.00$ & Salvacañete & SALVACAÑETE & R. Cabriel \\
\hline F003 & JU06340003 & $562,273.00$ & $4,414,700.00$ & $\begin{array}{l}\text { Alerta Saih (Aforo } \\
\text { Castellar) }\end{array}$ & $\begin{array}{ll}\text { MOTA } & \text { DE } \\
\text { ALTAREJOS } & \end{array}$ & R. Júcar \\
\hline F201 & JU06360001 & $610,397.00$ & $4,421,989.00$ & Pajaroncillo (COCA) & PAJARONCILLO & R. Cabriel \\
\hline G206 & JU06640006 & $616,750.00$ & $4,402,280.00$ & $\begin{array}{l}\text { Cola del Embalse de } \\
\text { Bujioso }\end{array}$ & VÍLLORA & R. Cabriel \\
\hline $\mathrm{H} 102$ & JU06910002 & $576,100.00$ & $4,379,650.00$ & $\begin{array}{l}\text { Embalse de Alarcón } \\
\text { (Estación Alerta) }\end{array}$ & ALARCÓN & R. Júcar \\
\hline $\mathrm{H} 302$ & JU06930002 & $628,825.00$ & $4,375,125.00$ & $\begin{array}{l}\text { Aforo del Embalse de } \\
\text { Contreras }\end{array}$ & $\begin{array}{ll}\text { VENTA } & \text { DEL } \\
\text { MORO } & \end{array}$ & R. Cabriel \\
\hline $\mathrm{I} 302$ & JU07190002 & $641,625.00$ & $4,356,850.00$ & Villatoya (cementerio) & VILLATOYA & R. Cabriel \\
\hline J101 & JU07420001 & $582,500.00$ & $4,343,850.00$ & $\begin{array}{lll}\text { Fuensanta } & \text { (C.H. La } \\
\text { Manchega) } & & \end{array}$ & FUENSANTA & R. Júcar \\
\hline $\mathrm{J} 201$ & JU07430001 & $627,450.00$ & $4,337,500.00$ & $\begin{array}{lll}\text { Azud de } & \text { (C.H. La } \\
\text { Recueja) } & & \end{array}$ & JORQUERA & R. Júcar \\
\hline $\mathrm{J} 301$ & JU07440001 & $652,150.00$ & $4,341,475.00$ & Embalse del Molinar & VILLA DE VES & R. Júcar \\
\hline $\mathrm{J} 302$ & JU07440002 & $646,350.00$ & $4,341,150.00$ & $\begin{array}{l}\text { Cola del Embalse del } \\
\text { Molinar }\end{array}$ & CASAS DE VES & R. Júcar \\
\hline $\mathrm{J} 403$ & JU07450003 & $679,056.00$ & $4,346,980.00$ & Cortes de Pallás & $\begin{array}{ll}\text { CORTES } & \text { DE } \\
\text { PALLÁS } & \end{array}$ & R. Júcar \\
\hline $\mathrm{J} 404$ & JU07450004 & $667,300.00$ & $4,342,575.00$ & Cofrentes & COFRENTES & R. Júcar \\
\hline $\mathrm{J} 405$ & JU07450005 & $667,100.00$ & $4,341,350.00$ & $\begin{array}{ll}\begin{array}{l}\text { Antigua } \\
\text { (Jalance) }\end{array} & \text { N-330 }\end{array}$ & JALANCE & R. Júcar \\
\hline $\mathrm{J} 406$ & JU07450006 & $664,478.00$ & $4,347,731.00$ & Cofrentes (COCA) & COFRENTES & R. Cabriel \\
\hline $\mathrm{J} 408$ & JU07450008 & $665,150.00$ & $4,345,775.00$ & Cofrentes (río Cabriel) & COFRENTES & R. Cabriel \\
\hline $\mathrm{J} 503$ & JU07460003 & $691,812.00$ & $4,348,177.00$ & Dinosaurio & DOS AGUAS & R. Júcar \\
\hline J601 & JU07470001 & $736,075.00$ & $4,339,958.00$ & Cullera & CULLERA & R. Júcar \\
\hline J604 & JU07470004 & $723,025.00$ & $4,340,103.00$ & $\begin{array}{l}\text { Júcar-Alcira a. arriba } \\
\text { confluencia Magro }\end{array}$ & ALZIRA & R. Júcar \\
\hline K202 & JU07660002 & $608,023.00$ & $4,333,092.00$ & Los Frailes & ALBACETE & R. Júcar \\
\hline K501 & JU07690001 & $713,034.00$ & $4,329,224.00$ & $\begin{array}{l}\text { Puente entrada } \\
\text { Castelló de la Ribera }\end{array}$ & $\begin{array}{l}\text { VILLANUEVA } \\
\text { DE CASTELLÓN }\end{array}$ & R. Júcar \\
\hline K502 & JU07690002 & $709,170.00$ & $4,328,000.00$ & Cotes (Júcar) & COTES & R. Júcar \\
\hline K504 & JU07690004 & $703,125.00$ & $4,334,015.00$ & Aforo Tous & TOUS & R. Júcar \\
\hline K601 & JU07700001 & $720,439.00$ & $4,336,755.00$ & Alcira & ALZIRA & R. Júcar \\
\hline
\end{tabular}

Tabla 1. Estaciones ICA utilizadas para la obtención de perfiles medios de calidad. 
En la siguiente tabla se recogen el resto de estaciones utilizadas para el diagnóstico de la calidad pero no en la obtención de los perfiles medios.

\begin{tabular}{|c|c|c|c|c|c|c|c|}
\hline Cod. Est. & Cod. ICA & X UTM & Y UTM & Nombre & Municipio & Cauce & PK Est. \\
\hline $\bar{D} 102$ & JU05870002 & $577,752.00$ & $4,454,046.00$ & $\begin{array}{l}\text { Villalba de la } \\
\text { Sierra }\end{array}$ & $\begin{array}{l}\text { VILLALBA DE } \\
\text { LA SIERRA }\end{array}$ & R. Júcar & 425.507 \\
\hline D104 & JU05870004 & $591,818.00$ & $4,451,890.00$ & $\begin{array}{l}\text { Embalse de } \\
\text { La Toba }\end{array}$ & CUENCA & R. Júcar & 445.405 \\
\hline D105 & JU05870005 & $586,825.00$ & $4,453,304.00$ & Uña & UÑA & R. Júcar & 439.869 \\
\hline D201 & JU05880001 & $598,657.00$ & $4,454,219.00$ & $\begin{array}{l}\text { Venta de Juan } \\
\text { Romero }\end{array}$ & HUÉLAMO & R. Júcar & 453.657 \\
\hline E103 & JU06100003 & $574,380.00$ & $4,438,000.00$ & $\begin{array}{l}\text { Playa de } \\
\text { Cuenca }\end{array}$ & CUENCA & R. Júcar & 405.001 \\
\hline E104 & JU06100004 & $573,639.00$ & $4,443,972.00$ & $\begin{array}{l}\text { Júcar } \\
\text { (Chantre) }\end{array}$ & CUENCA & R. Júcar & 411.8 \\
\hline F204 & JU06360004 & $618,466.00$ & $4,425,552.00$ & $\begin{array}{l}\text { Azud } \\
\text { Boniches }\end{array}$ & BONICHES & R. Cabriel & 199.591 \\
\hline G003 & JU06620003 & $568,890.00$ & $4,399,280.00$ & $\begin{array}{l}\text { Valverde del } \\
\text { Júcar (COCA) }\end{array}$ & $\begin{array}{l}\text { VALVERDE DE } \\
\text { JÚCAR }\end{array}$ & R. Gritos & 8.095 \\
\hline G004 & JU06620004 & $556,170.00$ & $4,408,000.00$ & $\begin{array}{l}\text { Belmontejo } \\
\text { (Aforo) }\end{array}$ & BELMONTEJO & $\begin{array}{l}\text { R. } \\
\text { Belmontejo }\end{array}$ & 6.64 \\
\hline$\overline{\text { G007 }}$ & JU06620007 & $557,525.00$ & $4,407,090.00$ & $\begin{array}{l}\text { Trasvase } \\
\text { Tajo-Segura }\end{array}$ & BELMONTEJO & $\begin{array}{l}\text { T. Tajo- } \\
\text { Segura (1) }\end{array}$ & 4.24 \\
\hline G207 & JU06640007 & $623,430.00$ & $4,392,350.00$ & $\begin{array}{l}\text { Aforo } \\
\text { Camporrobles }\end{array}$ & MIRA & $\begin{array}{l}\text { R. Ojos de } \\
\text { Moya }\end{array}$ & 5.038 \\
\hline G208 & JU06640008 & $622,470.00$ & $4,401,270.00$ & $\begin{array}{l}\text { Villora } \\
\text { (Aforos E- } \\
141 \text { ) }\end{array}$ & VÍLLORA & R. Martín & 9.259 \\
\hline G210 & JU06640010 & $615,100.00$ & $4,397,170.00$ & $\begin{array}{l}\text { Embalse de } \\
\text { Batanejo }\end{array}$ & ENGUÍDANOS & $\begin{array}{l}\text { R. } \\
\text { Guadazaón }\end{array}$ & 4.668 \\
\hline G211 & JU06640011 & $611,212.00$ & $4,397,783.00$ & $\begin{array}{l}\text { Paracuellos } \\
\text { (COCA) }\end{array}$ & PARACUELLOS & $\begin{array}{l}\text { R. } \\
\text { Guadazaón }\end{array}$ & 12.172 \\
\hline G212 & JU06640012 & $607,910.00$ & $4,402,490.00$ & $\begin{array}{l}\text { Piscifactoría } \\
\text { Yémeda }\end{array}$ & YÉMEDA & $\begin{array}{l}\text { R. } \\
\text { Guadazaón }\end{array}$ & 19.986 \\
\hline $\bar{G} 301$ & JU06650001 & $632,970.00$ & $4,396,138.00$ & $\begin{array}{l}\text { Molino de la } \\
\text { Hoz }\end{array}$ & MIRA & $\begin{array}{l}\text { R. Ojos de } \\
\text { Moya }\end{array}$ & 19.088 \\
\hline H101 & JU06910001 & $579,050.00$ & $4,378,150.00$ & $\begin{array}{l}\text { Presa de } \\
\text { Henchideros }\end{array}$ & ALARCÓN & R. Júcar & 306.295 \\
\hline $\mathrm{I} 301$ & JU07190001 & $642,900.00$ & $4,356,000.00$ & $\begin{array}{l}\begin{array}{l}\text { Villatoya } \\
\text { (antigua } \\
\text { COCA) }\end{array} \\
\end{array}$ & VILLATOYA & R. Cabriel & 39.056 \\
\hline $\mathrm{J} 104$ & JU07420004 & $580,373.00$ & $4,350,412.00$ & $\begin{array}{l}\text { Villalgordo } \\
\text { del Júcar }\end{array}$ & $\begin{array}{l}\text { VILLALGORDO } \\
\text { DEL JÚCAR }\end{array}$ & R. Júcar & 269.907 \\
\hline $\mathrm{J} 407$ & JU07450007 & $660,650.00$ & $4,351,630.00$ & Molino Noria & REQUENA & R. Cabriel & 12.334 \\
\hline $\mathrm{J} 410$ & JU07450010 & $667,996.00$ & $4,340,372.00$ & $\begin{array}{l}\text { Cautabán } \\
\text { (Jalance) }\end{array}$ & JALANCE & R. Cautabán & 3.487 \\
\hline J605 & JU07470005 & $719,382.10$ & $4,342,678.00$ & $\begin{array}{l}\text { Magro } \\
\text { (Tritublok) }\end{array}$ & ALGEMESÍ & R. Magro & 5.745 \\
\hline K206 & JU07660006 & $601,956.00$ & $4,336,096.00$ & Madrigueras & MADRIGUERAS & R. Júcar & 232.592 \\
\hline K503 & JU07690003 & $708,000.00$ & $4,328,750.00$ & $\begin{array}{l}\text { Azud de } \\
\text { Acequia Real } \\
\text { (Antella) }\end{array}$ & ANTELLA & R. Júcar & 68.323 \\
\hline K507 & JU07690007 & $712,230.00$ & $4,333,300.00$ & $\begin{array}{l}\text { Acequia Real } \\
\text { del Júcar }\end{array}$ & ALBERIC & $\begin{array}{l}\text { Ac. Real del } \\
\text { Júcar }\end{array}$ & 41.141 \\
\hline K602 & JU07700002 & $720,693.00$ & $4,338,460.00$ & $\begin{array}{l}\text { Alcira (río } \\
\text { Verde) }\end{array}$ & ALZIRA & R. Verde & 0.985 \\
\hline K606 & JU07700006 & $715,729.00$ & $4,326,292.00$ & $\begin{array}{l}\text { Acceso } \\
\text { Escalona }\end{array}$ & $\begin{array}{l}\text { VILLANUEVA } \\
\text { DE } \\
\text { CASTELLÓN }\end{array}$ & R. Albaida & 4.811 \\
\hline
\end{tabular}

Tabla 2. Resto de estaciones ICA utilizadas en el diagnóstico de la calidad. 
Para un mayor entendimiento del análisis de la calidad realizado, las siguientes figuras muestran esquemas de diferentes zonas de la cuenca de estudio.

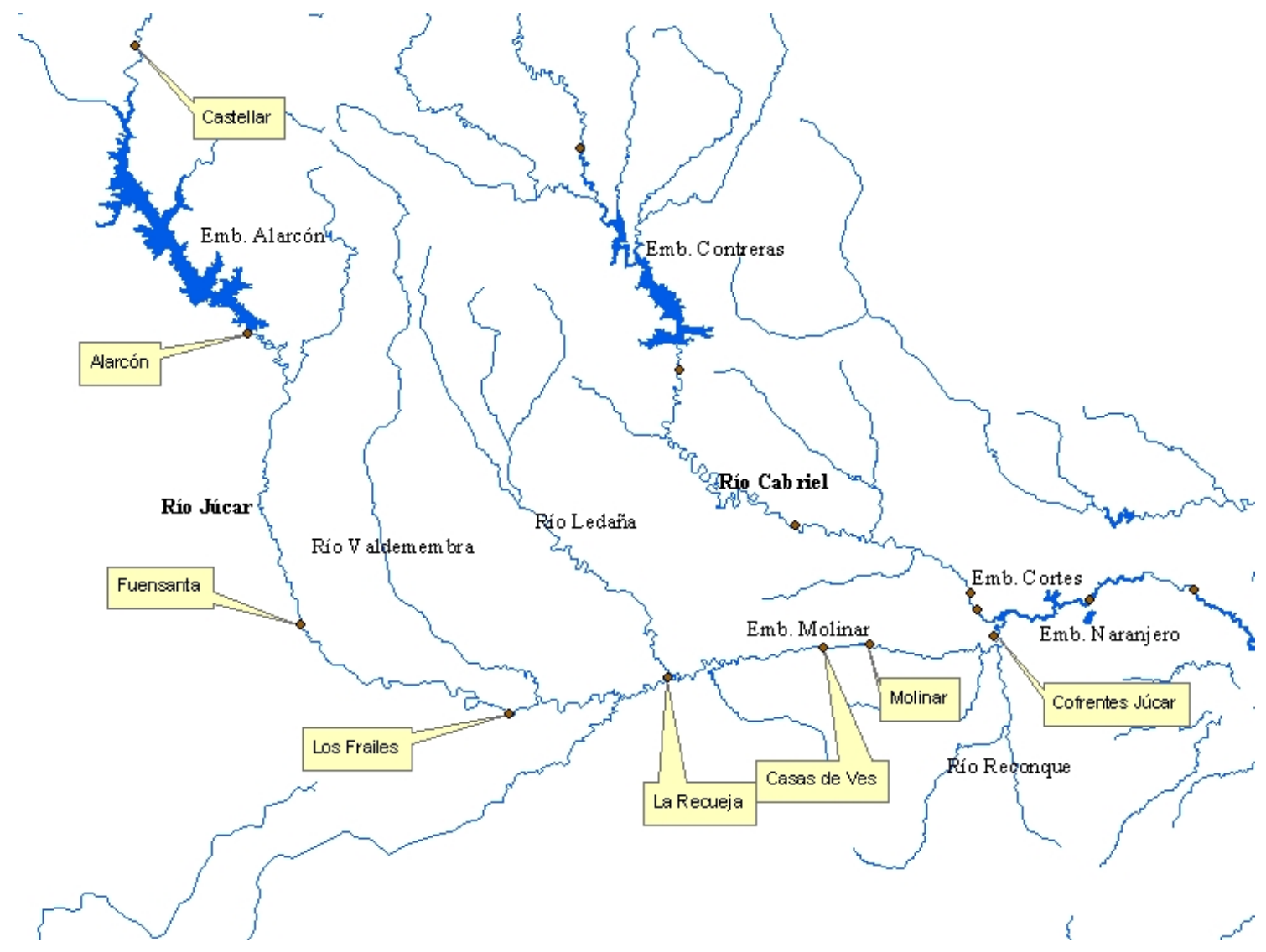

Figura 20. Esquema del río Júcar entre su nacimiento y el embalse de Tous. 


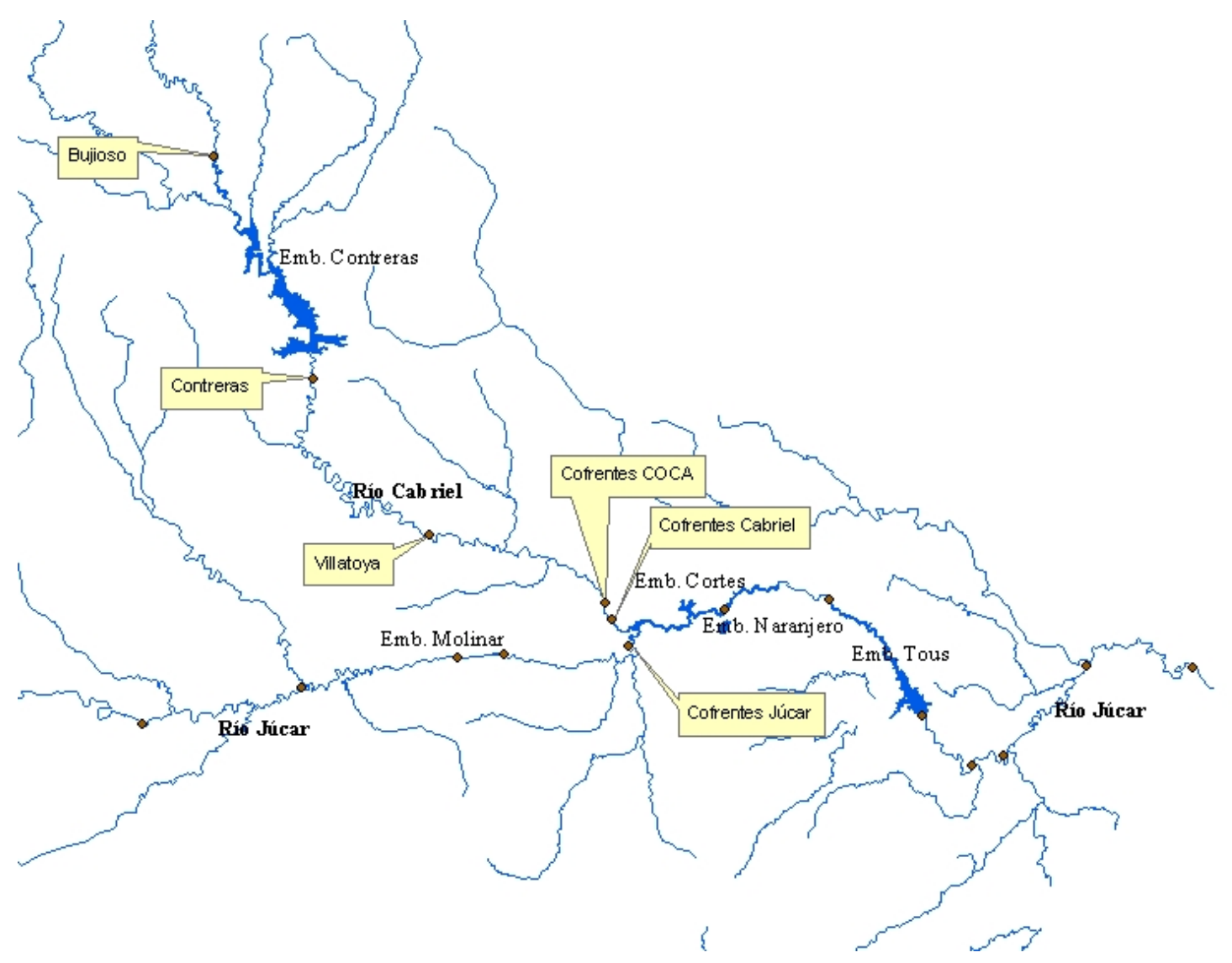

Figura 21. Esquema del río Cabriel.

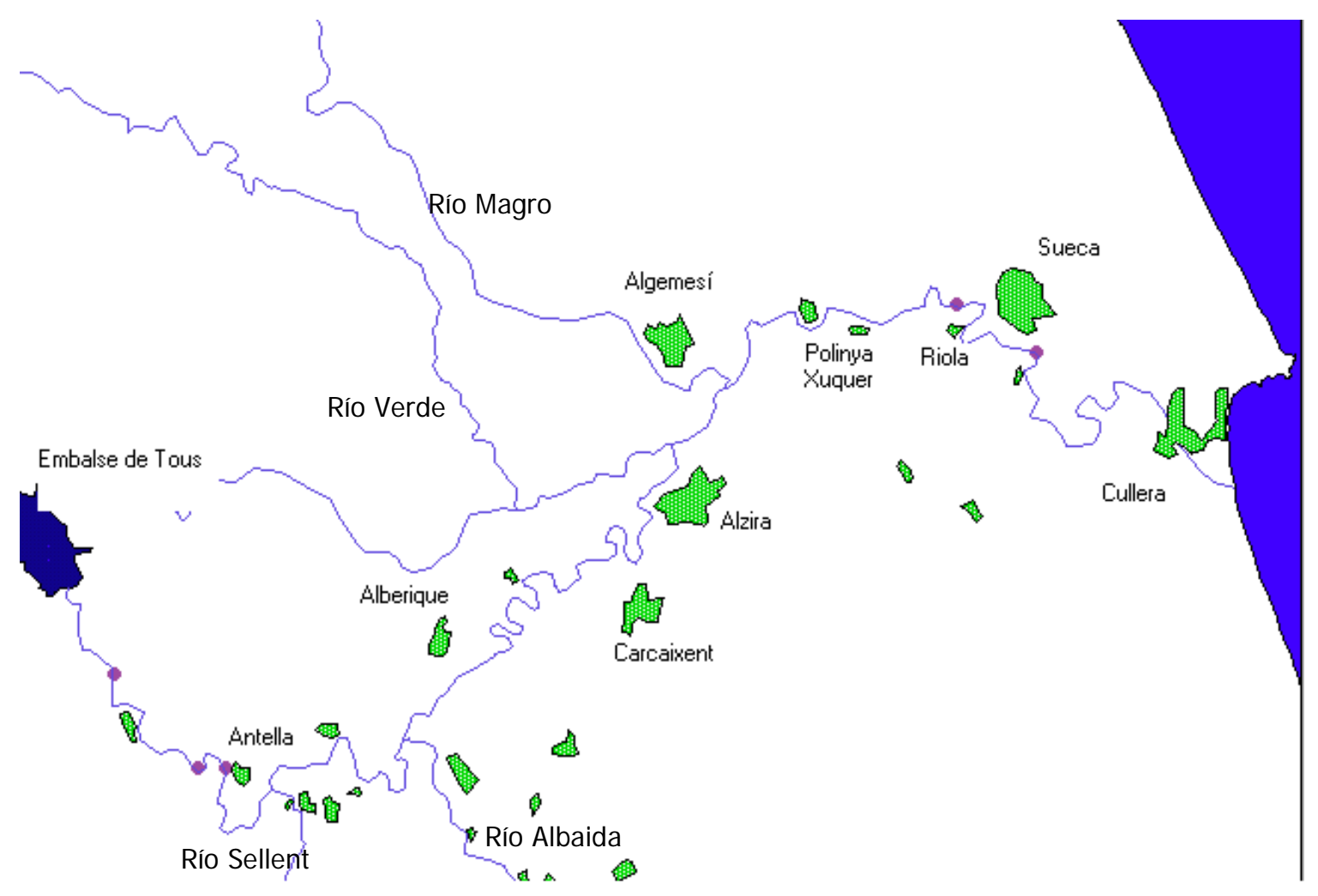

Figura 22. Esquema del río Júcar aguas abajo del embalse de Tous. 
A parte del análisis de la calidad del agua se añade un apartado de posibles mejoras de la red ICA en el ámbito de estudio con especial énfasis en el uso de sus datos para la posterior modelación de la calidad.

\subsubsection{Análisis de los caudales en la cuenca.}

El estudio de los caudales circulantes es importante ya que por una parte su conocimiento es necesario para la calibración de cada elemento y por otra ayuda a aclarar y reforzar el análisis de la calidad del resto de variables. Entre los estudios previos analizados algunos del ellos, (Herrero, 2002; Albín, 2001) analizan los caudales circulantes entre los diferentes tramos de río de la cuenca previamente a la evaluación del recurso hídrico. Para ello se utilizan, en general, datos de la red de las estaciones de aforo así como de la explotación de los embalses. En este estudio además se han analizado los datos de mediciones de caudal de las estaciones de la red ICA.

A continuación se realiza un análisis del régimen de caudales circulantes en la cuenca. Posteriormente se realiza una comparación de los caudales medidos en las estaciones de aforo y en las estaciones de calidad ICA.

\subsubsection{Régimen de caudales en la cuenca del río Júcar.}

La cuenca del río Júcar se caracteriza, como muchas de las cuencas mediterráneas, por unos aportes marcados por una hidrología irregular junto con unos consumos basados en un marcado carácter agrícola. Ello ha llevado a una alta regulación del río y a un régimen de caudales circulantes de grandes sueltas en las épocas de riego y bajos caudales el resto del año.

Aguas arriba de los embalses de Alarcón y Contreras existe poca influencia del hombre, por lo que los caudales siguen unos regímenes naturales típicos del clima de la zona, con mayores caudales en invierno y mínimos en verano. Prueba de ello es la siguiente gráfica que muestra los promedios mensuales de las entradas a los embalses de Alarcón y Contreras. 


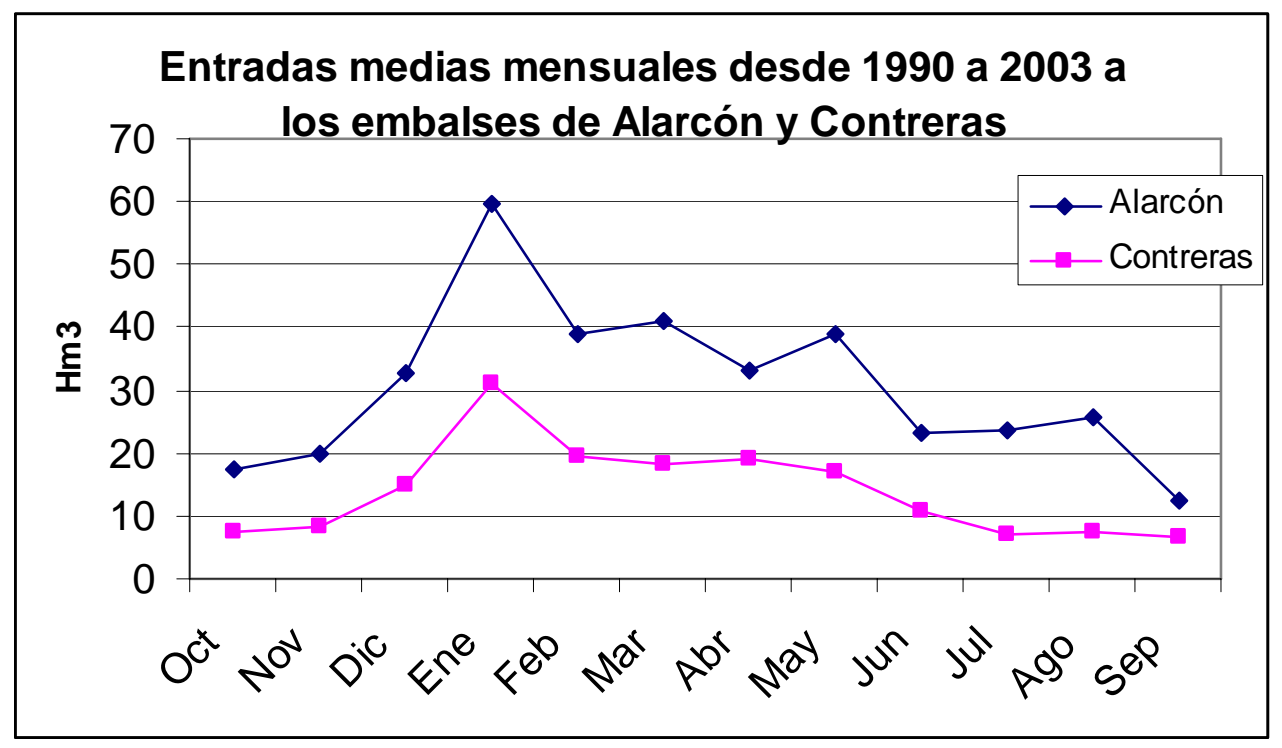

Figura 23. Entradas medias a los embalses de Alarcón y Contreras.

En la siguiente figura se muestra los promedios mensuales de los caudales circulantes aguas abajo de los embalses de Alarcón y Contreras.

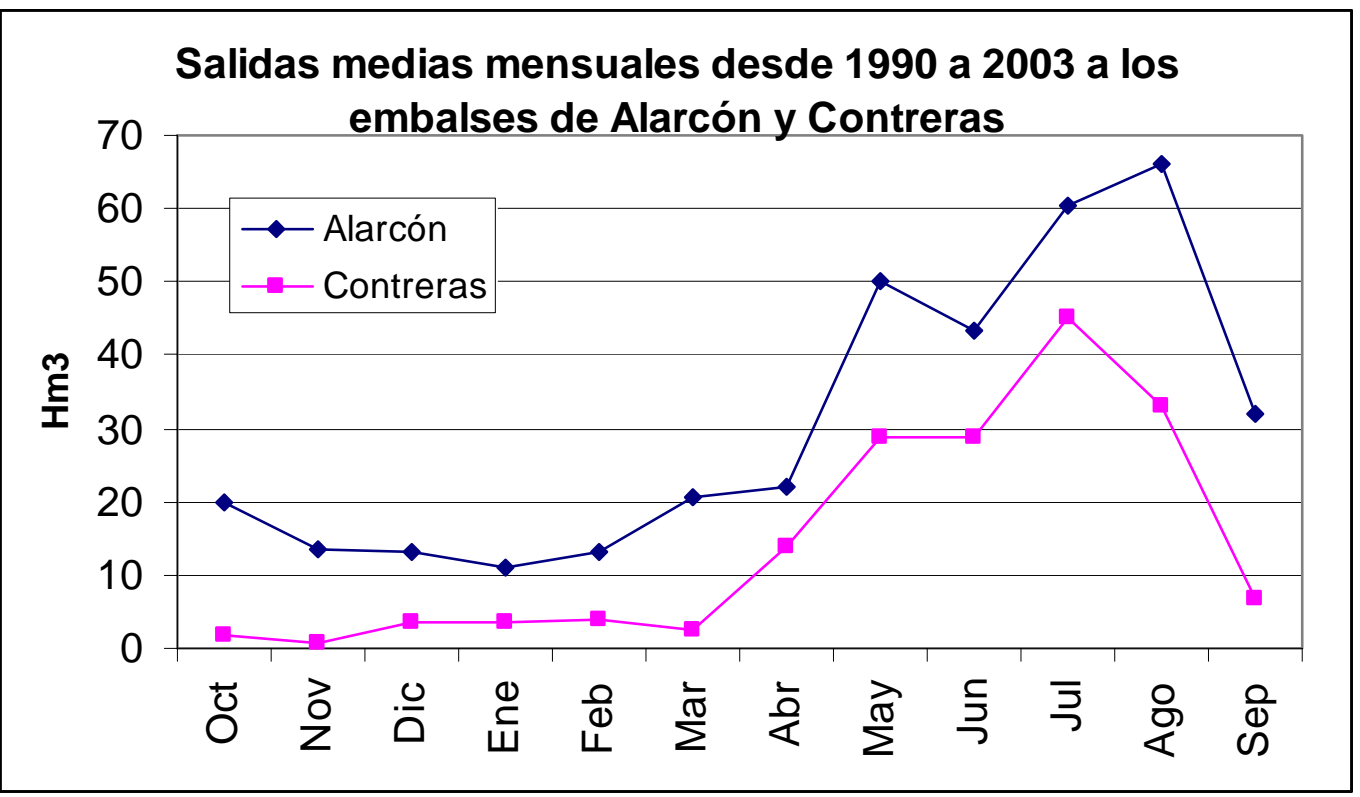

Figura 24. Salidas medias mensuales de los embalses de Alarcón y Contreras.

La figura muestra como las sueltas se realizan entre los meses de Mayo y Agosto mientras que el resto del año los caudales son muy inferiores.

Entre los embalses de Alarcón y Molinar la relación con el acuífero y la aportación de la intercuenca modifican los caudales circulantes.

El tramo aguas abajo del embalse de Molinar está marcado por caudales bajos ya que, por regla general, la mayor parte del agua se bombea a la central hidroeléctrica de Cofrentes con destino final el río Cabriel. El caudal mínimo que se está manteniendo en 
el tramo aguas abajo del embalse de Molinar es de 300 1/s (fuente Iberdrola). Este caudal mínimo se ve incrementado aguas abajo por la incorporación del río Reconque.

En el río Cabriel, aguas arriba del embalse de Contreras los caudales pueden considerase en régimen natural mientras que aguas abajo del mismo están completamente influidos por la sueltas del embalse y por las aportaciones intermedias.

La evolución espacial de los caudales aguas abajo del embalse de Tous es fruto de un complejo sistema de derivaciones, retornos y aportaciones. En la siguiente figura se muestra un esquema de los elementos más influyentes en los caudales de este tramo de río.

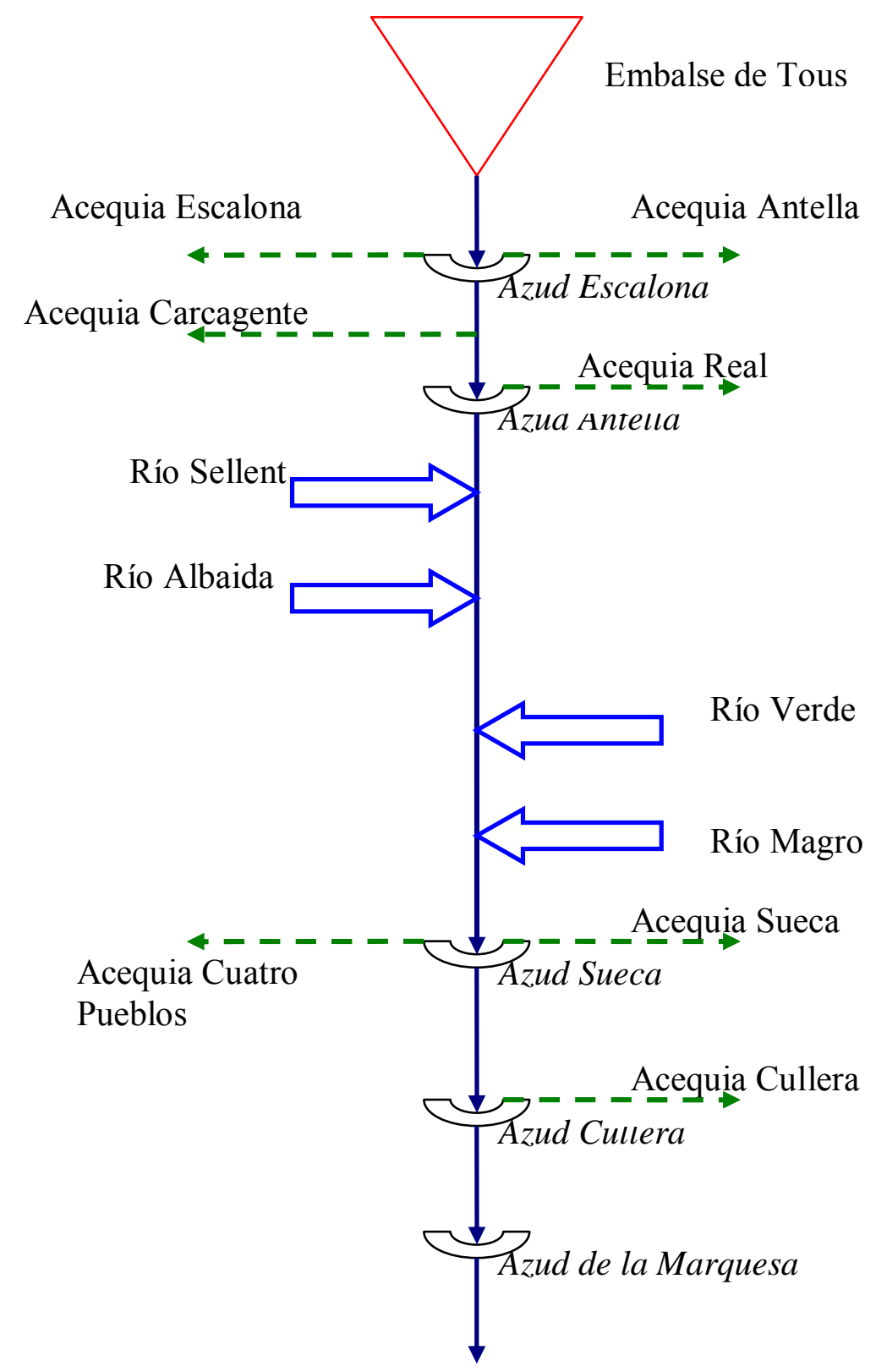

Figura 25. Esquema de elementos de afección de caudales en el río Júcar aguas abajo de Tous. 
La evolución temporal de los caudales viene muy influenciada por las necesidades de riego a lo largo del año. Como se puede ver en el siguiente gráfico, las salidas de Tous son bastante elevadas, incluso en época sin riego son del orden de 10-30 $\mathrm{hm}^{3} /$ mes. Sin embargo aguas abajo de las tomas de las acequias superiores el caudal se reduce fuertemente hasta quedar en invierno con valores medios inferiores a $5 \mathrm{hm}^{3} /$ mes.

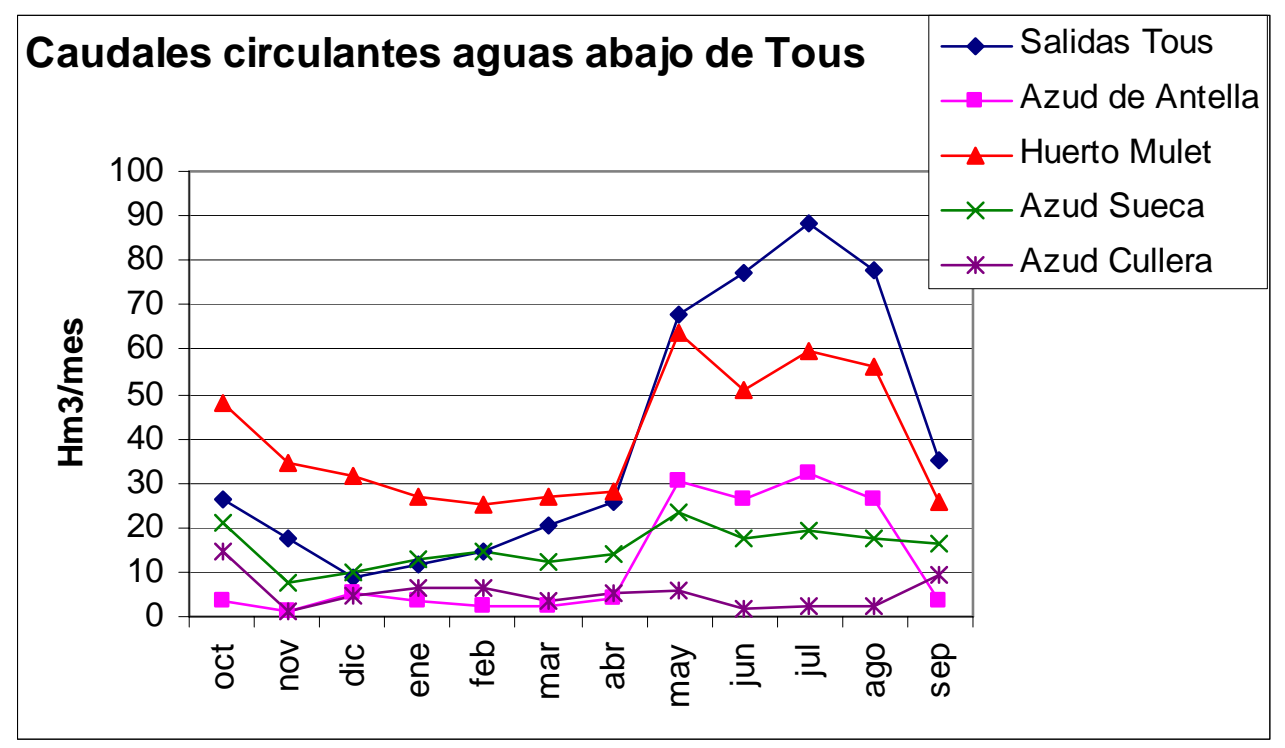

Figura 26. Caudales medios circulantes aguas abajo del embalse de Tous

Entre el azud de Antella y la estación de aforos de Huerto Mulet, sita entre la incorporación del Magro y el azud de Sueca, se incrementan los caudales debido a la incorporación de los afluentes inferiores: Sellent, Albaida, Verde y Magro y a los retornos de riego.

Finalmente se produce una disminución del caudal debido a las tomas de riego en los azudes de Sueca y Cullera, siendo los caudales muy bajos entre el azud de Cullera y la desembocadura.

\subsubsection{Caudales instantáneos versus medios.}

En este apartado se comparan los caudales instantáneos, medidos en las estaciones de calidad ICA, con los valores medios del mes proporcionados por las estaciones de aforo y de explotación de embalses. La principal diferencia entre los datos es que, el dato de un mes en las series de las estaciones de aforo se corresponde con la media del caudal circulante que se ha medido de forma casi continua con una estación de aforos mientras que por otro lado, la medida de la red ICA es un valor instantáneo medido con molinete o de forma instantánea en la estación de aforos. De la comparación de los caudales se puede concluir lo siguiente: 
- Existe bastante similitud en los valores medidos por las ICAs y las estaciones de aforo en muchos puntos. Ello es debido a la alta regulación en la que se encuentra el río.

- Este efecto refuerza la base del estudio en la que se utilizan medidas instantáneas de calidad como representativas de la situación media del sistema en cada mes.

- Debido al mayor número de estaciones de calidad que de aforos y al buen comportamiento de los valores de caudal medidos, el análisis de los caudales circulante, permite mejorar el conocimiento de la circulación de caudales y por consiguiente de la evaluación del recurso.

Particularmente se destacan los siguientes casos:

En la parte del Júcar aguas abajo de Alarcón las estaciones de Alarcón y de Los Frailes presentan buena coherencia con las estaciones de aforo ubicadas en los mismos puntos. No se disponen de muchos datos de la estación de Fuensanta siendo este un punto estratégico para la caracterización de la relación del río con el acuífero de La Mancha. La siguiente figura muestra la coherencia de los caudales medidos entre las estaciones ICA y de aforos de Los Frailes.

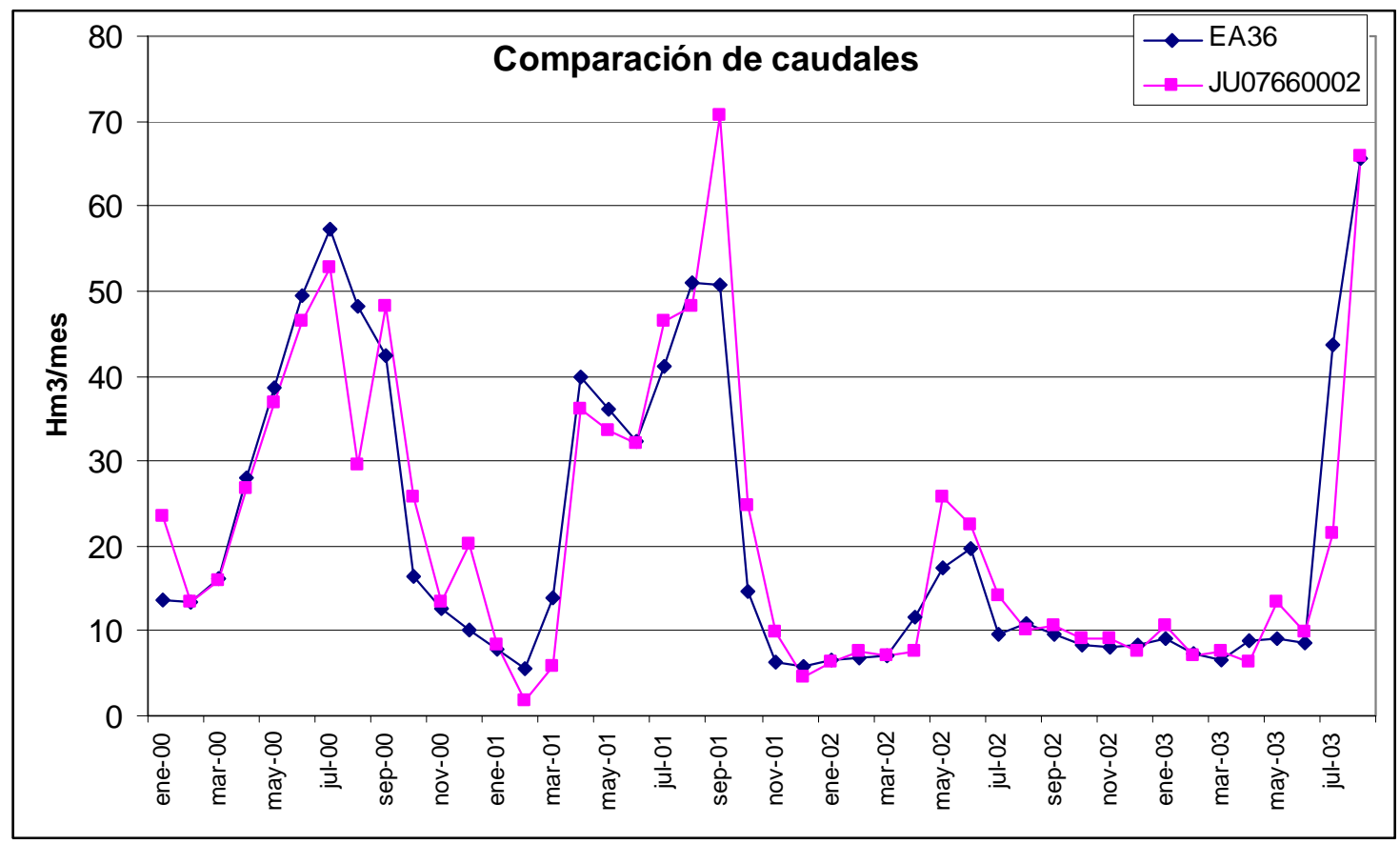

Figura 27. Comparación de caudales de la estación de aforos EA-36 y de la estación ICA de Los Frailes

Otra zona de interés es el área del río Cabriel aguas abajo del embalse de Contreras y hasta su confluencia con el río Júcar. Esta es, en cuanto a la evaluación del recurso hídrico, una de las zonas más problemáticas. Se disponen de pocas estaciones de aforos y hay problemas en los datos de tal forma que no se puede evaluar las 
aportaciones de cada río de forma separada y se evalúa en una sola aportación el aporte de agua de las intercuencas entre el embalse de Molinar, Contreras y Tous. El estudio de los caudales medidos por las estaciones de calidad arroja cierta luz sobre este problema. En primer lugar en la parte del Cabriel la comparación de caudales de las estaciones EA130 y la JU06930002 (Contreras) ambas sitas aguas abajo del embalse de Contreras reflejan bastante concordancia.

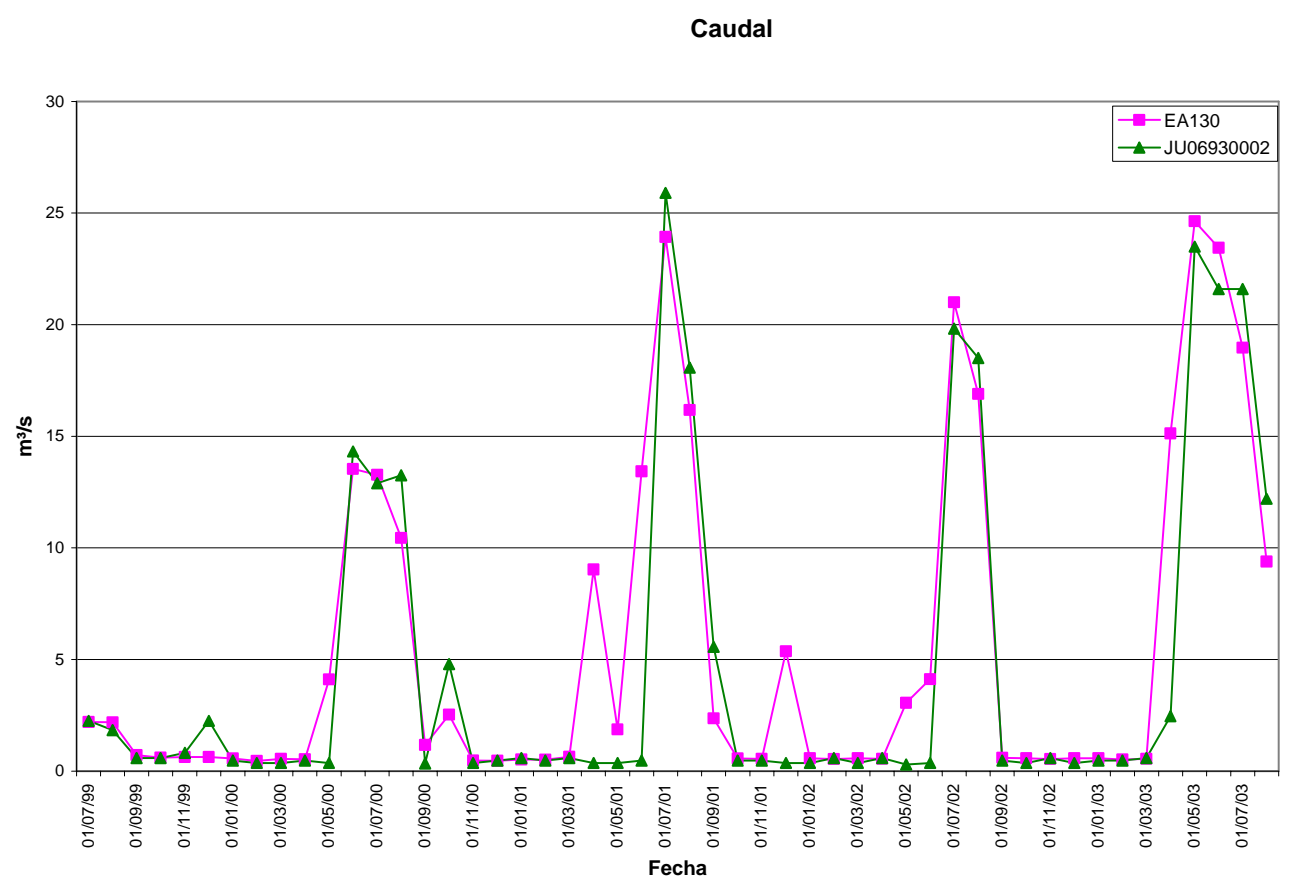

Figura 28. Comparación de caudales entre la estación de aforos EA130 y la estación de calidad de Contreras.

Lo mismo pasa al comparar las estaciones EA112 y la JU0745006 (CofrentesCoca) aguas arriba de la confluencia. Finalmente, el siguiente gráfico compara los caudales medidos por las dos estaciones ICAs anteriores y la JU7190002 Villatoya Coca a mitad del tramo. 


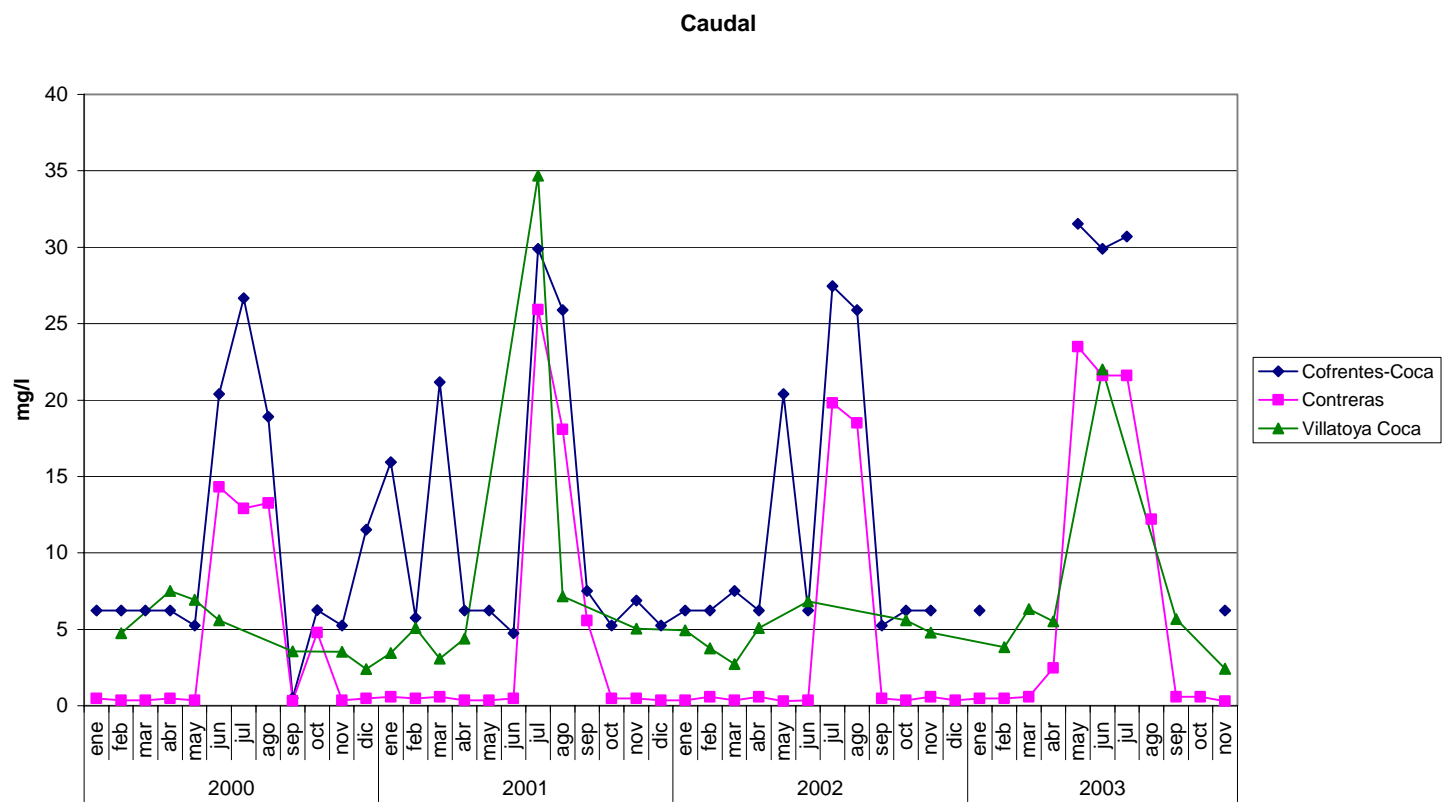

Figura 29. Caudales medidos por las estaciones ICA de Cofrentes-Coca, Contrers y Villatoya.

El gráfico muestra un incremento de caudal en la parte inicial del tramo entre Contreras y Villatoya bastante sustancial de unos $4 \mathrm{~m}^{3} / \mathrm{s}$ de media. Este incremento se puede ver, sobre todo, en las épocas de caudales bajos. Además, por otra parte el aporte de agua de la subcuenca del río Júcar desde el embalse de Molinar hasta la confluencia con el Cabriel es muy baja. Esto se deduce de los datos de caudal de la estación ICA de Cofrentes - Júcar, la cual, refleja valores de caudal bastante bajos, del orden de $0.4 \mathrm{~m}^{3} / \mathrm{s}$ y bastante parecidos a los de la estación del Reconque. Por todo ello, se puede afirmar que la subcuenca que realiza un mayor aporte de agua es la parte del río Cabriel entre el embalse de Contreras y la población de Villatoya.

Esto puede ayudar a establecer nuevas estaciones de aforo o a seleccionar cuencas en las que interesa realizar modelos precipitación escorrentía con el objetivo de mejorar el conocimiento de los recursos hídricos de la cuenca.

\subsubsection{Conductividad.}

La conductividad es una medida de la capacidad del agua como conductor de la corriente eléctrica. Dependiendo su valor de los sólidos disueltos. Debido a su carácter altamente conservativo, su medición y análisis permite establecer fuentes de contaminación ya sea de origen antrópica o natural. En aguas naturales suele oscilar entre 100 y $1000 \mu \mathrm{s} / \mathrm{cm}$ (WHO, 1992) aunque se puede exceder de este valor máximo de forma natural, como suele pasar en las cuencas mediterráneas de la península ibérica. Las concentraciones en la cuenca del río Júcar son altas, incluso muy altas en algunos puntos. Sin embargo el origen de esta contaminación es natural debido principalmente a 
la geología yesífera de la cuenca. Ello hace que la escorrentía natural, en algunas zonas de la cuenca, tenga un alto contenido en aniones como sulfatos o cloruros. Incluso en varios puntos de la cuenca los sulfatos son superiores a los $250 \mathrm{mg} / \mathrm{l}$, marcados como límite para el abastecimiento de agua potable. Aunque se disponen de algunos datos de sulfatos y cloruros no suelen medirse de forma continuada ni espacialmente ni temporalmente sin que se haya podido hacer un análisis para toda la cuenca.

\subsubsection{Análisis de la conductividad en el río Júcar.}

Analizando el perfil longitudinal del río Júcar se puede ver que la conductividad sufre un proceso ascendente hasta finalizar con una conductividad media de 1150 $\mu \mathrm{s} / \mathrm{cm}$. Todos los incrementos significativos de conductividad se explican por aportes de escorrentía en subcuencas con afloramientos geológicos de yesos o evaporitas que aportan aniones, sobre todo sulfatos y cloruros.

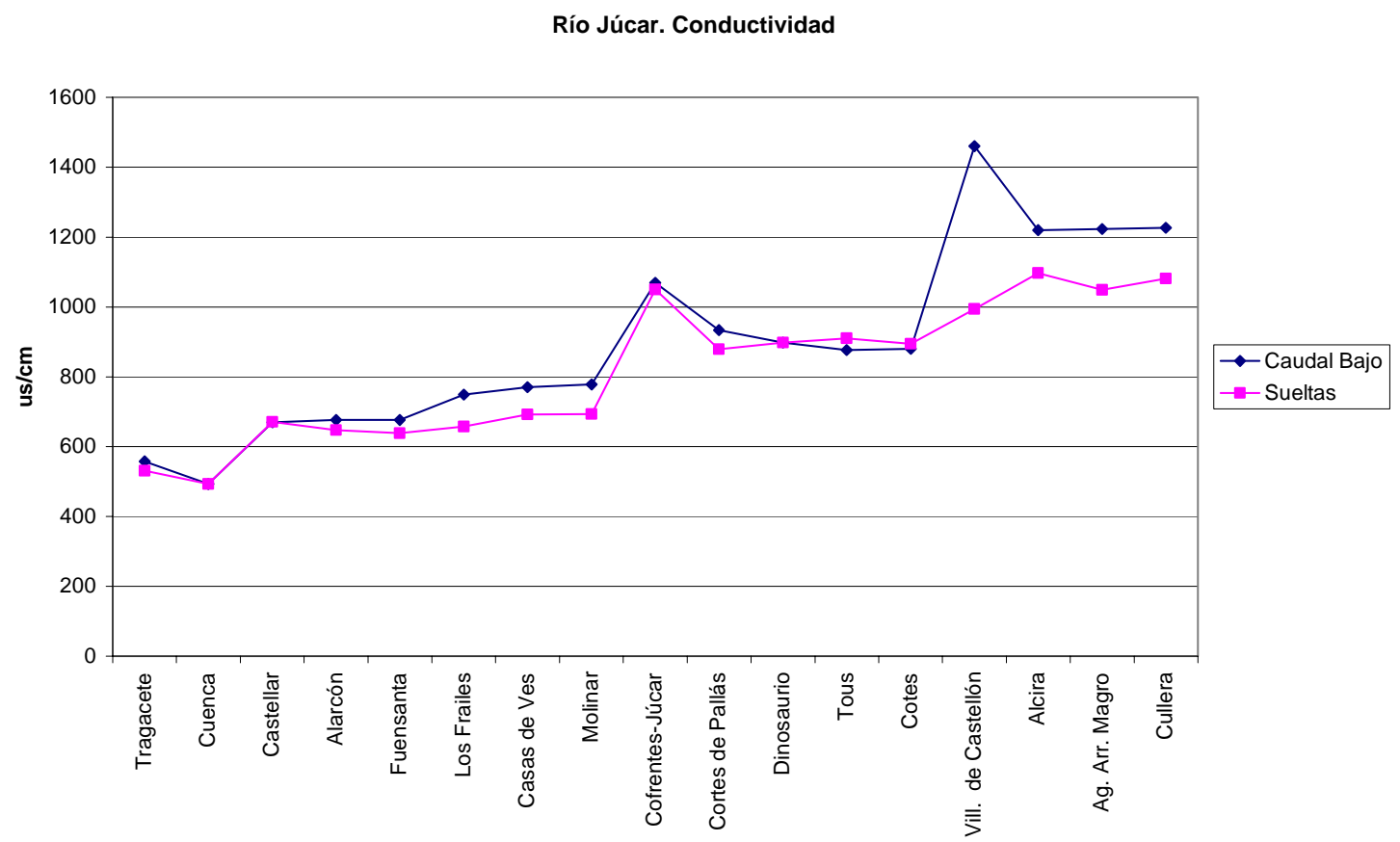

Figura 30. Perfiles medios de conductividad en el río Júcar.

Las zonas de mayor aportación son: el tramo entre Cuenca y Castellar, la zona entre el embalse de Molinar y Cortes y la zona de Villanueva de Castellón. Además, es importante estudiar las conductividades entre los embalses de Alarcón y Molinar porque permite establecer la influencia del acuífero sobre los flujos de agua y su calidad.

El primer incremento significativo de conductividad en el río se produce entre la estación de Cuenca, sita en la estación de aforos de la homónima ciudad, y la estación de Castellar representativa de la calidad del agua de entrada el embalse de Alarcón. La mayor parte de las estaciones de calidad aguas arriba de la estación de Cuenca presentan valores de conductividad medios de $500 \mu \mathrm{s} / \mathrm{cm}$ con baja dispersión. Entre la estación de 
Cuenca y Castellar se produce un fuerte incremento de la conductividad arrojando la última estación del tramo un valor medio de $670 \mu \mathrm{s} / \mathrm{cm}$.

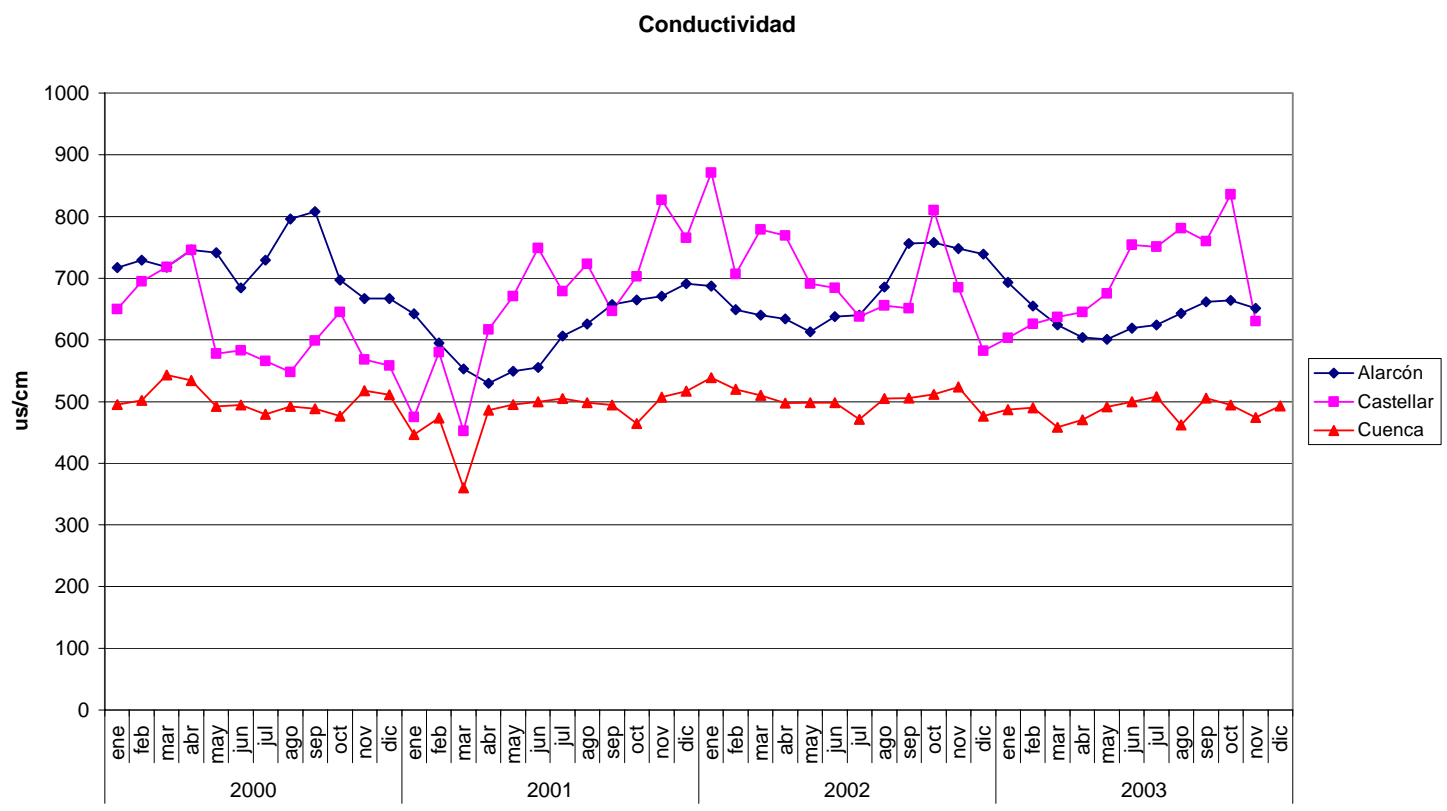

Figura 31. Conductividad de las estaciones Cuenca, Castellar y Cautabán.

Como se puede ver en el gráfico la conductividad de la estación de Cuenca presenta una evolución más constante mientras que las estaciones de Castellar y Alarcón presentan mayores oscilaciones. En el mapa de la geología reclasificada de la zona se puede ver la explicación. 


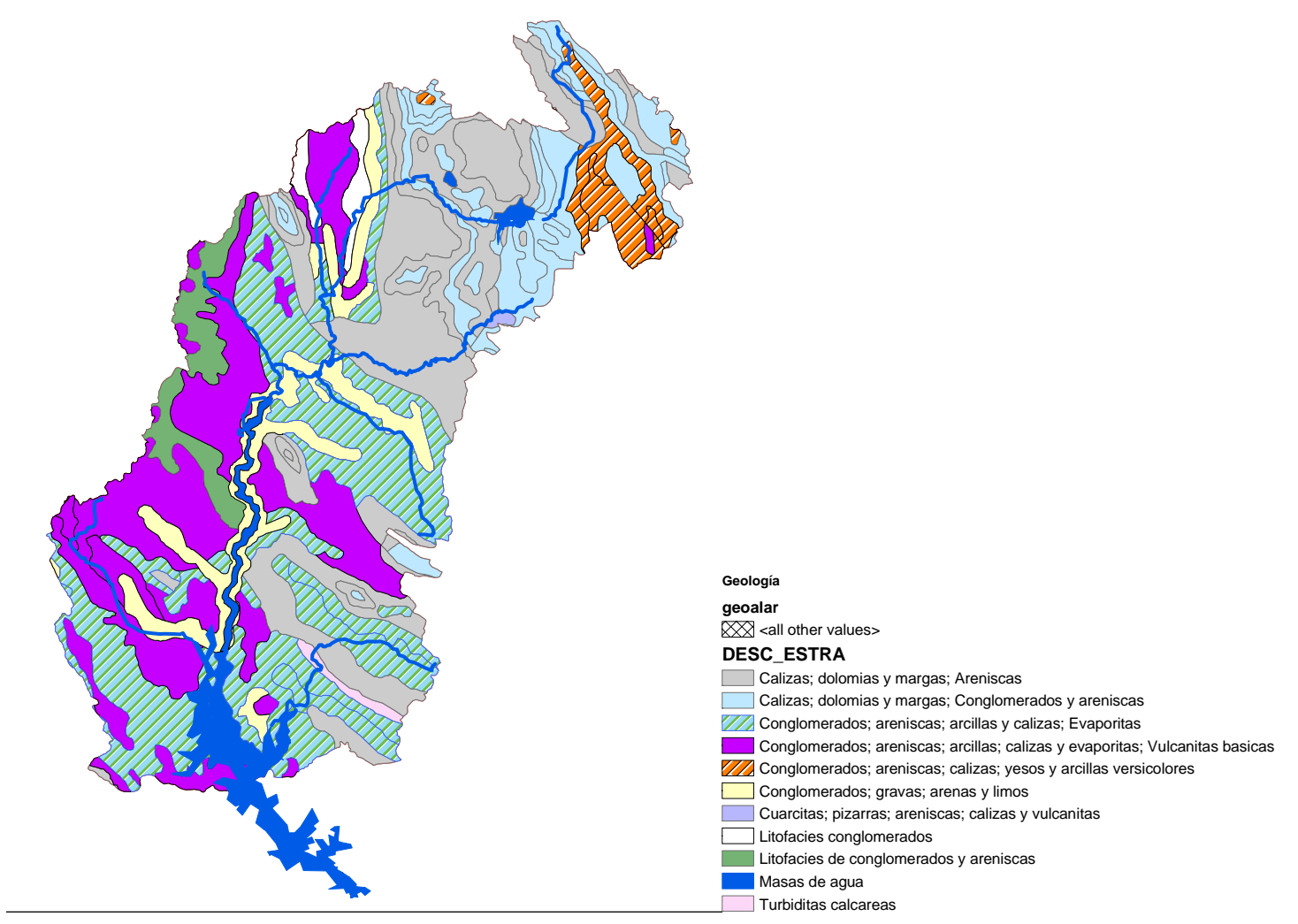

Figura 32. Geología de la cuenca del río Júcar aguas arriba del embalse de Alarcón.

La geología de la zona inmediatamente aguas arriba del embalse presenta afloramientos de compuestos entre los que se encuentran las evaporítas, que aportan este tipo de sales. También se puede observar, cercano al nacimiento del río, como en la margen derecha hay un afloramiento con yesos aunque a la vista datos no parece que tenga una gran influencia.

Los afluentes aportantes directamente al embalse, como son el río Marimota y el río Gritos, también presentan conductividades muy altas aunque hay que destacar que ambas estaciones están muy influencias por vertidos urbanos cercanos a las mismas.

Con los datos disponibles, se puede afirmar que el incremento de conductividad en esta zona es debido a la geología de la cuenca. Aunque no se dispone de datos de la estación de Castellar, las estaciones del resto de aportes al embalse presenta concentraciones de sulfatos extremadamente altas. Asimismo la estación de aguas abajo del embalse, "Alarcón", presenta concentraciones de sulfatos entre 100 y 450 mg/l. Los sulfatos se presentan de forma natural en muchos minerales haciendo que las concentraciones en aguas naturales puedan variar desde unos pocos a miles de mg/l. La contaminación natural procede fundamentalmente de procesos de disolución de yesos.

En cuanto al efecto del embalse sobre la conductividad, los datos reflejan un efecto laminador del embalse sobre las conductividades de entrada. Sin embargo existen diversos factores que dificultan que la comparación de ambas estaciones reflejen 
totalmente el efecto del embalse. Estos factores son: la geología de la cuenca cercana al embalse, la influencia de episodios de tormenta en la zona y la distancia a la que se encuentran las estaciones de aguas arriba y aguas abajo respecto al embalse. Estos efectos repercutirán en la calidad del modelo ya que son factores que con los datos disponibles no se pueden cuantificar y por consiguiente no se tienen en cuenta.

En el tramo entre el embalse de Alarcón y el de Molinar, el perfil longitudinal muestra un comportamiento diferente entre la época de caudales bajos y la de sueltas. Mientras que no existe un incremento de la sales en la época del año en la que los caudales circulantes son altos, cuando la sueltas de Alarcón son bajas se puede observar un incremento significativo de las mismas. Este efecto se produce entre las estaciones de Fuensanta y la de los Frailes y es debido a la conexión del acuífero de la Mancha con el río en esa zona. La siguiente figura muestra las conductividades medidas en ambas estaciones y se comparan con las sueltas realizadas desde el embalse Alarcón.

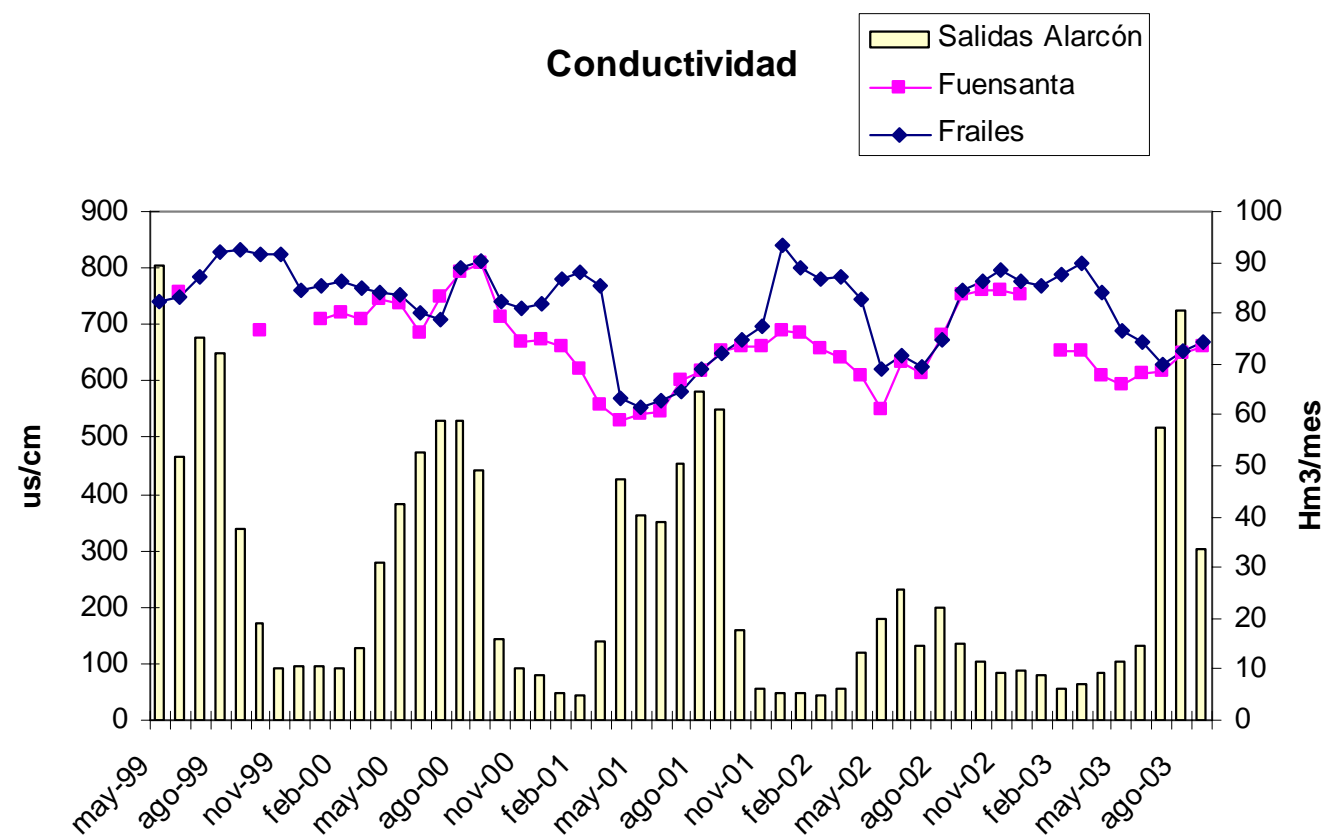

Figura 33. Conductividades medidas en las estaciones ICA de Fuensanta y los Frailes comparadas con las salidas de Alarcón.

Cuando los caudales son bajos la calidad del agua del acuífero tiene mayor influencia en la calidad del agua superficial. Este efecto también aparece en el análisis de los nitratos y de la temperatura. Del análisis de caudales se deduce que, entre estas dos estaciones, más que una aporte de caudal por parte del acuífero se está produciendo un intercambio de agua con filtraciones y aportes subterráneos con un balance nulo de aportación pero que sí afecta a la calidad del agua.

El siguiente punto en el que se presenta un incremento de sales considerable es el tramo de río entre el embalse de Molinar y el de Cortes. Los gráficos comparativos 
entre las estaciones de aguas arriba y aguas abajo del embalse de Molinar muestran una concordancia total. La conductividad del tramo aguas abajo de este embalse está muy marcada por la influencia del río Reconque, con un alto contenido en sales de forma natural. Además, en la misma zona, se realiza el vertido de la central nuclear de Cofrentes. La central nuclear toma agua del embalse de Cortes II y tras utilizarla para refrigerar la vierte aguas arriba de la estación ICA Cofrentes - Júcar. El proceso de refrigeración implica una evaporación de parte del agua y consecuentemente un incremento de las sales en el agua remanente.

En la siguiente figura se muestra las medidas de conductividad tomadas en los últimos años para las estaciones ICA de Molinar, Cofrentes Júcar y Cautabán esta última representativa del río Reconque. El gráfico refleja la diferencia entre el período en que la central estuvo en reparaciones y no se bombeo agua al Cabriel y el período en que el funcionamiento fue el habitual. Entre diciembre de 2001 y abril de 2003 la conductividad final del tramo es prácticamente la misma que la del embalse de Molinar. Fuera de ese tramo se puede ver que la mayor influencia la tiene la conductividad del río Reconque. Es de destacar la alta conductividad de este río donde la mayoría de los valores son superiores a $1300 \mu \mathrm{s} / \mathrm{cm}$. La estación de Cautabán presenta estacionalidad en las mediciones de conductividad con marcados incrementos en verano.

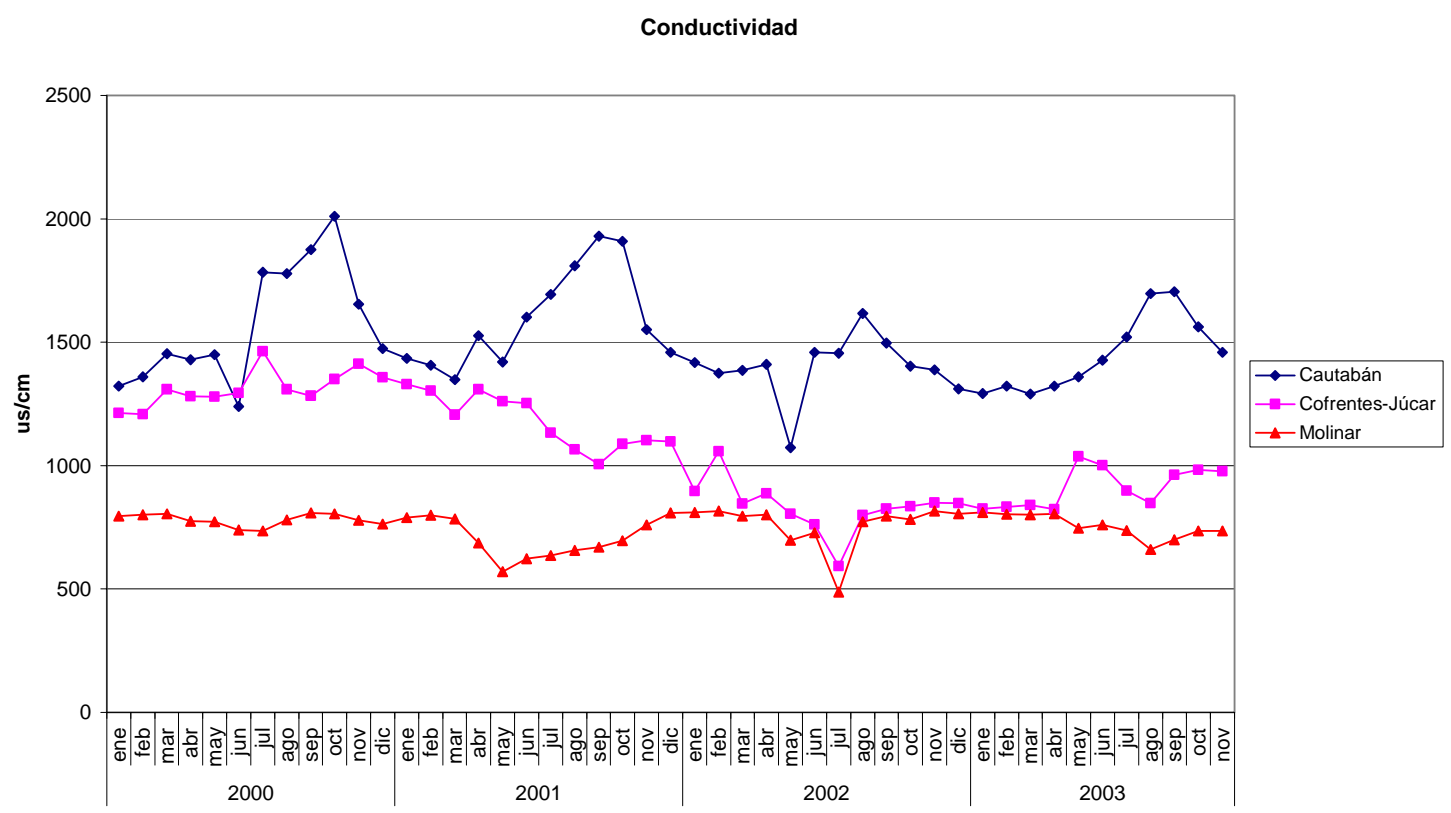

Figura 34. Conductividad medida en las estaciones de Cautabán, Cofrentes-Júcar y Molinar.

En la siguiente figura se muestra la geología de la zona de confluencia de los ríos Júcar y Cabriel. Como se puede ver tanto la parte final del Cabriel como del río Reconque hay afloramientos con yesos que están modificando el contenido de sales del agua. 


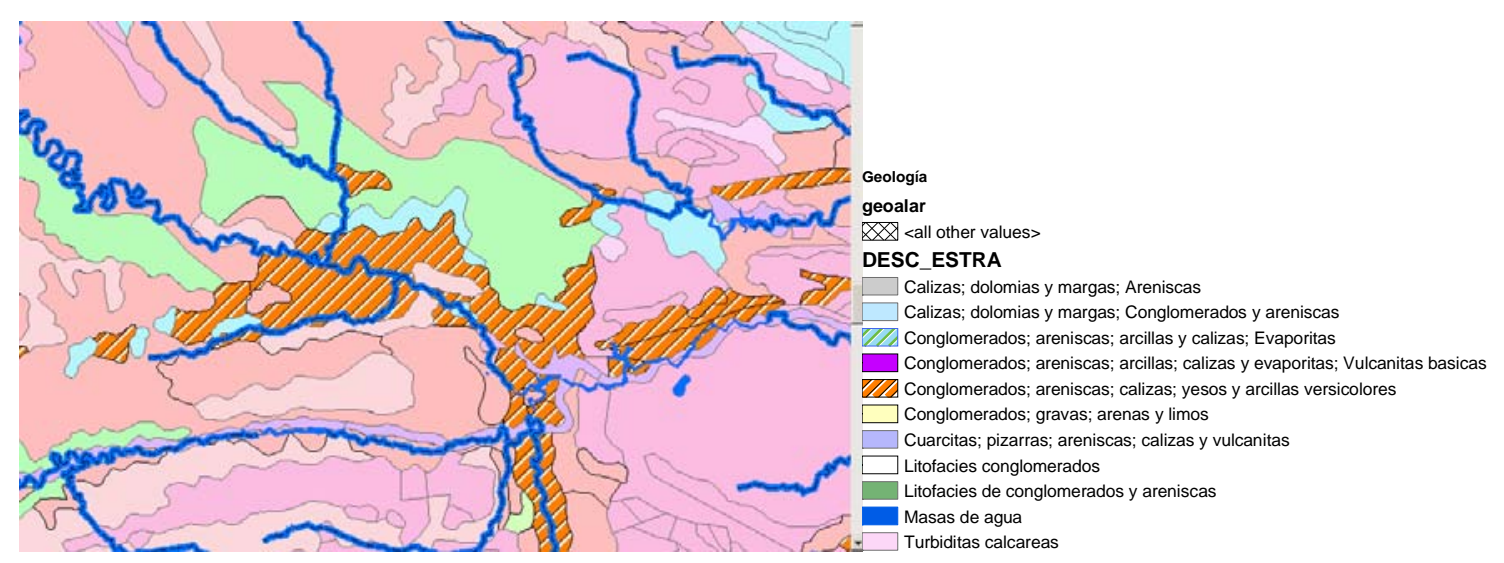

Figura 35. Geología de la confluencia de los ríos Júcar y Cabriel.

En la siguiente figura se muestra las medidas de conductividad de las dos estaciones de la confluencia y las estaciones Dinosaurio (aguas abajo del embalse de Naranjero) y Tous (aguas abajo del embalse de Tous).

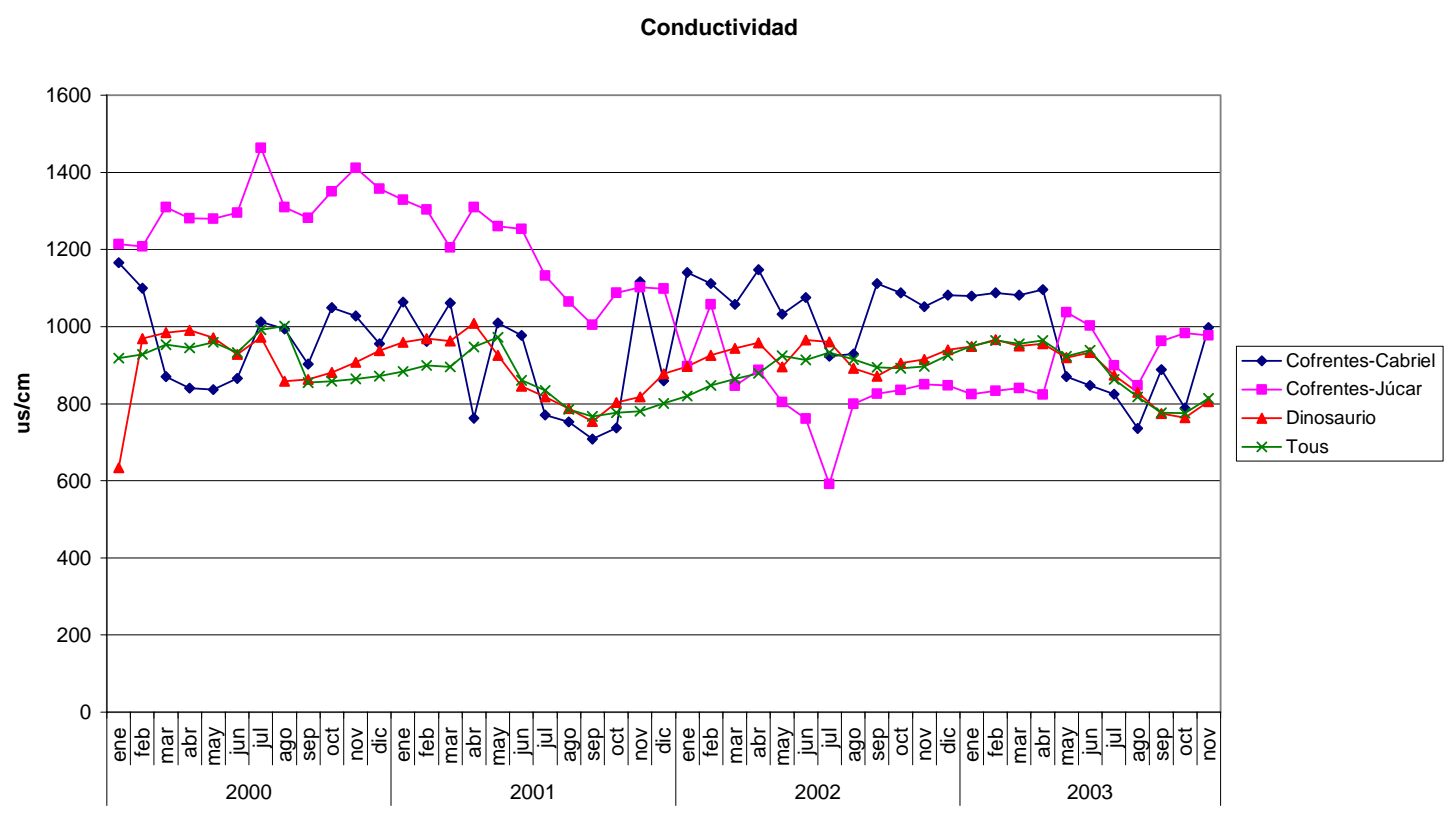

Figura 36. Conductividad medida en diferentes estaciones ICA de la confluencia de los ríos Júcar y Cabriel.

En la figura se puede ver como, debido a la transferencia de caudales, la conductividad de los embalses de la confluencia, en los períodos normales de gestión, vienen muy marcados por la estación de Cofrentes del río Cabriel. En el período en que no hubo transferencia, representativo de la forma natural de circulación en el río, las conductividades medidas son una mezcla de ambas estaciones. Además los valores medidos en ese período reflejan que la conductividad aportante por el río Cabriel es bastante superior a la del río Júcar. Por otra parte el gráfico refleja la concordancia entre las medidas aguas arriba y aguas abajo del embalse de Tous. 
Por último el perfil longitudinal de conductividad muestra un incremento significativo entre las estaciones de Cotes y Villanueva de Castellón. El incremento es más marcado en la época de caudales bajos. Este incremento se debe al aporte de agua por parte del río Sellent con unas conductividades muy elevadas debido a la geología yesífera de la cuenca. Las aguas del río Sellent son las más cargadas en sales de toda la cuenca. De los datos se demuestra que el mayor aporte de sal es debida al ión cloruro en donde pocas veces baja de los $500 \mathrm{mg} / \mathrm{l}$. Por lo general los ríos suelen tener unas concentraciones entre 10 y $40 \mathrm{mg} / \mathrm{l}$ de dicha sal. Comparando la conductividad de la estación de Cotes con la del Sellent se puede apreciar como mientras en el río Júcar hasta ese momento las concentraciones se mantenían sobre los $1000 \mu \mathrm{s} / \mathrm{cm}$ en el río Sellent pocas veces se baja de 3000 alcanzándose máximos de $9000 \mu \mathrm{s} / \mathrm{cm}$.

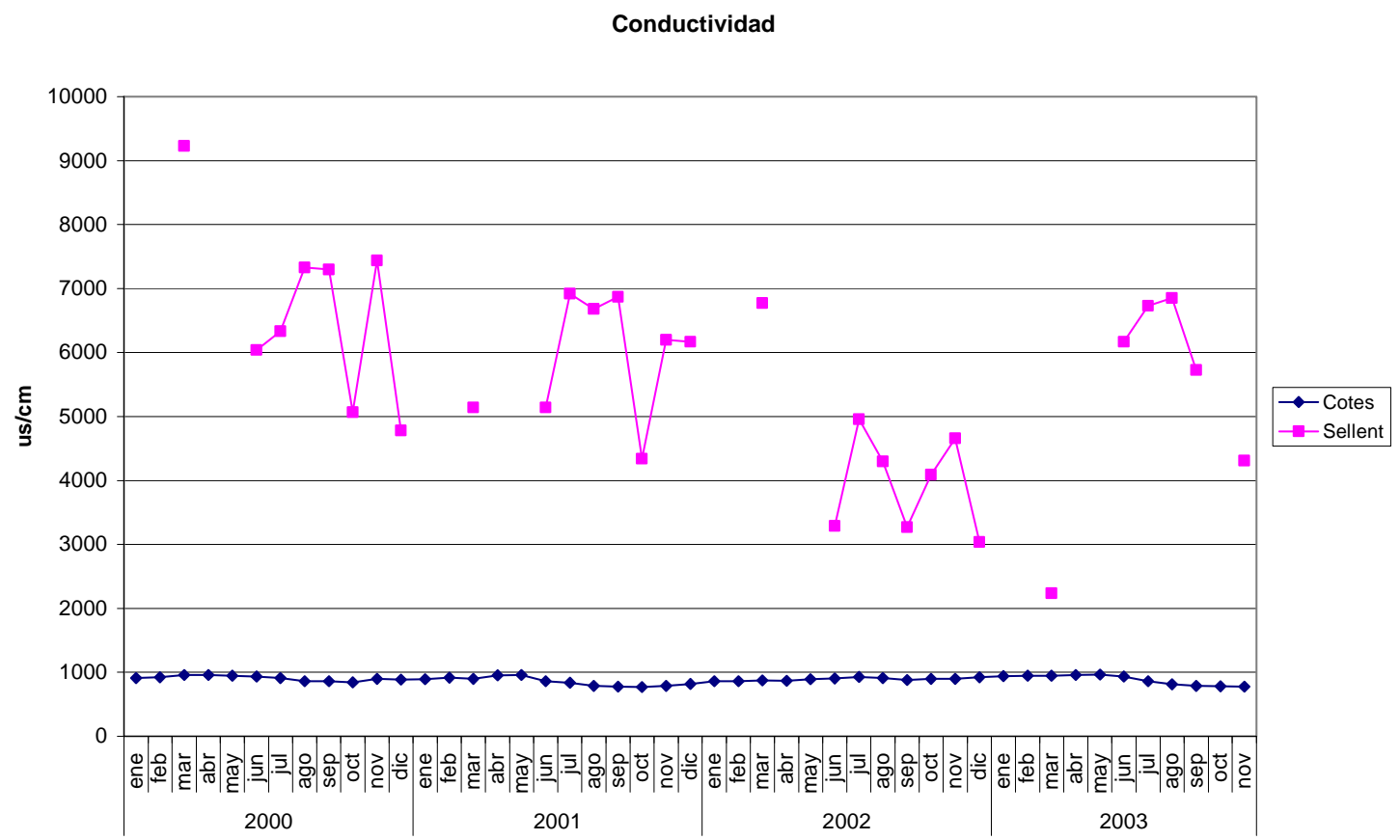

Figura 37. Conductividad de las estaciones ICA de Cotes y Sellent.

Para este último período de estudio (2000-2003), las concentraciones de sulfatos en Cotes rondan los $250 \mathrm{mg} / \mathrm{l}$ moviéndose en un intervalo entre 200 y $300 \mathrm{mg} / \mathrm{l}$ mientras que las concentraciones en el Sellent no bajan de $300 \mathrm{mg} / \mathrm{l}$ y presentan un valor medio de $500 \mathrm{mg} / 1$. 


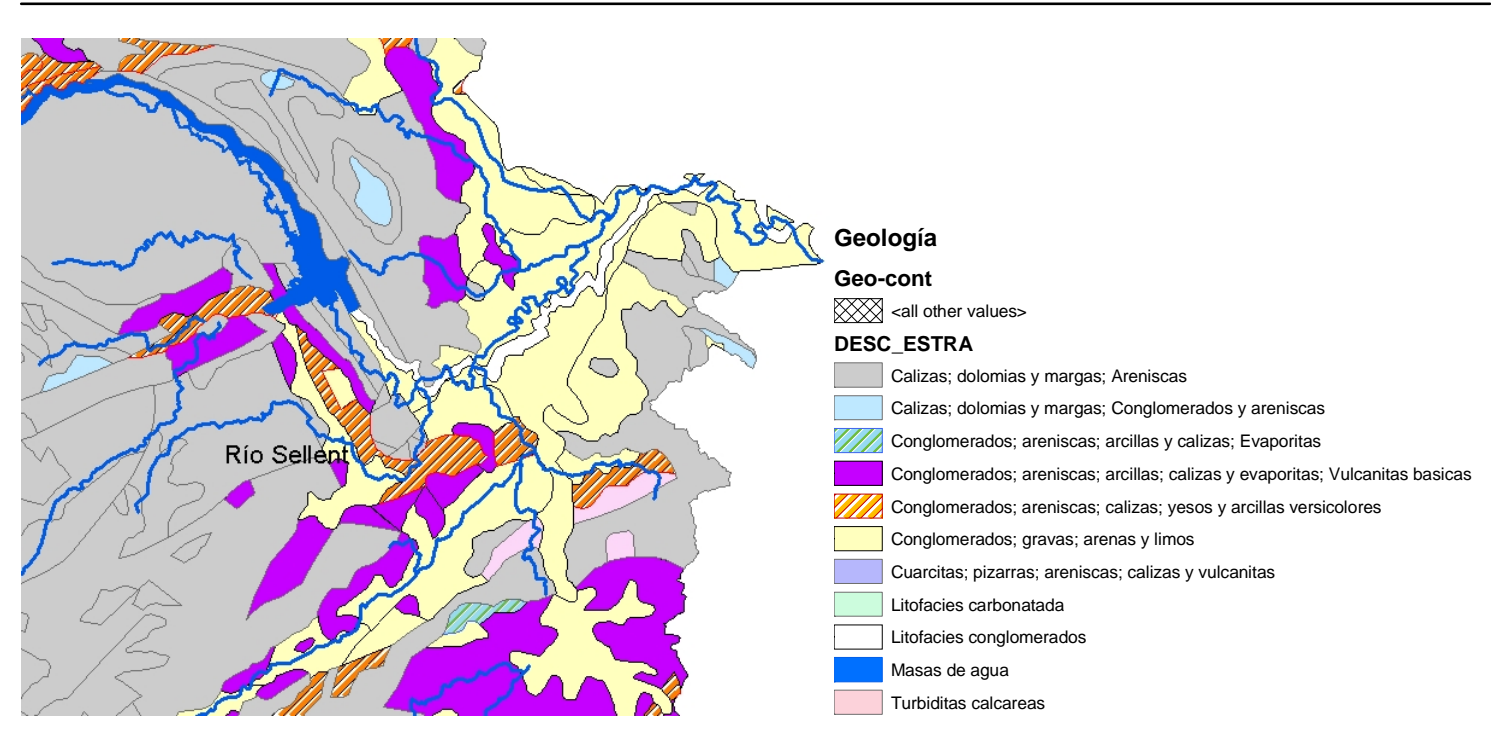

Figura 38. Geología del tramo del río Júcar aguas abajo del embalse de Tous.

En cuanto a los cloruros, mientras que la estación de Cotes presenta una concentración media de $70 \mathrm{mg} / \mathrm{l}$ la del Sellent es de $800 \mathrm{mg} / \mathrm{l}$. La siguiente figura muestra las concentraciones de cloruros en el río Sellent desde 1994.

\section{Cloruros}

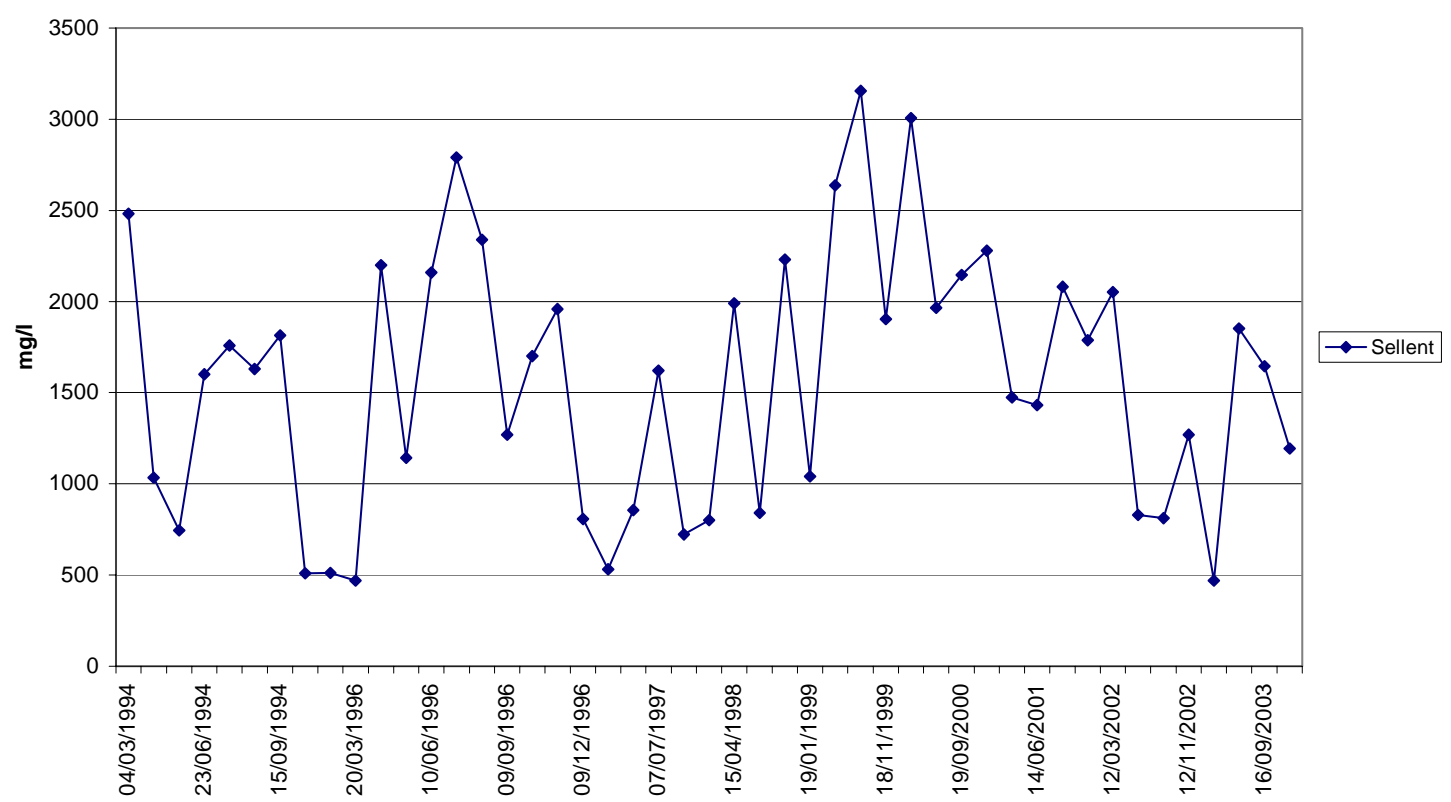

Figura 39. Concentraciones de cloruros medida en la última estación ICA del río Sellent antes de su confluencia con el río Júcar.

\subsubsection{Análisis de la conductividad en el río Cabriel.}

En el río Cabriel también se producen incrementos de sales por motivos naturales en diferentes puntos de la cuenca. Las zonas que presentan un mayor 
incremento de la misma son entre la estación de Pajaroncillo y Bujioso, aguas arriba del embalse de Contreras, y en la zona de confluencia.

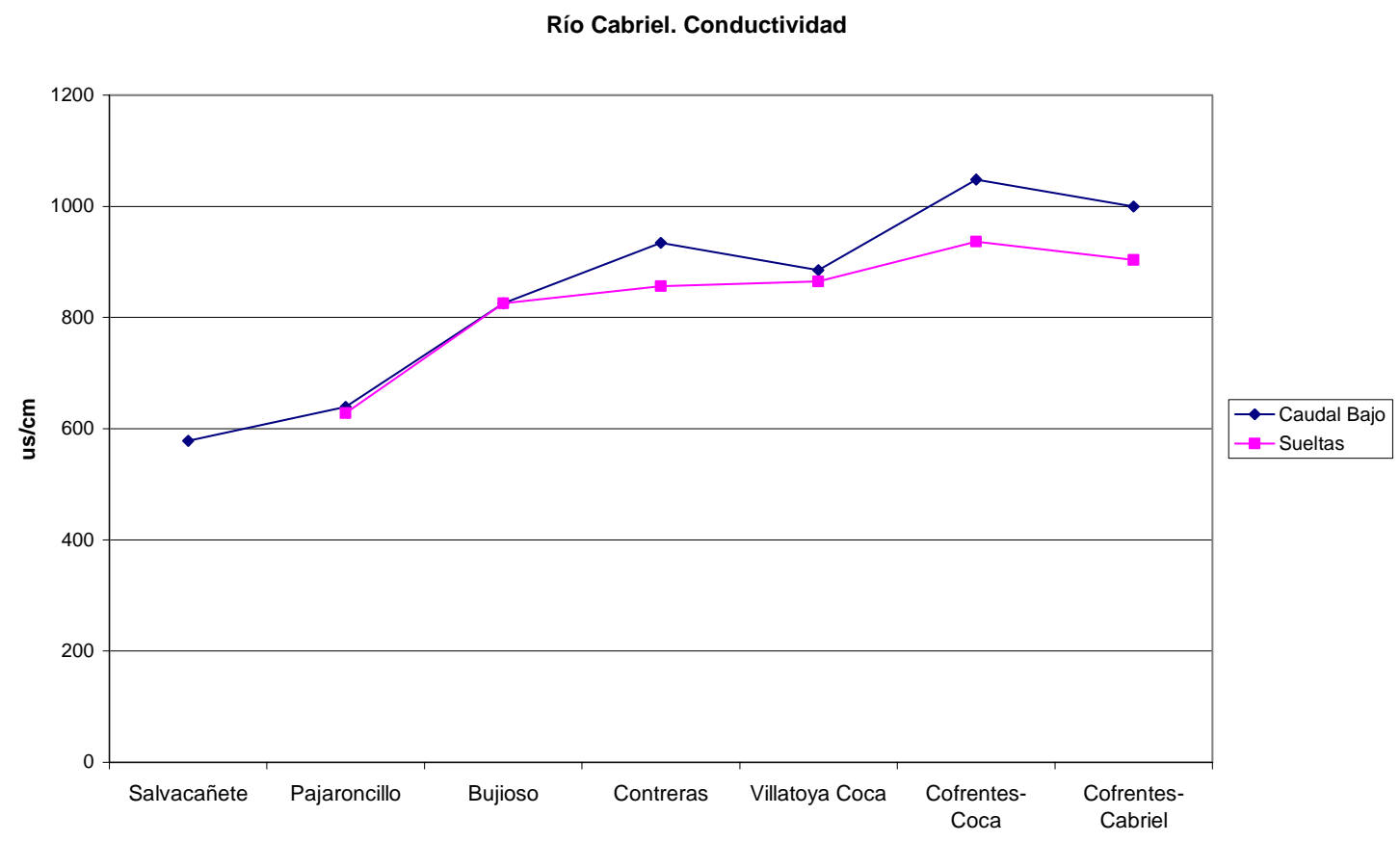

Figura 40. Perfiles medios de conductividad del río Cabriel.

Como se muestra en el perfil longitudinal, la variación de conductividad se produce en casi todos los tramo de la cuenca. La primera gran variación se produce entre las estaciones de Pajaroncillo y Bujioso, donde la media aumenta casi $200 \mu \mathrm{s} / \mathrm{cm}$. Todas las estaciones aguas arriba de Bujioso presenta valores de conductividad muy similares entre sí, cercanas a los $600 \mu \mathrm{S} / \mathrm{cm}$. No obstante, la estación de Bujioso presenta valores superiores con un valor medio de aproximadamente $830 \mu \mathrm{S} / \mathrm{cm}$. Este aumento de conductividad entre la estación de Pajaroncillo y el embalse de Bujioso se debe a motivos geológicos de la cuenca. Hay pocas mediciones de cloruros y sulfatos, sólo la estación de Pajaroncillo presenta algunos valores. El mapa de geología de la zona presenta una gran zona en la margen izquierda del río con afloramientos yesíferos responsables de la alta conductividad de todos los ríos aportantes al embalse. 


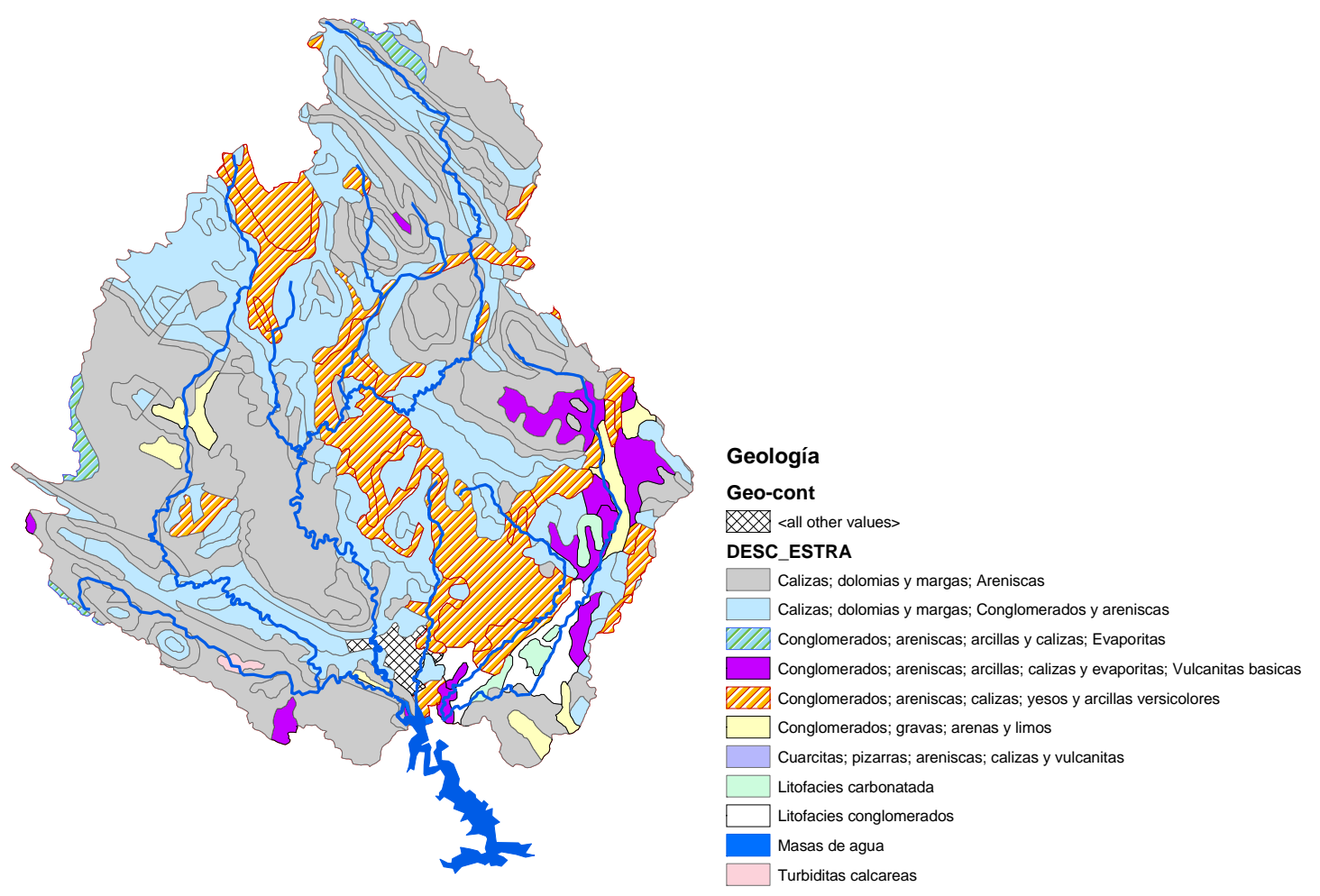

Figura 41. Geología de la cuenca del río Cabriel aguas arriba del embalse de Contreras.

En el siguiente gráfico se muestra las medidas de conductividad para las estaciones de Pajaroncillo, Bujioso y Contreras. En el gráfico se puede ver el incremento de conductividad en la subcuenca entre la estación de Pajaroncillo y el embalse de Contreras.

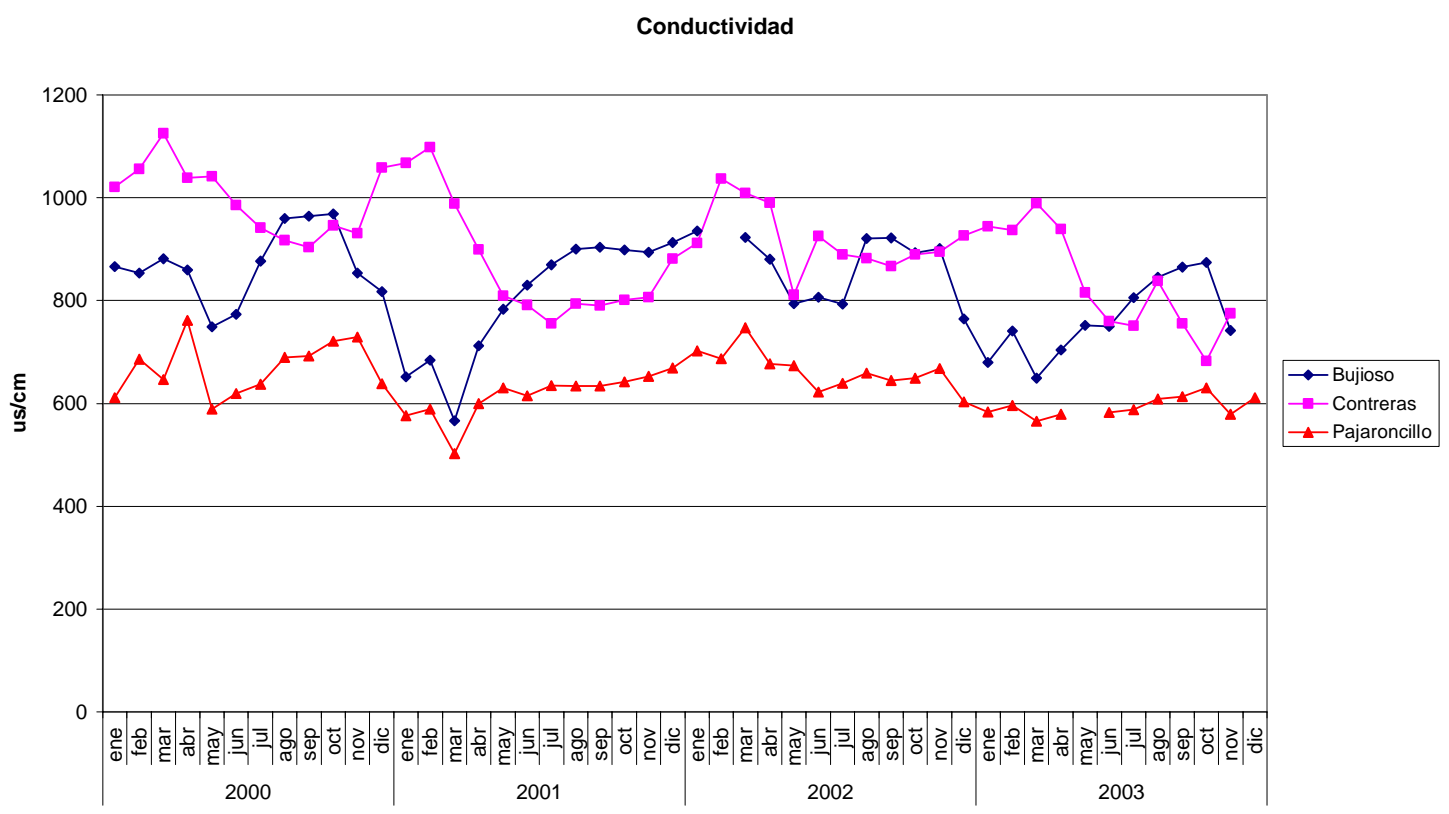

Figura 42. Conductividad medida en las estaciones de Bujioso, Pajaroncillo y Contreras.

Por otra parte, al igual que pasaba en el embalse de Alarcón, la estación de aguas abajo del embalse presenta valores modificados mediante cierta modulación, a los de la 
estación de aguas arriba del embalse. Esto se debe a los mismos factores explicados en el embalse de Alarcón así como la influencia de las filtraciones del embalse sobre la estación de aguas abajo.

En la zona aguas abajo del embalse y hasta la población de Villatoya el contenido de sales en el agua muestra variaciones debidas principalmente al aporte de agua de la intercuenca. La estación de Villatoya presenta valores parecidos a los de la estación de Contreras en épocas de sueltas altas. Cuando los caudales se reducen la conductividad en esta estación es menor. Este efecto es debido a la aportación de la intercuenca que representa, cuando desde Contreras sólo se suelta el caudal mínimo, gran parte del caudal fluyente.

Finalmente, existe un incremento de conductividad en el último tramo del río antes de su confluencia con el río Júcar. Entre la estación de Villatoya y Cofrentes-Coca se producen incrementos de conductividad haciendo aumentar la media de $846 \mu \mathrm{s} / \mathrm{cm}$ a $1010 \mu \mathrm{s} / \mathrm{cm}$. Este incremento se debe principalmente a la geología de la zona. Finalmente, como ya se comentó previamente, entre las estaciones de Cofrentes-Coca y Cofrentes -Cabriel se incorpora el agua del Júcar procedente de la central hidroeléctrica produciéndose un descenso en la conductividad.

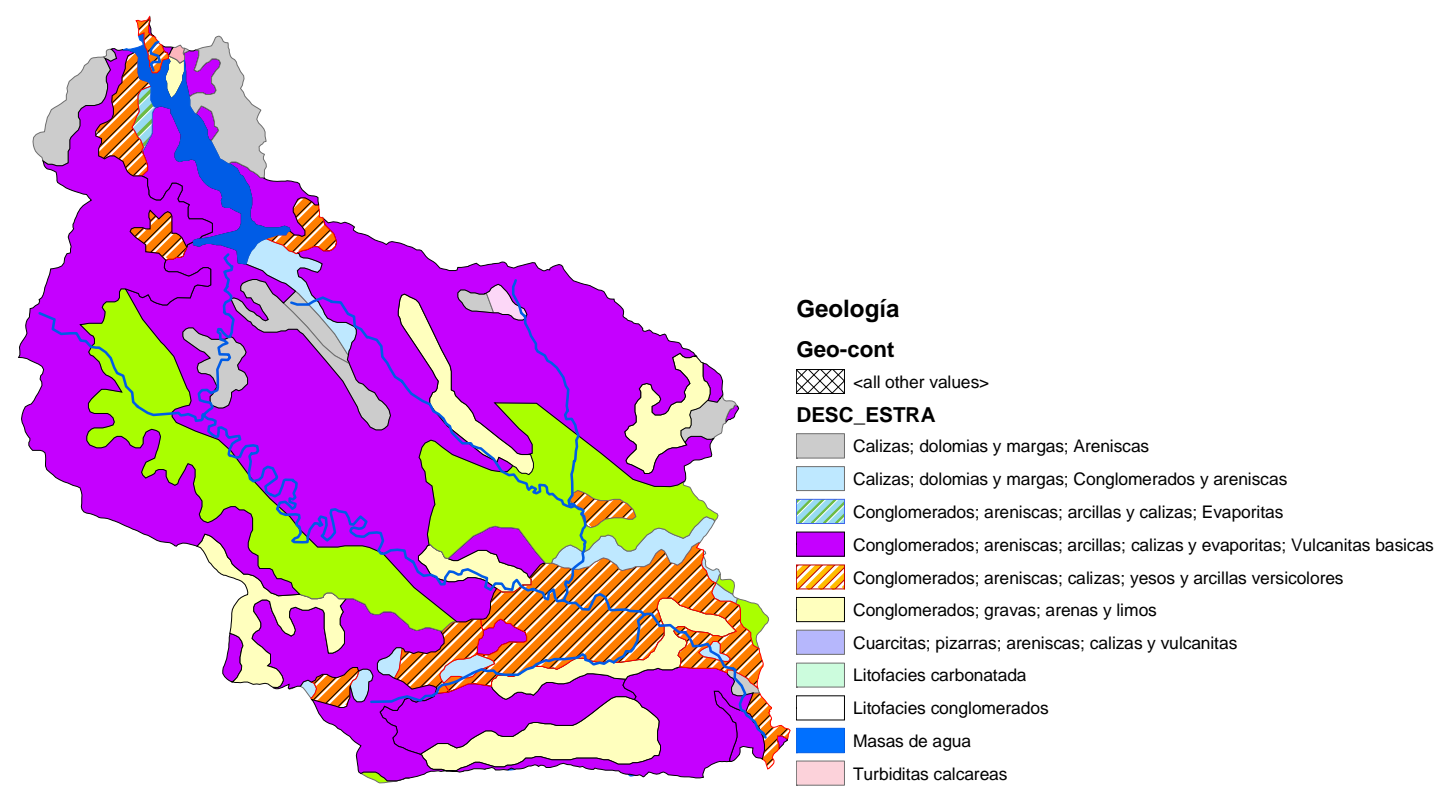

Figura 43. Geología del río Cabriel aguas abajo del embalse de Contreras.

La figura muestra la geología de la zona. Se puede ver que toda la zona aguas abajo del embalse esta formada por afloramientos con evaporítas. También se aprecian afloramientos con yesos en el tramo final responsables de la subida de conductividad entre las estaciones finales del río. 


\subsubsection{Sólidos suspendidos.}

La materia suspendida está compuesta por limos, arcillas, finas partículas de materia orgánica e inorgánica, plancton y otros organismos microscópicos. Su contenido puede variar estacionalmente por variaciones en la actividad biológica y en eventos de tormenta por el incremento de sólidos suspendidos en la escorrentía. Los sólidos suspendidos afectan tanto a la transparencia como a la turbidez de las aguas y por ello a la vida acuática.

\subsubsection{Análisis de sólidos suspendidos en el río Júcar.}

Las concentraciones de sólidos suspendidos (SS) en el río Júcar son bajas, con medias inferiores a 35mg/l en todos los puntos, debido principalmente a la sedimentación en los diversos embalses y azudes del sistema. Además de este efecto de sedimentación las infraestructuras de regulación producen un efecto erosivo, de menor orden, en los tramos aguas abajo de las mismas. Otros factores que influyen en el contenido de sólidos suspendidos son: la hidrodinámica de cada tramo, los retornos de riego y los vertidos urbanos. En la siguiente figura se muestra los perfiles longitudinales de las concentraciones medias de SS para los dos regímenes de caudales circulantes.

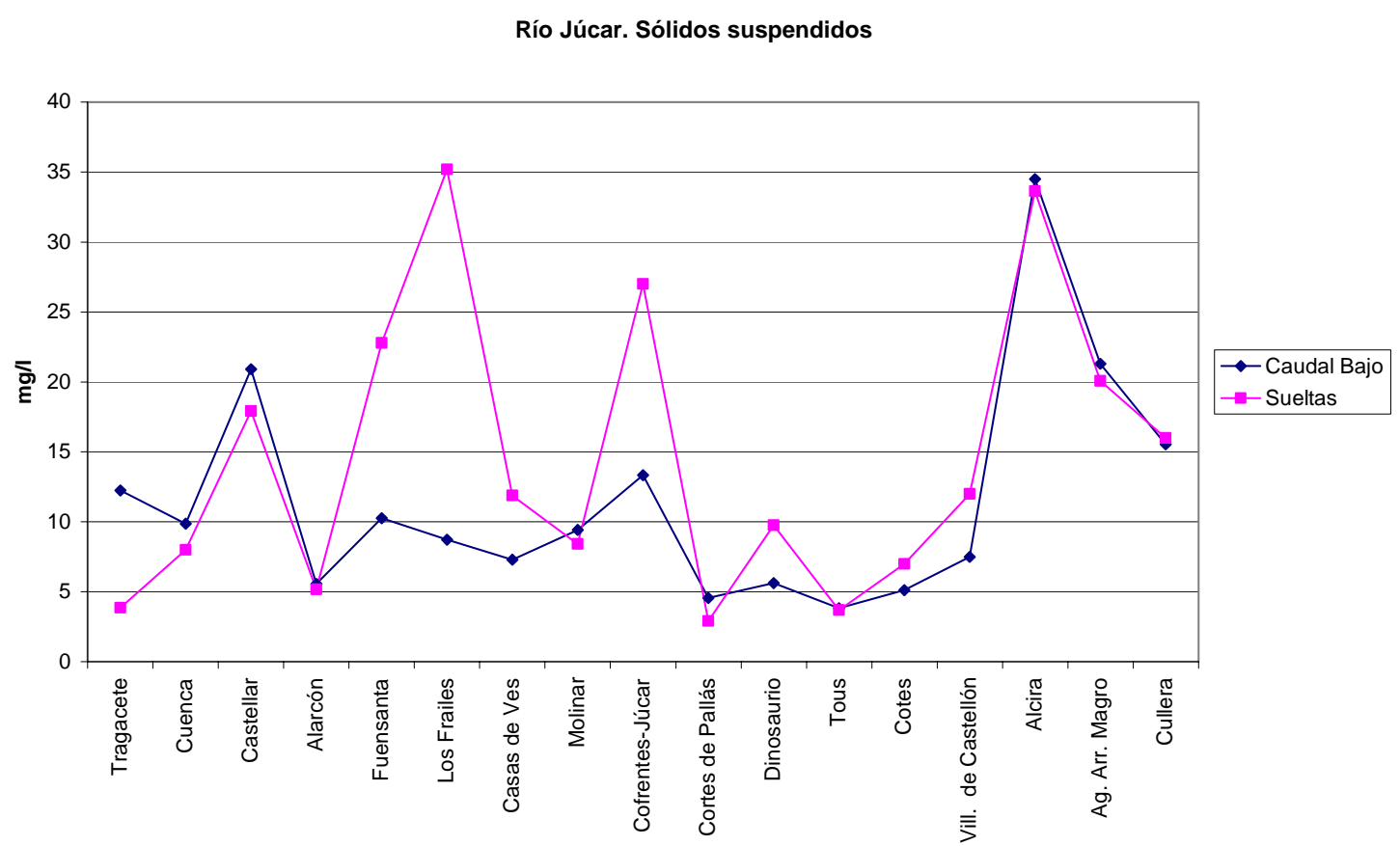

Figura 44. Perfiles medios de los sólidos suspendidos en la cuenca del río Júcar.

Como muestra el gráfico las diferencias de concentraciones entre las épocas de caudales bajos y altos se da sobre todo en la zona aguas abajo del embalse de Alarcón. Las concentraciones mínimas se dan en la zona de confluencia en donde los embalses de 
Cortes, Naranjero y Tous hacen que las concentraciones de SS lleguen a valores medios mínimos de $5 \mathrm{mg} / \mathrm{l}$.

Aguas arriba de el embalse de Alarcón las concentraciones presentan un incremento muy importante en el último tramo en donde se produce un aumento del valor medio de 10 a $20 \mathrm{mg} / \mathrm{l}$. Analizando las medias mensuales se comprueba que para la estación de Castellar los valores medios entre mayo y noviembre son todos superiores a $20 \mathrm{mg} / 1$ alcanzando un pico en Agosto de $45 \mathrm{mg} / 1$. Este efecto es debido a una escorrentía en la zona cargada de limos. Las concentraciones de las estaciones aguas arriba de Cuenca son bastante parecidas aunque destaca en algunos puntos, como en Venta Juan Romero, el incremento de las mismas por el efecto del vertido de la piscifactoría.

El gráfico siguiente muestra la ganancia de SS entre las estaciones de Cuenca y Castellar y la sedimentación que se produce en el embalse de Alarcón.

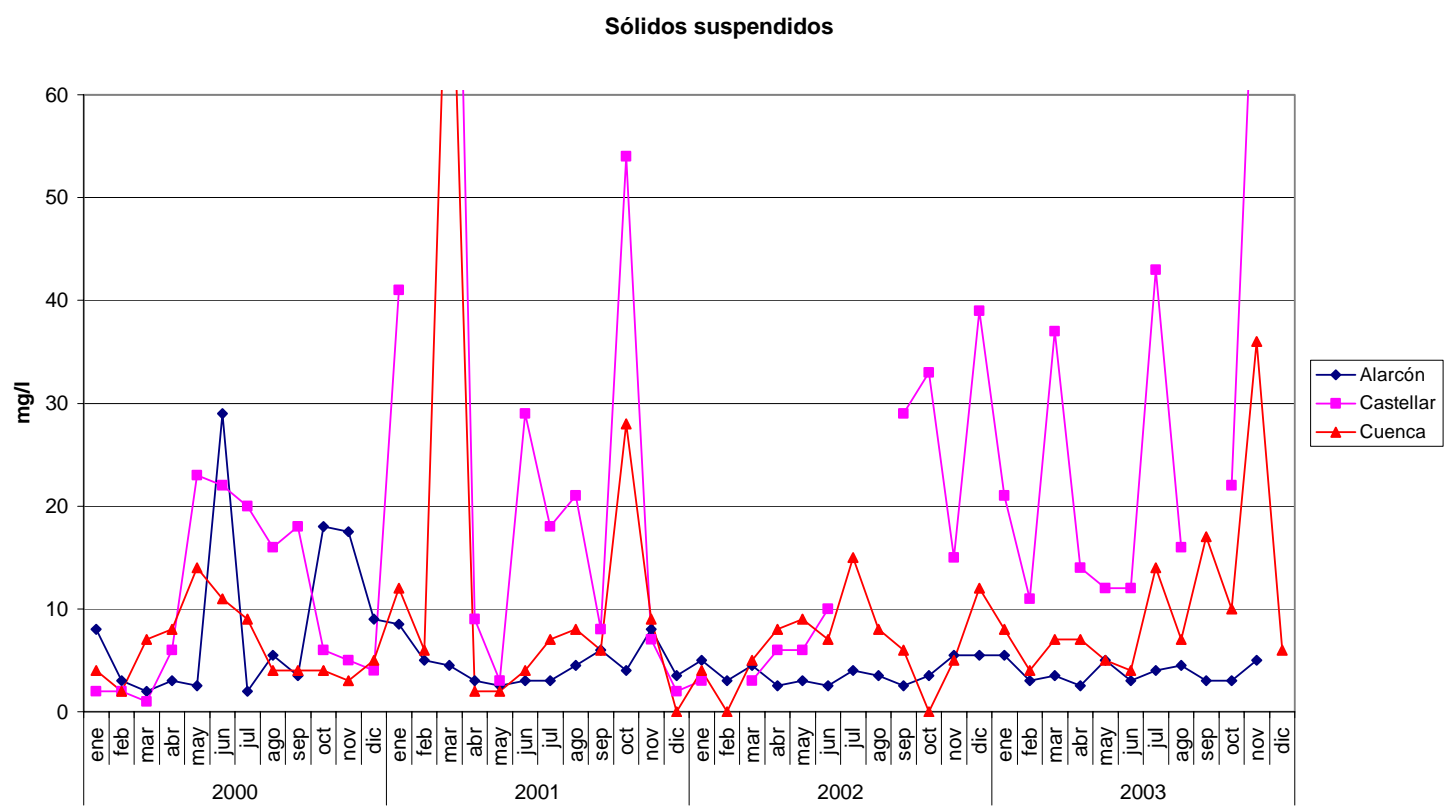

Figura 45. Concentraciones de sólidos suspendidos medidas en las estaciones de Cuenca, Castellar y Alarcón.

El gráfico refleja concentraciones de salida de embalse inferiores a $10 \mathrm{mg} / \mathrm{l}$. Esto hace que el agua tenga un mayor poder erosivo aguas abajo del embalse.

El tramo entre los embalses de Alarcón y Molinar es una de las zonas de mayor dinámica de la cuenca en cuanto a SS se refiere. Este tramo es una de las zonas con mayor número de azudes para aprovechamiento hidroeléctrico de toda la cuenca. En estos azudes se suele dar un doble efecto de sedimentación aguas arriba y erosión aguas abajo. En el caso del tramo aguas abajo de Alarcón el incremento de sólidos suspendidos es más que notable en épocas de sueltas. Cuando los caudales son bajos no 
se produce tal incremento sin duda por las velocidades menores. La siguiente figura muestra que gran parte del incremento de sólidos suspendidos se produce entre la estación de Alarcón y la de Fuensanta.

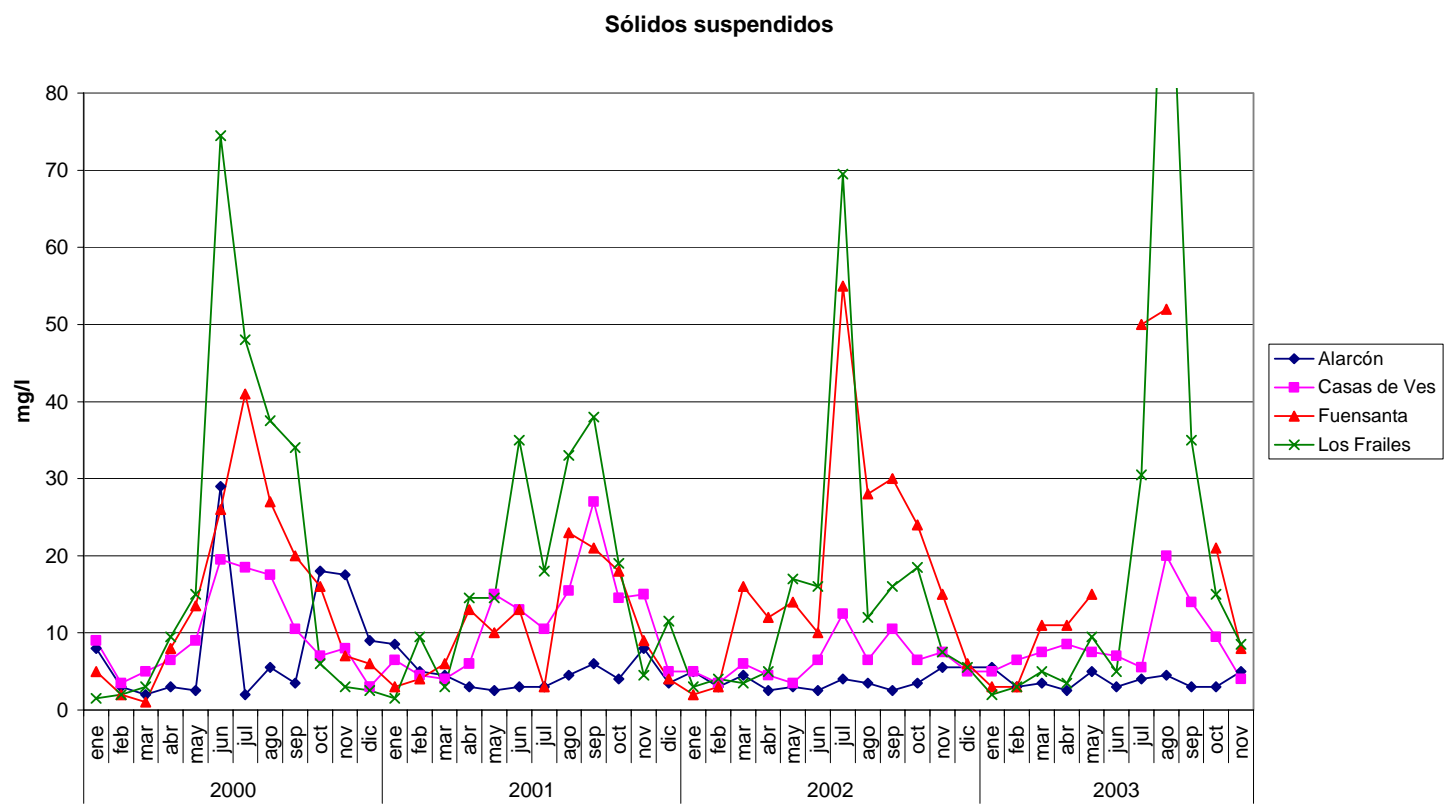

Figura 46. Concentraciones de sólidos suspendidos medidas en las estaciones ICA entre los embalses de Alarcón y Molinar.

Por otra parte, se puede ver la reducción de los SS en la estación de Casas de Ves debido principalmente a que en el tramo aguas arriba del embalse de Molinar se produce una disminución de velocidades y consecuentemente una sedimentación de los sólidos en suspensión.

En el gráfico del perfil medio de SS se muestra un incremento de las concentraciones entre la estación de Molinar y la de Cofrentes-Júcar. La causa es el río Reconque ya que en ese tramo de río la mayor parte de caudal en el río Júcar proviene de ese afluente.

El siguiente gráfico muestra la serie de concentraciones de SS para tres estaciones de calidad cercanas a la zona de confluencia. 


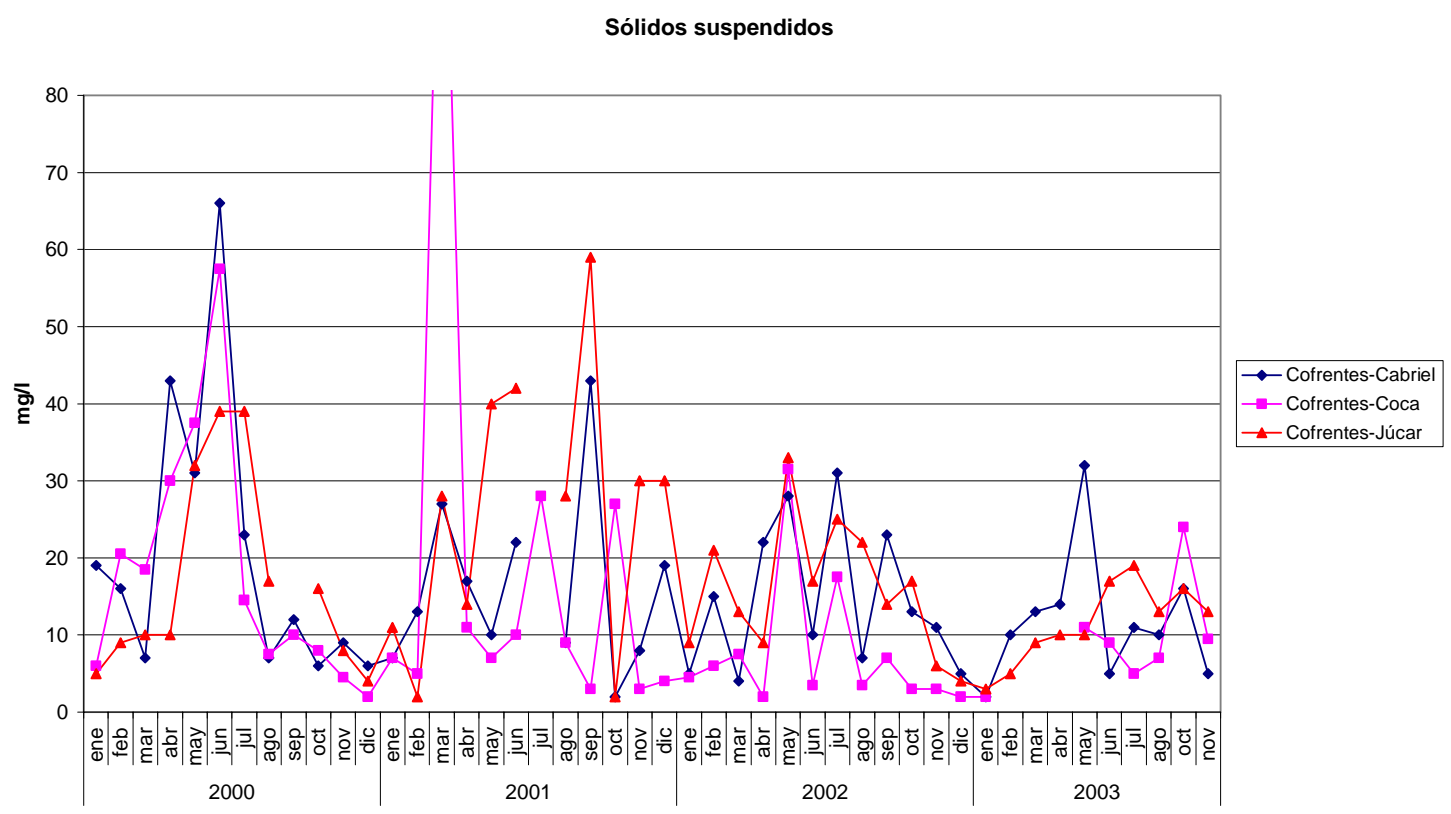

Figura 47. Concentraciones de sólidos suspendidos medidas por las estaciones ICA de la confluencia entre los ríos Júcar y Cabriel

Sorprende en el gráfico el parecido de las concentraciones ya que mientras las concentraciones provenientes del río Cabriel son concentraciones de agua regulada e influenciada por los embalses de agua arriba en el Reconque las aguas no tienen ningún tipo de regulación. La explicación puede estar en los vertidos en la cuenca del Reconque que tienen bastante influencia en la calidad que se mide en la estación. Así en las épocas de sueltas en el río Júcar coinciden con las de caudales bajos en el Reconque y por consiguiente mayores concentraciones en ambos.

El efecto de los embalses de confluencia queda patente en el siguiente gráfico, en el cual, se puede ver la disminución de concentraciones en los primeros embalses, que no parece tan determinante como el efecto del embalse de Tous sobre los mismos. Hay que matizar que la estación de Dinosaurio está ubicada a cierta distancia de la salida de Naranjero con lo cual entre medias puede haber un efecto de incremento de sólidos suspendidos que no permita cuantificar realmente la sedimentación real en los embalses de Cortes y Naranjero. 
Sólidos suspendidos

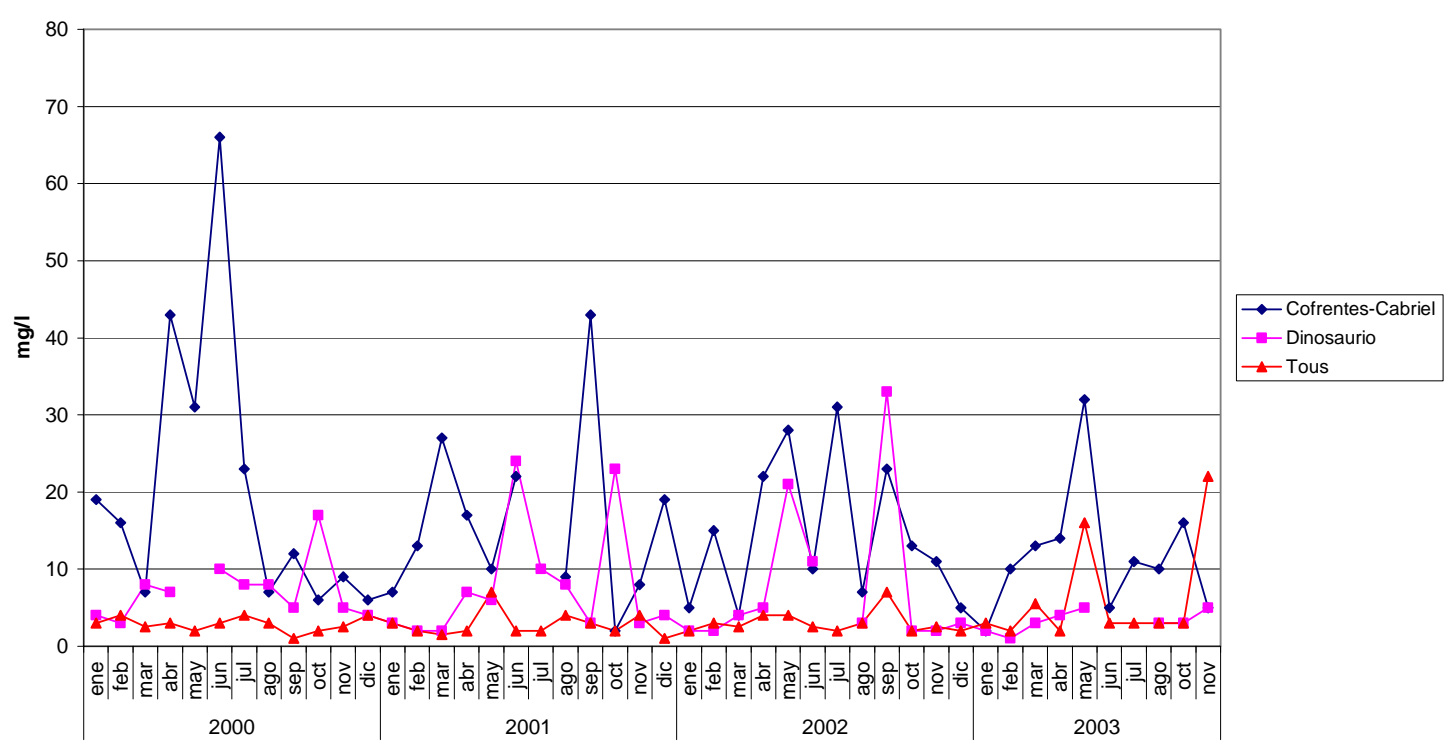

Figura 48. Concentraciones de sólidos suspendidos en las estaciones de Cofrentes-Cabriel, Dinosaurio y Tous.

Sin duda el efecto del embalse de Tous es determinante. Como muestra la figura las concentraciones pasan de tener una media de $15.86 \mathrm{mg} / \mathrm{l}$ aguas arriba de la confluencia a una inferior a $4 \mathrm{mg} / 1$ en la salida de Tous.

La evolución de las concentraciones de sólidos suspendidos en la ribera del río Júcar vienen marcadas por tres factores: el aporte de sólidos por parte de los retornos agrícolas, la influencia del vertido de Alcira, las bajas velocidades en los últimos tramos con la consecuente sedimentación y el incremento producido en el azud de Antella por la fuerte actividad biológica existente.

En el primer tramo, entre el embalse de Tous y Villanueva de Castellón, se produce un incremento de los sólidos suspendidos debido por un lado a la capacidad erosiva del agua saliente de Tous y por otro a la entrada del Sellent, el cual presenta concentraciones de SS superiores. Entre la estación de Villanueva de Castellón y Alcira las concentraciones se incrementan fundamentalmente por los retornos agrícolas así como los diferentes vertidos urbanos que se dan en la zona. En la estación de Alcira se miden concentraciones medias de $35 \mathrm{mg} / 1$, de las más altas en toda la cuenca. Hay que mencionar que hasta 1996 la frecuencia de muestreo era mensual y a partir de ese año se convirtió en trimestral. Aunque para este último período se disponen de pocos datos el análisis realizado para todo el período muestra este mismo comportamiento a lo largo del tiempo.

Finalmente los últimos tramos vienen marcados por la hidrodinámica del río en donde las bajas velocidades hacen que se sedimente gran parte de los sólidos suspendidos. Se alcanza una media de sólidos suspendidos al final del río en torno a los 
15mg/l. Del análisis de los principales afluentes de la ribera destaca la diferencia de concentraciones entre los afluentes sin regulación y los que disponen de ella. El siguiente gráfico muestra las concentraciones de sólidos suspendidos para los ríos Verde, Albaida, Sellent y Magro.

Sólidos suspendidos

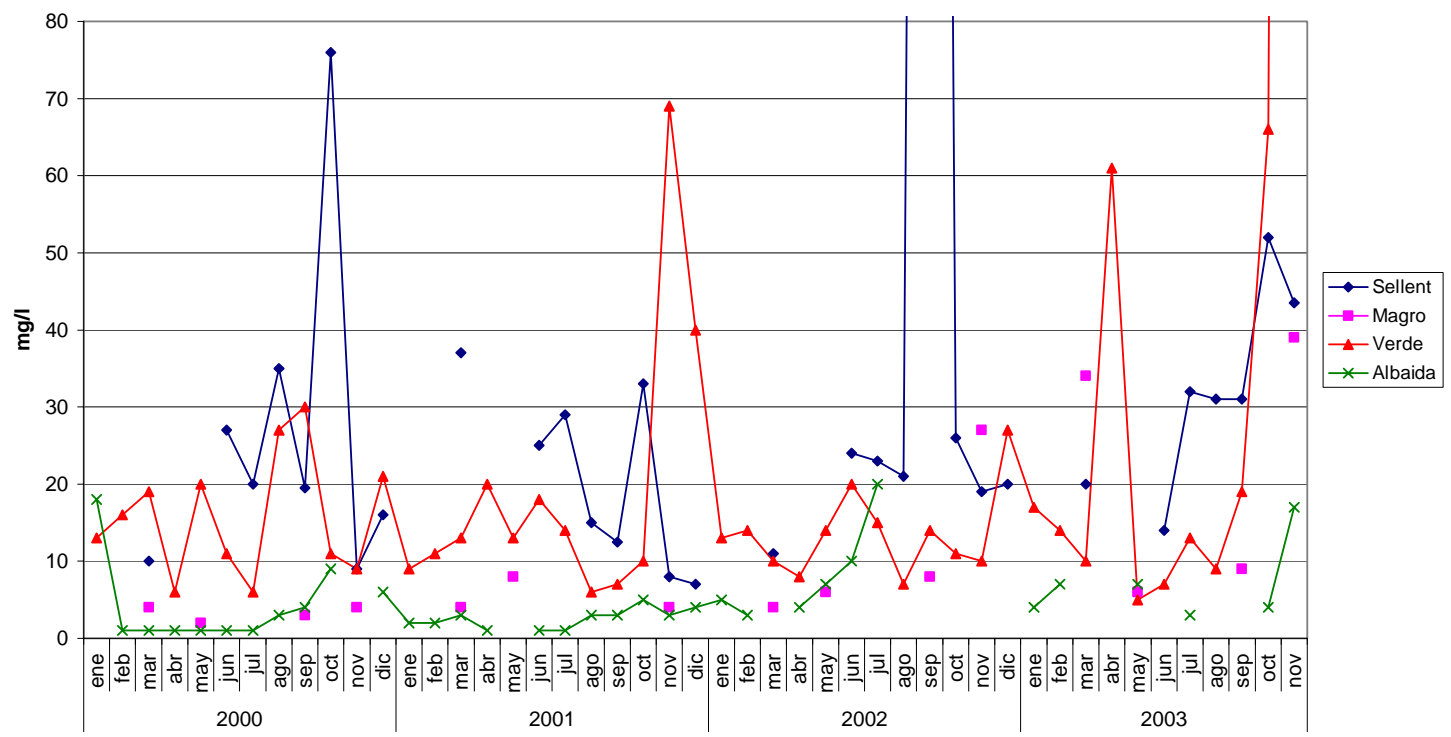

Figura 49. Concentraciones de sólidos suspendidos en las estaciones finales de los afluentes inferiores del Júcar.

Como se refleja en el gráfico, el que presenta mayores concentraciones es el Sellent con una media de $49.62 \mathrm{mg} / 1$. Por otro lado el río Verde, que dispone de una mayor cantidad de datos, presenta una media de $31.02 \mathrm{mg} / 1$. Finalmente los afluentes con algún tipo de regulación ,el Albaida y el Magro, presentan concentraciones muy bajas con medias de 4.85 y $10.8 \mathrm{mg} / \mathrm{l}$ respectivamente.

\subsubsection{Análisis de sólidos suspendidos en el río Cabriel.}

En el río Cabriel los sólidos suspendidos, al igual que en caso del Júcar, presentan concentraciones muy bajas. Como se puede ver en el siguiente gráfico todas las estaciones muestran concentraciones medias inferiores a los $25 \mathrm{mg} / 1$ y en muchas de las estaciones inferiores a los $10 \mathrm{mg} / 1$. 
Río Cabriel. Sólidos suspendidos

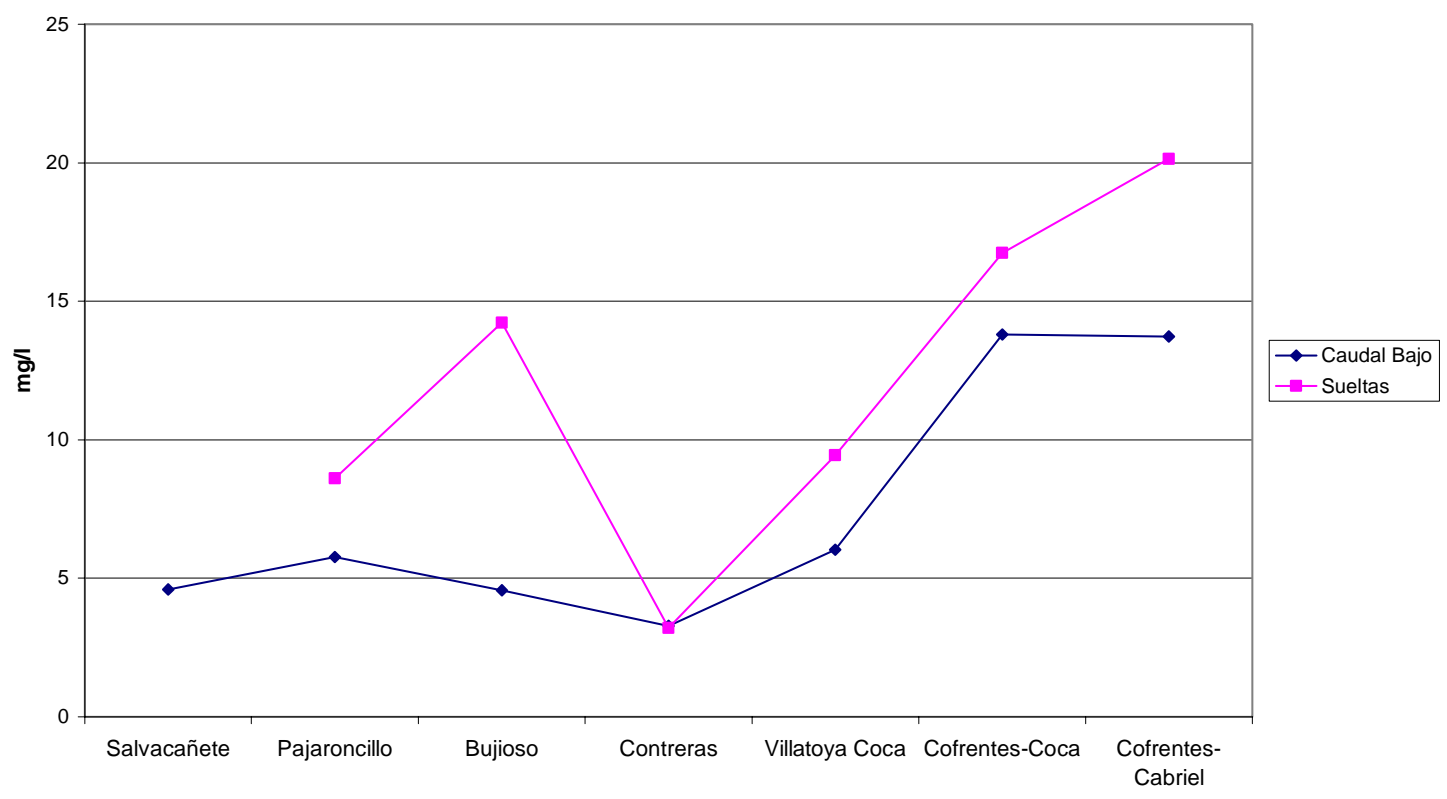

Figura 50. Perfiles medios de las concentraciones de sólidos suspendidos del río Cabriel

Analizando el perfil longitudinal se puede ver el punto de inflexión de Contreras en donde se pasa de una zona en la que las concentraciones disminuyen por el efecto de los embalses de Bujioso y Contreras a otra en donde la tendencia es de crecimiento en todos los puntos. Aunque en la estación de Salvacañete se tengan pocos datos en este período el análisis de todo el período histórico muestra que las concentraciones son de ese orden de magnitud.

En el siguiente gráfico se muestra las concentraciones de SS en el período 200003 de las estaciones de Pajaroncillo, Bujioso y Contreras. Como se puede ver existe una similitud bastante grande en las tendencias de las mismas entre las dos primeras estaciones. 
Sólidos suspendidos

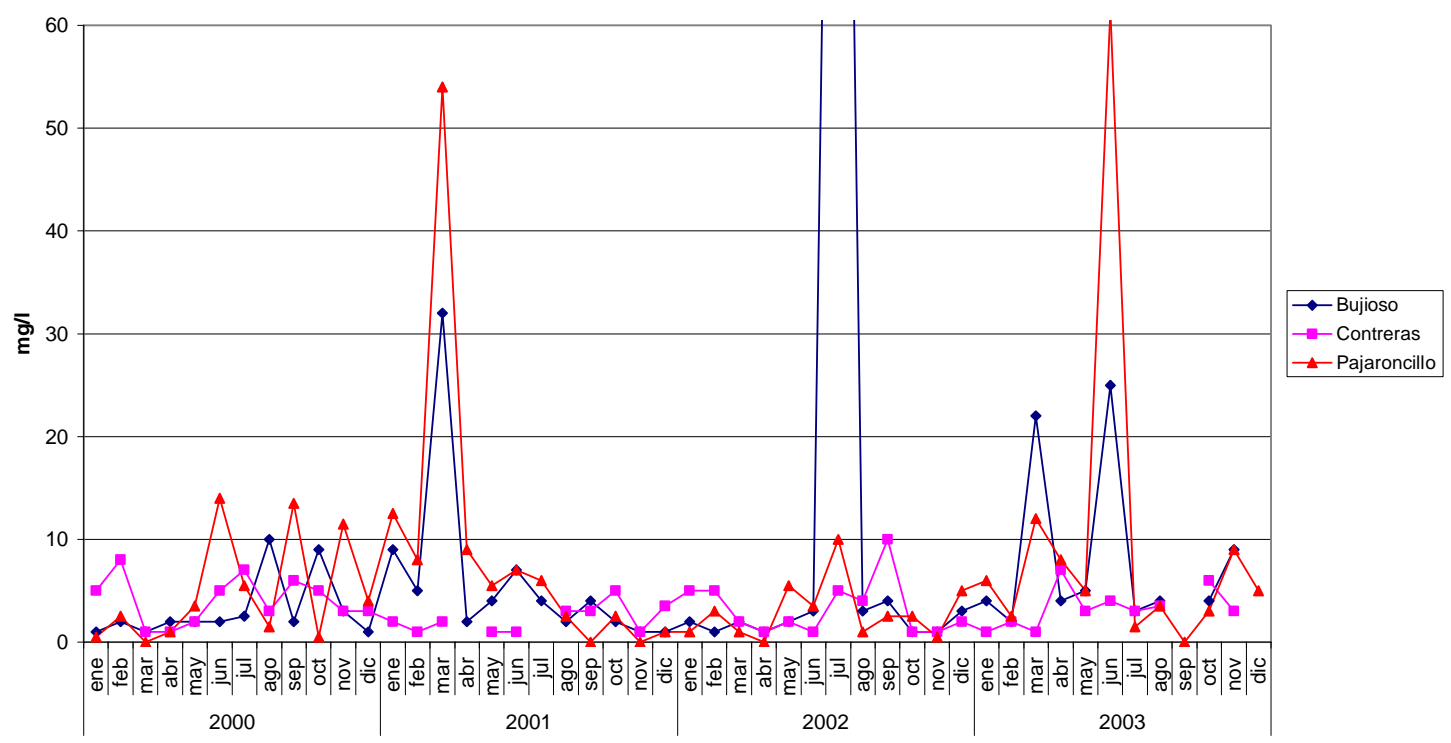

Figura 51. Concentraciones de sólidos suspendidos medidas en las estaciones ICA de Bujioso, Contreras y Pajaroncillo.

Además el gráfico muestra el efecto de la sedimentación en el embalse de Contreras en donde las concentraciones se hacen inferiores a $10 \mathrm{mg} / 1$.

Finalmente el gráfico de las concentraciones medidas en las estaciones aguas abajo de Contreras muestran como en la primera parte de la cuenca, hasta Villatoya hay un incremento de sólidos suspendidos significativo, aunque no excesivamente grande. El siguiente gráfico muestra que el incremento de las concentraciones de este constituyente se da en mayor grado en la segunda parte del río entre la estación de Villatoya y la de confluencia. 
Sólidos suspendidos

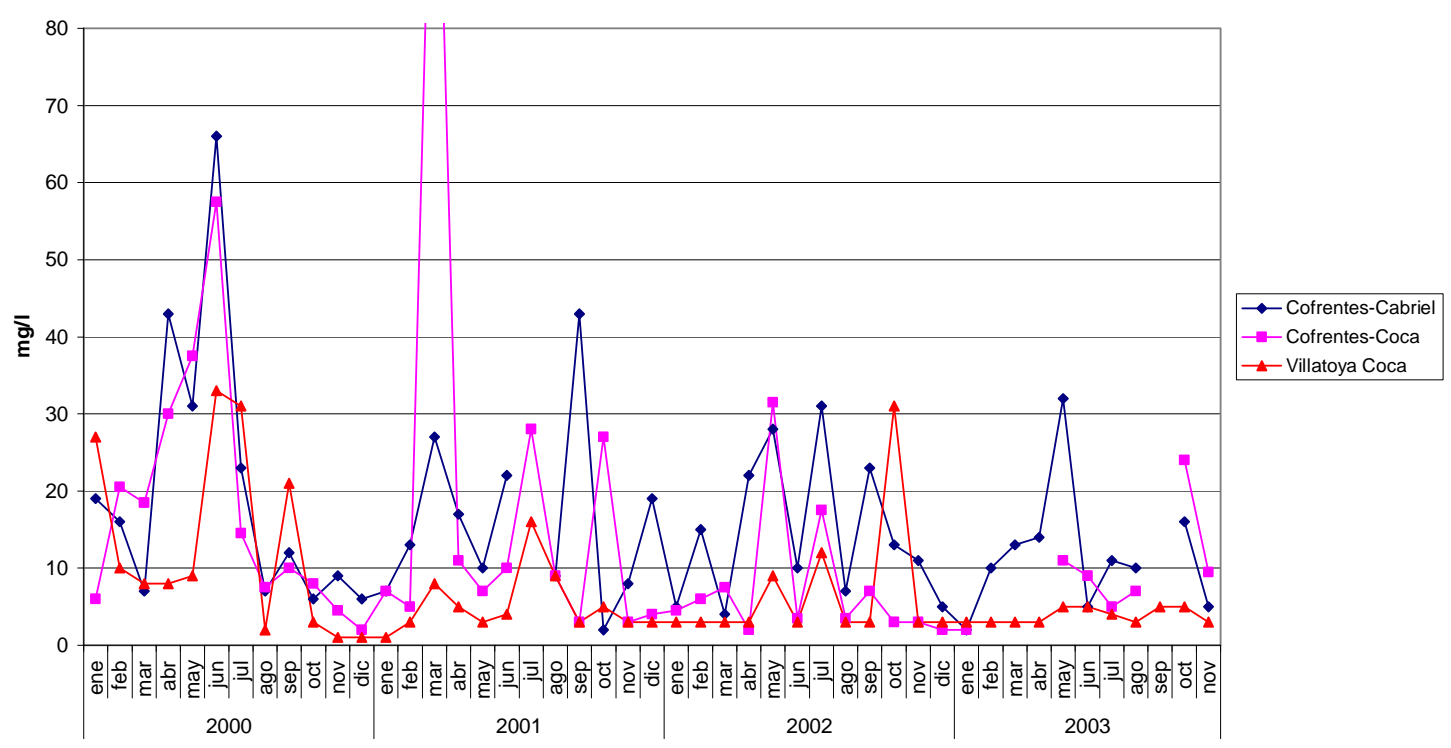

Figura 52. Concentraciones de sólidos suspendidos medidas en las estaciones del río Cabriel aguas abajo del embalse de Contreras.

El río llega a la zona de confluencia con concentraciones en sólidos suspendidos en torno a los $15 \mathrm{mg} / \mathrm{l}$ de media y con grandes oscilaciones en las concentraciones.

\subsubsection{Oxígeno Disuelto y Demanda Biológica de Oxígeno.}

Tradicionalmente se ha considerado el oxígeno disuelto como el parámetro más significativo a la hora de evaluar la salud de un ecosistema. Una de las principales causas de disminución de oxígeno disuelto es la degradación de la materia orgánica. Por ello en general se analizan ambos parámetros de forma conjunta. En aguas naturales (poco contaminadas) las concentraciones de oxígeno disuelto deben ser cercanas a la concentración de saturación dependiendo esta de la temperatura, salinidad, presión atmosférica y presión parcial del agua.

\subsubsection{Análisis del oxígeno disuelto y la materia orgánica en el río Júcar.}

El análisis del porcentaje de saturación indica si las concentraciones medidas son próximas a las concentraciones naturales. Con temperaturas medias de la cuenca oscilando entre 5 y $25^{\circ} \mathrm{C}$ la concentración de saturación del oxígeno disuelto está en el intervalo entre 12.82 y $8.28 \mathrm{mg} / 1$. Como se puede ver en el gráfico de perfil medio las concentraciones medias, en gran parte de la cuenca, se mueven dentro de ese intervalo.

La demanda biológica de oxígeno es una medida aproximada de la cantidad de materia orgánica biodegradable presente en el agua. La materia orgánica presente en aguas naturales procede del lavado de suelos por los que pasa la escorrentía y por el 
metabolismo de los organismos acuáticos. Aguas naturales suelen presentar rangos de $\mathrm{DBO}_{5}$ inferiores a $2 \mathrm{mg} / \mathrm{l}$ mientras que aguas con influencia antropogénica pueden presentar valores superiores a $10 \mathrm{mg} / \mathrm{l}$.

En la siguiente figura se muestra los perfiles para épocas de sueltas y de caudales bajos de la Demanda Biológica de Oxígeno a 5 días $\left(\mathrm{DBO}_{5}\right)$ y la concentración de oxígeno disuelto (OD).

Río Júcar. DBO5 y Oxígeno Disuelto

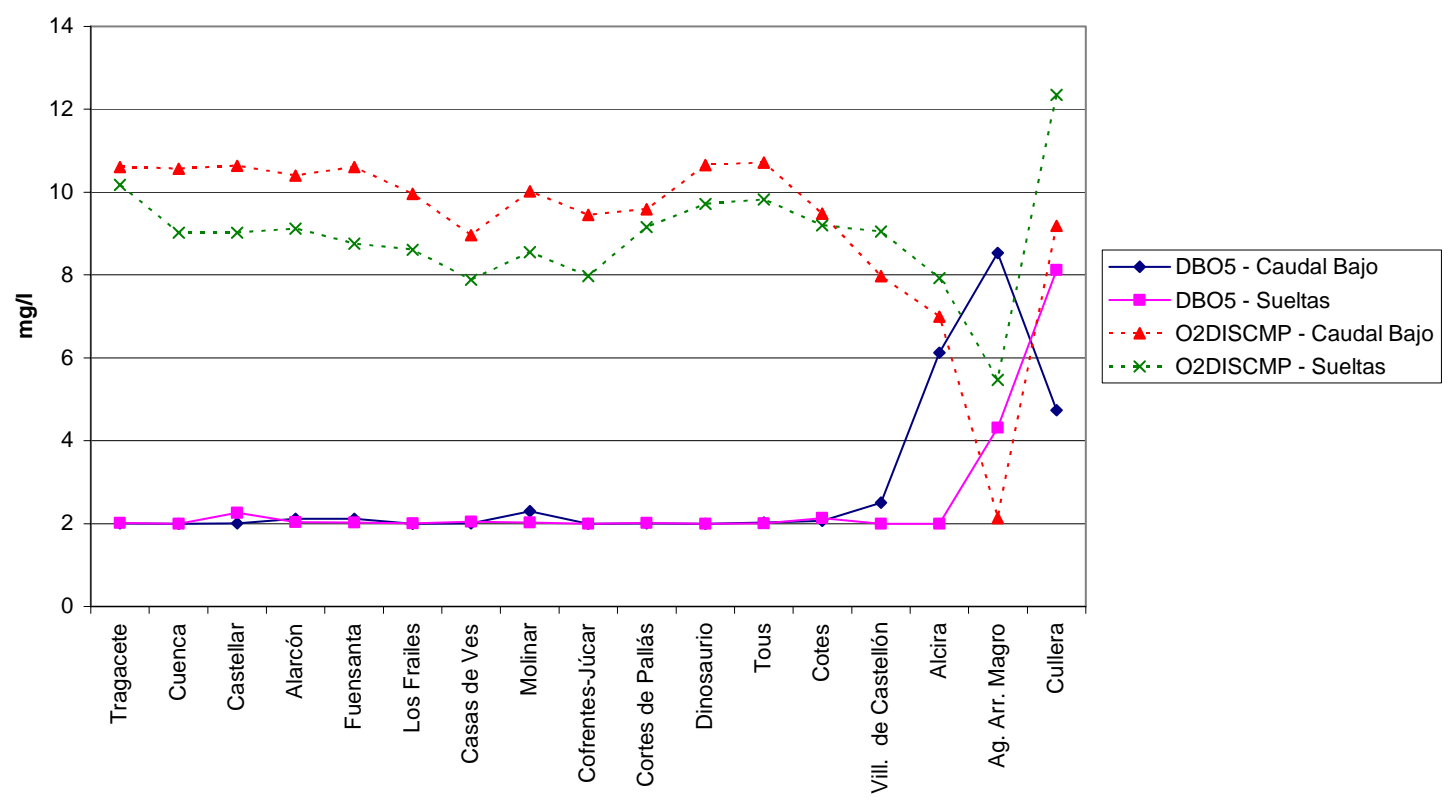

Figura 53. Perfiles medios de las concentraciones de OD y DBO5 del río Júcar.

Como se puede ver en la mayor parte del río, desde su nacimiento hasta Villanueva de Castellón, las concentraciones de $\mathrm{DBO}_{5}$ son $2 \mathrm{mg} / 1$ siendo éste el umbral de medición. Esto refleja que el contenido de materia orgánica en gran parte del río es muy pequeño. Como se puede ver en el perfil en la zona entre Villanueva de Castellón y la confluencia del río Magro el contenido en materia orgánica aumenta hasta concentraciones superiores a $8 \mathrm{mg} / 1$ en épocas de caudales bajos. Los perfiles medios en las épocas de sueltas y de caudales bajos son muy diferentes. Mientras que en las épocas de sueltas el aumento de concentraciones se produce sobre todo entre las dos últimas estaciones en épocas de caudales bajos la punta de concentración se produce aguas abajo de Alcira. Esto se debe a que mientras que en la época de caudales bajos la afección más importante es el vertido de Alcira y sus colindantes en época de sueltas el caudal de dilución es mayor y el río sufre problemas cuando las acequias de la ribera baja han tomado agua y el caudal circulante es menor.

El contenido de materia orgánica en el río depende de varios factores como son: el volumen de vertidos urbanos o industriales, la capacidad de autodepuración del río, la 
infraestructura de depuración, presiones difusas como retornos de riego, etc. En la siguiente figura se puede ver los vertidos en la cuenca del río Júcar.

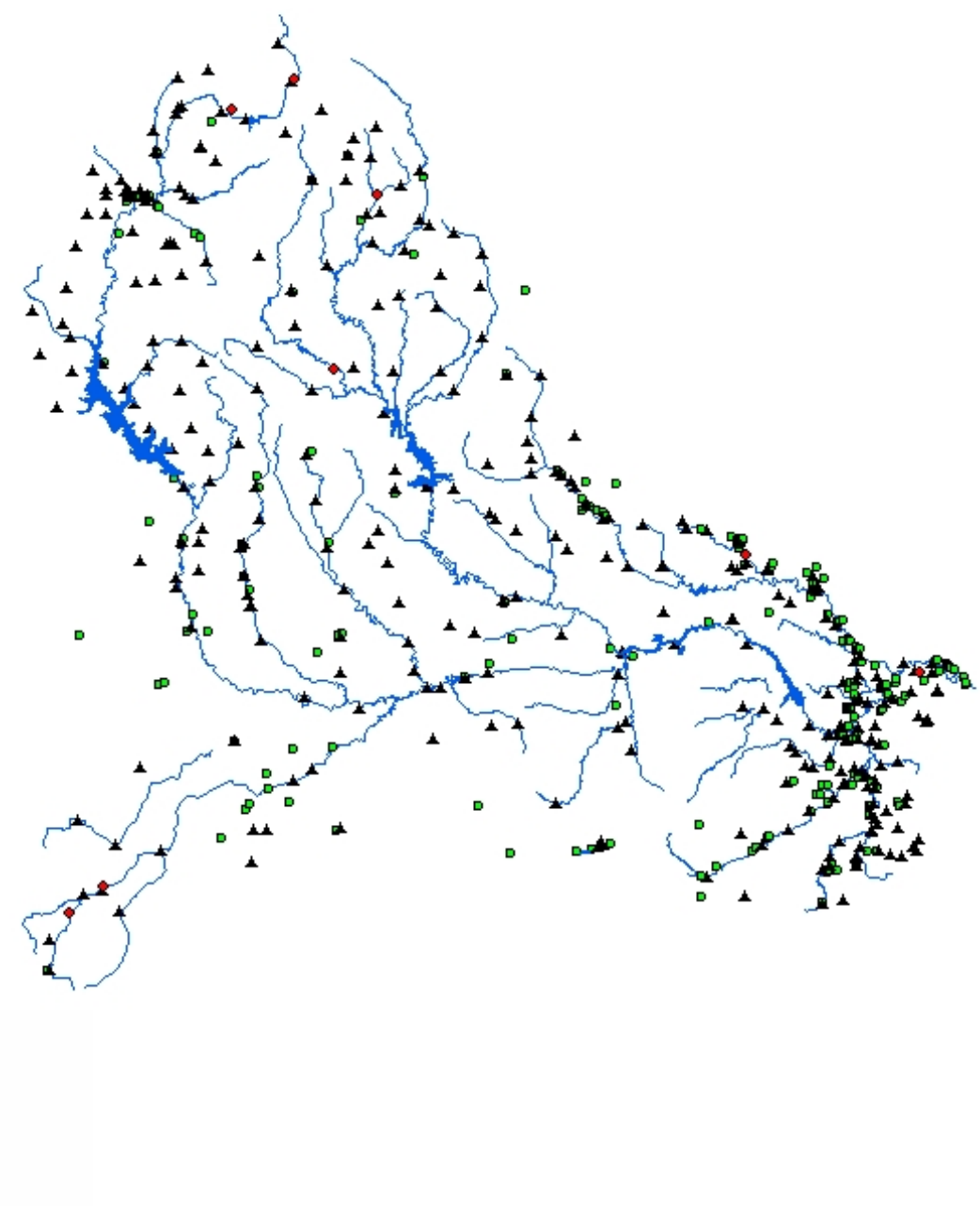

Figura 54. Vertidos en la cuenca del río Júcar.

Para analizar la evolución del oxígeno disuelto a lo largo del río junto al perfil de concentraciones de dicho gas se analiza el perfil del tanto por ciento de saturación del mismo. Esto se puede ver en la siguiente figura. 


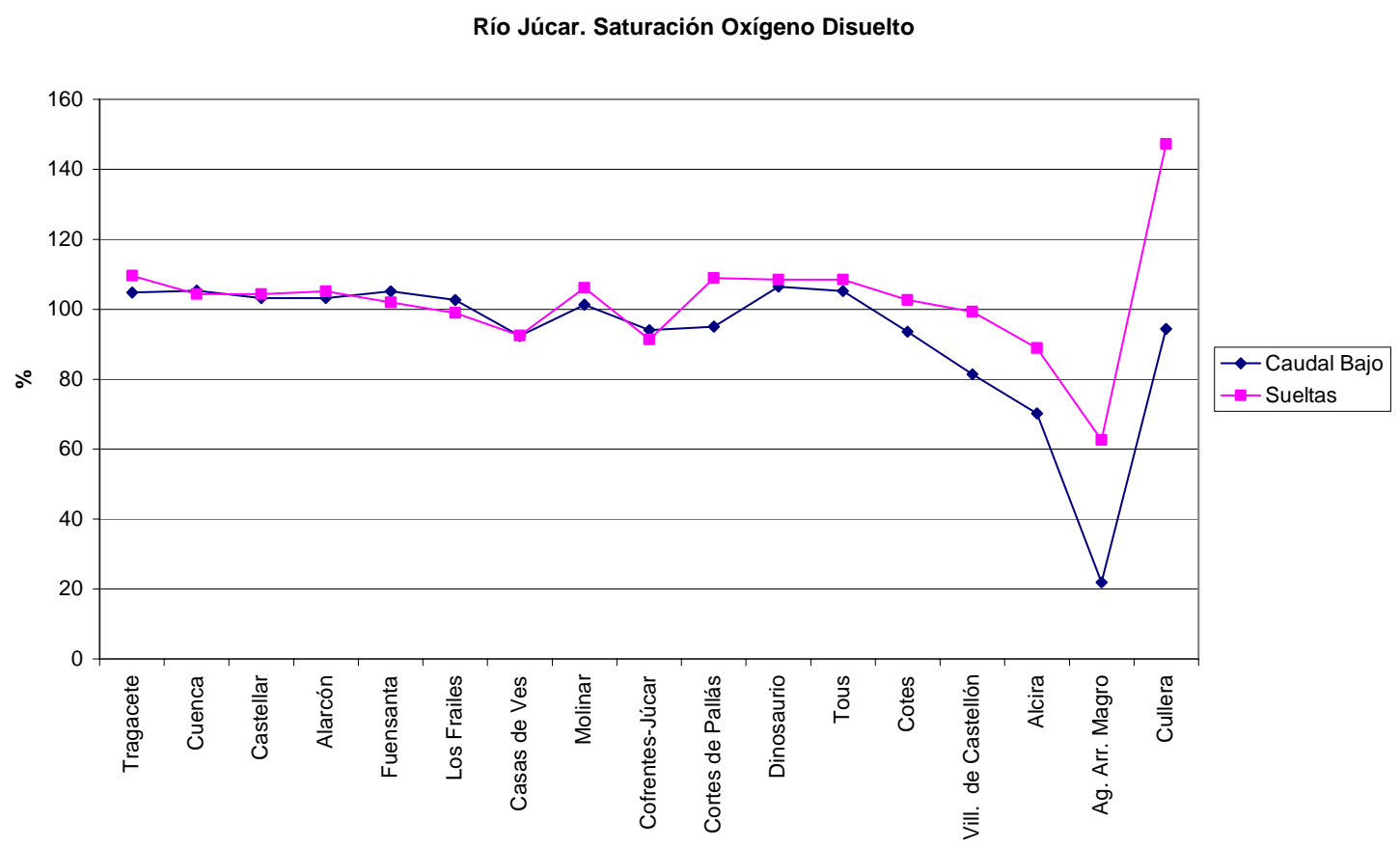

Figura 55. Perfiles medios de la saturación de oxígeno disuelto en el río Júcar.

El primer efecto que se desprende de los gráficos es que en general la época de caudales bajos representa concentraciones superiores. Viendo el gráfico, del tanto por cien de saturación se desprende que este efecto es debido a factores naturales principalmente por temperatura, ya que el tanto por cien de saturación es muy similar en todos los puntos cercanos al 100\% de saturación. Del análisis realizado se puede concluir que, en general, el río Júcar tiene contenidos de oxígeno disuelto típicos de aguas naturales, sin afección antrópica, excepto en la parte baja del río y en algunos puntos como la zona de Casas de Ves y aguas abajo de la confluencia con el Reconque (en las inmediaciones a la confluencia con el Cabriel).

La primera estación que presenta concentraciones de oxígeno disuelto que denotan afección antrópica es la de Casas de Ves sita en el embalse de Molinar. En las siguientes figuras se compara la concentración de oxígeno disuelto y tanto por ciento de saturación de las estaciones de los Frailes, situada aguas arriba, y la de Casas de Ves. 
Oxígeno Disuelto

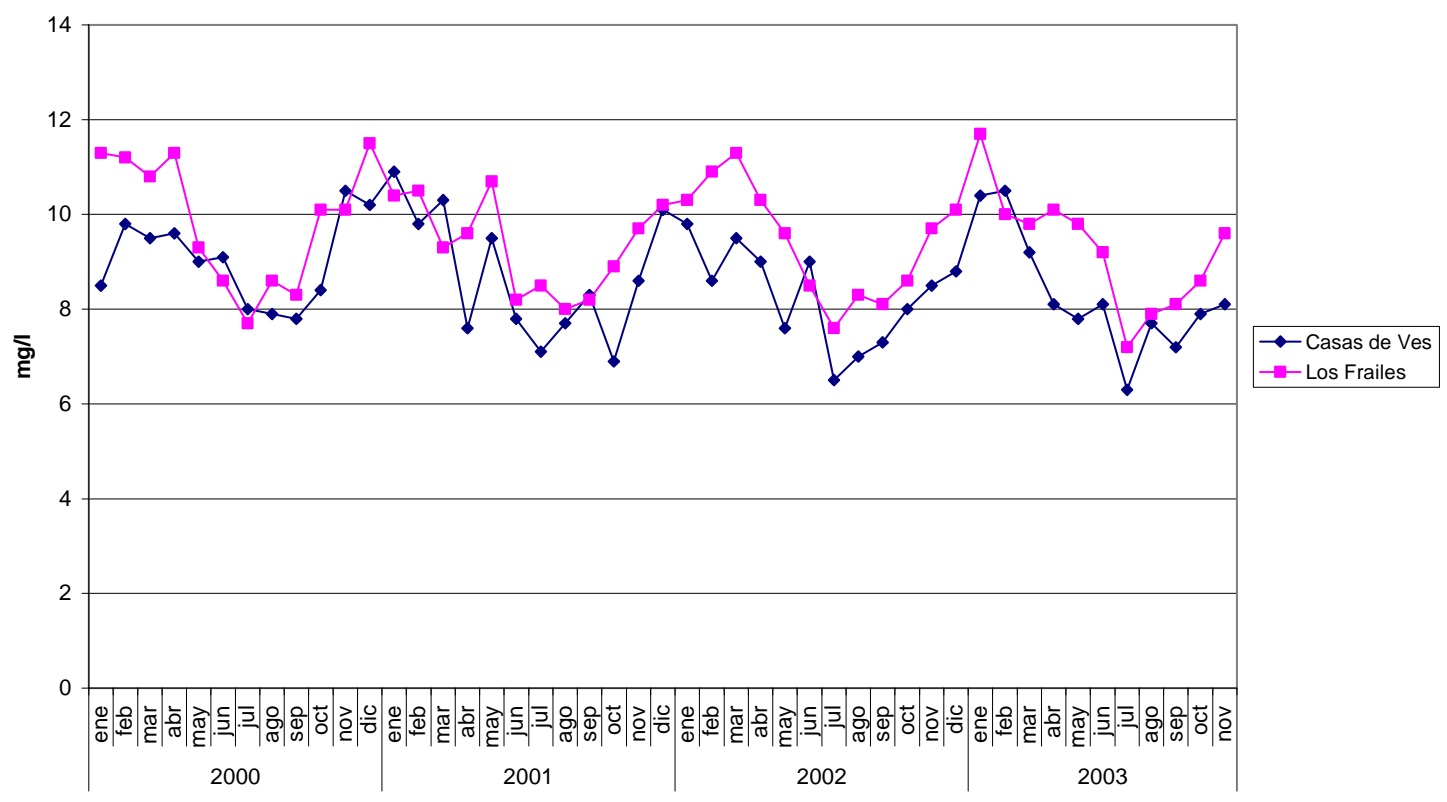

Figura 56. Concentraciones de OD en las estaciones de Casas de Ves y de los Frailes

Saturación Oxígeno Disuelto

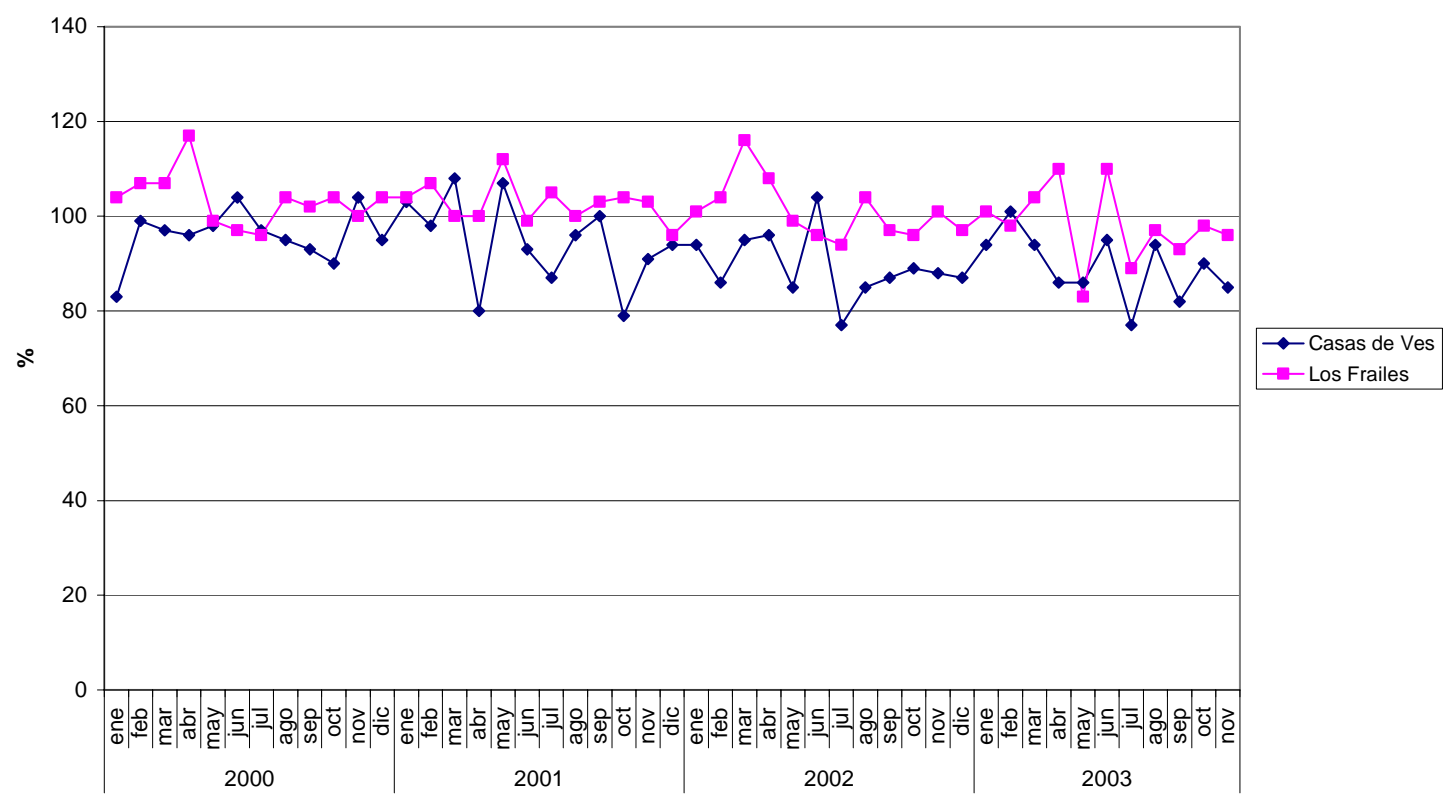

Figura 57. Medidas de saturación de OD en las estaciones de Casas de Ves y de los Frailes.

Como se puede ver en la estación de Casas de Ves existe alguna afección ya que se están midiendo valores de OD inferiores a los medidos en la estación de aguas arriba. Por otra parte el tanto por cien de saturación medido en la citada estación es inferior, en la mayoría del tiempo, al 100\%. El análisis de los vertidos de la zona nos muestra que la zona está afectada por un conjunto de vertidos a lo largo de dos afluentes del Júcar, el 
Valdemembra y el Ledaña, además de unos cuantos vertidos en el propio río como el de la población de Alcalá del Júcar.

Es importante comentar que la estación de Casas de Ves está reflejando el agua casi ya autodepurada por parte del río. Las concentraciones de $\mathrm{DBO}_{5}$ son inferiores a $2 \mathrm{mg} / \mathrm{l}$ en la mayor parte de los meses y el oxígeno disuelto indica que ha habido una afección antrópica pero esta estación no refleja que grado de contaminación se está dando en el tramo del río Júcar entre los Frailes y el embalse de Molinar.

Otra estación que presenta valores que muestran cierta afección antrópica es la de Cofrentes - Júcar. Esta estación está fuertemente condicionada por el agua del río Reconque cuya calidad se mide en la estación de Cautabán. Este afluente del Júcar recoge el agua de diferentes vertidos que se van autodepurando en el río. Aún así los valores de la estación final recogen cierta afección que se traslada al río Júcar debido a los bajos caudales circulantes en ese tramo.

Finalmente, la zona de mayor afección antrópica en cuanto a la materia orgánica y oxígeno disuelto se refiere es la zona de la Ribera. El primer tramo en el que se nota de forma significativa los vertidos urbanos es el tramo de río entre Villanueva de Castellón y la estación ICA de Alcira aguas arriba de la homónima población. En dicho tramo se realizan cuatro vertidos significativos, la mayoría sin depurar, de los que destacan por su volumen los del los ayuntamientos de Alberique y Villanueva de Castellón. Analizando los datos de ambas estaciones de calidad se puede observar varios defectos: En primer lugar que la toma de datos en ambas estaciones se realiza en meses alternos lo que tienen consecuencias muy negativas sobre cualquier intento de modelación de la calidad en el tramo. 
DBO5

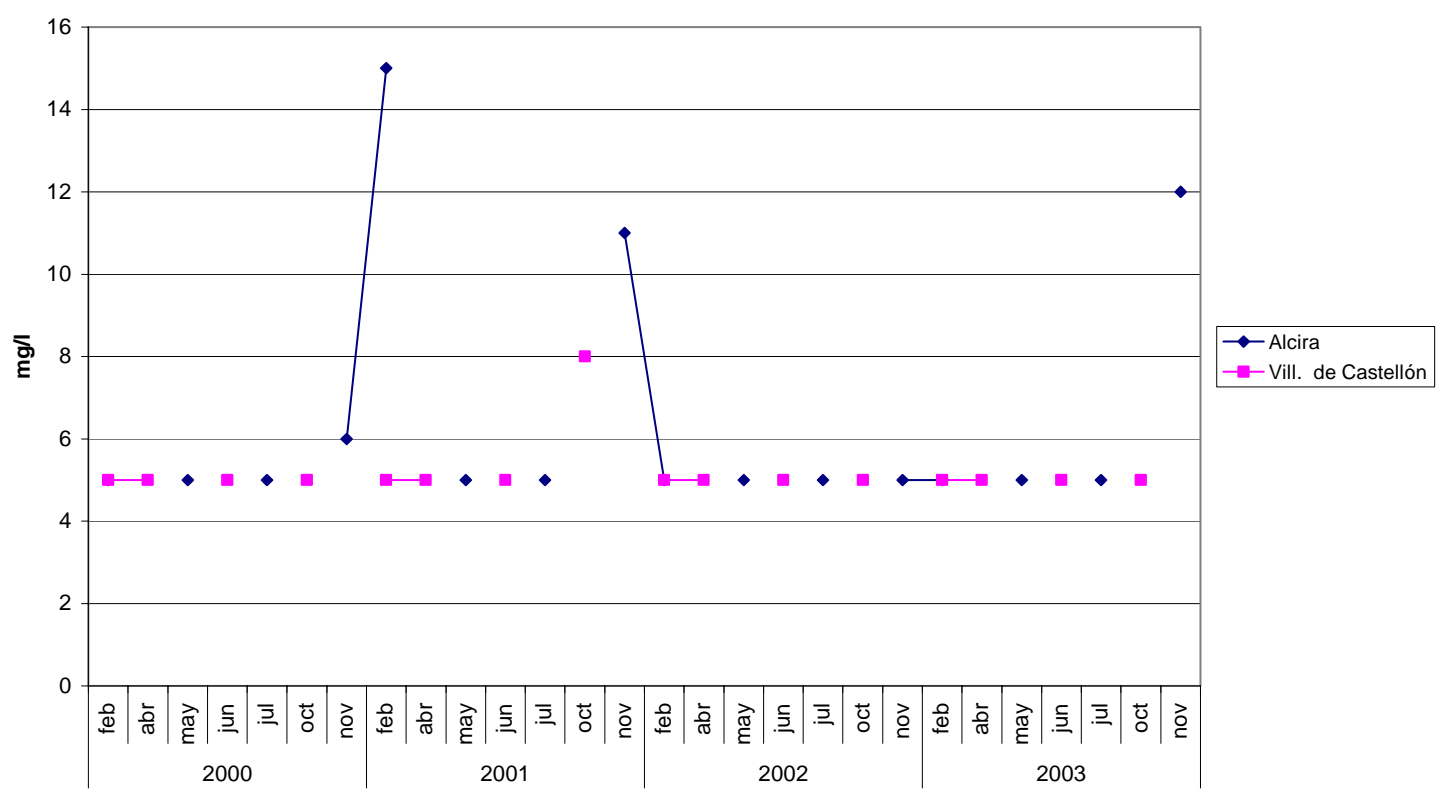

Figura 58. Concentraciones de DBO5 en las estaciones de Alcira y Villanueva de Castellón.

Por otra parte las concentraciones de $\mathrm{DBO}_{5}$ no reflejan ningún tipo de contaminación en el río. El oxígeno disuelto por su parte si que muestra concentraciones indicativas de cierta actividad antropogénica (entre 6 y $8 \mathrm{mg} / \mathrm{l}$ ). Ello es indicativo de la conveniencia de dar una mayor importancia a la medición de la demanda química de oxígeno (DQO) como indicador de la demanda real de oxígeno.

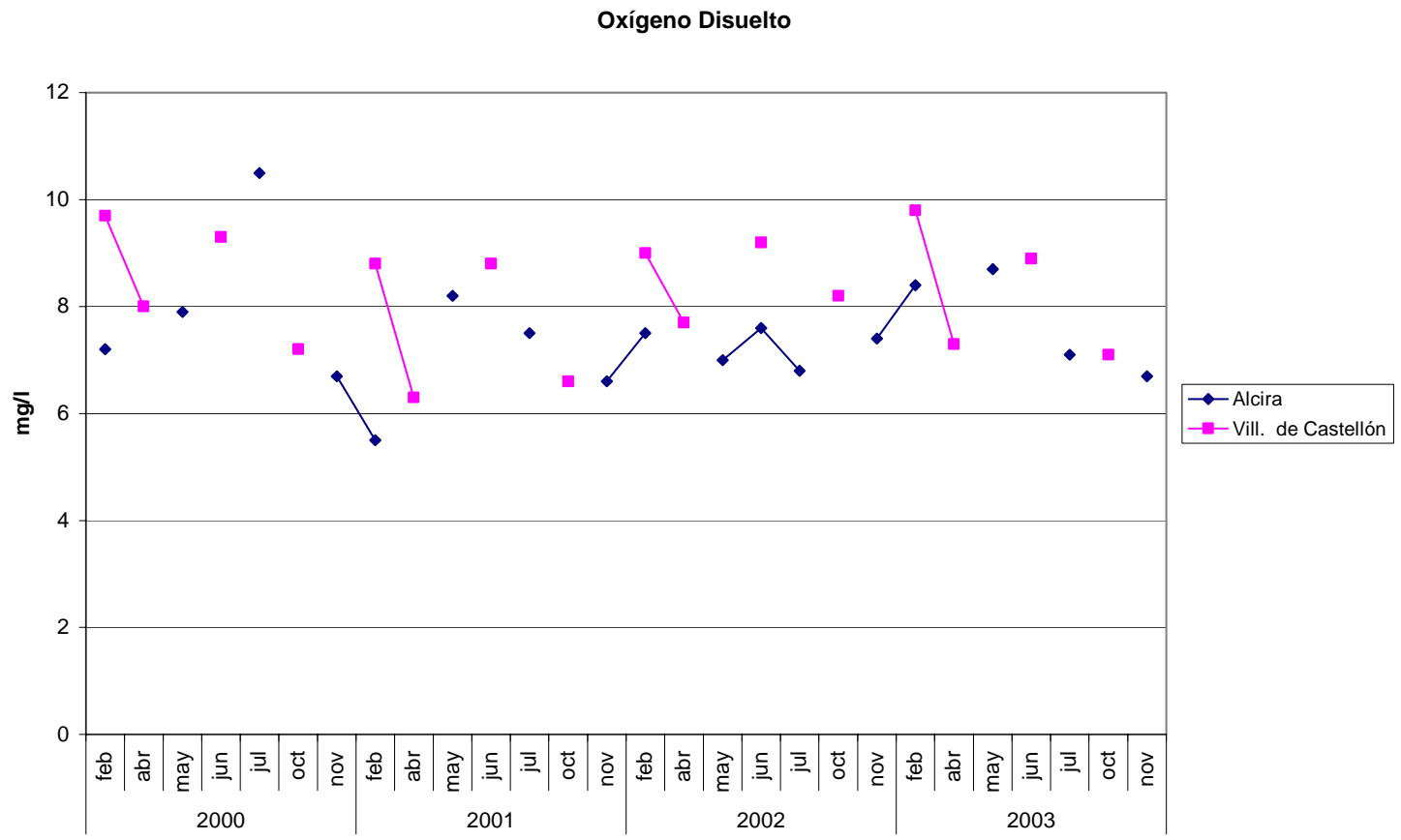

Figura 59. Concentraciones de OD en las estaciones de Alcira y Villanueva de Castellón. 
El siguiente tramo es el que más problemas presenta en la actualidad en cuanto al oxígeno disuelto se refiere. Transcurre entre la estaciones calidad de Alcira y Aguas arriba de confluencia con el Magro. La calidad del agua en el mismo viene influenciada por diversos vertidos como el de Alcira, los recogidos por el barranco del Barcheta y otros de la zona. Además también afecta la entrada del afluente del Júcar el río Verde, con agua de pésima calidad. Como era de esperar, por la gran cantidad de vertidos que hay en este río, la $\mathrm{DBO}_{5}$ sufre un aumento importante de concentración, sobre todo en los meses de invierno y primavera, superando en varias ocasiones los $12 \mathrm{mg} / \mathrm{l}$. Este aumento es debido también a las altas concentraciones que presenta el río Verde. Todo esto hace que este tramo sea uno de los más conflictivos de todo el río desde su nacimiento. Como consecuencia de la subida del contenido de materia orgánica el oxígeno disuelto sufre una bajada muy importante, con valores al final del tramo de 1 ó $2 \mathrm{mg} / \mathrm{l}$ siendo pocos valores superiores a $6 \mathrm{mg} / \mathrm{l}$.

Como se muestra en los perfiles longitudinales las concentraciones, tanto para $\mathrm{DBO}_{5}$ como para oxígeno disuelto, son muy diferentes en las épocas de sueltas y en las de caudales bajos sobre todo por el efecto de dilución de los caudales.

DBO5

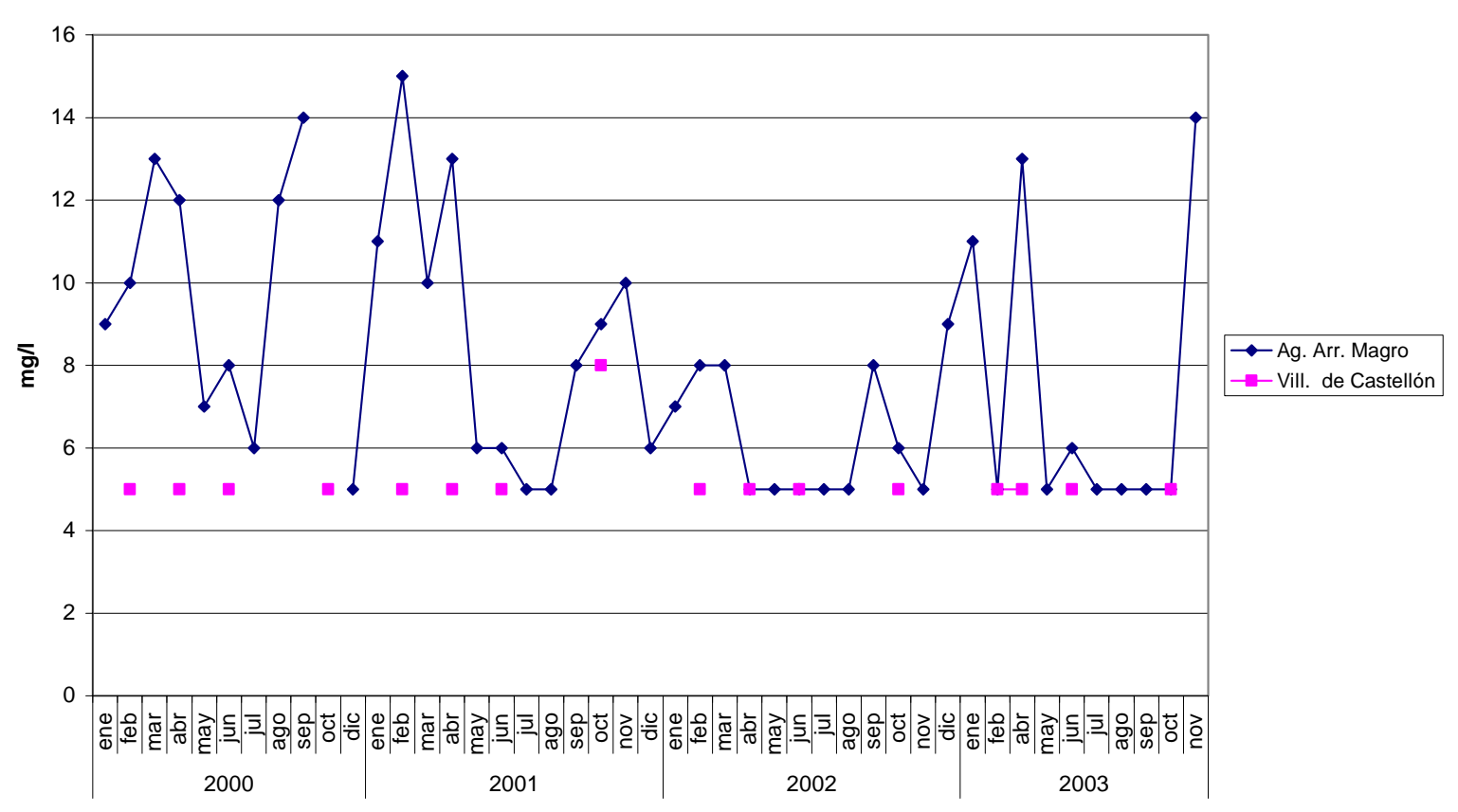

Figura 60. Concentraciones de DBO5 en las estaciones de Villanueva de Castellón y aguas arriba del Magro 
Oxígeno Disuelto

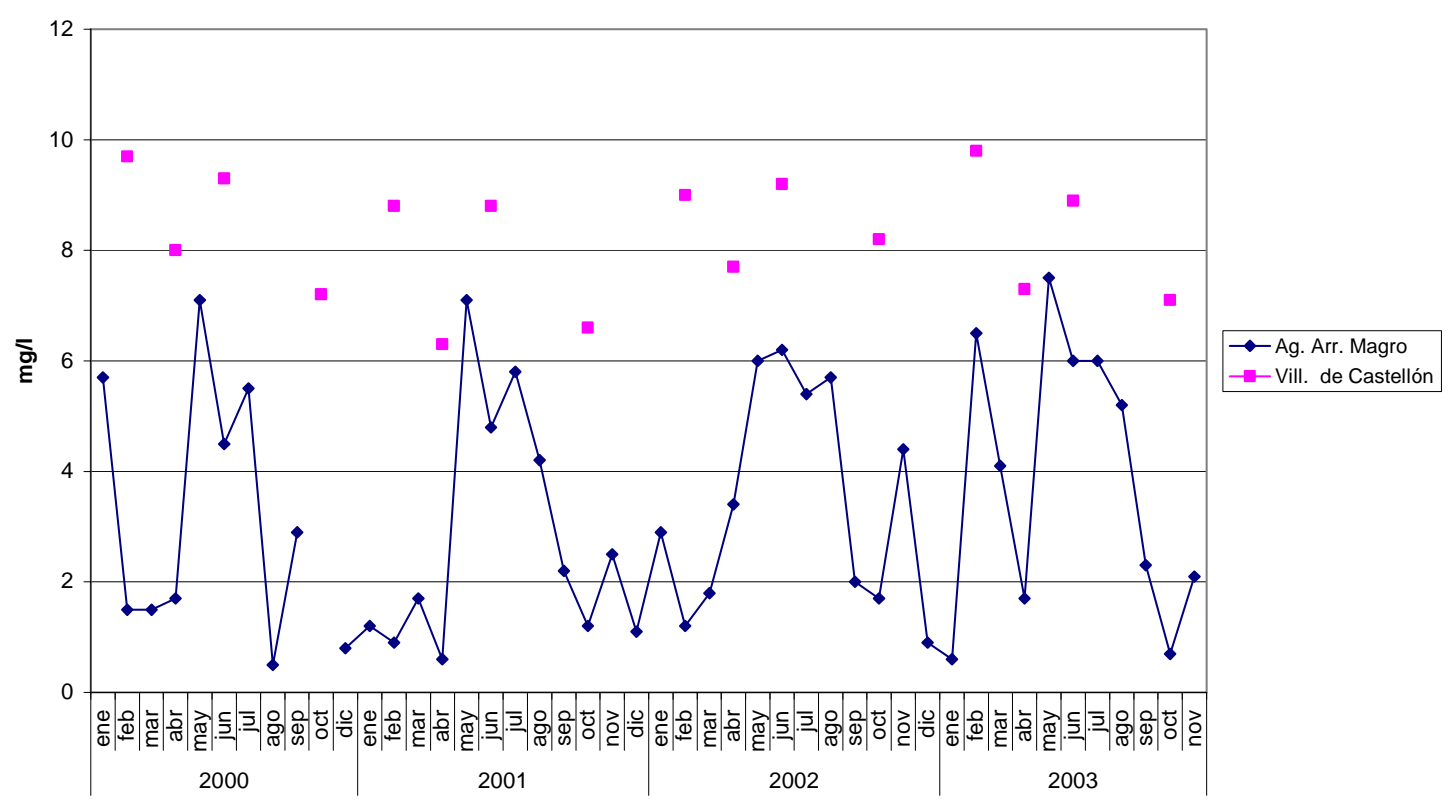

Figura 61. Concentraciones de OD en las estaciones de Villanueva de Castellón y aguas arriba del Magro

Las siguientes figuras presentan las concentraciones de $\mathrm{DBO}_{5}$ y $\mathrm{OD}$ del río Verde. Los afluentes Sellent y Albaida presentan en sus estaciones de calidad finales valores de $\mathrm{DBO}_{5}$ iguales al umbral de medición y de oxígeno disuelto normales. Por su parte el río Magro no presenta valores suficientes para su caracterización.

DBO5 y Oxígeno Disuelto

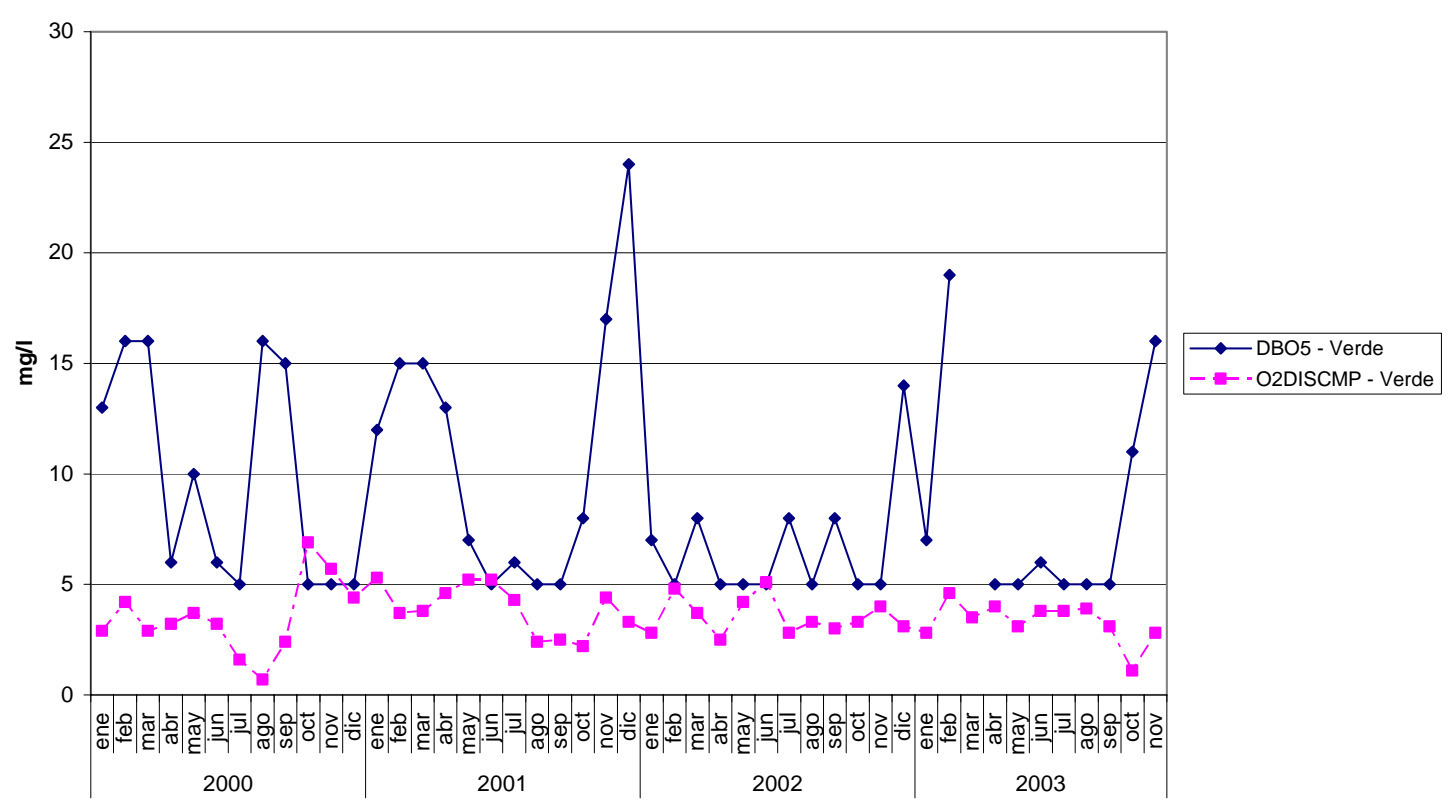

Figura 62. Concentraciones de OD y DBO5 en la estación ICA final del río Verde. 
Las dos últimas estaciones del río que presentan datos de forma continua, son la estación "Aguas arriba del Magro" y "Cullera" situada en el azud de la Marquesa, justo aguas arriba del tramo de río en donde se mezcla el agua del mar con la del río. Aunque la distancia entre ambas estaciones es coherente con la densidad de estaciones, en toda la cuenca con dos estaciones no es suficiente caracterizar la calidad del agua en este tramo final del río. En el río Júcar entre su confluencia con el Magro y la desembocadura existen diferentes afecciones sobre el río que modifican la calidad del mismo. Entre las más importantes se puede remarcar: las detracciones de las acequias de la ribera baja, los azudes en el mismo, vertidos urbanos e industriales y los retornos de riego. Todas estas afecciones modifican la calidad del agua en el tramo y no puede ser caracterizada sólo con dos estaciones. Para solventar este problema se han utilizado los datos obtenidos del Laboratorio de Comisaría de la $\mathrm{CHJ}$ de un estudio reciente específico para esa zona. Aunque dichos datos han sido de gran ayuda a la hora de caracterizar la calidad del tramo son muy pocos los datos disponibles y hay que tomar con cierta precaución todo lo que se deduzca de los mismos.

En el siguiente gráfico se muestra las medidas de oxígeno disuelto realizadas por el laboratorio de la $\mathrm{CHJ}$ para las estaciones entre la confluencia con el río Magro y el azud de la Marquesa.

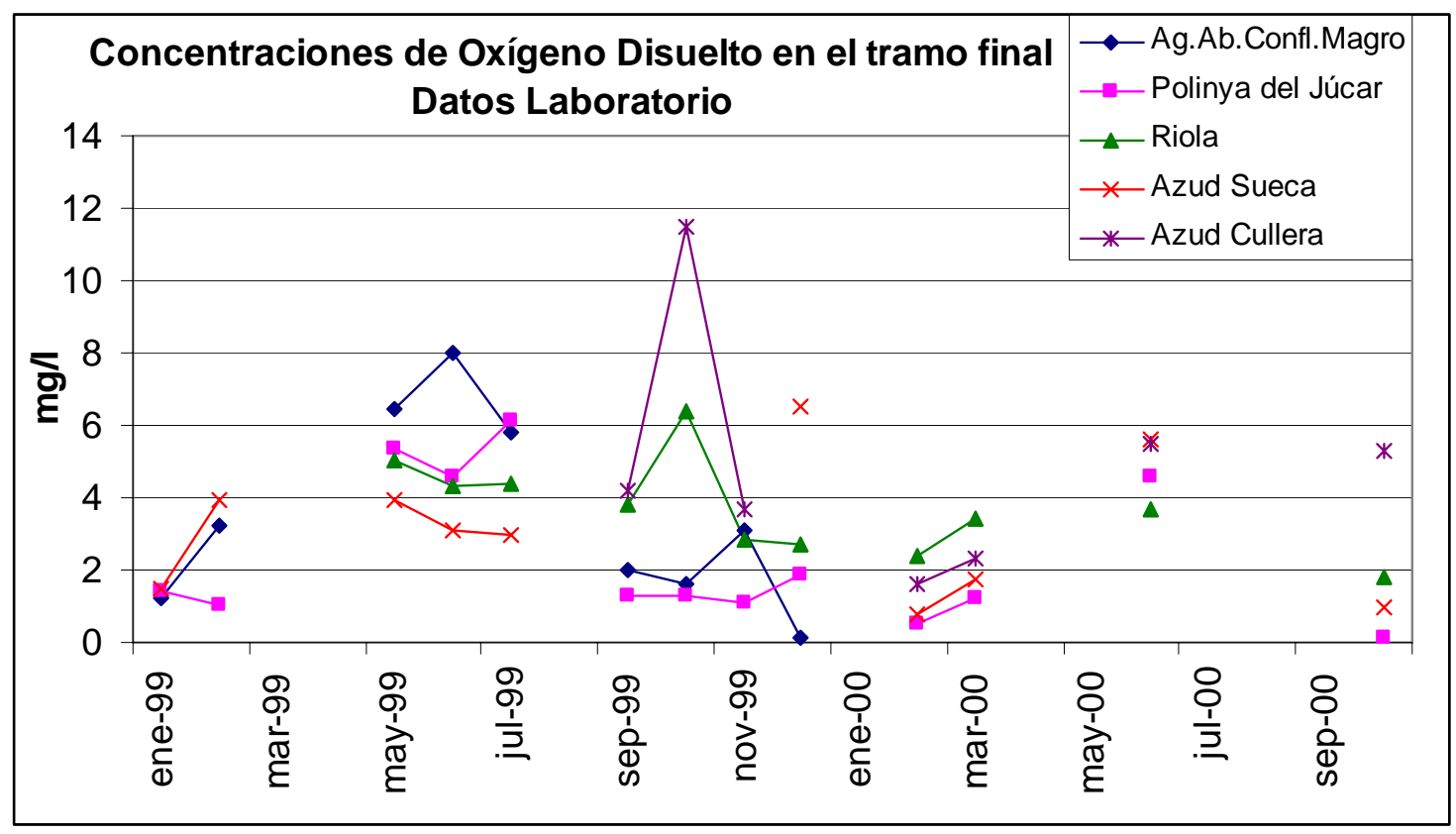

Figura 63. Concentraciones de OD en la estaciones de laboratorio en el tramo final del Júcar.

El gráfico muestra cierta concordancia entre todos los puntos de muestreo con concentraciones casi siempre inferiores $6 \mathrm{mg} / \mathrm{l}$. Las concentraciones de oxígeno disuelto inferiores a $2 \mathrm{mg} / \mathrm{l}$ se siguen siendo frecuentes en todo este tramo. 
Finalmente, si se comparan los datos de las dos últimas estaciones ICA, ag. Arr. Magro y Azud Marquesa, se puede ver como en el azud de la Marquesa se está dando un proceso de eutrofización. El oxígeno disuelto presenta concentraciones muy altas en los meses de verano con tantos por ciento de saturación medios superiores al 120\%. Este proceso de eutrofización es normal en esta zona debido a que el agua esta bastante estancada, las temperaturas son muy altas y las concentraciones de nutrientes son muy elevadas ya que gran parte del agua procede de los retornos agrícolas de la ribera.

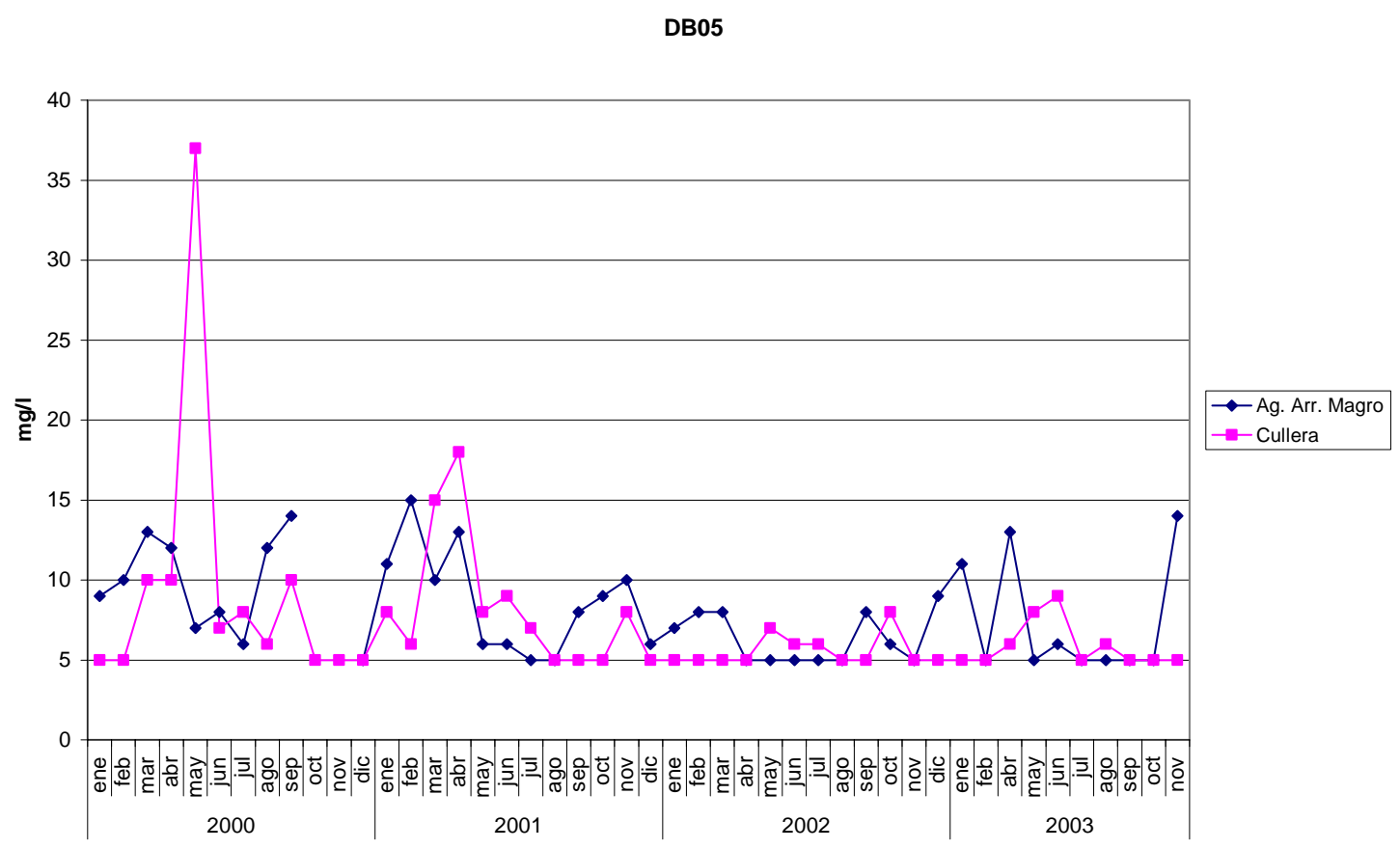

Figura 64. Concentraciones de DBO5 en las estaciones ICA Ag. Arr. Magro y Cullera. 


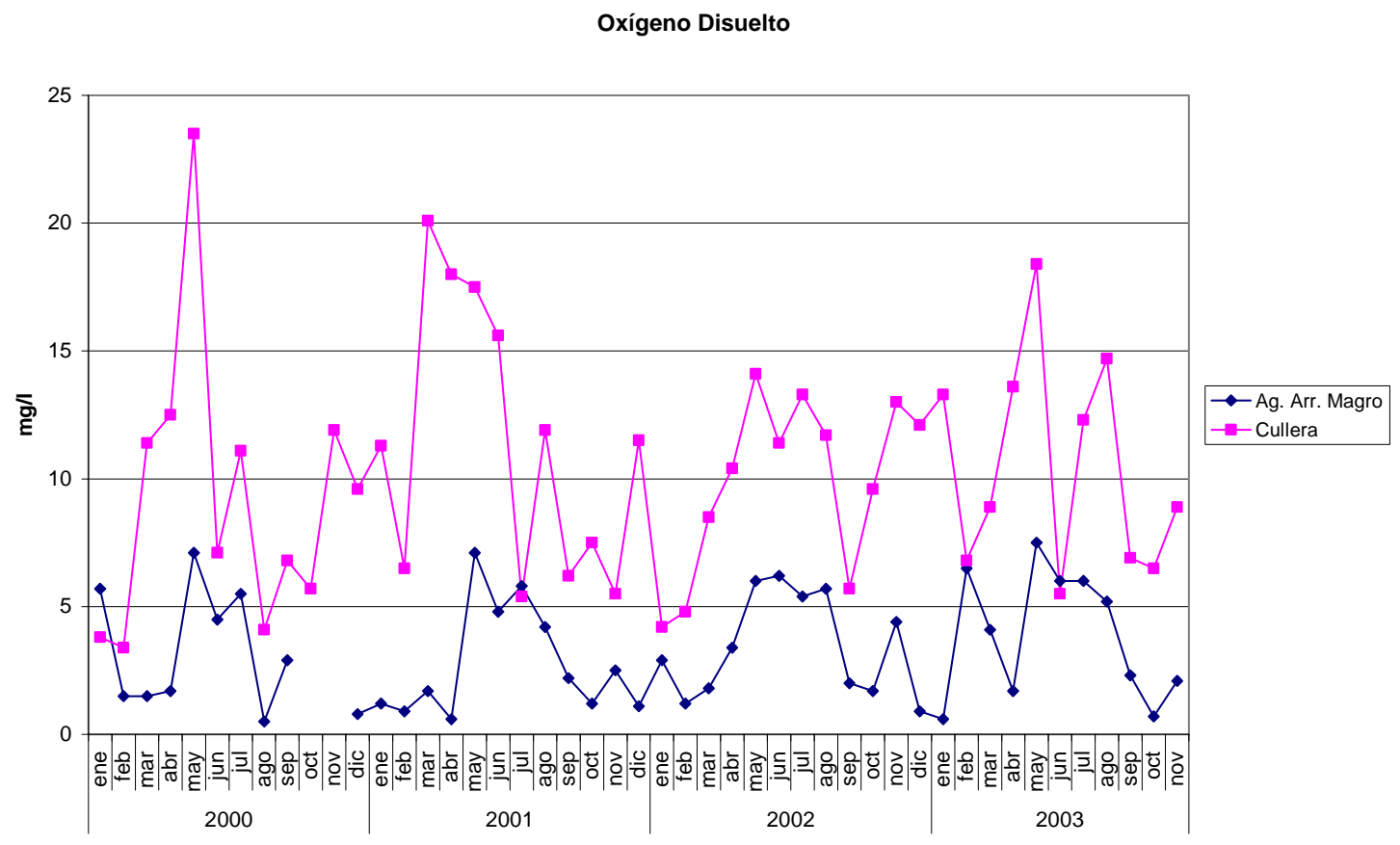

Figura 65. Concentraciones deOD en las estaciones ICA Ag. Arr. Magro y Cullera.

\subsubsection{Análisis del oxígeno disuelto y la materia orgánica en el río}

\section{Cabriel.}

El perfil longitudinal de las concentraciones medias de $\mathrm{DBO}_{5}$ y oxígeno disuelto para las estaciones de calidad del río Cabriel presentan valores de aguas naturales. El contenido de materia orgánica es igual, en todos los casos, al umbral de medición $(2 \mathrm{mg} / \mathrm{l})$ mientras que el oxígeno disuelto, en torno a los $10 \mathrm{mg} / \mathrm{l}$, es propio de aguas naturales no contaminadas. 
Río Cabriel. DBO5 y Oxígeno Disuelto

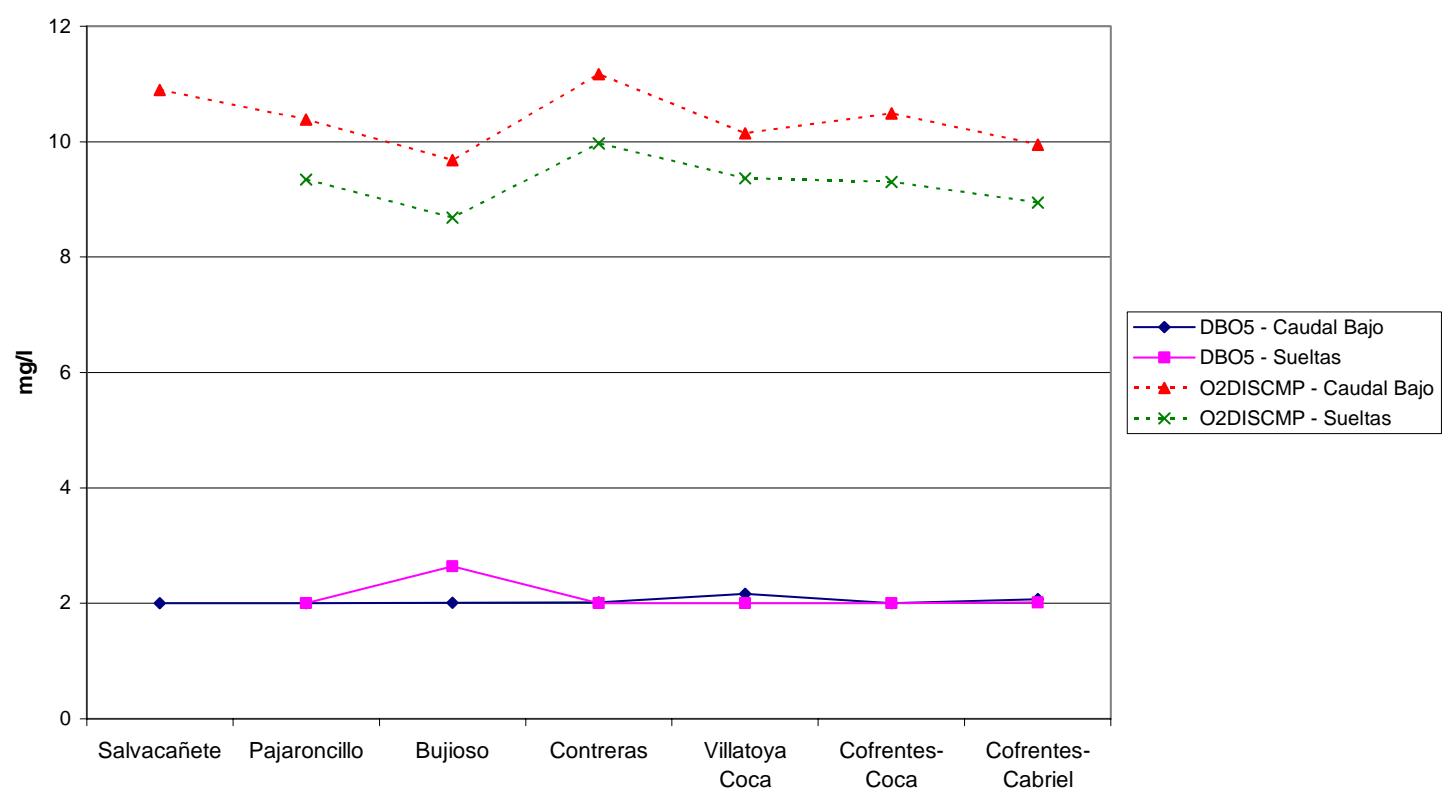

Figura 66. Perfiles medios de las concentraciones de OD y DBO5 del río Cabriel.

Río Cabriel. Saturación Oxígeno Disuelto

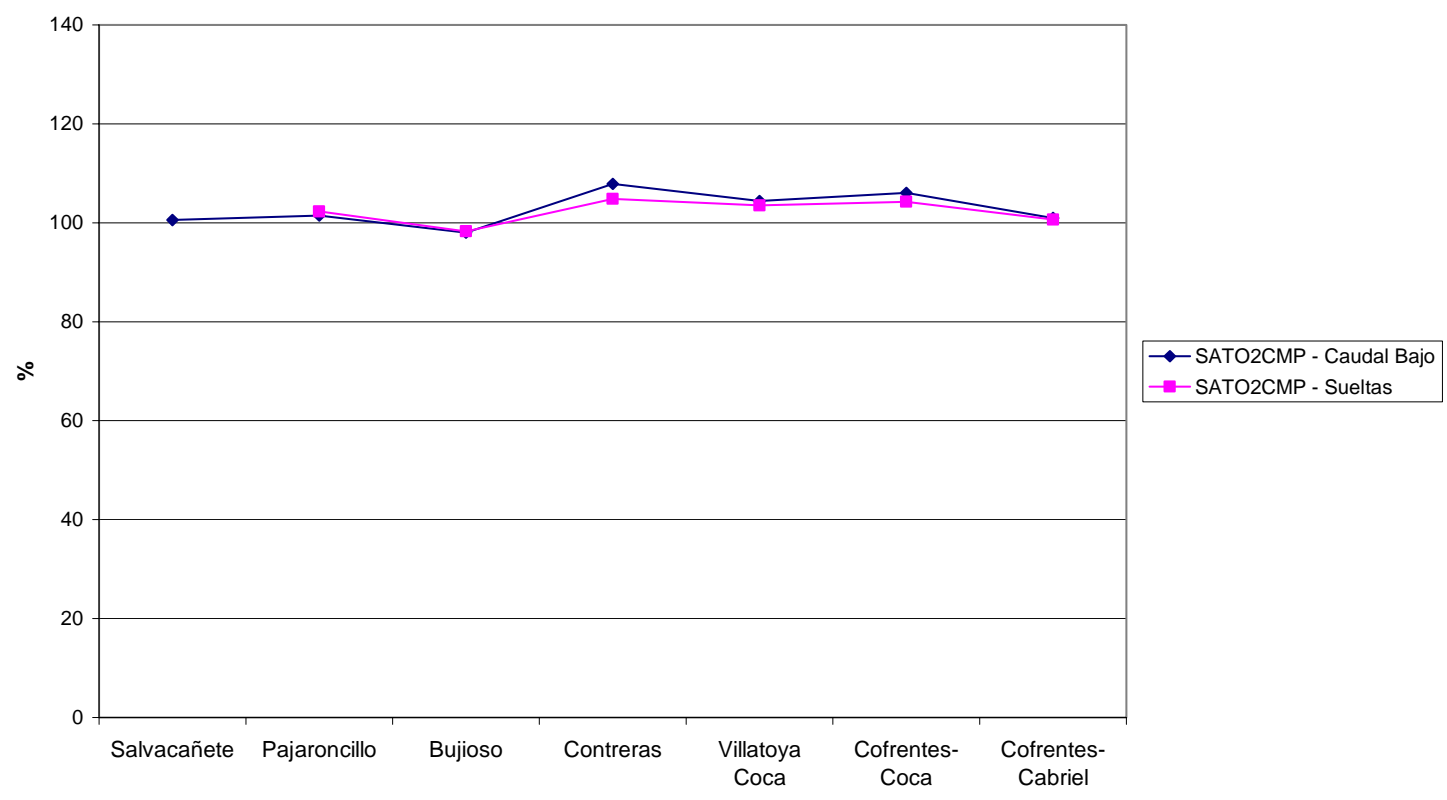

Figura 67. Perfiles medios de la saturación del OD del río Cabriel.

Todo esto es indicativo tanto de la baja presión antropogénica en materia de vertidos sobre el río Cabriel así como de la capacidad de autodepuración del mismo. 


\subsubsection{Nitrógeno.}

El nitrógeno es un nutriente fundamental para los seres vivos. La disponibilidad de nitrógeno en el medio ambiente es muy grande. En volumen casi el $80 \%$ de la atmósfera esta formada por nitrógeno gas $\left(\mathrm{N}_{2}\right)$. Sin embargo el nitrógeno como gas debe ser convertido a formas asimilables, como el amonio $\left(\mathrm{NH}_{4}{ }^{+}\right)$o los nitratos $\left(\mathrm{NO}_{3}{ }^{-}\right)$para la mayoría de los organismos vivos. Esta transformación entra dentro de llamado ciclo del nitrógeno. En los sistemas acuáticos el nitrógeno puede darse en diversas formas: Nitrógeno gas $\left(\mathrm{N}_{2}\right)$, Amonio $\left(\mathrm{NH}_{4}{ }^{+}\right.$y NH3), nitritos $\left(\mathrm{NO}_{2}{ }^{-}\right)$, nitratos $\left(\mathrm{NO}_{3}{ }^{-}\right)$y nitrógeno orgánico en forma particulada o disuelta. En este estudio de la cuenca del río Júcar se han analizado las concentraciones de amonio, nitritos y nitratos ya que no se dispone de medidas de nitrógeno orgánico.

\subsubsection{Amonio.}

El amonio en el agua natural procede del arrastre de la escorrentía de nitrógeno orgánico e inorgánico, excreciones de la biota, de la reducción de nitrógeno gas por microorganismos y del intercambio de gas con la atmósfera. Las fuentes no naturales que aportan amonio al medio acuático son los vertidos urbanos e industriales. El amonio puede presentarse como $\mathrm{NH}_{4}{ }^{+} \mathrm{o}$ en su forma no ionizada $\mathrm{NH}_{3}$ la cual puede ser tóxica para los organismos acuáticos. El equilibrio entre los das formas de amonio viene marcado por el $\mathrm{pH}$, la temperatura, la concentración de oxígeno disuelto, salinidad, dióxido de carbono y compuestos tóxicos, siendo los dos primeros los más influyentes. La toxicidad del $\mathrm{NH}_{3}$ tiene especial importancia sobre las comunidades de peces mientras que los invertebrados y plantas acuáticas tienen una mayor tolerancia. Aguas naturales, no contaminadas, tienen concentraciones muy bajas de amonio, generalmente inferiores a $0.1-0.2 \mathrm{mg} / \mathrm{l}$. Concentraciones superiores puede ser indicativo de contaminación antropogénica.

\subsection{Análisis del amonio en el río Júcar.}

Al igual que la mayoría de constituyentes, si se analizan las concentraciones de amonio el río Júcar puede dividir en dos zonas. La primera hasta el embalse de Tous en donde las concentraciones son bastante bajas y del mismo orden de magnitud. Por el contrario la zona de la ribera presenta concentraciones superiores y con una marcada diferencia entre las épocas de caudales bajos y de sueltas. El siguiente gráfico muestra el perfil longitudinal de los valores medios de las concentraciones de amonio. 


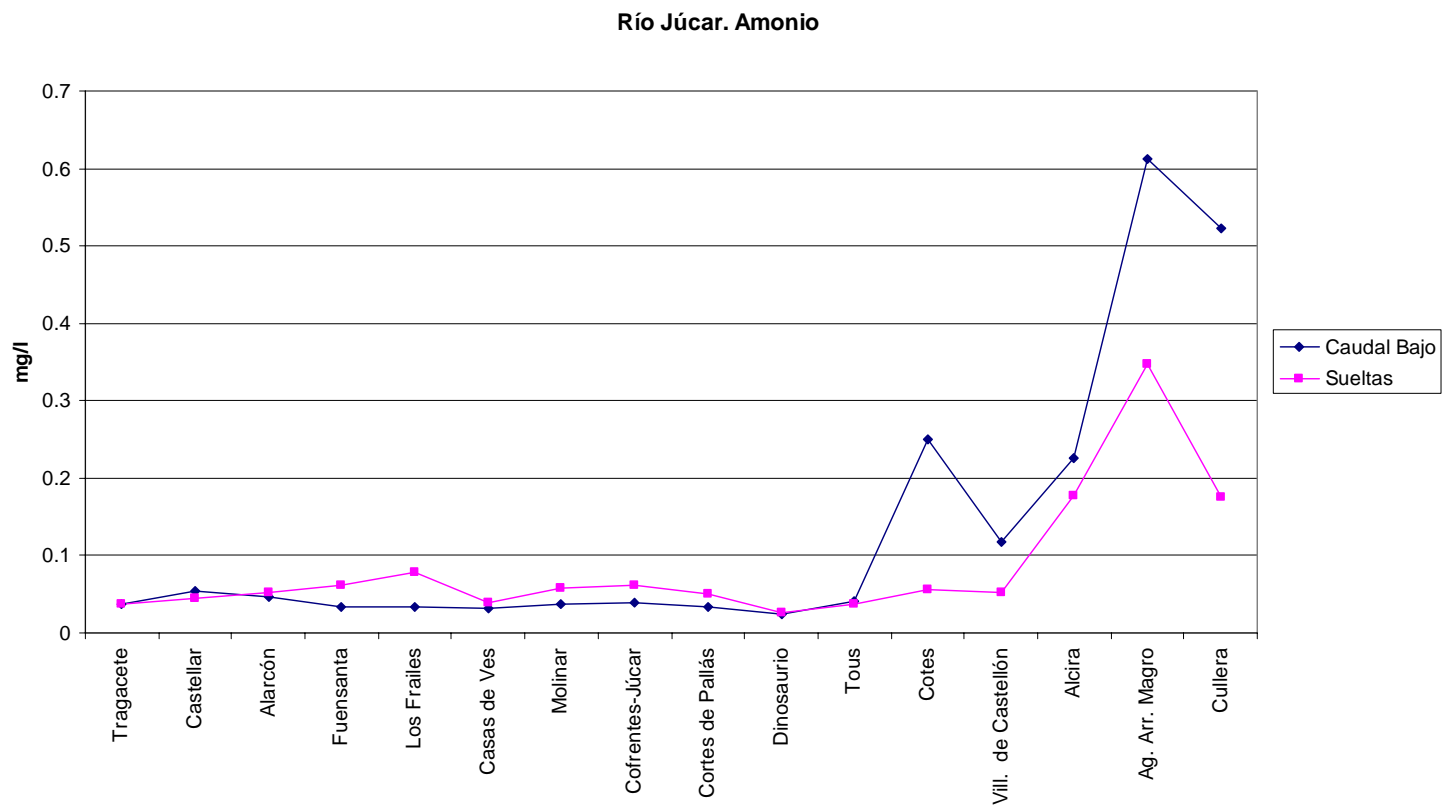

Figura 68. Perfiles medios de concentraciones de amonio del río Júcar

En la siguiente figura se realiza un reescalado del gráfico anterior para poder analizar con mayor detenimiento la zona de aguas arriba.

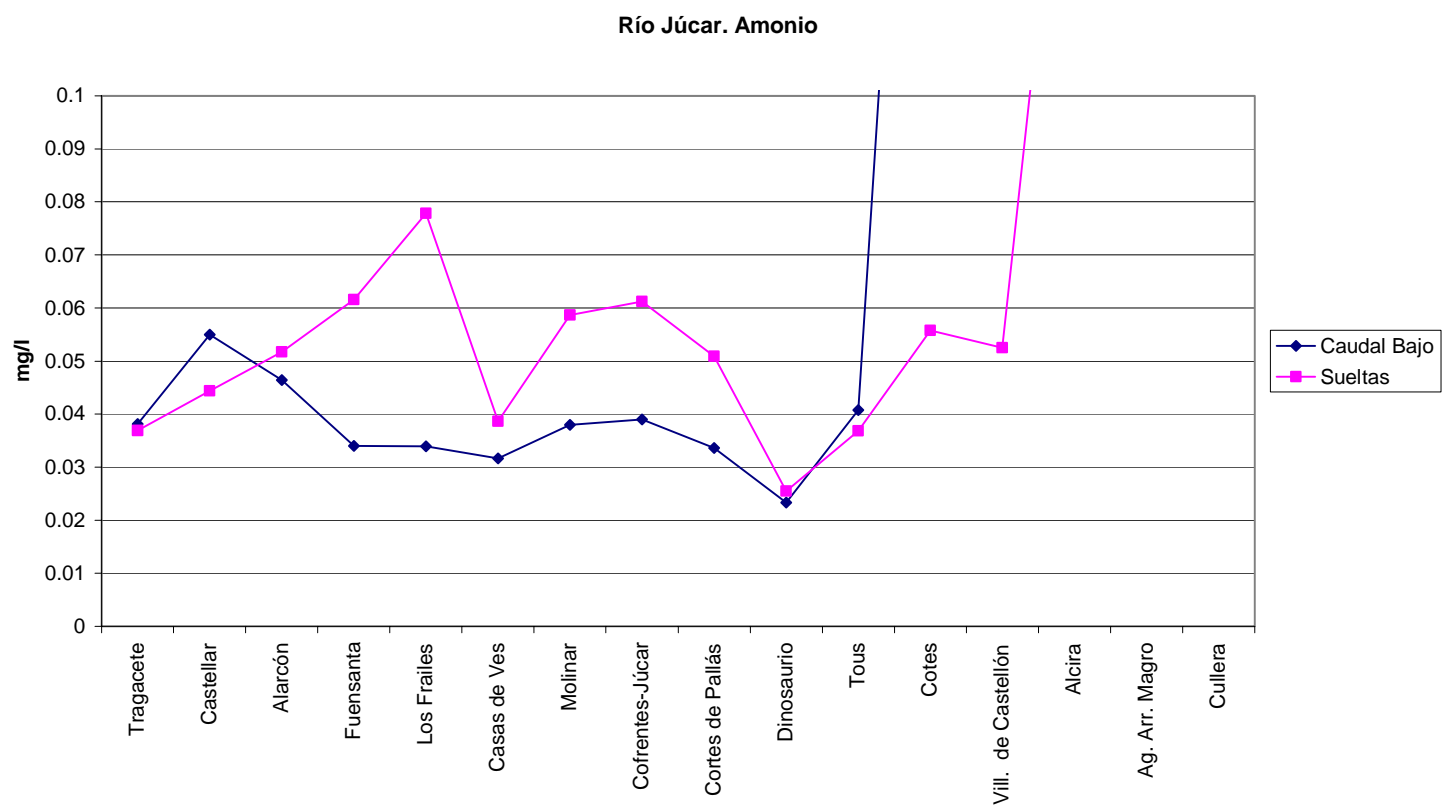

Figura 69. Reescalado del Perfiles medios de amonio en el río Júcar aguas arriba del embalse de Tous.

El gráfico reescalado muestra que en las épocas de sueltas las concentraciones son superiores en la zona aguas abajo de Alarcón. En esta zona existe bastante concordancia entre las concentraciones de sólidos suspendidos y las de amonio en cuanto a su evolución temporal se refiere. 
Por otra parte la disponibilidad de datos, como pasa también con otros constituyentes, es mucho mayor en las estaciones de la parte media y alta del río que en la zona de la ribera. Como se verá a continuación las estaciones aguas abajo de Tous presentan frecuencias de muestreo inferiores al resto.

En la siguiente figura se muestra los valores medidos para las estaciones de Tragacete, Castellar y Alarcón. No parece que exista un incremento de concentraciones entre las estaciones así como tampoco se puede establecer ningún efecto del embalse sobre los mismos. Esto, que se repite en la mayoría de las estaciones de aguas arriba del embalse de Tous, se debe a que las concentraciones de amonio son bastante bajas en toda esa parte de la cuenca.

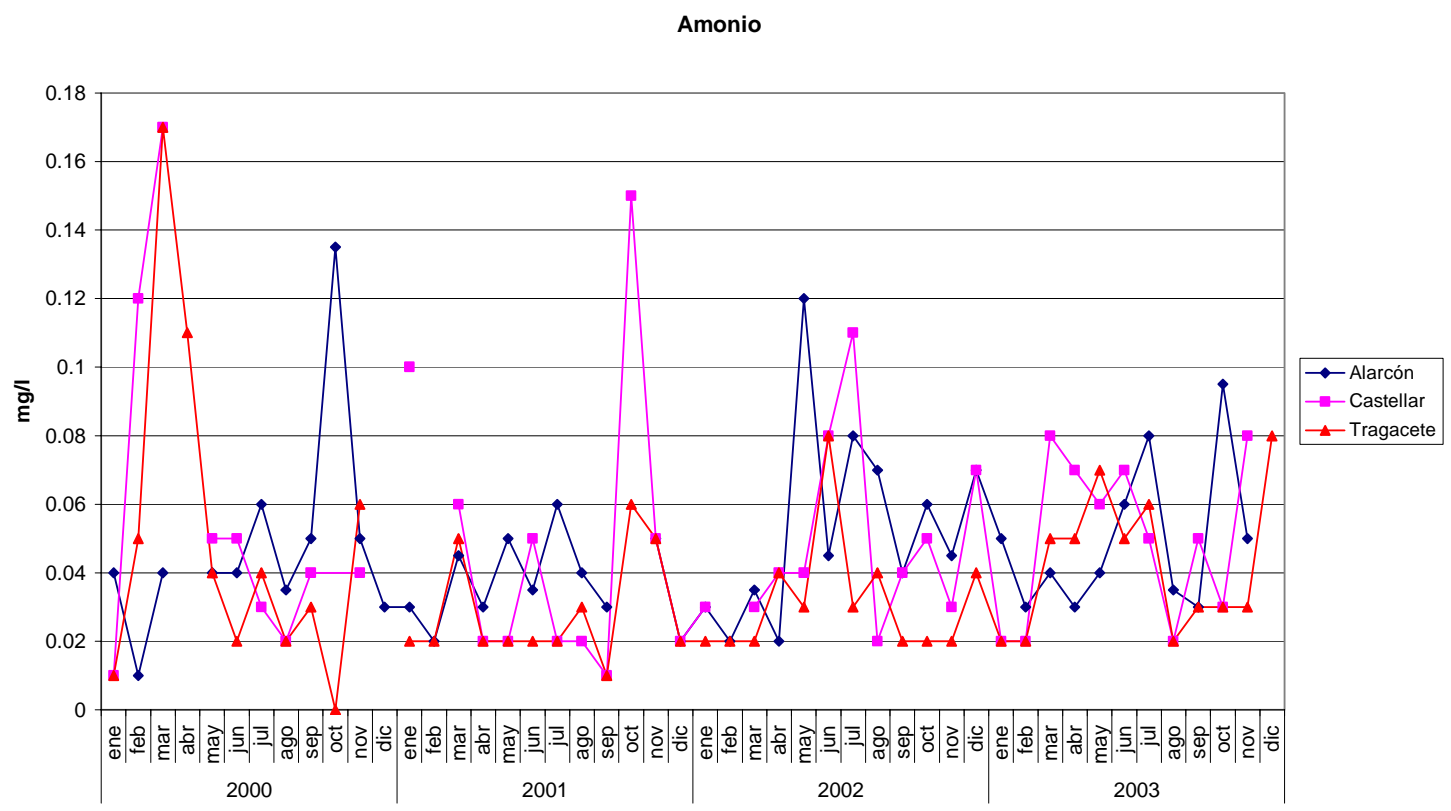

Figura 70. Concentraciones de amonio medidas en las estaciones de Alarcón Castellar y Tragacete.

En la siguiente figura se muestra los datos disponibles para las cuatro estaciones de calidad situadas más aguas abajo. El gráfico muestra como la frecuencia de muestreo es muy baja, en algunas estaciones incluso inferior al trimestre. 
Amonio

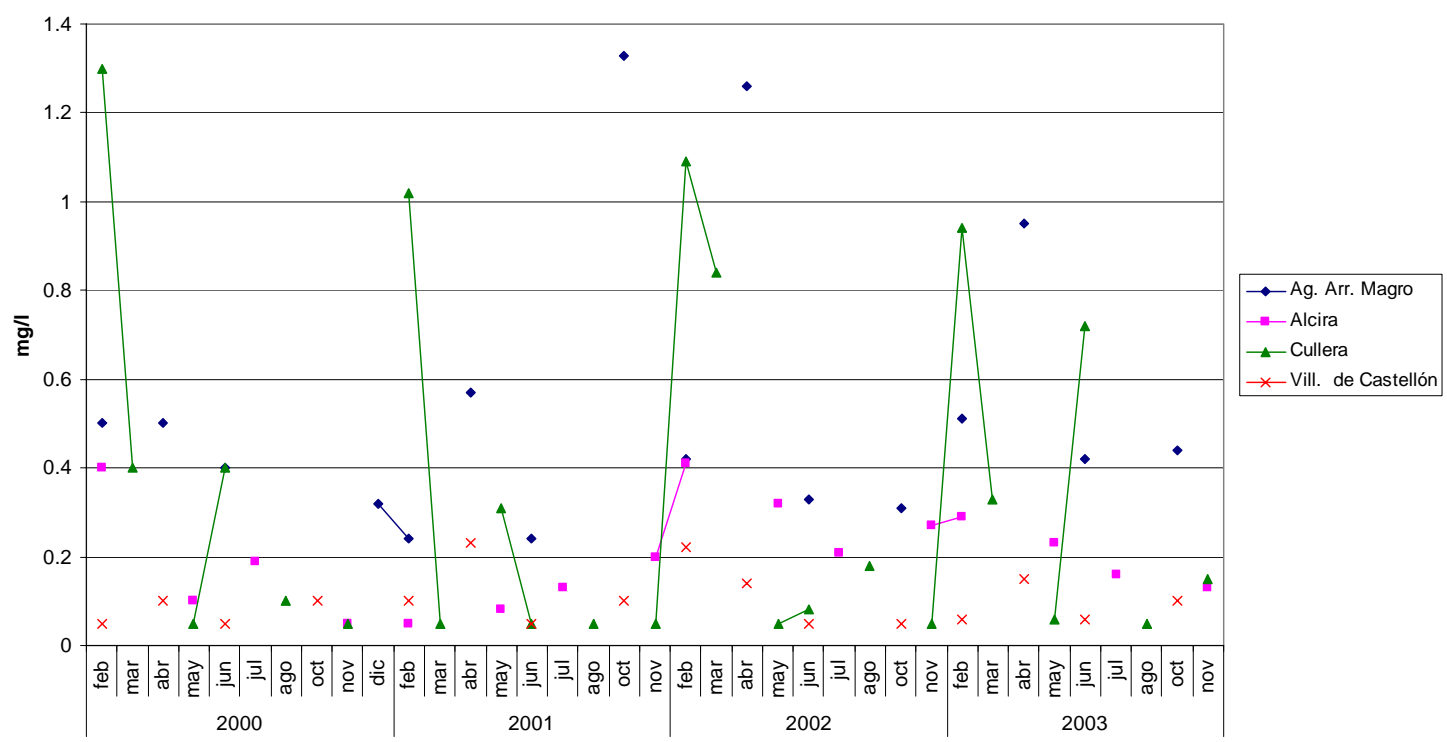

Figura 71. Concentraciones de amonio medidas en las estaciones finales del río Júcar

Aún con la baja disponibilidad de datos el gráfico refleja las altas concentraciones en las estaciones de calidad de Cullera y Ag. Arr. Magro con medias de 0.35 y $0.54 \mathrm{mg} / \mathrm{l}$, respectivamente. Las estaciones de Villanueva de Castellón y Alcira aunque no presentan valores tan altos, medias de 0.1 y $0.2 \mathrm{mg} / 1$ respectivamente, reflejan la incipiente contaminación de la zona.

Para la caracterización del amonio en los afluentes inferiores del Júcar hay pocos datos disponibles. Aún así del gráfico muestra una clara diferencia entre el río Verde y los otros tres. Mientras que el Sellent, Magro y Albaida presentan valores en la mayor parte de los meses entre 0.03 y $0.1 \mathrm{mg} / 1$ que denotan cierta contaminación pero no son excesivamente elevados en el caso del Sellent los valores medidos presentan una media de $0.855 \mathrm{mg} / 1$ reflejo de la alta contaminación del río. 


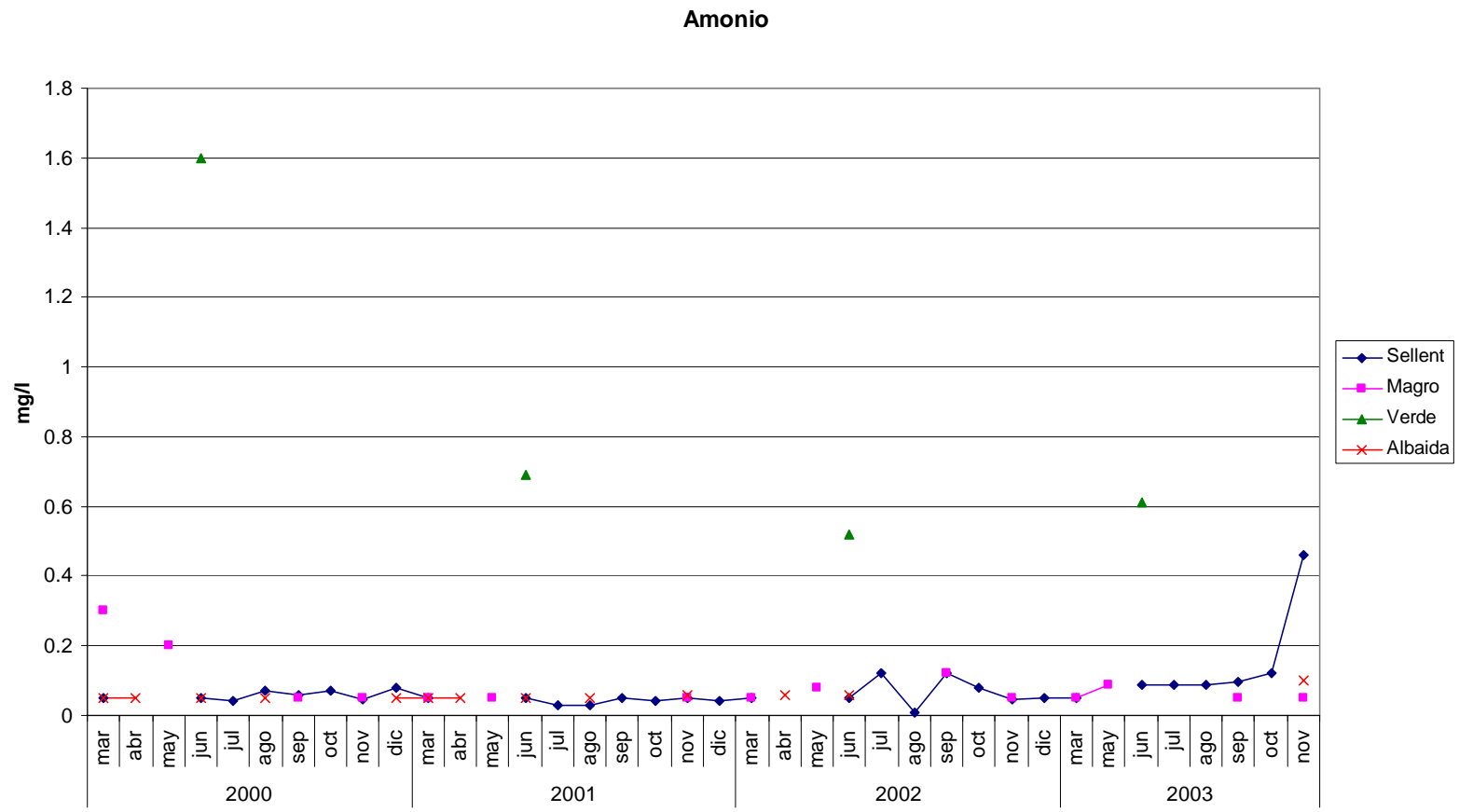

Figura 72. Concentraciones de amonio medidas en las estaciones finales de los afluentes inferiores.

\subsection{Análisis del amonio en el río Cabriel.}

Al igual que en la parte alta y media del Júcar en el río Cabriel los valores de amonio son bastante bajos con medias inferiores a $0.06 \mathrm{mg} / \mathrm{l}$.

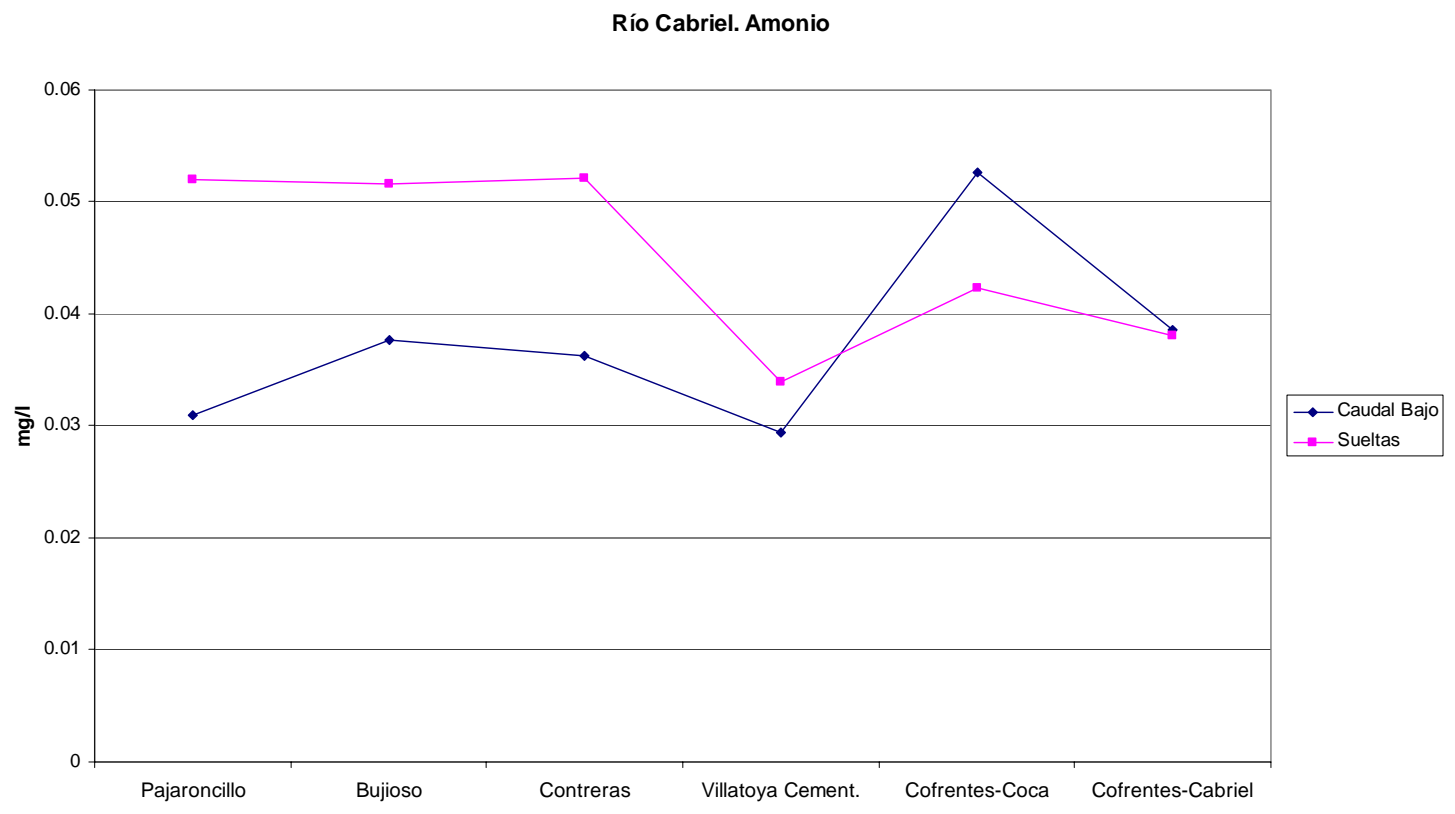

Figura 73. Perfiles medios de las concentraciones de amonio en el río Cabriel.

El gráfico del perfil longitudinal de las concentraciones de amonio presenta el mismo efecto que en el caso del Júcar en donde para la época de sueltas las 
concentraciones de amonio son, en media, superiores a las épocas de caudales bajos. Este efecto se produce hasta la estación de Villatoya.

El siguiente gráfico muestra el bajo efecto del embalse de Contreras sobre las concentraciones de amonio.

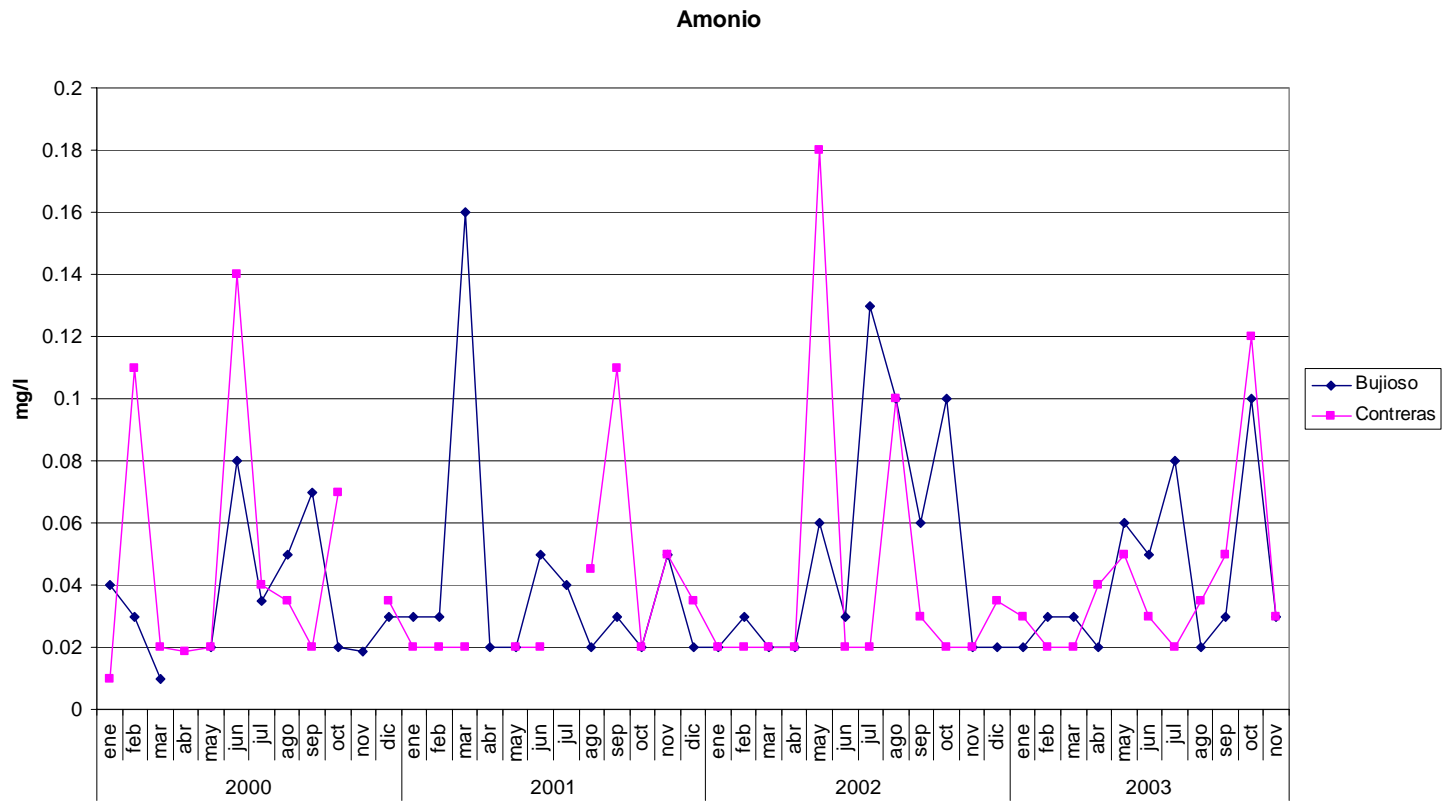

Figura 74. Concentraciones de amonio medidas en las estaciones de Bujioso y Contreras.

\subsubsection{Nitritos.}

La oxidación de nitritos a nitratos por bacterias nitrificadoras es muy rápida, por lo que se su presencia se considera como un buen indicador de concentración urbana reciente.

\subsection{Análisis de los nitritos en el río Júcar.}

A continuación se muestra el perfil longitudinal de los valores medios medidos en las estaciones elegidas a lo largo del río Júcar. La estación de Cuenca no ha sido representada por falta de datos. Como se puede observar, al igual que la mayoría de los constituyentes, en las últimas estaciones se producen los valores más elevados y en las estaciones aguas arriba de Tous la contaminación es mucho menor. 
Río Júcar. Nitritos

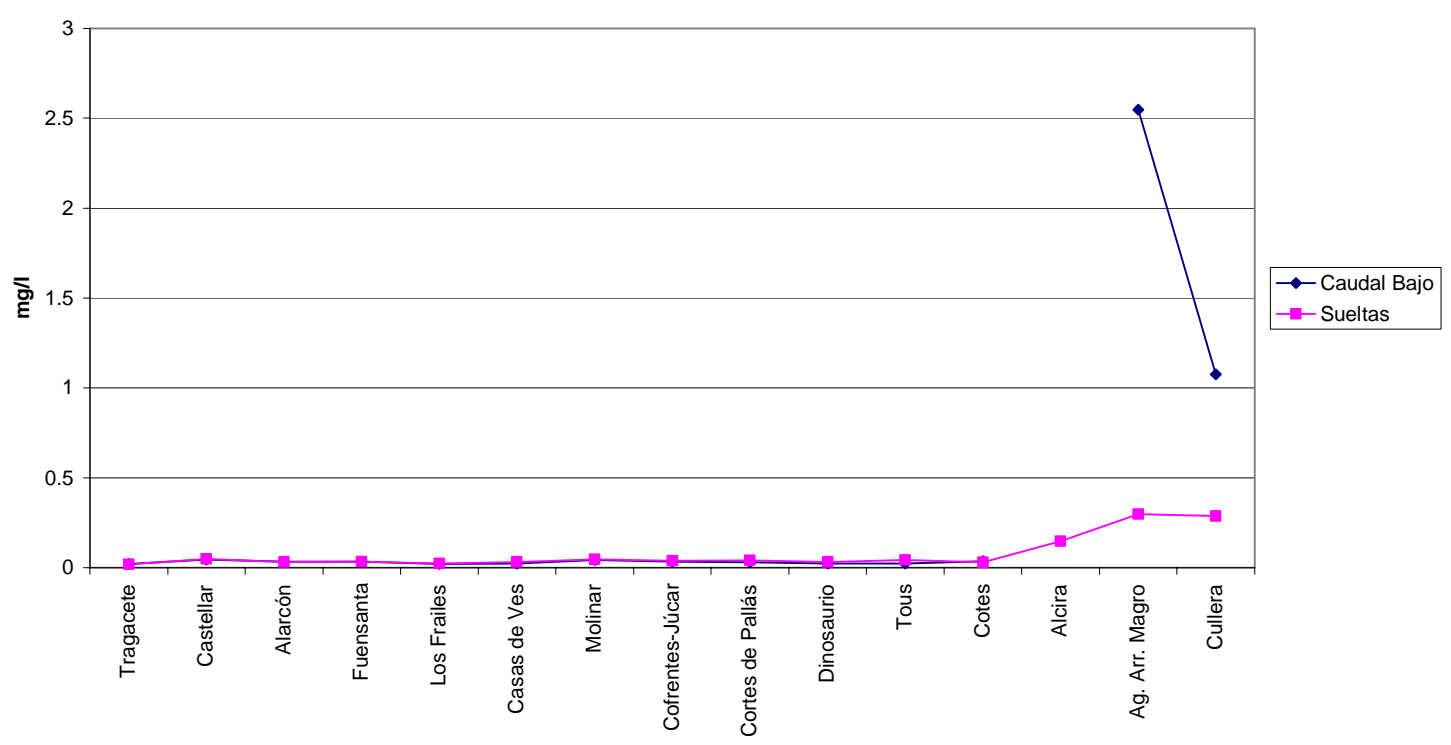

Figura 75. Perfiles medios de las concentraciones de nitritos del río Júcar.

Debido a las altas concentraciones en las dos últimas estaciones se ha realizado un reescalado para poder analizar la zona aguas arriba de Tous.

Río Júcar. Nitritos

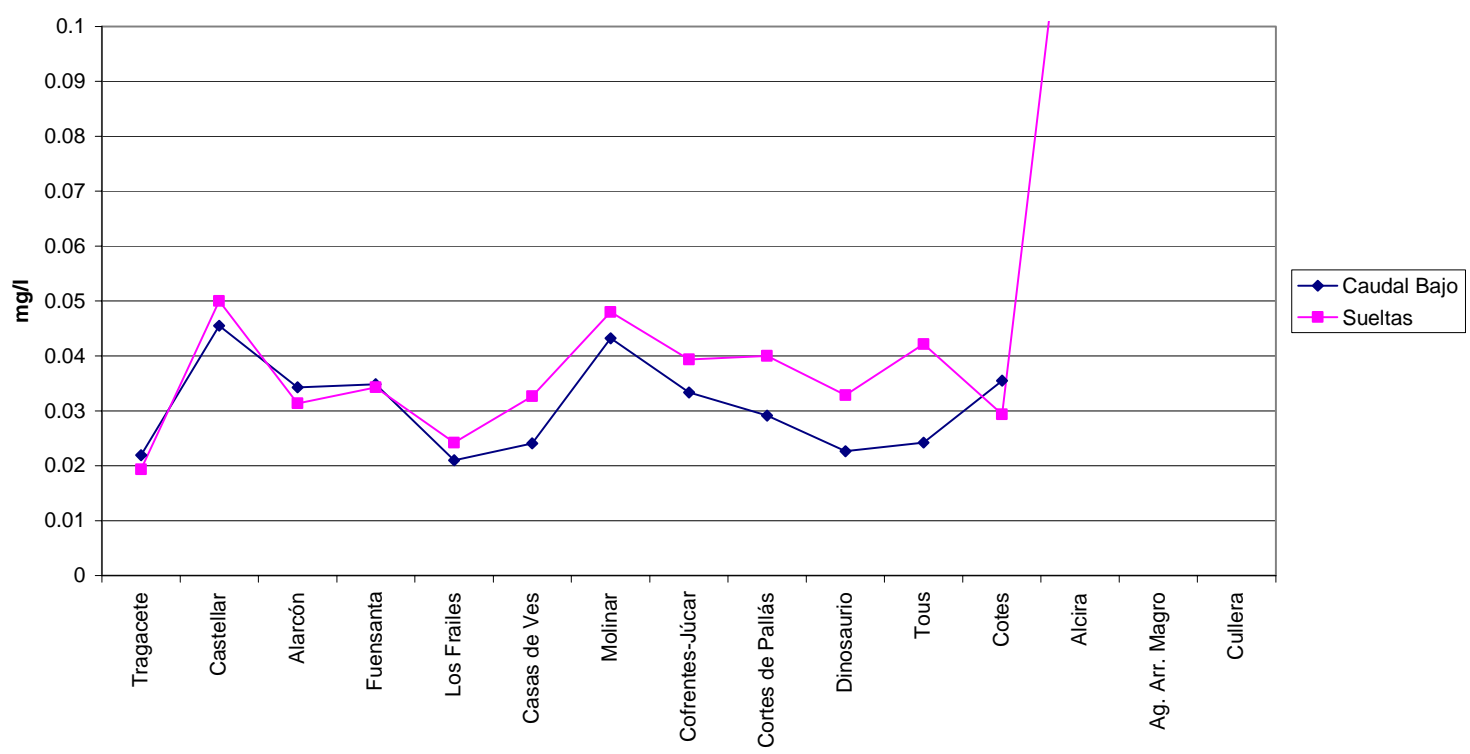

Figura 76. Reescalado de los perfiles medios de nitritos del río Júcar de la parte aguas arriba de Tous.

El gráfico muestra que los valores medios se mueven entre 0.02 y $0.05 \mathrm{mg} / \mathrm{l}$. Entre la estación de los Frailes y Tous los valores medios muestran un ligero aumento de concentraciones en la época de sueltas. 
El gráfico siguiente compara las concentraciones de nitritos entre las estaciones de aguas arriba y aguas abajo del embalse de Alarcón.

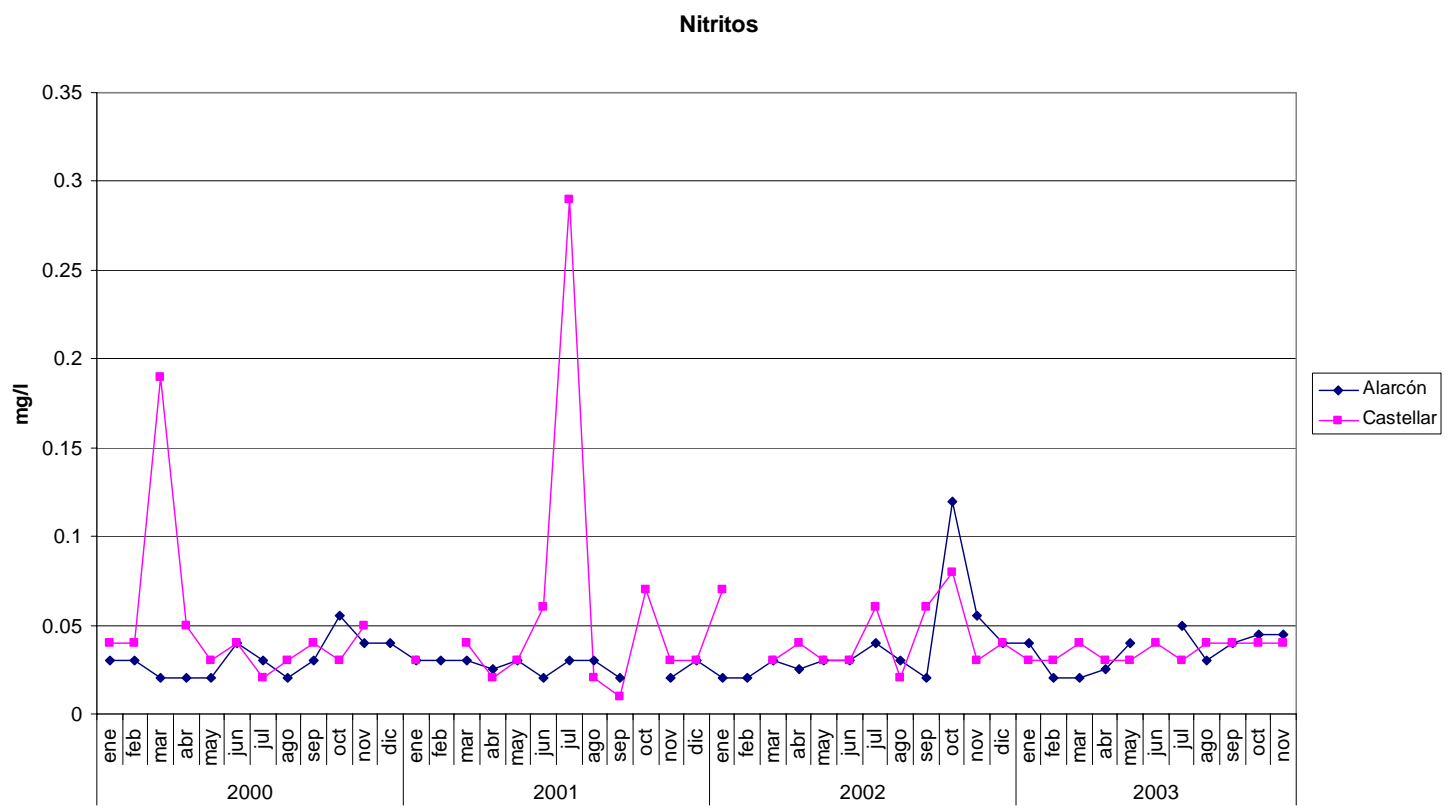

Figura 77. Concentraciones de nitritos medidas en las estaciones de Alarcón y Castellar.

Como se desprende del gráfico no se puede deducir ningún efecto claro del embalse sobre las concentraciones de nitritos. No es así en el embalse de Molinar, que como muestra el gráfico, existe un claro aumento de las concentraciones de nitritos entre las estaciones de aguas arriba (Casas de Ves) y la de aguas abajo (Molinar).

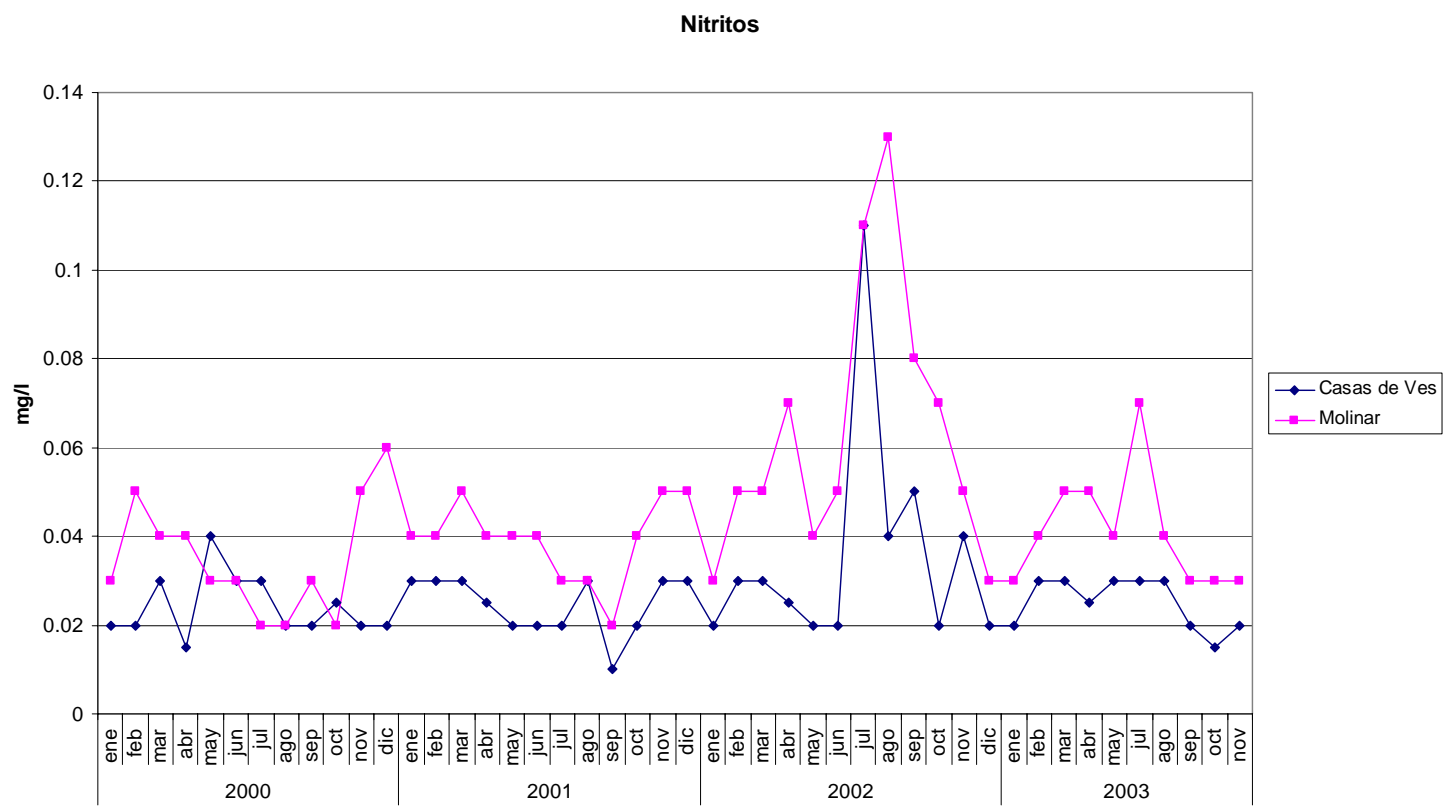

Figura 78. Concentraciones de nitritos medidas en las estaciones de Casas de Ves y Molinar.

No se tiene constancia de ningún vertido directo sobre el embalse que pueda estar influyendo de esta manera. Aunque el incremento de concentración es muy 
pequeño resulta muy marcado. Este efecto puede ser debido a que en el entorno al embalse las velocidades disminuyen y existe una oxidación de parte del amonio a nitritos. Esta oxidación del amonio no se ha detectado en el análisis del mismo debido a que este pequeño incremento en las concentraciones de nitratos supone una disminución mucho menor en las del amonio.

Analizando los datos de las estaciones de la zona de la ribera se puede ver que el comportamiento es similar al explicado para el amonio. La estación de Villanueva de Castellón presenta concentraciones de amonio indicativas de cierta contaminación. Estas concentraciones aumentan en la estación de Alcira con máximos de $0.4 \mathrm{mg} / \mathrm{l}$. Las concentraciones de Ag. Arr. Magro y Cullera presentan valores muy altos con máximos para ambas estaciones en torno a $1.3 \mathrm{mg} / \mathrm{l}$.

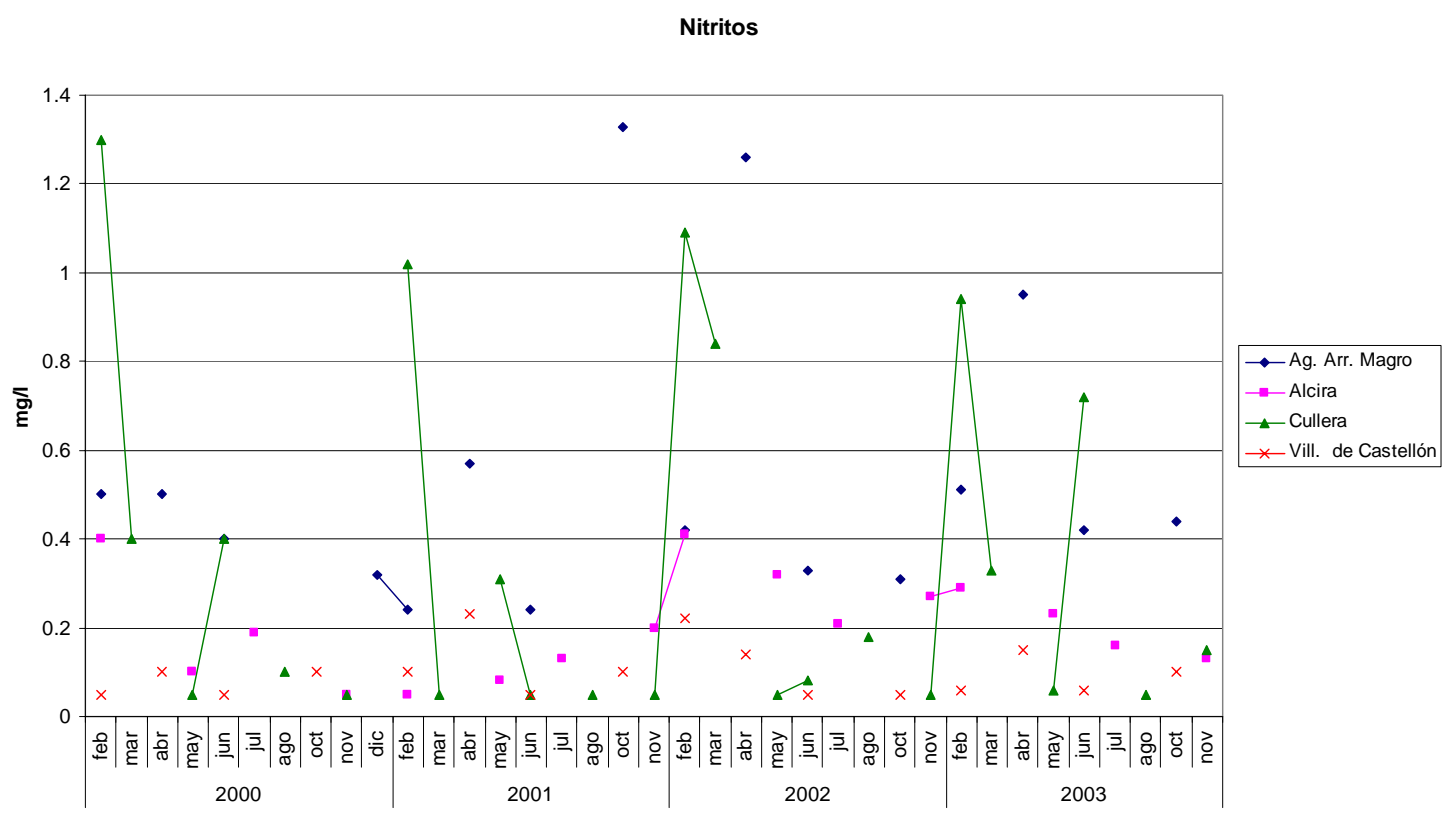

Figura 79. . Concentraciones de nitritos medidas en las estaciones finales del río Júcar.

La frecuencia de muestreo en todas las estaciones es bastante baja. Además la alternancia mensual dificulta posteriormente la modelación del constituyente.

El gráfico de las concentraciones medidas en las estaciones finales de los afluentes inferiores refleja, al igual que en el amonio, la marcada contaminación del río Verde frente al resto. No se ha graficado los valores del río Magro al no haber mediciones en dicha estación. 


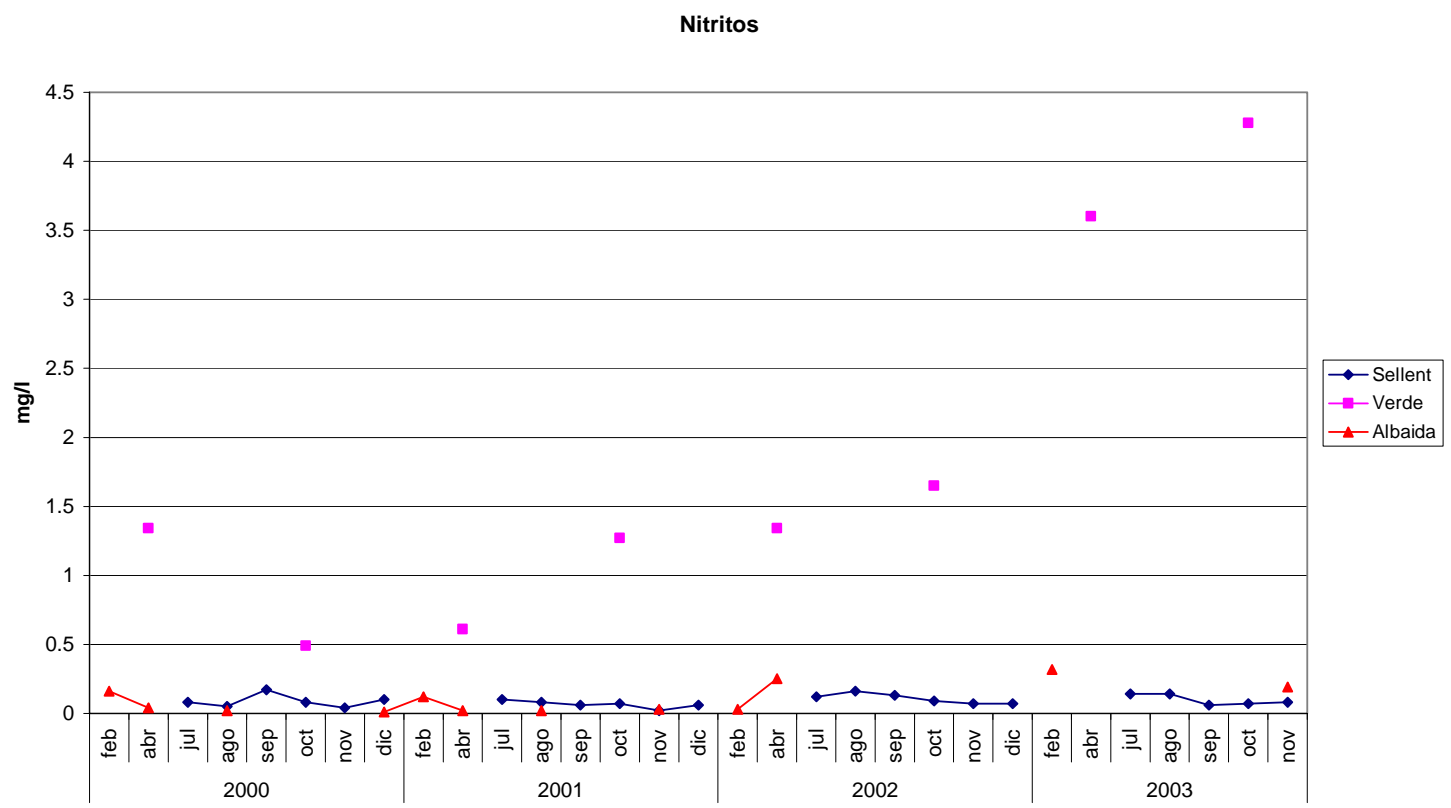

Figura 80. Concentraciones de nitritos medidas en las estaciones finales de los afluentes inferiores.

\subsection{Análisis de los nitritos en el río Cabriel.}

En el río Cabriel las concentraciones de nitritos en todas las estaciones son muy bajas. El gráfico del perfil de las concentraciones medias muestra valores medios en la mayoría de las estaciones entre 0.02 y $0.03 \mathrm{mg} / 1$. Esto refleja la baja presión antropogénica sobre la cuenca.

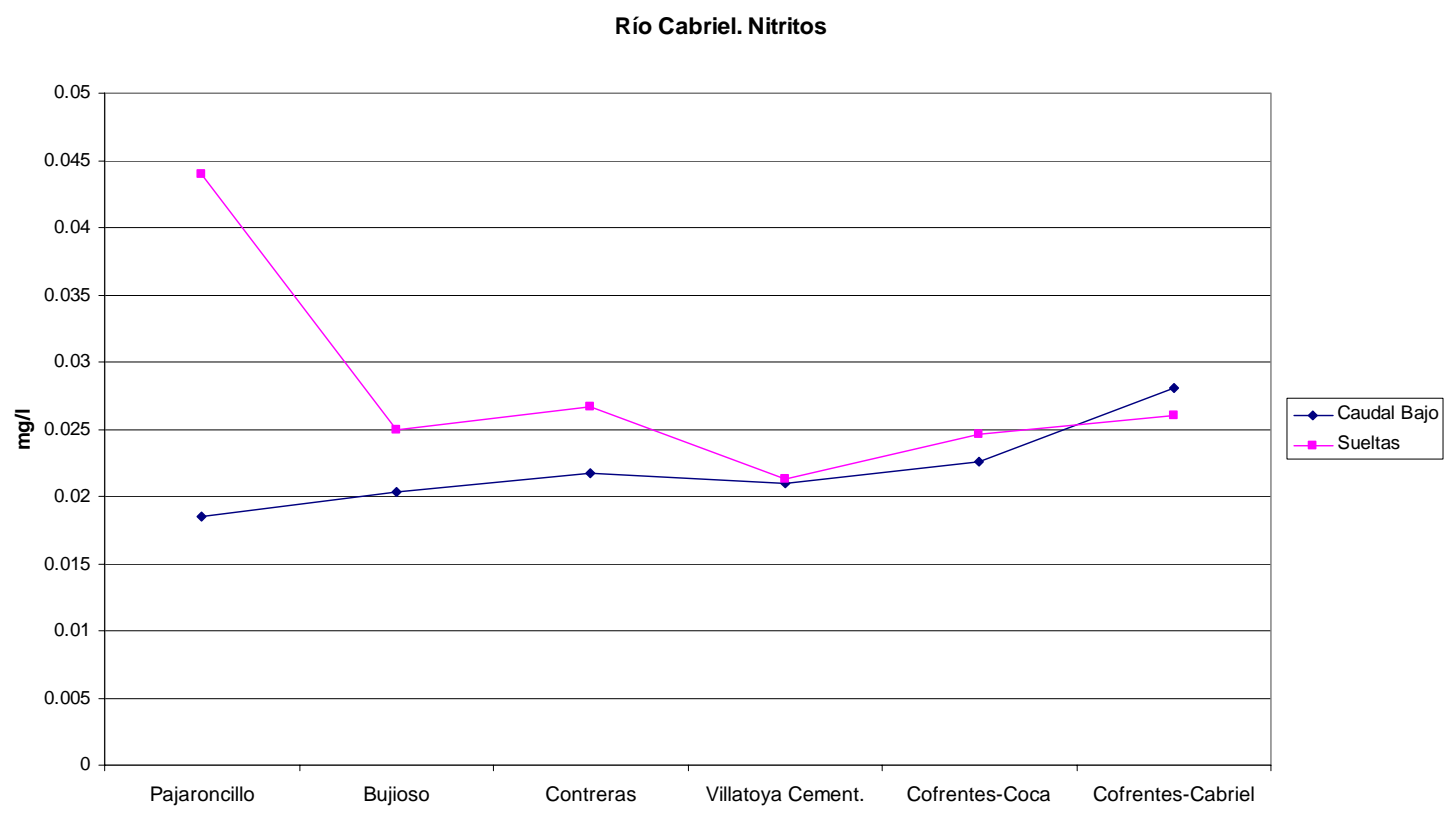

Figura 81. Perfiles medios de las concentraciones de nitritos del río Cabriel. 


\subsubsection{Nitratos.}

El ión nitrato es un nutriente esencial para la vida. Concentraciones en aguas no contaminadas no suelen exceder de los $5 \mathrm{mg} / 1$ (de $\mathrm{NO}_{3}{ }^{-}$). Altas concentraciones suelen ser indicativas de contaminación difusa de origen agrario o ganadero. La OMS recomienda un límite máximo de $50 \mathrm{mg} / 1$ para suministro humano. En lagos y embalses la disponibilidad de nitratos suele estimular el crecimiento de las algas y puede provocar, junto con otros factores, situaciones de eutrofización. En aguas subterráneas la contaminación por nitratos suele provenir de la aplicación de fertilizantes en la agricultura. Las concentraciones en las aguas subterráneas suelen alcanzar valores muy superiores a los de las superficiales.

\subsection{Análisis de los nitratos en el río Júcar.}

Aunque en ningún punto de la cuenca del Júcar las concentraciones de nitratos en aguas superficiales son un problema para cualquier uso los valores que se obtienen reflejan bastante influencia antropogénica de forma creciente conforme avanza el río aguas abajo. La importancia de su caracterización y modelación es fundamental debido a que puede llegar a ser un problema importante en las aguas superficiales a medio y largo plazo. En cuanto a la medición de este constituyente aunque se controla en diferentes puntos hay algunas "zonas en sombra" en que no se están midiendo y que perjudican la modelación de los mismos y el establecimiento y cuantificación de los focos contaminantes.

En el perfil longitudinal de las concentraciones medias de nitratos en el río Júcar se puede ver que de las estaciones seleccionadas para realizar dicho perfil sólo miden de forma más o menos continua dicho parámetro las siguientes: Cuenca, Alarcón, Frailes, Casas de Ves, (Cautabán), Alcira, Ag Arr Magro y Cullera. La mayor zona con falta de datos de nitratos es la zona entre el embalse de Molinar y la estación de Cotes aguas abajo de Tous. 
Río Júcar. Nitratos

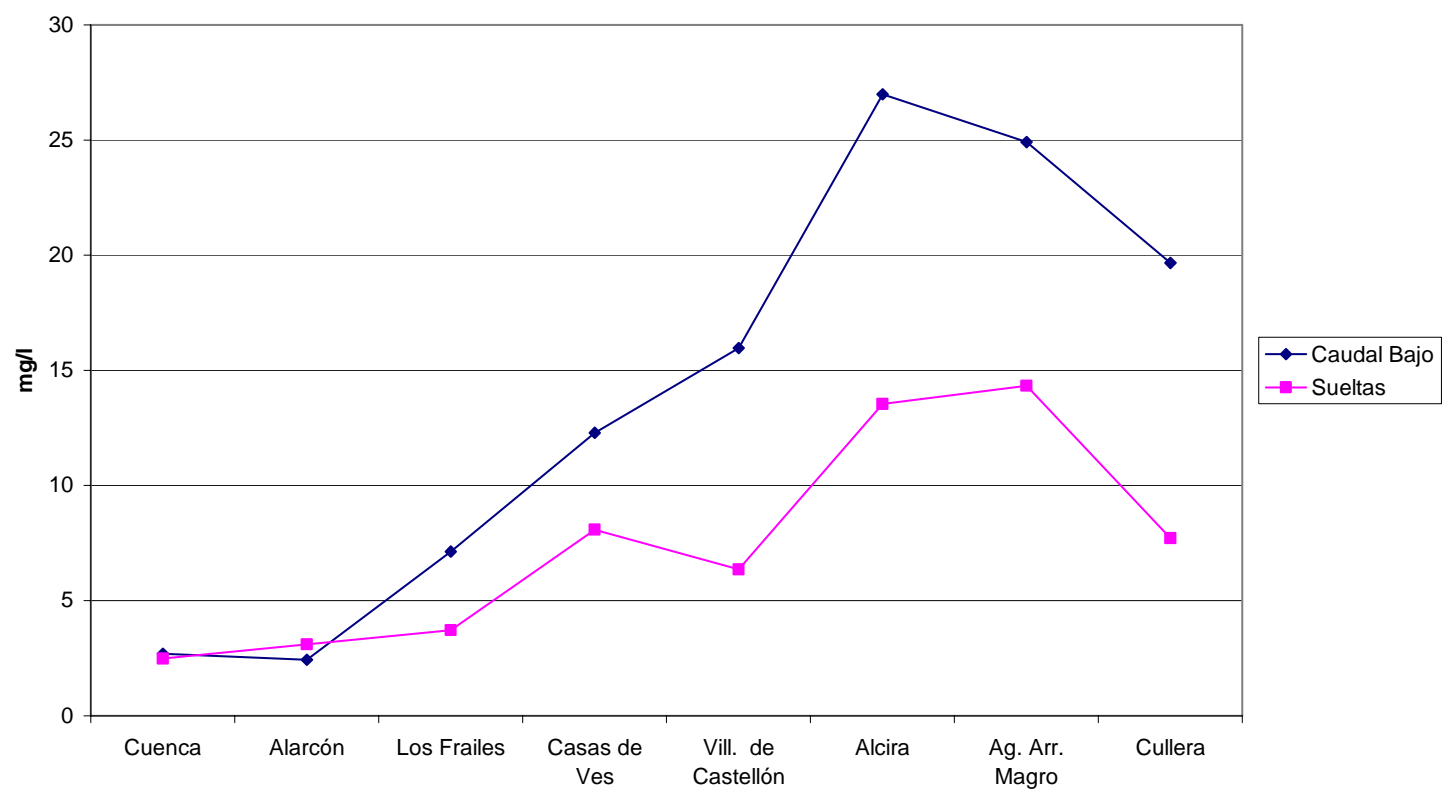

Figura 82. Perfiles medios de las concentraciones de nitratos del río Júcar.

El perfil longitudinal de las concentraciones de nitratos presenta valores ascendentes conforme avanza el río con diferencias entre las épocas de caudales bajos y altos. Las mayores concentraciones se dan en el tramo de río entre Alcira y la confluencia con el Magro. La mayor fuente de contaminación de nitratos son los retornos de la agricultura ya sea de modo superficial o por el aporte de aguas subterráneas contaminadas.

La primera estación que mide concentraciones es la de Cuenca presentando valores inferiores a los $10 \mathrm{mg} / 1$ con una media de $2.61 \mathrm{mg} / 1$ para el período estudiado. Aguas abajo del embalse de Alarcón las concentraciones aumentan en las zonas en las que el río mantiene una conexión hidráulica con el acuífero de la Macha con concentraciones de nitratos afectadas por los retornos de riego. El incremento de concentraciones de nitratos entre las estaciones de Alarcón y la de los Frailes y entre esta y la de Casas de Ves se muestra en el siguiente gráfico. 


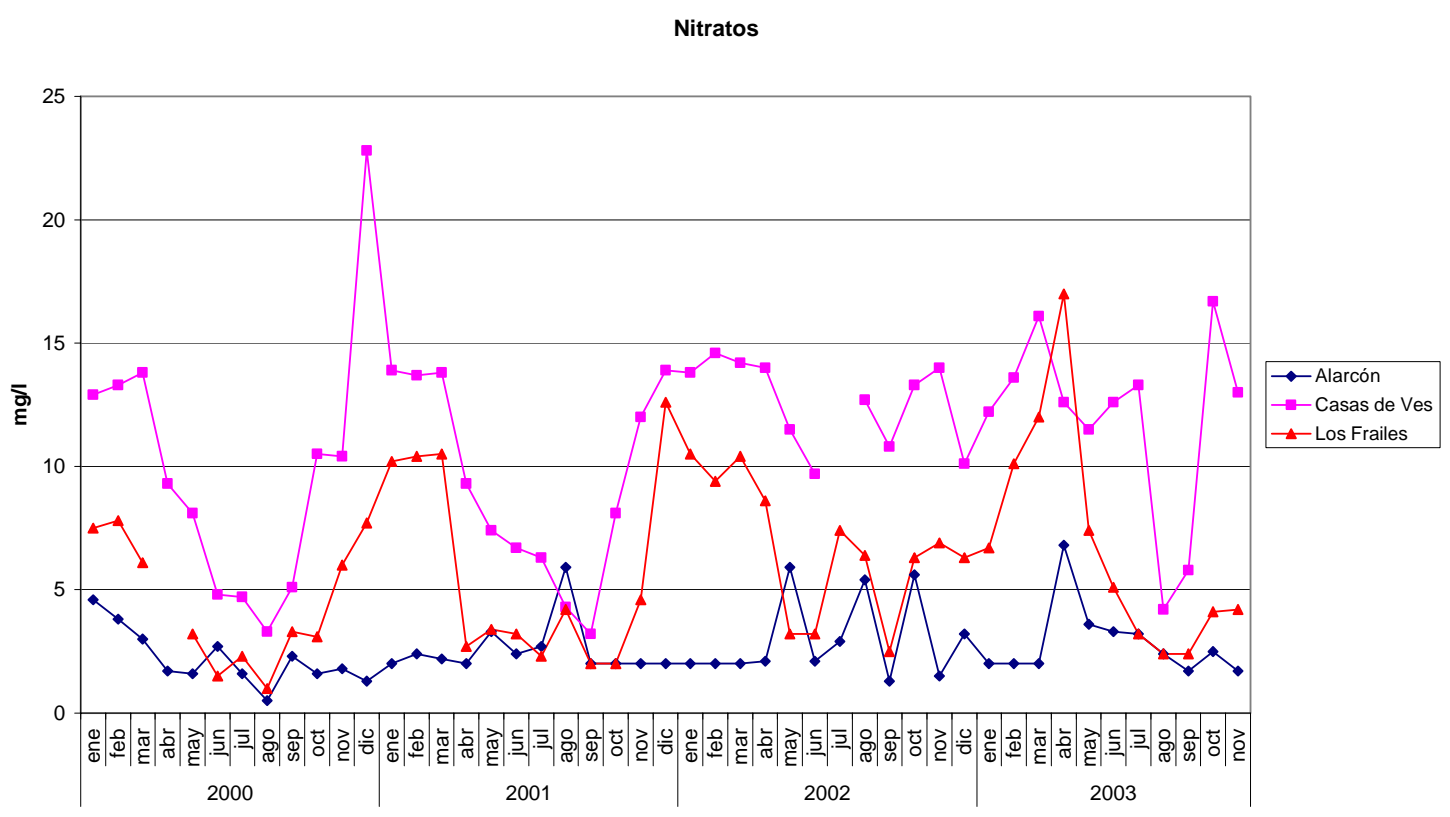

Figura 83. Concentraciones de nitratos medidas en las estaciones de Alarcón, Casas de Ves y Los Frailes.

Los incrementos de concentraciones en media son de $2.65 \mathrm{mg} / \mathrm{l}$ en la estación de Alarcón a $5.94 \mathrm{mg} / 1$ en la de los Frailes y $10.91 \mathrm{mg} / 1$ en la de Casas de Ves. Como se puede ver en el siguiente gráfico los incrementos de concentraciones de nitratos en la estación de los Frailes se producen en épocas de caudales circulantes bajos en donde la relación río acuífero tiene un mayor efecto.

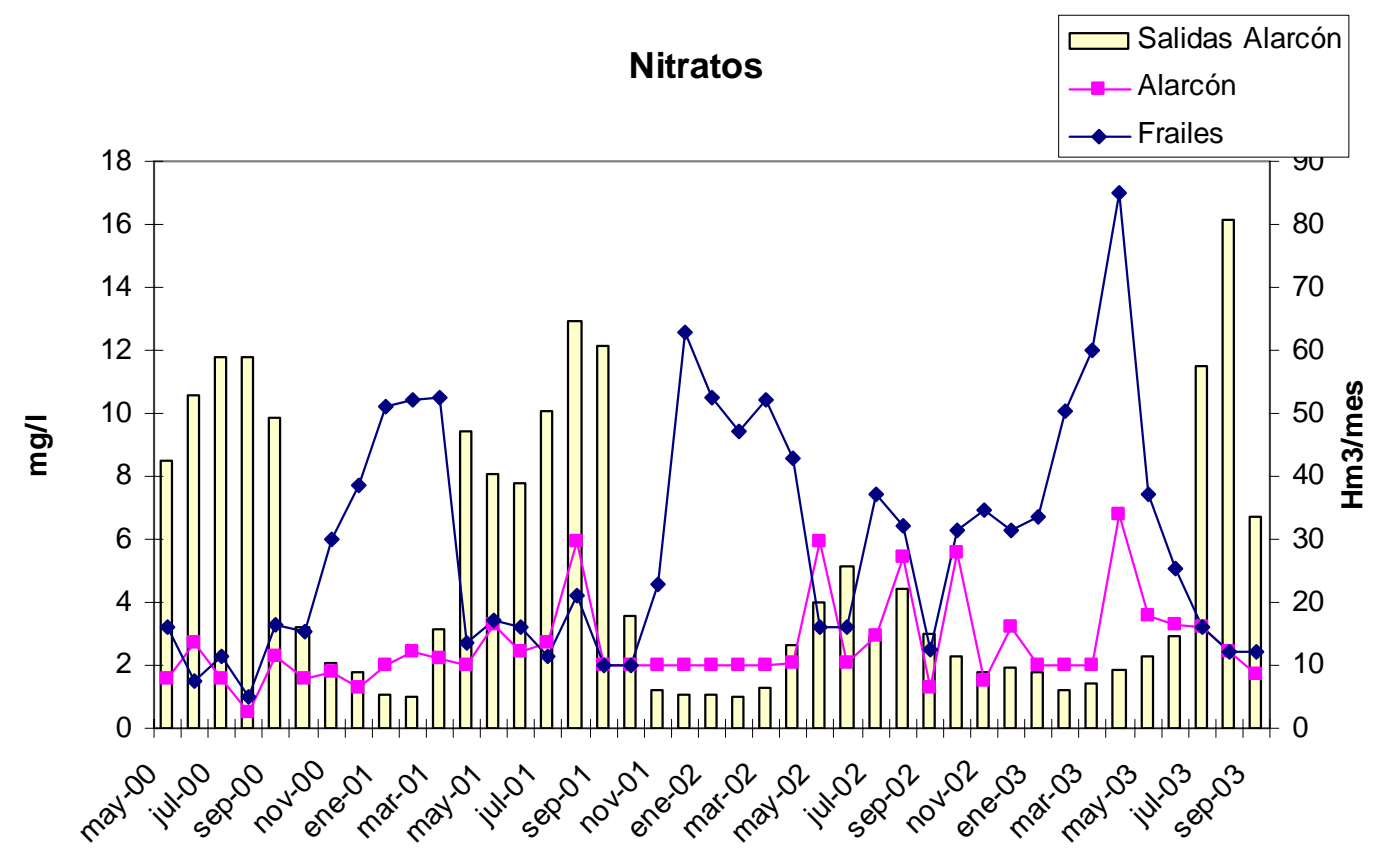

Figura 84. . Concentraciones de nitratos medidas en las estaciones de Alarcón y los Frailes comparadas con las sueltas de Alarcón. 
En la siguiente figura se muestra los usos de suelo de la zona en donde destacan los riegos de la zona de la Mancha Oriental causa de los incrementos de concentraciones de nitratos en el río.
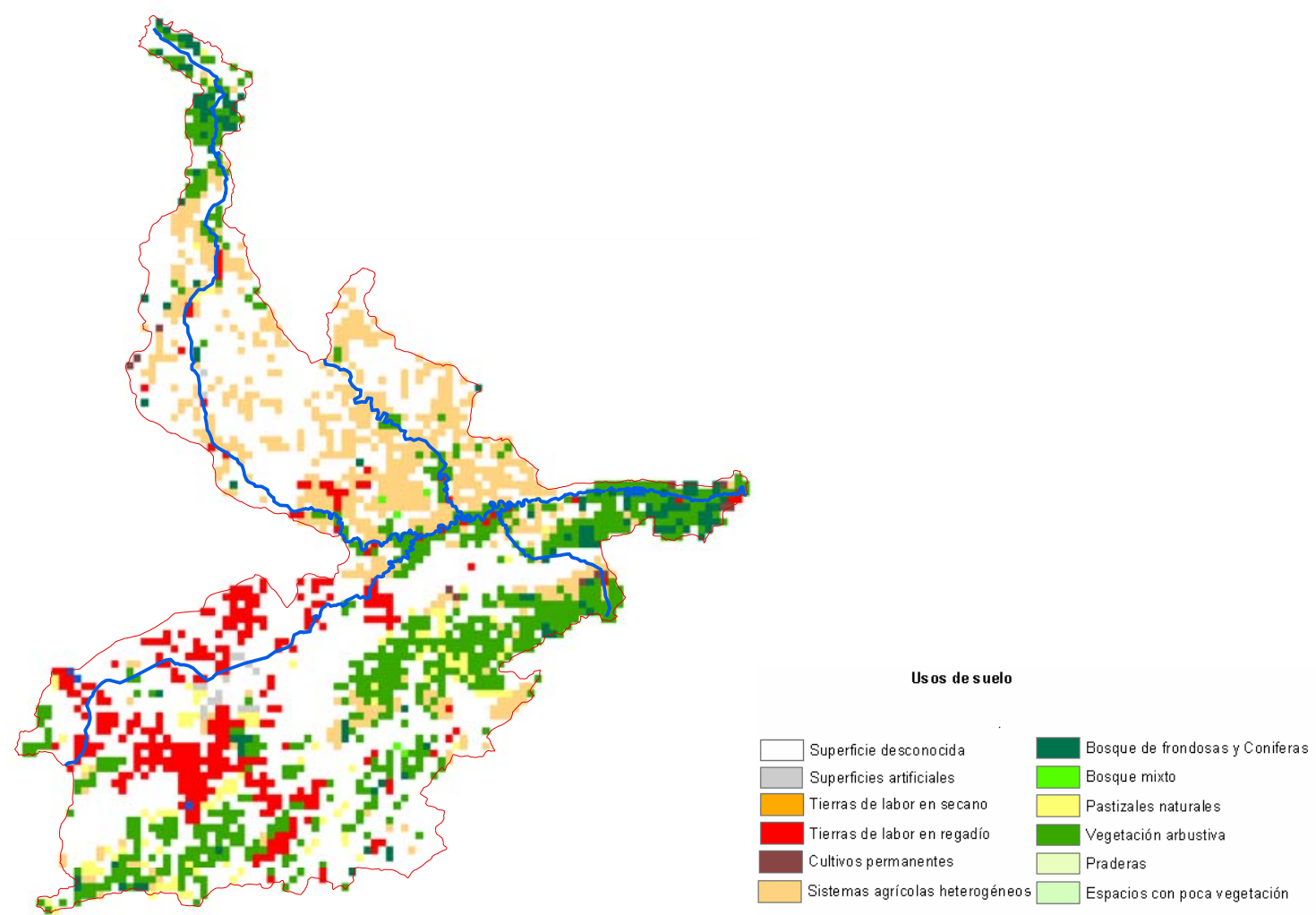

Figura 85. Usos de suelo en la zona del acuífero de la Macha Oriental.

En la parte aguas abajo de Tous se disponen de muy pocos datos para la estación de Villanueva de Castellón, mayor frecuencia para la estación de Alcira y series bastante completas para las estaciones de Aguas arriba del Magro y Cullera. 


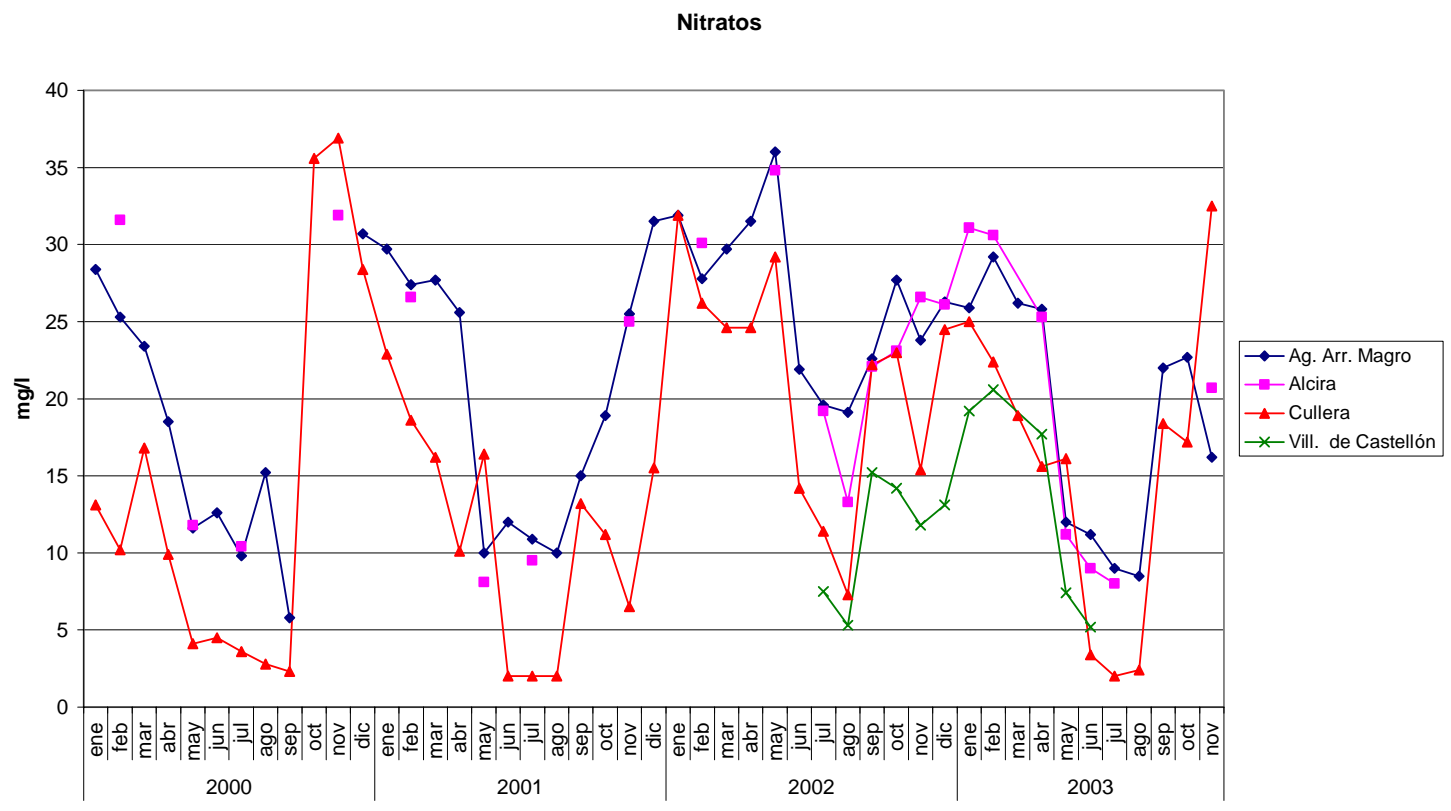

Figura 86. Concentraciones de nitratos medidas en las estaciones finales del río Júcar.

Como se puede ver en el gráfico existe bastante concordancia entre los valores de la estación de Alcira y los de de Ag. Arr. del Magro. Además los pocos datos disponibles para la estación de V. Castellón se muestra un incremento entre los valores medidos por esta estación y los medidos por las de aguas abajo. El factor más destacable en este gráfico es que las concentraciones en la estación de Cullera presentan valores inferiores a los de aguas arriba. Como se puede ver los valores en las épocas de sueltas son muy bajos. Los meses de Junio, Julio y Agosto presentan valores inferiores a $5 \mathrm{mg} / \mathrm{l}$ en tres de los cuatro años analizados. Esta disminución de concentraciones es debida al proceso desnitrificación que se suele dar en masas de agua eutrofizadas. Para una mejor caracterización del problema sería necesario más puntos de control en el río entre la ICA Ag. Arr. Confluencia con el Magro y la denominada como Cullera (sita en el azud de la Marquesa). 


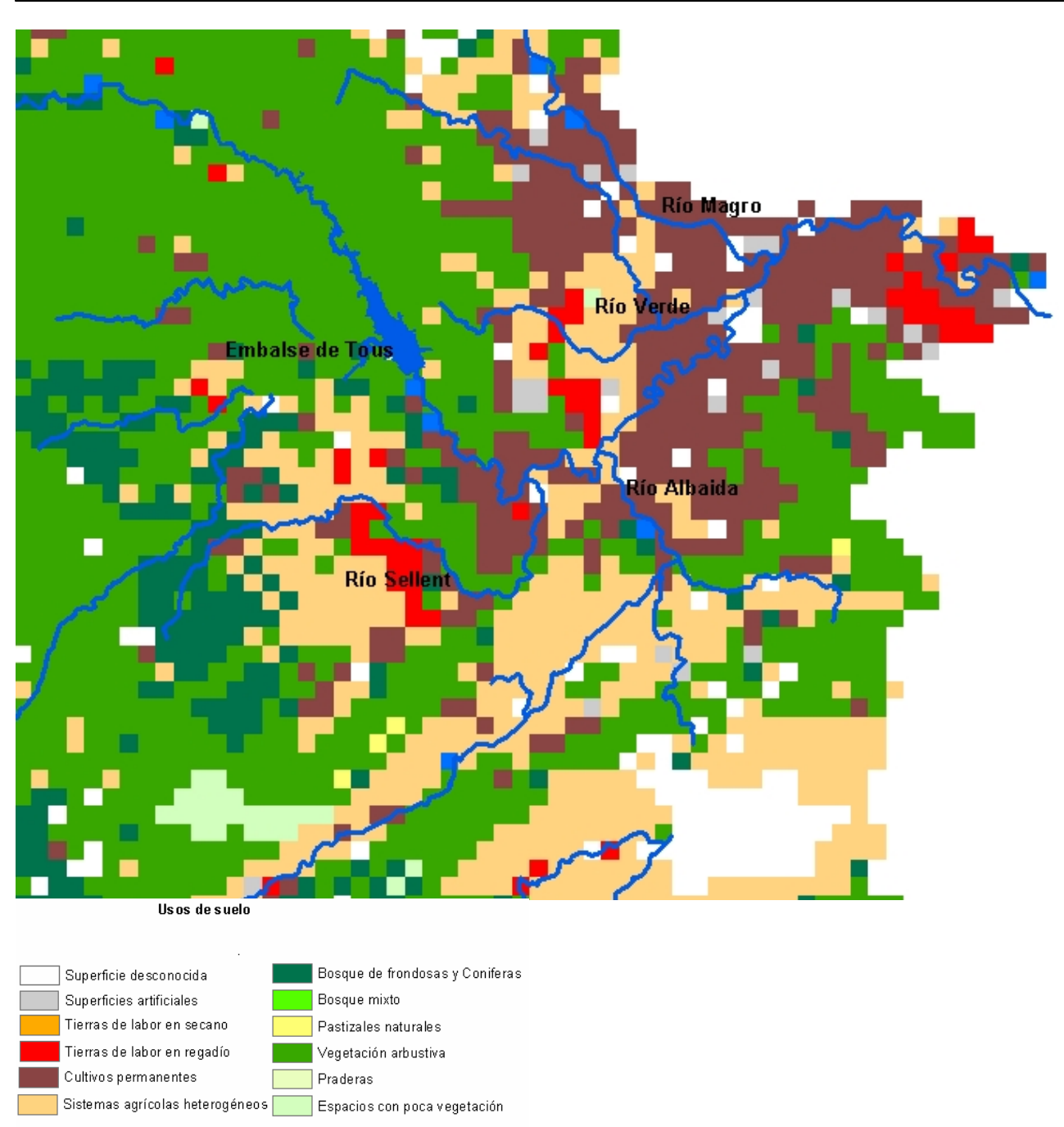

Figura 87. Usos de suelo en el tramo bajo de la cuenca del Júcar.

Por otra parte se ha estudiado la evolución histórica de los nitratos en la estación de Cullera. Para ello se han utilizado los datos de la estación de la red COCA sita en el mismo lugar. Se ha intentado realizar este mismo análisis en diferentes puntos de la cuenca pero sin mucho éxito debido a la insuficiencia de datos. En la siguiente figura se puede ver los datos medidos de concentraciones de nitratos para la estación de Cullera desde 1980 hasta la actualidad con un período de carencia de datos entre 1992 y 2000. 


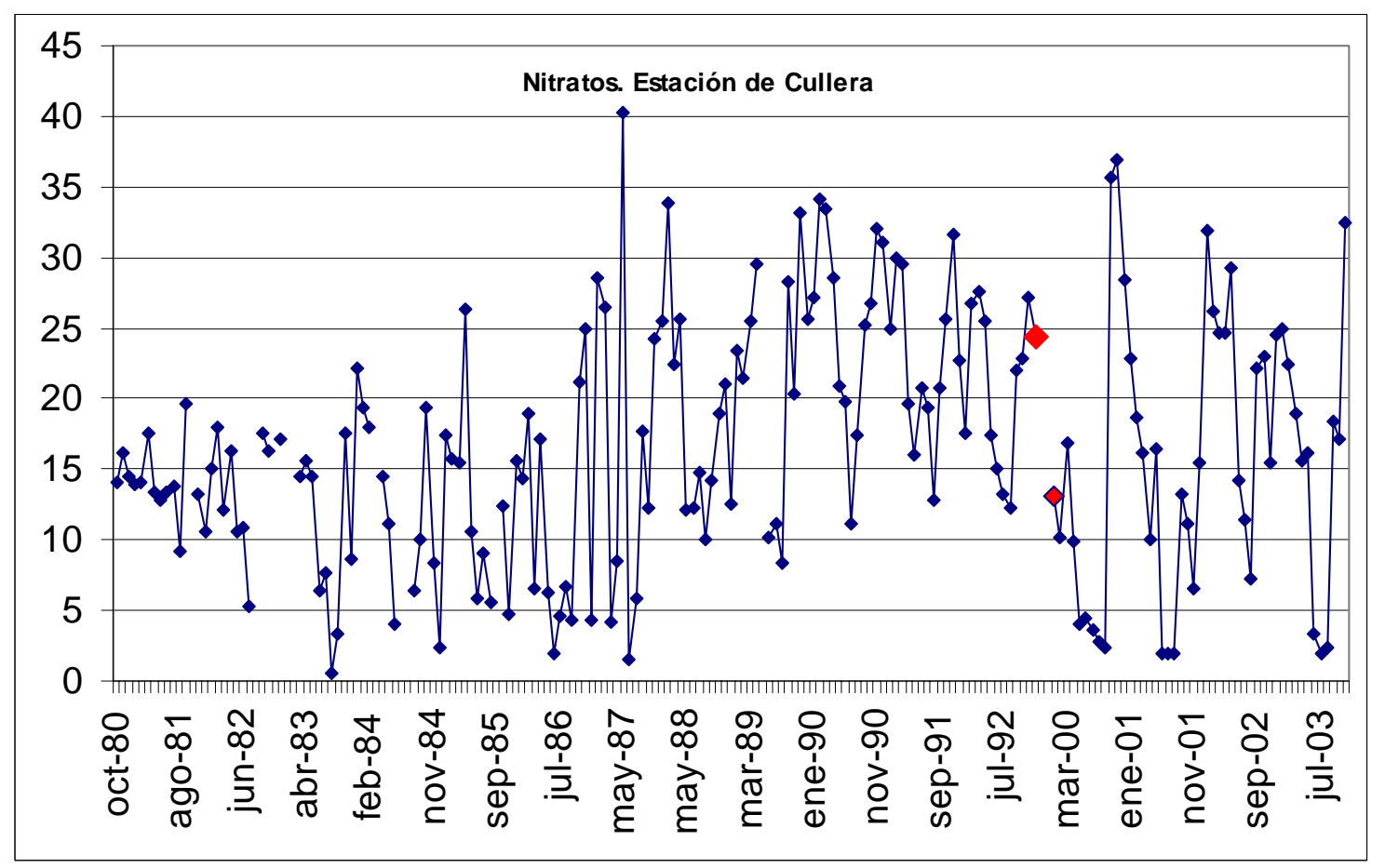

Figura 88. Evolución histórica de las concentraciones de nitratos en la estación ICA de Cullera.

Se pueden diferenciar tres zonas en el gráfico. La primera entre 1980 y 1986 de concentraciones entre los 5 y 20mg/l. En la segunda etapa entre 1987 y 1992 existe un incremento de las concentraciones de nitratos oscilando en un rango entre 10 y $35 \mathrm{mg} / 1$. Finalmente en la última etapa, entre el año 2000 y 2003 se mantienen los niveles máximos de la etapa anterior aunque las concentraciones de verano se reducen debido a la desnitrificación de los nitratos. Posteriormente al analizar las concentraciones de fósforo se realiza el mismo análisis y se ve el mismo efecto pero de forma más marcada. De este gráfico se puede concluir que las concentraciones de nitratos en esta zona no tienen una tendencia temporal a largo plazo creciente sino que por otro lado parece que en la última década representa un período de estabilización de concentraciones.

Para la caracterización del contenido de nitratos en los afluentes del Júcar el gráfico siguiente muestra los datos disponibles en las estaciones de los ríos Sellent, Albaida, Verde y Magro en las estaciones más cercanas a la confluencia con el Júcar. Mientras el Sellent no presenta valores, el Magro dispone de muy pocos datos. Los otros dos afluentes muestran concentraciones muy elevadas, incluso en algunos puntos superiores a 50mg/1 límite establecido para consumo humano. 


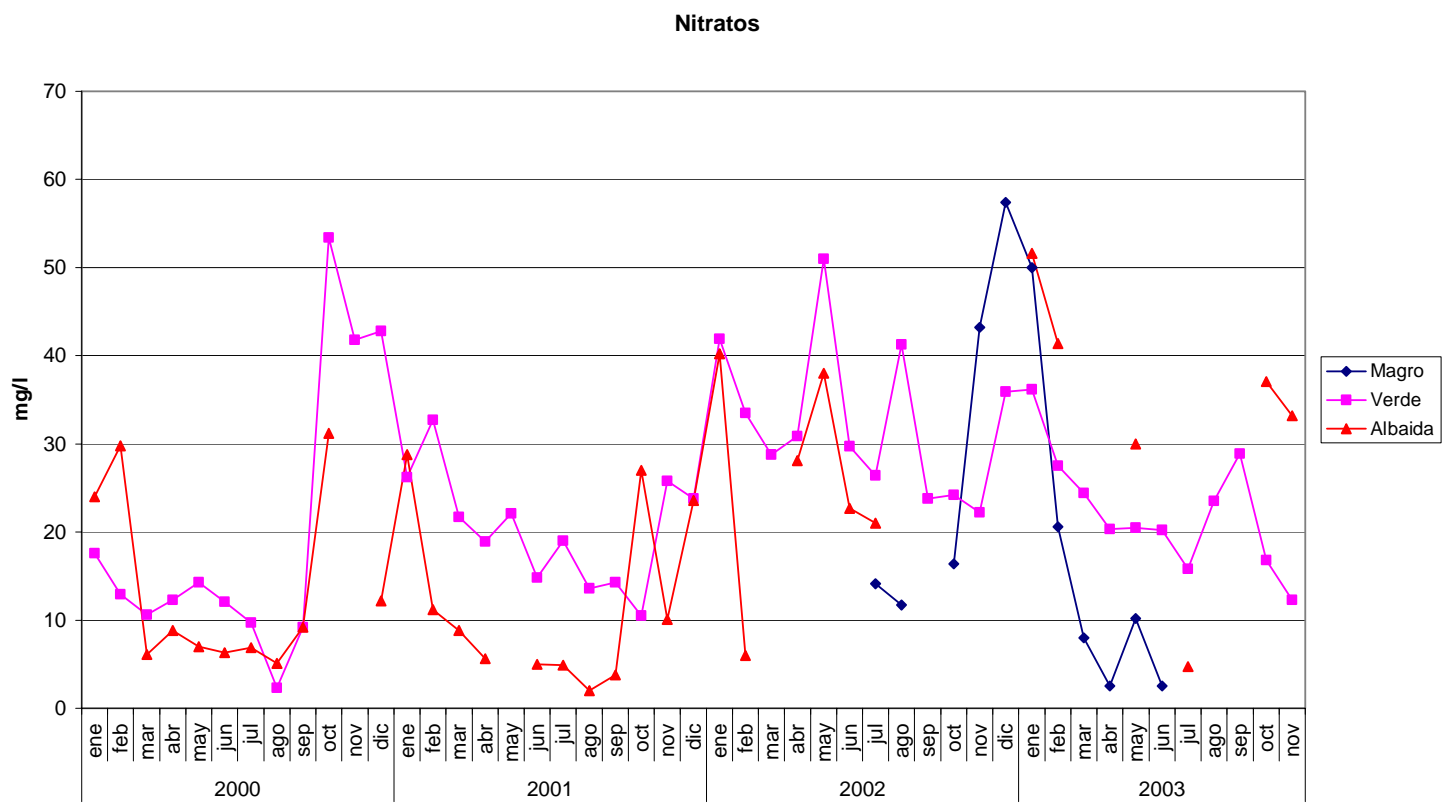

Figura 89. Concentraciones de nitratos medidas en las estaciones finales de los afluentes inferiores.

Ello es debido a que gran parte del caudal recogido por estos afluentes se corresponde con los retornos de riego, superficiales o subterráneos, cargados de nitratos.

\subsection{Análisis de los nitratos en el río Cabriel.}

En el río Cabriel la primera zona que presenta problemas de caracterización es la del embalse de Contreras. Los nitratos se miden en la estación de Pajaroncillo pero no se miden en la de aguas arriba del embalse, Bujioso, ni en la de aguas abajo. La estación más cercana donde se vuelven a medir es en la Villatoya. Las mediciones de la estación de Villatoya presentan valores indicativos de contaminación por nitratos. Un seguimiento de los mismos en la zona cercana al embalse de Contreras podría aclarar la fuente de los mismos e incluso arrojar luz sobre los aportes de caudal en la zona. 
Río Cabriel. Nitratos

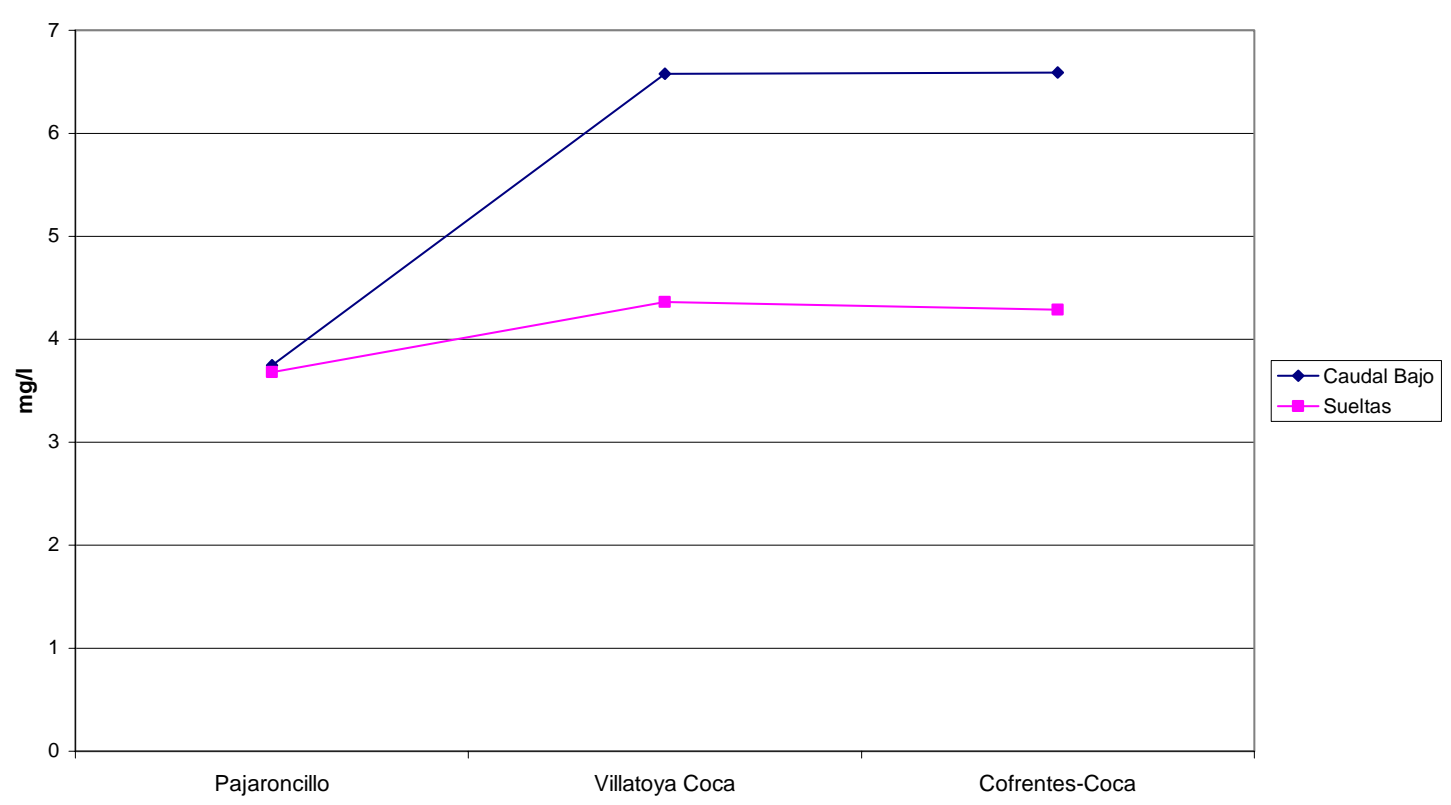

Figura 90. Perfiles medios de las concentraciones de nitratos en el río Cabriel.

El gráfico del perfil medio de nitratos muestra un incremento de las concentraciones de los mismos entre Pajaroncillo y Villatoya.

El siguiente gráfico muestra los valores medidos en las estaciones de VillatoyaCoca y Cofrentes-Coca. El gráfico muestra el carácter conservativo de los nitratos en ausencia de actividad biológica.

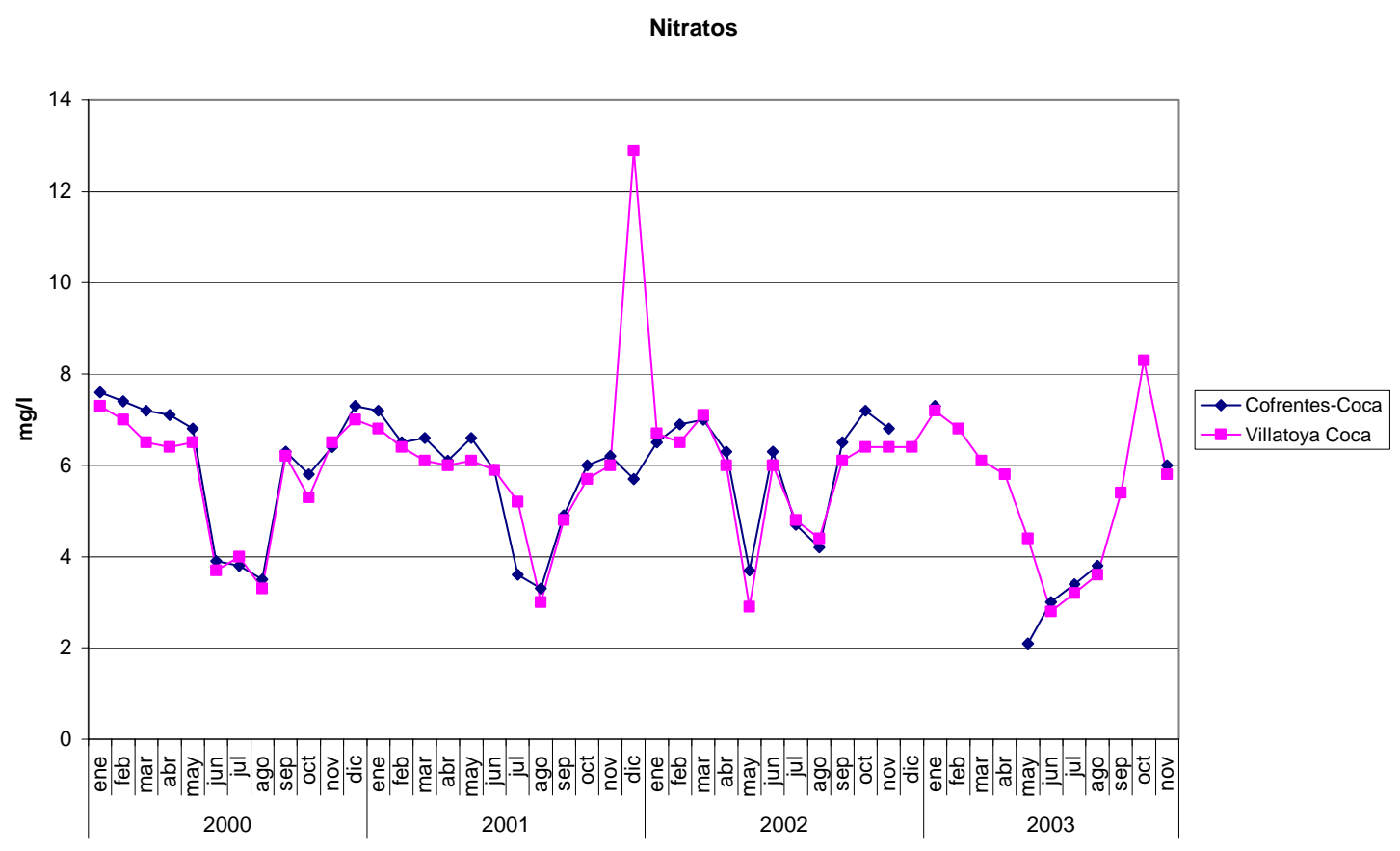

Figura 91. Concentraciones de nitratos medidas en las estaciones de Cofrentes Coca y Villatoya. 


\subsubsection{Fósforo.}

En condiciones naturales el fósforo es un elemento escaso en medios acuáticos. A diferencia del nitrógeno, el fósforo no existe como gas y por consiguiente la atmósfera no supone una fuente de aporte a los sistemas acuáticos. Algunos tipos de roca pueden ser una fuente natural de aporte de fósforo en la escorrentía. En los sistemas acuáticos el fósforo se encuentra en forma orgánica e inorgánica, ambas en forma particulada o disuelta. En cuanto al fósforo inorgánico las formas solubles son el $\mathrm{H}_{2} \mathrm{PO}_{4}{ }^{-}, \mathrm{HPO}_{4}{ }^{2-} \mathrm{y}^{-} \mathrm{PO}^{3-}$. Este último es el principal componente del fósforo soluble reactivo fácilmente asimilable por las plantas. Las medidas de fósforo total que se realizan comúnmente en el agua incluyen todas las formas vistas. Sin embargo el fósforo soluble reactivo es el más importante en temas de eutrofización ya que es el más fácilmente asimilable por la vegetación y en especial por el fitoplancton. Sin embargo otras formas pueden ser transformadas en compuestos más biológicamente asimilables. La rapidez de estas transformaciones depende del tipo de medio y de la actividad microbiológica. En ríos con tiempos de residencia relativamente cortos es poco probable este tipo de transformaciones siendo el FSR la fuente principal de fósforo disponible. En lagos o masas de agua con tiempos de residencia mayores el fósforo total se puede considerar como una buena estimación del fósforo biológicamente disponible. Las actividades humanas son la principal causa de aporte de fósforo a los sistemas acuáticos.

\subsubsection{Análisis del fósforo en el río Júcar.}

El perfil longitudinal del río Júcar respecto a concentraciones medias de fósforo total finaliza en la estación de Cotes ya que en todas las de aguas abajo se miden fosfatos en vez de fósforo total. En las estaciones aguas arriba de Tous la gran mayoría miden fósforo total y algunas como se muestra posteriormente miden también fosfatos. 


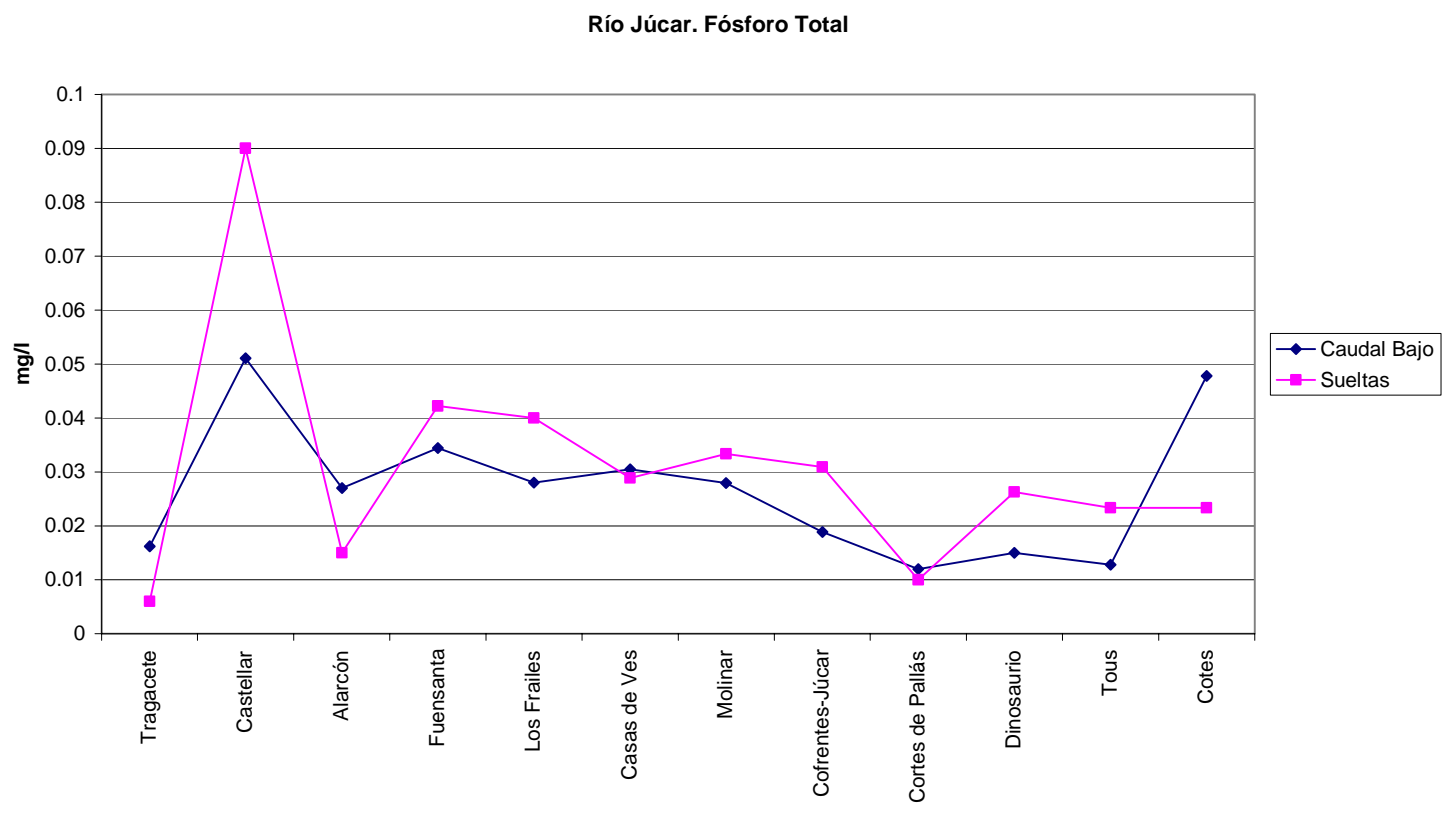

Figura 92. Perfiles medios de concentraciones de fósforo en el río Júcar.

Del gráfico se destaca el incremento de concentraciones entre las estaciones de Tragacete y Castellar es debido fundamentalmente al aporte de fósforo de la ciudad de Cuenca y otros vertidos de la misma zona. El embalse de Alarcón tiene un efecto claro de disminución del mismo por sedimentación de la parte particulada. En el tramo de río entre los embalses de Alarcón y el de Molinar las concentraciones se mantienen y la diferencia entre las épocas de sueltas y caudales bajos son pequeñas. Las concentraciones de las estaciones de confluencia son algo menores que las anteriores. En general se puede decir que excepto en el aporte al embalse de Alarcón las concentraciones de fósforo total son bastante bajas.

El siguiente gráfico compara las concentraciones de fósforo total entre las estaciones aguas arriba y aguas abajo del embalse de Alarcón. La gráfica muestra el efecto del embalse sobre dichas concentraciones en donde la reducción de concentraciones es muy significativa. 


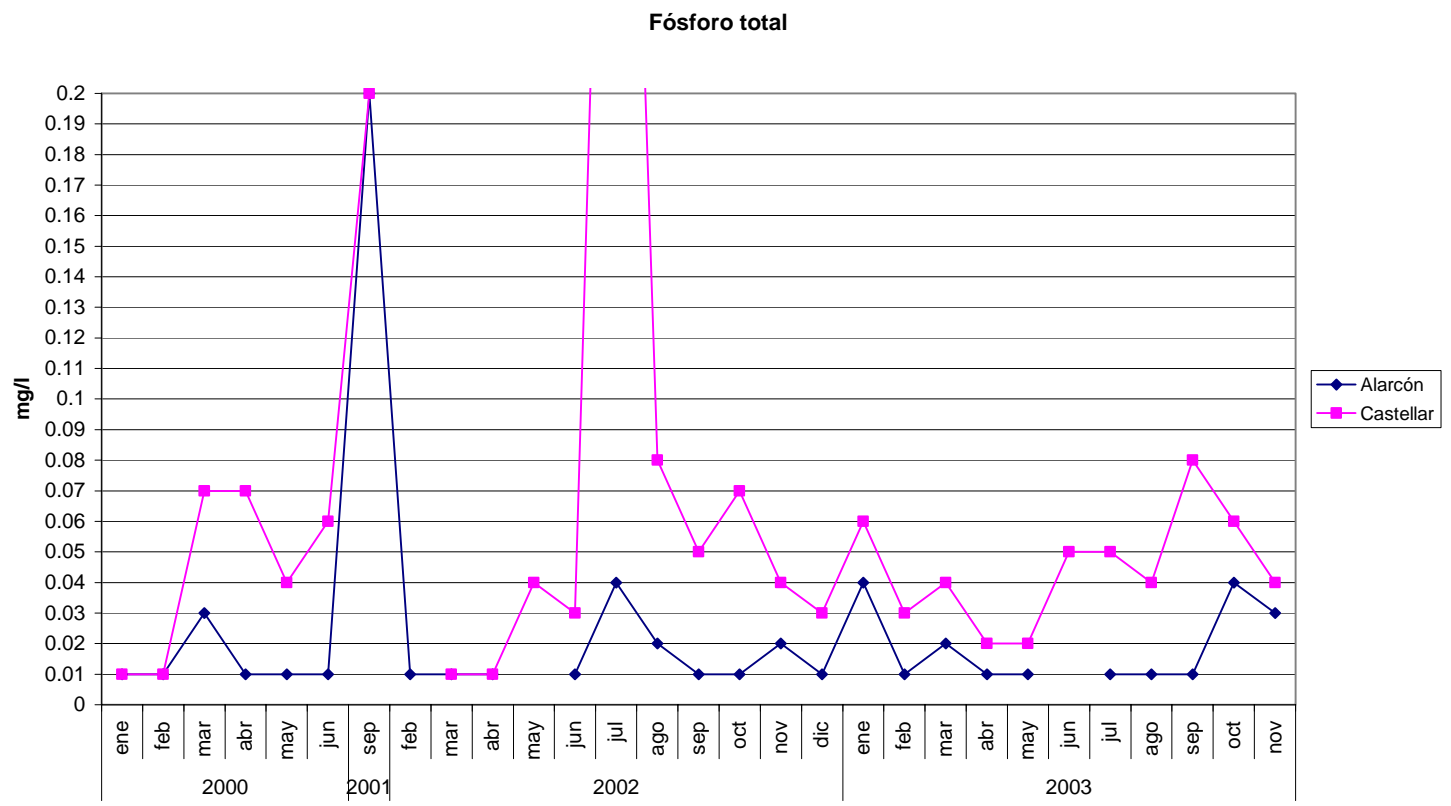

Figura 93. Concentraciones de Fósforo Total medias por las estaciones de Alarcón y Castellar.

Por otra parte, si se analizan las mediciones de fosfatos, estas se realizan en un número menor de estaciones. El siguiente gráfico muestra las estaciones que miden fosfatos aguas arriba del embalse de Tous tanto para el río Júcar como para el Cabriel. Como refleja el gráfico las concentraciones en la mayor parte de los meses son iguales al umbral de medición.

Fosfatos

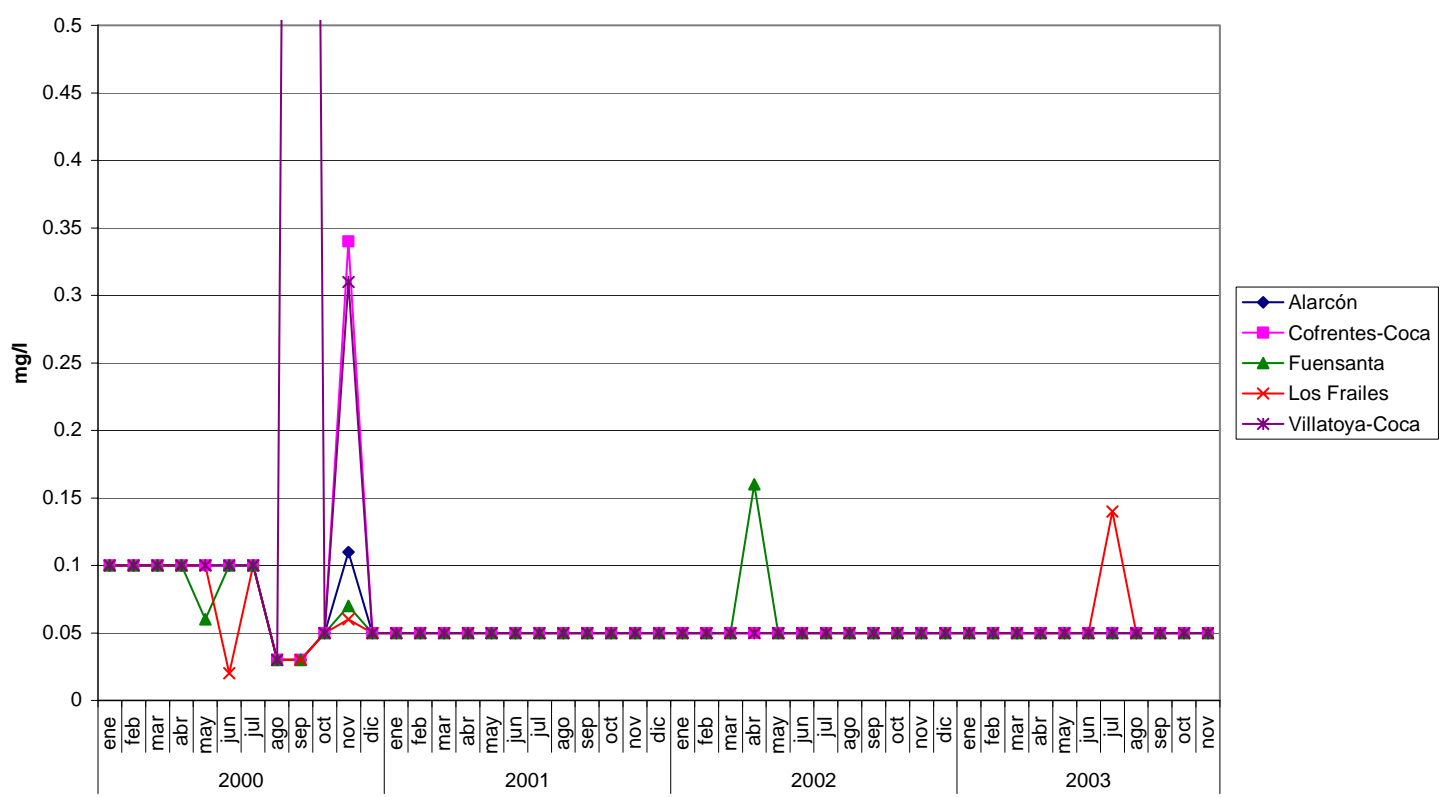

Figura 94. Concentraciones de Fosfatos medias por las estaciones de calidad aguas arriba del embalse de Tous. 
Por otro lado en el siguiente gráfico se muestra los valores medidos de fosfatos de las estaciones de calidad aguas abajo de Tous. Las estaciones donde no se miden fosfatos son: Tous, Cotes, Villanueva de Castellón. En la estación de Cotes sólo se mide Fósforo Total mientras que en la de Villanueva de Castellón no se mide ningún tipo de fósforo.

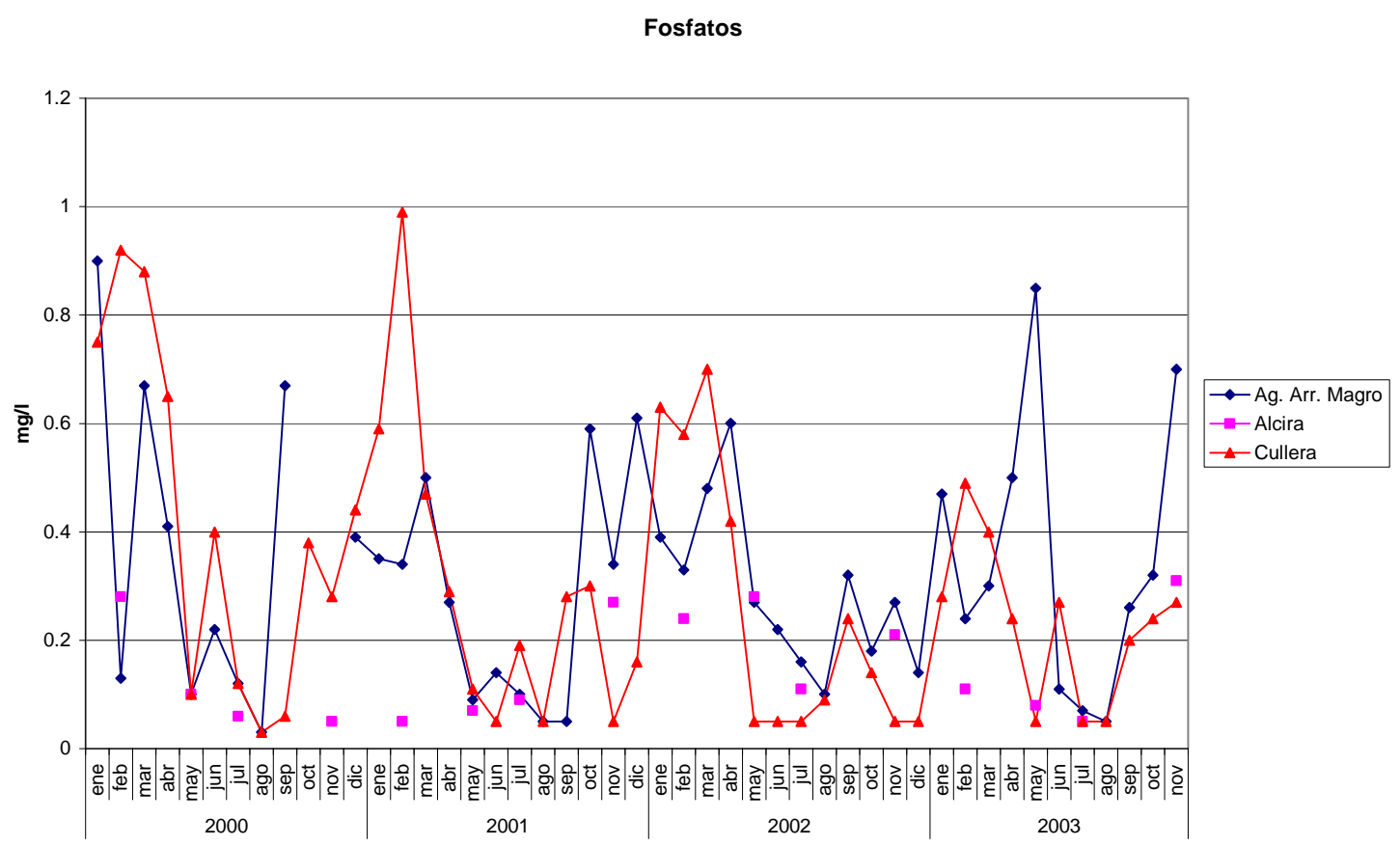

Figura 95. Concentraciones de Fosfatos medias por las estaciones finales del río Júcar.

Al igual que se hizo para los nitratos se ha estudiado la evolución histórica de los fosfatos a partir de los datos de la red COCA para ello se ha utilizado las medidas de la estación de Cullera. El siguiente gráfico muestra dicha evolución. 


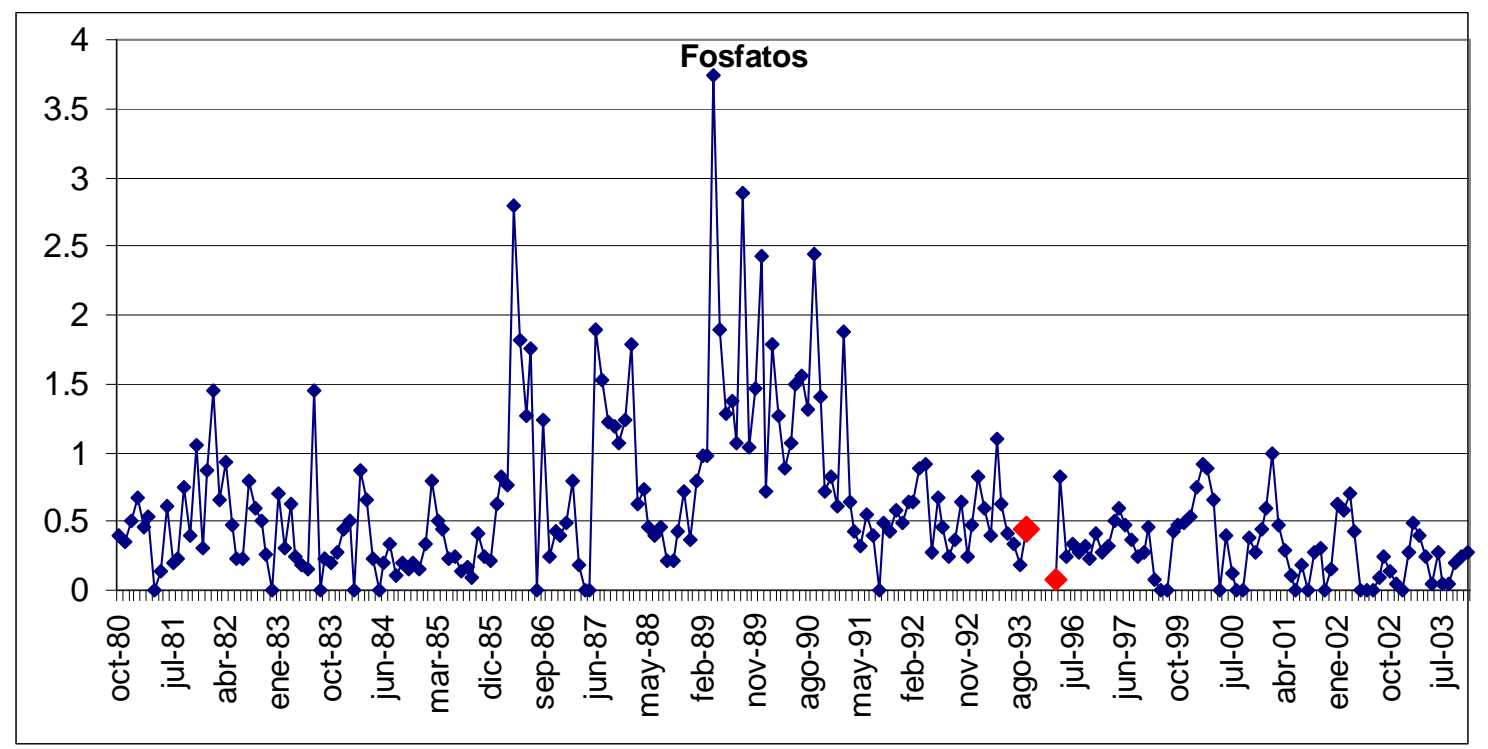

Figura 96. Evolución a largo plazo de las concentraciones de fosfatos en la estación de calidad de Cullera.

La evolución histórica de los fosfatos en la estación de Cullera, a falta de datos entre 1993 y 1996, se puede diferenciar en tres etapas: la primera etapa entre 1980 y 1985 donde las concentraciones son en casi todos los meses menores a $1 \mathrm{mg} / \mathrm{l}$ con un promedio de $0.43 \mathrm{mg} / \mathrm{l}$. La segunda etapa, entre 1985 y 1991, los valores de las concentraciones experimentan un incremento significativo tanto en valores máximos en donde muchos de ellos superan los $2 \mathrm{mg} / \mathrm{l}$ como valores mínimos cercanos a los 5mg/l. Esto hace que la media de esa época sea de $0.96 \mathrm{mg} / \mathrm{l}$. Finalmente a partir de $1991 \mathrm{y}$ hasta 2003 las concentraciones son del orden de magnitud de la primera etapa con un valor medio de $0.39 \mathrm{mg} / \mathrm{l}$. Además, en esta última etapa, en los meses de verano se produce un descenso de concentraciones debido a la eutrofización del azud. Estas tres etapas coinciden con las analizadas para los nitratos en la misma estación.

\subsubsection{Análisis del fósforo en el río Cabriel.}

Para el río Cabriel las estaciones de calidad presentan valores bastante bajos de fósforo total. La mayoría de las estaciones presentan valores inferiores a $0.03 \mathrm{mg} / \mathrm{l}$ menores que los medidos en la cuenca del Júcar. 


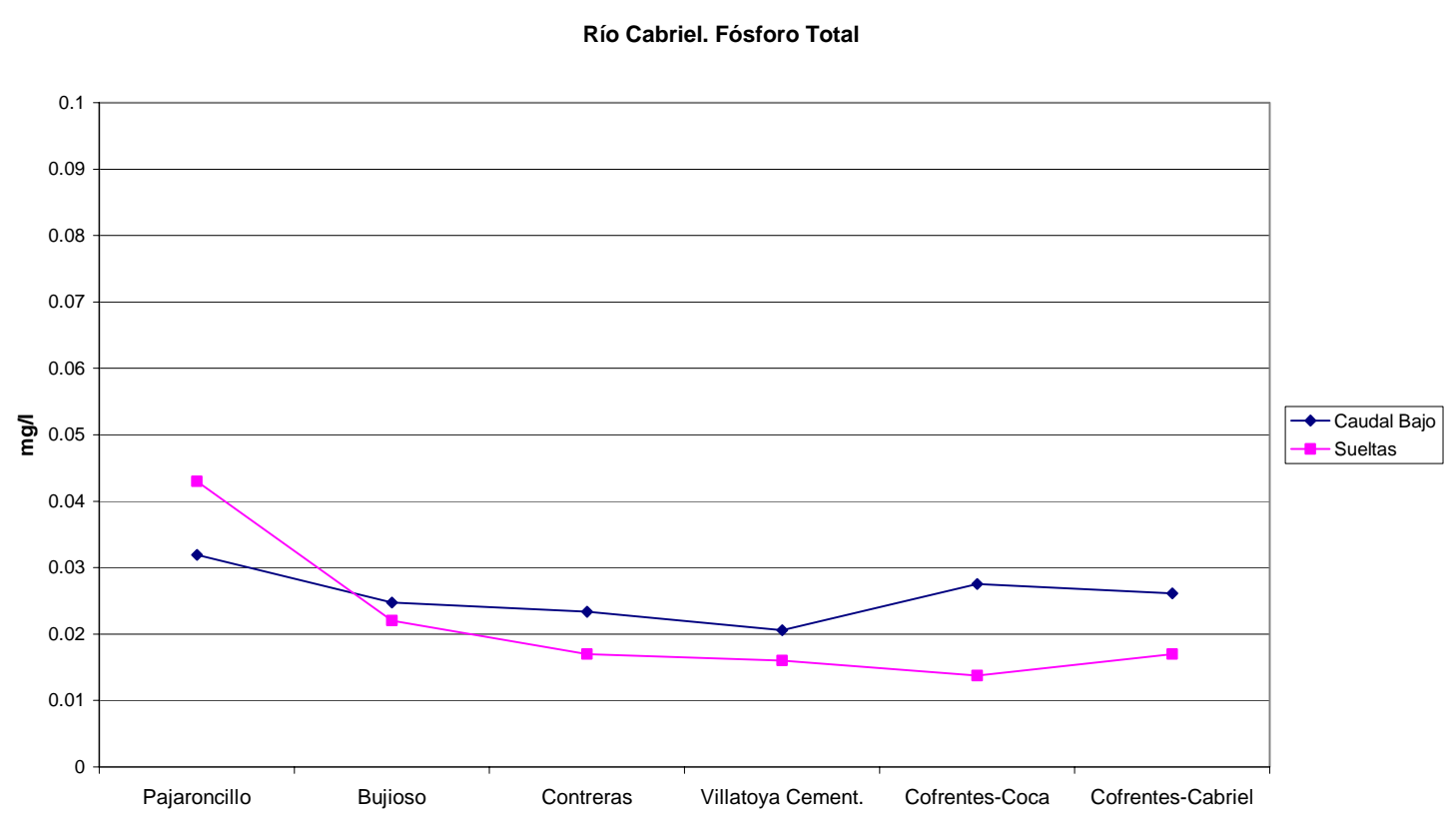

Figura 97. Perfiles medios de las concentraciones de fósforo total en el río Cabriel.

Al igual que pasaba con el amonio la estación de Pajaroncillo muestra valores un poco superiores al resto. Ello es debido a la influencia de vertidos cercanos a la estación.

La siguiente gráfica compara las concentraciones de fósforo entre las estaciones de Bujioso y Contreras mostrando el poco efecto del embalse sobre el constituyente.

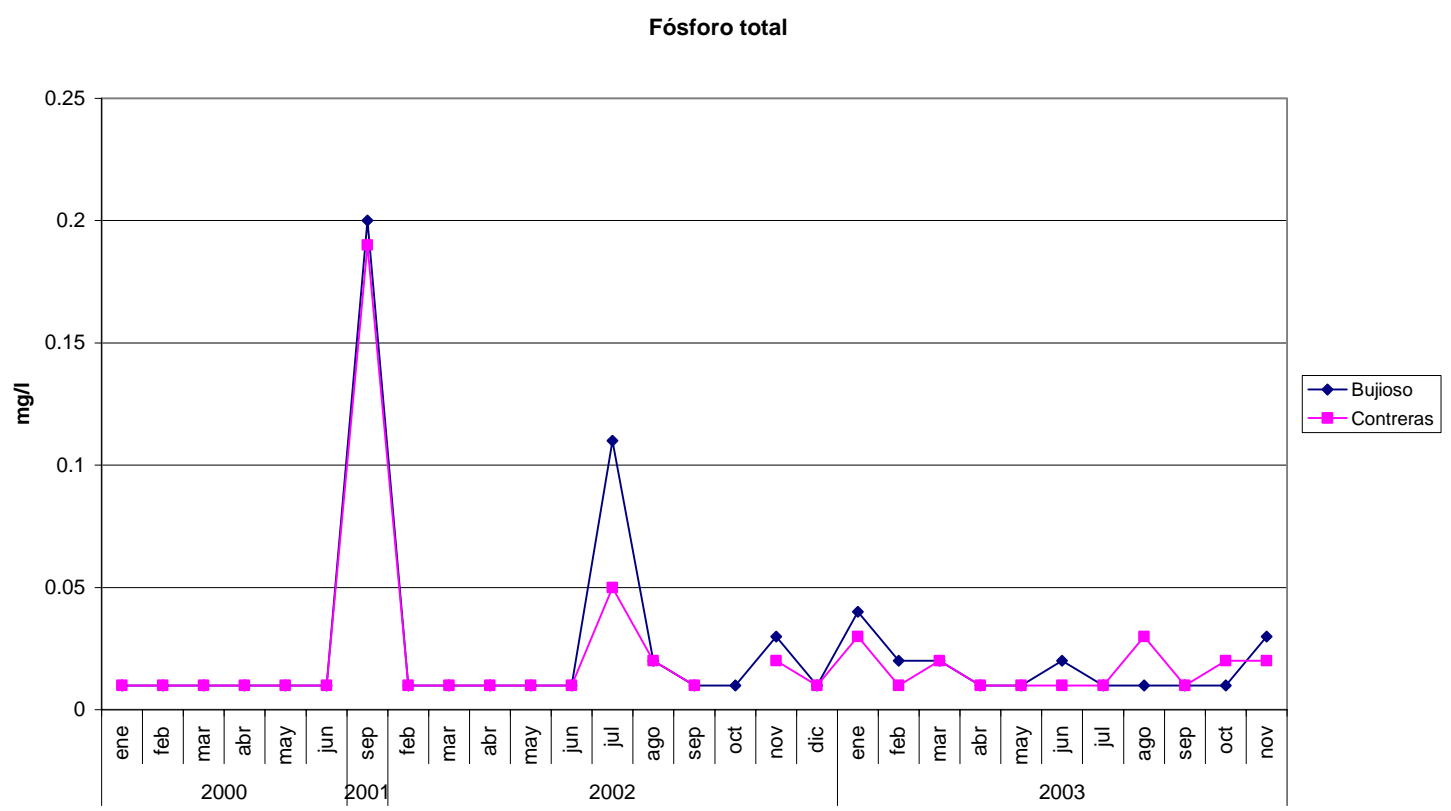

Figura 98. Concentraciones de Fósforo Total medias por las estaciones de Bujioso y Contreras. 


\subsubsection{Temperatura.}

La temperatura del agua es un factor fundamental en la calidad y salud de los ecosistemas acuáticos. De ella dependen numerosos procesos físicos, químicos y biológicos en los medios acuáticos $\mathrm{y}$, por consiguiente, la concentración de muchos constituyentes. El incremento de la temperatura del agua implica un incremento en las reacciones químicas y una disminución de la solubilidad de los gases. Bajo el punto de vista biológico cuanto mayor es la temperatura del agua mayor es el metabolismo de los organismos acuáticos y su respiración. En aguas naturales las fluctuaciones en la temperatura se dan a escala tanto estacional como diaria. En general las aguas naturales oscilan en intervalos entre los 0 y $40{ }^{\circ} \mathrm{C}$. En aguas subterráneas la temperatura suele ser bastante constante y si el acuífero es superficial la temperatura suele ser próxima a la temperatura del aire.

\subsubsection{Análisis de la temperatura del río Júcar.}

En el río Júcar, del análisis de los datos de temperatura se concluye que no existen causas antropogénicas directas que estén modificando la temperatura del río en ningún punto de la cuenca. Para este caso, debido al marcado carácter estacional del constituyente, se han realizado los perfiles longitudinales medios por estaciones y no por regimenes de caudales circulantes. A priori, se puede decir que el régimen de caudales actuales implica unas temperaturas más frías en verano y más calientes en invierno si se compara con su condición natural. Aunque el caudal circulante es un factor en la temperatura del agua la radiación es la variable determinante.

Río Júcar. Temperatura

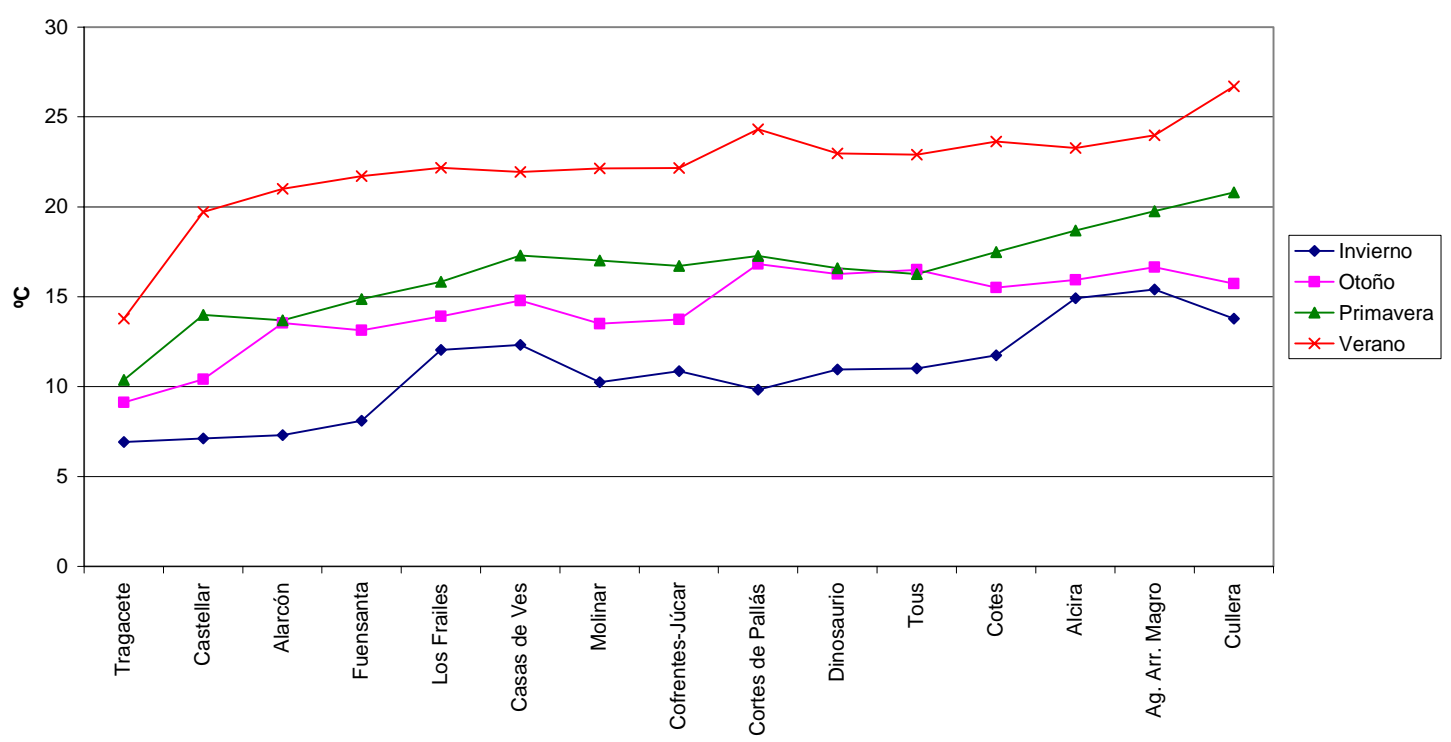

Figura 99. Perfiles medios estacionales de temperatura en el río Júcar. 
El gráfico muestra el aumento de temperaturas conforme disminuye la altitud de las estaciones. Los perfiles de invierno y primavera son los más parecidos, siendo el de verano el que presenta más diferencias con el resto. Destaca el marcado incremento entre las dos primeras estaciones de calidad.

El perfil longitudinal muestra valores típicos de un río mediterráneo con inviernos suaves y veranos calurosos. Del análisis detallado se destaca los ciclos anuales que presenta la temperatura en todas las estaciones de calidad.

El siguiente gráfico muestra la comparación de la temperatura entre las estaciones de Tragacete y Castellar. Como se puede apreciar mientras que en los meses de invierno no existen grandes diferencias en el resto del año el calentamiento en este tramo de río es bastante significativo, sobre todo en los meses de verano en donde el gradiente térmico es de unos $5^{\circ} \mathrm{C}$.

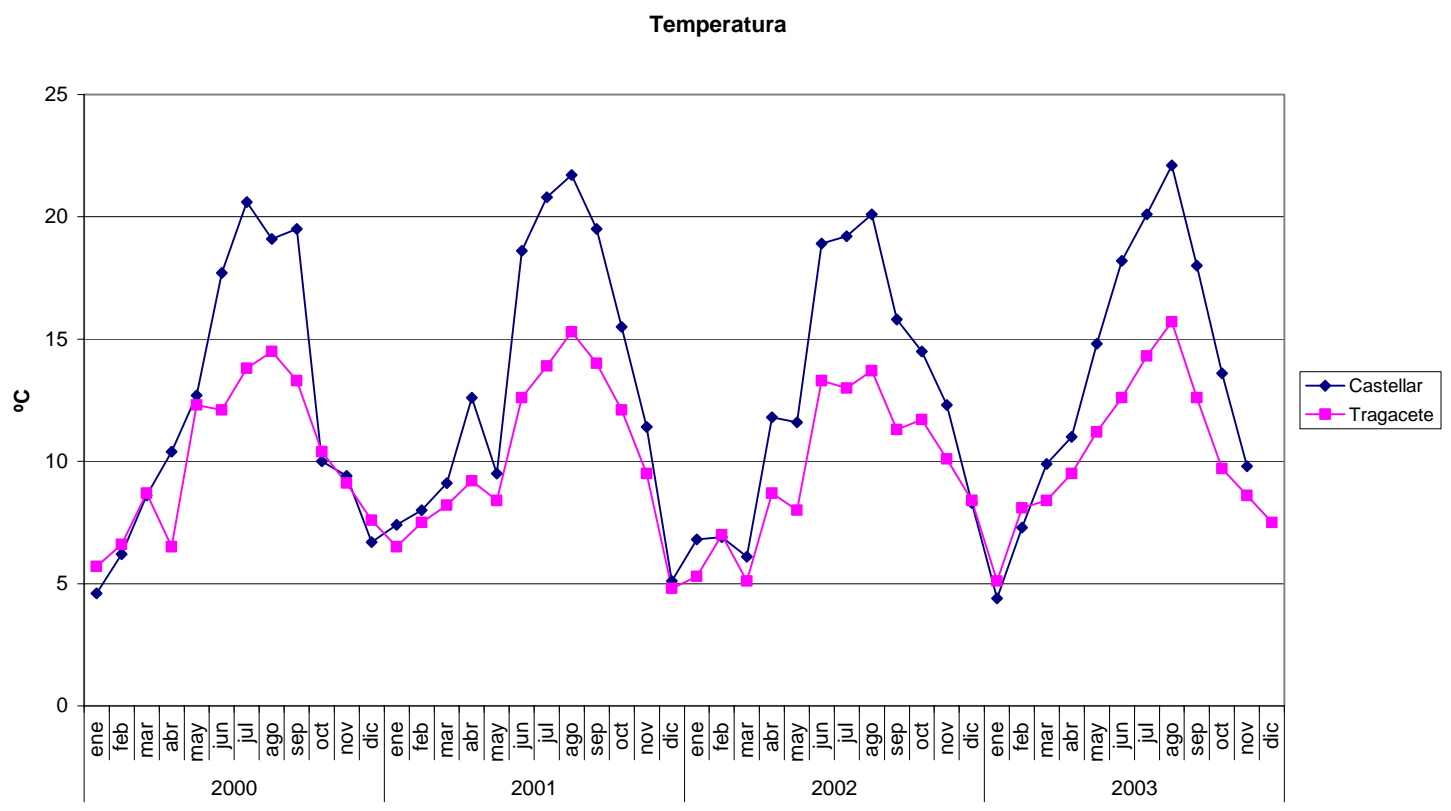

Figura 100. Temperaturas medidas por las estaciones de Castellar y Tragacete.

Si se comparan los valores medios mensuales de las estaciones de aguas arriba y aguas abajo del embalse de Alarcón se puede ver como las temperaturas difieren sobre todo en los meses de otoño. Al final del verano, la pérdida de la estratificación térmica provoca que la temperatura del agua en esos meses sea unos grados superior a los de la estación de entrada. 
Temperatura

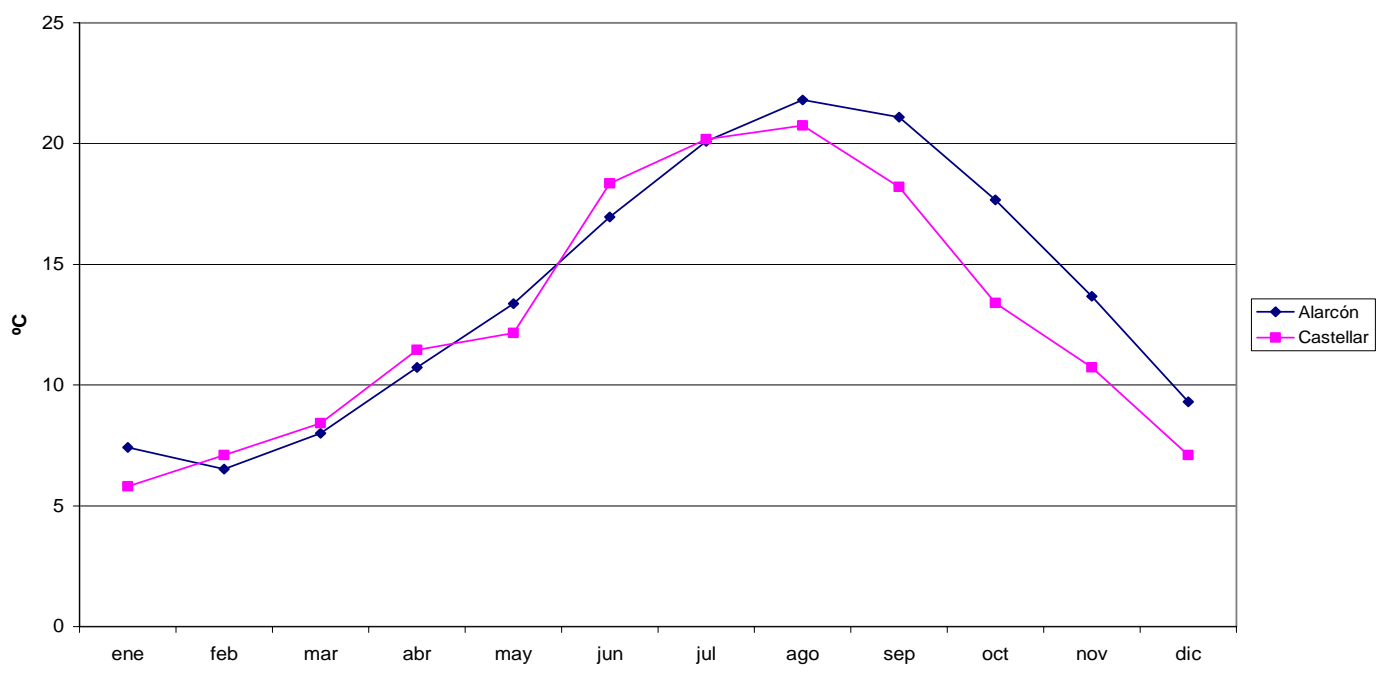

Figura 101. Temperaturas medias de las estaciones de Alarcón y Castellar.

Si se comparan las temperaturas medidas por las estaciones de Fuensanta y los Frailes y las sueltas de Alarcón se pueden ver los incrementos de temperatura que se producen en este tramo de río en épocas de sueltas bajas debido a la afección del acuífero de la Mancha.

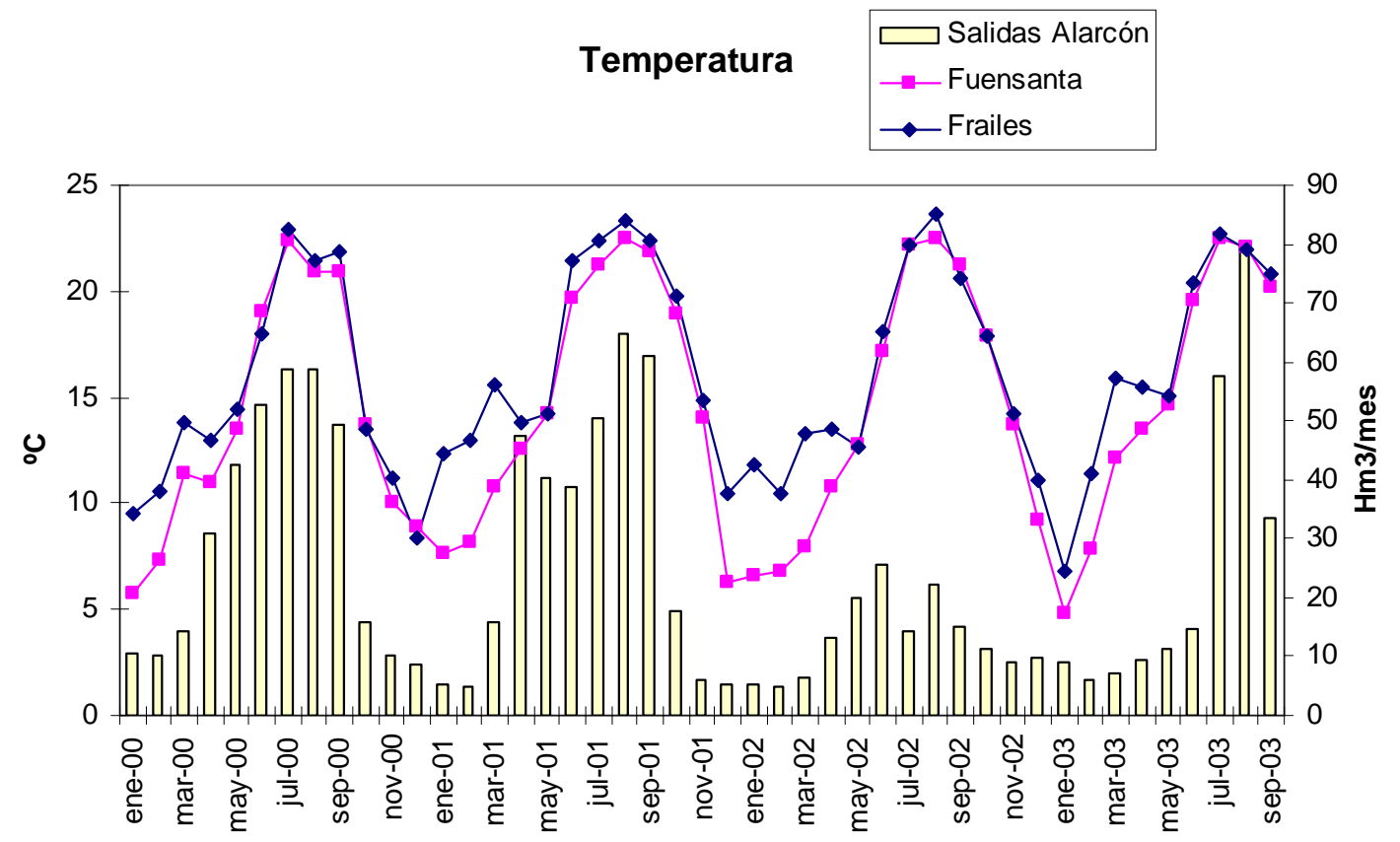

Figura 102. Temperaturas medidas por las estaciones de Fuensanta y los Frailes y su comparación con las salidas del embalse de Alarcón.

La similitud de las temperaturas de entrada y salida del embalse de Tous se deben al régimen de toma del agua en donde por lo general siempre se coge el agua de la zona superficial. 


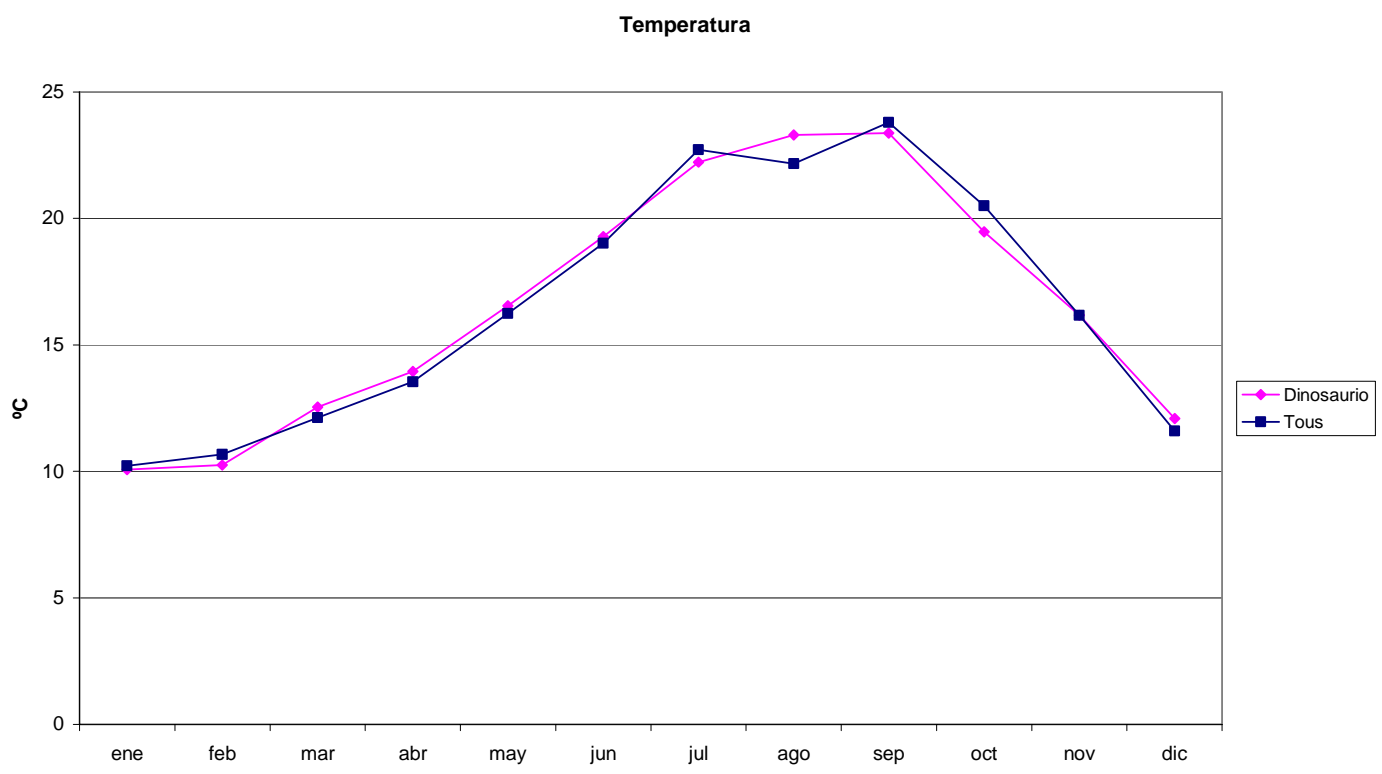

Figura 103. Temperaturas medias de las estaciones de Dinosaurio y Tous

\subsubsection{Análisis de la temperatura del río Cabriel.}

Las temperaturas medidas a lo largo del río Cabriel presentan bastante similitud con las del río Júcar. Como se puede ver en el perfil longitudinal hay fuertes gradientes de temperatura en el primer tramo. Además el embalse tiene un efecto de disminución de la temperatura por la estratificación térmica que se produce en el mismo.

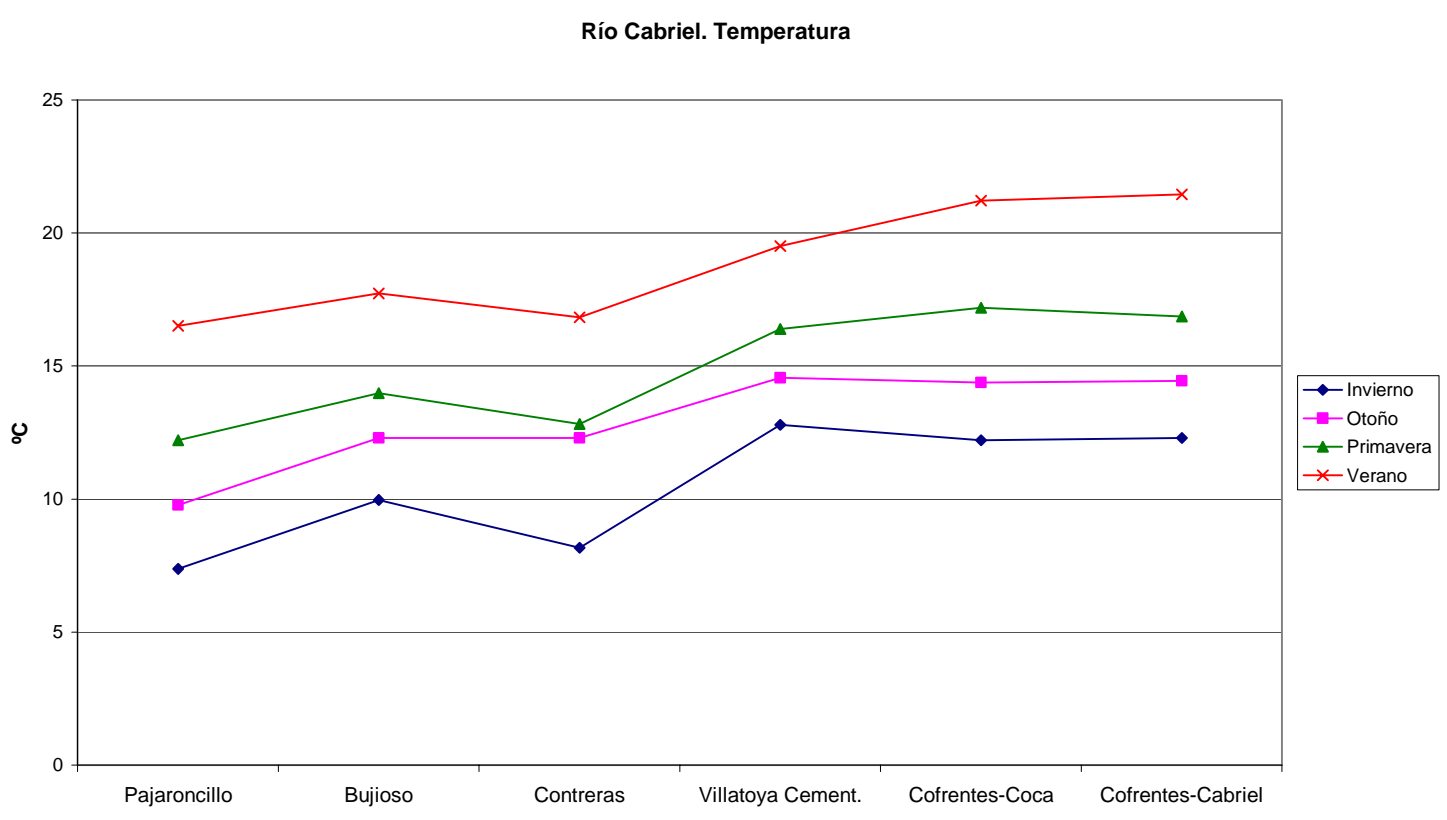

Figura 104. Perfiles medios estacionales de temperatura en el río Cabriel 
Ello produce un incremento de temperatura bastante significativo en el tramo aguas abajo del embalse. También hay que tener en cuenta la posible influencia de la posición de la estación ICA aguas arriba del embalse de Contreras, sita en la cola del embalse de Bujioso, en la caracterización de la temperatura del embalse.

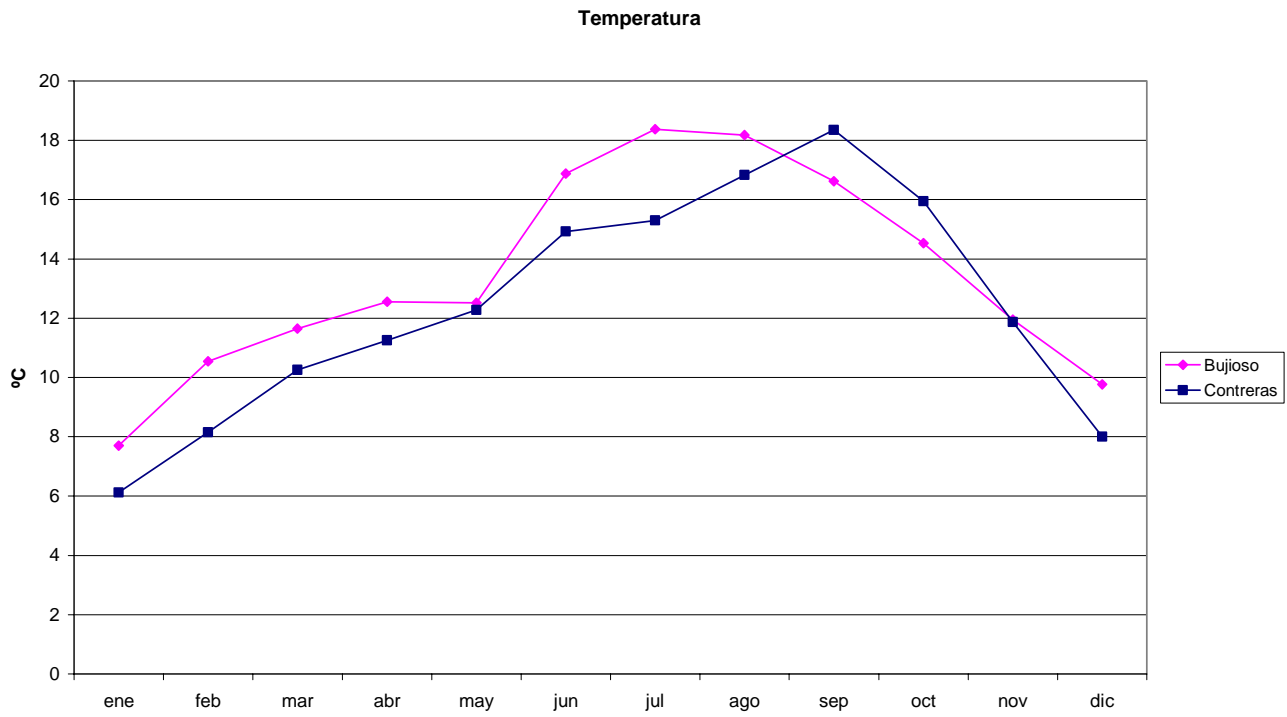

Figura 105. Temperaturas medias de las estaciones de Bujioso y Contreras.

El gráfico muestra temperaturas superiores en la estación de Bujisoso en todo el año excepto en los meses de otoño en donde la estación de Contreras presenta valores ligeramente superiores.

En el siguiente gráfico se muestra los valores de las temperaturas para las estaciones ICA aguas abajo del embalse de Contreras. 


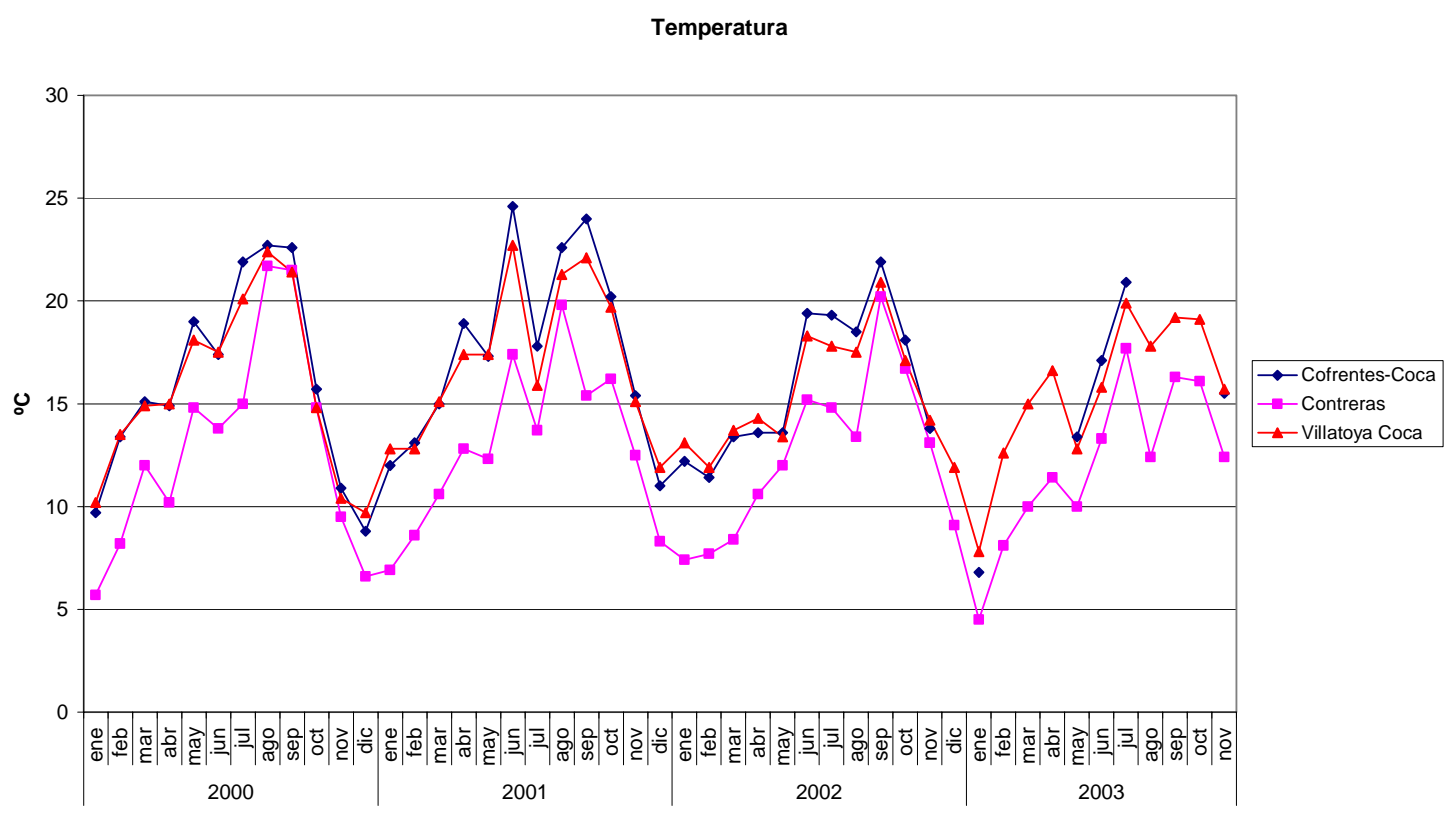

Figura 106. Temperaturas medidas por las estaciones de Cofrentes Coca, Contreras y Villatoya Coca.

Se puede ver un incremento importante de temperatura en el primer tramo y una estabilización de la misma en el segundo.

\subsubsection{Procesos de eutrofización en la cuenca.}

Entre los mayores problemas de calidad de aguas en embalses y zonas bajas de los ríos se encuentra la eutrofización de las aguas. Los procesos de eutrofización en las masas de agua tiene efectos adversos sobre diferentes los usos del agua como pueden ser suministro, recreativos y sobre el ecosistema acuático. Una masa de agua eutrofizada presenta un indeseable crecimiento vegetativo en particular de fitoplancton, perifiton y macrófitos.

La eutrofización produce un crecimiento desmesurado de cierta vegetación como el fitoplancton. Este crecimiento desmesurado afecta a las concentraciones de oxígeno disuelto provocando ciclos diarios extremos. Estas grandes oscilaciones de oxígeno afectan tanto a la vegetación como a algunas especies de peces, macroinvertebrados, etc. Sobre sistemas de abastecimiento de agua, las diatomeas y algas filamentosas pueden obstruir los filtros de las plantas de tratamiento de aguas así como reducir su eficiencia e incrementar el mantenimiento. Además, si la desinfección es por cloración se produce un aumento de la producción de sub-productos, como los trialometanos, cancerígenos a altas concentraciones. Otra afección se produce sobre los usos recreativos como el baño, la navegación o la pesca ya que se reduce la transparencia del agua y por los procesos de putrefacción. 
Los factores que controlan la eutrofización son el contenido de nutrientes, donde el limitante suele ser el fósforo, la luz, la temperatura y el caudal.

\subsubsection{Estado Trófico de los embalses de la cuenca del Júcar.}

Cabe decir que existe muy poca información para la caracterización de la calidad de los principales embalses de la cuenca del Júcar. No se disponen de perfiles de medición de ningún tipo de constituyente. Ni siquiera se disponen de perfiles térmicos. Por otro lado las estaciones de aguas arriba y aguas abajo de los embalses, en algunos casos están situadas en puntos bastante separados del embalse, haciendo que se pierda representatividad del mismo. Por otra parte a la vista de los datos disponibles se concluye que, en general, la calidad de los principales embalses es buena o, incluso, muy buena en algunos de ellos.

Se disponen de datos de clorofila-a de los embalses de Alarcón y Contreras desde 1994 hasta la actualidad con periodicidad trimestral. Estos datos han sido proporcionados por Comisaría de aguas de la CHJ. El siguiente gráfico muestra la serie de medidas disponible.

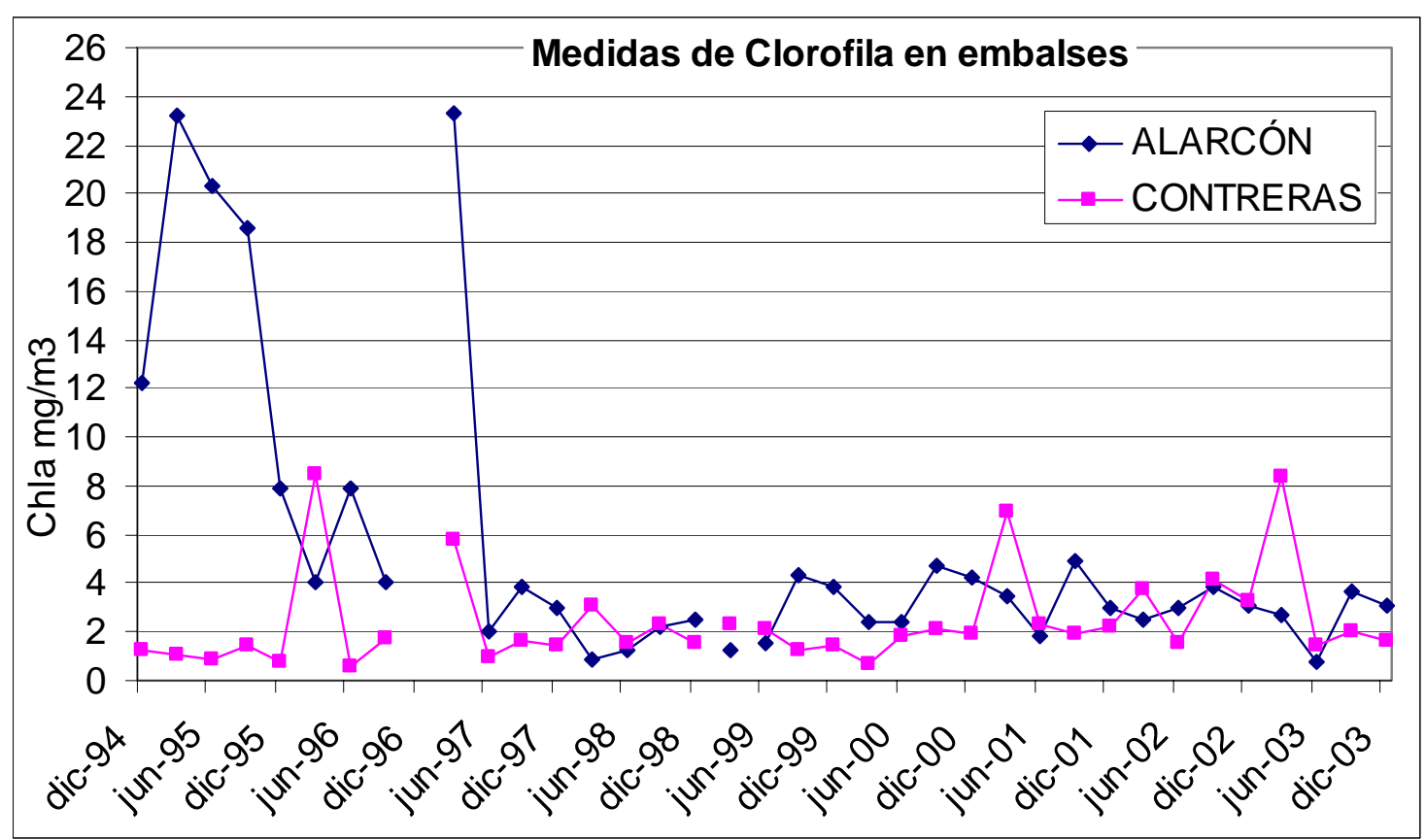

Figura 107. Medidas de clorofila-a en los embalses de Alarcón y Contreras.

Para el caso de Alarcón el episodio más problemático se dio en el verano de 1995. Existen diferentes estudios sobre el proceso de eutrofización de ese verano y sus consecuencias biológicas. El estudio TMConsult (1995) realiza un análisis sobre el estado trófico del embalse en el verano de 1995 y lo clasificaba como mesotrófico. Los problemas se debieron al escaso volumen con el que se quedo el embalse debido a la 
sequía del momento. Teniendo en cuenta todo el período el embalse se clasifica como mesotrófico mientras que si no se considera el episodio de sequía extrema acaecida en los años 1994-95, podría considerarse que estamos hablando de un embalse oligotrófico con tendencia a mesotrófica. Es de destacar que aunque se han realizado inversiones en depuración, en general los tratamientos no incluyen la eliminación de fósforo, que es de vital importancia para reducir el riesgo de eutrofización. Así es el caso de la depuradora de Cuenca, principal aporte de fósforo al embalse de Alarcón, que no cuenta con ningún tratamiento de eliminación de fósforo.

El embalse de Contreras presenta concentraciones de clorofila-a inferiores a los de Alarcón en la mayoría de los meses. Con los datos disponibles y atendiendo a la clasificación fijada se puede decir que el embalse de Contreras se encuentra en un estado oligotrófico.

Del embalse de Tous no se disponen de datos de medición de clorofila-a. Sin embargo el estudio CEDEX (2000) diagnostica un estado oligotrófico para el embalse. Los valores de fósforo medidos en la estación de calidad de entrada del embalse indican claramente los bajos contenidos de este constituyente.

\subsubsection{Eutrofización en tramos del río.}

El tramo final del río Júcar se caracteriza por una fuerte presión antropogénica tanto de vertidos urbanos como de retornos agrícolas, velocidades del agua lentas, con estancamiento del agua en los azudes de derivación y con altas temperaturas en los meses de verano. Esto hace que la zona sea de alto riesgo frente a procesos de eutrofización. No se dispone de información de clorofila-a en ningún punto de la zona. El punto en donde se puede diagnosticar una eutrofización clara es en el azud de la Marquesa. Los datos muestran concentraciones altas de nutrientes, con fuertes descensos en los meses de verano. Sin embargo lo más indicativo son las concentraciones de oxígeno disuelto. Varios meses del año, sobre todo en los meses de verano, se dan valores excesivamente altos llegando a superar los $20 \mathrm{mg} / 1$ en varios momentos.

Para los azudes de Sueca y de Cullera se tienen los datos del laboratorio de la $\mathrm{CHJ}$ que tampoco permiten clarificar mucho ya que aunque los contenidos de nutrientes son altos el oxígeno disuelto presenta tanto concentraciones casi nulas como cercanas a $\operatorname{los} 8 \mathrm{mg} / \mathrm{l}$. 
Oxígeno Disuelto

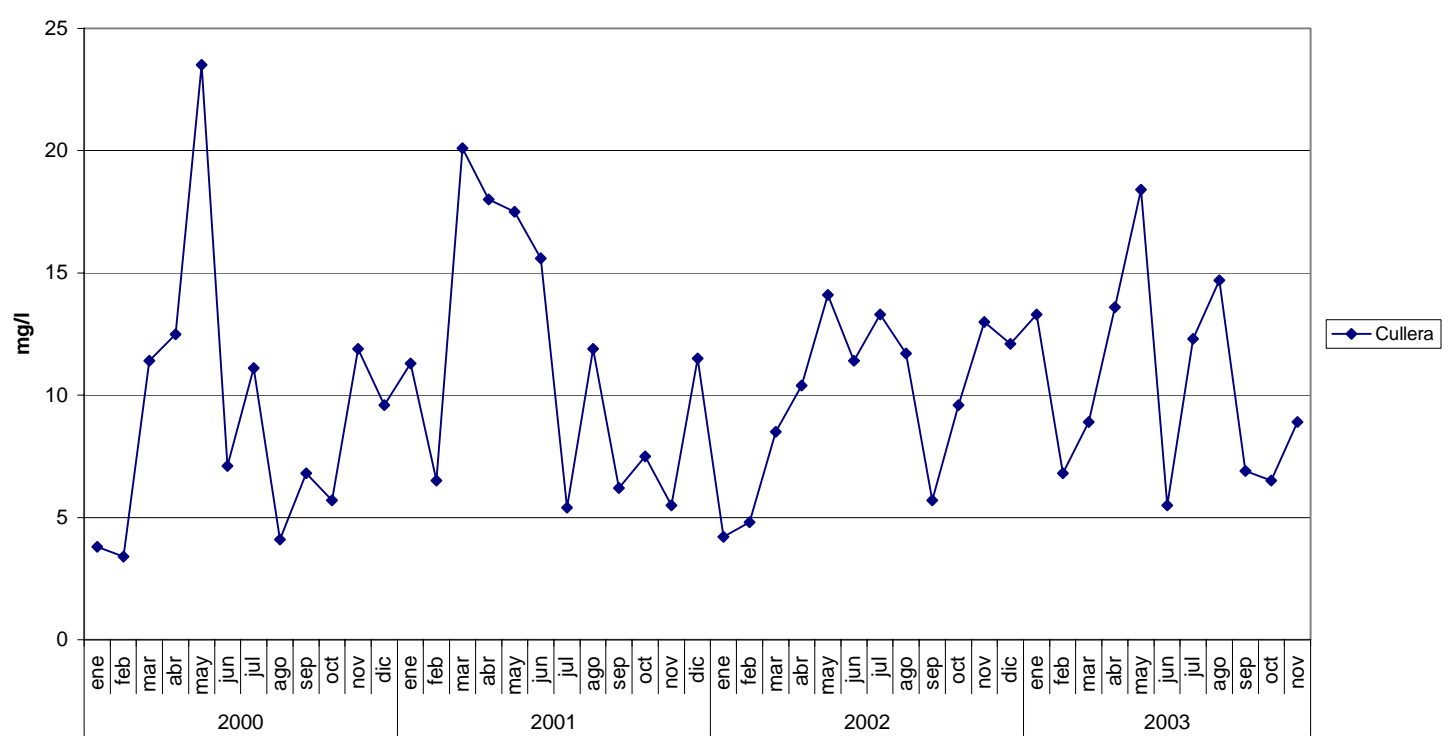

Figura 108. Concentraciones de OD medidas en la estación de Cullera.

Dadas, las características de alto riesgo de eutrofización la zona de los azudes con aguas lentas o estancadas, temperaturas altas y un alto contenido de nutrientes - es de destacar que posiblemente el factor sobre el que más fácilmente se pueda actuar es el tiempo de renovación del agua embalsada en los azudes. Probablemente el régimen de caudales altos en verano, con la consecuente renovación del agua de los azudes sea un factor muy favorable para evitar la eutrofización en los azudes. Aún así, es necesario un estudio de detalle de la zona en cuanto a la calidad de la misma y el riesgo de eutrofización. 


\subsubsection{Mejoras en la red ICA para la modelación de la calidad del agua.}

Las redes de control de la calidad del agua no están diseñadas para utilizar sus datos en la modelización de la calidad del agua. Sin embargo, los datos obtenidos pueden ser una fuente de gran valor ya que contienen series históricas de datos de calidad que pueden ser utilizadas para dicho fin. El objetivo de este apartado es establecer posibles mejoras en el diseño y forma de medición de la red de calidad ICA de la Confederación Hidrográfica del río Júcar con el objetivo de poder aplicar dichos datos a la modelación de la calidad del agua en ríos y embalses. Debido al ámbito del estudio se han analizado los datos de las estaciones pertenecientes al río Júcar y su afluente el Cabriel.

La red presenta diferencias entre la zona aguas arriba del embalse de Tous y aguas abajo del mismo. La parte de aguas arriba presenta un diseño bastante completo y una frecuencia de muestreo continua sobre todo a partir del año 2000. Por otro lado la zona aguas abajo de Tous, con una mayor presión antropogénica, presenta más problemas tanto de diseño como de frecuencia de muestreo, acentuándose los problemas conforme avanza el río hacia aguas abajo. 


\subsubsection{Consideraciones sobre la forma de medición.}

El primer problema que aparece a la hora de modelar la calidad con los datos de la red ICA son los umbrales de medición, o sea el límite por debajo del cual se considera nula la concentración del constituyente. En la mayoría de constituyentes es suficientemente baja sin embargo, en la medición de la demanda biológica de oxígeno a 5 días (DBO5) el umbral es de 2 ó $5 \mathrm{mg} / \mathrm{l}$ en función del laboratorio que lo mida. Aunque estas concentraciones representan aguas no contaminadas el establecimiento de estos umbrales implica no poder utilizar esos datos para la realización de cualquier modelo. Por otra parte hay que destacar que, en general, las mediciones de laboratorio permiten la medición de la DBO5 con una mayor precisión. En la siguiente figura se muestra los valores de algunas estaciones entre los embalses de Molinar y Cortes en el río Júcar.

DBO5

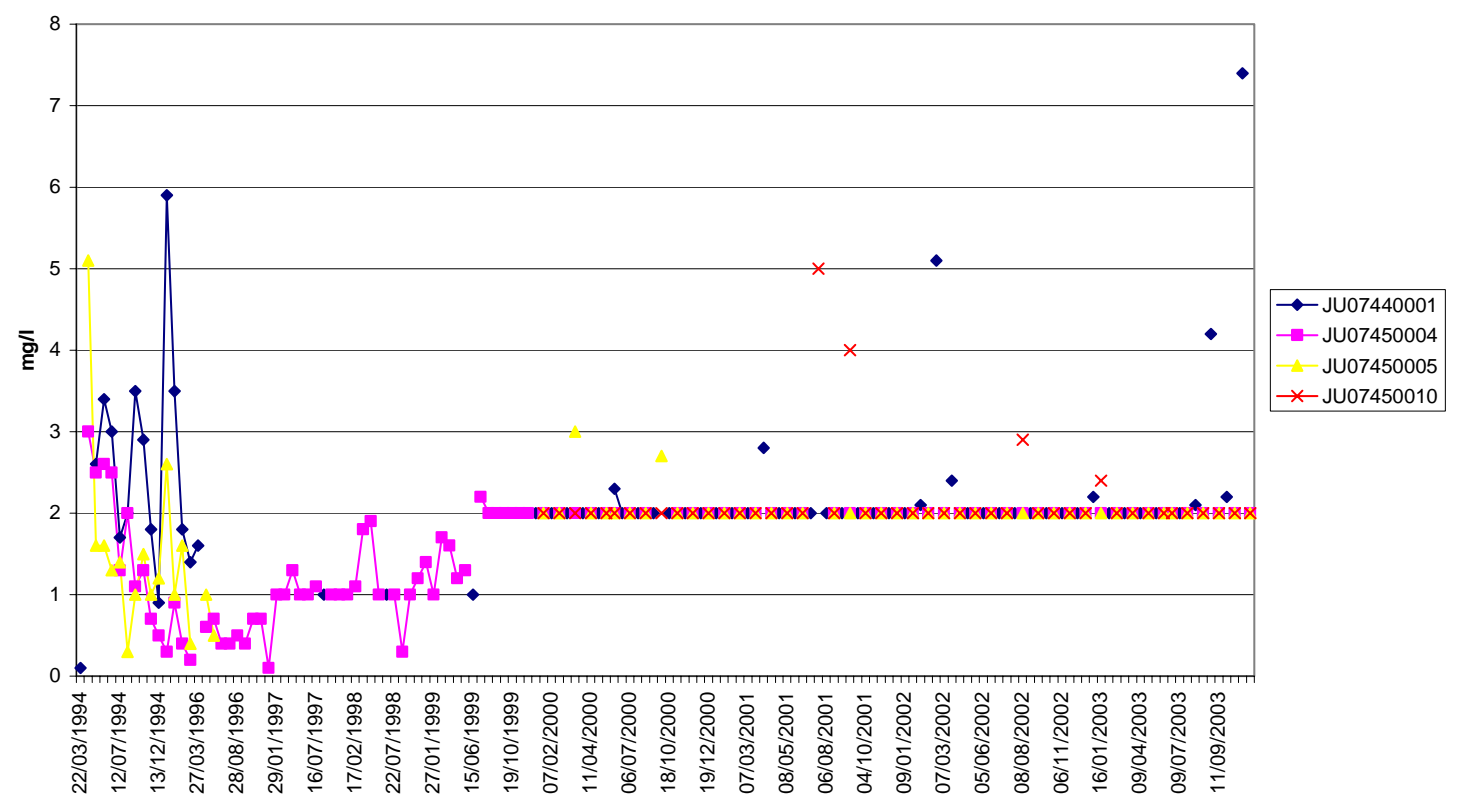

Figura 109. Medidas de DBO5 para las estaciones de JU0744001 - Embalse de Molinar; JU0745004 - Cofrentes Júcar; JU0745005 - Jalance y JU0745010 - Cautaban

Este efecto es generalizado en todas las estaciones analizadas y como se puede ver en el gráfico antes del verano de 1999 las mediciones se realizaban con valores inferiores a estos umbrales. La siguiente figura muestra el mismo efecto en algunas estaciones aguas abajo de Tous. En este caso el umbral de medición está en 5mg/1 
DBO5

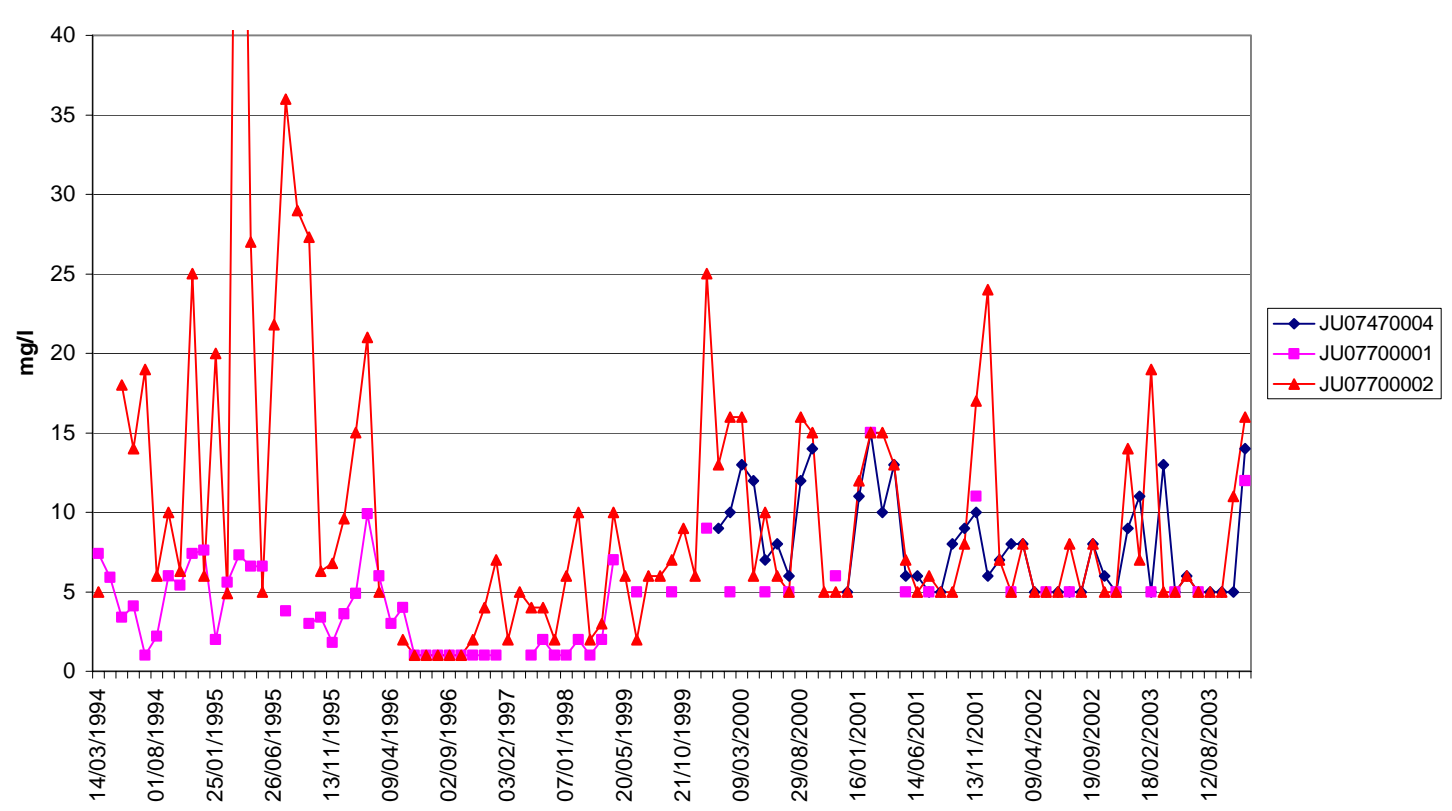

Figura 110. Medidas de DBO5 para las estaciones JU07470004-Alcira aguas arriba de confluencia con el Magro; JU07700001 - Alzira y JU07700002 - Río Verde.

Por otra parte, dado el rango de contenido de materia orgánica en que se está situando el río convendría utilizar la DQO o la DBO límite como indicador del contenido de la misma.

\subsubsection{Consideraciones sobre frecuencia de muestreo.}

Como se ha mencionado previamente, la frecuencia de muestreo en la zona aguas arriba del embalse de Tous han mejorado a partir del año 2000. Anteriormente a esa fecha no se pueden obtener series de medidas para períodos relativamente largos. Un ejemplo se estos problemas se da en el embalse de Contreras donde entre 1994 y 1996 se midió de forma alternativa en la estación de aguas arriba o en la de aguas abajo del embalse. Posteriormente entre 1996 y 1999 se pasó a medir sólo en la estación de aguas abajo excepto en algunos pocos meses en que se midió en la de aguas arriba en vez de la de aguas abajo. A partir del año 2000 se mide de forma continua en ambas estaciones.

La zona aguas abajo de Tous presenta más problemas en la frecuencia de muestreo que no han mejorado con el tiempo. En el tramo situado entre la ICA JU07690001 - Villanueva de Castellón y la JU07700001 - Alcira la frecuencia con la que se están tomando las medidas hace difícil la caracterización cualitativa del tramo, ya que en muchos de los parámetros, algunos de ellos tan importantes como el oxígeno disuelto, las medidas se realizan cada dos meses. Además los datos de las dos estaciones 
se están tomando de forma alterna en una u otra estación. Esta alternancia de datos dificulta su uso para la modelación. Este efecto se refleja en la siguiente figura.

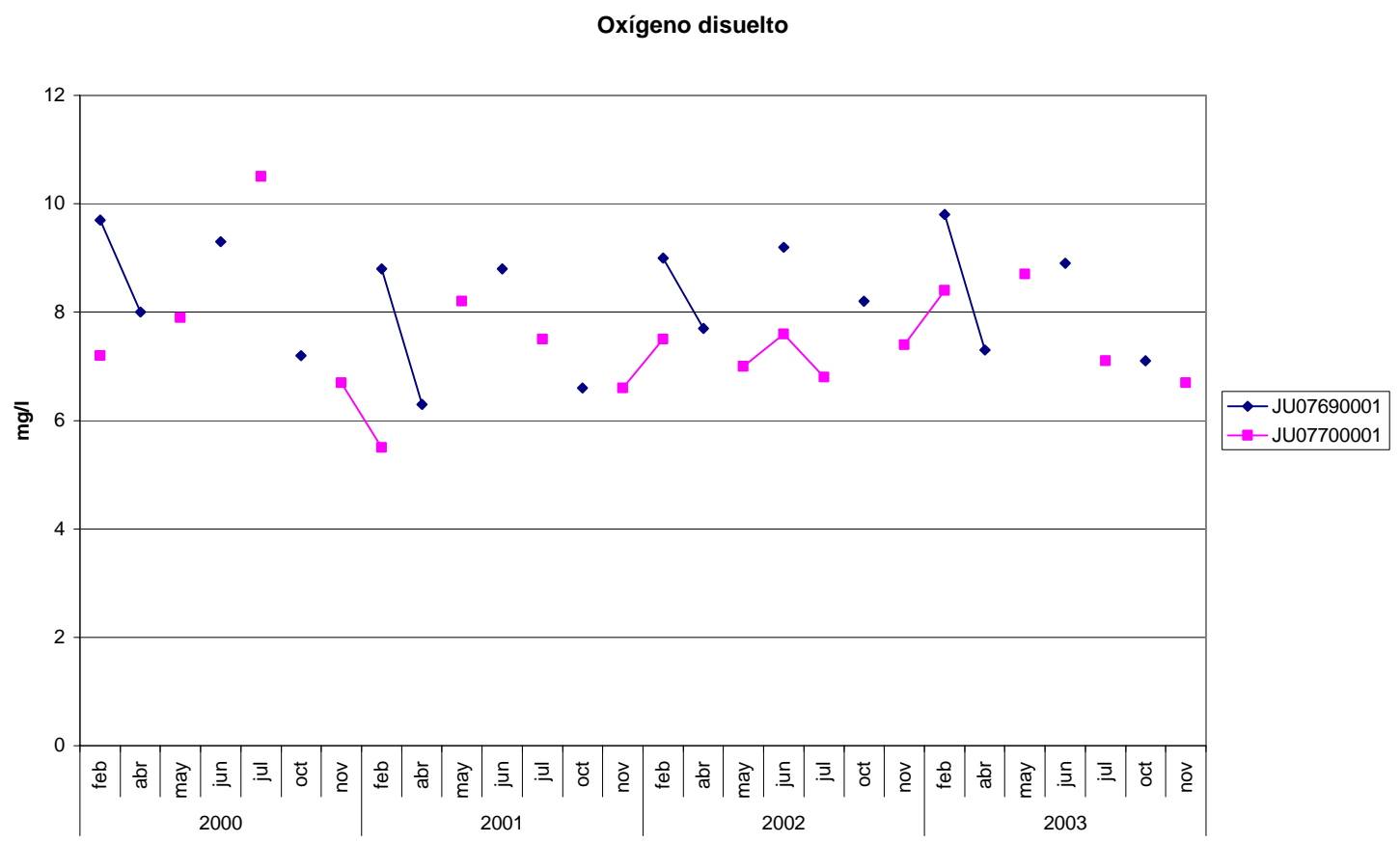

Figura 111. Mediciones para el oxígeno disuelto de las estaciones de JU07690001 - Villanueva de Castellón y JU07700001 - Alcira.

\subsubsection{Consideraciones sobre ubicación de estaciones.}

Aunque el diseño de la red es mejor en la zona aguas arriba de Tous se debe resaltar algunas posibles mejoras.

Las estaciones de Villatoya cementerio (JU07190002) y Villatoya antigua Coca (JU7190001) están separadas por $2 \mathrm{~km}$ sin que se presente ningún tipo de afección entre las mismas. En ambas estaciones se miden los mismos parámetros básicos como son el oxígeno disuelto, conductividad, temperatura, etc. Sin embargo el amonio, los nitritos y el fósforo total sólo lo mide la estación JU07190002 mientras que en la otra estación se miden los nitratos. Esto hace que se tenga una zona en donde los parámetros básicos se miden dos veces mientras que si se quiere obtener toda la información se debe utilizar las dos estaciones.

Algo parecido pasa con la estación JU07450007 - Molino Noria que aunque tiene una frecuencia de muestreo bastante baja está caracterizando la misma zona que la JU07450006 - Cofrentes Coca con valores prácticamente iguales. 


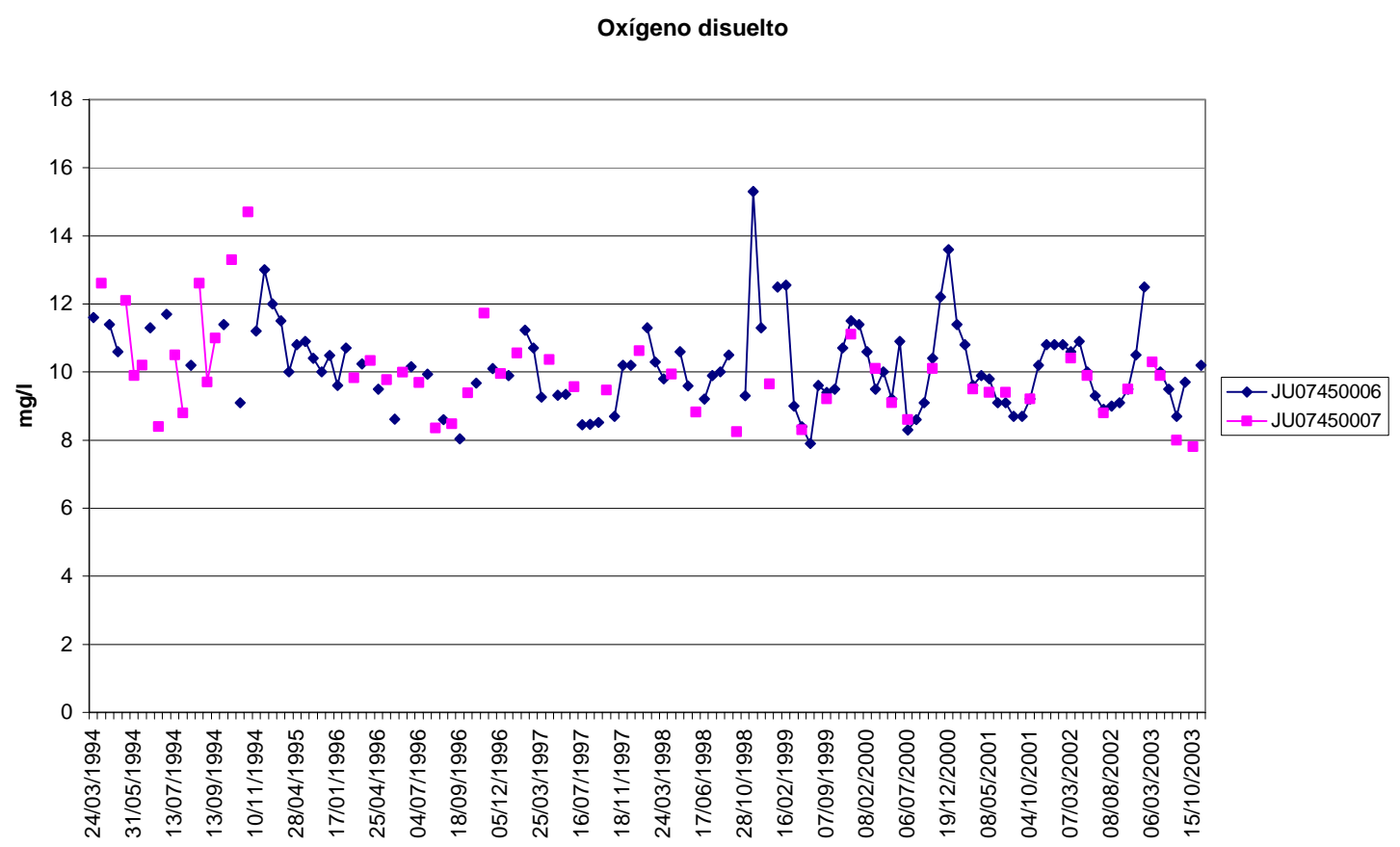

Figura 112. Medidas de oxígeno disuelto de las estaciones JU07450007 - Molino Noria y JU07450006 - Cofrentes Coca.

Por otra parte, hay que destacar que en la zona entre la estación de los Frailes hasta el embalse de Molinar puede que las estaciones no estén caracterizando la calidad del agua del río en la zona ya que la ubicación de las mismas no refleja la contaminación del tramo ni su evolución. Si se realizaran mediciones de calidad del agua aportante por los afluentes de Valdemembra y Ledaña o de alguna estación intermedia, se mejoraría la caracterización de la calidad del agua la zona.

El mayor problema que presenta el diseño de la red para la caracterización y modelación de la calidad del agua es el tramo aguas abajo de Tous agudizándose en la parte final del mismo. Destaca que, entre la confluencia del Magro y la desembocadura tan sólo existen dos estaciones una en el azud de Cullera y otra en el de la Marquesa. Además, como se ha comentado anteriormente la del azud de Cullera tan sólo dispone de tres medidas. Todo ello hace que se dispongan de muy pocos datos para caracterizar la calidad del agua en la zona con mayores problemas de calidad.

\subsubsection{Consideraciones sobre parámetros.}

Centrándose en los parámetros de estudio, existen dos parámetros de los seleccionados con problemas para establecer un modelo a escala global.

La medición de los nitratos en la cuenca presenta, espacialmente, algunas "zonas en sombra" en donde no se están midiendo. Esto perjudica a la modelación de los mismos y el establecimiento y cuantificación de los focos contaminantes. La primera 
zona que presenta problemas de caracterización es la del embalse de Contreras. Los nitratos se miden en la estación JU0636001- Pajaroncillo pero no se miden en la estación aguas arriba del embalse, JU06640006 - Bujioso, ni en la de aguas abajo JU06930002- Contreras. La estación más cercana donde se vuelven a medir es en la JU07910001 - Villatoya. Las mediciones de la estación de Villatoya presentan valores indicativos de contaminación por nitratos. Un seguimiento de los mismos en la zona cercana al embalse de Contreras podría aclarar la fuente de los mismos e incluso arrojar luz sobre la cuantificación de las filtraciones del embalse de Contreras.

En el río Júcar la primera estación que mide nitratos es la JU06100005 - Cuenca. Aunque la estación JU06340003 - Castellar no los mide la estación del embalse de Alarcón JU06910002 - Alarcón muestra que no es necesario debido a que no se produce un incremento de los mismos en esa zona. Las concentraciones aumentan conforme avanza el río sobre todo por la aportación subterránea del acuífero de la Mancha Oriental con concentraciones de nitratos afectadas por los riegos. Este efecto puede ser estudiado gracias a que se tienen mediciones en bastantes estaciones entre el embalse de Alarcón y el de Molinar. A partir de este punto ya no se tienen datos hasta las estaciones aguas abajo de Tous. Lo mismo pasa en el río Cabriel que aguas abajo de la estación JU07450006 - Cofrentes Coca ya no se tienen medidas. Esto hace que no se puedan analizar los nitratos en toda la zona aguas abajo el embalse de Molinar y en la zona de confluencia de los ríos Júcar y Cabriel.

Otro problema que se presenta es el análisis del fósforo. Como ya se comentó en el análisis de la calidad, la mayor parte de las medidas son de fósforo total excepto en las estaciones de calidad aguas abajo del embalse de Tous que sólo miden fosfatos. De las estaciones de aguas arriba sólo unas pocas miden fosfatos. Esta diferencia, a priori, tiene sentido ya que frente a problemas de eutrofización en lagos y embalses es más indicativo el fósforo total mientras que en tramos de río el fósforo disponible suele ser sólo el soluble reactivo. Sin embargo, esto provoca una interrupción en los datos a la hora de plantear un análisis o un modelo de toda la cuenca. Además, diversos autores abogan, en la medida de lo posible por el control de ambas variables tanto en embalses como en tramos de ríos.

\subsubsection{Otras posibles mejoras.}

Aunque no incide sobre la red de calidad ICA, algunos aspectos podrían mejorar y completar la información necesaria para la modelación de la calidad del agua en la cuenca. Estos son:

- Es importante que se conozcan los tiempos de viaje en las diferentes partes del río. 
- Por otra parte la caracterización hidrodinámica de los principales tramos de río permitiría un mayor conocimiento de la dinámica del mismo además de ser una fuente de información muy valiosa para modelos biológicos y de calidad del agua.

- Para la caracterización de la calidad del agua en los embalses, convendría disponer de perfiles de calidad (al menos térmicos) en los principales embalses. Con ello se podría caracterizar la calidad de los mismos a lo largo del año.

- Finalmente, el tramo final debería haber un control continuo sobre la posible eutrofización en el mismo en donde se realizasen medidas de nutrientes, clorofila-a, transparencia, macrófitas y perifiton.

\subsection{DESARROLLO DEL MODELO.}

Un modelo es una simplificación de la realidad que permite simular el comportamiento de la misma. La modelación conjunta a escala de cuenca representa un equilibrio entre los modelos simplificados de simulación de la gestión y los detallistas de la calidad. En este capítulos se describe cual ha sido el proceso para la construcción del modelo conjunto gestión - calidad para la cuenca del río Júcar.

Lo más común es, como pasa en este caso, disponer previamente de un modelo de gestión y modificarlo para tener en cuenta la calidad. En el caso de estudio se parte de un modelo actualmente utilizado por la Oficina de Planificación de la CHJ representante de la situación actual del sistema. En el anejo A se incluyen de forma ordenada todos los datos del modelo de gestión.

Debido a la simplicidad de los modelos de gestión se suele tener que realizar adaptaciones para poder acoplar un modelo de calidad. En particular suele ser bastante común tener que ampliar el número de tramos debido a diferentes causas como son:

- Es conveniente que los puntos en donde se dispone de datos de calidad sean inicio y fin de tramo para poder calibrar el modelo.

- Puede que, para algunas zonas, existan modelos previamente desarrollados y que interese una coordinación de elementos entre los modelos.

- Los tramos de río deben presentar zonas homogéneas en cuanto a propiedades hidráulicas se refiere.

- Debido a que el módulo de calidad desarrollado sólo admite la ubicación de vertidos en nudos, esta puede ser una causa de incremento de elementos en el modelo. 
- Otro condicionante puede ser un particular interés en una zona de estudio. En general, en las zonas más conflictivas suele ser necesario un mayor detalle de estudio lo que repercute en la fragmentación de un tramo de río.

En el caso del Júcar, el incremento de tramos de río no ha sido numeroso. Tan sólo en la parte de aguas abajo de Tous se han incluido más tramos. Ello obedece a la necesidad de obtener un modelo de mayor detalle que contemplara toda la complejidad de la zona. Otras modificaciones que se han realizado han tenido que ver con:

- Algunos embalses que sólo se consideraban como nudos ya que no tenían capacidad reguladora han tenido que considerarse por su afección sobre la calidad del agua.

- En algunas zonas la distribución de flujos estimada por el modelo no era suficientemente realista. Aunque este efecto no influía en el modelo de gestión debido que no se variaba la disponibilidad del recurso en los puntos de toma. Este hecho se ha tenido que modificar incluyendo nuevos elementos $\mathrm{y}$ cambiando costes para que la circulación a través de la red fuese lo más parecida a la realidad.

- Finalmente, en el apartado de "acoplamiento" se explican los últimos ajustes que se han realizado para que ambos modelos funcionen correctamente de forma conjunta.

\subsubsection{Esquema del modelo.}

A continuación se realiza una descripción de los elementos considerados en la modelación conjunta gestión - calidad. En la siguiente figura se muestra un grafo del esquema completo. Para una mayor claridad se realiza una descripción por tramos. El sistema del Júcar considerado consta del río Júcar y su afluente el Cabriel. El sistema esta regulado por tres embalses reguladores: Alarcón, Contreras y Tous. Otros como los de Cortes, Naranjero y Molinar tienen un uso exclusivamente hidroeléctrico.

El mayor volumen de agua es demandado por el sector agrícola. Las demandas urbanas suministradas desde este sistema son las poblaciones de Valencia, Albacete y Sagunto. La demanda industrial más significativa es la refrigeración de la Central Nuclear de Cofrentes. La mayor parte de los usos se ubican en el tramo final del río, la Ribera del Júcar. 


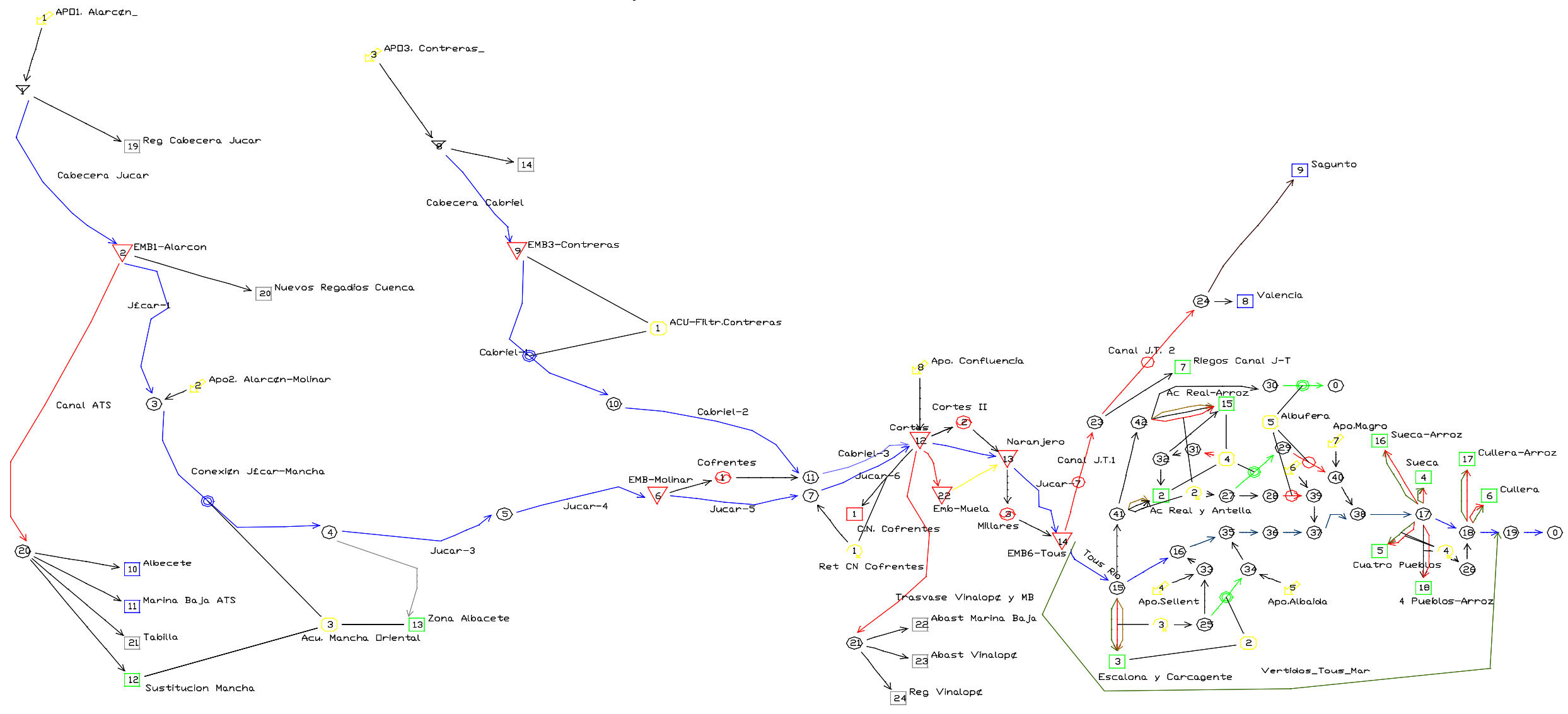

Figura 113. Figura esquema de la cuenca del río Júcar. 


\subsubsection{Río Júcar hasta el embalse de Molinar.}

El gráfico siguiente muestra los elementos considerados en el modelo entre el nacimiento del río hasta el embalse de Alarcón.

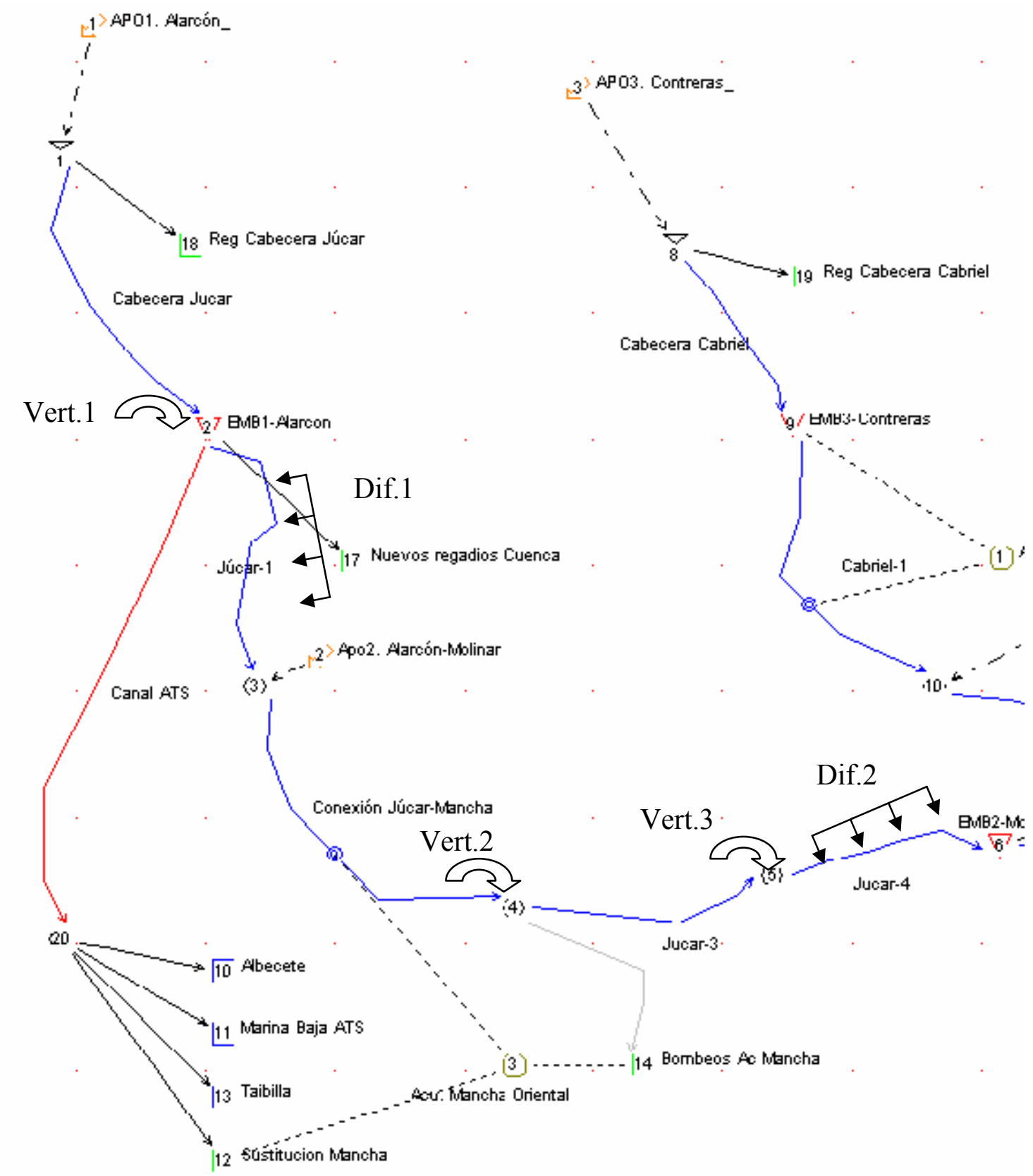

Figura 114. Esquema del río Júcar hasta el embalse de Molinar.

La parte de la cuenca aguas arriba del embalse de Alarcón se modela mediante un elemento aportación, "Apo1. Alarcón” que representa la cantidad de agua que aporta del cuenca sobre el embalse. Aguas abajo el elemento "EMB1.-Alarcón" sirve para modelar el embalse de Alarcón sobre el que se considera un elemento de vertido "Vert.1" que recoge todos los vertidos directos que se producen sobre el embalse. De este embalse parte una conducción, Canal ATS, que representa el acueducto Tajo - 
Segura que permite suministrar a las demanda de Albacete, Marina Baja, y Sustitución Mancha recogidas en el modelo. También del embalse de Alarcón parte la conducción "Júcar-1" que representa el tramo del río Júcar entre el embalse de Alarcón y la estación de calidad ICA de Fuensanta. Sobre ese tramo de río se ubica el elemento de contaminación difusa "Dif.1" que representa el efecto de un conjunto de vertidos urbanos ubicados a lo largo del tramo.

Al final de este tramo se ubica la aportación “Apo2.Alarcón-Molinar" que representa el aporte de agua tanto superficial como subterráneo de la intercuenca entre el embalse de Alarcón y el de Molinar. La relación del acuífero con el sistema superficial se tiene en cuenta modelando el acuífero, "Acu. Mancha Oriental", los bombeos sobre el mismo (modelados mediante el elemento de demanda "Bombeos Ac. Mancha") y considerando el tramo de río entre Fuensanta y los Frailes, "Conexión Júcar-Macha”, como un elemento conducción con conexión hidráulica con el acuífero.

La siguiente conducción, "Júcar-3", representa el tramo del río Júcar entre las estaciones ICA de los Frailes y la Recueja. En el inicio del tramo se ubica el vertido "Vert.2" que representa el efecto del conjunto de vertidos ubicados a lo largo del río Valdemembra.

El elemento "Júcar-4" representa el tramo del río Júcar entre la estación de calidad de la Recueja y el embalse de Molinar. Al inicio de este tramo se ubica el vertido "Vert.3" que representa el efecto de los vertidos del afluente de La Recueja y otros vertidos sobre el Júcar entre los cuales el de mayor importancia es el de la población Alcalá del Júcar. Sobre esta conducción se ubica el elemento de contaminación difusa "Dif.2" que representa el aporte de nitratos en la zona.

El elemento "EMB2-Molinar" sirve para modelar el embalse de Molinar.

\subsubsection{Río Júcar entre los embalses de Molinar y Tous.}

La figura siguiente muestra el esquema concebido para la modelación del sistema entre los embalses Molinar y Tous. 


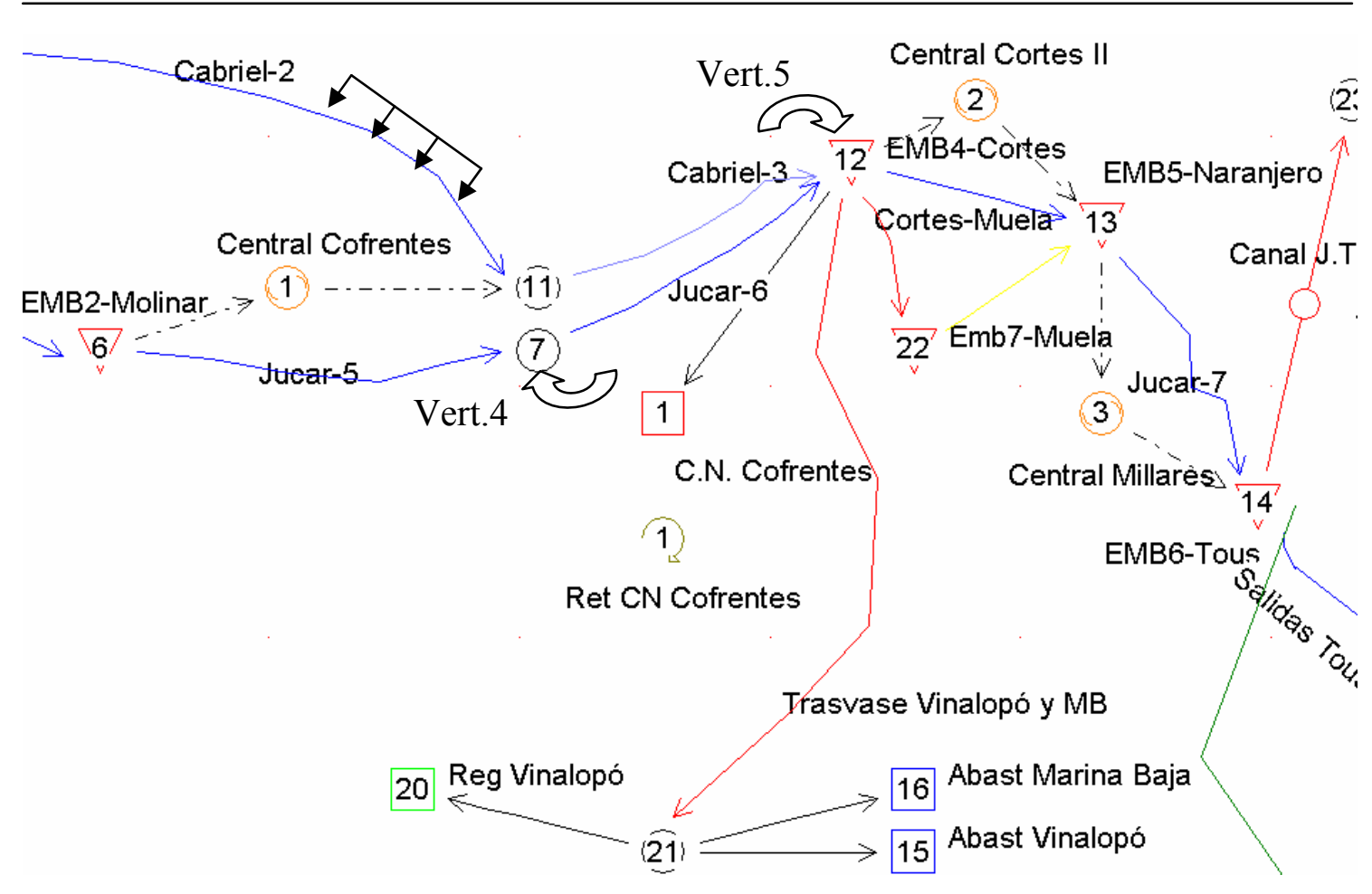

Figura 115. Esquema del río Júcar entre los embalses de Molinar y Tous.

Del embalse de Molinar parte la conducción "Júcar-5" y la estación hidroeléctrica "Central Cofrentes". Este último elemento representa tanto la central hidroeléctrica como la conducción de derivación a la misma. El elemento de conducción "Júcar-5" representa el río Júcar entre el embalse de Molinar y la confluencia con el afluente Reconque. El tramo de río entre ese punto y el embalse de Cortes se considera mediante el elemento "Júcar-6". Al inicio de dicho elemento se considera el vertido puntual "Vert.4" que representa la influencia del río Reconque sobre el sistema. Además en el mismo punto se produce el retorno de la Central Nuclear de Cofrentes que se suministra desde el embalse de Cortes.

Los embalses hidroeléctricos de Cortes, Naranjero y el depósito de la Muela se tienen en cuenta con los elementos "EMB4-Cortes", "EMB5-Naranjero" y "EMB7Muela".

Además se consideran las centrales hidroeléctricas de dichos embalses con los elementos "Central Cortes II" y "Central Millares".

En el embalse de Cortes se ubica un vertido, "Vert.5", que considera un conjunto de pequeños vertidos sobre el embalse. Partiendo de este embalse se considera, mediante un elemento de conducción la futura infraestructura de transferencia JúcarVinalopó. De esta transferencia toman agua las demandas "Reg. Vinalopó”, "Abast. Marina Baja" y "Abast. Vinalopó".

La conducción "Júcar-7" representa el tramo del Júcar entre los embalses de Naranjero y el de Tous (“EMB6-Tous"). 


\subsubsection{Río Cabriel.}

El siguiente grafo muestra el esquema de modelación del río Cabriel desde su nacimiento hasta su confluencia con el río Júcar en el embalse de Cortes.

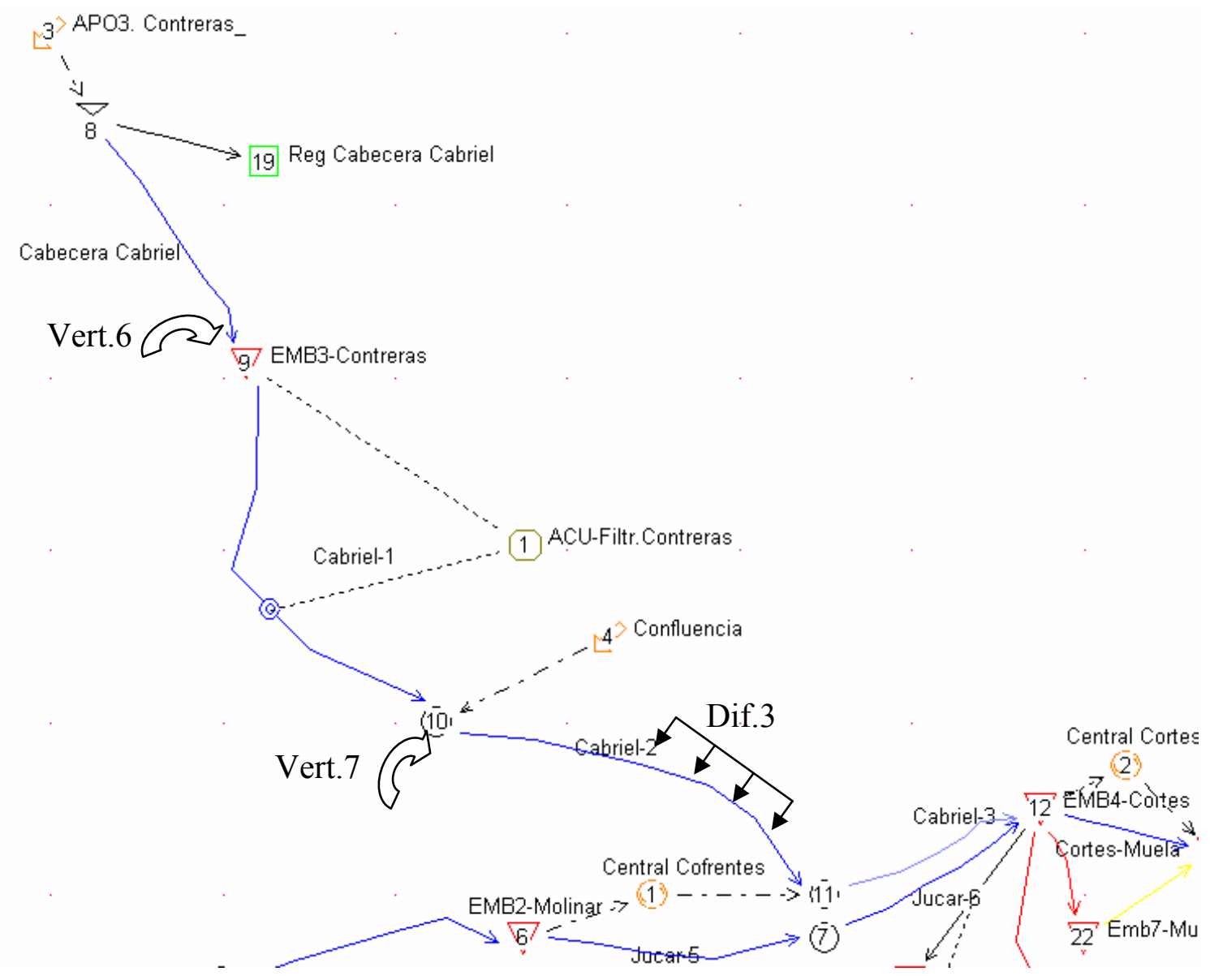

Figura 116. Esquema del río Cabriel.

El elemento aportación, “Apo3.Contreras", representa el aporte de agua de la cuenca del río Cabriel aguas arriba del embalse de Contreras. Dicho embalse se tiene en cuenta mediante el elemento embalse "EMB3-Contreras". Sobre el mismo se considera un elemento de vertido puntual, "Vert.6" que representa los vertidos que se producen de forma directa sobre el embalse. La conducción "Cabriel-1", representa el tramo del río Cabriel entre el embalse de Contreras y la población de Villatoya. Dicha conducción se ha considerado del tipo conexión hidráulica para junto con el acuífero "ACU-Filtr. Contreras" permitir modelar la incorporación de las filtraciones del embalse de Contreras aguas abajo del mismo.

El siguiente elemento conducción, "Cabriel-2", representa el río Cabriel entre Villatoya y el punto donde vierte sus aguas la central hidroeléctrica de Cofrentes. Al 
inicio del tramo se ubica el elemento de aportación Confluencia que representa la aportación estimada entre los embalses de Contreras, Molinar y el de Tous. La ubicación en ese punto se debe a que como se vio en el análisis de la calidad gran parte de esa aportación se genera en la intercuenca entre el embalse de Contreras y Villatoya.

En el mismo punto se ubica el vertido "Vert.7" que representa el vertido de la población de Villatoya. Sobre la conducción "Cabriel-2" se considera el elemento de contaminación difusa, "Dif.3", que permite incorporar el incremento de conductividad que se produce en el río en esa zona.

Finalmente el elemento de conducción "Cabriel-3" permite la modelación del río Cabriel entre la incorporación de las aguas del Júcar y el embalse de Cortes II.

\subsubsection{Río Júcar aguas abajo del embalse de Tous.}

El tramo final del Júcar se caracteriza por su complejidad y densificación de usos. En la siguiente figura se muestra el esquema de la zona. Además para una mayor claridad la figura 117 representa un esquema más sencillo de los elementos de la zona.

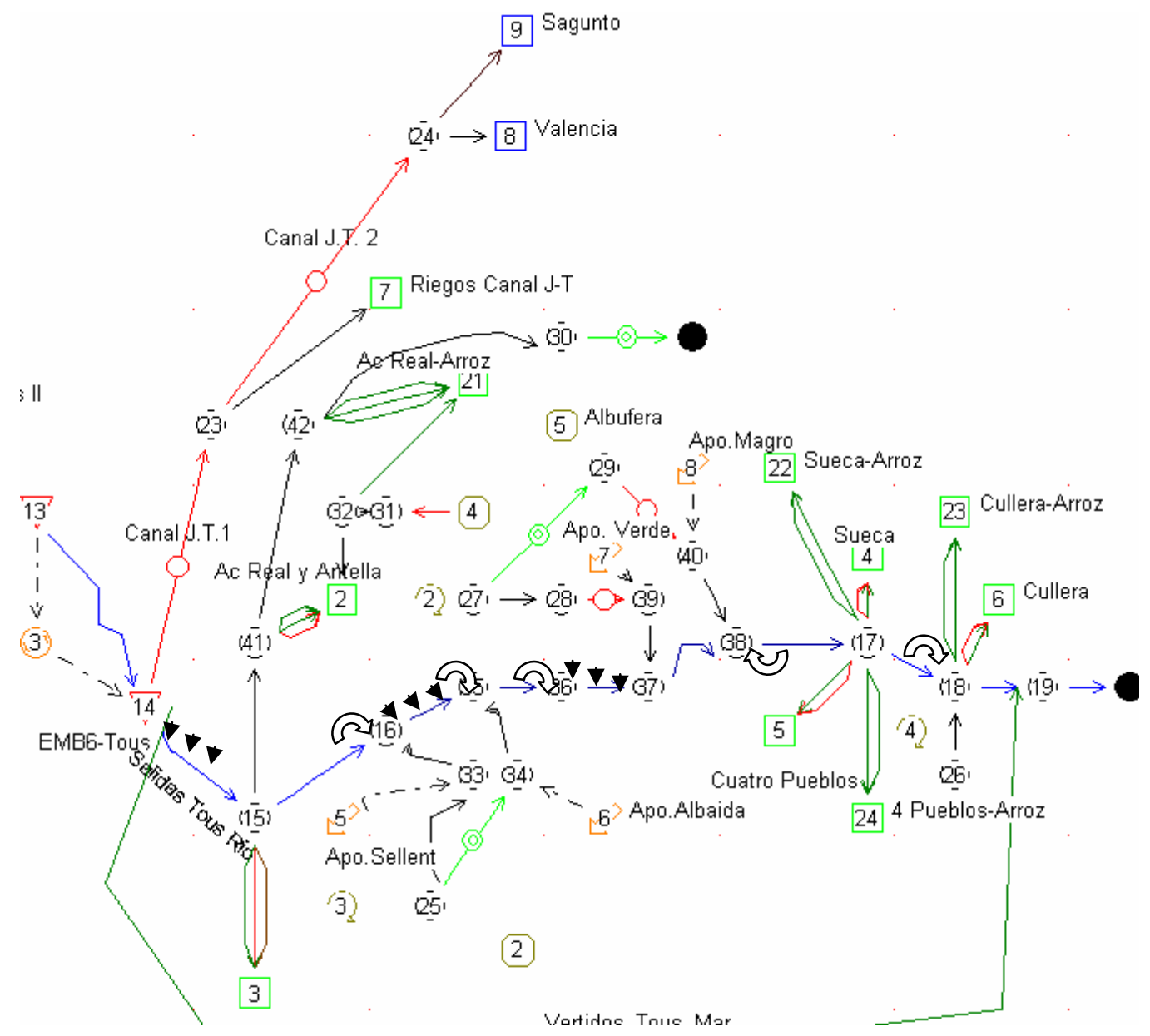

Figura 117. Esquema del río Júcar aguas abajo del embalse de Tous. 
Aunque existen muchos elementos que se utilizan para representar la compleja distribución de flujos en la zona, a continuación se realiza una explicación de los elementos más importantes. Una explicación más detallada del modelo y sus elementos puede encontrarse en (Ms-Ingenieros, 2002).

Se puede ver como desde el embalse de Tous parte una conducción denominada "Canal-J.T.1" a la que le sigue "Canal-J.T.2" que representan el canal Júcar Turia. Esta conducción permite el suministro de las demandas "Riegos Canal Júcar-Turia", "Valencia" y "Sagunto".

Por otro lado, partiendo también del embalse la conducción "Salidas de Tous a Río" representa el río Júcar entre el embalse de Tous y el azud de Antella. Aunque las tomas de las demandas de la Ribera Alta se realiza en diversos puntos de este tramo en el esquema se considera todas ellas ubicadas en el punto final. Estas demandas son "Acequia Real", "Antella", "Escalona" y "Carcagente". Además en este elemento de conducción se considera el elemento de contaminación difusa "Dif.4" que representa la erosión del lecho y el consecuente aporte de sólidos suspendidos debido al alto potencial erosivo de las sueltas de Tous.

El siguiente elemento de conducción "Antella-Sellent" representa el río Júcar entre el azud de Antella y su confluencia con el Sellent.

Este afluente se considera el elemento de aportación "Apo. Sellent" que recoge la aportación de la cuenca de este río. En el mismo nudo, junto a la aportación se incorporan los retornos superficiales de las acequias de Escalona y Carcagente.

Además el vertido "Vert.8" que representa el vertido urbano de las poblaciones de Álcantara del Júcar y Villanueva de Castelón se ubica en el mismo punto.

Este nudo es el nudo inicial de la conducción "Sellent - Albaida" que permite modelar el río Júcar entre las confluencias con los ríos Sellent y Albaida. En este tramo de río se considera un elemento de contaminación difusa, "Dif.5" que representa el efecto de un conjunto de vertidos que se ubica a lo largo del tramo.

El siguiente elemento conducción, "Albaida - Alcira", permite modelar el río Júcar entre su confluencia con el Albaida y la población de Alcira. En el nudo inicial de esta conducción se ubica la aportación "Apo. Albaida" que representa el aporte de agua de la cuenca del Albaida sobre el río Júcar. Además también se ubica el vertido puntual "Vert.9" que recoge el efecto de un conjunto de vertidos que se ubican en el río Albaida aguas abajo de la última estación ICA. Junto con el Albaida se incorporan los retornos subterráneos de las acequias de Escalona y Carcagente.

El tramo de río entre la población de Alcira y el río Verde se modela con el elemento conducción "Alcira-Verde". En el nudo inicial del elemento se ubica el 
vertido "Vert.10" que recoge el efecto de los vertidos de la población de Alcira, Alberique y un conjunto de poblaciones que realiza sus vertidos sobre el barranco de Barcheta. Además en este elemento se considera un elemento de contaminación difusa "Dif.6" de aporte de nitratos en la zona.

El elemento de conducción "Verde-Magro" representa el tramo del río Júcar entre las confluencias con el río Verde y el Magro. A inicio del elemento se considera el efecto del río Verde mediante un elemento de aportación "Apo.Verde". En el mismo nudo se incorporan los retornos superficiales de los riegos de las acequias Antella y Real.

El siguiente elemento de conducción, "Magro-Azud de Sueca", representa el tramo del río Júcar entre su confluencia con el Magro y el azud de Sueca. En el nudo inicial de esta conducción se considera el aporte del afluente del Magro, "Apo.Magro" y la incorporación de los retornos subterráneos de los riegos de las acequias Antella y Real.

El elemento conducción Azud de Sueca - Azud de Cullera representa el tramo del río Júcar entre ambos azudes. En el nudo inicial de esta conducción, representativo del azud de Sueca, se ubican las detracciones de los riegos de las acequias Sueca y Cuatro Pueblos. Además, en el mismo nudo, se considera un vertido "Vert.12" representativo del vertido producido por un matadero avícola en la zona.

El siguiente elemento de conducción "Azud de Cullera - Azud de la Marquesa" representa el tramo del río Júcar entre ambos azudes. En el nudo inicial, representativo del azud de Cullera se considera la detracción de agua por parte de de los riegos de la acequia de Cullera.

El siguiente elemento de conducción, "Salidas al mar", sirve para contabilizar las salidas de agua al mar. 


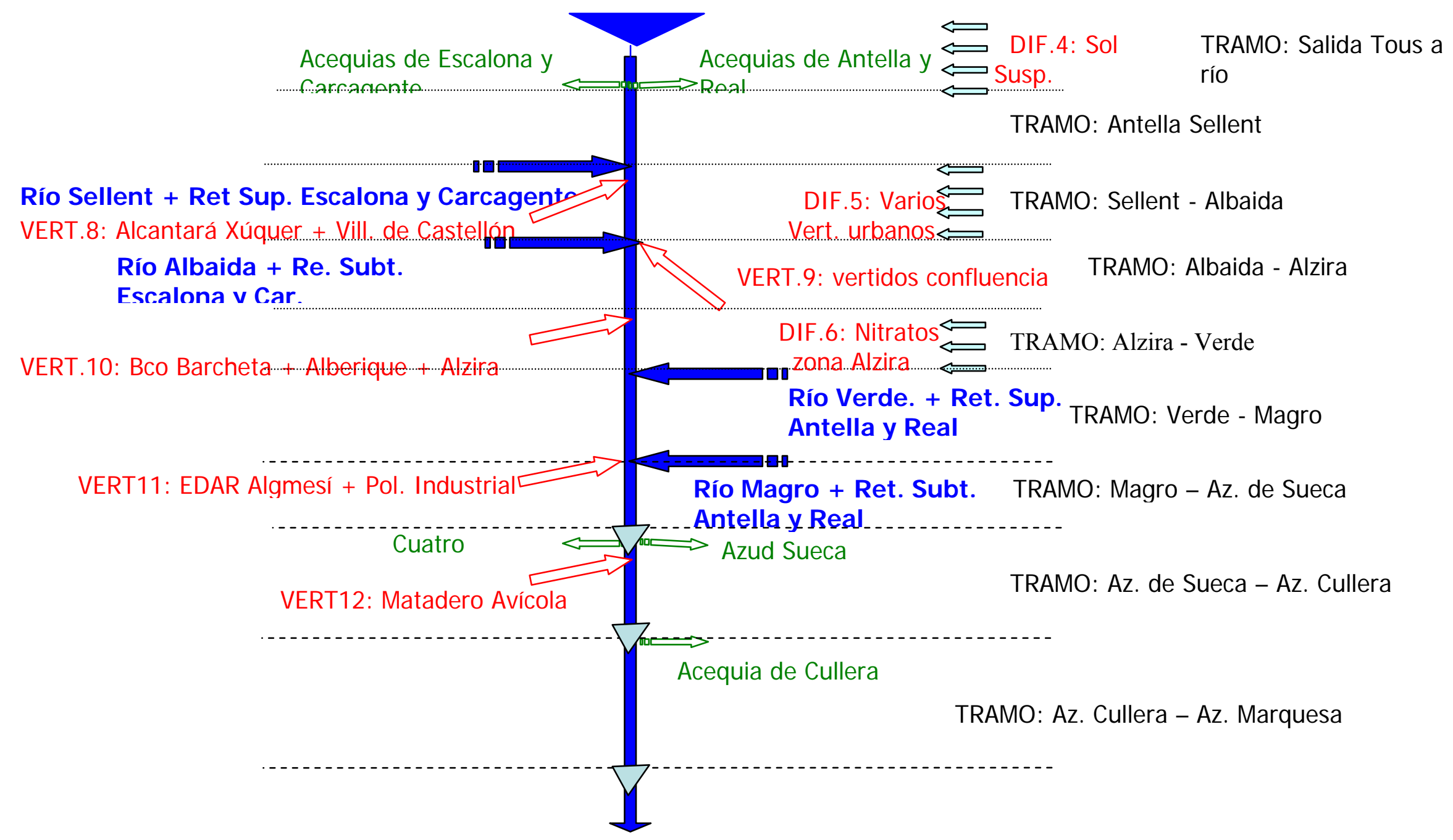

Figura 118. Esquema simplificado del río Júcar aguas abajo del embalse de Tous. 


\subsubsection{Descripción de los elementos del modelo.}

A continuación se describen los diferentes elementos concebidos en el modelo y las estimaciones necesarias para su inclusión en el modelo de Calidad. En el anejo A se aportan todos los datos necesarios para la modelación de la calidad del sistema. Se ha realizado la modelación de las siguientes variables de calidad:

- Conductividad

- Sólidos Suspendidos

- $\mathrm{DBO}_{5}$

- Oxígeno Disuelto

- Amonio

- Nitritos

- Nitratos

- Fósforo Total

Dentro del ciclo del nitrógeno no se ha considerado el nitrógeno orgánico por la falta de disponibilidad de datos. El fitoplancton no ha sido considerado por el mismo motivo, el único punto en donde la actividad biológica tiene especial importancia es en el azud de la Marquesa.

\subsubsection{Aportaciones.}

Todo modelo de gestión necesita como datos de entrada las aportaciones al sistema. En el módulo SIMGES se han definido como elementos de aportación. El modelo del sistema del Júcar dispone de 8 aportaciones.

- Apo1. Alarcón.

- Apo2. Alarcón - Molinar.

- Apo3. Contreras.

- Apo4. Confluencia.

- Apo. Sellent.

- Apo. Albaida.

- Apo. Verde.

- Apo. Magro. 
En el modelo original las cuatro últimas aportaciones se concebían como una sola. En este modelo debido al mayor detalle desarrollado para la zona baja del río se han considerado de forma desagregada. Para ello se han estimado unos coeficientes de reparto según datos disponibles para algunos años de las aportaciones de los diferentes afluentes.

Para incorporar los elementos aportación al modelo de calidad se deben obtener las series de calidad de cada una de las aportaciones para los períodos simulados. Para el período entre octubre de 1999 y 2001 en el que muchos de los elementos se calibran se han estimado de la siguiente manera:

- Apo1. Alarcón: se asume la calidad de la estación ICA aguas arriba del embalse Castellar.

- Apo2. Molinar: se considera la misma calidad que la de la estación ICA de los Frailes. Para la conductividad y los nitratos los valores se obtienen mediante un balance de masas.

- Apo3. Contreras: se obtiene mediante balance de masas de las diferentes estaciones de calidad de los ríos aportantes al embalse.

- Apo4. Confluencia: se considera la estación ICA Cofrentes-Cabriel como representativa de esta aportación.

- Las aportaciones inferiores, Sellent, Albaida, Verde y Magro se obtienen mediante las estaciones de calidad ICA finales de cada río. Debido a los pocos datos que se disponen del Magro cuando había falta de los mismos se ha asumido que la calidad es igual a la del Verde. Esta es una consideración bastante desfavorable en cuanto a la calidad del agua del río Magro. Cuando, en cualquier aportación, no había datos suficientes de alguna variable se han utilizado datos de estaciones cercanas.

Para el período de simulación de los escenarios, entre octubre de 1985 hasta septiembre de 2001, no se dispone de una serie de datos lo suficientemente larga. De forma global sólo desde el año 2000 puede decirse que se disponen de datos para montar series de aportaciones. Para los períodos en que no se disponen de datos la estimación de series de aportaciones puede realizarse por los siguiente métodos:

- Modelos precipitación escorrentía de simulación continua que incorporen módulos de calidad.

- Generación de series sintéticas.

- Estimaciones directas a partir de los datos disponibles. 
La primera opción supone un trabajo excesivo para el fin que se busca en este estudio. Por otro lado no se disponen de datos suficientes para establecer un modelo estocástico lo suficientemente robusto. Por ello se han realizado una serie de hipótesis para realizar una estimación directa a partir de los datos:

- Para todas las aportaciones, excepto las de Alarcón y Contreras, se han estimado un año medio y se supone que se repite todos los años de la serie.

- Para las dos aportaciones de cabecera se realiza la misma hipótesis para las variables consideradas como naturales, o sea el oxígeno disuelto y la conductividad. Para el resto de variables se ha obtenido, mediante estimación directa, la carga media de contaminante que produce la cuenca de cada uno de ellos. La aportación se considera con valores muy bajos de concentraciones y adicionalmente se crea un vertido ficticio, sobre el mismo nudo que la aportación que esta vertiendo la carga estimada. Aunque el método produce cierta dependencia sobre el caudal de la aportación la simulación del modelo refleja el buen funcionamiento de la hipótesis.

\subsubsection{Infraestructuras.}

Como infraestructura de almacenamiento se consideran los embalses de Alarcón, Contreras, Molinar, Tous, Cortes y Naranjero así como el depósito de la Muela. En cuanto a canales artificiales se tienen en cuenta el canal Júcar - Turia, la parte del acueducto Tajo Segura y la el tramo de salida del futuro trasvase Júcar - Vinalopó.

La modelación de los canales se hace mediante conducciones de tipo 1 (normales) menos la del canal Júcar - Turia que se realiza mediante una conducción con filtraciones (tipo 2). Además esta conducción se impone un máximo de circulación $82.94 \mathrm{hm}^{3} /$ mes debido a la capacidad del canal.

En cuanto a los embalses los datos de entrada para su consideración en el modelo de gestión son los siguientes:

- Capacidades máximas mensuales

- Curva Cota Superficie Volumen

- Valores medios de evaporación mensual

- Posibles filtraciones, mediante una ley potencial

- Volúmenes mínimos mensuales

- Volúmenes objetivo mensuales

- Volumen inicial al inicio de la simulación. 
Debido a que todos los embalses se consideran en el modelo de calidad como un depósito completamente mezclado los datos necesarios para la modelación de la calidad son los siguientes:

- Curva de temperatura mensual en el embalse.

- Número de intervalos en el cálculo de la calidad dentro de un mes.

Se han realizado pruebas para cada uno de los embalses para estimar el diferencial de cálculo a escoger. Finalmente se ha escogido un número de intervalos de 50 para todos los embalses.

En cuanto a la temperatura de los embalses se ha obtenido el año medio de las estaciones de calidad inmediatamente aguas abajo de cada uno de ellos. En el análisis de la calidad se comprueba que la temperatura en la mayor parte de la cuenca se mantiene bastante constante de año en año. Por otro lado, no se dispone de valores de temperatura dentro del embalse por lo que se ha tenido que utilizar los de las estaciones de aguas abajo.

\subsubsection{Demandas.}

En la siguiente tabla se recogen las demandas consideradas en el modelo. 
Capítulo 5. Aplicación del módulo GESCAL a la cuenca del río Júcar.

\begin{tabular}{|c|c|}
\hline TIPO DE DEMANDA & \\
\hline INDUSTRIAL & C.N. Cofrentes \\
\hline \multirow[t]{6}{*}{ URBANAS } & Valencia \\
\hline & Sagunto \\
\hline & Albacete \\
\hline & Marina Baja ATS \\
\hline & Taibilla \\
\hline & Abast. Vinalopó \\
\hline \multirow[t]{17}{*}{ AGRARIAS } & Abast. Marina Baja \\
\hline & Ac. Real y Antella \\
\hline & Ac. Real Arroz \\
\hline & Escalona y Carcagente \\
\hline & Sueca \\
\hline & Sueca Arroz \\
\hline & Cuatro Pueblos \\
\hline & Cuatro Pueblos -Arroz \\
\hline & Cullera \\
\hline & Cullera - Arroz \\
\hline & Riegos canal J-T \\
\hline & Sustitución Macha \\
\hline & Bombeos Ac. Mancha \\
\hline & Nuevos Regadíos Cuenca \\
\hline & Regadíos cabecera Júcar \\
\hline & Regadíos cabecera Cabriel \\
\hline & Regadíos Vinalopó \\
\hline
\end{tabular}

Tabla 3. Demandas consideradas en el modelo.

\subsubsection{Caudales ecológicos.}

Se han tenido en cuenta los caudales mínimos definidos en el PHJ aguas abajo de los embalses de Alarcón, Contreras y Tous. Además como resultado del acople de 
los modelos se han establecido nuevos caudales mínimos que mejoran el comportamiento del modelo de gestión.

\subsubsection{Acuíferos.}

Se han incluido cinco acuíferos para modelar el efecto de las aguas subterráneas en el sistema:

- El acuífero “Acu. Mancha Oriental” se modela como un acuífero pluricelular englobado en dos celdas, con un coeficiente de descarga para cada una de ellas. La calidad del acuífero se asume igual a la de la aportación “Apo2. Alarcón Molinar".

- El acuífero "Acu. Filtr. Contreras" recoge las filtraciones del embalse de Contreras y las incorpora aguas abajo del mismo con cierto desfase temporal. Se asume que la calidad del acuífero es la misma que la de la ICA aguas arriba del embalse.

- El acuífero "Acu. Ret. Esc. y Carcaj." permite incorporar los retornos subterráneos de los riegos de las acequias Escalona y Carcagente. Se asume que estos retornos subterráneos retornan con la escorrentía del afluente Albaida por lo que la calidad del acuífero se considera igual a la aportación del citado afluente.

- Del mismo modo el acuífero “Acu. Ret. Real” permite incorporar los retornos de los riegos de la acequia con el mismo nombre. Se asume que estos retornos se reincorporan con las aguas del Magro por lo que la calidad de este acuífero se asume que es la misma que la de la aportación "Apo. Magro".

- Finalmente el acuífero "Albufera" es un acuífero ficticio y que no modifica la calidad del agua en el sistema por lo que se han dispuesto unos valores arbitrarios.

\subsubsection{Centrales Hidroeléctricas.}

Las centrales consideradas han sido las de "Cofrentes", "Cortes II" y "Millares". La central de Cofrentes representa la central que turbina el agua procedente del embalse de Molinar. La central hidroeléctrica de Cortes II representa el turbinado de agua en el embalse del mismo nombre. La central de Millares representa el turbinado de la central con el mismo nombre en el embalse de Naranjero. 
En el modelo se asume que las centrales hidroeléctricas no tienen ningún efecto sobre la calidad del sistema.

\subsubsection{Retornos.}

Los retornos considerados en el modelo han sido los siguientes:

- Retorno de la Central Nuclear de Cofrentes: se considera la misma calidad que la de la estación ICA de Dinosaurio excepto la conductividad que se asume un valor constante de $1500 \mu \mathrm{s} / \mathrm{cm}$.

- Retorno Antella y Ac. Real representativo de los retornos de los riegos de las acequias Antella y Real asumiendo la misma calidad que la medida en la última estación de calidad ICA del río Verde.

- Retorno Sup. Escalona y Carc. Representa los retornos de los riegos de las acequias Escalona y Carcagente con una calidad similar a la del río Sellent excepto la conductividad, la cual se considera con un valor fijo de $1000 \mu \mathrm{s} / \mathrm{cm}$.

\subsubsection{Conducciones.}

De todas las conducciones consideradas en el modelo de gestión sólo algunas de ellas se consideran en el modelo de calidad. Ello es debido a que, muchas otras conducciones son ficticias o de corta longitud por lo que no tienen ningún efecto sobre la calidad del agua.

En la tabla siguiente se muestra las conducciones en las que se considera la calidad con los datos necesarios para su modelación. 


\begin{tabular}{|l|l|l|l|l|l|l|}
\hline & $\begin{array}{l}\text { Longitud } \\
(\mathrm{m})\end{array}$ & $A x(m)$ & $\alpha_{u}$ & $\beta_{u}$ & $\alpha_{H}$ & $\beta_{H}$ \\
\hline Júcar-1 & 47683 & 100 & 0.744 & 0.1 & 0.222 & 0.4 \\
\hline Júcar-3 & 37012 & 100 & 0.744 & 0.1 & 0.222 & 0.4 \\
\hline Júcar-4 & 21311 & 100 & 0.744 & 0.1 & 0.222 & 0.4 \\
\hline Júcar-5 & 18500 & 100 & 0.744 & 0.1 & 0.222 & 0.4 \\
\hline Júcar-6 & 1242 & 100 & 0.744 & 0.1 & 0.222 & 0.4 \\
\hline Cabriel-2 & 35207 & 100 & 0.744 & 0.1 & 0.222 & 0.4 \\
\hline Cabriel-3 & 3849 & 100 & 0.744 & 0.1 & 0.222 & 0.4 \\
\hline Jucar-7 & 10000 & 100 & 0.744 & 0.1 & 0.222 & 0.4 \\
\hline Salidas Tous Rio & 15000 & 100 & 1.057 & 0.1 & 0.323 & 0.4 \\
\hline Antella-Sellent & 500 & 5 & 1.057 & 0.1 & 0.323 & 0.4 \\
\hline Sellent-Albaida & 7750 & 100 & 0.376 & 0.1 & 0.303 & 0.4 \\
\hline Albaida-Alzira & 22000 & 100 & 0.376 & 0.1 & 0.303 & 0.4 \\
\hline Alzira-Verde & 2500 & 10 & 0.15 & 0.14 & 0.6 & 0.5 \\
\hline Verde-Magro & 2250 & 10 & 0.15 & 0.14 & 0.6 & 0.5 \\
\hline Magro-Azud Sueca & 10000 & 100 & 0.15 & 0.14 & 0.6 & 0.5 \\
\hline Azud Sueca-Azud Cullera & 9900 & 100 & 0.16 & 0.1 & 0.9 & 0.4 \\
\hline AzCullera-Azud Marquesa & 3500 & 10 & 0.16 & 0.1 & 0.9 & 0.4 \\
\hline Conexión Júcar-Mancha & 40819 & 100 & 0.744 & 0.1 & 0.222 & 0.4 \\
\hline Cabriel-1 & 64993 & 100 & 0.744 & 0.1 & 0.222 & 0.4 \\
\hline
\end{tabular}

Tabla 4. Elementos conducción en los que se ha modelado la calidad del agua.

Donde:

- La longitud del tramo de río está expresada en metros. Esta longitud se ha obtenido a partir de la información de la red hidrográfica disponible.

- AX representa el incremento para el cálculo de la calidad de cada tramo. Para estimar el diferencial de cálculo de las conducciones, en primer lugar se ha comprobado que un diferencial de $100 \mathrm{~m}$ producía resultados suficientemente precisos para todas las variables. Posteriormente, se ha realizado un análisis de las conducciones de menor longitud obteniéndose, para cada una de ellas, un diferencial de cálculo que proporcionase resultados precisos. 
- $\alpha_{\mathrm{u}}$ y $\beta_{\mathrm{u}}$ representan los coeficientes de estimación de velocidad a partir del caudal.

- $\alpha_{\mathrm{H}}$ y $\beta_{\mathrm{H}}$ representan los coeficientes de estimación de profundidad a partir del caudal.

La explicación de la obtención de los coeficientes hidráulicos se realiza en el siguiente apartado.

La temperatura mensual de cada tramo de río se ha obtenido como un promedio entre los valores medidos en las estaciones de calidad de aguas arriba y aguas abajo. Estos valores se pueden ver en el anejo A sobre los datos del modelo.

\subsection{Cálculo hidráulico de los tramos de río.}

Tanto para la modelación como para la caracterización de la calidad del agua en los tramos de ríos es necesario conocer la hidráulica del sistema es decir la relación entre los caudales y las variables hidráulicas como son: las velocidades, calados, áreas, etc.

Las dos posibilidades de modelización hidráulica de los ríos que permite el programa GESCAL son: el establecimiento de ecuaciones empíricas potenciales entre el caudal y las distintas variables o la aplicación de la ecuación de Manning para resolver el problema.

Para el caso de la cuenca del Júcar por los pocos datos disponibles se optó por la primera opción. Para ello se utilizan los datos obtenidos de la red Biológica, proporcionados por la Confederación Hidrográfica del Júcar. En esta red se tienen datos de caudales, anchura y calado, medidos periódicamente en diferentes puntos de la cuenca. Estos datos constan de una serie histórica corta, y con algunos no coincidentes en fechas para distintas estaciones, lo que hace más complicado un estudio exhaustivo. Las relaciones que se establecen en el modelo son las siguientes:

$$
\begin{aligned}
& y=\alpha_{H} Q^{\beta_{H}} \\
& w=\alpha_{w} Q^{\beta_{w}} \\
& v=\alpha_{u} Q^{\beta_{u}}
\end{aligned}
$$

donde:

- $y$ es el calado en metros.

$-w$ es el ancho en metros.

- $v$ la velocidad en metros/segundo.

Los parámetros $\alpha_{\mathrm{H}}, \beta_{\mathrm{H}}, \alpha_{\mathrm{u}}, \beta_{\mathrm{u}}, \alpha_{\mathrm{w}}, \beta_{\mathrm{w}}$, son constantes que deben cumplir las siguientes condiciones: 
$\alpha_{H} \alpha_{u} \alpha_{w}=1(5.4)$

$\beta_{H}+\beta_{u}+\beta_{w}=1(5.5)$

Debido a la falta de datos se han agrupado estaciones por homogeneidad de localización perfil del río etc.

Se ha realizado una calibración de los coeficientes de las relaciones asumiendo los valores de los exponentes establecidos en la literatura. Los parámetros adoptados son los aportados en la tabla 4. Posteriormente se han comprobado los tiempos de viaje que presentaba el modelo hidráulico con datos reales de diversas fuentes.

\subsubsection{Vertidos Puntuales.}

Los vertidos puntuales, en su mayoría representan acumulaciones de vertidos urbanos e industriales de la zona que se pueden considerar como fuentes localizadas de contaminación. Aunque el modelo permite la incorporación de curvas temporales de variación de vertido en ninguno de los elementos de vertido se ha considerado tal posibilidad.

\begin{tabular}{|c|c|c|c|c|c|c|c|c|c|c|}
\hline Den & Descripción & $Q$ & Cond & SS & DBO5 & $O D$ & $\mathrm{NH}_{4}^{+}$ & $\mathrm{NO}_{2}{ }^{-}$ & $\mathrm{NO}_{3}$ & $P$ \\
\hline VERT.1 & Alarcón & 0.05 & 1300 & 220.00 & 220 & 2.00 & 32.14 & 0.00 & 0.00 & 8.00 \\
\hline VERT.2 & Frailes & 0.02 & 1300 & 220.00 & 220 & 2.00 & 32.14 & 0.00 & 0.00 & 8.00 \\
\hline VERT.3 & Alcalá & 0.03 & 1300 & 220.00 & 220 & 2.00 & 32.14 & 0.00 & 0.00 & 8.00 \\
\hline VERT.4 & Reconque & 1.11 & 1503 & 15.69 & 2 & 9.67 & 0.16 & 0.13 & 6.96 & 0.15 \\
\hline VERT.6 & Contreras & 0.02 & 973 & 14.27 & 2.17 & 9.83 & 0.08 & 0.05 & 0.02 & 0.06 \\
\hline VERT.5 & Cortes & 0.02 & 1300 & 176.00 & 176 & 2.00 & 32.14 & 0.00 & 0.00 & 8.00 \\
\hline VERT.7 & Villatoya & 0.01 & 1300 & 220.00 & 220 & 2.00 & 25.00 & 0.00 & 0.00 & 8.00 \\
\hline $\begin{array}{l}\text { VERT.8 } \\
\end{array}$ & Antella-Vill & 0.01 & 1300 & 220.00 & 220 & 2.00 & 32.14 & 0.00 & 0.00 & 8.00 \\
\hline VERT.9 & $\begin{array}{l}\text { Albaida } \quad A g \\
\text { Ab ICA }\end{array}$ & 0.05 & 1300 & 220.00 & 220 & 2.00 & 32.14 & 0.00 & 0.00 & 8.00 \\
\hline VERT.10 & $\begin{array}{l}\text { Alzira-Alber.- } \\
\text { Barcheta }\end{array}$ & 1.74 & 1300 & 220.00 & 220 & 2.00 & 19.00 & 0.00 & 0.00 & 4.00 \\
\hline VERT.11 & $\begin{array}{l}\text { Algemesi- } \\
\text { EDAR }\end{array}$ & 0.36 & 1300 & 44.00 & 44 & 2.00 & 32.14 & 0.00 & 0.00 & 8.00 \\
\hline \multirow[t]{2}{*}{ VERT.12 } & $\begin{array}{l}\text { Sueca- } \\
\text { Avícola }\end{array}$ & 0.02 & 1300 & 380.00 & 900 & 2.00 & 32.14 & 0.00 & 0.00 & 8.00 \\
\hline & UNIDADES & $\mathrm{Hm}^{3} / \mathrm{mes}$ & $\mu \mathrm{s} / \mathrm{cm}$ & $\mathrm{mg} / \mathrm{l}$ & $\mathrm{mg} / \mathrm{l}$ & $\mathrm{mg} / \mathrm{l}$ & $\mathrm{mg} / \mathrm{l}$ & $\mathrm{mg} / \mathrm{l}$ & $\mathrm{mg} / \mathrm{l}$ & $\mathrm{mg} / \mathrm{l}$ \\
\hline
\end{tabular}

Tabla 5. Datos sobre vertidos puntuales 
La información disponible sobre vertidos consiste en una capa de un Sistema de Información Geográfica en la que se localizan los vertidos. Dentro de la tabla asociada se encuentra información sobre el volumen de vertido, tipo de vertido, cauce receptor, etc. El proceso de tratamiento de esta información ha consistido en lo siguiente:

- Se ha realizado una clasificación de los vertidos según sean urbanos, industriales o de piscifactoría.

- Sólo se consideran como significativos los vertidos con un volumen superior a $10000 \mathrm{~m}^{3} /$ año.

- Se eliminan los vertidos con cauce receptor pozo, acequia, terreno, etc.

- Una vez obtenida la información disociada, para cada elemento a modelar, se estudian que vertidos afectan al elemento en cuestión y su posible agregación. Algunos conjuntos de vertidos, ubicados de forma continua a lo largo de un tramo de río, se han considerado como elementos de contaminación difusa.

- Para la estimación de las concentraciones de vertido se han asumido valores teóricos medios de vertido urbano. Previamente se ha comprobado que vertidos disponían de estaciones depuradoras de aguas residuales (EDAR).

- Respecto a las EDARs se ha tenido en cuenta su fecha de inicio, volumen de vertido, tipo de tratamiento, etc.

- Para vertidos industriales se han utilizado valores en función del tipo de industria o sector de la literatura científica (Nemerow, 1997) y (CCCCV, 1994).

El vertido Reconque representa el efecto de dicho afluente sobre el río. Las concentraciones, en este caso, se han obtenido a partir de la estación ICA Cautaban sita al final de dicho afluente.

Además de estos vertidos se han introducido los vertidos ficticios de Alarcón y Contreras que permiten introducir la carga auxiliar para modelar la aportación de las cuencas aguas arriba. Estos son los valores utilizados.

\begin{tabular}{|l|l|l|l|l|l|l|l|l|l|l|}
\hline Den & Descrip. & $\mathbf{Q}$ & Cond & SS & DBO5 & OD & $\mathrm{NH}_{4}{ }^{+}$ & $\mathrm{NO}_{2}{ }^{-}$ & $\mathrm{NO}_{3}{ }^{-}$ & $P$ \\
\hline & hm3/mes & & $(m g / l)$ & $(m g / l)$ & & $(m g / l)$ & $(m g / l)$ & $(m g / l)$ & $(m g / l)$ \\
\hline $\begin{array}{l}\text { VERT. } \\
\text { FICT.1 }\end{array}$ & $\begin{array}{l}\text { Eq } \\
\text { Alarcon }\end{array}$ & 0.01 & 0 & 56329 & 200 & 0 & 90 & 80 & 5000 & 170 \\
\hline $\begin{array}{l}\text { VERT. } \\
\text { FICT.2 }\end{array}$ & $\begin{array}{l}\text { Eq } \\
\text { Contreras }\end{array}$ & 0.01 & 0 & 20956 & 2 & 0 & 102.41 & 54.29 & 6454.34 & 42 \\
\hline
\end{tabular}

Tabla 6. Datos sobre los vertidos ficticios de Alarcón y Contreras. 


\subsubsection{Elementos de contaminación difusa.}

Los elementos de contaminación difusa se han utilizado para modelar aportes de sólidos suspendidos, nitratos o conductividad de forma longitudinal en algún tramo de río o grupos de vertidos urbanos distribuidos a lo largo de algún tramo de río.

\begin{tabular}{|l|l|l|l|l|l|l|l|l|l|}
\hline DENOM & Descripción & Cond & SS & DBO5 & OD & $\mathrm{NH}_{4}^{+}$ & $\mathrm{NO}_{2}^{-}$ & $\mathrm{NO}_{3}^{-}$ & $P$ \\
\hline & UNIDADES & $\mathrm{ms} / \mathrm{cm} /$ día & gr/día & gr/día & gr/día & gr/día & gr/día & gr/día & gr/día \\
\hline DIF1. & $\begin{array}{l}\text { Vert. en } \\
\text { Júcar-1 }\end{array}$ & 177071 & 29966 & 29966 & 272 & 3405 & 0 & 0 & 1090 \\
\hline DIF.2 & $\begin{array}{l}\text { Aporte } \\
\text { nitratos Ag. } \\
\text { arr. Molinar }\end{array}$ & 0 & 0 & 0 & 0 & 0 & 0 & 2500000 & 0 \\
\hline DIF.3 & $\begin{array}{l}\text { Aporte de } \\
\text { Conduct. en } \\
\text { Cabriel 2 }\end{array}$ & 64800000 & 0 & 0 & 0 & 0 & 0 & 0 & 0 \\
\hline DIF.4 & $\begin{array}{l}\text { Aporte SS } \\
\text { hasta Antella }\end{array}$ & 0 & 1319523 & 0 & 0 & 0 & 0 & 0 & 0 \\
\hline DIF.5 & $\begin{array}{l}\text { Vertidos } \\
\text { Sellent- } \\
\text { Albaida }\end{array}$ & 0 & 425097 & 425097 & 3864 & 62103 & 0 & 0 & 15458 \\
\hline DIF.6 & $\begin{array}{l}\text { Nitratos } \\
\text { entre } \\
\text { Albaida y } \\
\text { Alzira }\end{array}$ & 0 & 0 & 0 & 0 & 0 & 0 & 4000000 & 0 \\
\hline
\end{tabular}

Tabla 7. Datos de los elementos de contaminación difusa.

En donde los valores se muestra en gr/día ya que los elementos de contaminación difusa se modelan como aportes de carga de contaminante.

Estos valores se han obtenido mediante balances de masas a partir del análisis de calidad realizado.

\subsection{CALIBRACIÓN.}

La calibración es el proceso por el cual se ajustan los parámetros del modelo para que el comportamiento del mismo sea lo más parecido a la realidad. En la modelación de la calidad es bastante habitual calibrar los modelos en la situación más desfavorable de caudales. En muchos casos suele utilizar el aQb representativo del 
caudal mínimo durante "a" días para un período de retorno de "b" años. En este modelo debido a que se realiza un modelación de simulación continua la calibración se realiza para todos los datos disponibles en los que se dan períodos secos y húmedos y lo que se intenta es obtener una representatividad del comportamiento del sistema en todas las situaciones.

En el caso de un modelo de toda una cuenca la calibración se realiza para cada uno de los elementos de la misma para luego con la simulación conjunta comprobar que no existen elementos de distorsión.

Por otra parte, debido a que el objetivo de los modelos de gestión no es la reproducción de los caudales históricos en el sistema, sino la representación el comportamiento del sistema actual frente a futuras situaciones, la simulación previa de un período no es útil para la calibración de los elementos, siendo necesario el desarrollo de una herramienta como la que a continuación se describe.

Sin embargo, como se comentará más adelante, no todos los elementos se han calibrado utilizando la herramienta desarrollada. Las conducciones cuya calidad depende, sobre todo, de otros elementos como acuíferos o aportaciones se han calibrado simulando el modelo completo. En estos casos se han realizado ciertas modificaciones para que los caudales circulantes fuesen lo más parecidos a la realidad, este es el caso de las conducciones "Conexión Júcar-Mancha” y "Cabriel-1".

\subsubsection{Descripción de la herramienta desarrollada para la calibración.}

Para la calibración de la mayor parte de los elementos se ha realizado una modificación en el programa original que permite calibrar cualquier conducción y/o embalse. La herramienta consta de una opción en el archivo de datos de entrada en que se indica si se va a calibrar alguna conducción o embalse y la ubicación del archivo/s de calibración. El archivo de calibración, para conducciones, consiste en un primer dato en el que se indica el número de conducción a calibrar y un conjunto de series de datos representativos de los caudales circulantes y de las concentraciones a inicio de tramo. Estas series tienen que coincidir, en longitud, con la simulación previa realizada para todo el modelo. Para los embalses en vez de la serie de caudales circulantes se debe aportar las series de volúmenes embalsados, salidas de embalse, evaporaciones, sueltas y vertidos.

Las concentraciones iniciales aportadas tienen que considerar posibles vertidos a inicio del tramo.

El proceso es bastante sencillo, el programa realiza una simulación normal de todos los elementos pero comprobando, cada vez, si el elemento a simular, ya sea 
conducción o embalse, coincide con el elemento a calibrar. Si es así, se realiza una sustitución de valores de entrada de calidad y de caudales del elemento obtenidos por modelación por los suministrados en el archivo de calibración. Esto permite calibrar las conducciones y embalses de forma sencilla sin tener que realizar modelos específicos para ello.

\subsubsection{Datos para la calibración.}

Para la calibración de cada elemento se necesita saber para un período determinado de tiempo: las calidades de entrada y salida a ese elemento, los caudales circulantes o volúmenes embalsados y las diferentes presiones ya sean vertidos puntuales o fuentes de contaminación difusa.

Del análisis de la calidad de la cuenca se obtienen, en función de la disponibilidad de datos, los períodos de calibración y las concentraciones de entrada y salida de los elementos. Por otra parte los datos de aforos, seguimiento y de la red de calidad permiten estimar los caudales circulantes en el período de calibración. Finalmente, la información sobre la infraestructura de depuración marca el período en que las condiciones de vertidos son homogéneas.

\subsubsection{Calibración de embalses}

La calibración de los embalses ha sido bastante sencilla debido a la simplicidad del modelo planteado. En general la calibración ha sido bastante buena aunque según parámetros y embalses. La mayoría de parámetros se mueven en valores mínimos debido a la situación de baja contaminación en que se encuentra el río en su parte media y alta.

Se han modelado todos los embalses aunque se asume que el depósito de la Muela no tiene efecto sobre la calidad del agua. Además los embalses de Cortes II y Naranjero se han calibrado de forma conjunta y asumiendo igualdad de parámetros para ambos. Ello es debido a los pocos datos disponibles de la estación ubicada en medio de ambos.

La siguiente tabla muestra los parámetros obtenidos tras la calibración y los períodos de calibración utilizados. En el anejo B se encuentran los gráficos comparativos de las calibraciones. 


\begin{tabular}{|l|l|l|l|l|l|l|l|}
\hline \multicolumn{6}{|l|}{ Calibración de Parámetros de los embalses } \\
\hline $\begin{array}{l}\left(\text { día }^{-1}\right) \\
\text { Alarcon }\end{array}$ & Molinar & Contreras & Cortes & Naranjero & Tous & $\begin{array}{l}\text { Valores } \\
\text { Ususales }\end{array}$ \\
\hline Vs & 0.1 & 0.05 & 0.5 & 0.7 & 0.7 & 0.25 & \\
\hline Ka & 0.1 & 1 & 1 & 10 & 10 & 10 & $0-100$ \\
\hline Kd & 0.001 & 0.001 & 0.001 & 0.001 & 0.001 & 0.001 & $0.02-5$ \\
\hline Knai & 0.01 & 0.1 & 0.03 & 0.01 & 0.01 & 0.001 & $0.1-1$ \\
\hline Knio & 0.035 & 0 & 0.06 & 0.03 & 0.03 & 0.01 & $0.2-2$ \\
\hline Kfosf & 0.02 & 0.02 & 0.01 & 0.02 & 0.02 & 0.005 & $0.07-0.7$ \\
\hline $\begin{array}{l}\text { Período } \\
\text { Calibr. }\end{array}$ & $\begin{array}{l}\text { Oct-97 } \\
\text { Sept-93 }\end{array}$ & $\begin{array}{l}\text { Ene-00 } \\
\text { Dic-03 }\end{array}$ & $\begin{array}{l}\text { Oct-99 } \\
\text { Sep-03 }\end{array}$ & $\begin{array}{l}\text { Ene-00 } \\
\text { Dic-03 }\end{array}$ & $\begin{array}{l}\text { Ene-00 } \\
\text { Dic-03 }\end{array}$ & $\begin{array}{l}\text { Ene-00 } \\
\text { Dic-03 }\end{array}$ & \\
\hline
\end{tabular}

Tabla 8. Parámetros obtenidos en la calibración de los embalses.

Donde:

- VsEmb es la velocidad de sedimentación de los sólidos suspendidos

- Ka es la constante de reaireación.

- Kd es la constante de degradación de materia orgánica. (La velocidad de sedimentación de materia orgánica se ha considerado nula).

- Knai es la constante de oxidación del amonio a nitritos.

- Knio es la constante de oxidación de nitritos a nitratos.

- Kfosf es la constante de degradación del fósforo total.

Los problemas en la calibración de los embalses se deben a dos factores:

- Algunas de las estaciones de aguas arriba y aguas abajo están ubicadas a cierta distancia del embalse lo que lleva a que para ciertos parámetros se pierda representatividad. Este efecto se da sobre todo en los embalses de cabecera. Por ejemplo la estación de Castellar, aguas arriba del embalse de Alarcón, esta ubicada varios kilómetros aguas arriba del mismo.

- En algunos parámetros se está modelando la variación natural de los parámetros ya que las bajas concentraciones son indicativas de la poca contaminación. En algunos puntos las concentraciones medidas son cercanas o iguales, en muchos meses, a los umbrales de medición.

Atendiendo a los elementos se destaca: 
- Los embalses de cabecera son los que presentan una mayor dificultad de calibración debido en gran parte al primer factor comentado.

- El embalse de Molinar, debido a su pequeña magnitud, presenta un comportamiento muy bueno en cuanto a la calibración se refiere.

- Los embalses de Naranjero (modelado conjuntamente con Cortes II) y Tous presentan una calibración bastante buena, mucho mejor que la de los embalses de cabecera. El mayor problema que se presenta en estos embalses es que para algunos constituyentes las concentraciones son muy bajas.

Atendiendo a las diferentes variables:

- En cuanto a la conductividad los embalses de cabecera presentan, en algunos momentos, una irregularidad no estimada del todo por el modelo el cual presenta valores más laminados. Sin embargo los embalses de Naranjero y sobre todo Tous presentan concentraciones estimadas muy parecidas a las medidas por las estaciones de calidad.

- La mayor dificultad que tiene el modelo es la estimación de ciertas puntas en concentraciones de sólidos suspendidos. Estas tienen relación con la forma de suelta del embalse y el arrastre de sólidos que se produce. Existe cierta dispersión entre los parámetros estimados siendo los valores más altos los de los embalses de Cortes II y Naranjero.

- El oxígeno disuelto mantiene valores bastante parecidos a los medidos en todos los embalses. En algún punto el modelo presenta valores ligeramente inferiores debidos fundamentalmente a la reaireación que se produce en las sueltas de los embalses.

- Tanto para el amonio como para los nitritos, los mayores problemas de calibración se presentan con los valores bajos que se presentan en los embalses inferiores. En muchos momentos se presentan valores de concentraciones iguales a los umbrales de medición. Como se puede ver en la tabla los valores calibrados para los parámetros son mínimos.

- Para los nitratos la mayor dificultad ha sido encontrar, en algunas zonas, valores para la calibración. Para obtener las concentraciones de entrada de los embalses de cabecera se ha tenido que recurrir a estaciones de más aguas arriba. Por otro lado en las estaciones de aguas abajo de Naranjero y Tous no se miden nitratos.

- El fósforo presenta concentraciones mínimas iguales al umbral de medición excepto en algún mes en que se produce un pico de concentración. En pocos 
embalses se representan estos picos con exactitud. Destacan por su buen comportamiento, en la calibración, los embalses de Molinar y Tous.

\subsubsection{Calibración de conducciones aguas arriba de Tous.}

Para la calibración de las conducciones, o tramos de río, aguas arriba del embalse de Tous se han utilizado dos métodos. Para la mayoría de las conducciones se ha utilizado la herramienta descrita previamente, mientras que para las conducciones "Conexión Júcar-Mancha" y "Cabriel-1" se ha utilizado la simulación del modelo completo modificando los volúmenes máximos de los embalses y los caudales mínimos de las conducciones para que la distribución de flujo fuese lo más parecido a la realidad.

En el anejo B se encuentran los gráficos de la calibración de todas las conducciones.

El período de calibración para todas las conducciones ha sido entre octubre de 1999 y septiembre de 2001. Se puede decir que la calibración en los tramos de río funciona mucho mejor que en los embalses. En la siguiente tabla se recogen los valores de los parámetros calibrados.

\begin{tabular}{|l|l|l|l|l|l|l|l|l|}
\hline \multicolumn{2}{|c|}{ Calibración conducciones aguas arriba embalse Tous } \\
\hline (día $\left.^{-1}\right)$ & Júcar-1 & $\begin{array}{l}\text { Conx.Júcar- } \\
\text { Mancha }\end{array}$ & Júcar-3 & Júcar-4 & Júcar-5 & Júcar-7 & Cabriel-1 & $\begin{array}{l}\text { Cabriel- } \\
2\end{array}$ \\
\hline Vs & 0 & 0 & 0 & 0 & 0 & 0 & 0 & 0 \\
\hline Ka & 10 & O\&D & 5 & O\&D & O\&D & O\&D & O\&D & O\&D \\
\hline Kd & 0.001 & 0.001 & 0.5 & 0.5 & 0.01 & 0.001 & 0.05 & 0.05 \\
\hline Knai & 0.001 & 0.001 & 1 & 1 & 0.1 & 0.001 & 0.1 & 0.01 \\
\hline Knio & 0.05 & 0.02 & 2 & 2 & 0.2 & 0.02 & 0.2 & 0.02 \\
\hline Kfosf & 0.1 & 0 & 0.1 & 0 & 0.1 & 0 & 0.1 & 0.01 \\
\hline
\end{tabular}

Tabla 9. Parámetros obtenidos en la calibración de las conducciones aguas arriba del embalse de Tous.

Donde O\&D se refiere al método de estimación de la constante de reaireación propuesto por O'Connor y Dobbins.

Atendiendo a los elemento se puede decir que el comportamiento general, al igual que los embalses, es de constantes de calibración muy bajas debido al bajo grado de polución. Excepción a esto son las conducciones "Júcar-3" y "Júcar-4" entre la estación de Frailes y el embalse de Molinar. Estos tramos están caracterizados por una fuerte presión de los vertidos urbanos y una alta autodepuración del río. El mayor problema que presenta la modelación y calibración de estos dos tramos de río es el 
desconocimiento de la calidad del agua de los afluentes Valdemembra y Ledaña, los cauales recogen un conjunto, bastante numeroso, de vertidos urbanos.

Atendiendo a la calibración por variables:

- La conductividad presenta una similitud muy grande entre valores observados y modelados.

- No se ha considerado sedimentación en ninguno de los tramos debido a que, en el análisis de calidad, no se ha visto que estas disminuyesen significativamente en algún tramo de río.

- En la mayor parte de los tramos se ha considerado la constante de reaireación por el método de O'Connor y Dobbins excepto en los tramos "Júcar-1" y "Júcar3" que se ha tenido que calibrar al comprobar que el ajuste no era bueno por el método anterior. Ello se debe a la cantidad de azudes ubicados en el tramo.

- Las constantes de degradación de materia orgánica son muy bajas excepto para los tramos de río aguas arriba de Molinar. También destaca que los parámetros calibrados sean superiores en el Cabriel que en el Júcar, ya que este último sufre una mayor presión antropogénica.

- Los parámetros de degradación del amonio y nitritos son muy bajos en la mayoría de tramos. En el tramo Júcar-3 y Júcar-4 se han impuesto concentraciones máximas debido a que hay un efecto de descomposición de estos compuestos en los afluentes que no se ha tenido en cuenta al definir la característica del vertido.

- Finalmente las constantes de descomposición de degradación del fósforo presenta valores muy bajos, incluso nulos en algunos de sus tramos.

\subsubsection{Calibración de conducciones aguas abajo de Tous.}

La calibración de esta parte del río es muy diferente a la de aguas arriba. En esta zona se produce un empeoramiento muy significativo de la calidad del agua, lo que conlleva un aumento de los valores de los parámetros obtenidos. El tramo también destaca por la presencia de numerosos elementos como afluentes, extracciones y vertidos que modifican la calidad en poco recorrido. En algunos de los tramos, como se ha comentado previamente, se ha tenido que reducir el diferencial de cálculo por su corta longitud. En la tabla siguiente se muestra los parámetros obtenidos después de la calibración. 


\begin{tabular}{|c|c|c|c|c|c|c|c|c|c|}
\hline \multicolumn{10}{|c|}{ Calibración tramos de río aguas abajo de Tous. } \\
\hline día $a^{-1}$ & 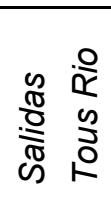 & 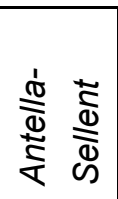 & 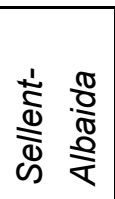 & 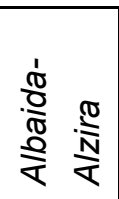 & $\frac{\sqrt{\frac{\pi}{N}}}{\stackrel{\frac{1}{2}}{\frac{1}{0}}}$ & 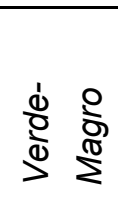 & 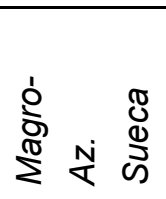 & 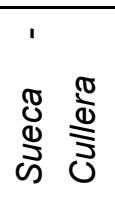 & 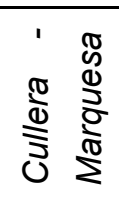 \\
\hline Vs & 0 & 0 & 0 & 0 & 0 & 0 & 5 & 0.5 & -2.5 \\
\hline Ka & O\&D & O\&D & O\&D & O\&D & O\&D & O\&D & O\&D & 3 & 3 \\
\hline Kd & 0.1 & 0.1 & 0.1 & 0.1 & 1 & 0.35 & 0.3 & 0.35 & 0.35 \\
\hline Knai & 0.5 & 0.5 & 0.8 & 0.9 & 1 & 1 & 1 & 0.75 & 0.5 \\
\hline Knio & 1.2 & 1.2 & 1 & 1.4 & 0.2 & 0.2 & 0.7 & 1.2 & 1.5 \\
\hline Kfosf & 0.1 & 0.1 & 0.1 & 0.1 & 0.5 & 0.5 & 0.2 & 0.2 & 0.2 \\
\hline
\end{tabular}

Tabla 10. Parámetros obtenidos en la calibración de las conducciones aguas abajo del embalse de Tous.

El mayor problema a la hora de calibrar los elementos de esta parte del río es la falta de datos sobre todo en el tramo entre el río Magro y el azud de la Marquesa. Además, contrasta la gran influencia, sobre la calidad del agua, de los afluentes inferiores con la falta de datos en los mismos.

Atendiendo a la variables se puede destacar:

- El modelo presenta unos valores de conductividad muy similares a los medidos en las estaciones ICA para todos los tramos de río.

- En los tramos bajos se han incluido una alta velocidad de sedimentación debido al efecto de los azudes. En el último tramo los sólidos suspendidos aumentan lo que puede ser debido a diversos motivos como son la hidráulica del tramo o los procesos de eutrofización que se dan en el citado azud. Por otro lado en el primer tramo se ha incluido un elemento de contaminación difusa de aporte de sólidos suspendidos que representa la ganancia de concentraciones por erosión que se presenta en ese tramo. La modelación de los sólidos suspendidos es uno de los parámetros que peor ajuste presenta en este tramo de río, sobre todo, en el tramo inicial.

- Para la obtención de la reaireación la estimación de O’Connor y Dobinns ha funcionado bien para todos los tramos de río excepto en los finales, en donde, se han tenido que imponer coeficientes superiores por la reaireación adicional de los azudes. En los primeros tramos el río se mantiene una concentración de oxígeno disuelto cercana a la saturación por lo que el modelo se ajusta bastante bien. En el tramo de Alcira se produce una caída de concentraciones de oxígeno disuelto que es representada, bastante bien, por el modelo. Aguas abajo de este punto existen pocos datos disponibles de los azudes de Sueca y Cullera aunque 
presentan un buen ajuste. En el azud de la Marquesa las concentraciones no presentan ningún tipo de ajuste debido a las extremas concentraciones que se presentan típicas de procesos de eutrofización.

- La constante de descomposición de materia orgánica va incrementándose conforme avanza el río debido al tipo de vertido cada vez más biodegradable. Destaca el tramo "Alcira-Verde" en donde la constante es de 1 día $^{-1}$. A partir de ese tramo los valores descienden, aunque con valores superiores a los del inicio del tramo. En los tramos finales la constante de descomposición de la materia orgánica está representando también la sedimentación de la materia orgánica. La calibración de la materia orgánica hasta casi la entrada del vertido de Alcira presenta el problema de las bajas concentraciones y los umbrales de medición. A partir de la entrada del citado vertido, en donde las concentraciones aumentan, el ajuste es bastante bueno.

- La constante de transformación del amonio sigue una evolución similar a la de la materia orgánica, alcanzando el máximo en la zona entre Alcira y el azud de Sueca. Esta evolución es inversa a la obtenida para la constante de descomposición de nitritos en donde en esa zona se dan los valores mínimos. El amonio y los nitritos presentan bastante irregularidad en la calibración ya que, en algunos tramos, su calibración es bastante buena mientras que en otros es deficiente. Este problema es debido a las concentraciones teóricas constantes asumidas para los vertidos. Los nitratos, por su parte, presentan un ajuste bastante bueno en los puntos en donde es posible su comparación.

- En cuanto al parámetro de calibración del fósforo presenta una evolución similar a la del amonio y de la materia orgánica. Destacan los pocos valores de los que se disponen. En algunos puntos debido a que no se disponían de valores de fósforo total se ha realizado la comparación con concentraciones de fosfatos. Los pocos datos de los que se disponen presentan un ajuste bueno.

\subsubsection{Análisis de Sensibilidad.}

El análisis de sensibilidad permite analizar la incidencia significativa de un parámetro sobre la variable que modela y el resto. Existen diferentes técnicas para realizar un análisis de sensibilidad de los parámetros de un modelo. Entre las más sencillas se encuentran los métodos de primer orden, el método de Rosenbleuth o el de Harrs. Técnicas más sofisticadas del análisis de sensibilidad son el análisis de Monte Carlo o el LHS (Latin Hypercube Sampling) (McKay et al. 1979; McKay, 1988). En 
esta tesis debido al gran número de elementos modelados se ha realizado un análisis de sensibilidad relativo, obteniendo el índice $\mathrm{S}_{\mathrm{x}}$ (Hopkins, 1983):

$$
S_{x}=\frac{\Delta x / x}{\Delta p} / p
$$

donde $\mathrm{S}_{\mathrm{x}}$ es la sensibilidad relativa, $\mathrm{x}$ es la variable de estado y $\mathrm{p}$ es el parámetro considerado.

En el anejo B se encuentran todas las tablas de sensibilidad relativa de los elementos modelados tanto embalses como tramos de río. Se han obtenido tanto valores máximos como medios. Debido a que los sólidos suspendidos y el fósforo total son variables que no tiene relación con el resto de constituyentes se han tratado por separado.

Los elementos que presentan una menor sensibilidad a la variación de lo parámetros son los embalses. Estos presentan sensibilidades relativas de la variable con el mismo parámetro muy bajas en valores medios y nulas para los valores máximos. Además la mayor parte de los valores cruzados de sensibilidad son nulos. Los tramos de río de la zona de aguas arriba presenta índices mayores que los de los embalses pero muy inferiores a los de la zona de aguas abajo. La zona de mayor sensibilidad se corresponde con la más contaminada debido a que en esos tramos los procesos físicoquímicos toman una mayor importancia.

En particular:

- Los sólidos suspendidos es la variable que representa una mayor sensibilidad en el modelo. Mientras que la de menor sensibilidad depende del elemento.

- Los tramos de los azudes son los que presentan una mayor sensibilidad frente al parámetro de reaireación. En cuanto a la sensibilidad cruzada, en los tramos de aguas arriba de los audes, la variación de este parámetro tiene un mayor impacto sobre las variables del ciclo del nitrógeno que sobre la $\mathrm{DBO}_{5}$.

- En cuanto a la constante de degradación de materia orgánica en los tramos de río tiene efecto sobre la propia variable y sobre el oxígeno disuelto. En los tramos entre Alcira y el azud de Sueca es la variable con mayor efecto sobre el oxígeno disuelto, mayor incluso que la constante de reaireación. En los embalses, la sensibilidad es muy baja debido a las bajas concentraciones que se dan.

- En cuanto a las constantes de oxidación del amonio y de los nitritos en todos los elementos la primera tiene una mayor afección sobre el oxígeno disuelto. Además las concentraciones de nitritos son bastante sensibles a las variaciones de la constante de oxidación del amonio. 
- Para los nitratos, la constante que ejerce una mayor influencia es la de oxidación de los nitritos aunque en ningún elemento es elevada. En la mayor parte de los tramos de río aguas arriba así como en los embalses ninguna de las constantes ejerce ningún tipo de influencia sobre los mismos.

- Finalmente la constante de degradación del fósforo tiene un comportamiento muy similar al del resto de parámetros. Los tramos en donde tiene una mayor influencia son los ubicados entre el vertido de Alcira y los azudes.

\subsubsection{Constantes utilizadas.}

Entre las constantes utilizadas se puede destacar:

- Para el cálculo de la reaireación en tramos de río, no en todos ellos, se ha utilizado la fórmula propuesta por (O'Connor \& Dobbins):

$$
K_{a}=3.93 * u^{0.5} / H^{1.5}
$$

- Además las constantes utilizadas para corregir los parámetros por la variación de la temperatura han sido las siguientes: reaireación 1.024; degradación de materia orgánica 1.047; oxidación del amonio 1.083 y oxidación de los nitritos: 1.047.

- Los coeficientes estequiométricos utilizados han sido los siguientes: oxidación amonio 3.43(mgO/mgN); oxidación nitritos $1.14(\mathrm{mgO} / \mathrm{mgN})$.

- Finalmente para el paso de $\mathrm{DBO}_{5}$ a DBO límite se ha utilizado una constante igual a $0.05\left(\mathrm{día}^{-1}\right)$ cuando es agua en medio natural y de $0.35\left(\mathrm{día}^{-1}\right)$ cuando son vertidos.

\subsubsection{Otros Aspectos de la Calibración y la Modelación}

\subsubsection{Modelación del Fitoplancton.}

Aunque no se disponía de datos suficientes se ha realizado un intento de modelación del fitoplancton en los embalses de Alarcón y Contreras. El objetivo era comprobar el funcionamiento del módulo de modelación en este aspecto. El módulo ha permitido modelar el fitoplancton y su relación con el resto de constituyentes. Los planteamientos de modelos de eutrofización suelen funcionar en situaciones de alta actividad biológica, no siendo el caso de los embalses de estudio. En la siguiente figura se muestra los resultados obtenidos por el modelo comparados con la clorofila-a medida. 
Embalse de Alarcón. Modelo con fitoplancton

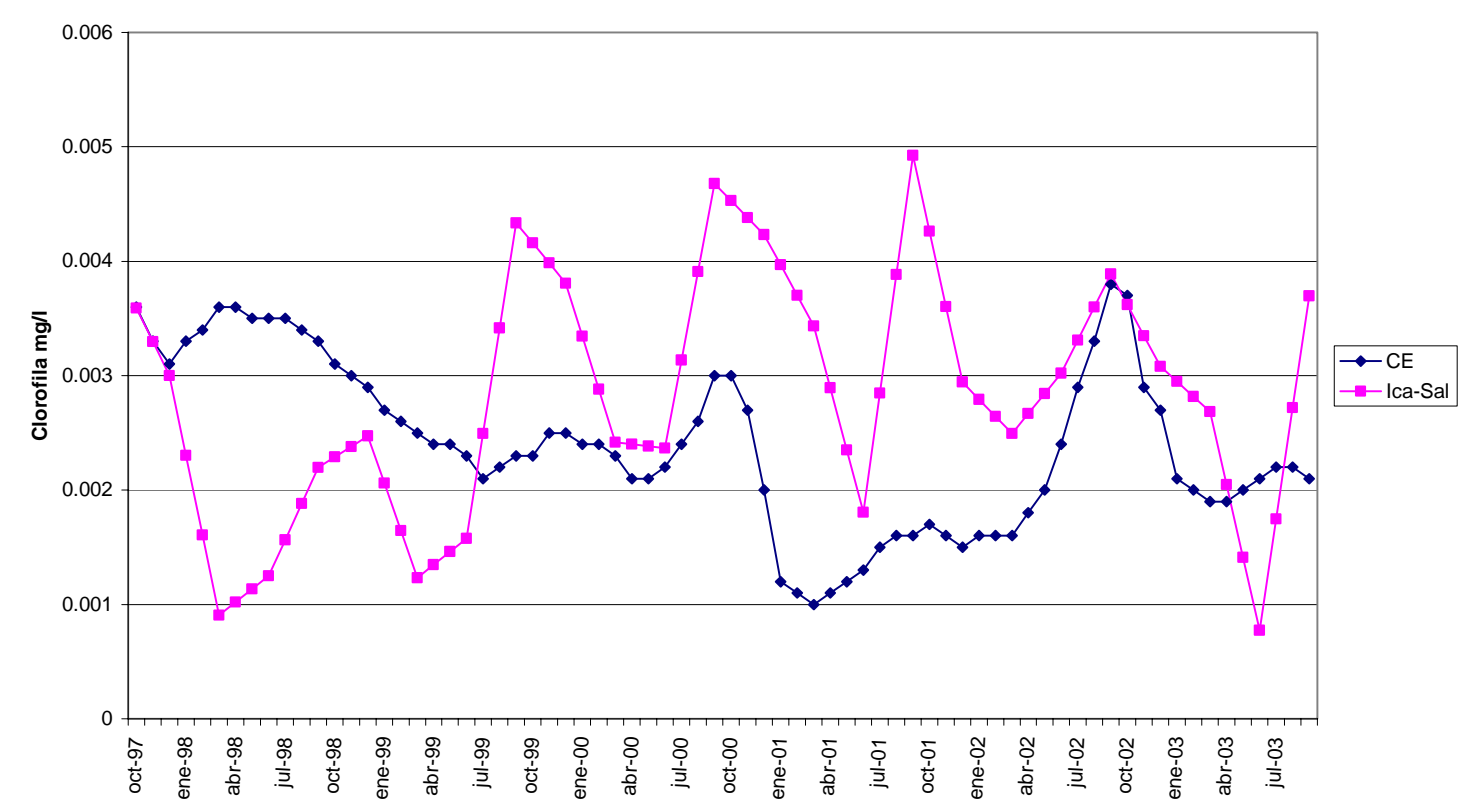

Figura 119. Modelación del fitoplancton en el embalse de Alarcón.

Como se puede ver las concentraciones de clorofila son muy bajas representativas de la situación de baja actividad biológica.

\subsubsection{Modelación de embalses en dos capas.}

Ninguno de los embalses presenta datos suficientes para su modelación en dos capas y a la vista de las bajas concentraciones no parece que un incremento en la complejidad del modelo vaya a mejorar los resultados. Por otro lado se ha realizado una modelación en dos capas del embalse de Alarcón para comprobar las posibilidades del módulo desarrollado. Tras la modelación se han realizado diferentes pruebas en función del coeficiente de dispersión entre ambas capas. Con todo esto se ha comporbado que la herramienta permite la modelación del los embalses en dos capas de estratificación.

\subsubsection{Acople y Recalibración.}

Una vez calibrados, por separado, cada uno de los elementos del sistema y previamente a la simulación de escenarios se debe realizar una comprobación del funcionamiento conjunto de los elementos y de la influencia del modelo de gestión sobre el de calidad.

El objetivo de un modelo de simulación no es repetir el pasado sino ser una base experimental para la gestión actual y la planificación hidrológica. Por otro lado, al incluir la modelación de la calidad, no se puede evitar el hacer comparaciones entre la 
calidad del agua estimada por el modelo y la real con el fin de demostrar cierta validez del modelo.

Para ello se realiza la simulación del modelo completo para un período suficientemente largo (1985-2001). Con los resultados obtenidos se analizan distorsiones entre diferentes elementos y se comprueba que la distribución de caudales en el sistema es coherente con la forma de gestión actual del sistema sin que se produzcan puntos en donde la calidad no es representativa de la situación actual.

El único problema que ha surgido, en el acople de los modelos, se debe a que el modelo SIMGES tiene un algoritmo de optimización interna para resolver el reparto del agua de forma mensual. Esto produce que se den caudales inferiores a los que circulan de forma frecuente en varios puntos de la cuenca. Los puntos más sensibles son tres: la zona aguas arriba del embalse de Molinar, la zona entre el azud de Antella y Sellent y el tramo aguas abajo del azud de Cullera. En los resultados iniciales, este efecto producía que en esos puntos las calidades del agua obtenidas por el modelo fueran bastante inferiores a las que de forma general se daban. La inclusión de caudales mínimos en cada uno de los tramos permite mejorar el modelo en estos puntos. Estos caudales han sido los siguientes $5 \mathrm{hm}^{3} /$ mes aguas arriba de Molinar, $2 \mathrm{hm}^{3} /$ mes aguas abajo de Antella y $0.25 \mathrm{hm}^{3} /$ mes aguas abajo del azud de Cullera. El primero de ellos representa el caudal mínimo histórico en ese tramo de río. Los otros dos, debido a la falta de datos, se han estimado, a partir del modelo, como los valores mínimos con los que se obtienen unas calidades representativas de la realidad en ambas zonas.

Una vez incluidos dichos caudales mínimos las calidades obtenidas se mueven para todos los parámetros entre los valores históricos obtenidos. Por otro lado no se ha detectado ninguna afección entre elementos que pudieran empeorar la eficacia del modelo en algún punto. Todo esto, aunque no supone una validación tradicional del modelo, da robustez al mismo ya que se comprueba que refleja la situación de la calidad en el sistema.

A continuación se presentan, para cada constituyente, perfiles medios, máximos y mínimos de valores estimados e históricos. Hay que tener en cuenta una serie de aspectos que interfieren en que las calidades medidas no sean similares a las reales:

- Las demandas consideradas en el modelo son las actuales y constantes a nivel anual. Por lo que no representa la evolución histórica del consumo en el sistema.

- La gestión real de los embalses no obedece a reglas fijas de prioridades como en el modelo. Las prioridades impuestas imponen un mayor uso del embalse de Contreras, al tener menor prioridad que el de Alarcón. Este comportamiento no se da de forma tan extrema en la realidad. 
- Se considera la infraestructura actual sin tener en cuenta su evolución en el tiempo. El caso más importante es el embalse de Tous que se finalizó en 1995.

- Las series de calidad de las aportaciones no son las reales habiéndose estimado por diferentes métodos.

Los perfiles desarrollados para la conductividad se presentan en el siguiente gráfico.

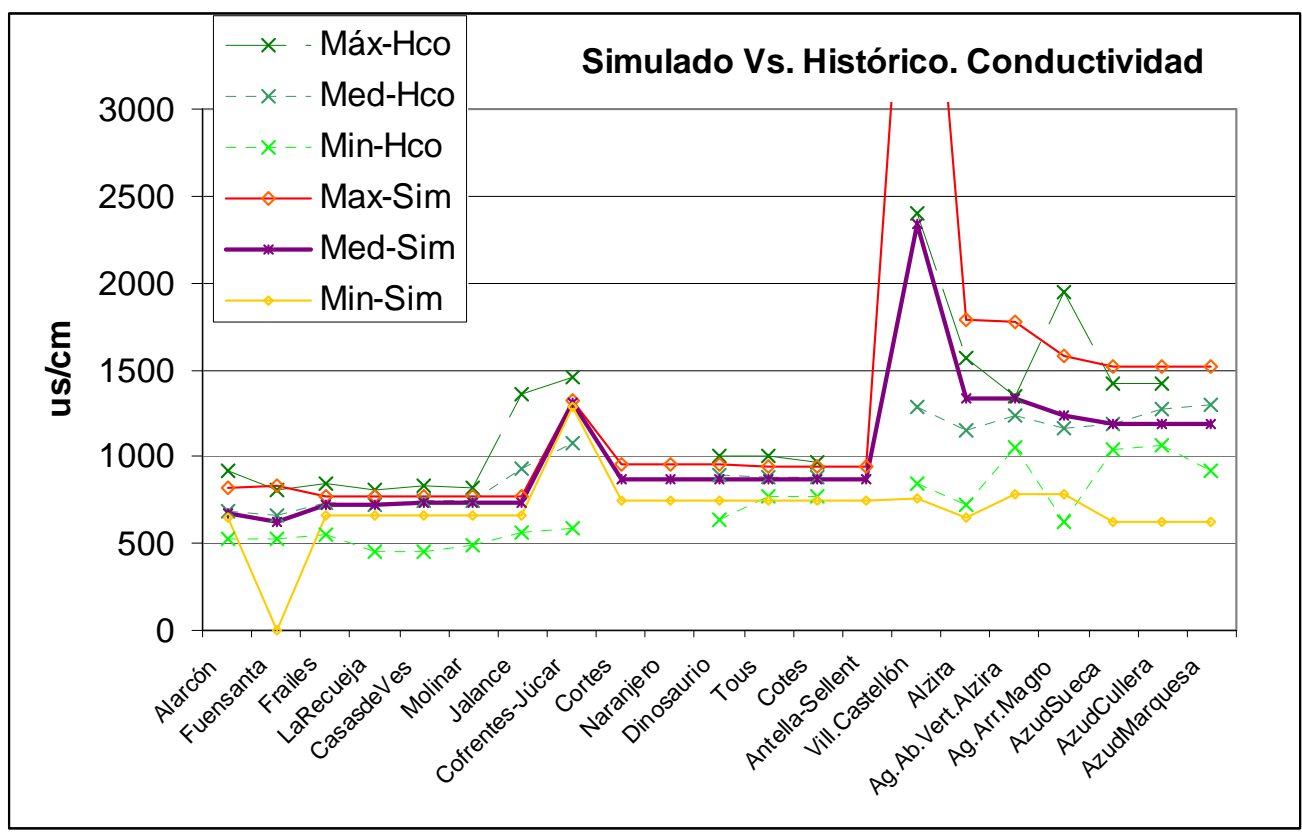

Figura 120. Perfiles simulados e históricos de conductividad.

El gráfico muestra un buen comportamiento del modelo tanto de valores medios, máximos y mínimos. Tan sólo, en la zona aguas abajo de la confluencia con el Sellent y hasta Alcira las concentraciones máximas estimadas por el modelo son muy superiores a las medidas históricamente. Por otro lado, el valor nulo obtenido en Fuensanta se debe a que en algún mes el río se queda seco en ese punto. 


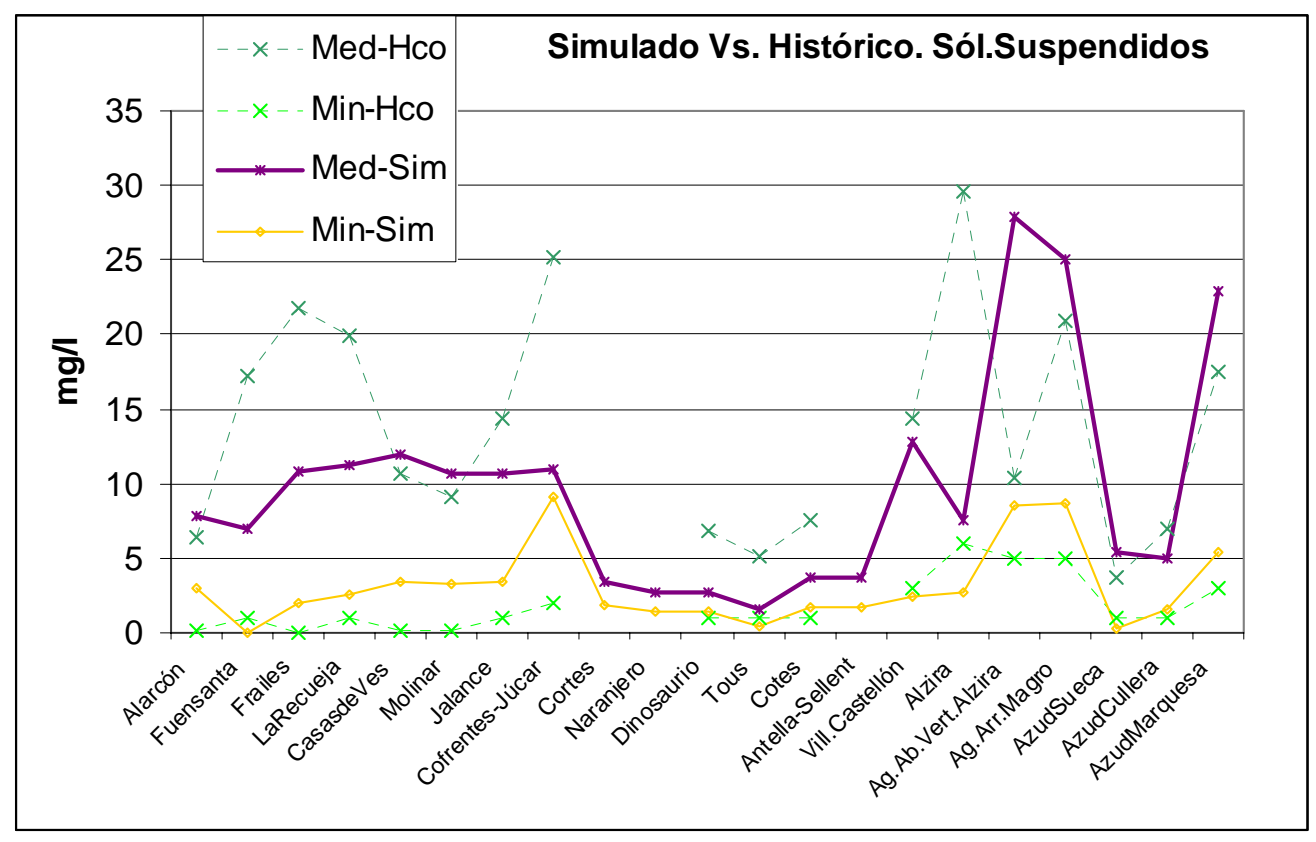

Figura 121. Perfiles simulados e históricos de Sólidos Suspendidos.

Para poder apreciar mejor las concentraciones medias se han suprimido de este gráfico las concentraciones máximas, ya que distorsionaban el gráfico. Como se puede ver, en bastantes puntos, los valores medios estimados son inferiores a los medidos. La parte final del río tiene un mejor comportamiento en cuanto a valores estimados se refiere.

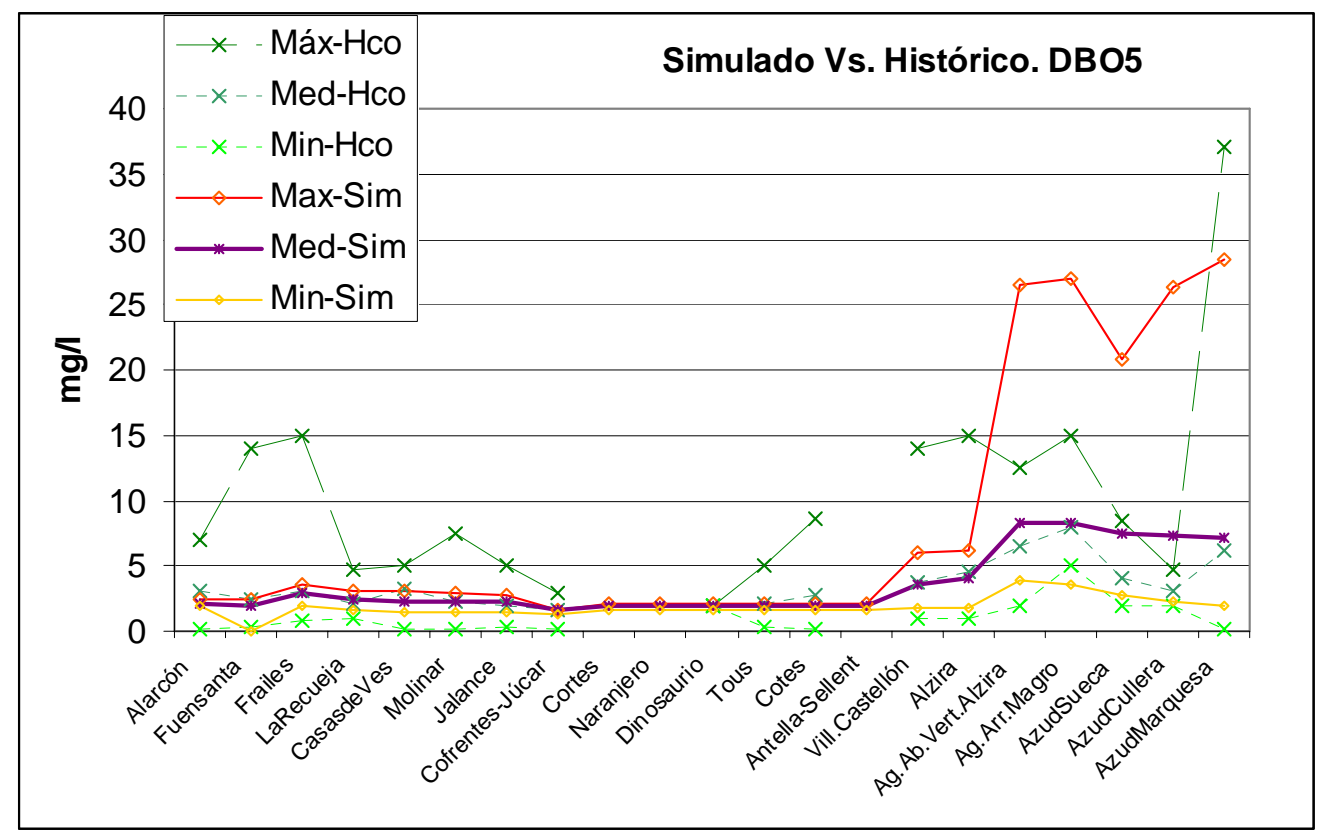

Figura 122. Perfiles simulados e históricos de $\mathrm{DBO}_{5}$.

El gráfico refleja un buen comportamiento del modelo en cuanto a valores medios y mínimos estimados. En lo que a valores máximos se refiere, mientras que en la zona inferior parece que el modelo esté estimando valores máximos superiores, en la 
parte aguas arriba de Tous los máximos históricos son superiores a los estimados. Este último efecto debe ser matizado ya que actualmente en todos los meses muestreados se obtienen concentraciones de oxígeno disuelto inferiores a los $2 \mathrm{mg} / \mathrm{l}$ en esa zona. Esos máximos históricos se dieron en épocas de sequía y previamente a la construcción de gran parte de la infraestructura de saneamiento actualmente disponible.

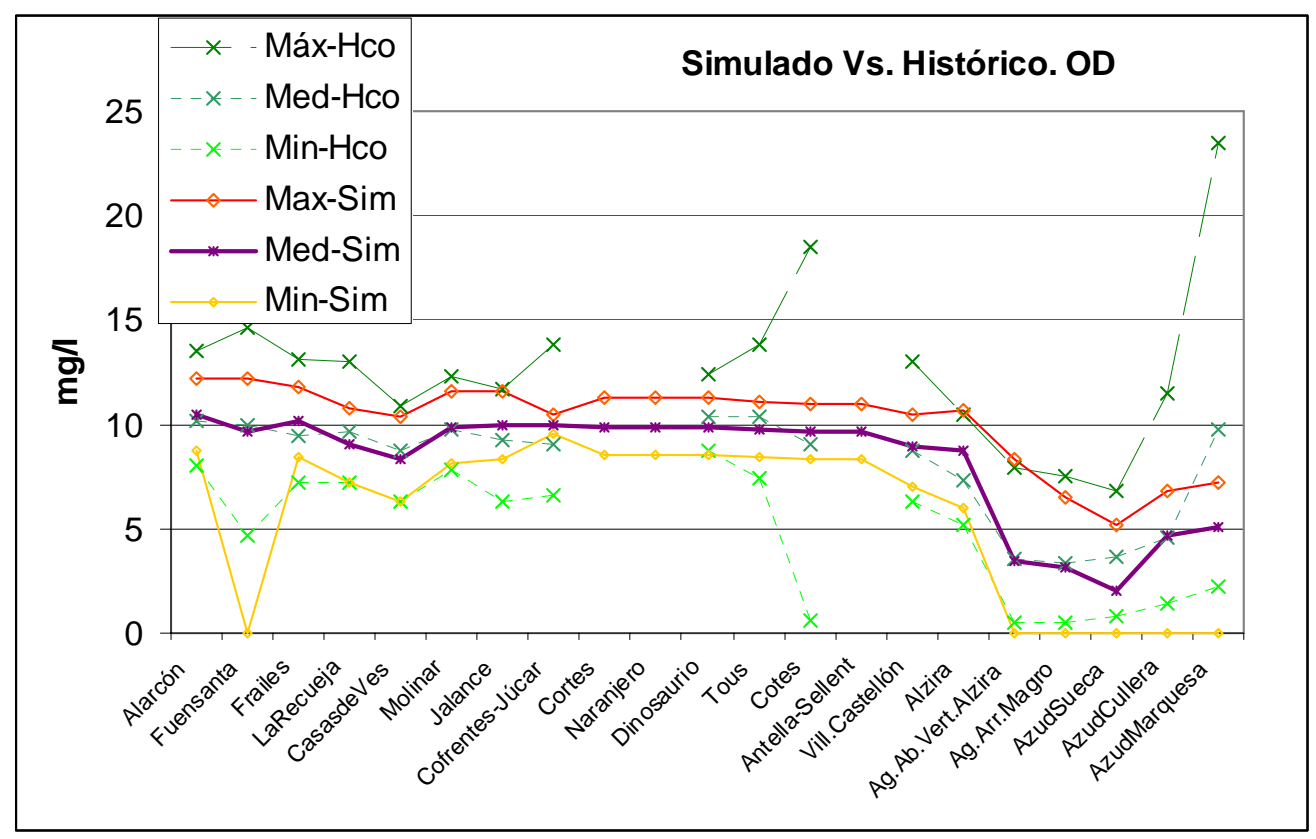

Figura 123. Perfiles simulados e históricos de oxígeno disuelto.

Para el oxígeno disuelto el ajuste es bastante bueno. Quizás en el tramo final mientras que el modelo estima valores mínimos nulos, las medidas históricas reflejan concentraciones muy bajas pero no nulas. Sobre este aspecto hay que destacar que en ese tramo de río se tienen muy pocos datos históricos. 


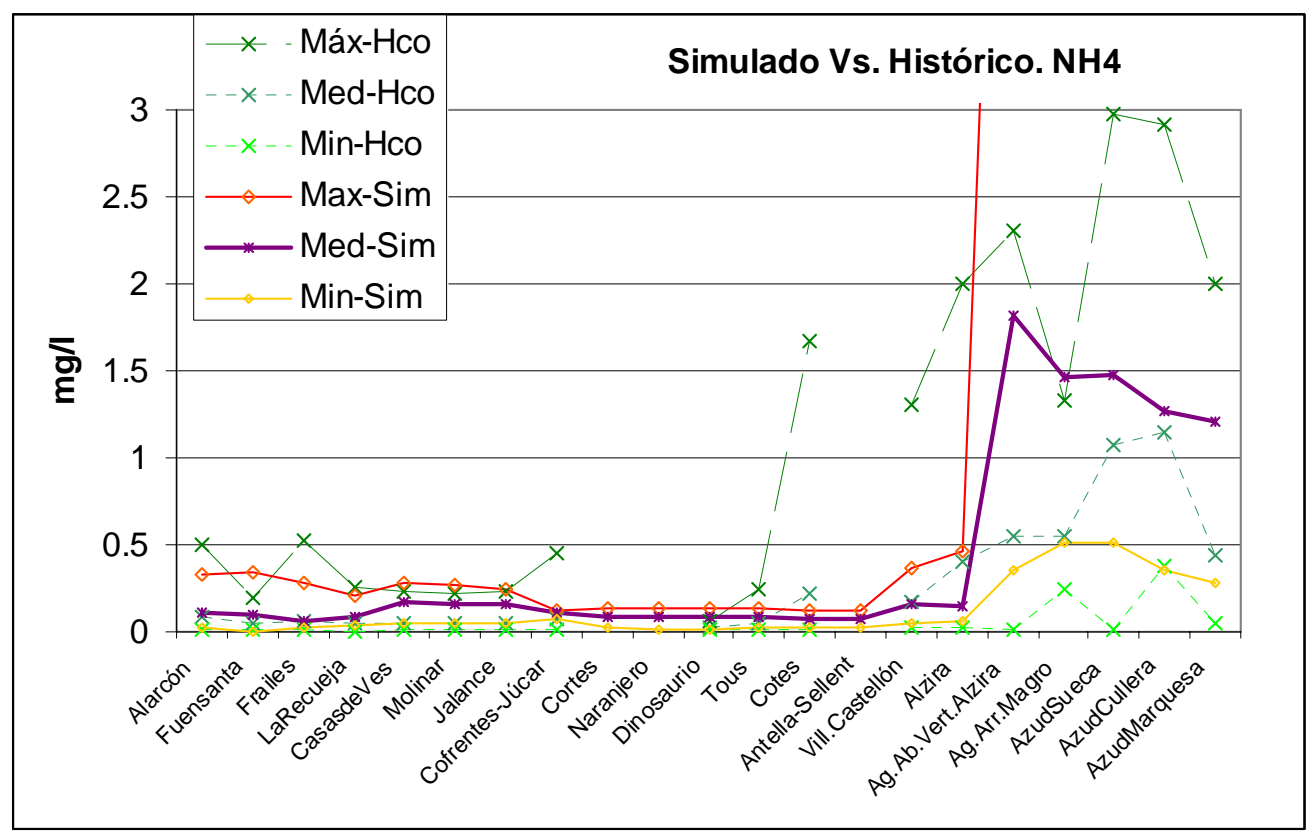

Figura 124. Perfiles simulados e históricos de Amonio

El amonio es uno de los constituyentes que mayores problemas presenta en los ajustes. Como se puede ver en el gráfico aguas arriba de Tous las concentraciones son bastante bajas y muy parecidas en cuanto a valores medios, mínimos y máximos se refiere. En la parte final, el modelo está estimando valores superiores a los de la red ICA. El gráfico se ha reescalado porque las concentraciones máximas del modelo aguas abajo de Alcira llegan hasta los $9 \mathrm{mg} / \mathrm{l}$ imposibilitando la comparación del resto de valores.

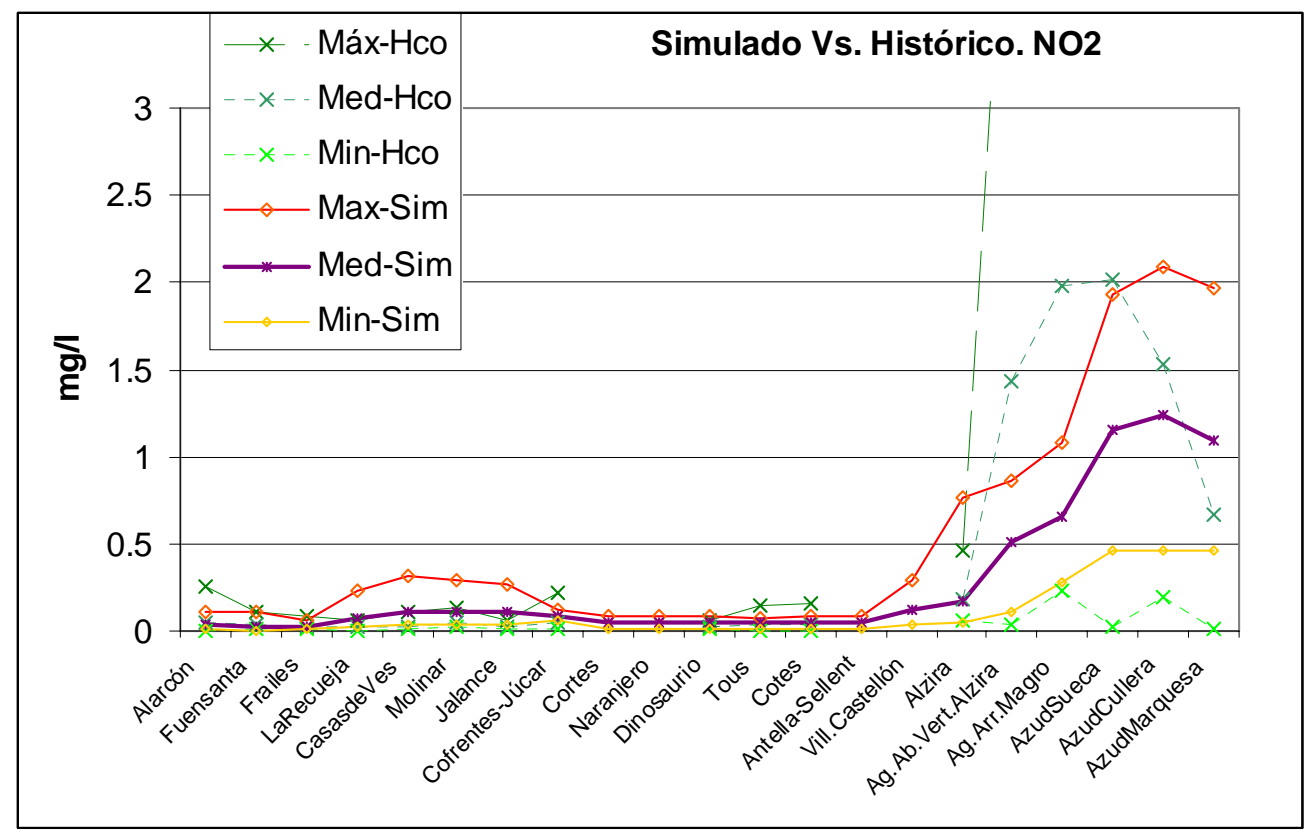

Figura 125. Perfiles simulados e históricos de nitritos. 
Para los nitritos pasa lo contrario que con el amonio, las concentraciones medias y máximas estimadas por el modelo son inferiores a las medidas históricamente.

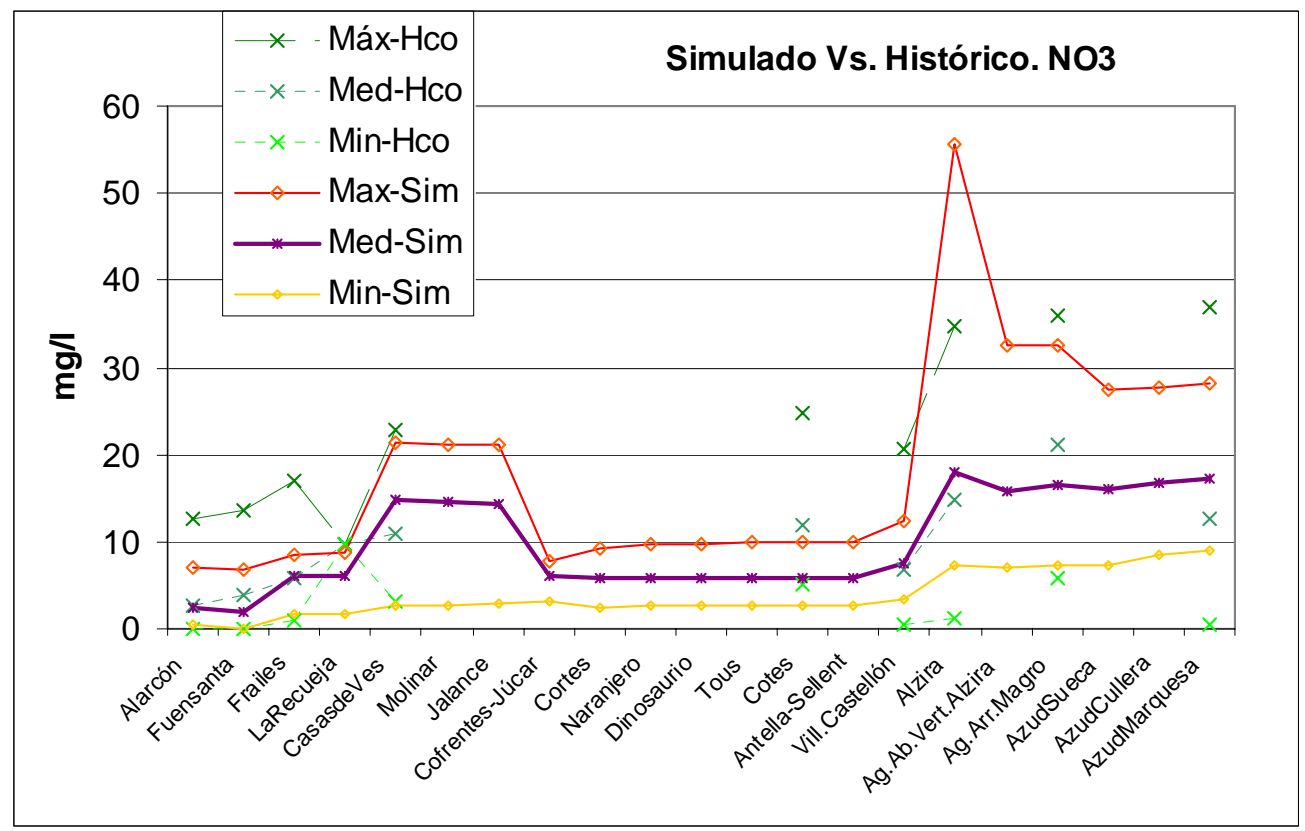

Figura 126. Perfiles simulados e históricos de nitratos.

El comportamiento de los nitratos es bastante bueno aunque no se dispone de muchos datos para su comparación. Las concentraciones máximas del área de Alcira presentan valores bastante superiores a los históricos debido a que el elemento de contaminación difusa, ubicado en ese tramo, es constante y no tiene en cuenta que en los momentos de sequía los aportes de nutrientes disminuyen.

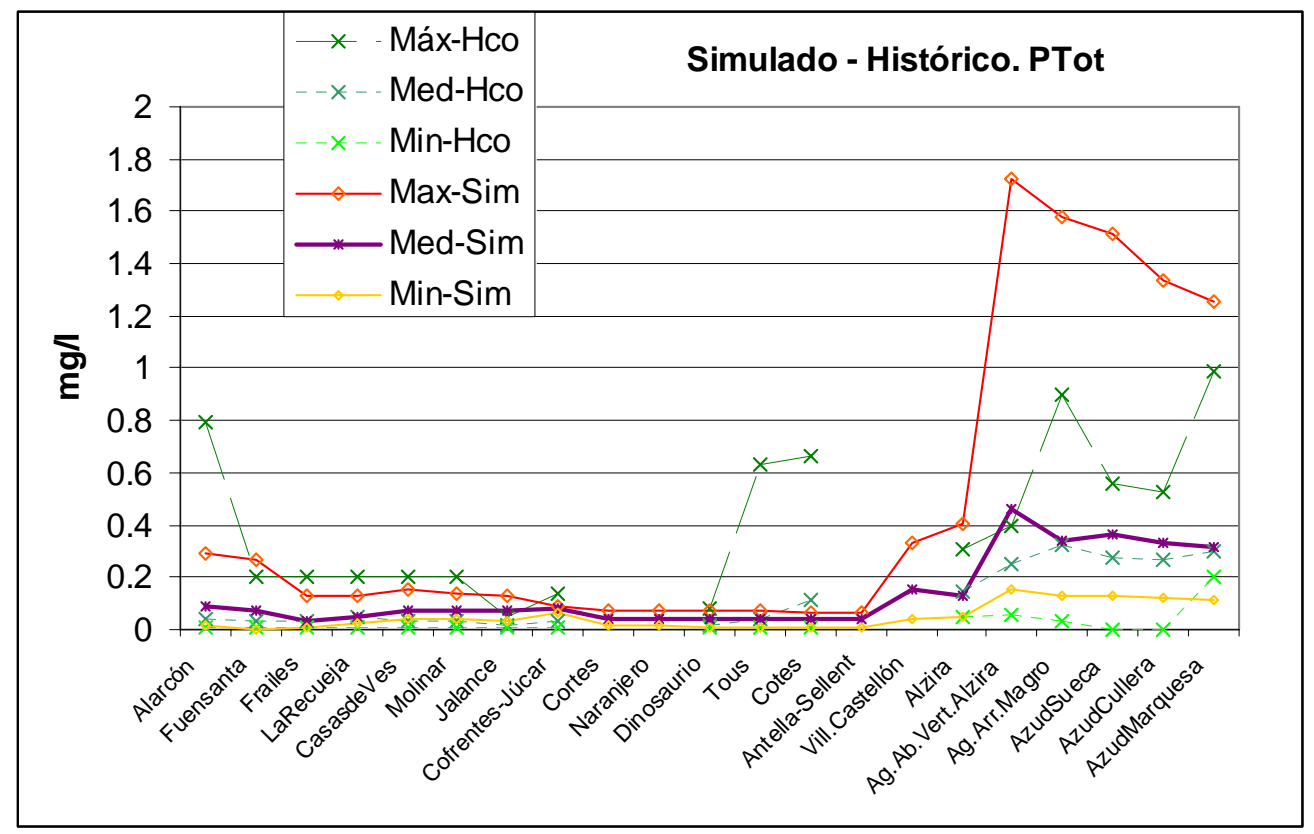

Figura 127. Perfiles simulados e históricos de Fósforo total. 
Finalmente, el comportamiento del fósforo total es bastante bueno aunque los valores máximos estimados por el modelo en la parte final son bastante superiores a los medidos en esa zona. Sin embargo hay que recordar que existen muy pocas medidas en esa zona y que son de fosfatos mientras que el modelo está estimando fósforo total.

De todo lo visto se puede concluir que el modelo es representativo de la realidad del sistema tanto para la gestión del mismo como para la calidad de los constituyentes modelados. Por otra parte, se debe recordar, que la implantación de la modelación de la calidad en un modelo de simulación no debe intentar hacer perder eficacia al modelo de gestión haciendo que este refleje el pasado ya que no es esa la finalidad de estos modelos. Sin embargo, el modelador, con la incorporación de este nuevo aspecto, debe establecer las modificaciones necesarias para que la simulación de la calidad tenga sentido y coherencia en algunas zonas.

\subsection{SIMULACIÓN DE ALTERNATIVAS.}

La simulación de escenarios permite analizar el comportamiento del sistema $\mathrm{y}$ de la calidad de sus aguas frente a diferentes situaciones.

\subsubsection{Escenarios planteados.}

A la hora de plantear los escenarios de simulación se ha querido tener en cuenta varios aspectos como son las posibles evoluciones del uso del recurso hídrico en el sistema, así como aspectos de depuración y medioambientales. En primer lugar se estudia el efecto que tendrá sobre la calidad la próxima puesta en funcionamiento de la EDAR de Alcira. El segundo aspecto a estudiar es, considerando la citada EDAR, la comparación de las situaciones de las demandas del sistema en la actualidad, a medio plazo y a largo plazo según lo concebido en el Plan Hidrológico del Júcar. Este cambio en las demandas afecta tanto a la circulación de caudales en el río como a la evolución de los embalses, los retornos de riego, etc. Finalmente sobre estos tres escenarios se estudian los caudales de dilución necesarios en la zona aguas abajo de Tous para alcanzar concentraciones de oxígeno disuelto suficientes para permitir la existencia de vida acuática en el río.

Las simulaciones se han realizado para el período entre los años 1985 y 2001. Este período está formado por una primera época húmeda entre 1985 y 1990 y dos épocas muy secas: la sequía producida entre 1993 y 1995 y la acaecida entre 1998 y 2001. Estas dos sequías son las más importantes en el sistema del Júcar de todas las sufridas desde 1940, fecha a partir de la cual se disponen de series de aportaciones. La 
elección de estos dieciséis años se debe a que por un lado se simula una época húmeda normal y por otro permite analizar el sistema en situación de extrema de sequía. Se puede considerar el período simulado como un escenario pesimista ya que refleja la peor hidrología producida en el sistema.

Se han planteado nueve escenarios que seguidamente se detallan:

- ACTUAL: representa la situación actual del sistema tanto del modelo de gestión como del de calidad.

- ACTUAL-EDAR: representa la situación actual de todo el sistema pero considerando que la EDAR de Alcira, actualmente en construcción, ha entrado en funcionamiento. Esta EDAR recogerá los vertidos de las poblaciones de Alcira y otras que vierten al barranco de Barcheta. El tratamiento previsto es biológico con eliminación de nitrógeno. Se han modificado las calidades del vertido asumiendo concentraciones teóricas de ese tratamiento. Además, se ha considerado que la constante de degradación de la materia orgánica variará en el tramo Alzira -Verde. Ante esta nueva situación, se considera que el parámetro se iguala al de los tramos colindantes. Dentro de ese vertido se consideran también los vertidos de Alberique y Pobla Llarga con EDAR de tratamiento secundario en funcionamiento desde el 2001. Por motivos de simplicidad no se ha desagregado el vertido en dos, asumiendo el mismo tratamiento que el de la EDAR de Alcira.

- ACTUAL-EDAR-ECO: partiendo del escenario anterior se estima, de forma iterativa, el caudal adicional necesario para que todo el tramo aguas abajo de Tous se den niveles de oxígeno disuelto suficientes para que exista vida piscícola. Se ha utilizado como umbral de oxígeno disuelto para que exista vida acuática 3mg/l (EPA, 1986). Se considera el cumplimiento de la regla cuando el $95 \%$ de los meses están por encima del umbral. El caudal se impone aguas abajo del azud de Antella ya que el tramo de río entre ese punto y el azud de Sueca es el que presenta la peor calidad de toda la cuenca.

- ACTUAL-GEST.EXTREMA: se considera la situación actual del sistema y se permite al modelo de simulación que realice una gestión del sistema de "máxima eficiencia" sin considerar los caudales mínimos explicados en el apartado de acoplamiento. Se ha considerado esta opción para poder comparar los resultados del resto de escenarios con una opción que representaría una situación teórica de gestión extrema.

- MEDPLA: representa la situación de las demandas del sistema a "medio plazo" teniendo en cuenta la modernización de la Acequia Real, el trasvase Júcar Vinalopó y la sustitución de bombeos en la Mancha. Los valores utilizados para 
las demandas se pueden ver en la tabla 12. En cuanto a la infraestructura de depuración se considera que la EDAR de Alcira está en funcionamiento.

- MEDPLA-ECO: partiendo del escenario anterior se estima el caudal necesario para que se cumpla, en toda la zona aguas abajo de Tous, el umbral establecido para vida piscícola.

- PHJ: representa el sistema en una situación de demandas contemplada en el segundo horizonte del Plan Hidrológico del Júcar. En esta situación se han materializado todas las asignaciones y reservas contempladas en el plan. Los valores utilizados de las demandas se encuentran en la tabla 12. En esta situación se considera la EDAR de Alcira en funcionamiento.

- PHJ-ECO: partiendo del escenario anterior se estiman las sueltas necesarias desde Tous para que se cumpla la condición de oxígeno disuelto impuesta en toda la zona aguas abajo del embalse.

- PHJ-ACC.FUT: se considera una situación de demandas similar a la del escenario PHJ y se asumen acciones de depuración, además de la EDAR de Alcira, en las cuencas de los ríos Verde y Magro de tal forma que se cumple el umbral establecido para vida piscícola. Además se considera una reducción del aporte de nitratos del Magro, Verde y del tramo de Alcira de un 30\%. En este escenario se quiere estudiar la mejora que se obtendría con ciertas acciones de depuración sobre los afluentes inferiores del Júcar y con el establecimiento de programas de buena práctica agrícola. 
En la tabla siguiente se encuentra un resumen de los escenarios planteados.

\begin{tabular}{|l|l|}
\hline Denominación & \multicolumn{1}{|c|}{ Descripción } \\
\hline ACTUAL & Situación actual del sistema. \\
\hline ACTUAL-EDAR & $\begin{array}{l}\text { Situación actual con la EDAR de Alcira en } \\
\text { funcionamiento. }\end{array}$ \\
\hline ACTUAL-EDAR-ECO & $\begin{array}{l}\text { Estimación del caudal de dilución para la situación } \\
\text { ACTUAL con la EDAR de Alcira en funcionamiento }\end{array}$ \\
\hline ACTUAL - GEST. & $\begin{array}{l}\text { Situación actual con una gestión del sistema de máxima } \\
\text { eficiencia. }\end{array}$ \\
\hline MEDPLA & $\begin{array}{l}\text { Situación de demandas a medio plazo (considerando la } \\
\text { modernización de la Ac. Real). EDAR Alcira. }\end{array}$ \\
\hline MEDPLA-ECO & $\begin{array}{l}\text { Estimación del caudal de dilución para la situación a } \\
\text { medio plazo. }\end{array}$ \\
\hline PHJ & $\begin{array}{l}\text { Situación de demandas según Plan Hidrológico del Júcar. } \\
\text { Modernización Ac. Real. EDAR Alcira. }\end{array}$ \\
\hline PHJ-ECO & $\begin{array}{l}\text { Estimación de caudal de dilución para la situación de } \\
\text { PHJ. }\end{array}$ \\
\hline
\end{tabular}

Tabla 11. Resumen de los escenarios planteados.

Las demandas utilizadas en los tres diferentes escenarios de situación de la cuenca - ACTUAL, MEDPLA y PHJ - se pueden ver en a siguiente tabla. 


\begin{tabular}{|l|l|l|l|}
\hline Demandas (Hm $\mathbf{3} / \mathbf{m e s})$ & ACTUAL & MEDPLA & PHJ \\
\hline Abast .Peq. Reg. Cuenca & 0 & 15 & 25 \\
\hline Abast. Albacete & 18 & 31 & 31 \\
\hline $\begin{array}{l}\text { Sust. Bombeos La } \\
\text { Mancha }\end{array}$ & 15 & 78 & 265 \\
\hline Bomb. Ac. Mancha & 445 & 290 & 103 \\
\hline Abast.Valencia & 95 & 106 & 190 \\
\hline Abast. Sagunto & 12 & 31 & 31 \\
\hline Riegos C.J.T. & 60 & 90 & 125 \\
\hline Reg. Tradic. & 410 & 171 & 206 \\
\hline Ribera Baja & 317 & 317 & 279 \\
\hline V. Alacantí & 0 & 69 & 170 \\
\hline Marina Baja & 0 & 12 & 0 \\
\hline Taibilla & 0 & 0 & 0 \\
\hline
\end{tabular}

Tabla 12. Demandas utilizadas en los distintos escenarios.

Una vez realizada la simulación de los diferentes escenarios se realiza un análisis de resultados para extraer las conclusiones sobre el sistema su gestión y la calidad del agua.

\subsubsection{Análisis de resultados.}

El análisis de las simulaciones de los diferentes escenarios planteados se realiza desde una perspectiva conjunta "cantidad" y "calidad" del agua. El análisis cuantitativo indica la medida de utilización del recurso hídrico mientras que el análisis de la calidad del agua muestra, espacio - temporalmente, la afección de las diferentes situaciones sobre la calidad del agua.

\subsubsection{Análisis cuantitativo.}

Para el análisis cuantitativo de los escenarios se estudian tres aspectos las garantías de suministro de algunas demandas, los caudales circulantes en el sistema y la evolución de los volúmenes embalsados en los diferentes embalses. 


\subsection{Análisis de las garantías}

En cuanto a las garantías se han analizado las variables que a continuación se definen:

- Número de Fallos: número de meses en donde el suministro es inferior a un tanto por ciento "A" de la demanda. Donde "A" es un umbral definido en función de la demanda. En este caso se ha considerado un valor nulo del umbral para todas las demandas por lo que los fallos obtenidos en las simulaciones serán bastante numerosos.

- Garantía mensual: definida como el cociente porcentual entre el número de fallos de suministro y el número de meses simulados.

- Garantía volumétrica: obtenida como el cociente entre el volumen suministrado por una demanda y el demandado.

Mientras que los dos primeros conceptos reflejan la garantía de la demanda bajo una perspectiva de probabilidad de fallo la garantía volumétrica es un indicador de la probabilidad de suministro total.

Para el estudio de las garantías se han elegido como indicadoras de la situación: la demanda urbana del abastecimiento de Valencia, la demanda de la acequia Real representativa de las de la ribera alta, la demanda de Sueca representando a las de la ribera baja y los Regadíos del canal Júcar-Turia que son riegos más modernos.

Hay que matizar que, mientras para el estudio de la calidad se han simulado dieciséis años, para la estimación de las garantías se ha realizado la simulación de los escenarios con un período histórico total de sesenta y un años (1940-2001) lo que permite una mejor comparación entre alternativas.

La tabla siguiente muestra las garantías obtenidas en las diferentes simulaciones. 


\begin{tabular}{|c|c|c|c|c|c|}
\hline \multicolumn{2}{|c|}{ RESULTADOS DE GARANTÍAS } & Ac Real & RCJT & Sueca & Val \\
\hline \multirow{7}{*}{$\begin{array}{l}\text { Garantía } \\
\text { (\%) }\end{array}$} & ACTUAL & 82.72 & 86.32 & 80.92 & 100 \\
\hline & ACTUAL-ECO & 82.02 & 85.72 & 80.12 & 99.92 \\
\hline & $\begin{array}{l}\text { ACTUAL- } \\
\text { GESTEXTR }\end{array}$ & 83.32 & 87.02 & 81.62 & 99.92 \\
\hline & MEDPLA & 99.92 & 94.72 & 84.32 & 100 \\
\hline & MEDPLA-ECO & 90.62 & 93.92 & 82.72 & 99.22 \\
\hline & $\mathrm{PHJ}$ & 85.02 & 88.32 & 78.82 & 98.52 \\
\hline & PHJ-ECO & 83.52 & 88.12 & 77.22 & 95.42 \\
\hline & & Ac Real & RCJT & Sueca & Val \\
\hline \multirow{8}{*}{$\begin{array}{l}\text { Garantía } \\
\text { Volumétrica } \\
\text { (\%) }\end{array}$} & $\overline{A C T U A L}$ & 92.22 & 90.22 & 94.72 & 100 \\
\hline & ACTUAL-ECO & 90.82 & 88.72 & 94.82 & 99.92 \\
\hline & $\begin{array}{l}\text { ACTUAL- } \\
\text { GESTEXTR }\end{array}$ & 92.62 & 90.72 & 94.72 & 100 \\
\hline & MEDPLA & 95.82 & 92.72 & 95.72 & 100 \\
\hline & MEDPLA-ECO & 94.52 & 91.72 & 95.42 & 99.72 \\
\hline & $\mathrm{PHJ}$ & 90.22 & 83.02 & 92.92 & 99.82 \\
\hline & PHJ-ECO & 88.32 & 82.12 & 94.22 & 98.12 \\
\hline & & Ac Real & RCJT & Sueca & Val \\
\hline \multirow[t]{7}{*}{$\mathrm{N}^{\circ}$ Fallos } & ACTUAL & 127 & 100 & 140 & 0 \\
\hline & ACTUAL-ECO & 132 & 105 & 146 & 1 \\
\hline & $\begin{array}{l}\text { ACTUAL- } \\
\text { GESTEXTR }\end{array}$ & 122 & 95 & 135 & 1 \\
\hline & MEDPLA & 52 & 39 & 115 & 0 \\
\hline & MEDPLA-ECO & 69 & 45 & 127 & 6 \\
\hline & $\mathrm{PHJ}$ & 110 & 86 & 155 & 11 \\
\hline & PHJ-ECO & 121 & 87 & 167 & 34 \\
\hline
\end{tabular}

Tabla 13. Garantías obtenidas en las distintas simulaciones.

Algunos escenarios, como por ejemplo ACTUAL-EDAR, no se incluyen debido a que no presentan cambios en las garantías. El análisis comparativo es prácticamente similar para los tres conceptos escogidos. El siguiente gráfico muestra los resultados de garantía volumétrica obtenidos. 
Garantía Volumétrica

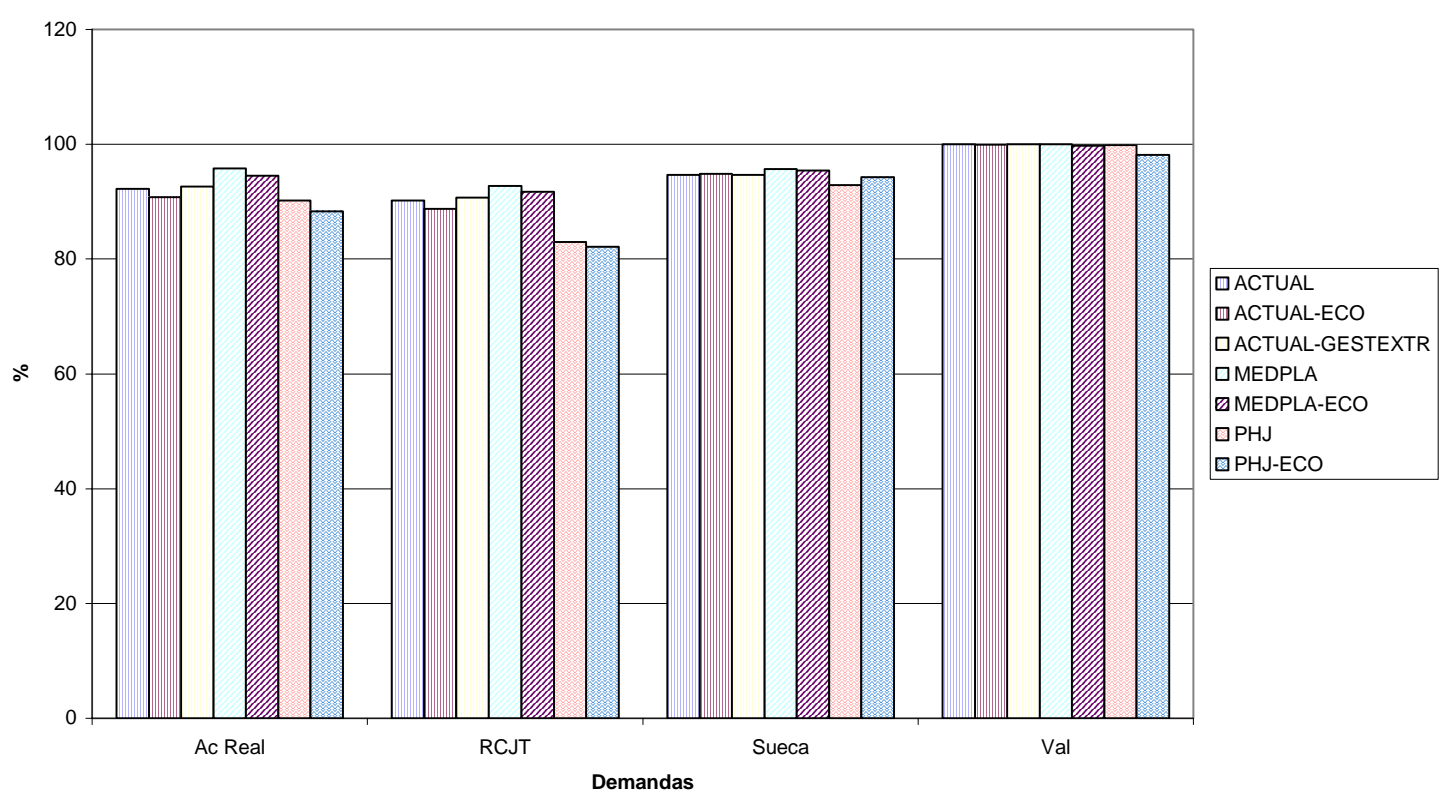

Figura 128. Garantías volumétricas de las demandas indicador en los diferentes escenarios.

Del análisis de las garantías se puede deducir lo siguiente:

- Existe una mejora de las garantías en casi todas las demandas en la situación de medio plazo frente a la actual y a la PHJ. Esta última situación es la que presenta valores más desfavorables de garantías y un mayor número de fallos en todas las demandas.

- En general la afección de las sueltas medioambientales es baja, sobre todo en cuanto a la garantía volumétrica se refiere donde las afecciones sobre las misma son, en todos los casos, inferiores al $2 \%$.

- Para la demanda de Sueca la garantía volumétrica mejora con la suelta del caudal de dilución en los escenarios ACTUAL y PHJ. No es así en la garantía mensual y en el número de fallos.

- La demanda urbana de Valencia mantiene valores muy altos en casi todas las alternativas debido a ser la más prioritaria. Sólo en la opción PHJ-ECO la garantía volumétrica baja del 99\%.

- En cuanto a la demanda de la Acequia Real existe una mejora sustancial entre la situación actual y la de medio plazo debido a la disminución de demanda considerada como efecto de la modernización de sus infraestructuras. 


\subsection{Análisis de los caudales circulantes}

El estudio comparativo de los diferentes caudales circulantes es un factor fundamental por su importancia sobre la calidad del agua en el sistema. La siguiente figura representa el perfil de los caudales medios circulantes en el río Júcar en algunos de los escenarios simulados.

Caudales medios circulantes

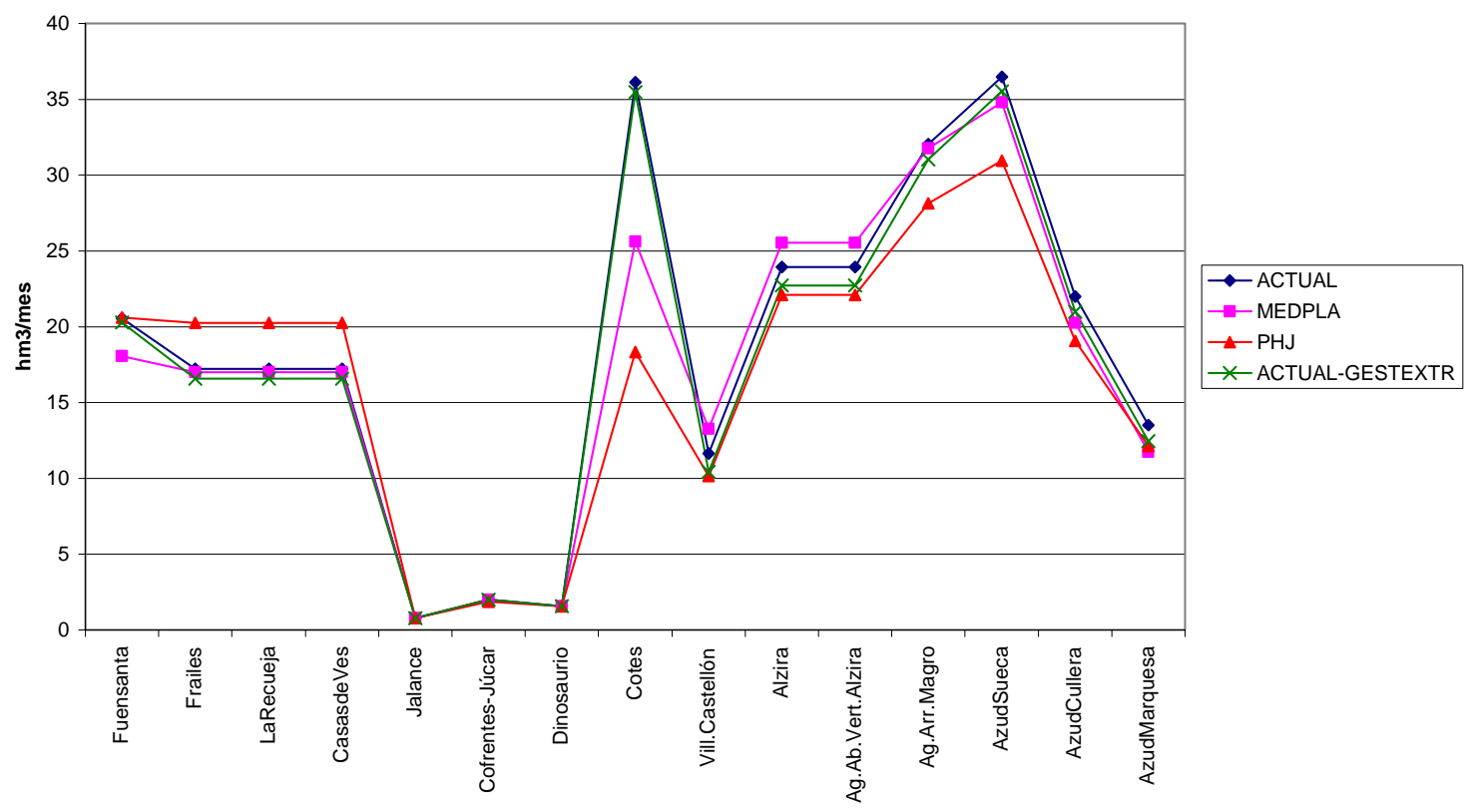

Figura 129. Perfiles medios de caudales circulantes para diferentes escenarios simulados.

Este gráfico sirve para analizar la diferencia de caudales circulantes entre las tres "situaciones de demanda" en las que se analiza el sistema. Como se puede ver, para los valores medios el escenario PHJ presenta diferencias respecto al resto de escenarios. Mientras que en la parte de aguas arriba los caudales circulantes son significativamente superiores en el tramo aguas abajo del embalse de Tous, esta alternativa presenta caudales inferiores al resto. Esto tiene como consecuencia, como se verá más adelante, el empeoramiento de la calidad del agua en ese tramo final en la hipótesis PHJ.

Además del caudal medio circulante es importante el análisis de los caudales mínimos ya que representan los momentos críticos para el sistema. En el siguiente gráfico se puede ver el mismo perfil de caudales pero esta vez con los valores mínimos en cada punto. 
Caudales mínimos circulantes

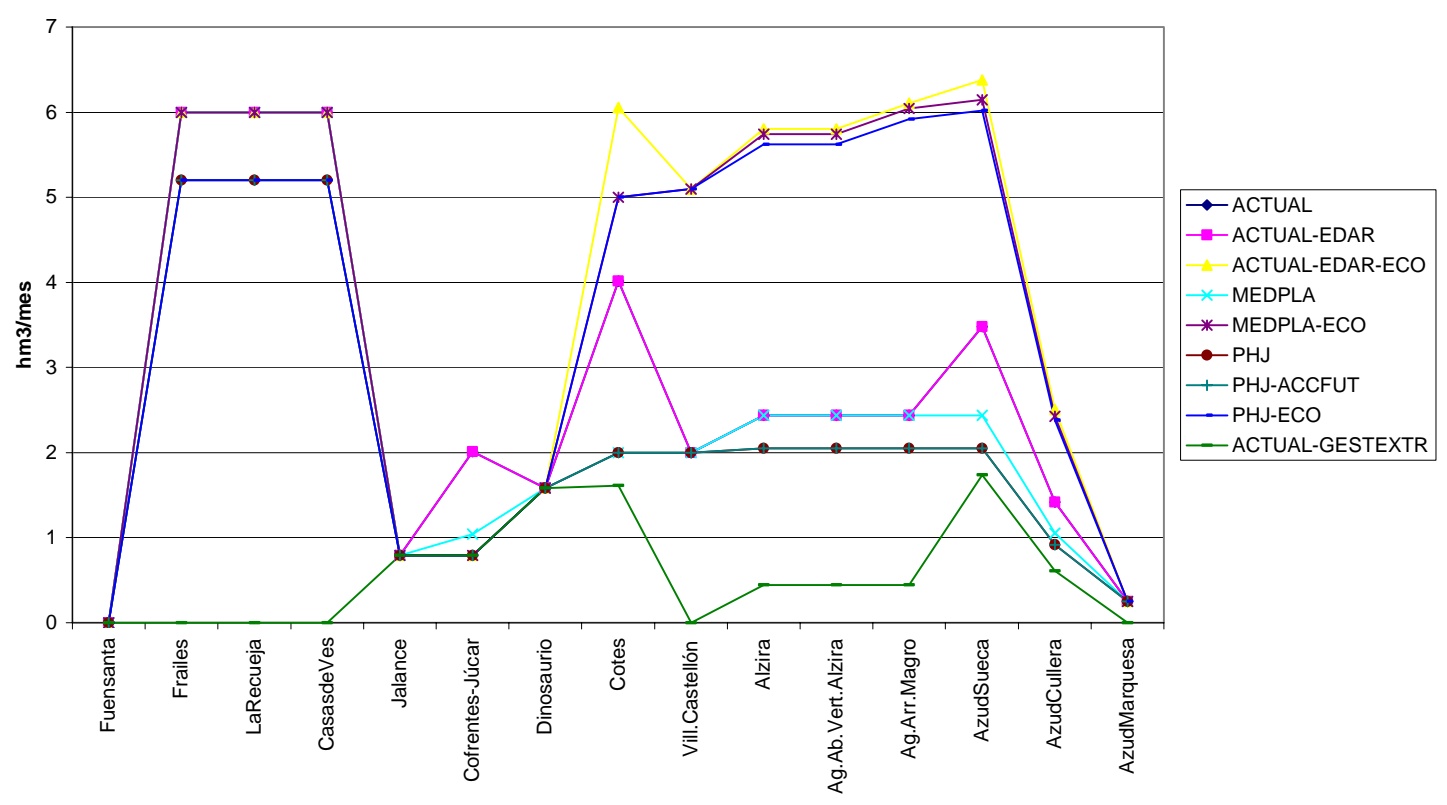

Figura 130. Perfiles mínimos de caudales circulantes para diferentes escenarios simulados

En el gráfico de caudales mínimos circulantes se observa que aguas arriba de Tous los caudales circulantes entre Fuensanta y Casas de Ves se comportan de forma distinta según el escenario. En la situación de gestión extrema (ACTUAL-GESTEXTR) el gráfico muestra que en alguna ocasión el río se queda seco en la zona. Para el resto de escenarios destacan los escenarios PHJ (PHJ-ECO, PHJ-ACCFUT), en los que los caudales mínimos son ligeramente superiores a los $6 \mathrm{hm}^{3} /$ mes establecido como caudal mínimo. El resto de escenarios muestran unos caudales mínimos en esa zona iguales a los impuestos.

En el gráfico se aprecia, para la zona aguas abajo de Tous, diferencias entre la opción de gestión extrema, situaciones sin caudal de dilución y escenarios con caudal de dilución. En los puntos de Villanueva de Castellón y Azud de la Marquesa el caudal mínimo circulante es nulo para el escenario de GESTEXTR. La imposición de los $2 \mathrm{hm}^{3} / \mathrm{mes}$ impuesta en el tramo de Cotes -Villanueva de Castellón hace que se cumpla dicho caudal en el resto de alternativas. Se puede distinguir que los caudales circulantes son ligeramente superiores en la alternativa ACTUAL frente a la de medio plazo (MEDPLA) y esta sobre la PHJ. Finalmente otro grupo de alternativas son las "ECO" en las que se han establecido los caudales de dilución. En ellas se pueden ver caudales mínimos en la zona aguas abajo de Tous entre 5 y $6 \mathrm{hm}^{3} / \mathrm{mes}$.

En cuanto al afluente Cabriel los caudales medios de todas las alternativas son muy similares. Lo mismo pasa con los caudales mínimos excepto para la alternativa ACTUAL-GESTEXTR que presenta valores mínimos ligeramente inferiores en el tramo final, $11.74 \mathrm{hm}^{3} /$ mes frente a $16.9 \mathrm{hm}^{3} /$ mes el resto. 
Finalmente la siguiente tabla muestran los caudales ecológico, o de dilución, estimados mediante un proceso de prueba y error. Este caudal se establece como requerimiento mínimo en el tramo "Antella - Sellent", aguas abajo de las tomas de las demandas de la ribera alta.

\begin{tabular}{|l|l|l|l|l|l|l|l|l|l|l|l|l|}
\hline Sueltas hm3/mes & Oct & Nov & Dic & Ene & Feb & Mar & Abr & May & Jun & Jul & Ago & Sep \\
\hline $\begin{array}{l}\text { ACTUAL- } \\
\text { EDAR-ECO }\end{array}$ & 5 & 5 & 5 & 5 & 5 & 5 & 5 & 5 & 5 & 5 & 10 & 10 \\
\hline MEDPLA-ECO & 5 & 5 & 5 & 5 & 5 & 5 & 5 & 5 & 5 & 5 & 12 & 12 \\
\hline PHJ-ECO & 5 & 5 & 5 & 5 & 5 & 5 & 5 & 5 & 5 & 8 & 15 & 15 \\
\hline
\end{tabular}

Tabla 14. Caudales de dilución estimados para los diferentes escenarios.

La estimación se ha realizado de forma mensual siendo la época más sensible la de los meses de verano. Entre Octubre y Julio un caudal de $5 \mathrm{hm}^{3} / \mathrm{mes}$ (aproximadamente $1.9 \mathrm{~m}^{3} / \mathrm{s}$ ) es suficiente para mantener los niveles de calidad necesarios para la vida piscícola en cualquier situación. Para los meses de verano el caudal debe incrementarse en función del escenario en estudio.

\subsection{Análisis de la evolución de los volúmenes embalsados}

Así como el caudal es fundamental en la calidad del agua del río la evolución del volumen embalsado tiene una gran influencia sobre la calidad del agua en los embalses. Las figuras siguientes muestran las diferencias de la evolución de los embalses entre los tres escenarios relativos a la situación de las demandas de la cuenca. 
Evolución del volumen del embalse de Alarcón

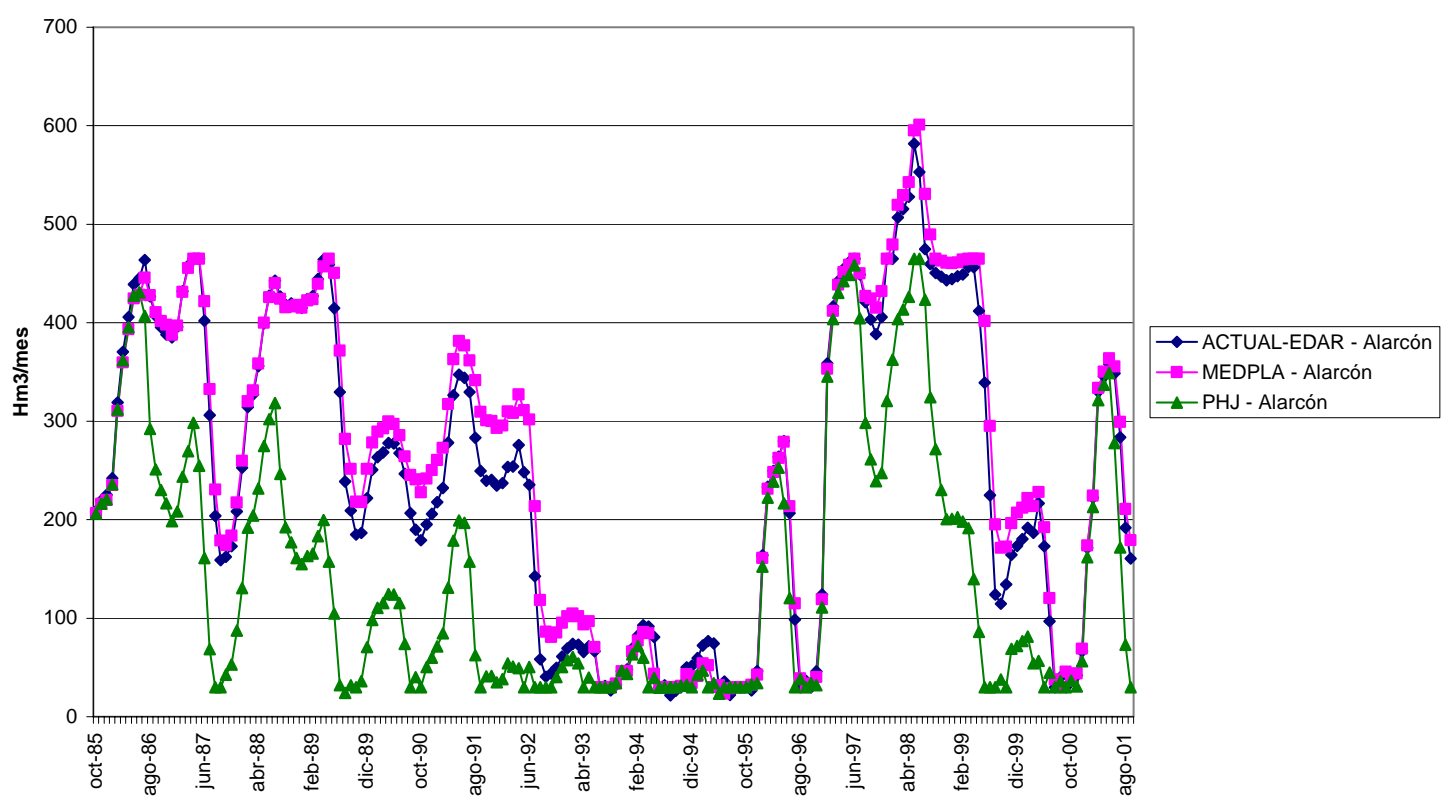

Figura 131. Evolución del volumen embalsado en Alarcón para los diferentes escenarios.

Para el embalse de Alarcón el escenario PHJ muestra un descenso de los volúmenes embalsados muy marcado frente a los otros dos escenarios, ACTUAL y MEDPLA, que mantienen niveles de embalse bastante similares. Por otra parte destaca que las mayores diferencias se dan en las épocas húmedas ya que en momentos de sequía los volúmenes son mínimos para todos los escenarios.

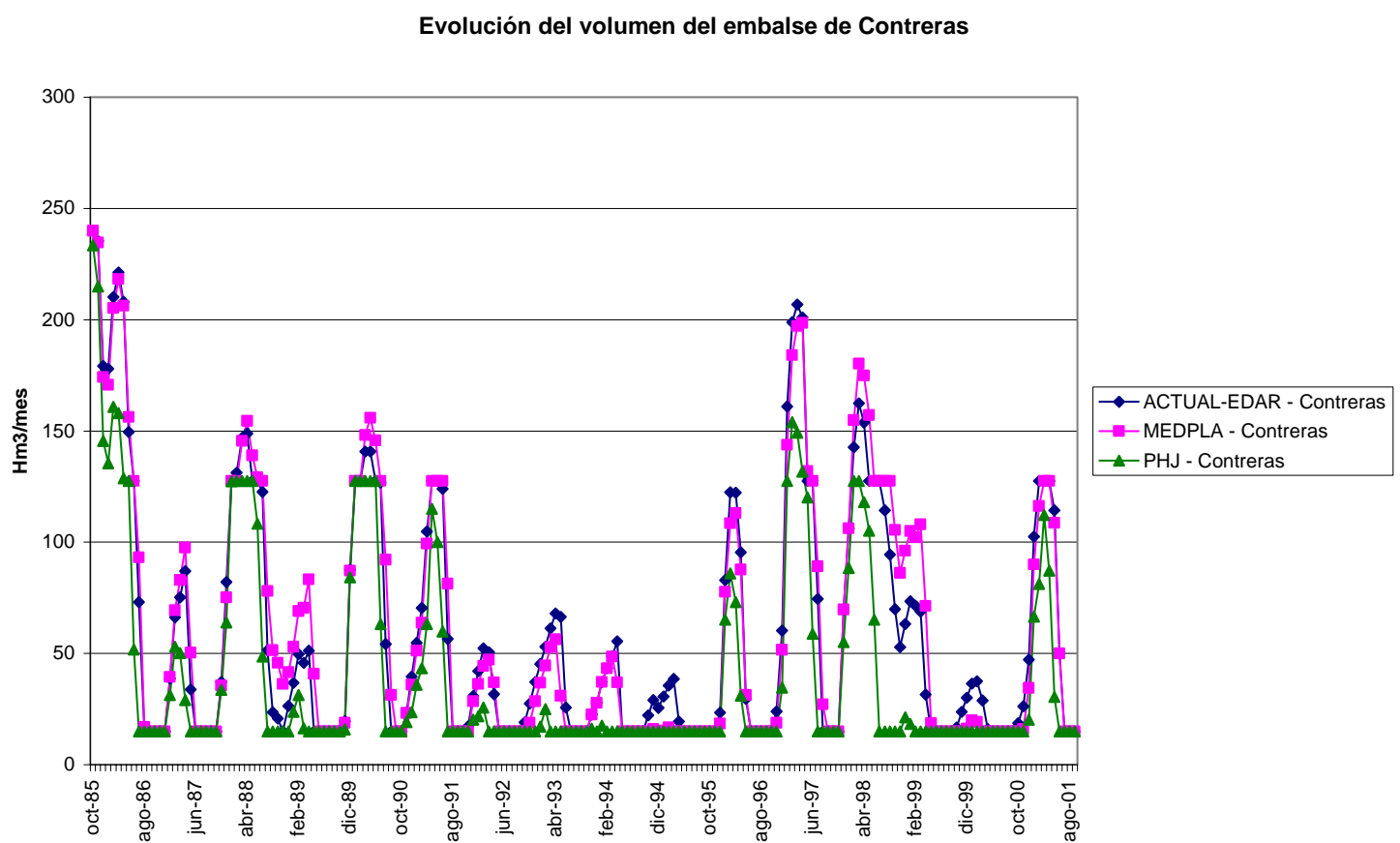

Figura 132. Evolución del volumen embalsado en Contreras para los diferentes escenarios. 
El gráfico del volumen embalsado para Contreras muestra que el embalse alcanza volúmenes mínimos en muchas más situaciones que el embalse de Alarcón. Ello es debido a las prioridades impuestas en el modelo de la gestión. Por otra parte en la comparativa de escenarios el PHJ muestra valores inferiores a los otros dos y destaca la cantidad de veces que se alcanza el volumen mínimo en este escenario.

Evolución del volumen del embalse de Tous

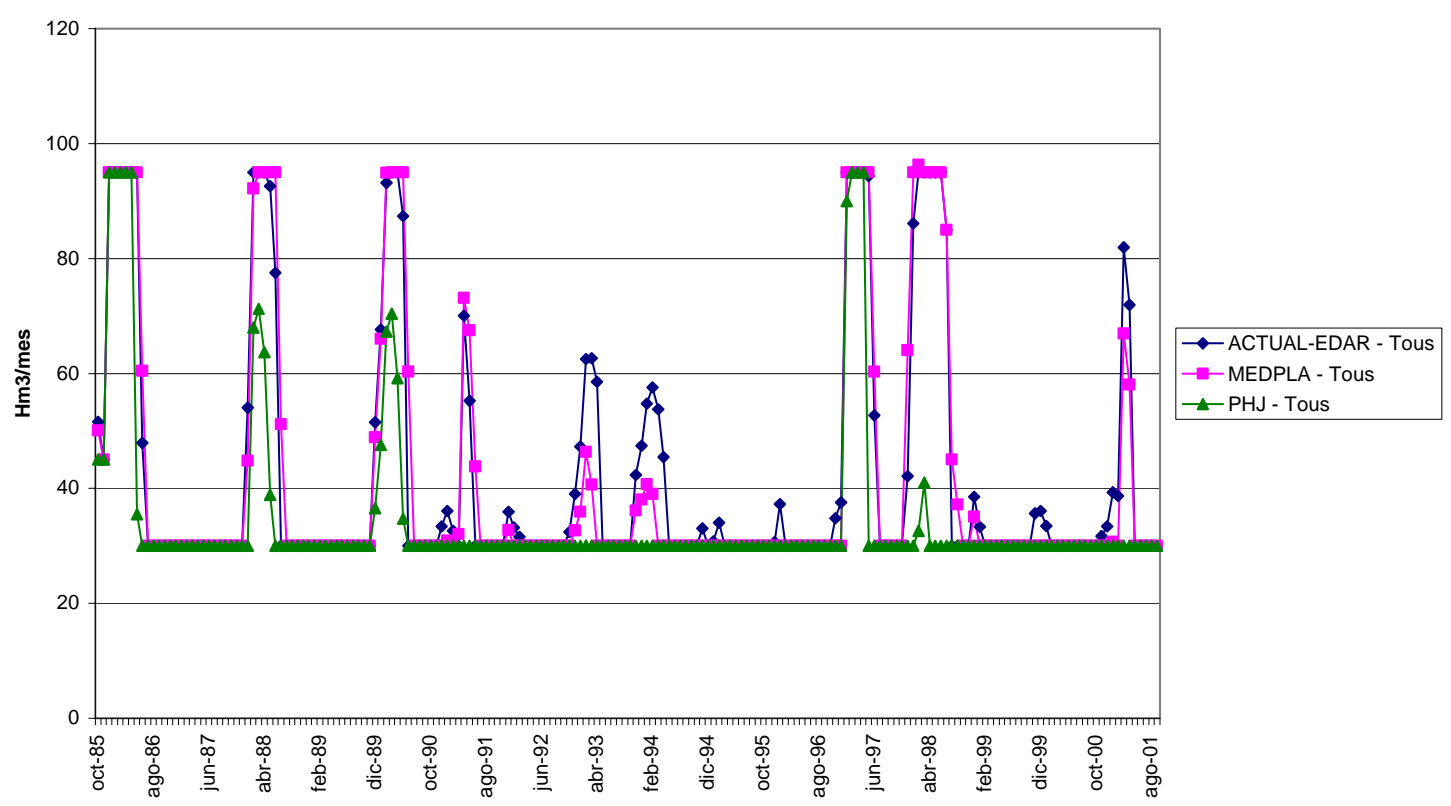

Figura 133. Evolución del volumen embalsado en Tous para los diferentes escenarios.

Las mismas conclusiones se desprenden para el embalse de Tous en donde en el escenario PHJ pocas veces el volumen es superior al volumen mínimo de embalse.

Por otra parte el caudal de dilución supone variaciones en el volumen embalsado del embalse de Alarcón y no en los otros dos embalses. Además la afección se produce sobre todo en los escenarios ACTUAL y MEDPLA sin que se produzca variaciones significativas en el escenario PHJ. Ello es debido a que en este escenario los incrementos de uso de recurso no pueden ser absorbidos por una mejor regulación de los embalses sino por afecciones al suministro de otras demandas.

\subsubsection{Análisis de los resultados sobre la calidad del agua.}

A continuación se realiza un análisis por constituyentes de los resultados obtenidos para los diferentes escenarios. Para poder establecer comparaciones se han utilizado perfiles medios de calidad y comparativas de evolución de concentraciones en puntos significativos. En algunos constituyentes se presentan también perfiles mínimos del río. Estos perfiles son el valor mínimo obtenido en cada punto del río y aunque 
puede ser posible no tiene por qué darse en todos los puntos ese valor en el mismo momento.

\subsection{Conductividad.}

Como cabría de esperar la conductividad es el constituyente en el que menos efecto tienen los diferentes escenarios. Ello es debido a que los mayores aportes de conductividad en toda la cuenca son de origen natural por lo que cambios en la gestión o en infraestructura de depuración no tendrán grandes efectos sobre la misma. Esto se puede ver en la figura siguiente que representa un perfil de la conductividad media para las distintas opciones.

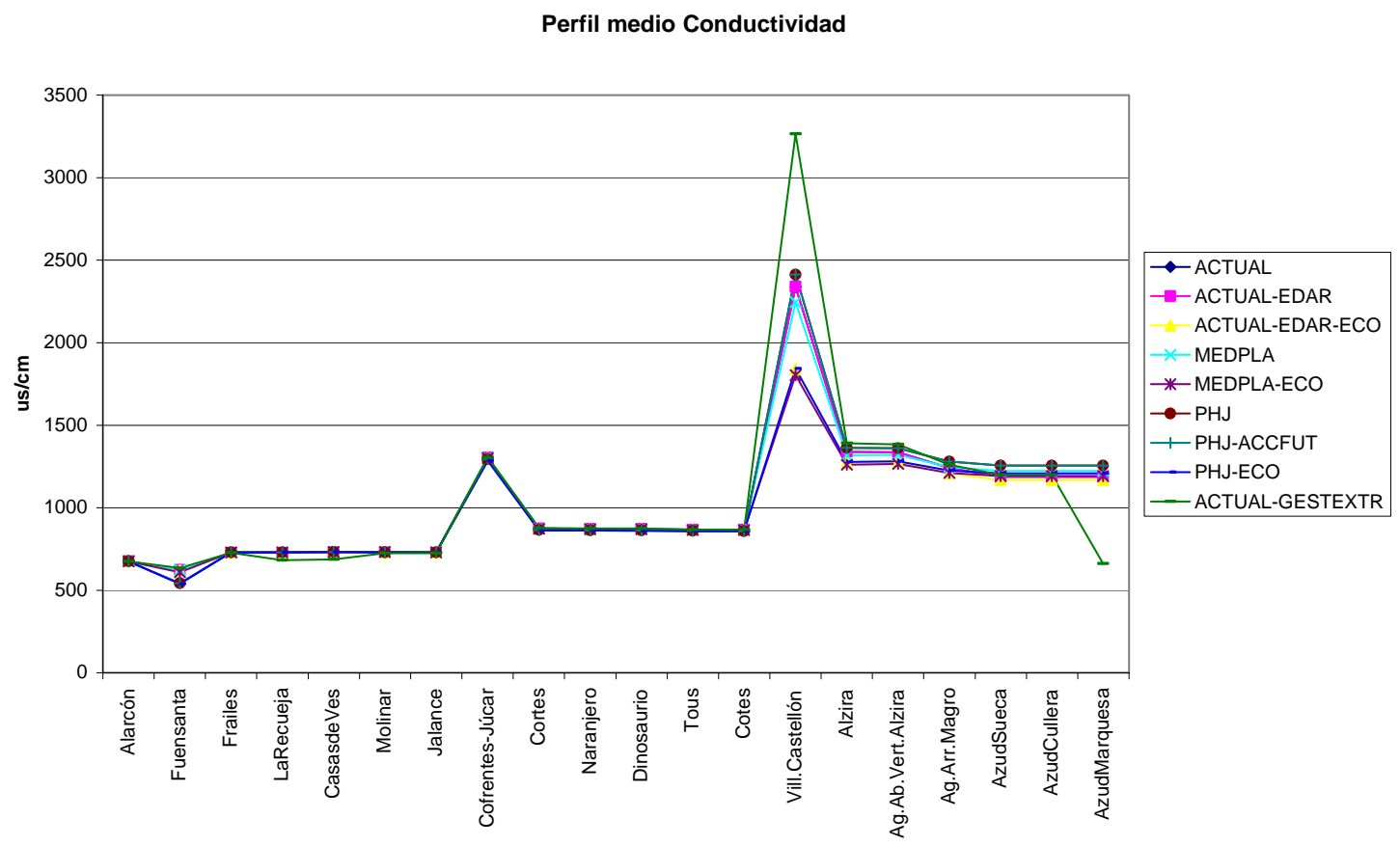

Figura 134. Perfil medio de conductividad en el río Júcar obtenido para los diferentes escenarios.

Como se aprecia en el gráfico la mayor diferencia se produce en Villanueva de Castellón aguas abajo de la confluencia entre el Júcar y el Sellent. Esto es así porque en ese tramo de río tiene mucha influencia la alta conductividad del Sellent. Según el caudal circulante por el río Júcar en ese punto el afluente tendrá mayor o menor influencia. Como se puede ver hasta en los mejores casos el incremento de conductividad pasa de valores medios inferiores a $1000 \mu \mathrm{s} / \mathrm{cm}$ a valores superiores a $1500 \mu \mathrm{s} / \mathrm{cm}$.

El gráfico siguiente compara la evolución temporal de las conductividades obtenidas para Villanueva de Castellón en los escenarios PHJ y PHJ-ECO. 


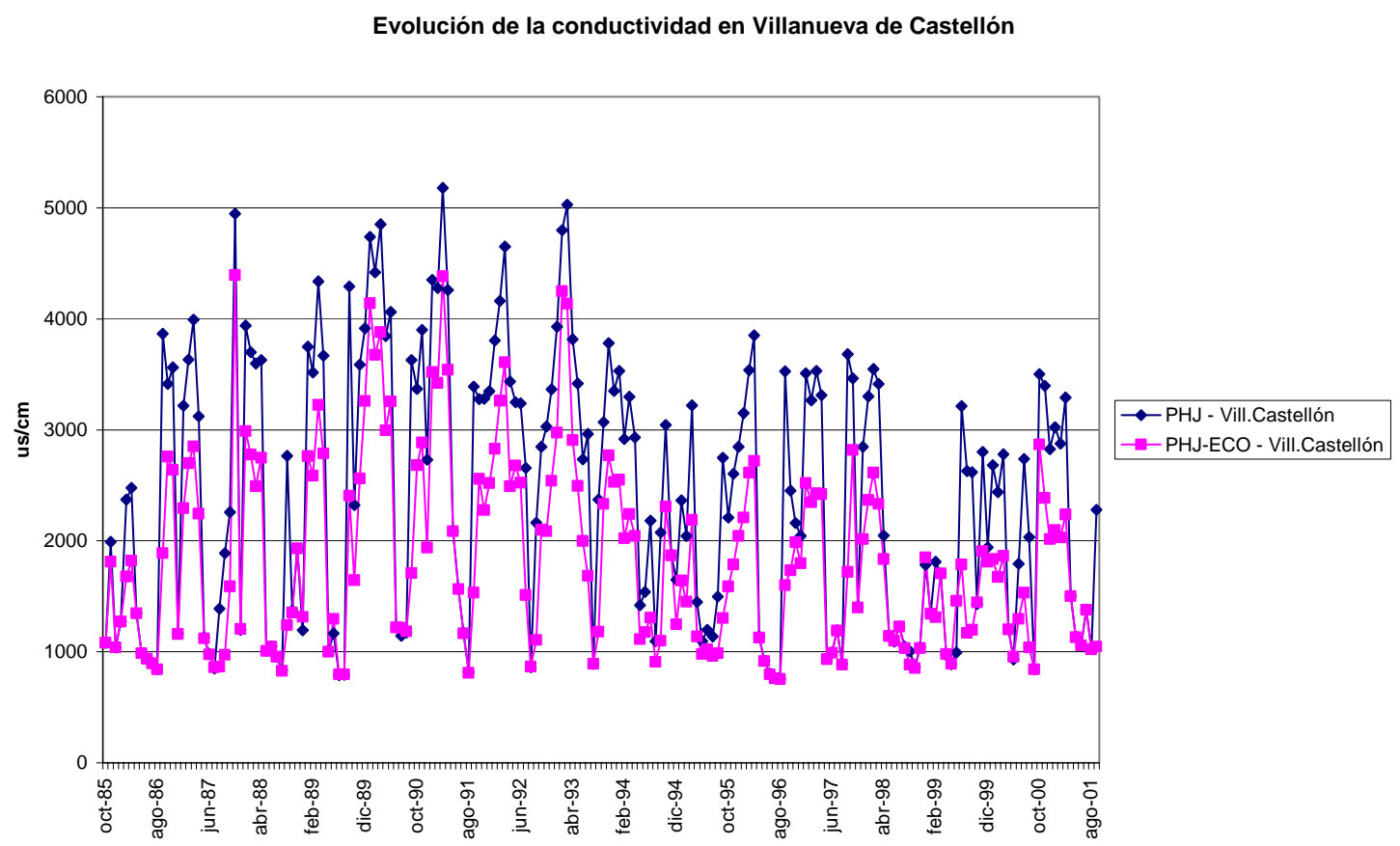

Figura 135. Evolución de la conductividad en V. de Castellón para las alternativas PHJ y PHJECO.

Se puede observar que el caudal adicional provoca un efecto de dilución de las aguas del Sellent y una disminución significativa de la conductividad aguas abajo de la confluencia.

En el Cabriel se puede distinguir para todas las alternativas un perfil ascendente de conductividad entre el embalse de Cabriel hasta la estación de Cofrentes-Coca y una disminución del contenido de sales debido a la incorporación del agua del Júcar llegando a la confluencia con unos valores medios de conductividad en torno a los 860$880 \mu \mathrm{s} / \mathrm{cm}$. La comparativa entre escenarios muestra que todos ellos son prácticamente iguales siendo la mayor diferencia entre los valores medios de $10 \mu \mathrm{s} / \mathrm{cm}$.

\subsection{Sólidos Suspendidos.}

Para analizar los contenidos de sólidos suspendidos, en el siguiente gráfico se presentan los diferentes perfiles de concentraciones medias obtenidos para los diferentes escenarios. 
Perfil medio concentraciones Sólidos Suspendidos

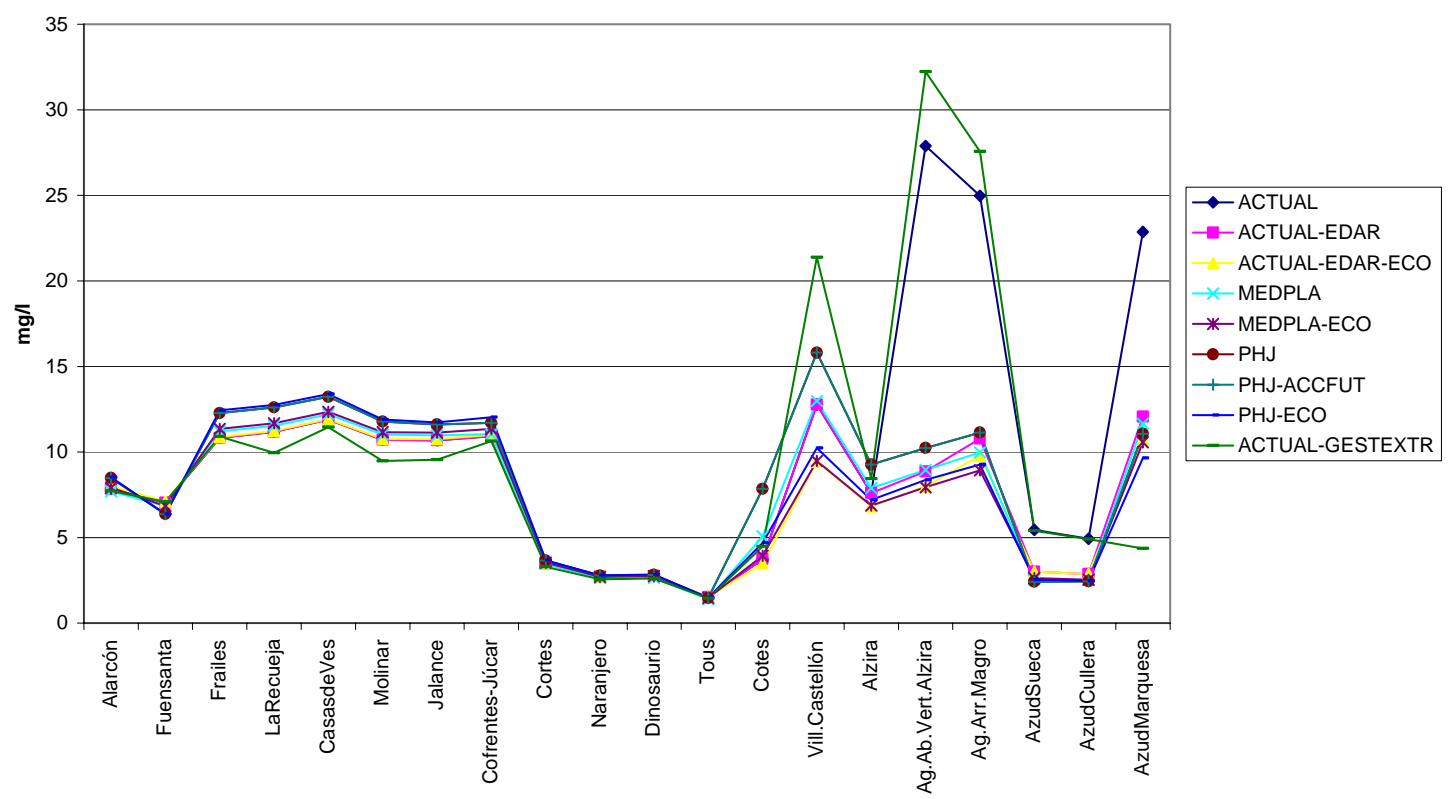

Figura 136. Perfil medio de sólidos suspendidos en el río Júcar obtenido para los diferentes escenarios.

Como se puede ver en el gráfico existe un incremento de concentraciones en la zona entre los Frailes y la confluencia con el Cabriel (Cofrentes-Júcar), sobre todo en los escenarios PHJ. Aguas abajo de Tous el mayor efecto lo tiene la puesta en funcionamiento de la EDAR de Alcira con una reducción de sólidos suspendidos muy notable.

Para analizar el efecto que se produce aguas arriba de Tous se grafica la evolución de concentraciones de sólidos suspendidos en los Frailes para las opciones ACTUAL, MEDPLA y PHJ. 
Evolución de las concentraciones de Sólidos Suspendidos en Los Frailes

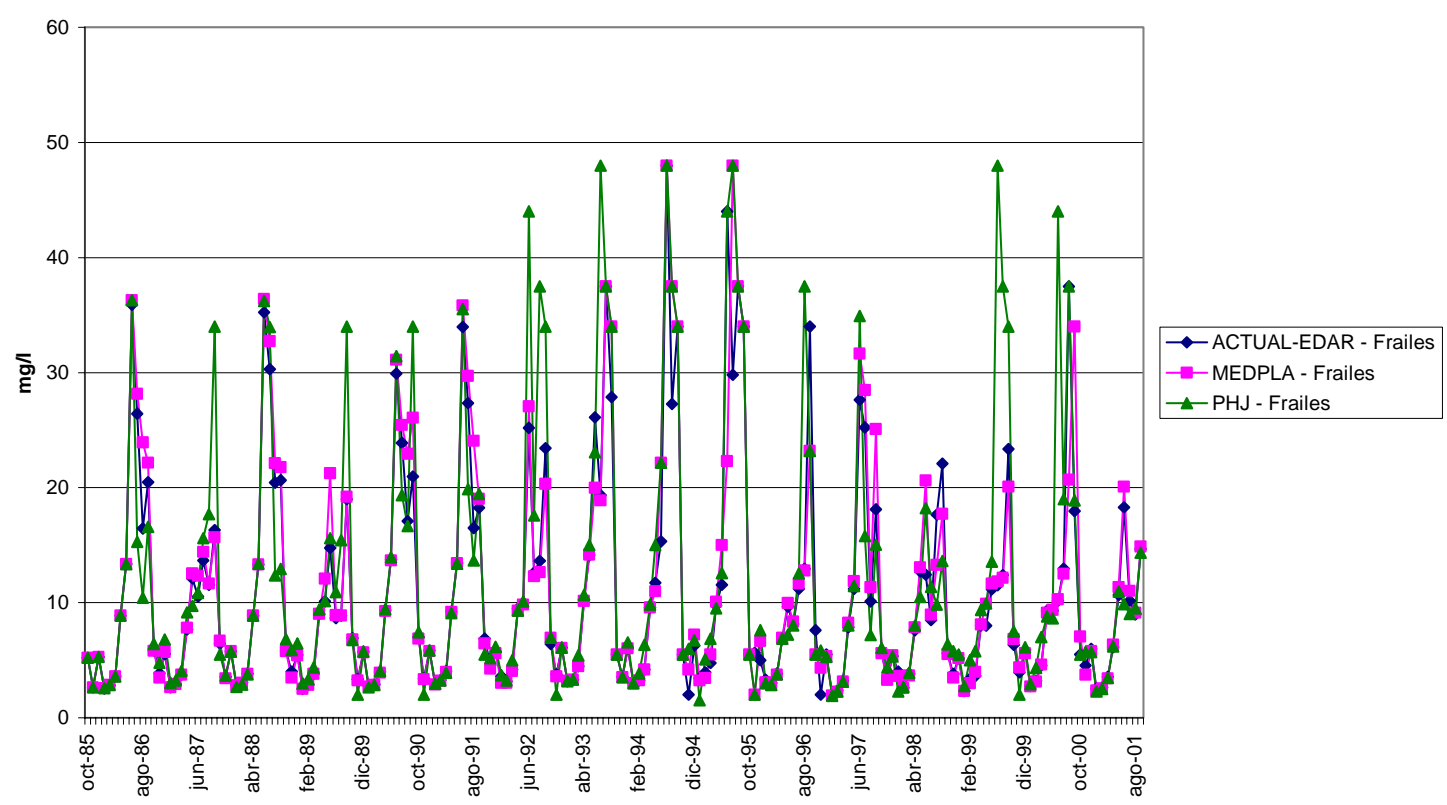

Figura 137. Evolución de las concentraciones de sólidos suspendidos en Los frailes para diferentes escenarios.

Como se puede ver las concentraciones son bastante similares aunque la opción PHJ presenta concentraciones máximas superiores a las de los otros dos escenarios. Ello es debido principalmente al régimen de caudales que, aunque en PHJ en media son superiores, en ese tramo presenta valores mínimos inferiores a las de las otras dos opciones.

Para estudiar en detalle el efecto de la EDAR y del caudal de dilución aguas abajo de Tous en el siguiente gráfico se presenta la evolución temporal de concentraciones de sólidos suspendidos en el azud de la Marquesa. 
Evolución de las concentraciones de Sólidos Suspendidos en Az. Marquesa

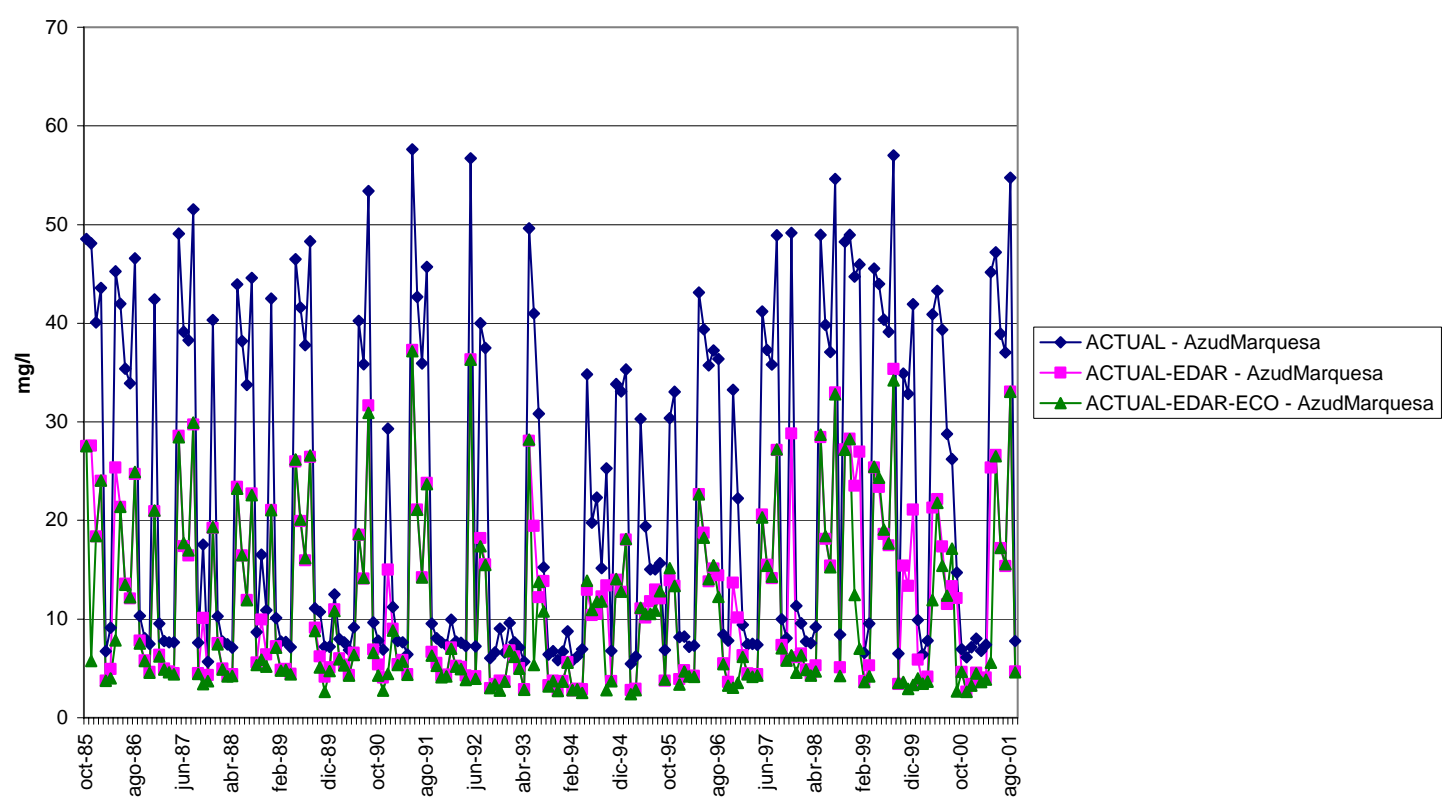

Figura 138. Evolución de las concentraciones de sólidos suspendidos en el azud de la Marquesa para diferentes escenarios.

Los resultados obtenidos muestran que con la puesta de funcionamiento de la EDAR de Alzira la reducción de sólidos suspendidos será del orden del $40 \%$ pasando de una media actual de $22.88 \mathrm{mg} / 1$ a $12.07 \mathrm{mg} / \mathrm{l}$. La reducción de concentraciones de sólidos suspendidos por implantar un caudal de dilución no es tan significativa ya que se ha obtenido una media de $10.72 \mathrm{mg} / \mathrm{l}$. La gráfica muestra que la reducción de concentraciones se debe sobre todo a una disminución de los valores máximos anuales los cuales, en la opción ACTUAL, son del orden de 40-50mg/l mientras que en los otros dos escenarios varían entre 20 y $30 \mathrm{mg} / 1$.

En el río Cabriel los resultados del modelo muestran concentraciones de sólidos suspendidos muy bajas, oscilando las medias entre 2 y $7 \mathrm{mg} / 1$ en todo el río y para todas las alternativas. El análisis comparativo de escenarios no muestra grandes diferencias de resultados.

\subsubsection{3. $\mathrm{DBO}_{5}$ y Oxígeno Disuelto.}

Los resultados de las simulaciones indican que aguas arriba de Tous y en el afluente Cabriel las concentraciones de $\mathrm{DBO}_{5}$ son bastante bajas y muy similares para todos los escenarios. Esto es consecuencia de la baja presión de vertidos urbanos en la zona. Sólo en el caso de una gestión extrema (ACTUAL-GESTEXTR) en la zona de Casas de Ves aparecerían concentraciones algo superiores. 


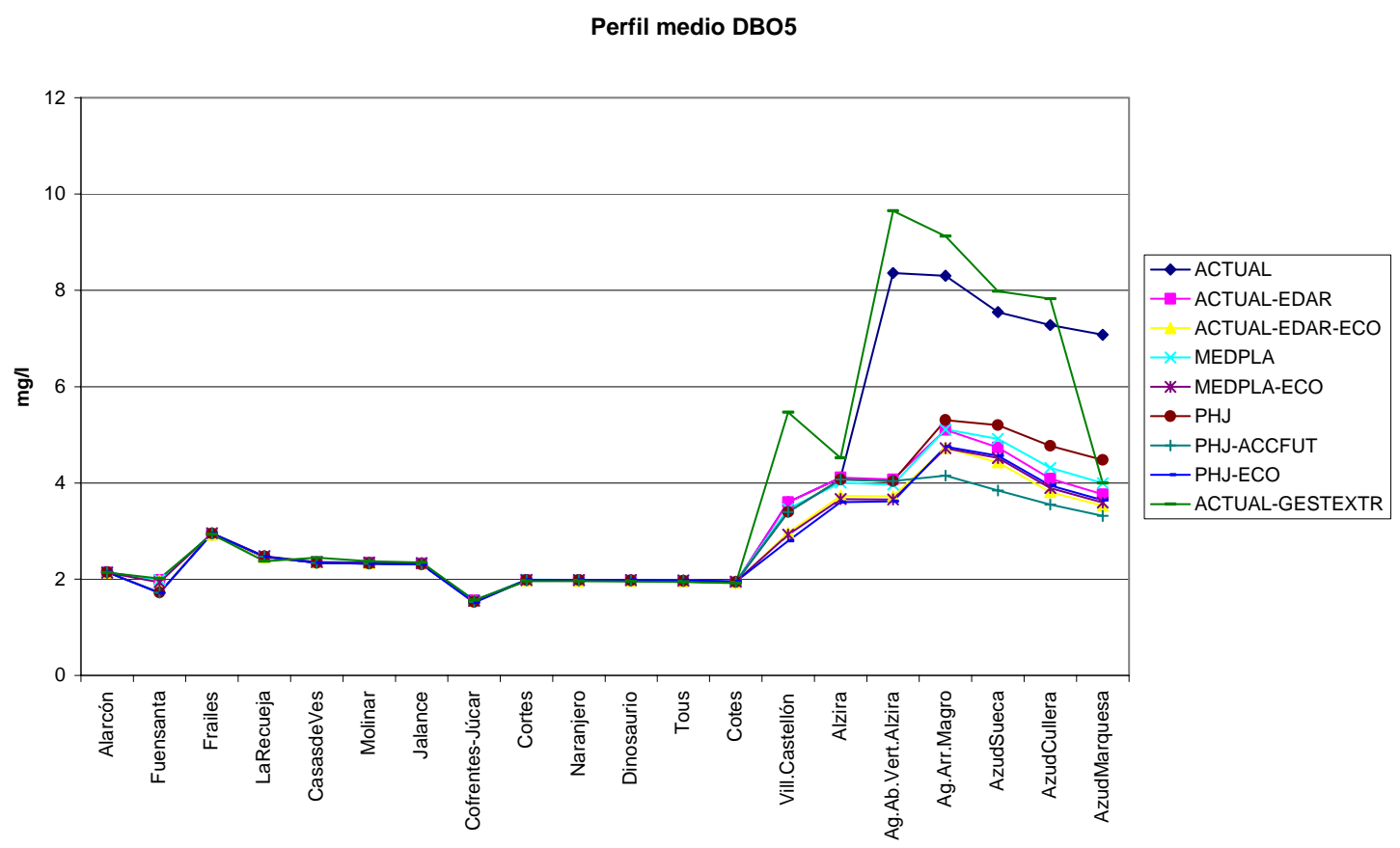

Figura 139. Perfil medio de $\mathrm{DBO}_{5}$ en el río Júcar obtenido para los diferentes escenarios.

El gráfico del perfil medio de concentraciones de $\mathrm{DBO}_{5}$ muestra diferencias notables entre los escenarios con y sin EDAR. Estas diferencias de concentraciones se aprecian desde el vertido de Alcira hasta el final del río. Además el perfil muestra que mientras en las opciones "sin EDAR" el máximo de concentraciones se produce justo aguas abajo del vertido. En el resto, el máximo, se produce aguas arriba del Magro. Esto es debido a que a que el mayor foco de contaminación pasa a ser el río Verde. Es de destacar que las concentraciones medias en los escenarios con EDAR son bastante bajas, todas ellas inferiores a $6 \mathrm{mg} / \mathrm{l}$.

Para analizar la evolución temporal en el gráfico siguiente se muestra las concentraciones de $\mathrm{DBO}_{5}$ obtenidas para el azud de Cullera en las opciones PHJ, PHJECO, PHJ-ACCFUT. 
Evolución de la DBO5 en Az. Cullera

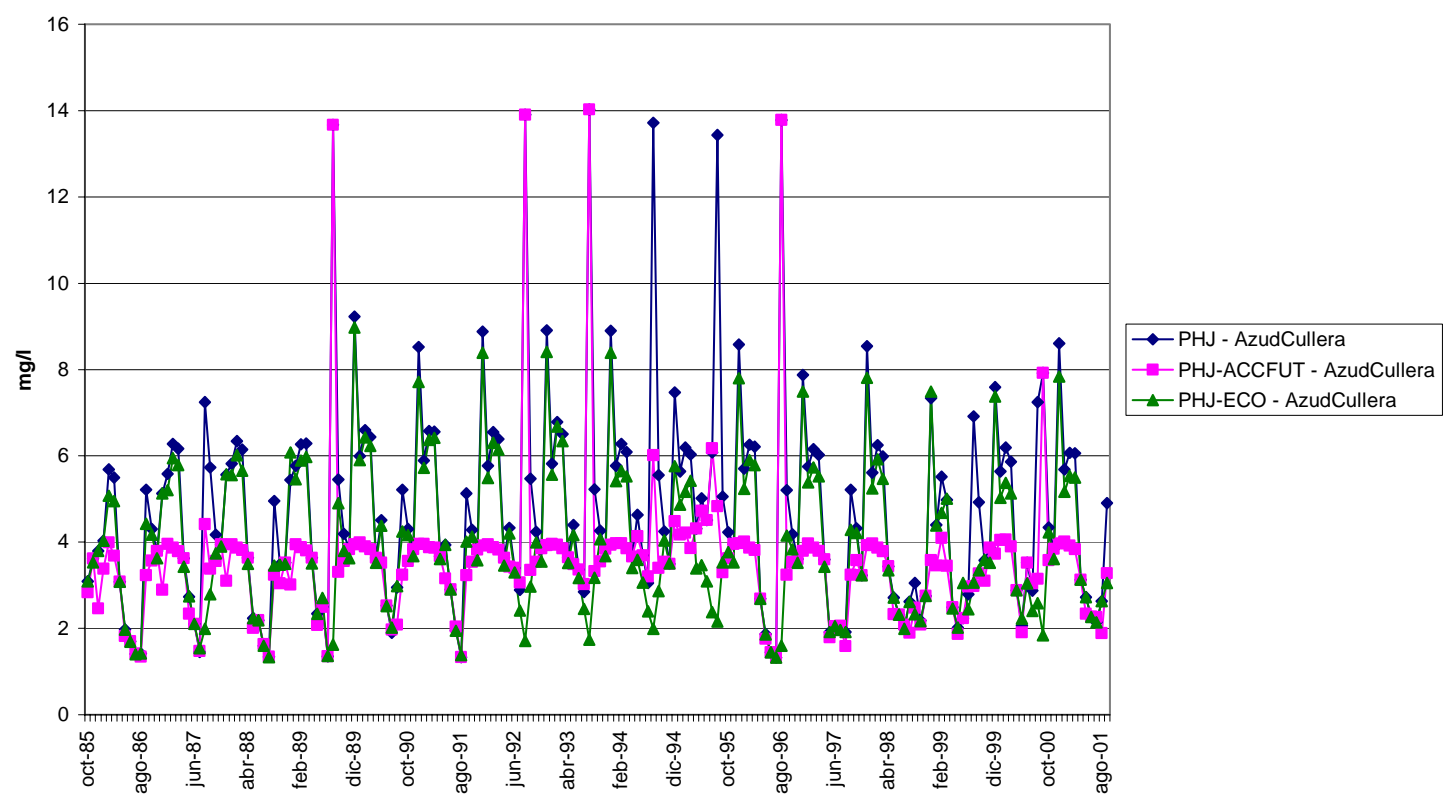

Figura 140. Evolución de las concentraciones de $\mathrm{DBO}_{5}$ en el azud de Cullera para distintos escenarios.

Como puede observase, los resultados para PHJ y PHJ-ECO muestran concentraciones muy similares aunque la imposición del caudal de dilución reduce algunos máximos. Sin embargo la alternativa PHJ-ACCFUT en la que se asume una mejora de la calidad en los afluentes Verde y Magro, presenta una reducción de las concentraciones muy significativa. Mientras que las otras dos alternativas presentan máximos anuales entorno a $6 \mathrm{mg} / \mathrm{l}$ en esta última opción esos máximos se reducen a 4 $\mathrm{mg} / \mathrm{l}$.

Para analizar el oxígeno disuelto, en los siguientes gráficos se presentan los perfiles medios y mínimos de las concentraciones en toda la cuenca. 


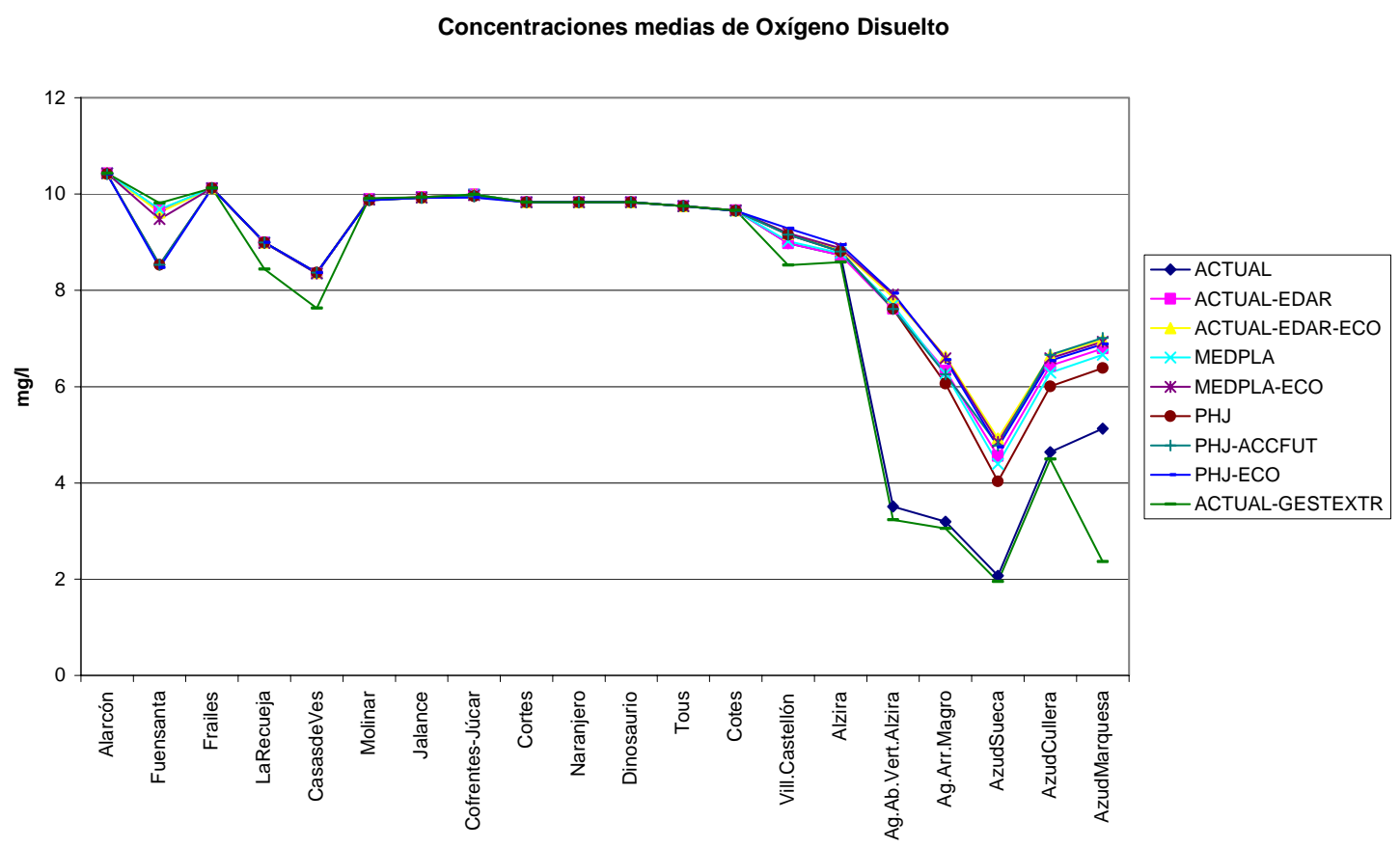

Figura 141. Perfil medio de oxígeno disuelto en el río Júcar obtenido para los diferentes escenarios.

Como muestra el gráfico el punto crítico es el azud de Sueca. En él se presentan las concentraciones medias menores en todos los escenarios. Aguas arriba del embalse de Tous las concentraciones medias presentan valores de aguas naturales bien oxigenadas. Tan sólo en dos zonas, Fuensanta y entre los Frailes y Casas de Ves, se presentan cierta reducción en las concentraciones. En la zona de Fuensanta se debe a que en algunos momentos el caudal en ese punto es nulo. En la zona entre Los Frailes y Casas de Ves la reducción se debe a una oxidación de la materia orgánica proveniente de los fuertes vertidos en la zona. Como se puede ver en el gráfico de concentraciones mínimas estas alcanzan un valor de $6 \mathrm{mg} / \mathrm{l}$, aguas arriba de Molinar, en todos los escenarios excepto el de gestión extrema. 
Concentraciones mínimas de Oxígeno Disuelto

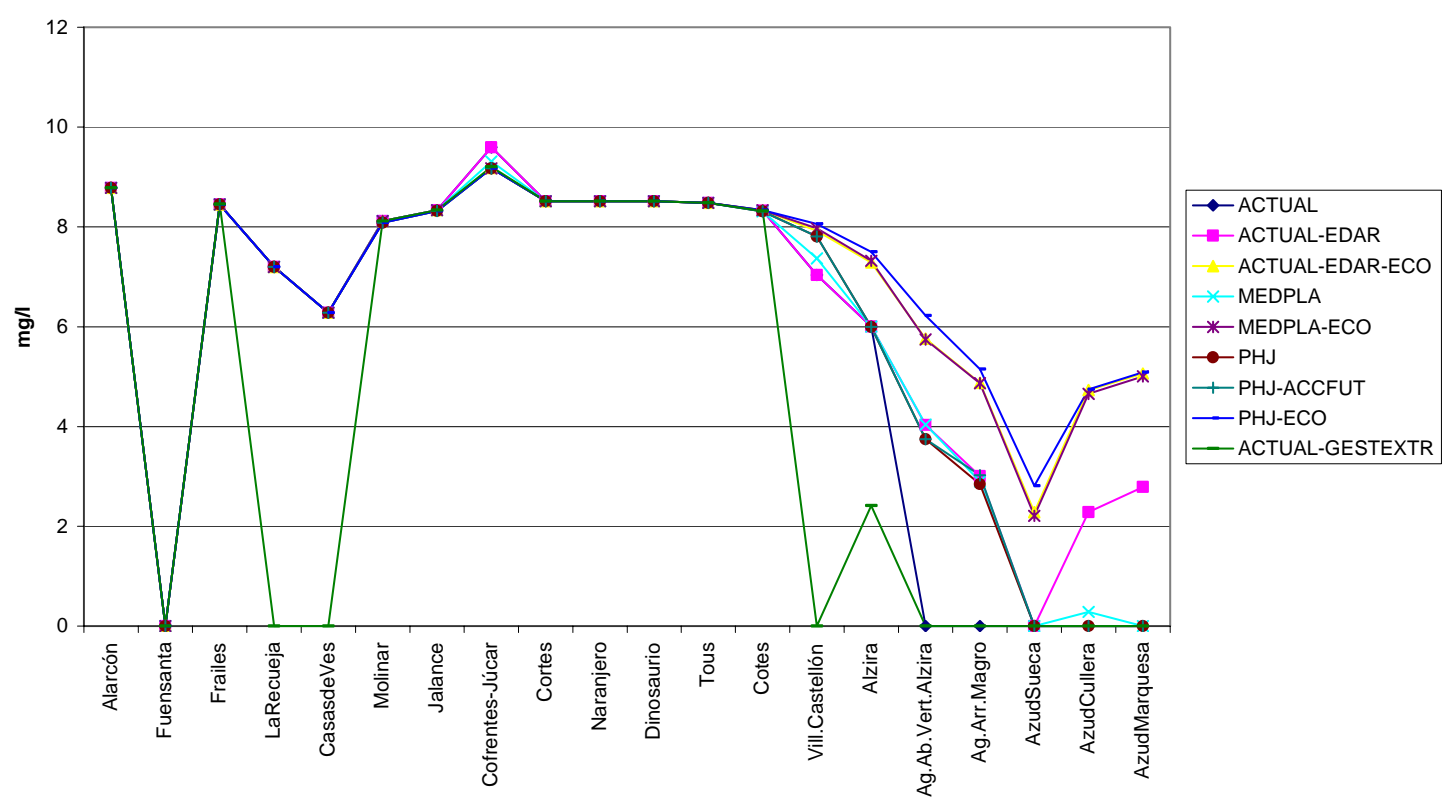

Figura 142. Perfil mínimo de oxígeno disuelto en el río Júcar obtenido para los diferentes escenarios.

En la zona aguas abajo de Tous, tanto en el perfil medio como en el de mínimos, existen diferencias entre las alternativas "con y sin EDAR". La mejora debida a la puesta en funcionamiento de la EDAR de Alcira supone incrementar las concentraciones medias de oxígeno disuelto en el azud de Sueca de aproximadamente 2 a entre 4 y $5 \mathrm{mg} / \mathrm{l}$. Tanto los perfiles medios como mínimos muestran la misma evolución, en donde, a partir de Villanueva de Castellón y hasta el azud de Seuca las concentraciones empiezan a disminuir debido al efecto de los vertidos y de la mala calidad de los afluentes. A partir del azud de Sueca se produce una mejora de las concentraciones sobre todo por el efecto reaireador de los azudes. Como se puede ver en el gráfico de perfiles de concentraciones mínimas en las opciones en las que no se considera la EDAR el río presenta concentraciones mínimas nulas en todos los puntos aguas abajo del vertido mientras que las que presentan EDAR esta situación se retrasa hasta el azud de Sueca. Sólo los escenarios con caudales de dilución presentan valores mínimos superiores a $2 \mathrm{mg} / \mathrm{l}$. Es de destacar que los caudales de dilución no suponen una gran mejora en las concentraciones medias de oxígeno pero sí en las concentraciones mínimas. Por otra parte es remarcable que una vez puesta en funcionamiento la EDAR de Alcira el factor de mayor influencia sobre la calidad del agua de la zona pasa a ser los afluentes Verde y Magro.

Sobre el perfil de mínimos se debe destacar que para las opciones "ECO" no se presentan los $3 \mathrm{mg} / \mathrm{l}$ establecidos como umbral porque se impuso un condición del 95\% de probabilidad de cumplimiento de la misma. 
En el siguiente gráfico se muestra la mejora directa de concentraciones de oxígeno disuelto aguas abajo del vertido de Alcira debido a la puesta en funcionamiento de la EDAR.

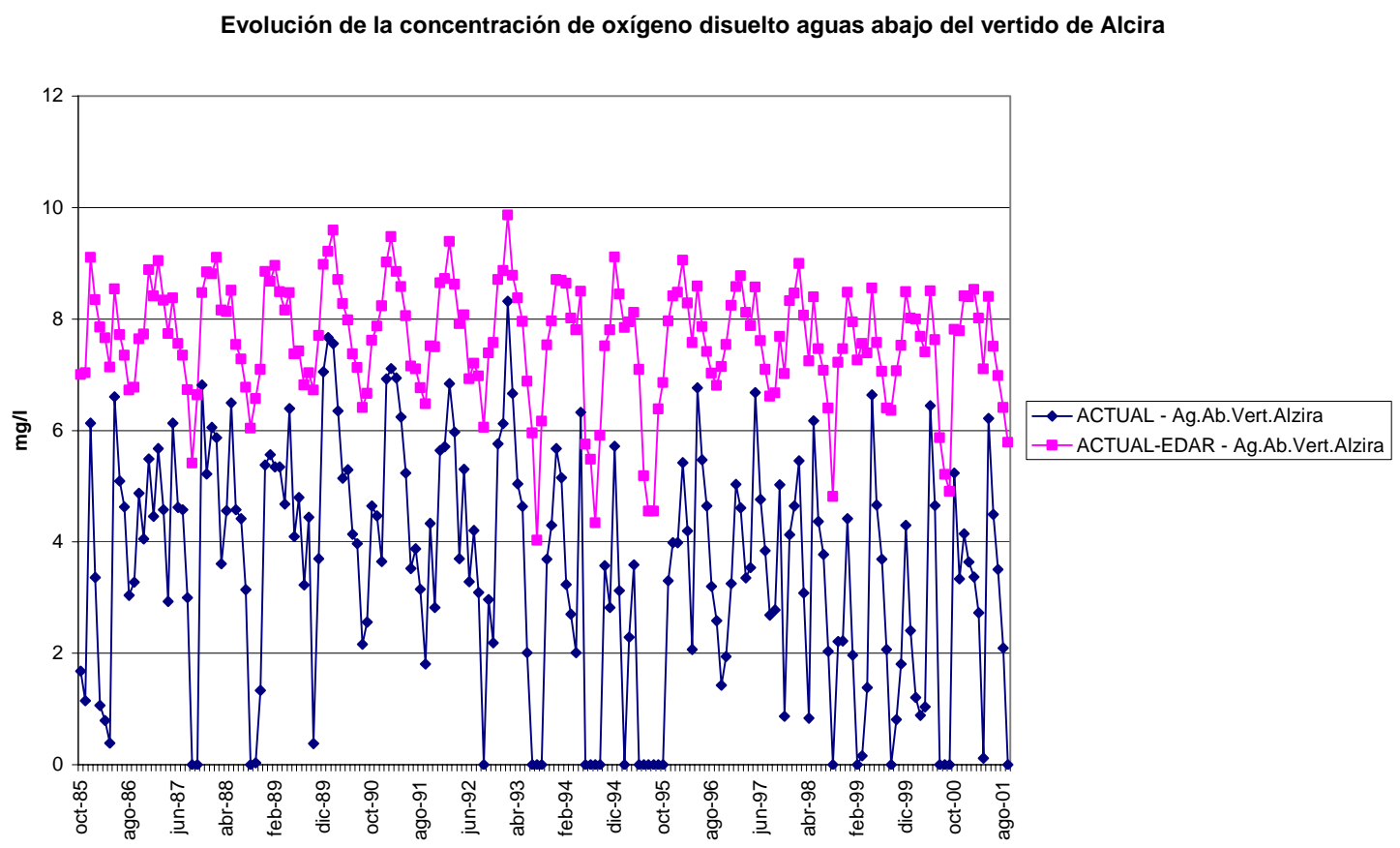

Figura 143. Evolución de las concentraciones de oxígeno disuelto aguas abajo del vertido de Alcira para los escenarios ACTUAL y ACTUAL-EDAR.

Se estima que gracias a la depuradora las concentraciones de oxígeno disuelto aguas abajo del vertido serán, en la mayor parte de los meses, superiores a los $6 \mathrm{mg} / \mathrm{l}$. En media, el oxígeno disuelto pasa de un valor de $3.5 \mathrm{mg} / 1$, en la situación actual, a 7.6 $\mathrm{mg} / \mathrm{l}$ con el vertido depurado.

En el gráfico siguiente se muestra los resultados obtenidos para el azud de Sueca para los escenarios ACTUAL, ACTUAL-EDAR y ACTUAL-EDAR-ECO. 
Evolución de la concentración de Oxígeno Disuelto en el azud de Sueca

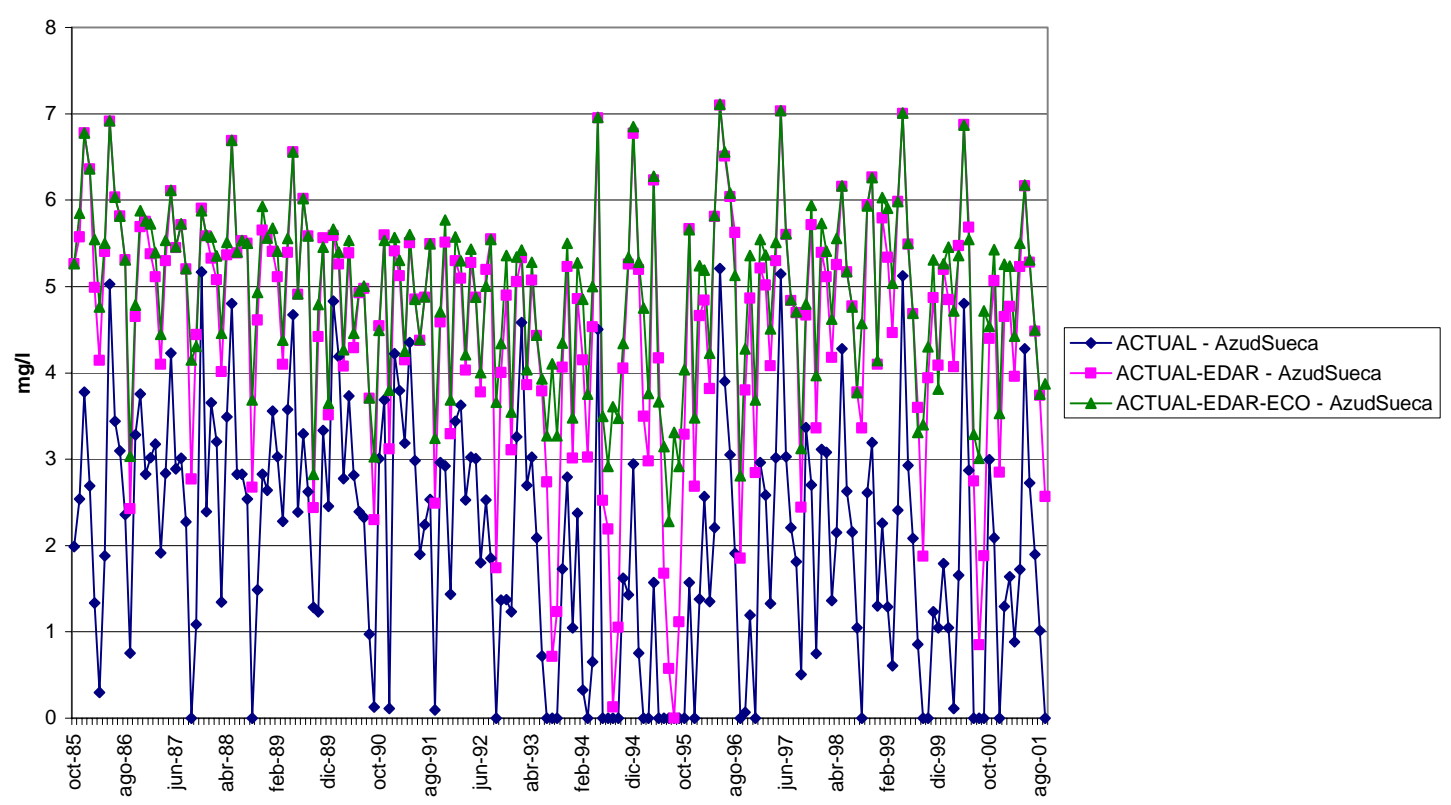

Figura 144. Evolución de las concentraciones de oxígeno disuelto en el azud de Sueca para los escenarios ACTUAL, ACTUAL-EDAR y ACTUAL-EDAR-ECO.

Como se puede ver la opción ACTUAL presenta valores muy bajos de oxígeno disuelto, oscilando entre valores mínimos nulos y máximos en torno a $5 \mathrm{mg} / \mathrm{l}$. La puesta en funcionamiento de la EDAR mejora las concentraciones en este azud, sólo en momentos críticos, como en la sequía de 1994-95, se producirían condiciones anóxicas. Es de destacar que, en este escenario, sólo cinco meses tienen concentraciones inferiores a $1 \mathrm{mg} / \mathrm{l}$. Además las concentraciones, en media, oscilan sobre los 4-5 mg/1 y las concentraciones máximas ascienden a $7 \mathrm{mg} / \mathrm{l}$. Con todo ello se puede decir que la EDAR de Alcira supondrá una mejora de concentraciones de oxígeno en la zona del azud del orden de $2 \mathrm{mg} / \mathrm{l}$. La alternativa ACTUAL-ECO presenta unas concentraciones muy similares a la opción ACTUAL-EDAR, variando el oxígeno disuelto la mayor parte de los meses entre 3 y $6 \mathrm{mg} / \mathrm{l}$ con lo que la media no se ve fuertemente incrementada (pasa de 4.55 a $4.92 \mathrm{mg} / \mathrm{l}$ ) pero sí muchos meses de valores mínimos en los que se eleva la concentración por encima de $3 \mathrm{mg} / \mathrm{l}$.

\subsection{Nitrógeno.}

El análisis del nitrógeno pasa por estudiar los resultados obtenidos para el amonio, nitritos y nitratos. Los dos primeros muestran comportamientos muy similares y muy relacionados con el oxígeno disuelto debido a la dependencia de todos ellos con las presiones de origen urbano. 
El perfil medio de concentraciones de amonio presenta el efecto marcado de la puesta en funcionamiento de la EDAR de Alcira reduciendo el valor medio aguas abajo del vertido de $1.8 \mathrm{mg} / \mathrm{l}$ a $0.1 \mathrm{mg} / \mathrm{l}$ en el mismo punto.

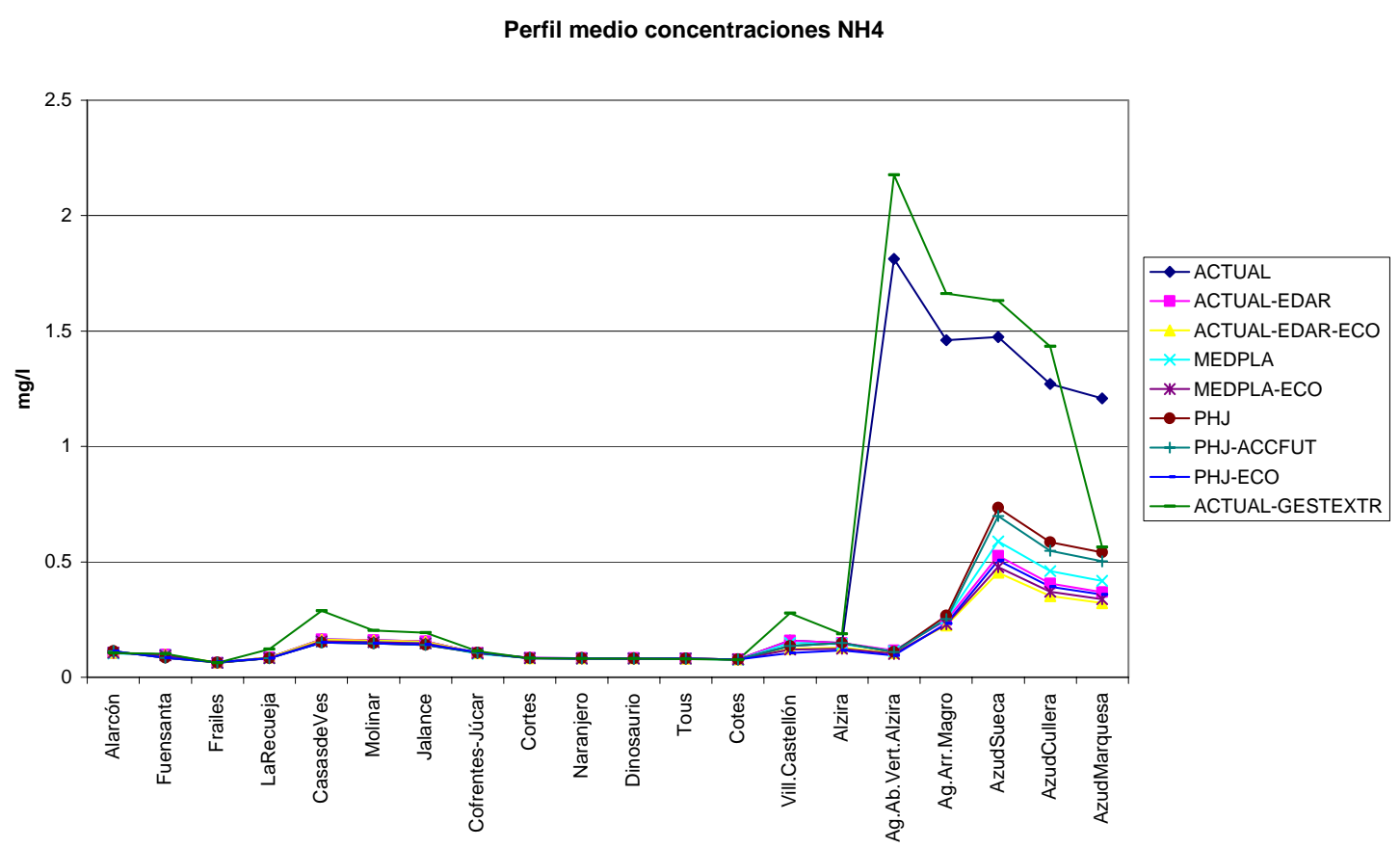

Figura 145. Perfil medio de amonio en el río Júcar obtenido para los diferentes escenarios.

El gráfico muestra como el punto más conflictivo actualmente es la zona aguas abajo del vertido de Alcira. Con la entrada en funcionamiento de la EDAR de Alcira el punto crítico pasará a ser el azud de Sueca. La mejor alternativa, en cuanto a concentración de amonio se refiere, es la ACTUAL-EDAR-ECO que presenta un valor medio de $0.45 \mathrm{mg} / \mathrm{l}$ en el azud de Sueca.

Para el caso de gestión extrema el perfil medio muestra un descenso brusco en el último punto. Ello es debido a que, en esa alternativa, en numerosas ocasiones el tramo se queda seco.

Aguas arriba del embalse de Tous y en el afluente Cabriel las concentraciones son muy bajas y bastante parecidas en todos los escenarios. Sin embargo, es interesante estudiar como va a afectar el distinto régimen de volúmenes embalsados en la calidad del agua de los embalses. En la siguiente figura se muestra la evolución de las concentraciones de amonio en los embalses de Alarcón y Contreras paras las alternativas ACTUAL, MEDPLA y PHJ. 
Evolución del NH4 en los embalses de Alarcón y Contreras

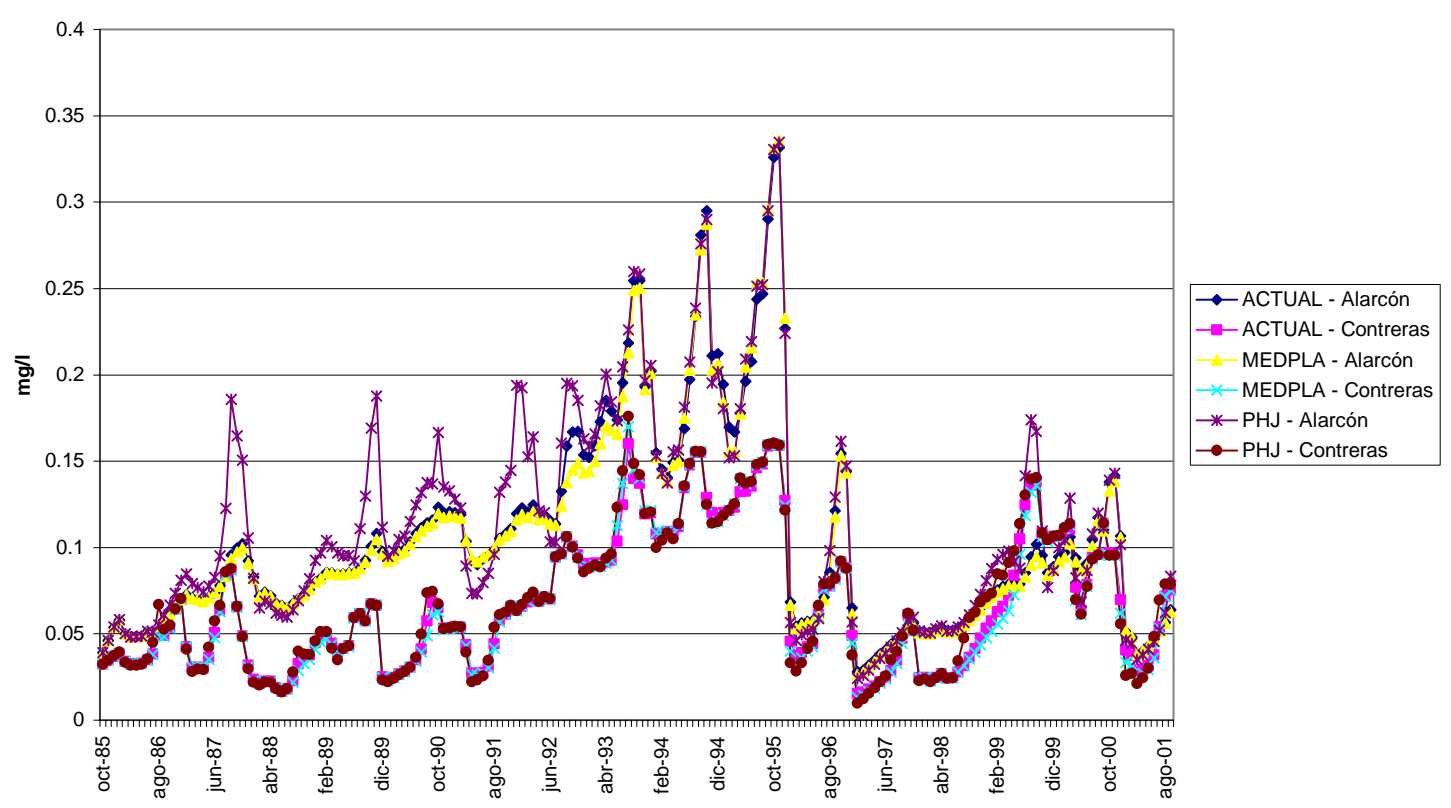

Figura 146. Evolución de las concentraciones de amonio en los embalses de Alarcón y Contreras para diferentes escenarios.

Como se puede ver en el gráfico, los tres escenarios mantienen concentraciones muy similares para el embalse de Contreras no siendo así para el embalse de Alarcón. En él la alternativa PHJ muestra concentraciones superiores, a las otras dos, en épocas húmedas. Este aumento de concentraciones se debe a que en la opción PHJ, como se ha visto previamente, se dan volúmenes inferiores a los otros dos escenarios en el embalse de Alarcón produciendo un empeoramiento en la calidad del agua del mismo. Sin embargo este empeoramiento de la calidad es relativo ya que las concentraciones se mantienen en niveles bastante bajos.

Los nitritos presentan, como muestra la siguiente figura, un comportamiento muy similar al amonio. 


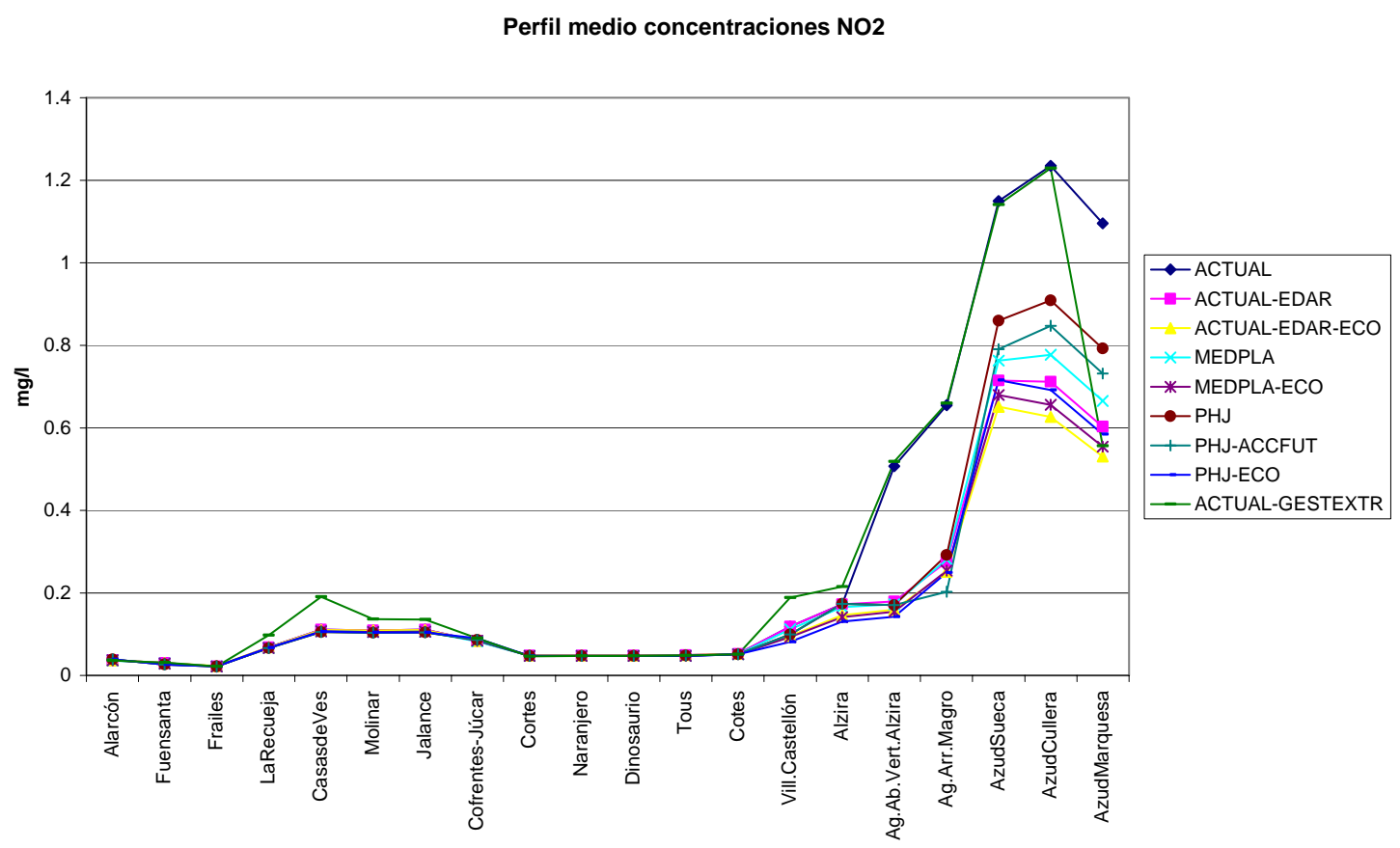

Figura 147. Perfil medio de nitritos en el río Júcar obtenido para los diferentes escenarios.

Como se puede ver aguas arriba de Tous y en el afluente Cabriel las concentraciones medias son muy bajas y prácticamente iguales para todos los escenarios. En el siguiente gráfico se muestra la evolución de las concentraciones de nitritos en la estación Cofrentes - COCA, en la parte final del río Cabriel, comprobándose que no sólo son los valores medios similares sino que las evoluciones de las concentraciones son muy similares. 
Concentraciones de nitritos en Cofrentes-Coca (Cabriel)

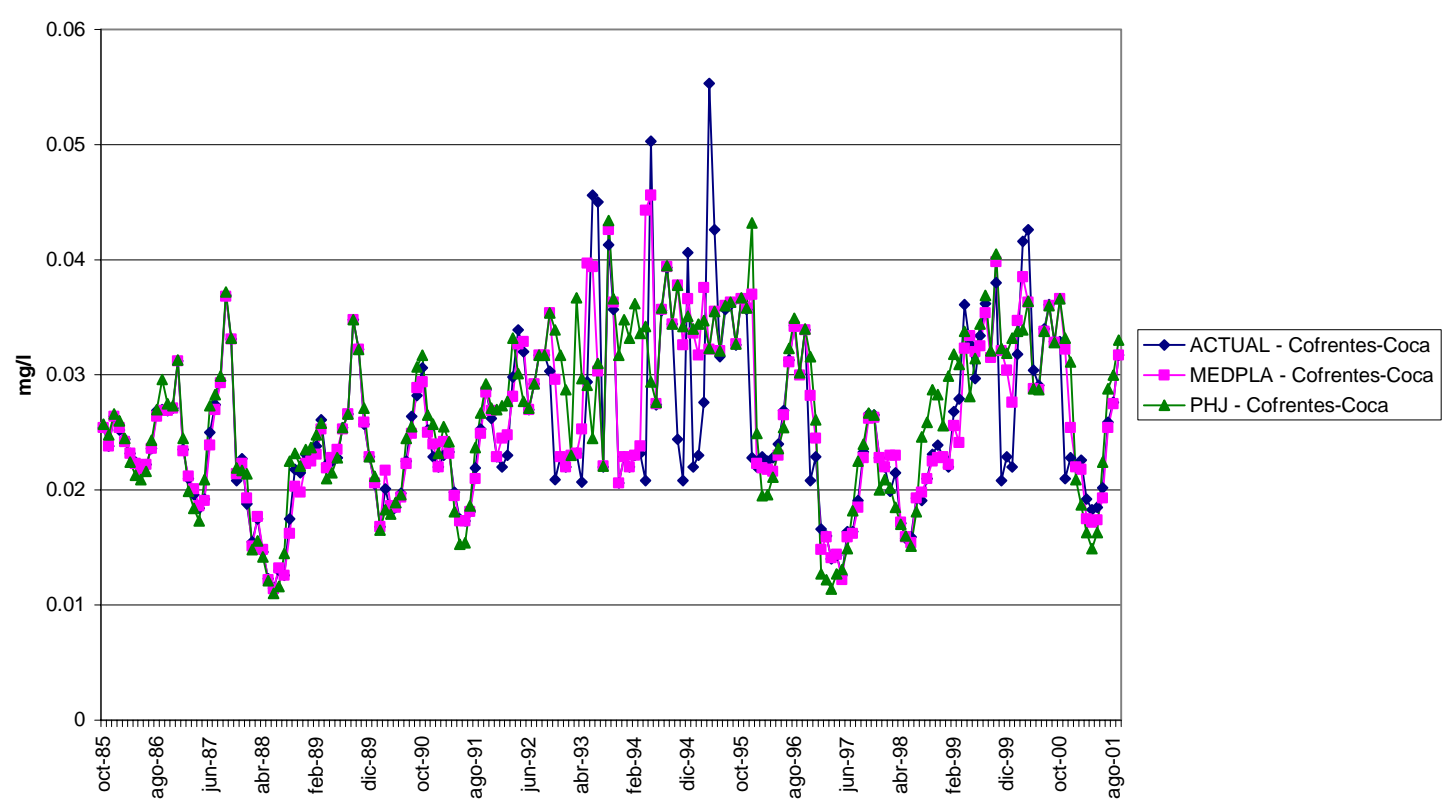

Figura 148. Evolución de concentraciones de nitritos en Cofrentes-Coca para diferentes escenarios.

Aguas abajo del embalse de Tous lo más destacable es la mejora de concentraciones debido a la EDAR de Alcira. Para estudiar este efecto en más detalle en el siguiente gráfico se muestra la evolución de las concentraciones de nitritos obtenidas para los escenarios ACTUAL, ACTUAL-EDAR y ACTUAL-EDAR-ECO aguas abajo del vertido y antes de la confluencia con el Magro.

Concentraciones de nitritos aguas arriba del río Magro (Júcar)

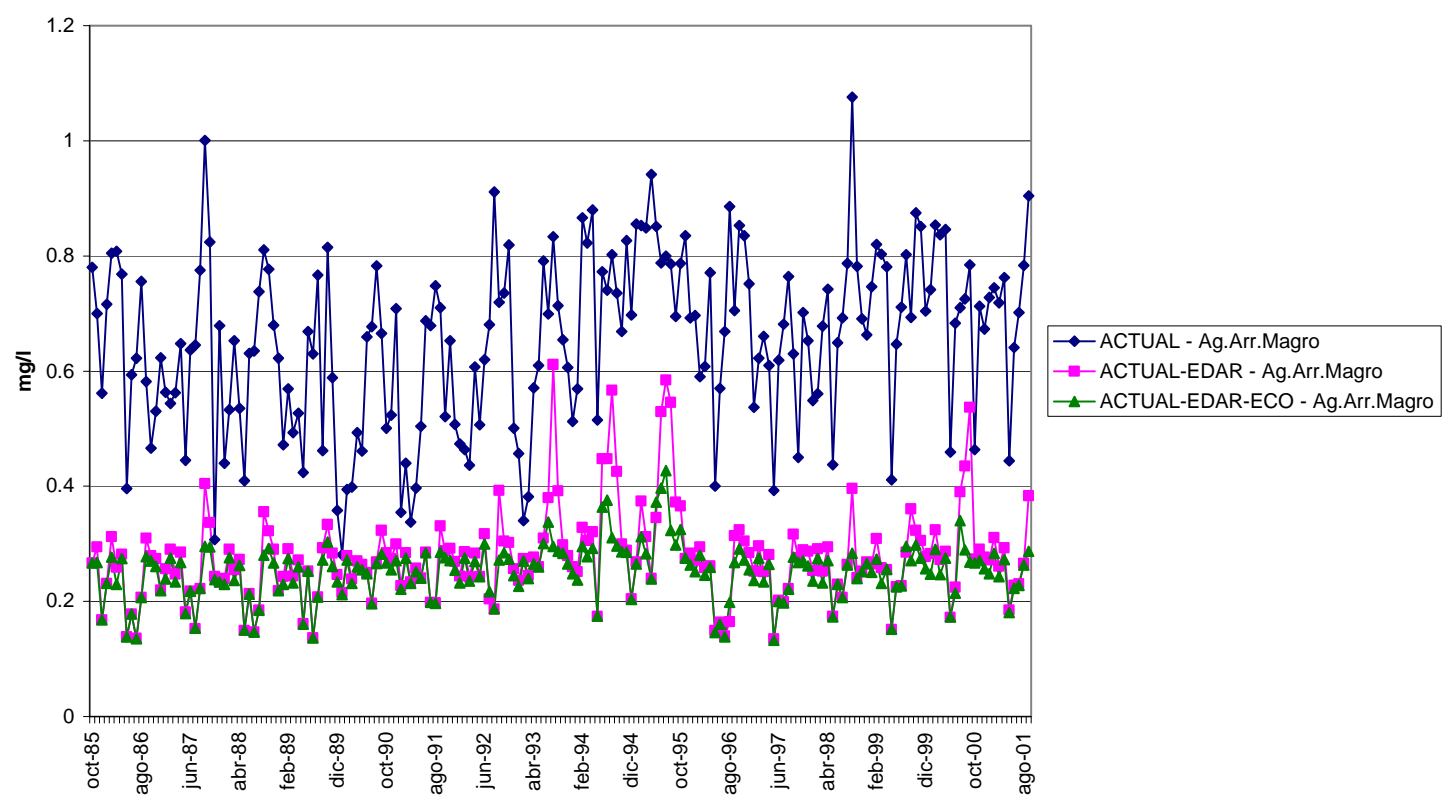

Figura 149. Evolución de las concentraciones de nitritos en el río Júcar aguas arriba de la confluencia con el río Magro para diferentes escenarios. 
En el gráfico se puede ver que la entrada en funcionamiento de la EDAR supondrá una mejora de las concentraciones de amonio. Se estima que la concentración media pase de $0.65 \mathrm{mg} / 1$ a $0.27 \mathrm{mg} / 1$. Por otra parte, como ya pasaba con otros constituyentes, el establecimiento del caudal de dilución no mejora excesivamente la concentración media (pasaría a ser $0.25 \mathrm{mg} / \mathrm{l}$ ) pero sí que reduce significativamente los máximos de concentraciones.

Debido a que la mayor fuente de nitratos es la actividad agrícola, el comportamiento entre las diferentes alternativas es diferente al resto de constituyentes. En el siguiente gráfico se muestra los perfiles de concentraciones medias de nitratos para los distintos escenarios.

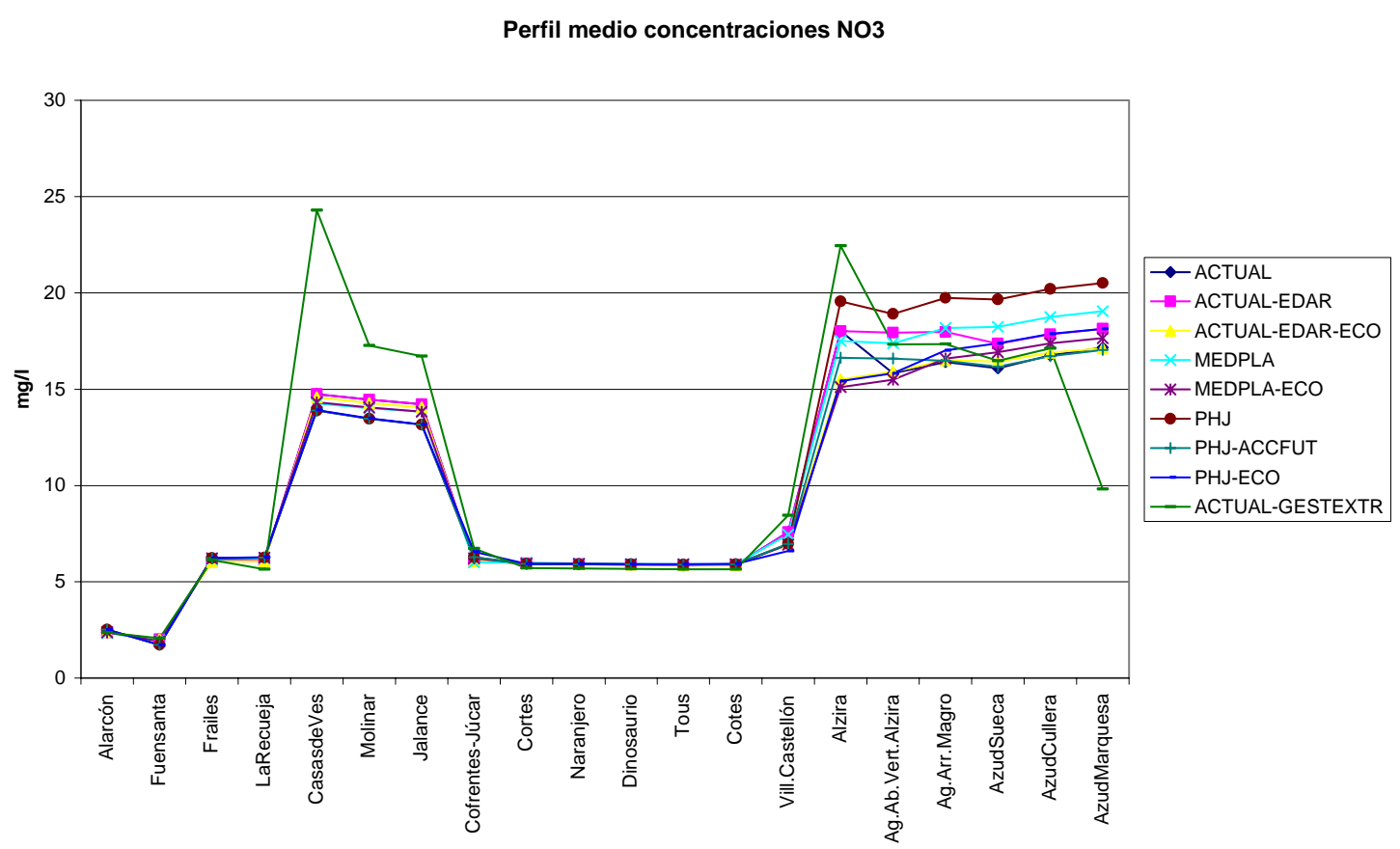

Figura 150. Perfil medio de nitratos en el río Júcar obtenido para los diferentes escenarios.

El escenario ACTUAL-GESTEXTR presenta, aguas arriba de Tous, concentraciones más elevadas que el resto. Ello es debido, fundamentalmente, a que las circulaciones de caudales en esa zona y para ese escenario son muy bajas. El resto de escenarios mantiene concentraciones muy similares en las zonas alta y media de la cuenca.

En el afluente Cabriel las concentraciones son bastante bajas y muy similares en todas las alternativas. No es así en la zona de la Ribera en donde el escenario PHJ muestra concentraciones medias superiores al resto. Las alternativas ACTUAL-EDAR y MEDPLA mantienen concentraciones bastante similares. Además se debe destacar que aunque la EDAR de Alcira se asume con tratamiento terciario de eliminación de nitrógeno el nitrógeno no eliminado se vierte en forma de nitratos. Esto produce que las 
alternativas con EDAR presenten un ligero aumento de concentraciones aguas abajo del vertido.

Para analizar en detalle el problema de los nitratos en esta zona en el gráfico siguiente se muestra la evolución de concentraciones en Alcira para las alternativas ACTUAL-EDAR, MEDPLA y PHJ.

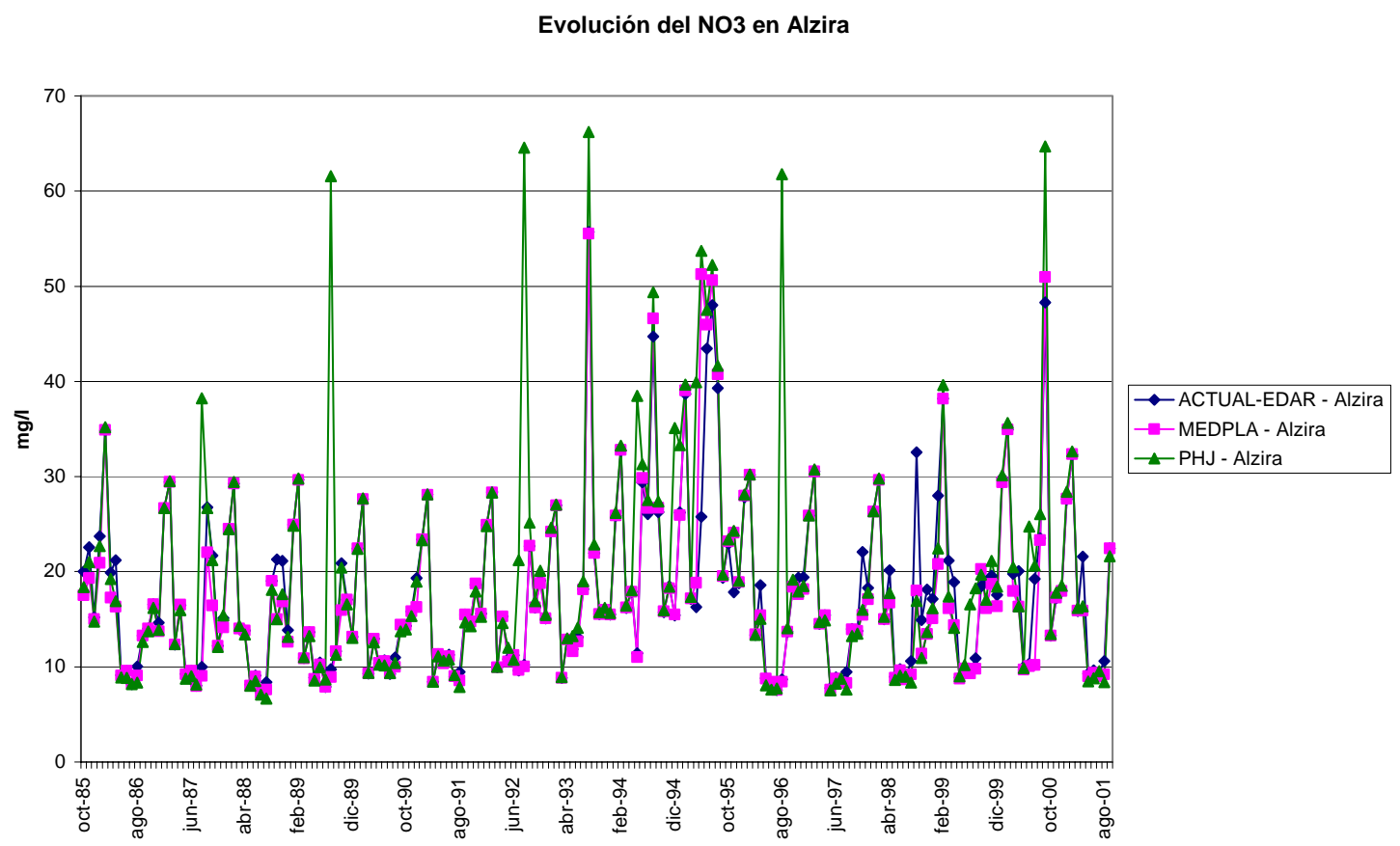

Figura 151. Evolución de las concentraciones de nitratos en el río Júcar a su paso por Alcira para diferentes escenarios.

Del gráfico se deduce que las concentraciones son bastante similares y que el valor medio superior presentado por la alternativa PHJ se debe a máximos puntuales superiores. Este gráfico y la comparativa en otros puntos del tramo muestran bastante similitud entre las diferentes alternativas. De los resultados obtenidos también se destaca las altas concentraciones, superiores a $50 \mathrm{mg} / \mathrm{l}$, que se estiman en momentos de sequía. Estas concentraciones no se están dando en la actualidad y es una deficiencia de muchos de los modelos de calidad en donde se modela la contaminación difusa como una carga o vertido constante. En la realidad, en momentos de sequía el riego se reduce y con ellos los retornos y la contaminación difusa. En el modelo desarrollado, este efecto se ha tenido en cuenta con los retornos de las acequias superiores, ya que se han modelado como elementos de retorno que son función del agua aplicada. No ha sido así en el tramo aguas arriba de Alcira en el que se ha considerado un elemento de contaminación difusa y es el que hace que se den las concentraciones tan altas en momentos de caudales extremadamente bajos.

En la alternativa PHJ-ACCFUT se considera una reducción del $30 \%$ en las concentraciones de nitratos provenientes de los afluentes del Magro y del Verde y en la 
carga difusa de Alcira como consecuencia de una hipotética puesta en práctica de buenas prácticas agrícolas. En el siguiente gráfico se recoge el efecto que tiene dichas acciones en las concentraciones de nitratos en el azud de Sueca.

Evolución del NO3 en el azud de Sueca

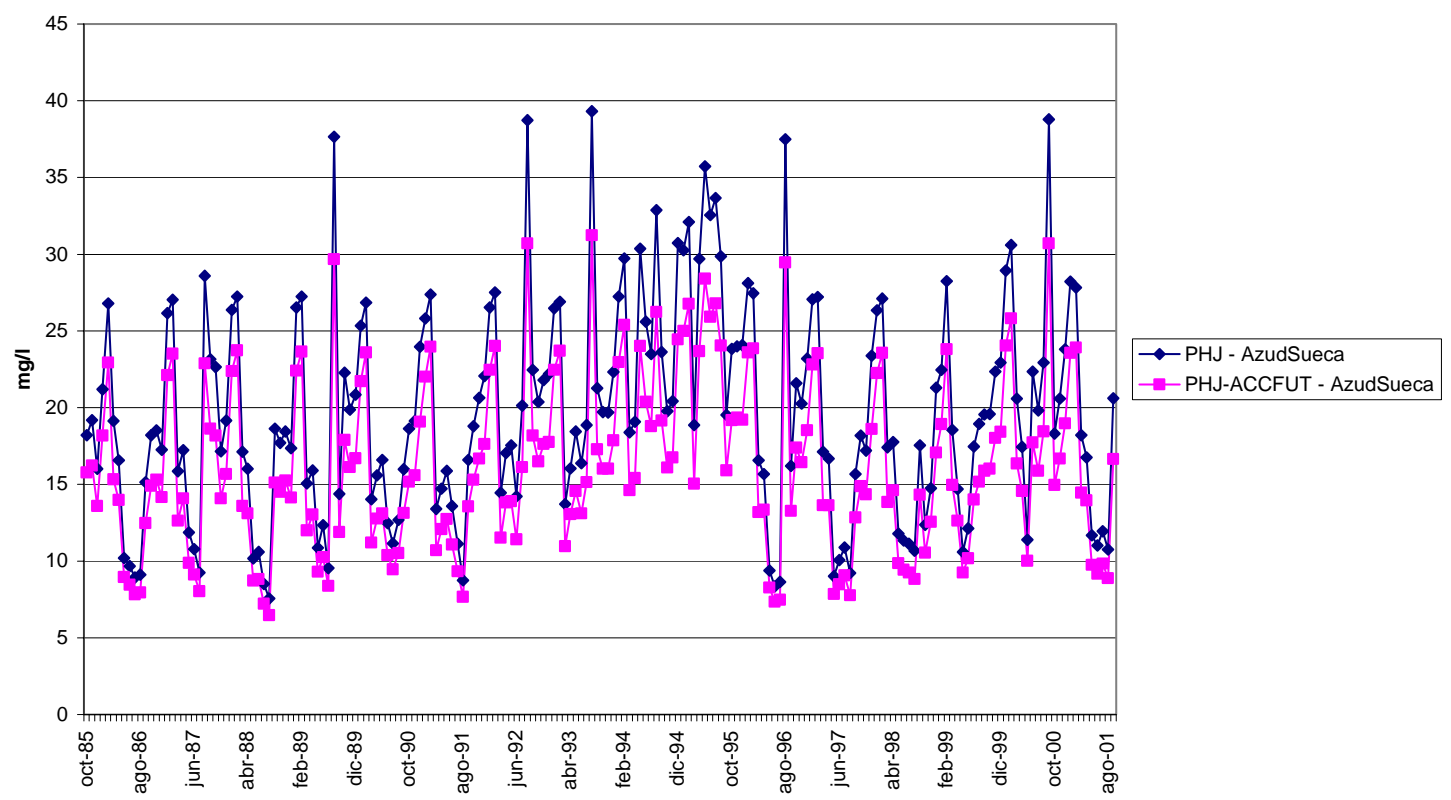

Figura 152. Evolución de las concentraciones de nitratos en el azud de Sueca para diferentes escenarios.

Como se puede ver existe un descenso de concentraciones de nitratos en el citado azud que en media supone una reducción de $19.65 \mathrm{mg} / \mathrm{l}$ a $16.16 \mathrm{mg} / \mathrm{l}$. Por otra parte las concentraciones máximas se reducen de $39.32 \mathrm{mg} / 1$ a $31.24 \mathrm{mg} / \mathrm{l}$.

Por último mencionar que en las alternativas MEDPLA y PHJ se consideran la modernización de la Acequia Real mediante la reducción de la demanda. Esto provoca una reducción de los retornos, tanto superficiales como subterráneos. En este estudio no se ha considerado, por falta de datos, la posible variación de la calidad de los retornos debido al cambio de forma de riego esperable con la modernización de la acequia Real.

\subsection{Fósforo Total.}

La comparativa entre las diferentes alternativas para el fósforo total depende sobre todo del régimen de caudales circulantes. A diferencia de otros constituyente la puesta en funcionamiento de la EDAR de Alcira no tiene efecto sobre el fósforo debido a que no se considera un tratamiento de eliminación del mismo. 
Perfil medio concentraciones PTot

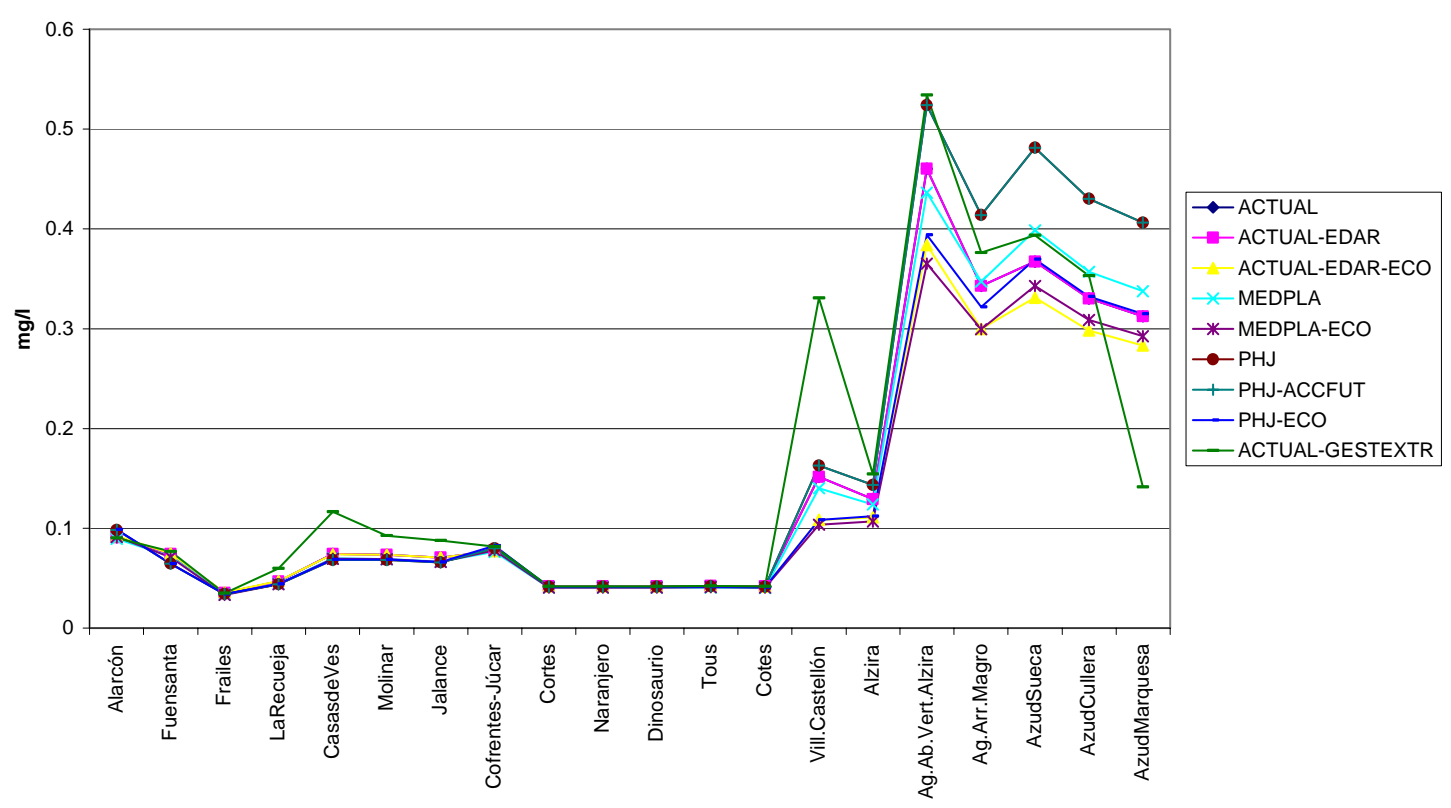

Figura 153. Perfil medio de fósforo total en el río Júcar obtenido para los diferentes escenarios.

Como se puede ver en el gráfico el mayor foco contaminante en toda la cuenca es el vertido de Alcira que hace que las concentraciones medias para todo el tramo aguas abajo del mismo sean superiores a $0.3 \mathrm{mg} / \mathrm{l}$. La alternativa que presenta concentraciones medias más elevadas es la PHJ.

Por otro lado si se analiza el efecto del cambio de régimen de volúmenes embalsados sobre las concentraciones de fósforo se concluye que las alternativas ACTUAL y MEDPLA mantienen concentraciones muy similares mientras que la PHJ presenta valores superiores en las épocas medias y húmedas. 


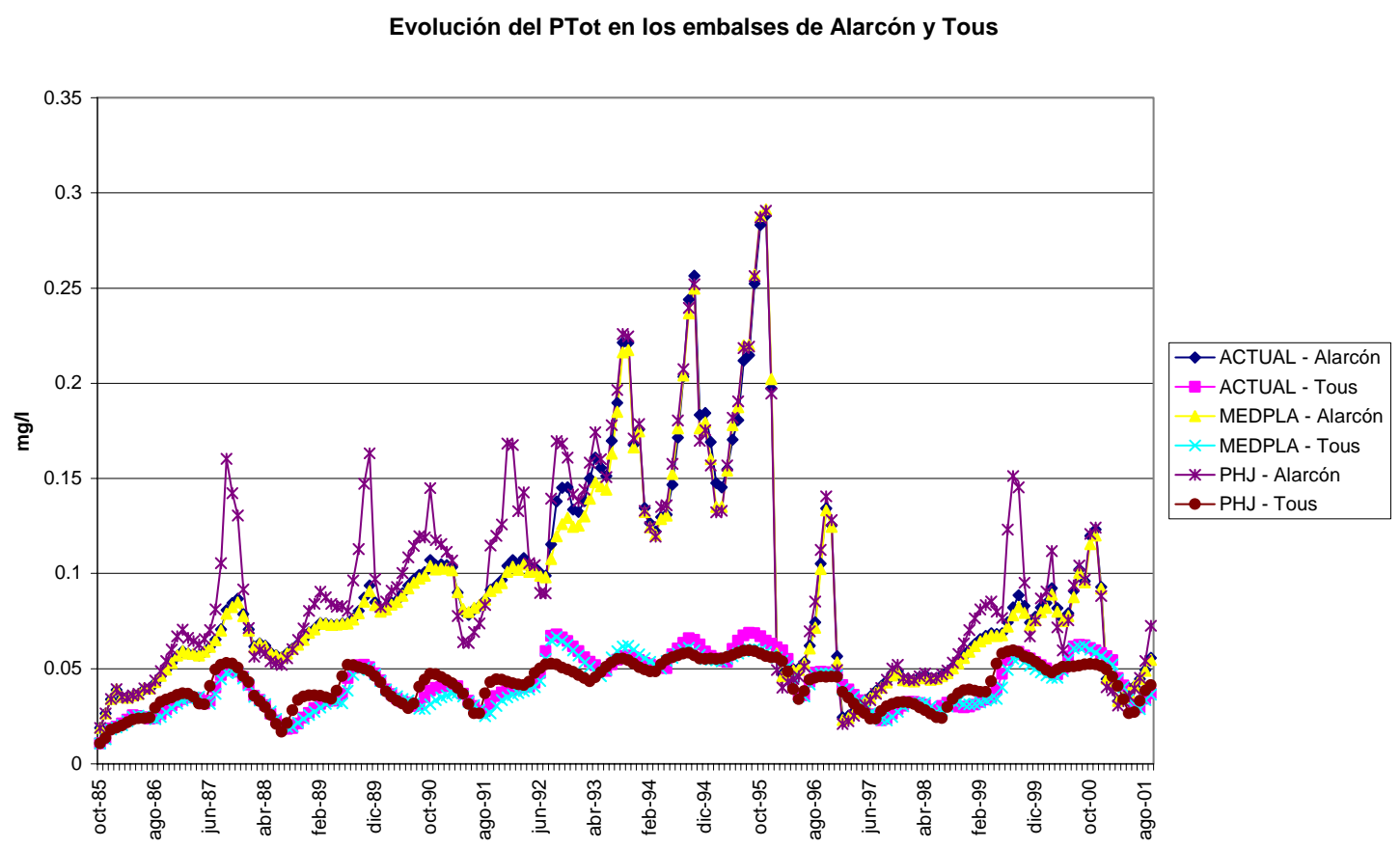

Figura 154. Evolución de las concentraciones de fósforo total en los embalses de Alarcón y Tous para diferentes escenarios.

En el gráfico anterior se presenta las concentraciones obtenidas para las tres alternativas citadas para los embalses de Alarcón y Tous. Como se puede ver no hay variaciones significativas de concentraciones de fósforo total en el embalse de Tous para las distintas alternativas.

Al igual que pasaba con el amonio las concentraciones en las épocas de sequía son iguales para todas las alternativas. En el caso de Alarcón el incremento de concentraciones en las épocas húmedas puede suponer un empeoramiento crónico del grado trófico del embalse.

\subsubsection{Conclusiones sobre la aplicación del módulo GESCAL al caso de la cuenca del río Júcar.}

De la aplicación del modelo GESCAL a la cuenca del río Júcar se pueden obtener las siguientes conclusiones:

Respecto a la puesta en funcionamiento de la EDAR de Alcira:

- Para la mayoría de las variables estudiadas la actuación supondrá un mejora muy significativa en todo el tramo desde el vertido hasta desembocadura.

- Prácticamente independientes a está actuación se mantendrán la conductividad, los nitratos y el fósforo total. 
- El parámetro en el que se estima que se produzca la mayor mejora es el oxígeno disuelto. Aguas abajo del vertido la mejora supondrá pasar de valores medios de oxígeno disuelto de $3.5 \mathrm{mg} / 1$ a $7.6 \mathrm{mg} / 1$.

- Además se ha podido cuantificar una significativa disminución de concentraciones en varios constituyentes como consecuencia de la puesta en funcionamiento de la citada estructura de depuración. Las concentración media de los sólidos suspendidos pasa de 28 a $9 \mathrm{mg} / \mathrm{l}$, en el amonio la media pasa de 1.81 a $0.12 \mathrm{mg} / 1$ y en los nitritos de 0.5 a $0.17 \mathrm{mg} / \mathrm{l}$.

- Una vez depuradas las aguas del citado vertido, el foco de mayor presión pasará a ser la contaminación de los afluentes Verde y Magro, que son los que más influirán en la calidad del río en el tramo final. Un incremento de la depuración de los vertidos industriales de la zona disminuiría la contaminación de los afluentes. Además la modernización de la acequia Real, que lleva asociada el cambio del tipo de riego, reducirá el aporte de nutrientes sobre ambos ríos.

En cuanto a las posibles situaciones en que se puede encontrar la cuenca:

- La situación a medio plazo en la que se considera la modernización de la Acequia Real, el trasvase Júcar-Vinalopó, parte de la sustitución de bombeos de la Mancha Oriental y el aumento de algunas demandas, mantendrá una calidad bastante similar a la actual. Ello se debe, sobre todo, a que los caudales circulantes y la evolución de los volúmenes embalsados se mantiene bastante similar a la situación actual.

- Además, en esta situación de medio plazo se produce una mejora de las garantías de todas las demandas de la Ribera, así como de la demanda de los riegos del canal Júcar-Turia.

- La situación a largo plazo, definida como la situación en la que todas las demandas y reservas del Plan Hidrológico del Júcar se han materializado (con la modernización de la Acequia Real, la sustitución de los bombeos de la Mancha y el trasvase Júcar - Vinalopó) presenta un empeoramiento de la calidad del agua en todas las variables, sobre todo en la parte baja del río.

- Además dicha situación presenta valores de garantía inferiores a los de la situación actual y la de medio plazo. Se ha estimado, por ejemplo, una perdida de garantía volumétrica de la demanda de la Acequia Real del 5\% en la alternativa PHJ frente a la MEDPLA.

- En está situación a largo plazo, en la zona entre el embalse de Alarcón y de Tous, los caudales medios son superiores a los otros escenarios pero se producen caudales mínimos inferiores y más frecuentemente. Ello tiene como 
consecuencia que algunas variables, como los sólidos suspendidos, presentan concentraciones de máximos superiores a los estimados en las otras dos alternativas.

- En la parte baja, la situación de largo plazo presenta caudales circulantes inferiores con lo que todas las variables de calidad estudiadas presentan valores peores respecto a las alternativas "actual" y "medio plazo". Cabe decir que este empeoramiento se debe fundamentalmente a concentraciones máximas superiores mientras que el resto del tiempo las concentraciones son bastante similares a las obtenidas en las otras dos alternativas.

- En cuanto a los embalses, la evolución del volumen embalsado depende del uso del recurso. En las situaciones "actual" y a "medio plazo" las evoluciones de embalse y las concentraciones son muy similares. El incremento de demandas considerado en la situación a largo plazo tiene como consecuencia que los embalses de Contreras y Tous alcancen más frecuentemente la situación de mínimos, pero no se produce una diferencia significativa de la calidad entre las alternativas. Además, el embalse de Alarcón es el que en está alternativa sufre una mayor disminución de los volúmenes embalsados. Debido a ello la calidad en muchas de las variables como son el amonio, los nitritos o el fósforo total sufren incrementos de concentraciones. Estos se suelen producir en épocas de funcionamiento normal del embalse ya que en momentos de sequía las tres alternativas presentan concentraciones similares. Este aumento de concentraciones puede llegar a suponer un empeoramiento crónico del grado trófico del embalse.

- La calidad del afluente Cabriel no se verá modificada significativamente por las posibles futuras situaciones estudiadas.

En cuanto a los caudales de dilución estimados:

- La afección del establecimiento de caudales ambientales en la zona aguas abajo de Tous sobre las garantías de las demandas es bastante baja. En el caso de la garantía volumétrica esta perdida de garantía es inferior en todos los casos al $2 \%$.

- En el futuro, una vez puesta en funcionamiento la EDAR de Alcira, el caudal a soltar desde Tous dependerá de la calidad del agua de los afluentes del Verde y el Magro, no teniendo porque ser algo estático.

- Para todas las alternativas es suficiente mantener $5 \mathrm{hm}^{3} /$ mes aguas abajo del las tomas de las acequias superiores en la mayoría de los meses. En los meses de 
Julio, Agosto y Septiembre se debe hacer un incremento del este caudal en función de la alternativa de estudio.

- Por lo general, la imposición de estos caudales de dilución incide más en mejorar las concentraciones mínimas en los momentos críticos que en las concentraciones medias.

Respecto a posibles acciones futuras:

- Del estudio se desprende que en un futuro la mejora de la calidad de la zona baja del río pasa por mejorar la calidad de los afluentes inferiores.

- Además se pone de manifiesto la mejora que se debe realizar en el control y seguimiento de la calidad de las aguas en la parte baja del río y de sus afluentes inferiores: Sellent, Albaida, Verde y Magro.

- Finalmente, una ampliación del tratamiento de la EDAR de Alcira, con un tratamiento de eliminación de fósforo, sería fundamental para la reducción de concentraciones de fósforo en todo el tramo final del río. 
Integración de la modelación de la calidad del agua en un sistema de ayuda a la decisión para la gestión de recursos hídricos. 


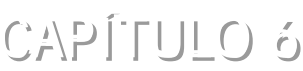

\section{CONCLUSIONES.}

\subsection{Conclusiones sobre el módulo GESCAL desarrollado.}

En esta tesis doctoral se ha desarrollado una herramienta para la modelación de la calidad de sistemas de recursos hídricos conjuntamente con la modelación de la gestión de los mismos.

Dicha herramienta permite modelar la evolución de la calidad en embalses, lagos, ríos y tramos de canal mediante un planteamiento mecanicista. Además, considerando la calidad en el resto de elementos del modelo de gestión, permite evaluar la calidad de sistemas de recursos hídricos complejos de forma completa. Con ello, se puede simular la calidad del agua en todo un sistema teniendo en cuenta las relaciones entre todos los elementos. Este método adquiere especial importancia en tramos de río en donde existen muchos elementos que influyen en la calidad del sistema de forma dinámica como son detracciones de agua, vertidos, retornos de demandas, etc. En la mayor parte de los modelos de calidad se consideran los agentes externos al tramo como entradas al modelo, en muchos casos de forma constante, perdiendo así representatividad de las diferentes situaciones que pudieran darse.

Para los tramos de río se asumen condiciones constantes dentro de cada mes. El modelo realiza una estimación de las condiciones estacionarias mediante un proceso iterativo de resolución de los sistemas de ecuaciones diferenciales planteado. Para los embalses se considera la variación temporal estimándose la evolución de la calidad en el tiempo.

Lo módulos han sido desarrollados completamente por el autor mediante programación informática en diversas plataformas de programación. La interfaz gráfica ha sido programada mediante Visual Basic 6.0 mientras que, los cálculos para la modelación de la calidad se han realizado en Compaq Visual Fortran.

El módulo desarrollado permite modelar, tanto en tramos de río como en embalses, los siguientes procesos:

o Modelación de la temperatura a partir de datos meteorológicos. Además, si no se dispone de datos suficientes para la modelación, la temperatura de cada elemento se puede introducir como una entrada al modelo variable de forma mensual. 
o Modelación de contaminantes arbitrarios, sin límite de número, en los que se incluyen un proceso de eliminación siguiendo una cinética de primer orden y un proceso de sedimentación.

o El oxígeno disuelto puede modelarse en tres niveles de complejidad. El primer nivel incluye la modelación del OD considerando su consumo por oxidación de la materia orgánica y el efecto de la reaireación. En este nivel para la materia orgánica carbonosa se considera tanto la oxidación de la misma como la sedimentación. En un segundo nivel de complejidad se incluye el ciclo del nitrógeno considerando el nitrógeno orgánico, amonio, nitritos y nitratos. Finalmente el último nivel de complejidad permite modelar un problema de eutrofización en el cual se incluyen adicionalmente el fósforo, en distintas formas, y el fitoplancton teniendo en cuenta las relaciones entre los constituyentes.

La aplicación informática desarrollada es un módulo independiente del SSD AQUATOOL por lo que para su aplicación sólo es necesario disponer de los ficheros de datos físicos y de resultados del modelo de gestión. Además la aplicación funciona, si se quiere, independientemente de la interfaz desarrollada.

La herramienta permite presentar los resultados de varias formas como son: diversos índices de calidad para cada elemento, alarmas de incumplimiento de estándares, informes escritos o resultados en formato importable por hoja de cálculo. Además, para los elementos indicados por el usuario se proporcionan resultados parciales de la evolución temporal o espacial según sea un embalse o tramo de río.

La herramienta desarrollada es fundamental en el desarrollo de la Directiva Marco Europea en política de aguas, sobre todo en el apartado de programa de medidas, ya que un modelo de este tipo permite:

- Comprobar la efectividad de medidas planteadas para la mejora de la calidad físico-química e investigar el impacto de las mismas sobre los diferentes elementos del sistema, como pueden ser las demandas.

- Plantear nuevas medidas a partir del conocimiento del sistema y de la herramienta disponible.

- Analizar la evolución del sistema frente a diferentes escenarios tanto en la parte de gestión como en la de calidad. Esta es una pieza fundamental en la elaboración de planes hidrológicos de cuencas o demarcaciones hidrográficas.

- Además, dentro del proceso seguido para la realización del modelo de simulación, el diagnóstico de la calidad permite establecer y evaluar presiones e impactos sobre la calidad del agua en la cuenca y cotejar con los resultados que otras metodologías están planteando para el establecimiento de los mismos. 
La interfaz visual desarrollada permite aplicar la herramienta desarrollada de forma sencilla y modular de diferentes sistemas, como ya ha ocurrido con el SSD sobre el que se ha implantado.

Por otra parte, la coherencia de planteamiento con modelos actuales permite la incorporación de modelos de detalle de una forma fácil y sencilla y una comprobación de los resultados.

En el diseño de la herramienta se ha tenido en cuenta la disponibilidad real de datos en los sistemas actuales a escala de cuenca, con lo que el módulo permite diferentes niveles de complejidad en la modelación.

\subsection{CONCLUSIONES SOBRE LA APLICACIÓN DEL MÓDULO.}

Se ha planteado una metodología, generalizable a cualquier sistema de recursos hídricos, sobre la modelación conjunta gestión calidad. Esta metodología se ha aplicado al sistema de la cuenca del Júcar. Con ello se ha demostrado la utilidad y el funcionamiento del módulo desarrollado y de la metodología planteada. El sistema del Júcar es típico de cuencas mediterráneas con un alto grado de complejidad, dada la elevada utilización del recurso. Uno de los procesos clave en la citada metodología, previo a la modelación, es el análisis de la calidad de toda la cuenca.

\subsubsection{Conclusiones sobre el diagnóstico de la calidad.}

A partir de datos de la red de calidad (red ICA) y de campañas especiales de muestreo de la Confederación Hidrográfica del Júcar, organismo gestor de la cuenca, se ha analizado la evolución histórica de la calidad para diferentes parámetros convencionales como son:

- Conductividad.

- Sólidos suspendidos.

- Materia orgánica carbonosa, oxígeno disuelto y saturación de oxígeno disuelto.

- Nitrógeno en sus formas inorgánicas: amonio, nitritos y nitratos.

- Fósforo como fósforo total y fosfatos.

- Temperatura.

- Clorofila-a en embalses.

Además, se han analizado otras variables como son el $\mathrm{pH}$, Coliformes fecales, DQO, sulfatos y cloruros. No se ha podido realizar un análisis global, para toda la cuenca, de estas últimas variables debido a la falta de datos. 
El sistema se caracteriza por estar fuertemente regulado, pudiéndose distinguir dentro del año dos períodos muy marcados de régimen de caudales: la época de almacenamiento con caudales muy bajos en todas las zonas de la cuenca, excepto en las no reguladas, y la época de riego en donde los caudales son muy elevados por las sueltas. Como se desprende del análisis realizado el régimen de caudales es determinante sobre la calidad del agua.

Espacialmente se pueden distinguir dos grandes zonas en la cuenca: aguas arriba y aguas abajo del embalse de Tous. Ello es debido a que la mayor parte de los usos y de la presión antropogénica se ubica en la parte baja de la cuenca.

En la parte alta de la cuenca la capacidad de autodepuración del río es más que suficiente para asimilar los vertidos que se van produciendo a lo largo del mismo. La mayor parte de los constituyentes presentan concentraciones bastante naturales. En esta zona sólo existen dos puntos de presión significativa. Por un lado los vertidos de la ciudad de Cuenca y alrededores con un aporte de fósforo importante al sistema. Por otro lado la zona aguas arriba del embalse de Molinar que se caracteriza por una fuerte contaminación urbana que afecta a la calidad del tramo, aunque las estaciones disponibles recogen el efecto muy atenuado.

Finalmente otro de los efectos de la actividad del hombre sobre la calidad del agua en la parte alta y media de la cuenca es el incremento de nitratos como consecuencia de las actividades agrícolas. El punto más significativo es la zona entre los embalses de Alarcón y Molinar en donde las concentraciones de nitratos se incrementan significativamente debido al aporte de agua del acuífero de la Mancha oriental contaminado por la actividad agrícola de la zona.

Aguas abajo del embalse de Tous las mayores presiones son los vertidos urbanos e industriales sin depurar, la contaminación por los retornos agrícolas y la mala calidad de algunos de los afluentes de la zona. Actualmente, el mayor foco de contaminación es el vertido de las poblaciones de Alcira y cercanas que no disponen de ningún tipo de depuración. Esto trae, como consecuencia, que el río mantenga una calidad pésima hasta su desembocadura. La mayor parte de las variables se ven afectadas por este vertido, siendo lo más significativo la disminución de concentraciones de oxígeno disuelto. En la actualidad, aguas abajo del vertido, se alcanzan concentraciones cercanas a cero.

Aguas abajo, la incorporación de los afluentes Verde y Magro no mejora la calidad del río debido a la baja calidad de los mismos. El tramo final, aguas abajo de la incorporación del Magro, se caracteriza por unas velocidades muy bajas, con agua estancada en los azudes de Sueca, Cullera y Marquesa. Los azudes producen ligeras mejoras en la calidad del agua debido, principalmente, a procesos de sedimentación de 
la materia orgánica y reaireación en el paso por los azudes. Destaca la eutrofización del último azud debido a un conjunto de factores como son: altos períodos de retención, temperaturas elevadas y altas concentraciones de nutrientes.

En términos generales la calidad del agua de los embalses de cabecera es buena mientras que la de los embalses de la zona de confluencia es incluso mejor.

En cuanto al afluente Cabriel la calidad es buena o muy buena sin que exista gran influencia de la actividad humana, excepto en lo que se refiere a la regulación de caudales.

Destaca el posible uso del análisis de la calidad, sobre todo de los constituyentes conservativos, para mejorar el conocimiento la evaluación del recurso. La mayor disponibilidad de estaciones de calidad que de estaciones de aforo permite concretar con mayor detalle en qué zonas se producen mayores aportes de recursos. Para la zona entre Alarcón y Molinar y el acuífero de la Mancha oriental permite establecer una primera zona entre las estaciones de Fuensanta y los Frailes en donde en la actualidad se producen filtraciones y aportes subterráneos con balance nulo de aporte. También se deduce que la zona de mayor aporte subterráneo se produce justo aguas arriba del embalse de Molinar.

En el río Cabriel los datos de la estación de la calidad permiten establecer la cuenca entre el embalse de Contreras y Villatoya como la de mayor aporte de recurso de toda el área entre el embalse de Molinar el de Contreras y hasta confluencia.

Finalmente se ha realizado una evaluación de la posible mejora de la red de calidad para la aplicación de sus datos en modelos de calidad. De ello se puede destacar lo siguiente:

- Existe un problema de medición de la demanda biológica de oxígeno $\left(\mathrm{DBO}_{5}\right)$ con un umbral de medición elevado. Además, en la situación, en la que se encuentra gran parte de la cuenca, de bajo contenido de materia orgánica se debería comenzar a medir con mayor regularidad la DQO o cambiar la medición a DBO límite. Estas variables darían mayor información sobre el contenido de la materia orgánica.

- Existen zonas donde convendría aumentar el control creando nuevas estaciones de calidad. La zona entre la confluencia con el Magro y el azud de la Marquesa debería disponer de varias estaciones, ya que es uno de los tramos más críticos de toda la cuenca. Además, una estación intermedia entre las de Recueja y Casas de Ves reflejaría el grado de degradación de la calidad en la zona, no captado con las estaciones actuales.

- En cuanto a los nitratos existen dos zonas "en sombra" que no permiten realizar un seguimiento de los mismos en toda la cuenca. Estas son: la zona 
alrededor del embalse de Contreras y, sobre todo, la zona de la confluencia de los ríos Júcar y Cabriel.

- Finalmente el fósforo total se está midiendo con mayor profusión en la parte alta y media de la cuenca mientras que en el tramo final se mide, sobre todo, los fosfatos. Esto dificulta la modelación y el diagnóstico de la calidad de toda la cuenca.

\subsubsection{Conclusiones obtenidas de la simulación.}

Con el desarrollo y uso del modelo de la cuenca del Júcar se ha demostrado la utilidad de la herramienta en la aplicación sobre una cuenca de tamaño medio y de gran complejidad.

Esta aplicación, además, parte de datos no obtenidos en campañas expresas para la modelación. Los datos de las estaciones de calidad presentan el inconveniente de no tener en cuenta los tiempos de viaje en la cuenca. Sin embargo la ventaja de los datos de las redes de calidad son las largas series disponibles. Tanto de la aplicación como de la comparación de caudales aforados y de medidos in situ se demuestra que la hipótesis de que las mediciones instantáneas son representativas de las condiciones medias es válida cuando se dispone de series de datos suficientemente largas como es el caso de las redes de calidad.

Se demuestra la ventaja del módulo que permite considerar la mayor parte de los elementos del sistema y su afección en la calidad de los diferentes tramos. En cuencas de elevada complejidad, como la estudiada, la calidad en los tramos de río depende tanto de los procesos físico - químicos y biológicos que pueden darse como del efecto del resto de elementos sobre el mismo. Este efecto es variable de forma temporal y no conviene considerarlo como constante como suele hacerse en la modelación tradicional de la calidad del agua.

Se ha desarrollado un modelo de calidad completo de toda la cuenca con 19 tramos de río y seis embalses. Se han modelado 8 constituyentes:

- Conductividad como conservativo.

- Sólidos suspendidos como arbitrarios.

- Oxígeno disuelto y materia orgánica carbonosa.

- Ciclo del nitrógeno: amonio, nitritos y nitratos y su efecto sobre el oxígeno disuelto.

- Fósforo total como arbitrario.

Los embalses se han modelado en una sola capa por la falta de datos. La calidad de los mismos no indica que sea necesario una modelización más compleja. Los tramos de 
río se han discretizado teniendo en cuenta la longitud y la precisión que se quiere obtener.

Se ha realizado una calibración de todos los elementos de la cuenca mediante un desarrollo complementario a la herramienta. Se han calibrado todos los elementos por separado. Algunos de los elementos se han tenido que calibrar con el modelo global debido a la gran dependencia sobre otros elementos. Además se ha realizado un análisis de sensibilidad de todas las variables para todos los elementos analizando también la sensibilidad entre variables. Posteriormente se ha realizado un acoplamiento en donde se comprueba que no existen distorsiones entre los elementos calibrados y se realizan las modificaciones pertinentes sobre el modelo de gestión para que la modelación de la calidad sea representativa del sistema.

Una vez calibrado el modelo se plantean diferentes escenarios de simulación atendiendo a diversos aspectos como son:

- Se analiza el efecto de la puesta en funcionamiento de la EDAR de Alcira prevista para que comience a funcionar en los próximos años.

- Se estudian tres escenarios diferentes de situación del sistema en cuanto a demandas se refiere: la situación actual, la situación a medio plazo y la situación a largo plazo. Las situaciones a medio y largo plazo consideran: el ahorro de agua debido a la modernización de la acequia real, la sustitución de bombeos en el acuífero de la Mancha, el trasvase Júcar-Vinalopó y un incremento de demandas, según que escenario, acorde con el Plan hidrológico del Júcar.

- Para cada una de estas situaciones se ha estimado un caudal de dilución capaz de mantener la vida piscícola.

- Además se ha estudiado una situación de gestión extrema en que la cuenca se gestiona exclusivamente bajo criterios de eficiencia y otra en la que se la cuenca se sitúa en el futuro pero en la que se han realizado actividades de depuración y mejora de las prácticas agrícolas en las cuencas de los afluentes del Verde y el Magro.

Respecto a la puesta en funcionamiento de la EDAR de Alcira se concluye:

- Existirá una mejora muy significativa de la calidad del agua en todo el tramo final. Se ha estimado una mejora de la concentración media de oxígeno disuelto, aguas abajo del vertido, de $3.5 \mathrm{mg} / \mathrm{l} \mathrm{a} 7.6 \mathrm{mg} / \mathrm{l}$.

- Otras variables que mejoraran muy significativamente son el amonio, los nitritos y los sólidos suspendidos. Para estos últimos se ha estimado una reducción de concentraciones del 40\%. Sin embargo la conductividad, el fósforo y los nitratos no tendrán grandes variaciones. 
- Con esta infraestructura de depuración el punto crítico de la cuenca se desplazará aguas abajo pasando a ser el azud de Sueca. Además, en el futuro, el elemento de mayor influencia sobre la calidad del agua en la zona pasará a ser la calidad del agua de los afluentes Verde y Magro.

En cuanto a los diferentes escenarios planteados sobre situaciones de demandas en el sistema se destaca:

- La situación a medio plazo representa una mejora en las garantías de las demandas. Además, la calidad del agua se asemeja bastante a la situación actual, incluso mejorando en algunos puntos.

- La situación a largo plazo presenta una calidad inferior generalizada en el tramo final y en el embalse de Alarcón. Es de destacar el incremento significativo de concentraciones de fósforo que se produciría en el embalse de Alarcón, bajo situaciones hídricas normales, en donde mientras los otros dos escenarios mantienen concentraciones inferiores a $0.1 \mathrm{mg} / \mathrm{l}$ en el escenario a largo plazo se superaría con bastante frecuencia este valor. De las simulaciones se estima que la situación a "largo plazo" de las demandas podría llevar a un empeoramiento crónico del grado trófico del embalse.

- Por otra parte se ha comprobado que, a la hora de comparar alternativas las épocas que establecen diferencias entre los escenarios son las épocas medias y húmedas mientras que en épocas de pésimas condiciones los resultados son bastante parecidos.

En cuanto a los caudales de dilución estimados para el tramo aguas abajo de Tous:

- El punto donde se deben establecer estos caudales es el tramo de río aguas abajo del azud de Antella. Se ha escogido como criterio el mantener 3mg/l de concentración de oxígeno disuelto en todo el tramo el 95\% de los meses.

- Se ha estimado que, la mayor parte del tiempo, este caudal de dilución es de aproximadamente $2 \mathrm{~m}^{3} / \mathrm{s}$. Esta cifra debe incrementarse en los meses de Agosto y Septiembre en función del escenario contemplado: $3.8 ; 4.55$ y $5.69 \mathrm{~m}^{3} / \mathrm{s}$ para la situación actual, medio y largo plazo respectivamente.

- Se ha comprobado que los caudales de dilución no mejoran significativamente la calidad del tramo incidiendo más en los momentos de situación crítica del caudal.

- Por otra parte se ha podido estimar una perdida de garantía de las demandas por el establecimiento de los caudales de dilución muy baja, siendo inferior al $2 \%$ en todos los casos. 
Por lo que respecta a la hipótesis de una gestión "extrema" bajo criterios exclusivamente de eficiencia se concluye:

- Se dan tramos del río con caudales mínimos incluso nulos con bastante frecuencia. Estas zonas serían: aguas arriba del embalse de Molinar, aguas abajo del azud de Antella y aguas abajo del azud de Cullera.

- Se produciría un empeoramiento generalizado de la calidad en todos los tramos del río. En los embalses, donde se obtienen unos volúmenes embalsados mayores, no mejorarían su calidad significativamente.

Finalmente, en la hipótesis de situación futura se ha evaluado el efecto de posibles medidas futuras como son la depuración de los vertidos de la cuenca del Verde y del Magro y la puesta en funcionamiento de buenas prácticas agrícolas que redujesen la contaminación difusa en la zona:

- Se ha estimado que una reducción del aporte de nitratos del orden del $30 \%$ en las cuencas de los ríos Magro y Verde supondrían una reducción, tanto de concentraciones medias como máximas, del orden de $5 \mathrm{mg} / 1$ de $\mathrm{NO}_{3}{ }^{-}$aguas abajo del azud de Sueca.

En definitiva para todas las alternativas planteadas el modelo conjunto de gestión y calidad ha permitido:

- Evaluar la calidad del agua para todos los constituyentes modelados y cada uno de los elementos en cada alternativa. Se han podido realizar comparaciones entre los resultados de cada alternativa tanto a nivel de toda la cuenca como en diferentes puntos específicos.

- Identificar puntos críticos futuros del sistema y evaluar diferentes posibles medidas a tomar.

- Analizar la afección que puedan tener las modificaciones de los flujos sobre las garantías de las demandas, ya sea por modificaciones de la situación de las demandas o por desembalses medioambientales para el mantenimiento de la vida.

La conclusión de la aplicación y de la metodología seguida es que la herramienta desarrollada es de gran utilidad a la hora de modelar la calidad del agua a escala de cuenca en sistemas de recursos hídricos para la evaluación de diferentes alternativas sobre el sistema.

\subsection{LÍNEAS FUTURAS.}

En relación a la herramienta desarrollada se encuentran los siguientes posibles trabajos futuros: 
- La principal acción a desarrollar en el futuro es la aplicación de la herramienta a otras cuencas con diferentes problemáticas. Debido al potencial de la herramienta desarrollada, en el caso del Júcar no se han podido utilizar toda su capacidad. Entre los temas más interesantes a aplicar destacan la modelación de la temperatura y los problemas de eutrofización.

- Como complemento al módulo desarrollado convendría, en un futuro, crear nuevos módulos para el pre-tratamiento de datos como puede ser la estimación de las series de temperaturas de equilibrio a partir de datos meteorológicos o para analizar posibles algoritmos de calibración automática de parámetros.

- Además, sobre los modelos SIMGES y OPTIGES se pondrían incluir en la optimización aspectos de calidad ya sea como limitaciones o dentro de la función objetivo.

- En cuanto a los procesos considerados se podría incorporar la posibilidad de la modelación de compuestos tóxicos.

- Por otra parte, se podría plantear la reducción de la escala temporal considerada. Ello permitiría utilizar la herramienta desarrollada como módulo de calidad convencional para tramos de río y embalses.

En cuanto a la mejora futura en la modelación de la cuenca del Júcar los trabajos futuros deberían seguir las siguientes direcciones:

- Realizar modelos de lluvia escorrentía que incluyan aspectos de calidad para la obtención de series de calidad de las aportaciones más largas; con especial necesidad en las aportaciones inferiores y aguas arriba de los embalses de Alarcón y Contreras.

- El estudio ha puesto en evidencia la necesidad de mejorar el control y seguimiento de la calidad del agua en la zona baja de la cuenca, sobre todo en la zona entre el río Magro y el azud de la Marquesa.

- Por último, pequeñas mejoras en la ubicación y el seguimiento de los parámetros de la red ICA pueden hacer que la red siga siendo una fuente muy valiosa de datos para la modelación de la calidad en el futuro. 


\section{REFERENCIAS}

$>$ Aalderink, R.H., Klaver, N.J. and Noorman, R. 1995. DUFLOW V 2.0: Microcomputer package for the simulation of one-dimensional flow and water quality in a network of open water courses. Modelling water quality and flow in river Vecht using DFLOW. In water quality modeling, Proceedings of the international conference on water quality modelling (ed. C. Heatwole), pp. 416426, Maerican Society of Agricultural Engineers, Orlando, FL.

$>$ ADCRM- AD Consultants Resource Management Associates, Inc. 2002. Stanislaus River Water Temperature Model. Prepared for U.S.Bureau of Reclamation, U.S. Fish and Wildlife Service, California Department of Fish and Game, Oakdale Irrigation District, Stockton East Water District.

$>$ Alvín, 2001. Vicente alvín. "Estudio para la determinación de las aportaciones intermedias entre el embalse de Tous y la estación de aforos de Huerto Mulet en el río Júcar". Proyecto final de carrera para la titulación de Ing. de Caminos, Canales y Puertos en la UPV, dirigido por D.Joaquín Andreu.

$>$ Ambrose, R.B. Jr., Wool, T.A., Conolly, J.P. and Schanz, R.W. 1988. WASP4, A hydrodynamic and water quality model - Model theory, User's manual and programmer's guide. Report EPA/600/3-87/039, US EPA, Athens, GA.

$>$ Ambrose, R.B. Wool, T.A., and Martin J.L., 1993 (a). The Water Quality Analysis Simulation Program WASP5, Part A: Model documentation, Version 5.10, US Environmental Protection Agency, Env. Research Lab., Athens Georgia

$>$ Ambrose, R.B. Wool, T.A., and Martin J.L., 1993 (b). The Water Quality Analysis Simulation Program WASP5, Part B: The WASP input dataset, Version 5.10, US Environmental Protection Agency, Env. Research Lab., Athens Georgia

Ambrose, R.B., Wool, T.A., and Martin, J.L., 1993 (c). The Dynamic Estuary Model Hydrodynamics Program, DYNHYD5, Model Documentation and User Manual, US Environmental Protection Agency, Env. Research Lab., Athens Georgia. The User's Manual is distributed with the software

> Ambrose, R.B., Barnwell, T.O. McCutcheon, S.C. and Williams, J.R. 1996. Computer models for water quality analysis. Chapter 14 In Water resources handbook (ed. L.W. Mays), McGraw-Hill, New York. 
Andreu, 1983. J. Andreu. "Modelos agregados y distribuidos. Modelos unicelulares. Modelos Glover-Jenkins". Editado en "Utilización conjunta de aguas superficiales y subterráneas", ed. por M. Varela, S.G.O.P., Madrid, 1983.

$>$ Andreu, 1989. J. Andreu. "Manual de usuario del modelo OPTIRED de optimización de sistemas de recursos hidráulicos", DIHMA, Universidad Politécnica de Valencia.

$>$ Andreu y otros, 1989. J.Andreu, J.Capilla y J.Ferrer, "Manual del usuario del modelo SGC de simulación de sistemas de recursos hidráulicos", DIHMA, Universidad Politécnica de Valencia.

$>$ Andreu et al., 1991. J.Andreu, J.Capilla and E.Sanchis. "AQUATOOL: $a$ computer-Assisted Support System for Water Resources Research Management Including Conjunctive Use", chapter: "Decision Support Systems". Edit. Daniel P. Loucks and Joao da Costa, Vol. G26, pp.333-355, Springer-Verlag, Berlín Heidelberg.

$>$ Andreu, 1992. J.Andreu. "Modelo optimes de optimización de la gestión de esquemas de recursos hídricos. Manual de usuario". SPUPV-92.2012. ISBN.847721-191-4

$>$ Andreu et al., 1992. J. Andreu, J.Capilla y J.Ferrer. "Modelo Simges de simulación de la gestión de recursos hídricos, incluyendo utilización conjunta. Manual del usuario". SPUPV-92.1097, ISBN 84-7721-169-8

$>$ Andreu. 1993a. J. Andreu. "Análisis de sistemas y modelación". Editado en "Concéptos y métodos para la planificación hidrológica", ed. J.Andreu, CIMNE, Barcelona, pp. 25-33.

> Andreu, 1994. "Informe Técnico sobre el Trasvase del Tajo al Segura en el Verano de 1994". Informe elaborado para el Sindicato Central de Regantes del Acueducto Tajo-Segura, Murcia. (no publicado).

$>$ Andreu et al., 1996. J. Andreu, J.Capilla y Emilio Sanchis. "AQUATOOL: A generalized decision support-system for water-resources planning and operational management". Publicado en "Journal of hidrology". 177 (1996) 269291

$>$ APHA American Public Health Association. 1992. Standard Methods for the Examination of Water and Wastewater, 18 ed. Washintong, D.C.

$>$ Arnold, U. and Orlob, G. T. (1989). "Decision support for estuarine water quality management.” J. Water Resour. Plng. and Mgmt., ASCE, 115(6), 775792.

ATV 1996. Allgemein verfuegbares Gewaesserguetemodell.

Projekabschlussbericht 02 WA9104/4 Abwassertechnishen Vereinigung, Hennef, Germany. 
$>$ Bartholow, J., Heasley, J., Laake, J., Sandelin, J. Coughlan, B.A.K., and Moos, A. 2000. SALMOD: A Population Model for Salmonids: User's Manual. Version 3. USGS/FORT Internal Publication. 82 pp.

$>$ Bartsch, A.F. y Gaksatter, J.H. 1978. Management decisions for lake systems on a survey of trophic status, limiting nutrients, and nutrient landings in AmericanSoviet. Symposium on use of mathematical models to optimize water quality management. ERL, ORD, USEPA Gulf Breeze, FL, pp. 371-394 EPA-600/9-78024.

> Bender, M.D., Hauser, G.E., Shiao, M.C., and Proctor W.D. 1990. BETTER: Atwo-dimensional reservoir water quality model. Technical reference manual and user's guide. Tennessee Valley Authority Engineering Laboratory. Report No. WR28-2-590-152.

$>$ Bicknell, B.R., Imhoff, J.C. Kittle, J.L. Jr., Donigian, A.S., Jr, and Johanson, R.C., 2001. Hydrological Simulation Program-Fortran: User's manual for version 12: U.S. Environmental Protection Agency, National Eposure Research Laboratory, Athens, Ga., EPA/600/R-97/080, 831 pp.

$>$ Branklin, R.W., Gladwell, I. y Shampire, L.F. (1991) RKSUITE: A suite of Runge-Kutta codes for the initial value problem for ODEs, Soft Report 91-1, Mathematics Department, Southern Methodist University, Dallas, Texas

$>$ Brown, L.C. and Barnell, T.O. 1987. The enhanced stream water quality models QUAL2E and QUAL2E-UNCAS: Documentation and User Manual. Report EPA/600/3-87/007, US EPA, ATHENS, GA.

$>$ Burns, L.A. 1990. Exposure analysis modelling system: User's Guide for EXAMS II Version 2.94. EPA/600/3-89/084. U.S. EPA, Atehns, GA, 30605.

$>$ Burt, W.V. 1958. Heat budget terms fro Middle Snake River Reservoir. In Water temperature studies on the Sanke river, Tech. Rep. 6, U.S. Fish and Wildlife Serv, Washington, D.C.

$>$ CAPJA, 1984. "Estudio de Gestión de Recursos Hídricos para Uso Agrícola en Andalucía" Convenio de investigación entre la Universidad de Córdoba y la Consejería de Agricultura y Pesca de la Junta de Andalucía.

> CCCCV.1994. Consejo de Cámaras de Comercio de la Comunidad Valenciana. Aguas Residuales Industriales: Minimización y Tratamiento. Generalitat Valenciana. Conselleria de Medi Ambient.

$>$ CEDEX, 2000. Seguimiento del grado trófico de veintisiete embalses. Embalse de Tous Valencia. Centro de Estudios Hidrográficos. Centro de Estudios y Experimentación de Obras Públicas. Ministerio de Fomento. Madrid. Informe técnico para Ministerio de Medio Ambiente. Secretaría de Estado de Aguas y 
Costas. Dirección General de Obras Hidráulicas y Calidad de las Aguas. Confederación Hidrográfica del Júcar.

$>$ Cerco, C.F., and Cole, T. 1995. User's guide to the CE-QUAL-ICM threedimensional eutrophication model, release version 1.0. Technical Report EL-9515, US Army Eng. Waterways Experiment Station, Vicksburg, MS.

$>$ Chapra, S. C. y S.J. Tarapchack, S. J. 1976. A chlorophyll-a model and its relationship to phosphorous loading plots for lakes. Water Res. Res., 12(6):1260-124.

> Chapra, S. C. 1997. Surface Water Quality Modeling. McGraw-Hill. New York.

$>$ CHJ. 1998. Plan Hidrológico de la Cuenca del Júcar. Confederación Hidrográfica del Júcar. Ministerio de Medio Ambiente.

$>$ Chaudhury, R.R., Sobrinho, J.A.H., Wright, R.M., and Sreenivas, M., 1998: Dissolved oxygen modeling of the Blackstone River (Northeastern United States), Water Research, vol. 32, no. 8, p. 2400-2412.

$>$ CHS, 1996. "Estudio sobre disponibilidades, regulación y balances hidráulicos de la cuenca del Segura". Desarrollado por EPTISA para la Confederación Hidrográfica del Segura del Ministerio de Obras Públicas y Urbanismo.

> Cockrum, D.K., and Warwick, J.J., 1994: Assessing the impact of agricultural activities on water quality in a periphyton-dominated stream using the Water Quality Analysis Program (WASP). In Proceedings of the Symposium on the Effects of Human-Induced Changes on Hydrologic Systems, American Water Resources Association, Jackson Hole, WY, June 26-29, 1994, p. 1157.

> Cole, T.M., and E.M. Buchak. 1995. A two-dimensional laterally averaged, hydrodynamic and water quality model. Version 2.0. U.S. Army Corps of Engineers, Waterways Experiment Station, Vicksburg, Mississippi.

> CR, 1987. "Estudio para la regulación del río Iregua (La Rioja)". Desarrollado por Control y Geología S.A. para la Comunidad de La Rioja.

$>$ Cubillo, F., Rodriguez, B., and Barnwell, T.O., Jr., 1992: A system for control of river water quality for the community of Madrid using QUAL2E. Water Science and Technology 26(7/8):1867-1873.

$>$ Dai, T. and Labadie, J. W. (2001) "River basin network model for integrated water quantity/quality management." J. Water Resour. Plng. and Mgmt., ASCE, 27(5).295-305.

$>$ de Azevedo, L.G. T. (1993). "Integration of water quantity and quality in multisector river basin planning." PhD thesis, Dept. of Civ. Engrg., Colorado State University, Fort Collins, Colo. 
$>$ de Azevedo, L. G. T., Gates, T. K., Fontane, D. G., Labadie, J. W., and Porto, R. L. (2000). "Integration of water quantity and quality in strategic river basin planning.” J. Water Resour. Plng. And Mgmt., ASCE, 126(2), 85-97

$>$ Deas, M.L., and Lowney C.L. 2000. Water Temperatura Modeling Review. Central Valley. California Water Modeling Forum

$>$ Delay, W.H., and Seaders, J. 1966. Predicting temperature in rivers and reservoirs. J. Sanit. Eng. Div. Am. Soc. Civ. Eng. 92: 115-134

$>$ De Smedt, F., Vuksanovic, V., Van Meerbeeck, S., and Reyns, D., 1998: A time-dependent flow model for heavy metals in the Scheldt estuary, Hydrobiologia, vol. 366, pp. 143-155.

$>$ DHI 1992. MIKE 11 User manual. Danish Hydraulic Institute, Denmark

> Dillon, P.J. y Rigler, F.H. 1974. The phosphorous-chorophyll relationship in lakes. Limnol. Oceanogr. 19(4):767-773.

> Di Toro, D. M., Fitzpatrick, J.J. y Thomann, R.V. 1983. Documentation for water quality analysis simulation program (WASP) and model verification program (MVP). Env. Res. Lab. ORD, USEPA, Duluth, MN, 145 pp. EPA600/3-81-044.

$>$ Dobbins, W.E. (1956). The nature of oxygen transfer coefficiente problem. Oper Re. 13.

$>$ Dongarra, J.J., Bunch, J.R., Moler, C.B., y Stewart, G.W. (1979) LINPACK Users' Guide, SIAM, Philadelphia.

$>$ DOPTC, 87. "Estudio complemetario de embalses de la vertiente mediterránea Navarra". Desarrollado por Control y Geología S.A. para el Departamento de Obras Públicas, Transportes y Comunicaciones de la Comunidad Foral Navarra.

$>$ Drolc, A. and Koncan, J.Z., 1996: Water quality modelling of the River Sava, Slovenia, Water Research, vol. 30, no. 11, pp. 2587-2592.

$>$ Edinger, J.E. and J.C. Geyer. 1965. Heat exchange in the environment. Department of Sanitary engineering and Water resources, Research Project No. 49. The John Hopkins University. Baltimore. Maryland.

$>$ Edinger, J.E., D.W. Dutweiler, and J.C. Geyer. 1968. Heat Exchange in the Environment, Cooling Water Discharge Project Report no. 2, Publication 65902, Edison Electric Institute, New York, NY.

Edinger, J.E., Brady, D.K., and Geyer, J.C. 1974. Heat exchange and transport in the environment. Report 14. Electric Power Resource Institute, Palo Alto, California. 
$>$ El-Beshri, M., and Labadie, J. (1994). "Optimal conjuctive use of surface and groundwater resources in Egypt.” Proc., $8^{\text {th }}$ IWRA World Congr. On Water Resour., Ministry of Public Works and Water Resources, Cairo, Egypt.

$>$ EL-WES. Environmental Laboratory - U.S. Army Engineering Waterways Experiment Station. 1986. CE-QUALR1: A numerical, one dimensional model of reservoir water quality, User's manual, Instruction report E-82-1. Vicksburg, MI. July 1986.

$>$ EL-WES. Environmental Laboratory- U.S. Army Engineering Waterways Experiment Station. 1990. CE-QUAL-RIV: A dynamic, one dimensional,(longitudinal) water quality model for streams: User's manual. Instruction Report E-90-1, Vicksburg, MS.

$>$ EL-WES. Environmental Laboratory- U.S. Army Engineering Waterways Experiment Station. 1995. A two-dimensional laterally averaged, hydrodynamic and water quality model, Version 2.0, User Manual. Instructional report NE-865. Vicksburg, MI. June 1995.

$>$ EPA, 1986. Quality Criteria for Water. U.S. Environmental Protection Agency. EPA 440/5-86-001. Technical Report.

$>$ EU,2000. "Directive of the European Parliament and of the Council 2000/60/ec establishing a Framework for Community action in the field of water policy". The european parliament, European Union, Luxembourg, 23 October 2000. Diario Oficial de las Comunidades Europeas de 22-12-2000.

$>$ Everson and Mosely, 1970. D.E. Evenson and J.C. Mosely. "simulation/optimization tecniques for multi-basin water resource planning". Revista Water Resources, 6(5), 725-723, 1970.

$>$ Fisher, H.B., E.J. List, R.C.Y. Koh, J. Imberger, and N.H. Brooks. 1979. Mixing in inland and coastal waters. Academic Press, New York, NY.

> Flug, M., Bartholow, J., and Campbell, S. 1999. System Impact Assesment Model for the Klamath-Trinity River. In: $26^{\text {th }}$ Annual ASCE Water Resources Planning and ManagementConferece Proceedings, June 6-9, 1999, Tempe, AZ; in Erin M.Wilson (Ed.), WRPMD '99 CD Proceedings: Preparing for the $21^{\text {st }}$ Century, July 11999.

> Flynn, K.M., Hummel, P.R., Lumb, A.M. and Kittle, J.L., 1995, User's manual for ANNIE, version 2, a computer program for interactive hydrologic data management. U.S. Geological Survey Water-Resources Invenstigations Report 95-4085, $211 \mathrm{p}$.

Fredericks, J. and Labadie, J. 1995. Decision Support System for Conjuctive Stream-Acuifer Management. Open File Report, No. 10 Colorado Water 
Resources Research Institute, Colorado State University, Ft. Collins, Colorado. 124pp. plus appendices

$>$ Freudberg, S.A. 1985. A post-audit of the Potomac eutrophication model. Met. Wash. Council of Govts. Paer presented at Amer.Soc. Civil Engr. Water Res. And Planning Div. Conf., Buffalo. NY, 12 pp.

> Gandía, 2001. Rafael Gandia "Análisis de la situación actual de explotación del sistema de recursos hídricos de La Marina Baja". Proyecto final de carrera para la titulación de Ingeniero de Caminos, Canales y Puertos presentado en la Escuela Técnica Superior de Ingenieros de C. C. y P. de valencia. Dirigido por Abel Solera.

$>$ Graham, L., Labadie, J., Hutchinson, I., and Ferguson, K. 1986. Allocation of augmented water supply under a priority water right system. Water Resour. Res. 22(7), 1083-1094.

> Gundelach, J.M., and Castillo, J.E. 1976. Natural Stream Purification Under Anaerobic Conditions, J. Water Poll. Contr. Fed. 48(7): 1753-1758.

$>$ Hall, C.A. y Porshing, T.A. 1990. Numerical Analysis of Partial Differential Equations . Precinte-Hall, Englewood Cliffs, N.J.

> Hanna, R.B., Campbell, S., Flug, M., and Scott, J. 1999. Using models to Evaluate System Management Flexibility on Water Quantity and Quality: Klamath River. Manuscript: submitted to ASCE July, 1999. 45 pp.

> Havnø, K., Madsen, M.N., and Dørge, J., 1995: MIKE 11- A Generalized River Modelling Package, in Computer Models of Watershed Hydrology, Vijay P. Singh, ed., Water Resources Publications, Highlands Ranch, Colorado

> Henze, M., Grady, C:P.L., Gujer, W., Marais, G.v.R. and Matsuo, T. 1987. Activated Sludge Model No. 1. Scientific and Technical Report No. 1, IAWPRC, London.

$>$ Herrero, 2002. Raúl Herrero Miñano. "Gestión del sistema de la cuenca del Júcar basada en riesgo de sequías con revisión de aportaciones aguas arriba del embalse de Tous". Ejercicio final de carrera en la titulación de Ingeniero de Caminos Canales y Puertos dirigido por D. Joaquín Andreu Alvarez, presentado en septiembre de 2002.

$>$ Hopkins, T., (ed.) 1983. Quantitative Analysis and Simulation of Mediterranean Coastal Ecosystem: The Gula of Naples, a case of study. Unesco Reports in Marine Science, 20. 158p.

$>$ Hydroqual, Inc. 1981. Development and application of the western Delta-Suisun Bay phytoplankton model. Prepared for the department of Water Resources, State of California, 5 chapters. 
Johnson, C.R., and Mercer, G., 1994: Modeling the water quality processes of the Chicago waterway. In Proceedings of the National Symposium on Water Quality, American Water Resources Association, Chicago, IL, November 6-10, 1994, p. 315.

$>$ Karpack y Palmer, 1992. L.M.Karpack and R.N.Palmer. "Use of interactive simulation environments for evaluation of water suppliy reliability". En Water resources Sessions at Water forum. Ed. M.Karamouz. 144-149 ASCE. New York, N.Y.

$>$ Labadie, J.W. 1988. Program MODSIM: River basin network flow model for the microcomputer. Department of Civil Engineering. Colorado State University, Ft. Collins, Colorado.

$>$ Labadie, 1992. J. W. Labadie . "Generalized river basin network flow model: Program MODSIM." Dept. of Civ. Engrg., Colorado State University, Fort Collins, Colorado.

$>$ Lang, G.A., and Fontaine, T.D., 1990: Modeling the fate and transport of organic contaminants in Lake St. Clair, Journal of Great Lakes Research, vol. 16(2), pp. 216-232.

$>$ Law, J.E., and Brown, M.L. (1989). Development of a large network model to evaluate yield of a proposed reservoir . Computerized decision support systems for water managers, J.W. Labadie et al., eds. ASCE, New York, 621-631.

$>$ Leoplod, L.B. and Maddock, T., 1953. The hydraulic geometry of stream channels and some physiographic implications. U.S. Geol. Surv. Prof. Paper no. 252.

$>$ Leopold, L.B. Wolman, M.G. and Miller, J.P., 1964, Fluvial Process in Geomorphology. Ed Freeman, San Francisco.

$>$ Little, K.W., and Williams, R.E., 1992: Least-squares calibration of QUAL2E. Water Environment Research 64(2): 179-185.

$>$ Loftis, B., Labadie, J. W., and Fontane, D.G. (1985). "Optimal operation of a system of lakes for quality and quantity." Computer applications in water resources, H.C. Torno ed., ASCE, New York, 693-702.

$>$ López, C., Andreu, A. y Solera, A. (1999). Desarrollo de módulo de calidad de aguas en simulación integral de sistemascomplejos de recursos hídricos.

Ejercicio Final de Carrera. ETSICCP. Valencia

$>$ Loucks et al., 1990. D.P.Loucks, K.A.Salewicz and M.R.Tailor "IRIS: an interactive river system simulation program, user's manual". Cornell University, Ithaca, N.Y. 
$>$ Lowney, Cynthia, L. 2000. Stream temperature variation in regulated rivers: Evidence for a spatial pattern in daily minimum and maximum magnitudes. Water Resources Research Vol. 36, No.10, 2947-2955.

$>$ Lowney, C.L., J.R. Lund, M.L. Deas. 1998. Optimization Modeling for River Restoration. Proceedings: Water Resources Planning and Environmental Regulations: Improving Coordination, American Society of Civil Engineers.

$>$ Lu, Z., April, G.C., Raney, D.C., and Schroeder, W.W., 1994: DO, BOD, and organic nitrogen transport in Weeks Bay, Alabama, In Proceedings of the National Symposium on Water Quality, American Water Resources Association, Chicago, IL, November 6-10, 1994, pp. 191-200.

$>$ Lung, W., and Larson, C.E., 1995: Water quality modeling of the upper Mississippi River and Lake Pepin, Journal of Environmental Engineering, vol. 121(10), pp. 691-699.

$>$ Mackay, R. and Riley, M. (1993). Chapter 10: Groundwater modeling. An introduction to water quality modeling. A. James, ed., Wiley, Chichester, U.K.

> Martin, 1983. Q.W.Martin. "Optimal operation of multiple reservoir systems". En Journal of Water Resources Planning and Management", 106(1), 58-74.

$>$ Martin, J.L. and S.C. McCutcheon. 1999. Hydrodynamics and Transport for Water Quality Models. Lewis Publishers, London.

$>$ Mays, 1996. L. W.Mays. "Water resources handbook", McGraw-Hill, New York.

$>$ McCutcheon, S.C. 1989. Water Quality Modeling, Volume I Transport and Surface Exchange in Rivers. CRC Press, Boca Raton, Florida.

$>$ Melching, C.S. and Yoon, C.G., 1996: Key sources of uncertainty in QUAL2E model of Passaic River, Journal of Water Resources Planning and Management, vol. 122, no. 2, pp. 105-114.

> Milhous, R.T., Updike, M.A., and Schneider D.M. 1989. Physical Habitat Simulation System (PHABSIM). Instream Flow Information Paper No. 11. U.S. Fish and Wildlife Service FWS/OBS-81/13 (revised).

$>$ MMA, 1999. Ministerio de Medio Ambiente. "Libro blanco del Agua en España".

> MMA, 2001a. "Plan hidrológico nacional: Vol. 3. Análisis de los sistemas hidráulicos". Ministerio de Medio ambiente.

$>$ MMA, 2001b. Ministerio de Medio Ambiente. "Real decreto legislativo 1/2001, de 20 de julio, por el que se aprueba el texto refundido de la Ley de Aguas". BOE de 24/07/2001 pp.26791-26817. 
Mohr, M., and Sandstroem, S., 1996: Comparison between measurements and simulations with WASP and the MIUU model, Swedish National Board for Industrial and Technical Development, Technical Report NUTEK-VIND-96-5, Stockholm, 53 p (NTIS Order number DE97706031INZ).

$>$ MS-Ingenieros. 2002. Estudio de utilización conjunta de los recursos hídricos superficiales y subterráneos en las cuencas media y baja de los ríos Júcar y Turia. Estudio realizado para la Oficina de Planificación Hidrológica de la CHJ. Ministerio de Medio Ambiente.

$>$ Nemerow, N. 1977. Aguas Residuales industriales. Teorías, aplicaciones y tratamientos. H. Blume Ediciones.

> Normandeu Associates. 1999. Lower Snake River temperature and biological productivity modelling. R-16031.007. Preliminary review draft. Prepared for the Department of the Army, Corps of Engineers, Walla Walla, Washington

$>$ NRA 1990. SIMCAT consent setting model - User guide. The national rivers authority's R\&D Programme, Project No. 022, Output Ref. P-61, NRA, Bristol, UK.

$>$ O'Connor, D.J. y Dobbins, W.E. 1962. Mechanism of Reareation in Natural Streams. ASCE Trans. 86(SA3):35-55

$>$ O'Connor, D.J. and Di Toro, D.M. 1970. Photosynthesis and oxygen balance in streams. J. Sanit. Engng. Div. ASCE 96:547

$>$ Orlob, G.T., 1983. "One-Dimensional Models for Simulation of Water Quality in Lakes and Reservoirs" in Mathematical Modeling of Water Quality in Lakes and Reservoirs, edited by G.T. Orlob, Wiley Interscience, New York.

$>$ Orlob, G.T., 1981. "Models for Stratified Impoundments" in Models for Water Quality Management, edited by A.K. Biswas, McGraw Hill, New York.

$>$ Paschal, J.E, Jr., and Mueller, D.K., 1991: Simulation of water quality and the effects of wastewater effluent on the South Platte River from Chatfield Reservoir through Denver, Colorado. USGS Water Resources Investigations Report 91-4016. US Geological Survey, Denver, CO.

$>$ Perez, 2000. Miguel A. Perez. "Modelación cuasidistribuida de los recursos hídricos y estudio de explotación del río Túria". Proyecto final de carrera para la titulación de Ingeniero de Caminos, Canales y Puertos presentado en la Escuela Técnica Superior de Ingenieros de C. C. y P. de valencia. Dirigido por Abel Solera.

$>$ Raphael, J.M. 1962. Prediction of temperature in rivers and reservoirs. J. Power Div. ASCE, (PO 2): 157-181. 
$>$ Rast, W. y Lee, G.F. 1978. Summary analysis of the north american (US portion) OECD eutrophication project: nutrient loading-lake response relationships and trophic state indices. USEPA, Corvallis environmental research laboratory, Corvallis, Or 454 pp. EPA-600/3-78-008.

> Reichert P., Borchardt, D., Henze, M., Rauch, W., Shanahan, P., Somlyódy, L., and Vanrolleghem, P.A. 2001. River Water Quality No.1. Scientific and Technical Report No. 12. IWA Task Group on River Water Quality Modeling. IWA Publishing

$>$ Ryan, P.J. and DRF. Harleman 1973. An analytical and experimental study of transient cooling pond behaviour. Report No. 161. Ralph M. Parsons Laboratory, Department of Civil Engineering, Massachusets Institute of Technology, Cambridge, MA.

$>$ Roesner, L.A., Giguere, P.R. and Evenson, D.E. 1981. Computer program documentation for the Stream Quality Model QUAL-II. Report EPA 600/9-81014, US EPA, Athens, GA.

> Salmon, M.E., Breitenbach, M.A., and Steiner, D.B. 1992. Report on Water Temperature Modeling on the Yuba River. Prepared for the Yuba County Water Agency. Prepared by Bookman-Edmonston Engineering, Inc., Sacramento, CA.

$>$ Shastry, J.S., Fan L.T. and Erickson L.E. 1973. Nonlinear parameter estimation in water quality modelling. Proceeding of American Society of Civil Engineers. Journal of environmental engineering division 99 (EE3):315-331.

$>$ Smith, V. H. y Shapiro, J. 1981. A retrospective look at the effects of phosphorous removal in lakes, in restoratio of lakes and inland waters. USEPA, Offic of water regulations and standards, Washington, D.C. EPA-440/5-81-010.

$>$ Snodgrass, W.J. 1974. A predictive Phosphorous model for lakes: Development and testing. Ph. D. Dissertation, University of North Carolina, Chapell Hill, NC.

> Solera, 1997. "Estudio sobre las políticas de explotación del sistema de la cabecera del Tajo y del Acueducto tajo-Segura" Proyecto final de carrera para la titulación de Ingeniero de Caminos, C. y P. presentado en la Esc. Téc. Sup. de Ing. de C. C. y P. de Valencia. Dirigido por Joaquín Andreu. Resumen publicado en "Premios Uralita. Obra Civil 1998. Conducciones, tratamiento de aguas y medio ambiente", Ed. Uralita.

Solera, A. 2004. Herramientas y métodos para la ayuda a la decisión en la gestión de recursos hídricos. Aplicación a las cuencas de los ríos Tajo y Júcar. Tesis Doctoral. Escuela Técnica Superior de Ingenieros de Caminos Canales y Puertos. Universidad Politécnica de Valencia. 
Sopeña, 2002. Francisco J. Sopeña. "Análisis del sistema del río Mijares y diseño de un plan de gestión óptimo para la mitigación de sequías". Proyecto final de carrera para la titulación de Ingeniero de Caminos, Canales y Puertos presentado en la Escuela Técnica Superior de Ingenieros de C. C. y P. de valencia. Dirigido por Abel Solera.

$>$ Streeter, W.H. and Phleps, E.B. 1925. A study of the pollution and natural purification of the Ohio river. Public Health Bulletin. 146, U.S. Public Health Service. Washington DC.

$>$ Strzepek and García, 1989. K.Strzepek and L.García. "MITSIM 2.1 river basin simulation model, user manual". Center for Advanced Decision Support for Water and Environmental Systems, University of colorado, Boulder, Colorado.

$>$ Tennessee Valley Authority (TVA). 1972. Heat and mass transfer between a water surface and the atmosphere. Water Resources Research Laboratory. Report No. 14. April. Tenesse Valley Authority, Division of water control planning, Engineering laboratory, Norris, TN.

$>$ Tetra Tech, 1995: Hydrodynamic and water quality mathematical modeling study of Norwalk Harbor, Connecticut: Final Report, Tetra Tech, Inc., Fairfax, VA.

$>$ Thomann, R.V. and J.A. Mueller. 1987. Principles of Surface Water Quality Modeling. HarperCollins Publishers, Inc. New York.

$>$ Thomas, H.A., Jr. 1948. Pollution load capacity of streams. Wat. Sewage Works 95,409 .

$>$ Tillman, D.H., 1992: Predicted water quality impacts from reducing flow out of Gavins Point Dam on the Missouri River, Technical Report WES/TR/EL-92-36, US Army Corps of Engineers Waterways Experiment Station, 184 p.

> TMConsult, 1995. Estado de eutrofización de los embalses de Alarcón, Arquillo de San Blas, Guadalest, Amatorio, Loriguilla y Beniarrés en el ámbito de la Confederación Hidrográfica del Júcar. UTE TMConsult Consultora de técnicas medioambientales S.A. con CINSA-EP. Ministerio de Obras Públicas, Transportes y Medio Ambiente. Dirección general de calidad de las aguas. Confederación Hidrográfica del Júcar

$>$ Tsihrintzis, V.A., Fuentes, H.R., and Rodriguez, L., 1995: Modeling water quality in low velocity sub-tropical streams, in Wrobel, L.C. and Latinopoulos, P. (eds), International Conference on Water Pollution: Modelling, Measuring and Prediction, Proceedings of the 3rd International Conference on Water Pollution, Porto Carras, Greece, 1995, Computational Mechanics, Inc., Billerica, MA., p. 171-178. 
$>$ TWDB 1971. Simulation of water quality in streams and canals. Theory and description of QUAL-1 mathematical modelling system. Report 128, Texas Water Development Board, Austin, TX.

$>$ UE-2000. Directiva 2000/60/CE del parlamento europeo y del consejo por la que se establece un marco comunitario de actuación en el ámbito de la política de aguas. UE. Parlamento Europeo, 23 de octubre de 2000.

$>$ USACE -HEC.(a) United States Army Corps of Engineers - Hydrologic Engineering Center. 1986. HEC5-Q Simulation of flood control and conservation Systems, Appendix on Water Quality Analysis.

$>$ USACE -HEC.(b). United States Army Corps of Engineers - Hydrologic Engineering Center. 1986. WQRRS Water Quality for River-Resrvoir systems, User's manual.

$>$ USACE -HEC. United States Army Corps of Engineers - Hydrologic Engineering Center. 1987. Water Quality Modeling of Reservoir System Operations Using HEC-5Q. Training Document No. 24. September.

$>$ USGS - US Geological Survey. 2001. PHABSIM for Windows User's Manual and Exercises. Midcontinent Ecological Science Center, USGS Open File Report 01-340, U.S. Department of the Interior.

$>$ Vollenweider, R.A. 1976. Advances in defining critical loading levels of phosphorous in lake eutrofication Mem. Ist. Ital. Idrobiol. 33:53-83.

$>$ Walton, R. and Webb, M., 1994: QUAL2E simulations of pulse loads, Journal of Environmental Engineering, vol. 120, no. 5, pp. 1017-1031.

$>$ Weiss, P., Labadie, J.W., and Baldo, M.L. (1997). Environmental impact evaluation using a river basin network flow model. Proc. $24^{\text {th }}$ annu. Water Resour. Conf., D.H. Merritt, ed., ASCE, New York. 74-81.

$>$ Wesolowski, E.A., 1995: Verification of Water-Quality Model to Simulate Effects of Discharging Treated Wastewater During Ice-Cover Conditions to the Red River of the North at Fargo, North Dakota, and Moorhead, Minnesota, USGS Water-Resources Investigations Report 95-4292, 20 p.

$>\mathrm{WHO}, 1992$. Water quality assesment to use of Biota, sediments and water in environmental monitoring. On the web www.who.org.UNESCO/WHO/UNEP

$>$ Vollenweider, R.A. 1968. Scientific funadamentals of the eutrophication of lakes and flowing waters, with particular reference to nitrogen and phosphorous as factors in eutrophication. OECD. Paris.

D Wlosinski, J.H. and Collins, C.D., 1985: Confirmation of the Water Quality Model CE-QUAL-R1 Using Data from Eau Galle Reservoir, Wisconsin, US 
Army Engineer Waterways Experiment Station Vicksburg, MS. Environmental Lab Final Report. Technical Report E-85-11, 72 p.

$>$ Wlosinski, J.H., 1985: Flux use for calibrating and validating models, Journal of Environmental Engineering, v 111, n 3, p 272-284.

$>$ Wool, T.A., Ambrose, R.B., Martin, J.L., and Comer, E.A., 2001. WASP Water Quality Simulation Program Version 6.0. Draft: User's manual. US Environmental Protection Agency - Region 4. Atlanta, GA.

$>$ Young, J.C., and Clark, J.W. 1965. Second order equation for BOD. J. Sanit Engng. Div. ASCE 91:43.

Zison, S.W., Mills, W.B., Diemer, D. y Chen C.W. 1978. Rates, Constants, and Kinetic Formulations in Surface Water Quality Modeling. U.S. Environmental Protection Agency, ORD, Athens, GA, ERL, EPA/600/3-78-105. 
ANEJO A. DATOS DEL MODELO. 



\section{DATOS DEL MODELO DE GESTIÓN}

\section{Simulacion Serie Histçrica. Larga}

Fecha y hora: $7 / 8 / 2004 \quad 6: 52: 31$

NO. DE A¥OS: 16 A¥O INICIAL: 1985
ECO DE DATOS: 11 ESCRITURA RESUMIDA: $0(0)$ SALIDA GRAFICOS: 16 SALIDA BALANCES: 0 SALIDA F. OBJ.: $0(0)$

HIPOTESIS: Periodo 1985 A 2001
NO. DE NUDOS SISTEMA FISICO:
NO. DE EMBALSES:
NO. DE TRAMOS DE RIO TIPO 1:

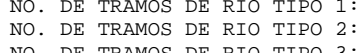
NO. DE CONDUCCIONES TIPO $4:$
NO. DE CONDUCCIONES TIPO $5:$
NO. DE APORTACIONES INTERMEDIAS:
NO. DE DEMANDAS CONSUNTIVAS:
No. DE DEMANDAS NO CONSUNTIVAS:
NO. INSTALACTONES RECARGA ARTIFICIA
NO. ACUIFEROS:
NO. BOMBEOS ADICIONALES
NO. RETORNOS:
NO. GRUPOS ISOPRIORITARIOS:
NO. INDICADORES DE RESTRICCION:

EMBALSES

* 1-EMB1-Alarcon

NUDO 2 NUDO VERTIDOS 2

COEF. FORMULA INFILTRACION: $A=0.0000 \mathrm{E}+00 \quad \mathrm{~B}=0.0000 \mathrm{E}+00 \quad \mathrm{C}=0.0000 \mathrm{E}+00$

$\begin{array}{lrrr}\text { ACUIFERO } & 0 & \text { NO. } & \text { ACCION ELEM. } \\ \text { VOL. INICIAL: } & 204.410 & \text { MAX. SUELTAS CONTROLADAS: } & 500.000\end{array}$

$\begin{array}{rrrrrrrrrrrrr} & \mathrm{N} & \mathrm{N} & \mathrm{D} & \mathrm{E} & \mathrm{F} & \mathrm{M} & \mathrm{A} & \mathrm{MY} & \mathrm{J} & \mathrm{JL} & \mathrm{AG} & \mathrm{S} \\ \text { VOL MAX } & 1112.000 & 1112.000 & 1112.000 & 1112.000 & 1112.000 & 1112.000 & 1112.000 & 1112.000 & 1112.000 & 1112.000 & 1112.000 & 1112.000 \\ \text { VOL OBJ } & 900.000 & 900.000 & 900.000 & 900.000 & 900.000 & 900.000 & 900.000 & 900.000 & 900.000 & 900.000 & 900.000 & 900.000\end{array}$

$\begin{array}{lrrrrrrrrrrrr}\text { VOL MIN } & 30.000 & 30.000 & 30.000 & 30.000 & 30.000 & 30.000 & 30.000 & 30.000 & 30.000 & 30.000 & 30.000 & 30.000\end{array}$

TABLA COTA-SUPERFICIE-VOLUMEN

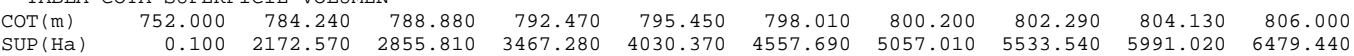

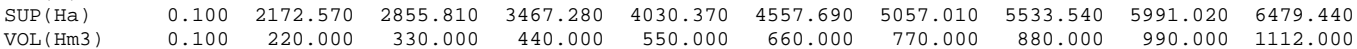

* 2-EMB2-Molinar

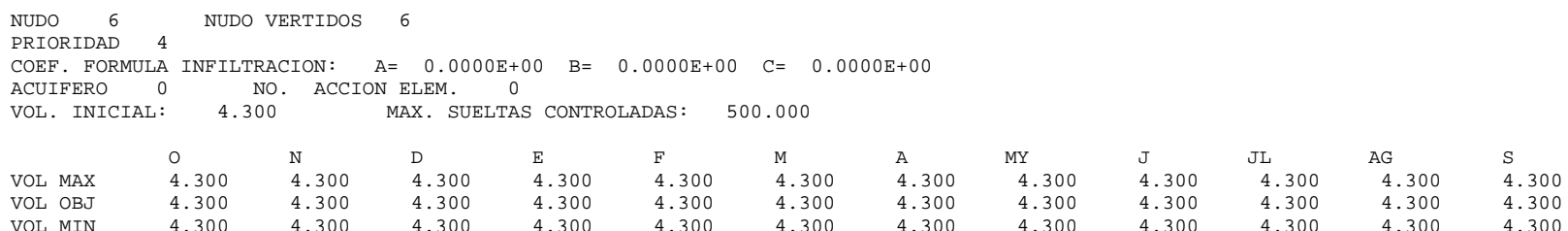




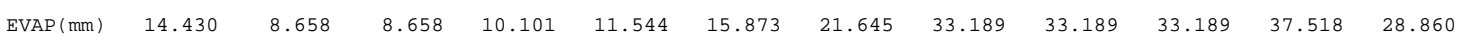

TABLA COTA-SUPERFICIE-VOLUMEN

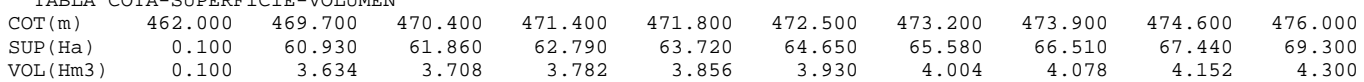

* 3-EMB3-Contreras

NUDO 9 NUDO VERTIDOS 9

COEF. FORMULA INFILTRACION: $A=0.3000 E+01 \quad B=0.8000 E-04 \quad C=0.1950 E+01$

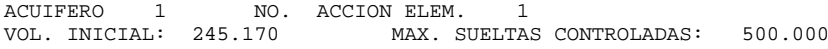

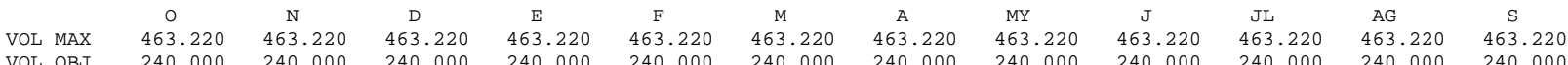

$\begin{array}{lrrrrrrrrrrrr}\text { VOL MAX } & 463.220 & 463.220 & 463.220 & 463.220 & 463.220 & 463.220 & 463.220 & 463.220 & 463.220 & 463.220 & 463.220 & 463.220 \\ \text { VVI OBJ } & 240.000 & 240.000 & 240.000 & 240.000 & 240.000 & 240.000 & 240.000 & 240.000 & 240.000 & 240.000 & 240.000 & 240.000 \\ \text { VOL MIN } & 15.000 & 15.000 & 15.000 & 15.000 & 15.000 & 15.000 & 15.000 & 15.000 & 15.000 & 15.000 & 15.000 & 15.000\end{array}$

$\begin{array}{lllllllllllll}\operatorname{EVAP}(\mathrm{mm}) & 100.000 & 55.000 & 40.000 & 40.000 & 50.000 & 105.000 & 110.000 & 150.000 & 200.000 & 240.000 & 215.000 & 150.000\end{array}$

TABLA COTA-SUPERFICIE-VOLUMFN

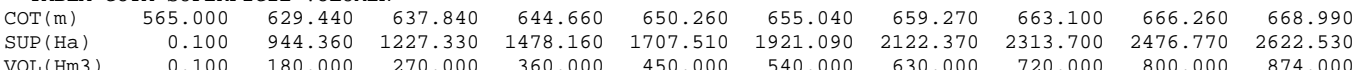

* 4-EMB4-Cortes

NUDO 12 NUDO VERTIDOS 12

COEF. FORMULA INFILTRACION: $A=0.0000 \mathrm{E}+00 \quad B=0.0000 \mathrm{E}+00 \quad \mathrm{C}=0.0000 \mathrm{E}+00$

$\begin{array}{llll}\text { ACUIFERO } 0 & \text { NO. ACCION ELEM. } & 0 \\ \text { VOL. INICIAL: } & 110.000 & \text { MAX. SUELTAS CONTROLADAS: } & 500.000\end{array}$

$\begin{array}{ccccccccccccc} & \mathrm{N} & \mathrm{N} & \mathrm{D} & \mathrm{E} & \mathrm{F} & \mathrm{M} & \mathrm{A} & \mathrm{MY} & \mathrm{J} & \mathrm{JL} & \mathrm{AG} & \mathrm{S} \\ \text { VOL MAX } & 111.000 & 111.000 & 111.000 & 111.000 & 111.000 & 111.000 & 111.000 & 111.000 & 111.000 & 111.000 & 111.000 & 111.000 \\ \text { VOL OBJ } & 100.000 & 100.000 & 100.000 & 100.000 & 100.000 & 100.000 & 100.000 & 100.000 & 100.000 & 100.000 & 100.000 & 100.000\end{array}$

$\begin{array}{llllllllllll}\text { VOL MIN } \quad 100.000 & 100.000 & 100.000 & 100.000 & 100.000 & 100.000 & 100.000 & 100.000 & 100.000 & 100.000 & 100.000 & 100.000\end{array}$

EVAP (mM) $100.000 \quad 57.000 \quad 60.00$

$\begin{array}{lcccccccccc}\text { COT (m) } & 220.000 & 314.420 & 316.260 & 318.050 & 319.740 & 321.300 & 322.580 & 323.650 & 324.640 & 325.720 \\ \operatorname{SUP}(\mathrm{Ha}) & 0.100 & 133.570 & 200.360 & 267.140 & 333.930 & 400.710 & 467.500 & 534.290 & 601.070 & 680.7000\end{array}$

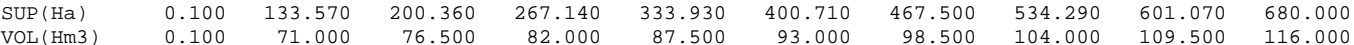

* 5-EMB5-Naranjero

NUDO 13 NUDO VERTIDOS 13

COEF. FORMULA INFILTRACION: $A=0.0000 \mathrm{E}+00 \quad B=0.0000 \mathrm{E}+00 \quad \mathrm{C}=0.0000 \mathrm{E}+00$

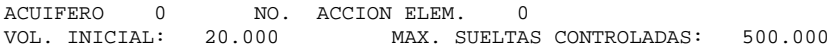

$\begin{array}{rrrrrrrrrrrrr} & 0 & \text { N } & \text { D } & \text { E } & \text { F } & \text { M } & \text { A } & \text { MY } & \text { J } & \text { JL } & \text { AG } & \text { S } \\ \text { VOL MAX } & 20.000 & 20.000 & 20.000 & 20.000 & 20.000 & 20.000 & 20.000 & 20.000 & 20.000 & 20.000 & 20.000 & 20.000 \\ \text { VOL OBJ } & 18.000 & 18.000 & 18.000 & 18.000 & 18.000 & 18.000 & 18.000 & 18.000 & 18.000 & 18.000 & 18.000 & 18.000\end{array}$

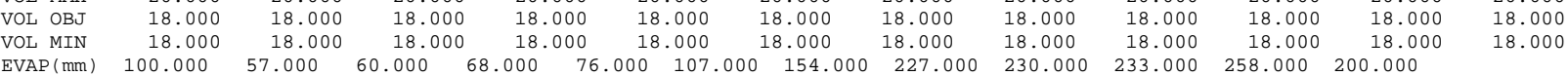

TABLA COTA-SUPERFICIE-VOLUMEN

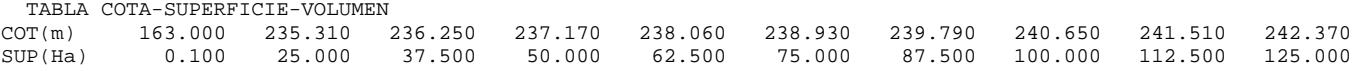

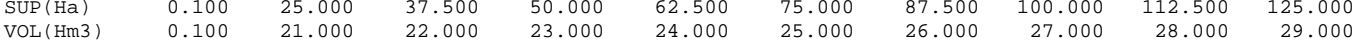




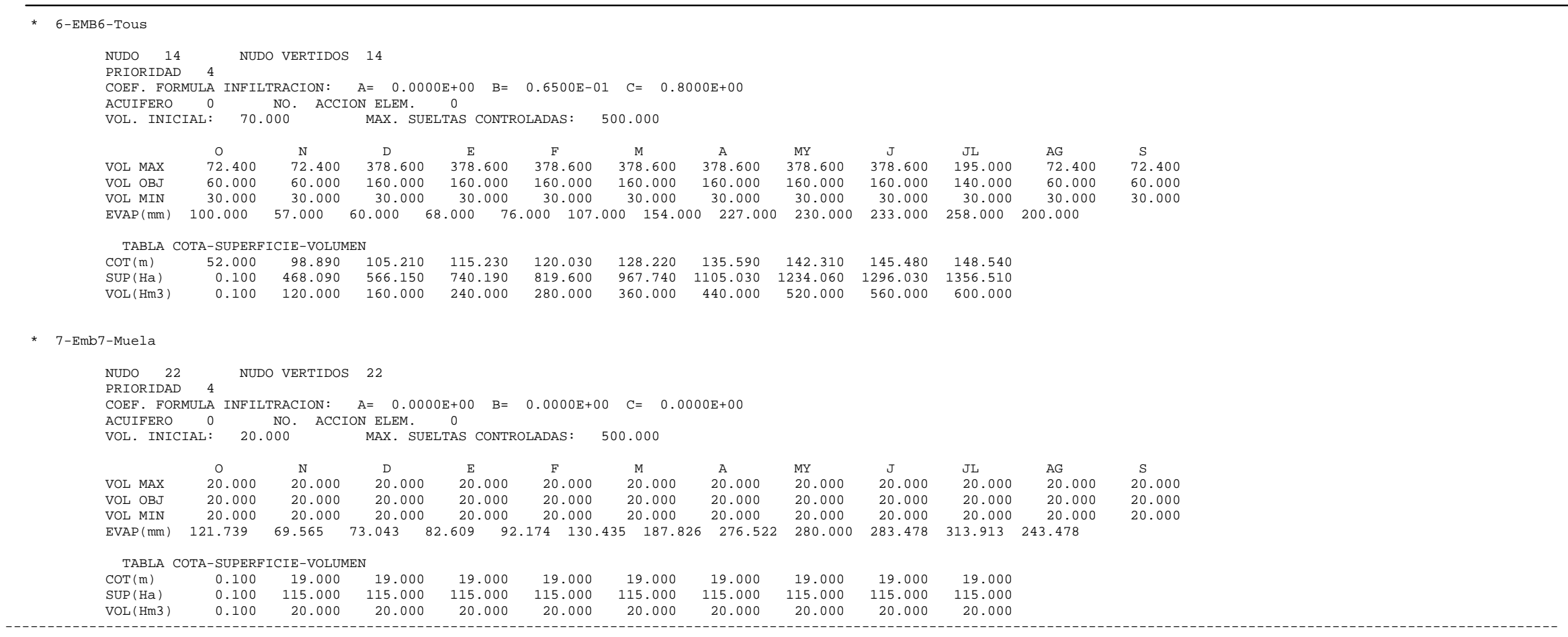

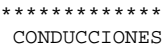

$\stackrel{\operatorname{TIPO} 1}{======}$

* 1-Cabecera Jucar NUdo InIC. 1 NUdo Final 2 I. COSTE: 0 COste: 0.

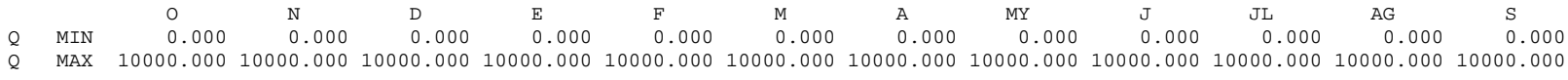

* 2-Jfcar-1 NUDO InIC. 2 NUDO FINAL 3 I. COSTE: 0 Coste: 0. PRIORIDAD: 0 UMBRAL DEFICIT 0.0

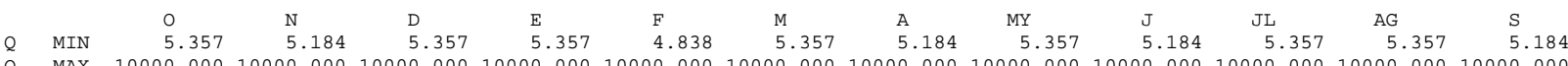

* 3-Jucar-3 NUDo Inic. 4 NUDO Final 5 I. COSTE: 0 COSTE: 0.

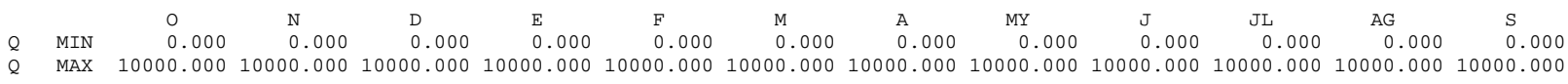


* 4-Jucar-4 NUDO INIC. 5 NUDO FINAL $6 \quad$ I. COSTE: 2 COSTE: 2. PRIORIDAD: 0 UMBRAL DEFICIT 1.0

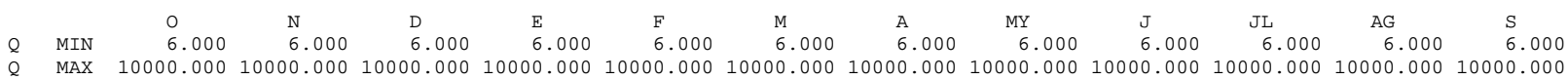

* 5-Jucar-5 NUDO INIC. 6 NUDO FINAL $7 \quad$ I. COSTE: 1 COSTE: 0. PRIORIDAD: 0 UMBRAL DEFICIT 1.0

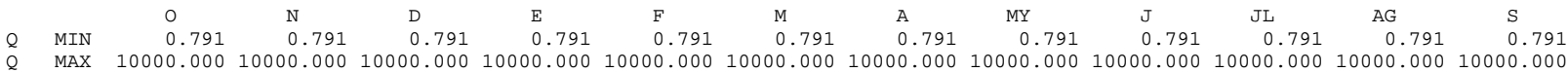

* 6-Jucar-6 NUdO InIC. 7 NUdo FinAl $12 \quad$ I. COSTE: $0 \quad$ COSTE: 0.

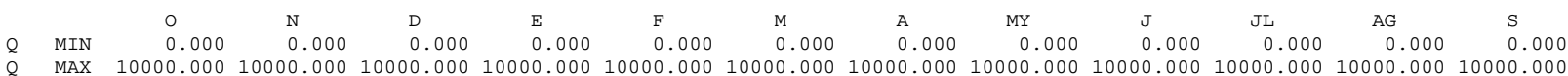

* 7-Cabecera Cabriel NUDO INIC. 8 NUDO FINAL $9 \quad$ I. COSTE: 0 COSTE: 0.

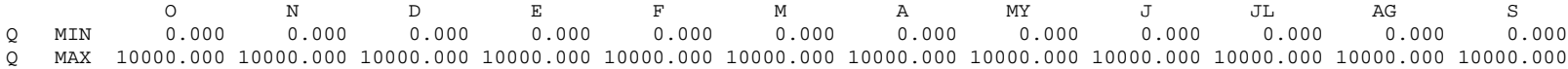

* 8-Cabriel-2 NUdo inic. 10 NUdo final 11 I. Coste: 0 Coste: 0.

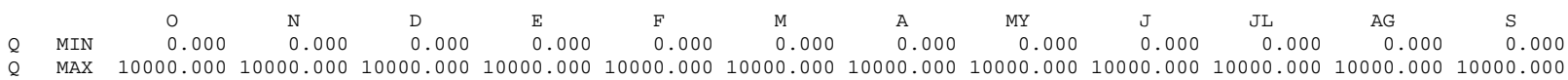

* 9-Cabriel-3 NUDO InIC. 11 NUDO FINAL 12 I. COSTE: 0 COSTE: 0.

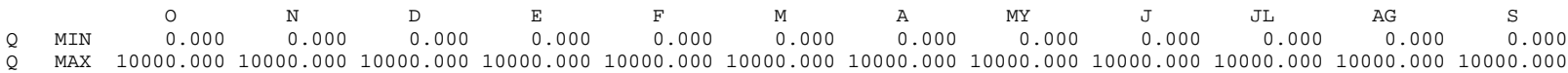

* 10-Cortes-Naranjero NUdo INIC. 12 NUDO FINAL $13 \quad$ I. COSTE: 0 COSTE: 0.

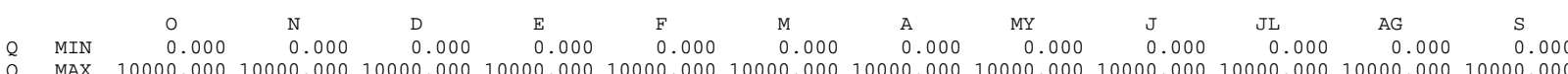

* 11-Jucar-7 NUDO INIC. 13 NUDO FINAL 14 I. COSTE: 0 COSTE: 0. PRIORIDAD: 0 UMBRAL DEFICIT 1.0

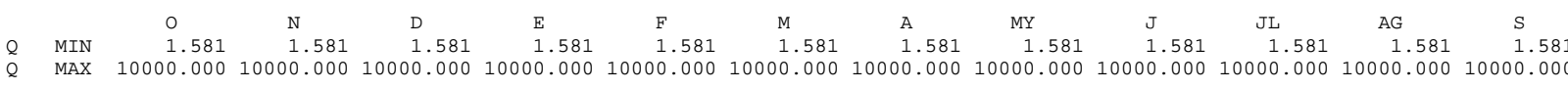

* 12-Salidas tous Rio NUdo INIC. 14 NUDO FInAL $15 \quad$ I. COSTE: 1 COSTE: 0. PRIORIDAD: 0 UMBRAL DEFICIT 1.0

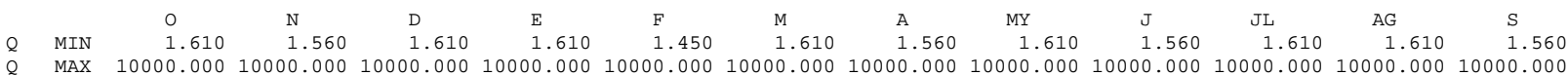

* 13-Antella-Sellent NUDO INIC. 15 NUDO FINAL 16 I. COSTE: 0 COSTE: 0. PRIORIDAD: 0 UMBRAL DEFICIT 1.0

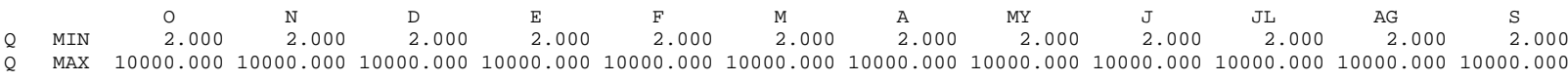


* 14-Sellent-Albaida

NUDO INIC. 16 NUDO FINAL 35 I. COSTE: 0 COSTE: -1.

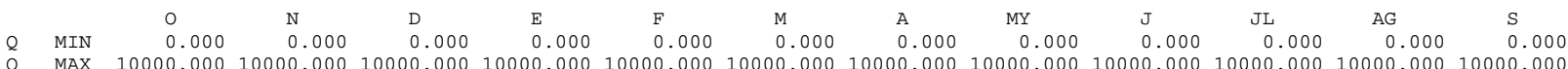

* 15-Albaida-Alzira

NUDO INIC. 35 NUDO FINAL 36 I. COSTE: 0 COSTE: 0.

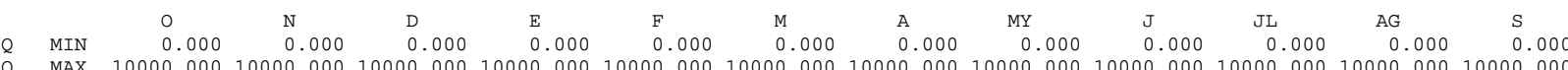

16-Alzira-Verde

NUDO INIC. 36 NUDO FINAL 37 I. COSTE: 0 COSTE: 0.

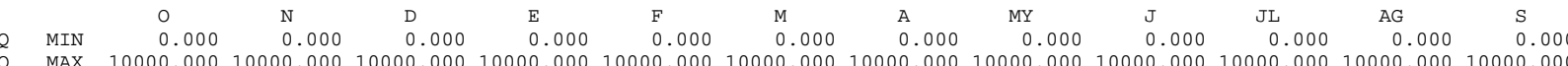

* 17-Verde-Magro

NUDO INIC.

NUDO FINAL 38 I. COSTE: 0 COSTE: 0

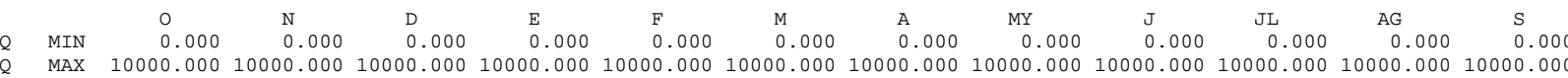

* 18-Magro-AzudSueca

NUDO INIC.

38 NUDO FINAL 17 I. COSTE: 0 COSTE: 0.

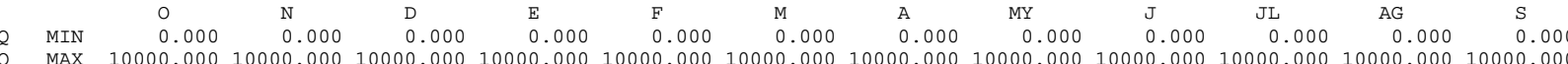

* 19-AzudSueca-AzudCullera NUDO INIC. 17 NUDO FINAL $18 \quad$ I. COSTE: 0 COSTE: 0.

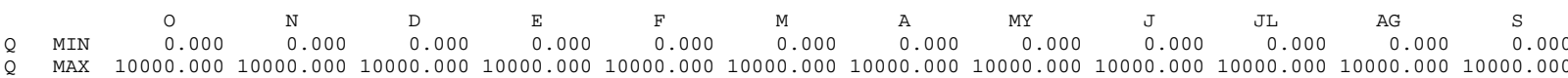

* 20-AzudCullera-AzudMarquesa NUDO INIC. 18 NUDO FINAL 19 I. COSTE: 0 COSTE: 0. PRIORIDAD: 0 UMBRAL DEFICIT 1.0

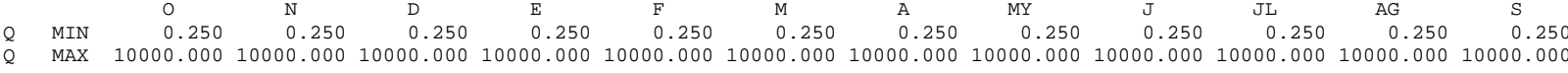

* 21-Salidas Totales Mar NUDO INIC. 19 NUDO FINAL 0 I. COSTE: 0 COSTE: 0.

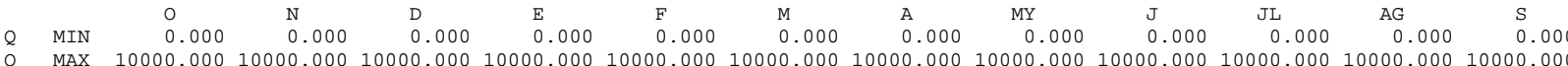

* 22-Canal ats NUdo inic. 2 NUdo final 20 I. COSTE: 0 COSTE: 0.

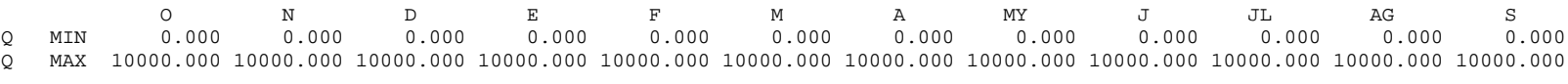

* 23-Cortes-Muela NUDO INIC. 12 NUDO FINAL 22 I. COSTE: 0 COSTE: 0.

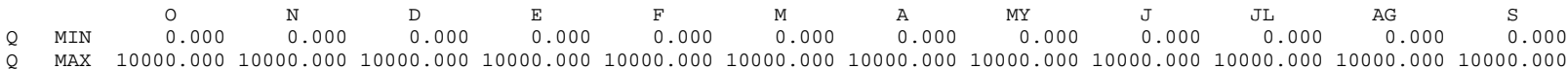




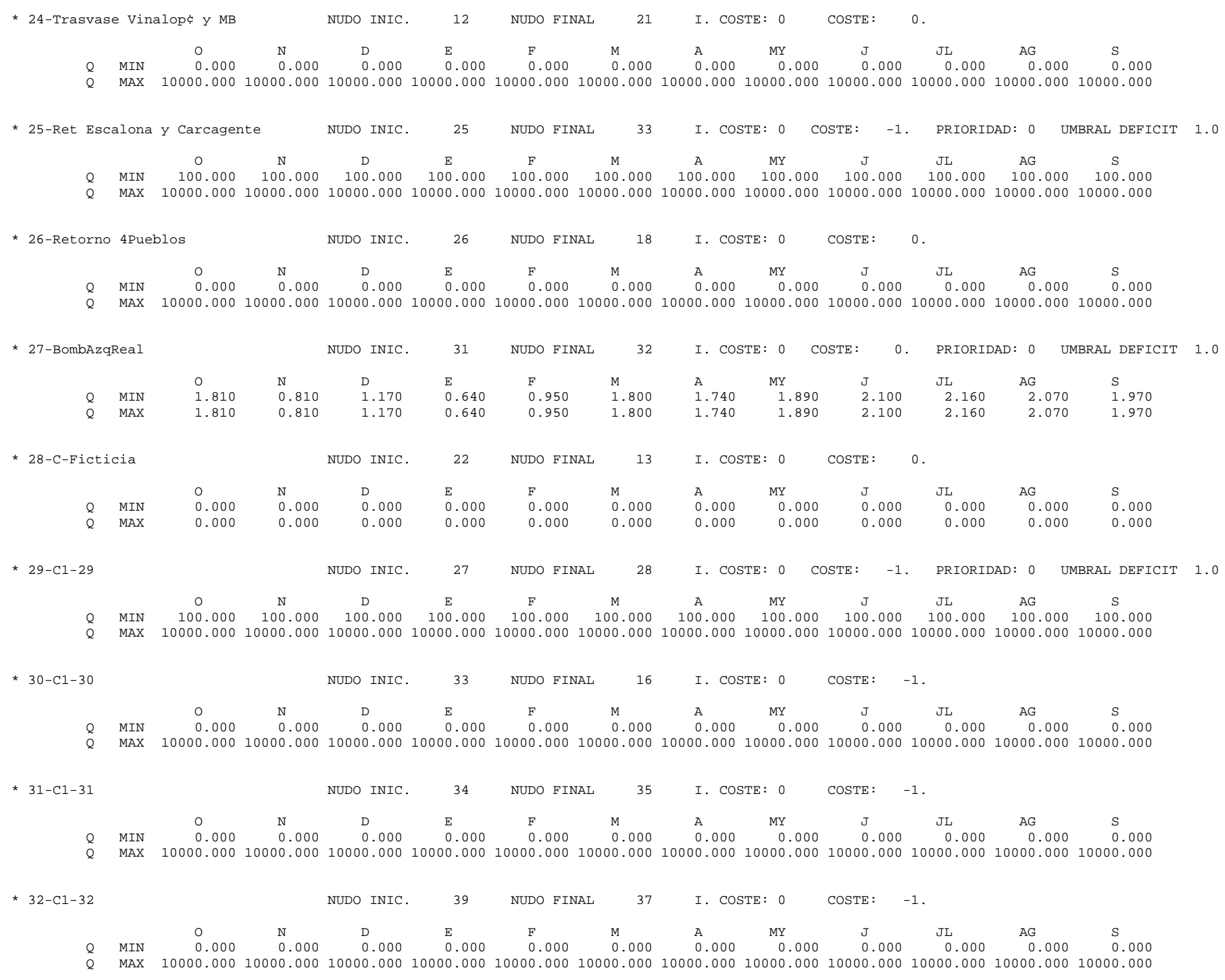




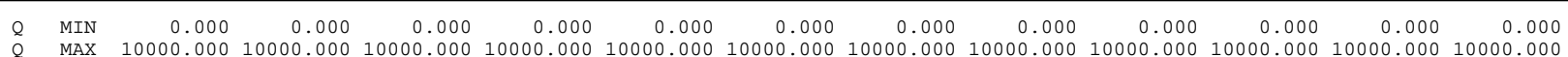

* 34-Vertidos_Tous_Mar

NUDO INIC.

14 NUDO FINAL 19 I. COSTE: 0 COSTE: 0.

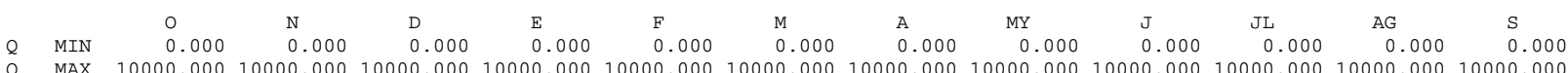

* 35-Ac Real-1

NUDO INIC. 15 NUDO FINAL 41 I. COSTE: 0 COSTE: -1.

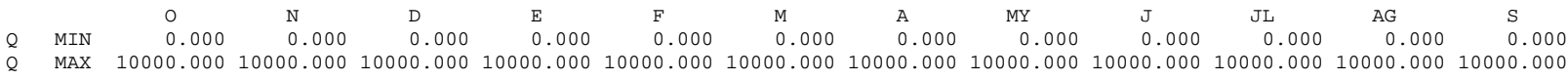

* 36-Ac Real-2

NUDO INIC.

41 NUDO FINAL

42 I. COSTE: 0 COSTE: -1.

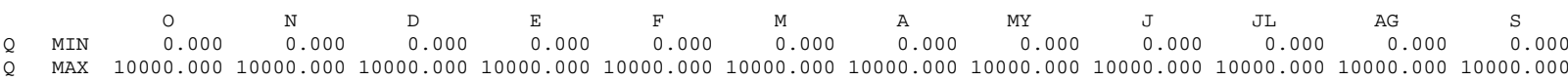

* 37-Ac Real-Albufera $\quad$ NUDO INIC. 42 NUDO FINAL $30 \quad$ I. COSTE: 0 COSTE: -1.

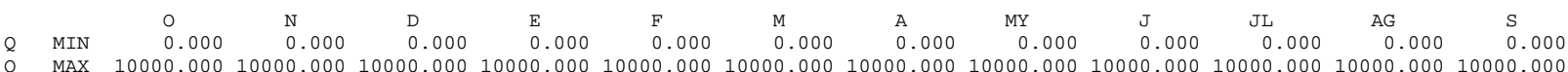

TIPO 2

* 1-Canal J.T.1 NUDO INIC. $14 \quad$ NUDO FINAL 23

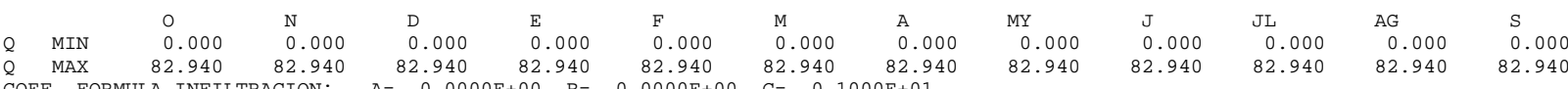

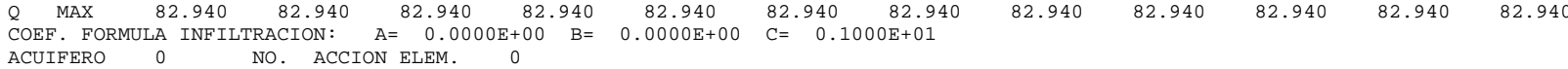

* 2-Canal J.T. 2 NUDO INIC. 23 NUDO FINAL 24

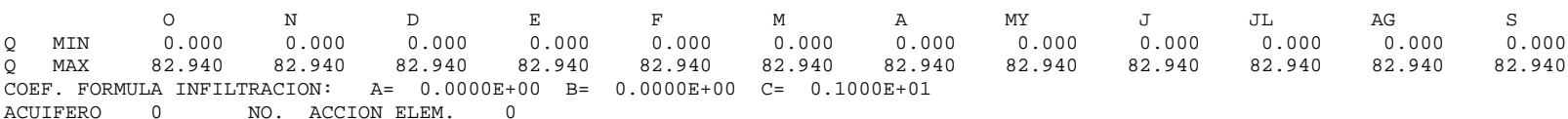

NUDO INIC. $28 \quad$ NUDO FINAL 39

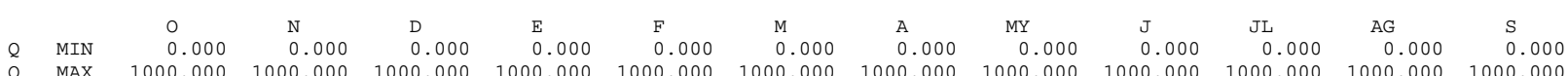
COEF. FORMULA INFILTRACION: $A=0.0000 \mathrm{E}+00 \quad \mathrm{~B}=0.4500 \mathrm{E}+00 \quad \mathrm{C}=0.1000 \mathrm{E}+01$

$\begin{array}{lll}\text { COEF. FORMULA INE ILTRACION: A A } & \text { A. } \\ \text { ACUIFERO } 5 & \text { NO. ACCION ELEM. }\end{array}$

* $4-\mathrm{C} 2-4$

NUDO INIC. 29 NUDO FINAL 40

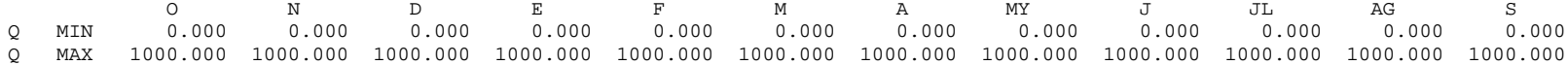


COEF. FORMULA INFILTRACiON: $A=0.0000 E+00 \quad B=0.4500 E+00 \quad C=0.1000 E+01$

TIPO 3

* 1-Conexiçn Jfcar-Mancha

NUDO INIC.

NUDO FINAL

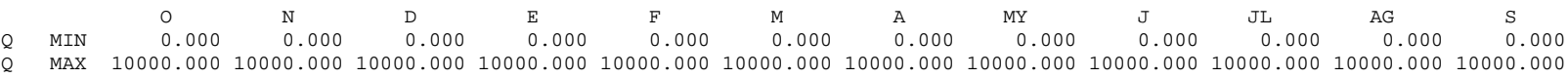

no. Acuifero 3 no. param. Control 2 accion elem.

* 2-Cabriel-1 NUDO INIC. 9 NUDO FINAL $10 \quad$ PRIORIDAD: 0 UMBRAL DEFICIT: 0.0

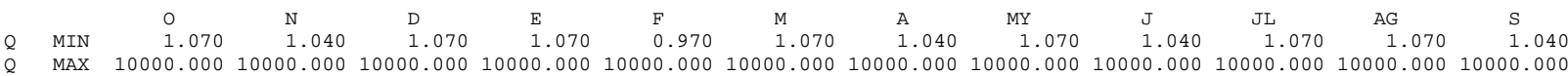

no. ACUtFero 1 No. PARAm. CONTrol 2 ACCion Elem.

* 3-Salidas Albufera NUDO INIC. 30 NUDO FINAL 0 PRIORIDAD: 0 UMBRAL DEFICIT: 0.0

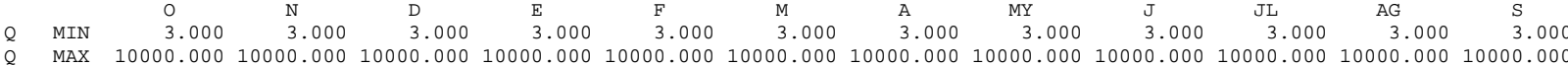

no. ACUifero 5 no. PARAm. CONTRol 2 ACCIon ELem.

* $4-\mathrm{C} 3-4$

NUDO INIC. 25 NUDO FINAL 34

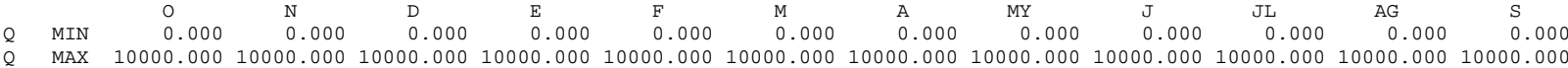

No. ACUIFERO 2 NO. PARAm. CONTROL 2 ACCION ELEM. 1

* 5-C3-5 NUDO INIC. 27 NUDO FINAL 29

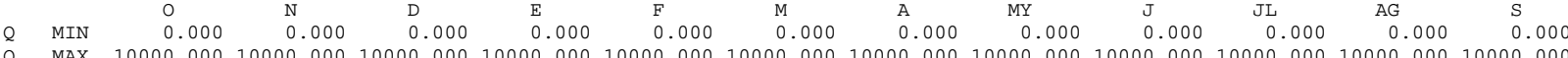

No. ACUIFERO 4 No. PARAm. CONTROL 2 ACCION ELEm.

* 1-C.N. Cofrentes

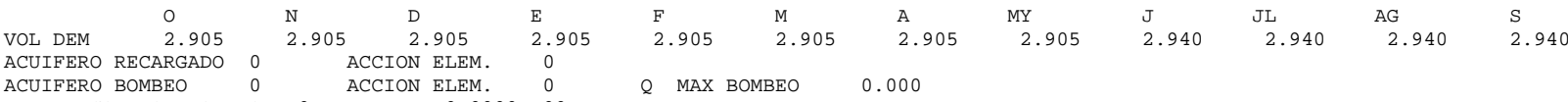

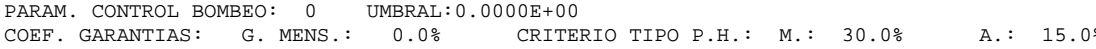

A-8 


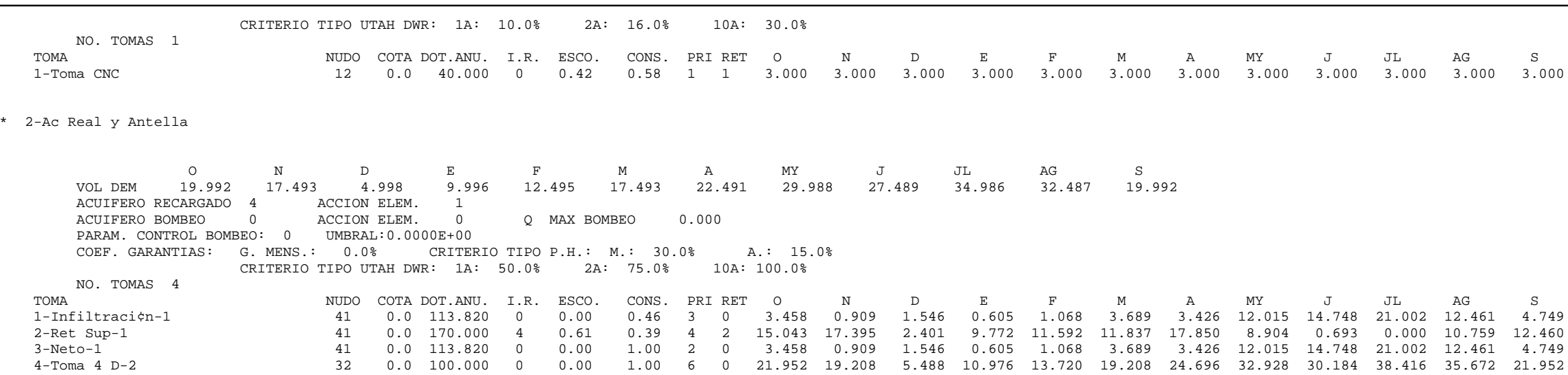

* 3-Escalona y Carcagente

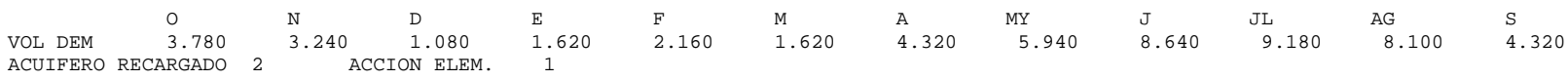

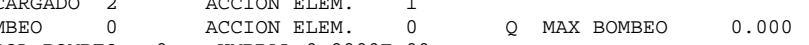

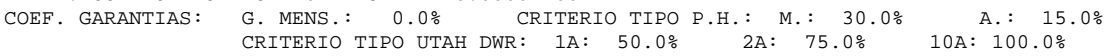

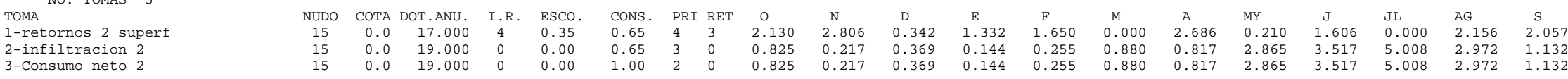

* 4 -Sueca

$\begin{array}{lllllllllllll} & 0 & \text { N } & \text { D } & \text { E } & \text { F } & \text { M } & \text { A } & \text { MY } & \text { J } & \text { JL } & \text { AG } & \text { S } \\ \text { VOL DEM } & 2.784 & 2.784 & 2.784 & 2.088 & 1.044 & 1.740 & 2.436 & 5.568 & 4.176 & 4.176 & 3.828 & 1.392\end{array}$

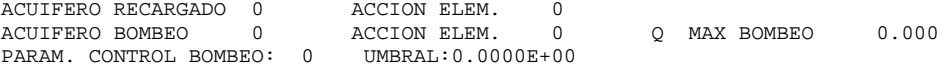

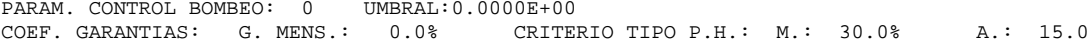

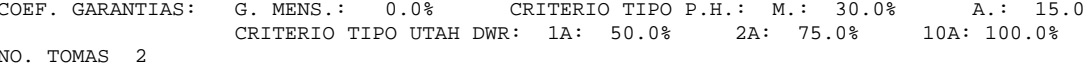

1 -Principsueca
2-CompSueca

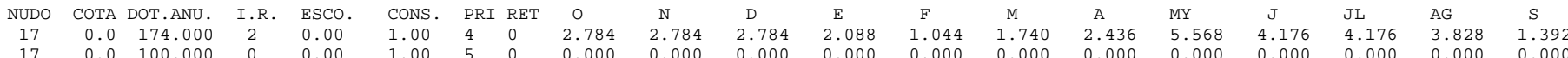

* 5-Cuatro Pueblos

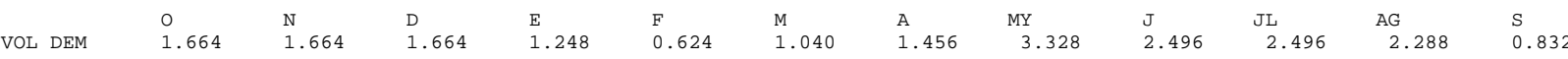

$\begin{array}{lllllll}\text { ACUIFERO RECARGADO } & 0 & \text { ACCION ELEM. } & 0 & & & \\ \text { ACUIFERO BOMBEO } & 0 & \text { ACCION ELEM. } & 0 & \varrho & \text { MAX BOMBEO } & 0.000\end{array}$

$\begin{array}{llll}\text { COEF. GARANTIAS: G. MENS.: } 0.0 \% & \text { CRITERIO TIPO P.H.: M.: } 30.0 \% & \text { A.: } 15.0 \% \\ \text { CRITERIO TIPO UTAH DWR: } 1 \mathrm{~A}: 50.0 \% & \text { 2A: } 75.0 \% & 10 \mathrm{~A}: 100.0 \%\end{array}$

томА

O. TOMAS 


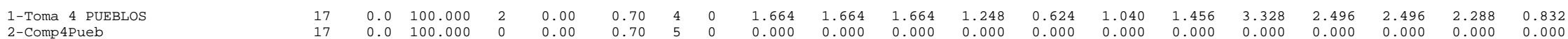

* 6-cullera

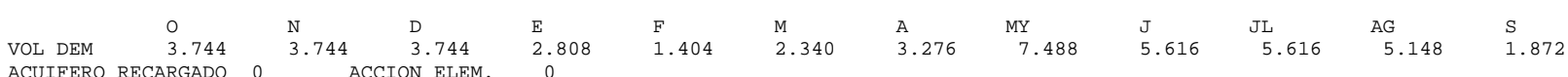

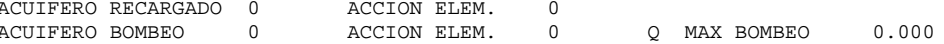

COEF. GARANTIAS: G. MENS.: $0.0 \%$ CRITERIO TIPO P.H.: M. : $30.0 \%$ A.: $15.0 \%$

NO. TOMAS 2

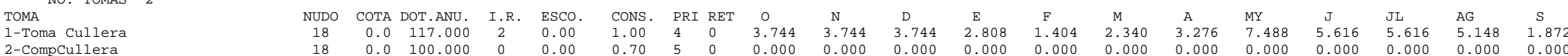

7-Riegos Canal J-T

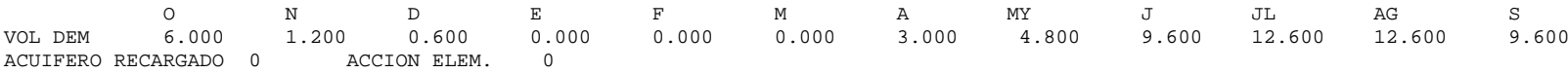

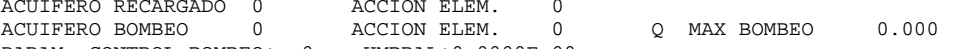

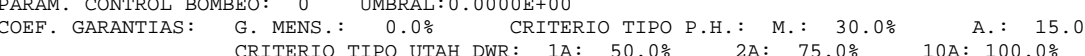

NO, TOMAS 1 -

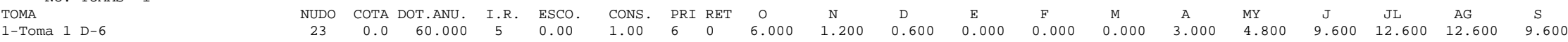

* 8-Valencia

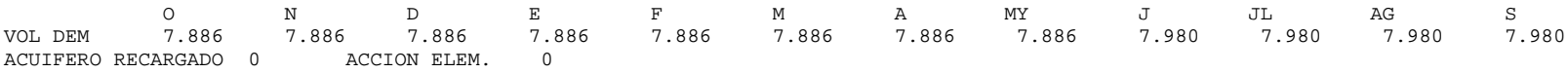

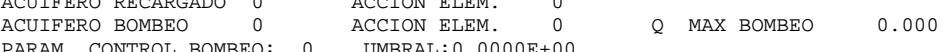

$\begin{array}{lll}\text { PARAM. CONTROL BOMBEO: } 0 & \text { UMBRAL: } 0.0000 \text { E+00 } \\ \text { COEF. GARANTIAS: G. MENS.: } & 0.0 \% & \text { CRITERIO TIPO P.H.: }\end{array}$

NO. TOMAS 1 - CRT

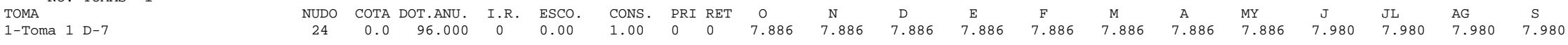

* 9-Sagunto

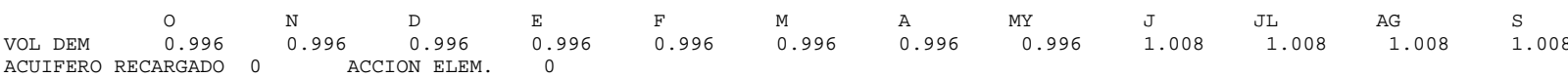

ACUIFERO BOMBEO 0
PARAM. CONTROL BOMBEO: $\quad \begin{gathered}\text { ACCION ELEM. } \\ \text { UMBRAL: } 0.0000 \text { E }+00\end{gathered}$

PARAM. CONTROL BOMBEO:

NO. TOMAS 1 CRITERIO TIPO UTAH DWR: $10.0 \%$ 2A: $16.0 \% \quad 10 \mathrm{~A}: 30.0 \%$

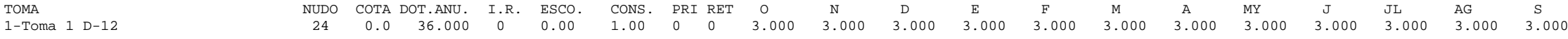

* 10-Albecete 


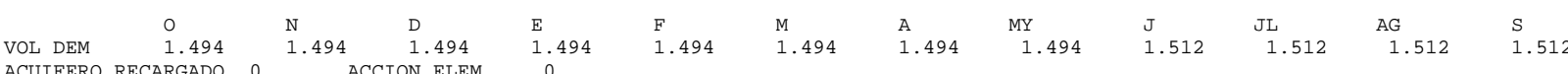

ACUIFERO BOMBEO 0 ACCION ELEM. 0 \& MAX BOMBEO 0.000

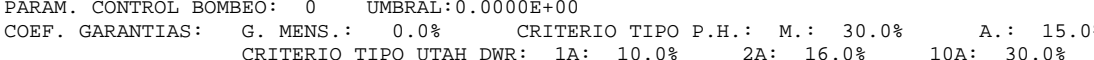

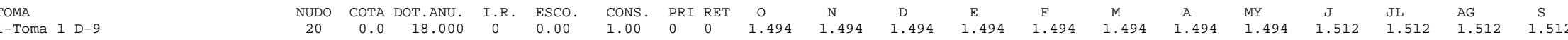

* 11-Marina Baja ATS

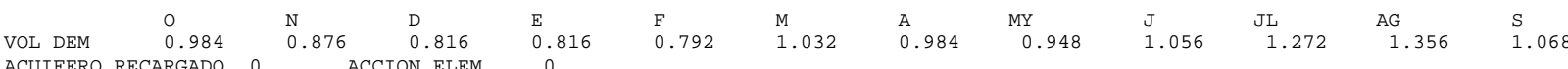

ACUIFERO BOMBEO O ACCION ELEM. 00 Q MAX BOMBEO 0.000

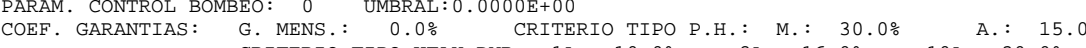

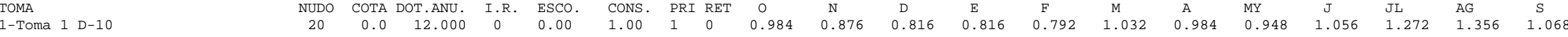

* 12-Sustitucion Mancha

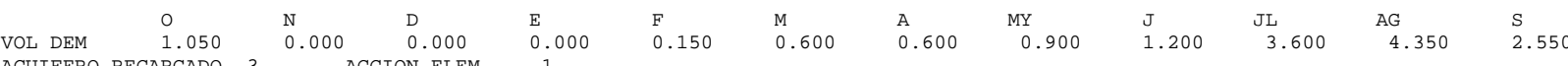

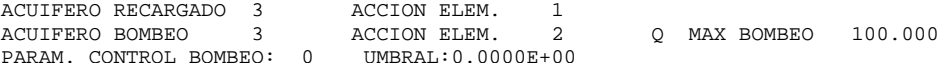

COEF. GARANTIAS: G. MENS.: $0.0 \%$ CRITERIO TIPO P.H.: M.: $30.0 \%$ A.: 15.0

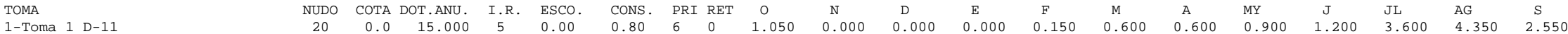

* 13-Taibilla

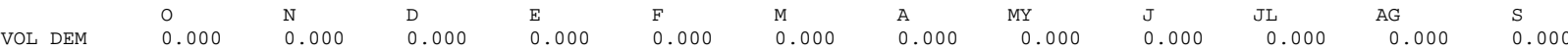

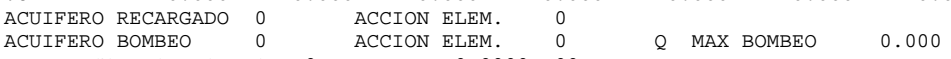

COEF. GARANTIAS: G. MENS.: $0.0 \%$ CRITERIO TIPO P.H.: M.: $30.0 \%$ A.: 15.08

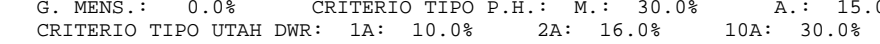

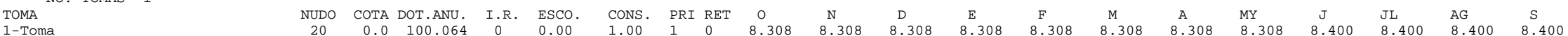

* 14-Bombeos Ac Mancha

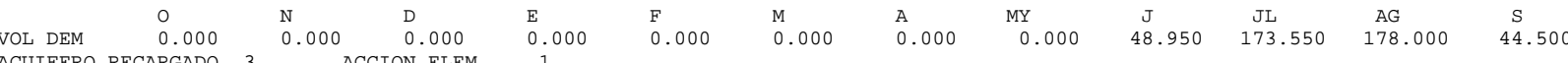

$\begin{array}{llll}\text { ACUIFERO RECARGADO } & 3 & \text { ACCION ELEM. } & 1 \\ \text { ACUIFERO BOMBEO } & 3 & \text { ACCION ELEM. } & 2\end{array}$

PARAM. CONTROL BOMBEO: 0 UMBRAL: $0.0000 \mathrm{E}+00$ -

$\begin{array}{llll}\text { COEF. GARANTIAS: G. MENS.: } 0.0 \% & \text { CRITERIO TIPO P.H.: M.: } 30.0 \% & \text { A.: } 15.0 \% \\ \text { CRITERIO TIPO UTAH DWR: } 1 \mathrm{~A}: 50.0 \% & \text { 2A: } 75.0 \% & 10 \mathrm{~A}: 100.0 \%\end{array}$

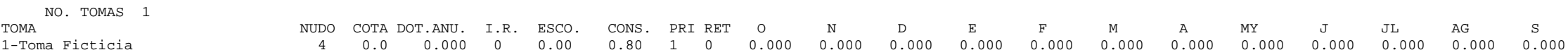


Integración de la modelación de la calidad del agua en un sistema de ayuda a la decisión para la gestión de recursos hídricos.

* 15-Abast Vinalop'

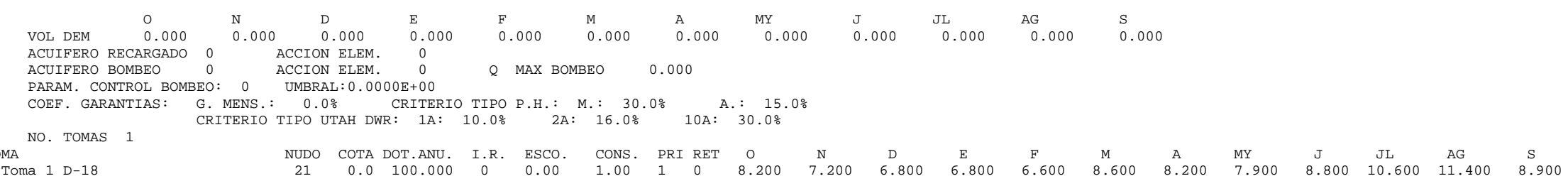

* 16-Abast Marina Baja

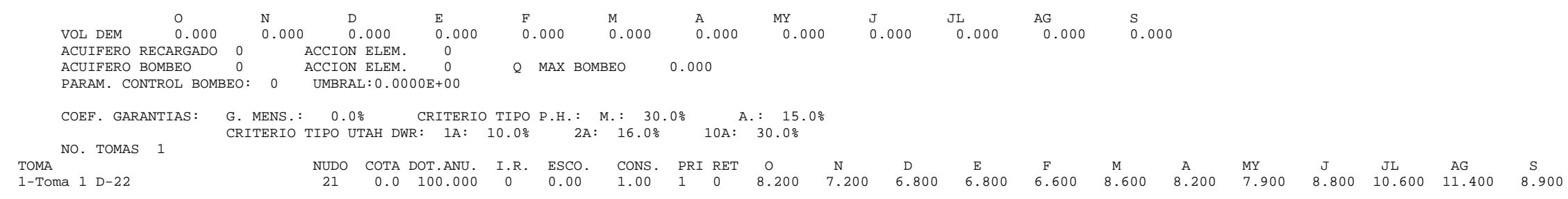

* 17-Nuevos regadios Cuenca

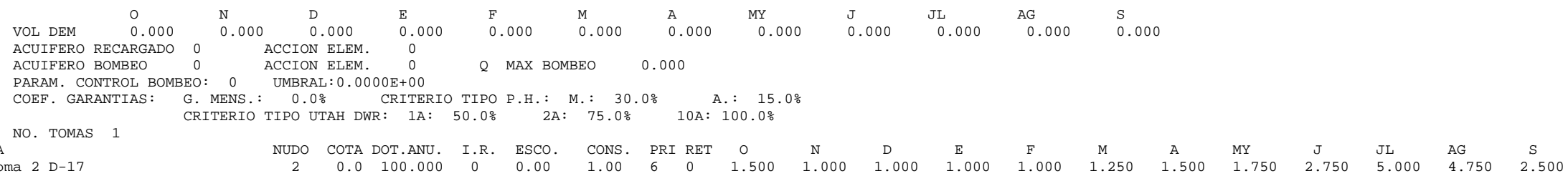

* 18-Reg Cabecera J£car

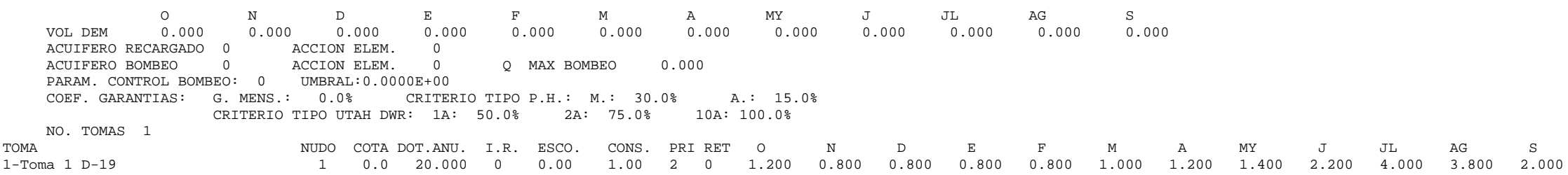

* 19-Reg Cabecera Cabriel

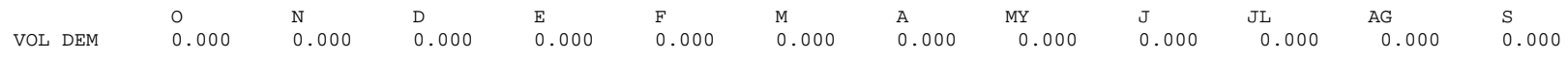

A-12 


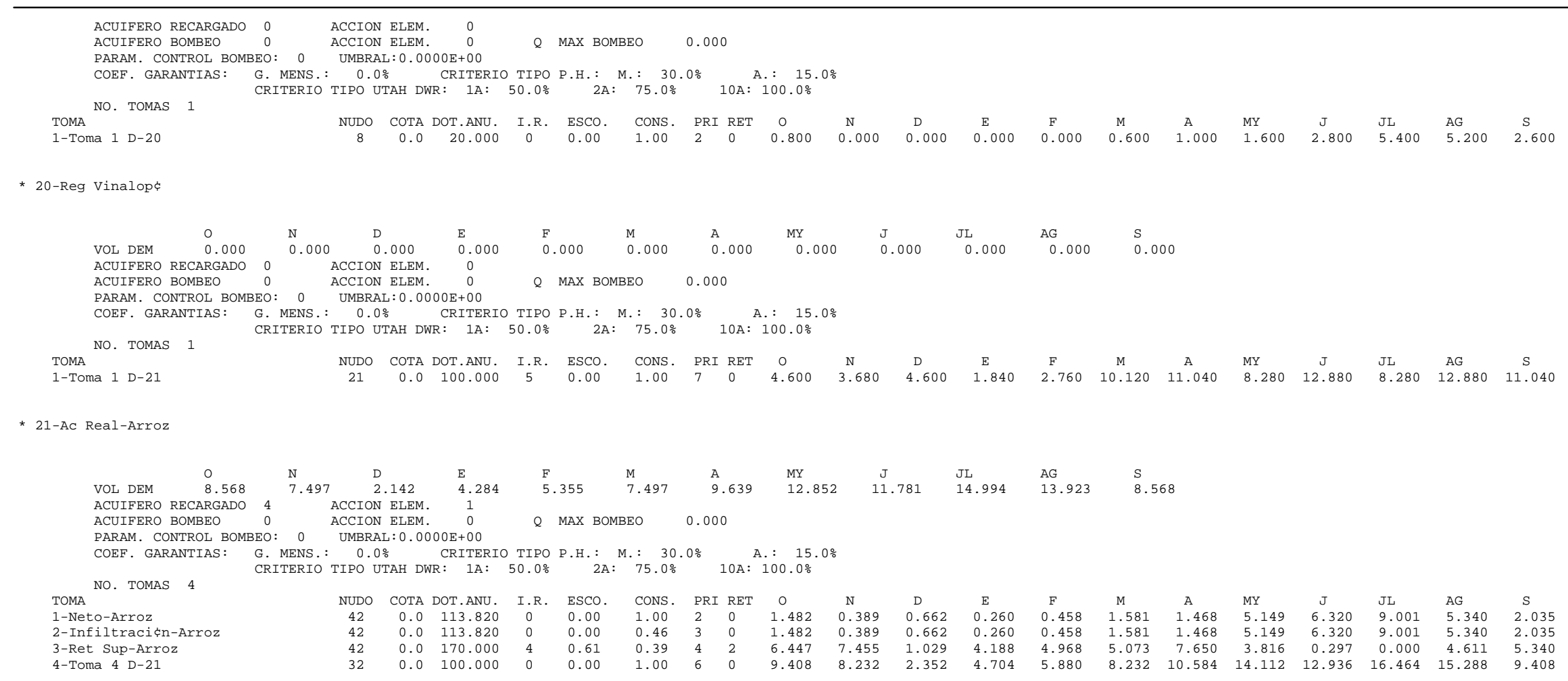

* 22-Sueca-Arroz

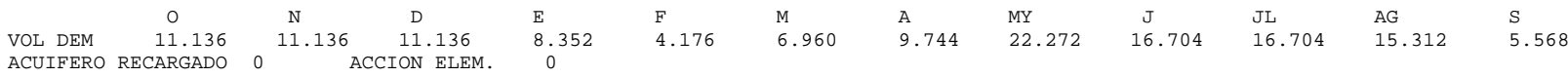

ACUIFERO BOMBEO 0 ACCION ELEM. 0 Q MAX BOMBEO 0.000

$\begin{array}{llll}\text { COEF. GARANTIAS: G. MENS.: } 0.0 \% & \text { CRITERIO TIPO P.H.: M.: } 30.0 \% & \text { A.: } 15.0 \% \\ \text { CRITERIO TIPO UTAH DWR: } 1 \mathrm{~A}: 50.0 \% & \text { 2A: } 75.0 \% & 10 \mathrm{~A}: 100.0 \%\end{array}$

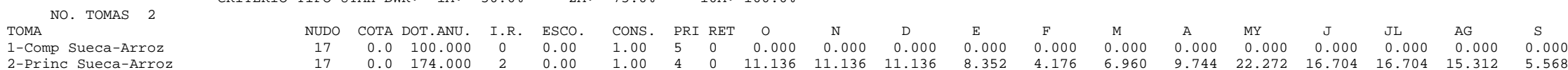

* 23-Cullera-Arroz

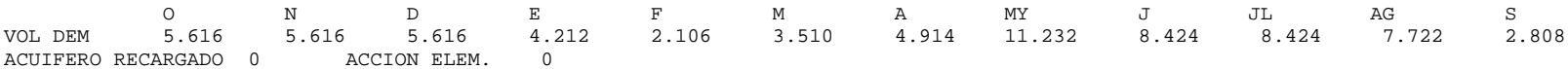

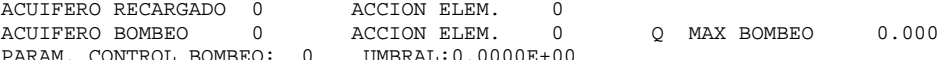

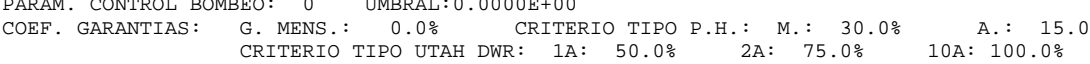




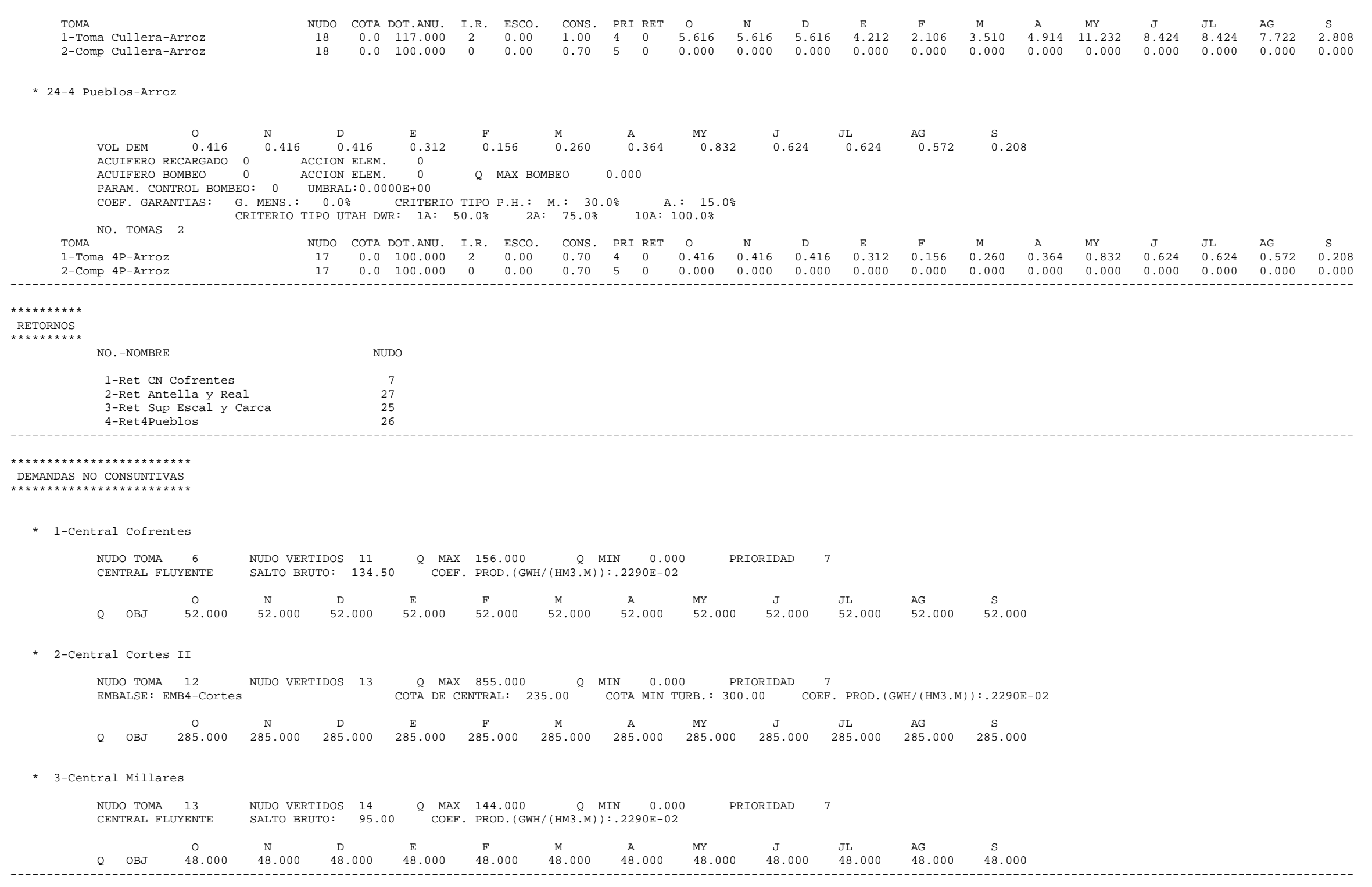

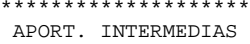


-APO1. Alarc $\mathrm{n}_{-}$

2-Apo2. Alarçn-Molinar

3-APO3. Contreras

4-Confluencia
5 -Apo.Sellent

6-Apo.Albaida

7-Apo. Verde

8-Apo.Magro

$\begin{array}{rr}1 & 1 \\ 3 & 2 \\ 8 & 3 \\ 10 & 4 \\ 33 & 5 \\ 34 & 6 \\ 39 & 7 \\ 40 & 8\end{array}$

ACUIFEROS

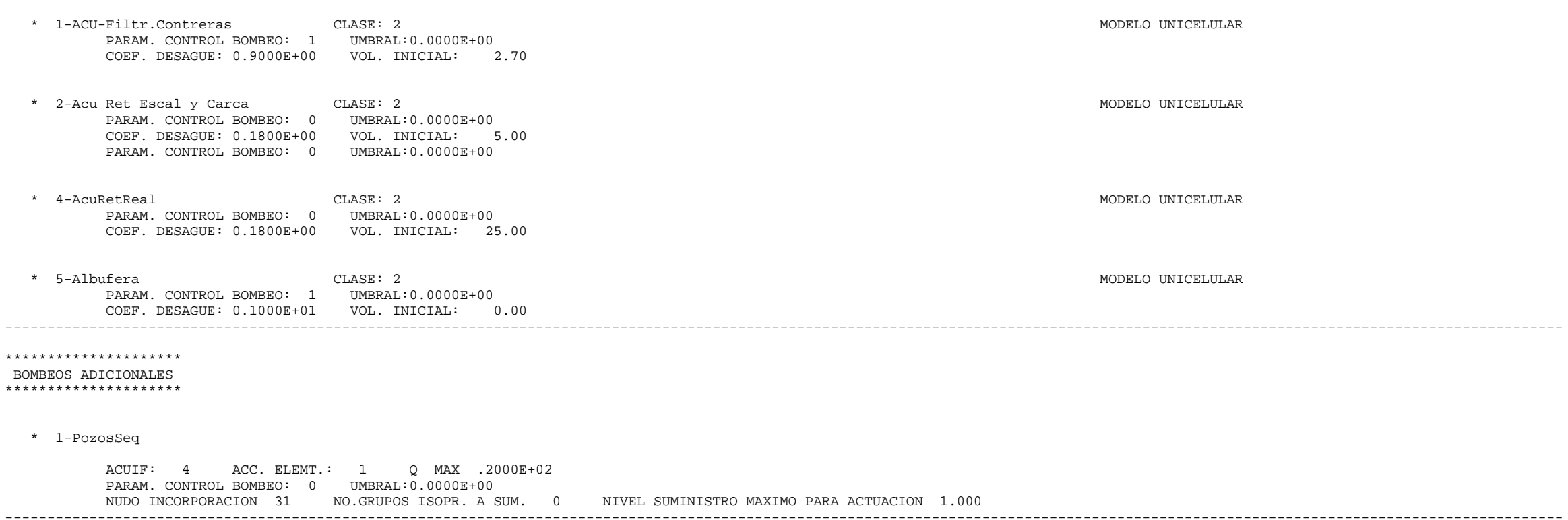

IND. RESTRICCION

* 1-ActAlarc

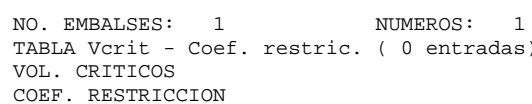


* 3-ActAC

NO. EMBALSES: 3 NUMEROS: 1 : 36

TABLA Vcrit - Coef. restric. ( 0 entradas)

COEF. RESTRICCION

* 4-RestacTtrad

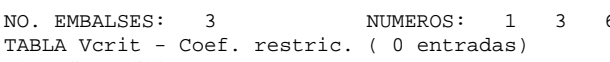

VOL. CRITICOS
COEF. RESTRICCION

* 5-Resactresto

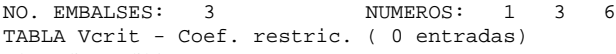

COFF, RESTRICCION

* 6-AbstAlbacete

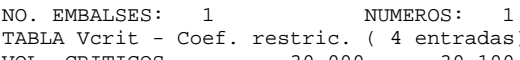

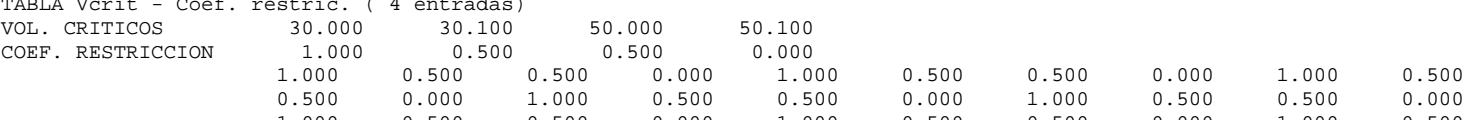

$\begin{array}{llllllllll}1.000 & 0.500 & 0.500 & 0.000 & 1.000 & 0.500 & 0.500 & 0.000 & 1.000 & 0.500 \\ 0.500 & 0.000 & 1.000 & 0.500 & 0.500 & 0.000 & 1.000 & 0.500 & 0.500 & 0.000 \\ 1.000 & 0.500 & 0.500 & 0.000 & 1.000 & 0.500 & 0.500 & 0.000 & 1.000 & 0.500 \\ 0.500 & 0.000 & 1.000 & 0.500 & 0.500 & 0.000 & 1.000 & 0.500 & 0.500 & 0.000 \\ 1.000 & 0.500 & 0.500 & 0.000 & 1.000 & 0.500 & 0.500 & 0.000 & & \end{array}$

TABLA VCrit - Coef. restricion modificados

$\begin{array}{llllll}\text { VOLUMEN } & 0.000 & 278.000 & 278.100 & 1000.000\end{array}$

$\begin{array}{lllll}2 & 0.000 & 287.000 & 287.100 & 1000.000\end{array}$

$\begin{array}{lllll}\text { RESTRICCION } & 0.000 & 0.000 & 1.000 & 1.000\end{array}$

$\begin{array}{lrrrr}\text { VOLUMEN } & 0.000 & 287.000 & 287.100 & 1000.000\end{array}$

$4 \quad 0.000 \quad 326.000 \quad 326.1001000 .000$

$\begin{array}{lrrrr}\text { VOLUMEN } & 0.000 & 326.000 & 326.100 & 1000.000 \\ \text { RESTRICCION } & 0.000 & 0.000 & 1.000 & 1.000\end{array}$

$\begin{array}{lllll}5 & 0.000 & 334.000 & 334.100 & 1000.000\end{array}$

RESTRICCION $\quad \begin{array}{llrl}0.000 & 0.000 & 1.000 & 1.000\end{array}$

$\begin{array}{lllll}\begin{array}{clll}6 \\ \text { VOLUMEN }\end{array} \quad 0.000 & 326.000 & 326.100 & 1000.000\end{array}$

A-16 
$\begin{array}{lllll}\text { RESTRICCION } & 0.000 & 0.000 & 1.000 & 1.000\end{array}$

$\begin{array}{lllll}\text { VOLUMEN } & 0.000 & 311.000 & 311.100 & 1000.000\end{array}$

$\begin{array}{llllll}8 & & & & \\ 8 & & 0.000 & 311.000 & 311.100 & 1000.000 \\ \text { VOLUMEN } & 0.000 & 278.000 & 278.100 & 1000.000\end{array}$

$\begin{array}{lrrrr}\text { VOLUMEN } & 0.000 & 278.000 & 278.100 & 1000.000 \\ \text { RESTRICCION } & 0.000 & 0.000 & 1.000 & 1.000\end{array}$

$\begin{array}{ccccc}9 & \\ \text { VOLUMEN } & 0.000 & 263.000 & 263.100 & 1000.000\end{array}$

\begin{tabular}{lrrrr} 
RESTRICCION & 0.000 & 263.000 & 263.100 & 1000.000 \\
\hline 10 & 0.000 & 1.000 & 1.000
\end{tabular}

$\begin{array}{lrrrr}10 & & & & \\ \text { VOLUMEN } & 0.000 & 263.000 & 263.100 & 1000.000 \\ \text { RESTRICCION } & 0.000 & 0.000 & 1.000 & 1.000\end{array}$

$\begin{array}{lllll}\text { VOLUMEN } & 0.000 & 263.000 & 263.100 & 1000.00\end{array}$

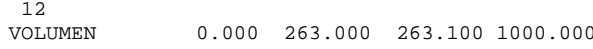

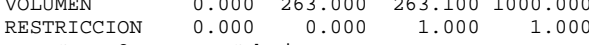

INDICE: 2 RestACTbaja

1 (1)

$\begin{array}{lrrrrrr} & 0.000 & 200.000 & 200.100 & 278.000 & 278.100 & 1000.000\end{array}$

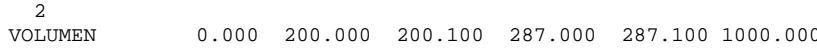

$\begin{array}{llllllll}\text { RESTRICCION } & 0.250 & 0.250 & 0.100 & 0.100 & 0.000 & 0.000 \\ 3 & 0.000 & 200.000 & 200.100 & 287.000 & 287.100 & 1000.000\end{array}$

$\begin{array}{lrrrrrr}3 & & & & \\ \text { VOLUMEN } & 0.000 & 200.000 & 200.100 & 287.000 & 287.100 & 1000.000 \\ \text { RESTRICCION } & 0.250 & 0.250 & 0.100 & 0.100 & 0.000 & 0.000\end{array}$

$\begin{array}{lrrrrrr}4 & 0.000 & 200.000 & 200.100 & 326.000 & 326.100 & 1000.000\end{array}$

$\begin{array}{lrrrrrr}5 & 0.000 & 200.000 & 200.100 & 334.000 & 334.100 & 1000.000 \\ \text { VOLUMEN } & 0.250 & 0.250 & 0.100 & 0.100 & 0.000 & 0.000 \\ \text { RESTRICCION } & 0.250 & & & \end{array}$

$\begin{array}{lllllll}\text { RESTRICCION } & 0.250 & 0.250 & 0.100 & 0.100 & 0.000 & 0.000\end{array}$

$\begin{array}{lrrrrrr}6 & 0.000 & 200.000 & 200.100 & 326.000 & 326.100 & 1000.000 \\ \text { VOLUMEN } & 0.250 & 0.250 & 0.100 & 0.100 & 0.000 & 0.000\end{array}$

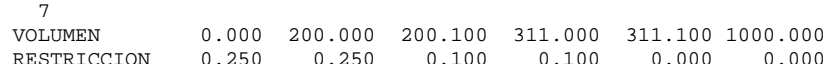

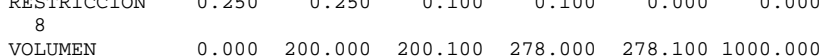

$\begin{array}{lrrrrrr}\text { VOLUMEN } & 0.000 & 200.000 & 200.100 & 278.000 & 278.100 & 1000.000 \\ \text { RESTRICCION } & 0.250 & 0.250 & 0.100 & 0.100 & 0.000 & 0.000\end{array}$

$\begin{array}{lllllll}9 & 0.000 & 200.000 & 200.100 & 263.000 & 263.100 & 1000.000\end{array}$

$\begin{array}{lrrrrrr}\text { VOLUMEN } & 0.000 & 200.000 & 200.100 & 263.000 & 263.100 & 1000.000 \\ \text { RESTRICCION } & 0.250 & 0.250 & 0.100 & 0.100 & 0.000 & 0.000\end{array}$

$\begin{array}{lllllll}10 & 0.000 & 200.000 & 200.100 & 263.000 & 263.100 & 1000.000\end{array}$

$\begin{array}{lrrrrrr}11 & 0.000 & 200.000 & 200.100 & 263.000 & 263.100 & 1000.000 \\ \text { VOLUMEN } & 0.250 & 0.250 & 0.100 & 0.100 & 0.000 & 0.000\end{array}$

12

$\begin{array}{lrrrrrr}\text { VOLUMEN } & 0.000 & 200.000 & 200.100 & 263.000 & 263.100 & 1000.000 \\ \text { RESTRICCION } & 0.250 & 0.250 & 0.100 & 0.100 & 0.000 & 0.000\end{array}$

INDICE: 3 ACTACT

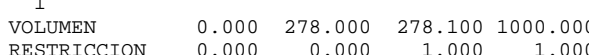

$2=0.000278 .000278 .1001000 .000$

$\begin{array}{lrrrr}2 & 0.000 & 287.000 & 287.100 & 1000.000 \\ \text { VOLUMEN } & 0.000 & 0.000 & 1.000 & 1.000\end{array}$

$\begin{array}{lrrrr}3 & 0.000 & 287.000 & 287.100 & 1000.000\end{array}$

$\begin{array}{lllll}4 & & 0.000 & 1.000 & 1.000 \\ \text { VOLUMEN } & 0.000 & 326.000 & 326.100 & 1000.000\end{array}$

$\begin{array}{lrrrr}\text { VOLUMEN } & 0.000 & 326.000 & 326.100 & 1000.000 \\ \text { RESTRICCION } & 0.000 & 0.000 & 1.000 & 1.000\end{array}$ 


\begin{tabular}{|c|c|c|c|c|c|}
\hline VOLUMEN & 0.000 & 334.000 & 334.100 & 1000.000 & \\
\hline $\begin{array}{l}\text { RESTRICCION } \\
6\end{array}$ & 0.000 & 0.000 & 1.000 & 1.000 & \\
\hline $\begin{array}{l}\text { VOLUMEN } \\
\text { RESTRICCION }\end{array}$ & $\begin{array}{l}0.000 \\
0.000\end{array}$ & $\begin{array}{r}326.000 \\
0.000\end{array}$ & $\begin{array}{r}326.100 \\
1.000\end{array}$ & $\begin{array}{r}1000.000 \\
1.000\end{array}$ & \\
\hline 7 & & & & & \\
\hline $\begin{array}{l}\text { RESTRICCION } \\
8 \\
\text { RESTREN }\end{array}$ & $\begin{array}{l}0.000 \\
0.000\end{array}$ & $\begin{array}{r}r 11.000 \\
0.000\end{array}$ & $\begin{array}{r}31.100 \\
1.000\end{array}$ & $\begin{array}{r}1000.000 \\
1.000\end{array}$ & \\
\hline VOLUMEN & 0.000 & 278.000 & 278.100 & 1000.000 & \\
\hline RESTRICCION & 0.0 & 0.000 & 1.000 & 1.000 & \\
\hline EN & .000 & 263.000 & 263.100 & 1000.000 & \\
\hline $\begin{array}{l}\text { RESTRICCION } \\
10\end{array}$ & 0.000 & 0.000 & 1.000 & 1.000 & \\
\hline VOLUMEN & 0.000 & 263.000 & 263.100 & 1000.000 & \\
\hline $\begin{array}{l}\text { RESTRICC } \\
11\end{array}$ & 0.000 & 0.000 & 1.000 & 1.000 & \\
\hline VOLUMEN & 0.000 & 263.000 & 263.100 & 1000.000 & \\
\hline $\begin{array}{l}\text { RESTRICCION } \\
12\end{array}$ & 0.000 & 0.000 & 1.000 & 1.000 & \\
\hline $\begin{array}{l}\text { VOLUMEN } \\
\text { RESTRICCION }\end{array}$ & $\begin{array}{l}0.000 \\
0.000\end{array}$ & $\begin{array}{r}263.000 \\
0.000\end{array}$ & 263.100 & 1000.000 & \\
\hline INDICE: 4 & RestACTt & & 1.000 & & \\
\hline VOLUMEN & 0.000 & 200.000 & 200.100 & 278.000 & 278.1001 \\
\hline $\begin{array}{l}\text { RESTRICC } \\
2\end{array}$ & & 1.000 & 0.400 & 0.400 & 0.000 \\
\hline & 0.000 & 00.000 & 200.100 & 287.000 & 287.1001 \\
\hline $\begin{array}{l}\text { RESTRICCION } \\
3\end{array}$ & 1.000 & 1.000 & 0.400 & 0.400 & 0.000 \\
\hline VOLUMEN & 0.000 & 200.000 & 200.100 & 287.000 & $287.100 \quad 1000.000$ \\
\hline $\begin{array}{l}\text { RESTRICCION } \\
4\end{array}$ & 1.000 & 1.000 & 0.400 & 0.400 & $0.000 \quad 0.000$ \\
\hline $\begin{array}{l}\text { VOLUMEN } \\
\text { RESTRICCION }\end{array}$ & 0.000 & $\begin{array}{r}200.000 \\
1.000\end{array}$ & 200.100 & 326.000 & $326.100 \quad 1000.000$ \\
\hline & & 1.000 & 0.400 & & $\begin{array}{ll}0.000 & 0.000\end{array}$ \\
\hline $\begin{array}{l}\text { VOLU } \\
\text { REST }\end{array}$ & 0.0 & 00.0 & 200. & 334.000 & 334.100100 \\
\hline & 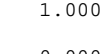 & $1.0 \quad 2-3$ & & 0.400 & $\mathrm{sec}_{\mathrm{s}}$ \\
\hline & 0.000 & 200.000 & 200.100 & 326.000 & $326.100 \quad 1000.000$ \\
\hline 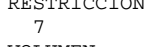 & & & & & \\
\hline $\begin{array}{l}\text { VOLUMEN } \\
\text { RESTRICCION }\end{array}$ & $\begin{array}{l}0.000 \\
1.000\end{array}$ & $\begin{array}{r}200.000 \\
1.000\end{array}$ & $\begin{array}{r}200.100 \\
0.400\end{array}$ & $\begin{array}{r}311.000 \\
0.400\end{array}$ & $\begin{array}{rr}311.100 & 1000.000 \\
0.000 & 0.000\end{array}$ \\
\hline VOLUMEN & & & & & \\
\hline $\begin{array}{l}\text { RESTRICCION } \\
9\end{array}$ & & & 0.400 & 0.400 & 0.000 \\
\hline & & & 0 & & 0010 \\
\hline $\begin{array}{l}\text { RESTRICCION } \\
10\end{array}$ & & & & & 0.000 \\
\hline $\begin{array}{l}\text { VOLUMEN } \\
\text { RESTRICCION }\end{array}$ & $\begin{array}{l}0.000 \\
1.000\end{array}$ & $\begin{array}{r}200.000 \\
1.000\end{array}$ & $\begin{array}{r}200.100 \\
0.400\end{array}$ & $\begin{array}{r}263.000 \\
0.400\end{array}$ & $\begin{array}{rr}263.100 & 1000.000 \\
0.000 & 0.000\end{array}$ \\
\hline & & & 0 & & \\
\hline CION & & & 0.400 & 0.400 & $0.000 \quad 0.000$ \\
\hline VoI & 0.0 & & & & 10010 \\
\hline $\begin{array}{l}\text { REST } \\
\text { INDI }\end{array}$ & $\begin{array}{r}1.0 \\
\text { ResAC }\end{array}$ & 1.000 & & & 0.000 \\
\hline & & & & & \\
\hline $\begin{array}{l}\text { VOLUMEN } \\
\text { RESTRICCION }\end{array}$ & $\begin{array}{l}0.000 \\
0.300\end{array}$ & $\begin{array}{r}200.000 \\
0.300\end{array}$ & $\begin{array}{r}200.100 \\
0.200\end{array}$ & $\begin{array}{r}278.000 \\
0.200\end{array}$ & $\begin{array}{rr}278.100 & 1000.000 \\
0.000 & 0.000\end{array}$ \\
\hline & & & & & \\
\hline REST & 0.300 & 0.300 & 0.200 & 0.200 & 0.000 \\
\hline
\end{tabular}


$\begin{array}{rrrrrrr}\text { RESTRICCION } & 0.000 & 200.000 & 200.100 & 287.000 & 287.100 & 1000.000 \\ & 0.300 & 0.300 & 0.200 & 0.200 & 0.000 & 0.000\end{array}$

$\begin{array}{lrrrrrr}\text { VOLUMEN } & 0.000 & 200.000 & 200.100 & 326.000 & 326.100 & 1000.000 \\ \text { RESTRICCION } & 0.300 & 0.300 & 0.200 & 0.200 & 0.000 & 0.000\end{array}$

$\begin{array}{lrrrrrr}\text { VOLUMEN } & 0.000 & 200.000 & 200.100 & 334.000 & 334.100 & 1000.000 \\ \text { RESTRICCION } & 0.300 & 0.300 & 0.200 & 0.200 & 0.000 & 0.000\end{array}$

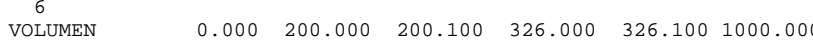

$\begin{array}{lrrrrrr}\text { RESTRICCION } & 0.300 & 0.300 & 0.200 & 0.200 & 0.000 & 0.000\end{array}$

$\begin{array}{lrrrrrr}\text { VOLUMEN } & 0.000 & 200.000 & 200.100 & 311.000 & 311.100 & 1000.000\end{array}$

$\begin{array}{lllllll}\quad & 8 \\ \text { VOLUMEN } & 0.000 & 200.000 & 200.100 & 278.000 & 278.100 & 1000.000\end{array}$

$\begin{array}{lrrrrrr}\text { VOLUMEN } & 0.000 & 200.000 & 200.100 & 278.000 & 278.100 & 1000.000 \\ \text { RESTRICCION } & 0.300 & 0.300 & 0.200 & 0.200 & 0.000 & 0.000\end{array}$

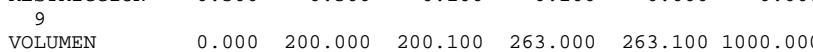

$\begin{array}{rrrrrrr}\text { RESTRICCION } & 0.300 & 0.300 & 0.200 & 0.200 & 0.000 & 0.000\end{array}$

$\begin{array}{lrrrrrr}\text { VOLUMEN } & 0.000 & 200.000 & 200.100 & 263.000 & 263.100 & 1000.000 \\ \text { RESTRICCION } & 0.300 & 0.300 & 0.200 & 0.200 & 0.000 & 0.000\end{array}$

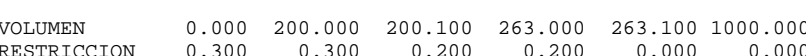

$\begin{array}{lrrrrrr}\text { VOLUMEN } & 0.000 & 200.000 & 200.100 & 263.000 & 263.100 & 1000.000 \\ \text { RESTRICCION } & 0.300 & 0.300 & 0.200 & 0.200 & 0.000 & 0.000\end{array}$ 
DATOS DEL MODELO DE CALIDAD

\section{EMBALSES}

\begin{tabular}{|c|c|c|c|c|c|c|c|c|}
\hline & **Temperat & atura** & & & & & & \\
\hline & Alarcon $\quad M$ & Molinar & Contreras & Cortes & Naranjero & Tous & LaMuela & \\
\hline Тетр ер & 20 & 20 & 20 & 20 & 20 & 20 & & 20 \\
\hline \# Curva ep & 2 & 3 & 4 & 5 & 5 & 13 & & 5 \\
\hline Temp hip & 20 & 20 & 20 & 20 & 20 & 20 & & 20 \\
\hline \# Curva hip & 2 & 3 & 4 & 5 & 5 & 13 & & 5 \\
\hline & $* * *$ Contami & ninantes Primer & r Orden $* * *$ & & & & & \\
\hline & Solidos & & & & & & & \\
\hline & Alarcon & Molinar & Contreras & Cortes $\quad \mathrm{Nal}$ & Taranjero Tous & $L a M t$ & Iuela & \\
\hline Kemb & 0 & 0 & 0 & 0 & 0 & 0 & & 0 \\
\hline$V s E m b$ & 0.1 & $1 \quad 0.05$ & 0.5 & 0.7 & 0.7 & 0.25 & & 0 \\
\hline & $* * *$ Oxígeno & o Disuelto*** & & & & & & \\
\hline & *Embalses* & & & & & & & \\
\hline & Alarcon & Molinar & Contreras & Cortes & Naranjero & Tous & LaMuela & \\
\hline$K a$ & 0.1 & 1 & 1 & 10 & 0 & 10 & & 1 \\
\hline$u w$ & 1 & 1 & 1 & & 1 & 1 & & 1 \\
\hline Curvauw & 1 & 1 & 1 & & 1 & 1 & & 1 \\
\hline$K d$ & 0.001 & 0.001 & 0.001 & 0.001 & 0.001 & 0.001 & & 0 \\
\hline$V s d$ & 0 & 0 & 0 & & 0 & 0 & & 0 \\
\hline Knoa & 0 & 0 & 0 & & 0 & 0 & & 0 \\
\hline Vnorg & 0 & 0 & 0 & & 0 & 0 & & 0 \\
\hline Knai & 0.01 & 0.1 & 0.03 & 0.01 & 0.01 & 0.001 & & 0 \\
\hline Knio & 0.035 & 0 & 0.06 & 0.03 & 0.03 & 0.01 & & 0 \\
\hline Кпоз & 0 & 0 & 0 & & 0 & 0 & & 0 \\
\hline Kgrow & 0 & 0 & 0 & & 0 & 0 & & 0 \\
\hline Kresp & 0 & 0 & 0 & & 0 & 0 & & 0 \\
\hline Valg & 0 & 0 & 0 & & 0 & 0 & & 0 \\
\hline Kfosf & 0.02 & 0.02 & 0.01 & 0.02 & 0.02 & 0.005 & & 0 \\
\hline
\end{tabular}

***Datos Generales de Elementos***

$* *$ Embalses**

Resultados Epilimnion

Alarcon Molinar Contreras Cortes Naranjero Tous LaMuela

ResultadosHipolimnion Alarcon

$\begin{aligned} & \text { Molinar } \\ 1 & \\ 0 & \\ 0 & \\ 0 & \\ 1 & \\ 50 & \\ 1 & \\ 1 & \\ 1 & \\ 1 & \\ 0 & \\ 1 & \end{aligned}$

1
0
0
0
1
50
1
1
1
1
0
1

Curva Zt

$\begin{aligned} 1 & \\ 0 & \\ 0 & \\ 0 & \\ 1 & \\ 50 & \\ 1 & \\ 1 & \\ 1 & \\ 1 & \\ 0 & \\ 1 & \end{aligned}$

1
0
0
0
1
0
1
1
1
1
0
1

${ }^{\star * \star}$ Datos Condiciones Iniciales ${ }^{\star \star *}$

\begin{tabular}{|c|c|c|c|c|c|c|c|c|c|c|c|}
\hline & Conduct & SS & & DBO5 & $O D$ & Norg & $\mathrm{NH} 4$ & No2 & No3 & Alg & $P$ \\
\hline Alarcón & 831 & & 3 & 2 & 9.2 & 0.5 & 0.03 & 0.03 & 3.5 & & $\begin{array}{ll}0 & 0.01\end{array}$ \\
\hline Molinar & 761 & & 9 & 2 & 8.3 & 0.5 & 0.05 & 0.04 & 10 & & $\begin{array}{ll}0 & 0.01\end{array}$ \\
\hline contreras & 937 & & 9 & 2 & 9.5 & 0.5 & 0.03 & 0.025 & 3.5 & c & $\begin{array}{ll}0 & 0.01\end{array}$ \\
\hline Cortes & 846 & & 4 & 2 & 11.5 & 0.5 & 0.01 & 0.01 & 10 & & $\begin{array}{ll}0 & 0.01\end{array}$ \\
\hline Naranjero & 846 & & 4 & 2 & 11.5 & 0.5 & 0.01 & 0.01 & 10 & & $\begin{array}{ll}0 & 0.01\end{array}$ \\
\hline Tous & 846 & & 3 & 2 & 9.2 & 0.5 & 0.03 & 0.01 & 10 & & $0 \quad 0.01$ \\
\hline La Muela & 846 & & 4 & 2 & 11.5 & 0.5 & 0.01 & 0.01 & 10 & c & 0.01 \\
\hline
\end{tabular}




\section{CONDUCCIONES}

${ }^{* *}$ Temperatura**

\section{\# Curva Cond}

Jecar-1

$6^{\text {Jucar-3' }} 8^{\text {Jucar-4' }} 9^{\text {Jucar-5' }} 10$

$10^{\text {Jucar-6' }}$

$10^{\text {Cabriel-2' }} 12^{\text {Cabriel-3' }} 12^{\text {Jucar-7 }}$

Salidas Tous Antella-Sellen

\section{Contaminantes Primer Orden ${ }^{\star \star}$}

Solidos

KSS

VsSS

J£car-1'

$0^{\text {Jucar-3' }}$

$0^{\text {Jucar-4' }}$

$0^{\text {Jucar-5' }}$

$0_{0}^{\text {Jucar-6' }}$

$\begin{array}{lll}\text { Cabriel-2' }^{\text {Cabriel-3' }} & 0^{\text {Jucar-7 }} \\ 0 & 0 & 0 \\ 0 & 0 & 0\end{array}$

Salidas Tous Antella-Sellen

O**ígeno Disuelto***

${ }^{*}$ Conducciones

J£car-1' Jucar-3' Jucar-4'

\begin{tabular}{rrrr} 
Jucar-5' & \multicolumn{2}{c}{ Jucar-6' $^{\prime}$ Cabriel-2' $^{\text {Cabriel-3' }}$} \\
-1 & -1 & -1 & -1 \\
0.5 & 0.01 & 0 & 0.05 \\
0 & 0 & 0 & 0 \\
0 & 0 & 0 & 0 \\
0 & 0 & 0 & 0 \\
1 & 0.1 & 0 & 0.01 \\
2 & 0.2 & 0 & 0.02 \\
0.01 & 0 & 0 & 0 \\
0 & 0 & 0 & 0 \\
0 & 0 & 0 & 0 \\
0 & 0 & 0 & 0 \\
0 & 0.1 & 0 & 0.01
\end{tabular}

Jucar-7' Salidas Tous Antella-Sellen

$K a$

Vsd

Knoa

Vnorg

Knai

Knio

Kno3

Kgrow

Kresp

Valg

$\begin{array}{rr}10 & \text { Jucar-3' } \\ 10 & 5 \\ 0.001 & 0.5 \\ 0 & 0 \\ 0 & 0 \\ 0 & 0 \\ 0.001 & 1 \\ 0.05 & 2 \\ 0 & 0 \\ 0 & 0 \\ 0 & 0 \\ 0 & 0 \\ 0.1 & 0.1\end{array}$

${ }^{* *}$ Datos Generales de Elementos ${ }^{* \star}$

${ }^{* *}$ Conducciones ${ }^{* *}$

Indicador Resultadc

Indicador resultado.

E

L

Manning(1) o Poter

Alfa veloc o $n$

Beta veloc o $B$

J£car-1'

Jucar-3'

$1^{\text {Jucar-4' }}$

AlfaProfo 1

Beta Prof os

S1

1
0
0
47683
100
2
0.744
0.1
0.222
0.4
0
0

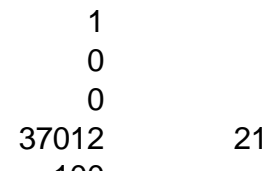

$1^{\text {Jucar-5' }}$
0
0
1311
100

$\begin{array}{rr}{ }^{\text {Jucar-6' }} \\ 1 & \\ 0 & \\ 0 & \\ 18500 & 124 \\ 100 & \\ 2 & \\ 0.744\end{array}$

$\begin{array}{rrr} & \text { Cabriel-2' }^{\prime} \text { Cabriel-3' }^{\prime} \\ 1 & 1 & \\ 0 & 0 & \\ 0 & 0 & \\ 1242 & 35207 & 3849 \\ 100 & 100 & 100 \\ 2 & 2 & \\ 0.744 & 0.744 & 0.74 \\ 0.1 & 0.1 & 0.1 \\ 0.222 & 0.222 & 0.22 \\ 0.4 & 0.4 & 0.4 \\ 0 & 0 & \\ 0 & 0 & \end{array}$

\begin{tabular}{rr}
$3^{\prime}$ & \multicolumn{2}{c}{ Jucar-7' } \\
1 & \\
0 & \\
0 & \\
3849 & 10000 \\
100 & 100 \\
2 &
\end{tabular}

$\begin{array}{rrr}-1 & -1 & -1 \\ 0.001 & 0.1 & 0.1 \\ 0 & 0 & 0 \\ 0 & 0 & 0 \\ 0 & 0 & 0 \\ 0.001 & 0.5 & 0.5 \\ 0.02 & 1.2 & 1.2 \\ 0 & 0 & 0 \\ 0 & 0 & 0 \\ 0 & 0 & 0 \\ 0 & 0 & 0 \\ 0 & 0.1 & 0.1\end{array}$

S2

100
2
0.744
0.1
0.222
0.4
0
0

2
0.744

0.744

0.1

0.1

0.222

0.4
0

0.4
0
0

744
0.1

0.1
0.222

0.222

$\begin{array}{rrr} & \text { Salidas Tous } & \text { Antella-Sellen } \\ 1 & 1 & 1 \\ 0 & 0 & 0 \\ 0 & 0 & 0 \\ 10000 & 15000 & 500 \\ 100 & 100 & 5 \\ 2 & 2 & 2 \\ 0.744 & 1.057 & 1.057 \\ 0.1 & 0.1 & 0.1 \\ 0.222 & 0.323 & 0.323 \\ 0.4 & 0.4 & 0.4 \\ 0 & 0 & 0 \\ 0 & 0 & 0\end{array}$




\section{**Temperatura**}

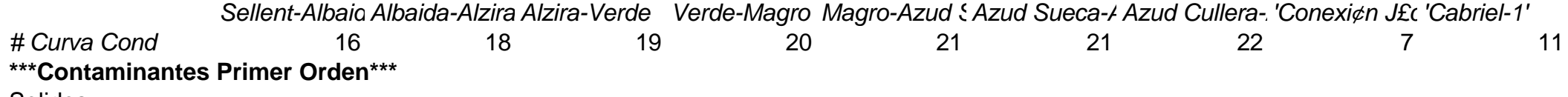

Solidos

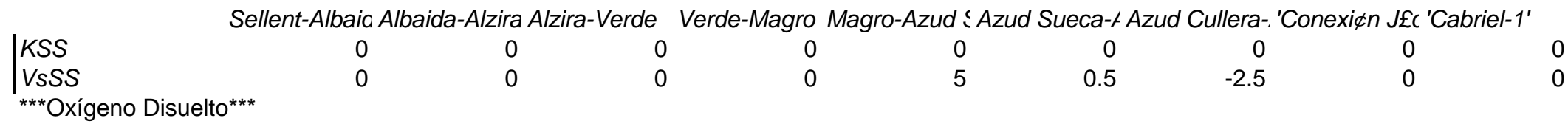

${ }^{\star}$ Conducciones ${ }^{\star}$

\begin{tabular}{|c|c|c|c|c|c|c|c|c|c|}
\hline & Sellent-Albaia & Alzira & rde & Verde-Magro & Magro-Azud $\leq$ & ecca-t & ullera- & $J £ c$ & \\
\hline$K a$ & -1 & -1 & -1 & -1 & -1 & 3 & 3 & -1 & -1 \\
\hline$K d$ & 0.1 & 0.1 & 1 & 0.35 & 0.3 & 0.35 & 0.35 & 0 & 0.05 \\
\hline$V s d$ & 0 & 0 & 0 & 0 & 0 & 0 & 0 & 0 & 0 \\
\hline Knoa & 0 & 0 & 0 & 0 & 0 & 0 & 0 & 0 & 0 \\
\hline Vnorg & 0 & 0 & 0 & 0 & 0 & 0 & 0 & 0 & 0 \\
\hline Knai & 0.8 & 0.9 & 1 & 1 & 1 & 0.75 & 0.5 & 0 & 0.1 \\
\hline Knio & 1 & 1.4 & 0.2 & 0.2 & 0.7 & 1.2 & 1.5 & 0 & 0.2 \\
\hline Kno3 & 0 & 0 & 0 & 0 & 0 & 0 & 0 & 0 & 0 \\
\hline Kgrow & 0 & 0 & 0 & 0 & 0 & 0 & 0 & 0 & 0 \\
\hline Kresp & 0 & 0 & 0 & 0 & 0 & 0 & 0 & 0 & 0 \\
\hline Valg & 0 & 0 & 0 & 0 & 0 & 0 & 0 & 0 & 0 \\
\hline Kfosf & 0.1 & 0.1 & 0.5 & 0.5 & 0.2 & 0.2 & 0.2 & 0 & 0.1 \\
\hline
\end{tabular}

***Datos Generales de Elementos***

${ }^{* *}$ Conducciones ${ }^{\star *}$

Indicador Resultad

Indicador resultado.

E

L

Manning(1) o Poter

Alfa veloc o $n$

Beta veloc o $B$

AlfaProf o I

Beta Prof os

S1

S2

Sellent-Albaia Albaida-Alzira Alzira-Verde

$\begin{array}{rrr}1 & 1 & 1 \\ 0 & 0 & 0 \\ 0 & 0 & 0 \\ 7750 & 22000 & 2500 \\ 100 & 100 & 10 \\ 2 & 2 & 2 \\ 0.375 & 0.376 & 0.15 \\ 0.1 & 0.1 & 0.14 \\ 0.303 & 0.303 & 0.6 \\ 0.4 & 0.4 & 0.5 \\ 0 & 0 & 0 \\ 0 & 0 & 0\end{array}$

$\begin{array}{rr}\text { Magro Magro-Azud } \leq \\ 1 & 1 \\ 0 & 0 \\ 0 & 0 \\ 2250 & 10000 \\ 10 & 100 \\ 2 & 2 \\ 0.15 & 0.15 \\ 0.14 & 0.14 \\ 0.6 & 0.6 \\ 0.5 & 0.5 \\ 0 & 0 \\ 0 & 0\end{array}$

$\begin{array}{rr}\text { Sueca-ł Azud Cullera-' } \\ 1 & 1 \\ 0 & 0 \\ 0 & 0 \\ 9900 & 3500 \\ 100 & 10 \\ 2 & 2 \\ 0.16 & 0.16 \\ 0.1 & 0.1 \\ 0.9 & 0.9 \\ 0.4 & 0.4 \\ 0 & 0 \\ 0 & 0\end{array}$

$\begin{array}{rr}1 & 1 \\ 0 & 0 \\ 0 & 0 \\ 40819 & 64993 \\ 100 & 100 \\ 2 & 2 \\ 0.744 & 0.744 \\ 0.1 & 0.1 \\ 0.222 & 0.222 \\ 0.4 & 0.4 \\ 0 & 0 \\ 0 & 0\end{array}$


${ }^{* *}$ Temperatura**

\section{\# Curva Cond}

Cabecera Juc Cabecera Cal Cortes-Naran, Salidas Totalt Canal ATS' Cortes-Muela Trasvase Vini Ret Escalona Retorno 4Puє BombAzqRea C-Ficticia' \# Curva Cond
${ }^{* * *}$ Contaminantes Primer Orden Solidos

KSS

Cabecera Juc Cabecera Cal Cortes-Naran, Salidas Totalє Canal ATS' Cortes-Muela Trasvase Vin; Ret Escalona Retorno 4Puє BombAzqRea C-Ficticia'

KSS

${ }^{* * *}$ Oxígeno Disuelto***

$\begin{array}{llll}0 & 0 & 0 & 0 \\ 0 & 0 & 0 & 0\end{array}$

${ }^{*}$ Conducciones*

Cabecera Juc Cabecera Cal Cortes-Naran, Salidas Totalı Canal ATS' Cortes-Muela Trasvase Vini Ret Escalona Retorno 4Puє BombAzqRea C-Ficticia'

$\mid \begin{aligned} & \text { Ka } \\ & \text { Kd } \\ & \text { Vsd } \\ & \text { Knoa } \\ & \text { Vnorg } \\ & \text { Knai } \\ & \text { Knio } \\ & \text { Kno3 } \\ & \text { Kgrow } \\ & \text { Kresp } \\ & \text { Valg } \\ & \text { Kfosf }\end{aligned}$

-1 Cabecera Juc Cabecera Cal Cortes-Naran, Salidas Totak Canal ATS'

$\begin{array}{cccc}-1 & -1 & -1 & -1 \\ 0 & 0 & 0 & 2 \\ 0 & 0 & 0 & 0 \\ 0 & 0 & 0 & 0 \\ 0 & 0 & 0 & 0 \\ 0 & 0 & 0 & 0.5 \\ 0 & 0 & 0 & 2 \\ 0 & 0 & 0 & 0 \\ 0 & 0 & 0 & 0 \\ 0 & 0 & 0 & 0 \\ 0 & 0 & 0 & 0 \\ 0 & 0 & 0 & 0.05\end{array}$

${ }^{\star * *}$ Datos Generales de Elementos ${ }^{* * *}$

${ }^{* *}$ Conducciones ${ }^{* *}$

Indicador Resultad Indicador resultado. E

Ax

Manning(1) o Poter

Alfa veloc o $n$

Beta veloc o $B$

AlfaProf o I

Beta Prof os

S1

S2

Cabecera Juc Cabecera Cak Cortes-Naran, Salidas Total€ Canal ATS' Cortes-Muela Trasvase Vini Ret Escalona Retorno 4Puє BombAzqRea C-Ficticia'

$\begin{array}{rrr}-1 & -1 & -1 \\ 0 & 0 & 0 \\ 0 & 0 & 0 \\ 1000 & 1000 & 1000 \\ 100 & 100 & 100 \\ 2 & 2 & 2 \\ 0.744 & 0.744 & 0.744 \\ 0.1 & 0.1 & 0.1 \\ 0.222 & 0.222 & 0.222 \\ 0.4 & 0.4 & 0.4 \\ 0 & 0 & 0 \\ 0 & 0 & 0\end{array}$

-1
0
0
1000
100
2
0.16
0.1
0.9
0.4
0
0

$\begin{array}{rr}-1 & -1 \\ 0 & 0 \\ 0 & 0 \\ 1000 & 1000 \\ 100 & 100 \\ 2 & 2 \\ 0.744 & 0.744 \\ 0.1 & 0.1 \\ 0.222 & 0.222 \\ 0.4 & 0.4 \\ 0 & 0 \\ 0 & 0\end{array}$

$\begin{array}{rr}-1 & -1 \\ 0 & 0 \\ 0 & 0 \\ 1000 & 1000 \\ 100 & 100 \\ 2 & 2 \\ 0.744 & 0.744 \\ 0.1 & 0.1 \\ 0.222 & 0.222 \\ 0.4 & 0.4 \\ 0 & 0 \\ 0 & 0\end{array}$

-1
0
0
1000
100
2
0.744
0.1
0.222
0.4
0
0

$\begin{array}{rr}-1 & -1 \\ 0 & 0 \\ 0 & 0 \\ 1000 & 1000 \\ 100 & 100 \\ 2 & 2 \\ 0.744 & 0.744 \\ 0.1 & 0.1 \\ 0.222 & 0.222 \\ 0.4 & 0.4 \\ 0 & 0 \\ 0 & 0\end{array}$




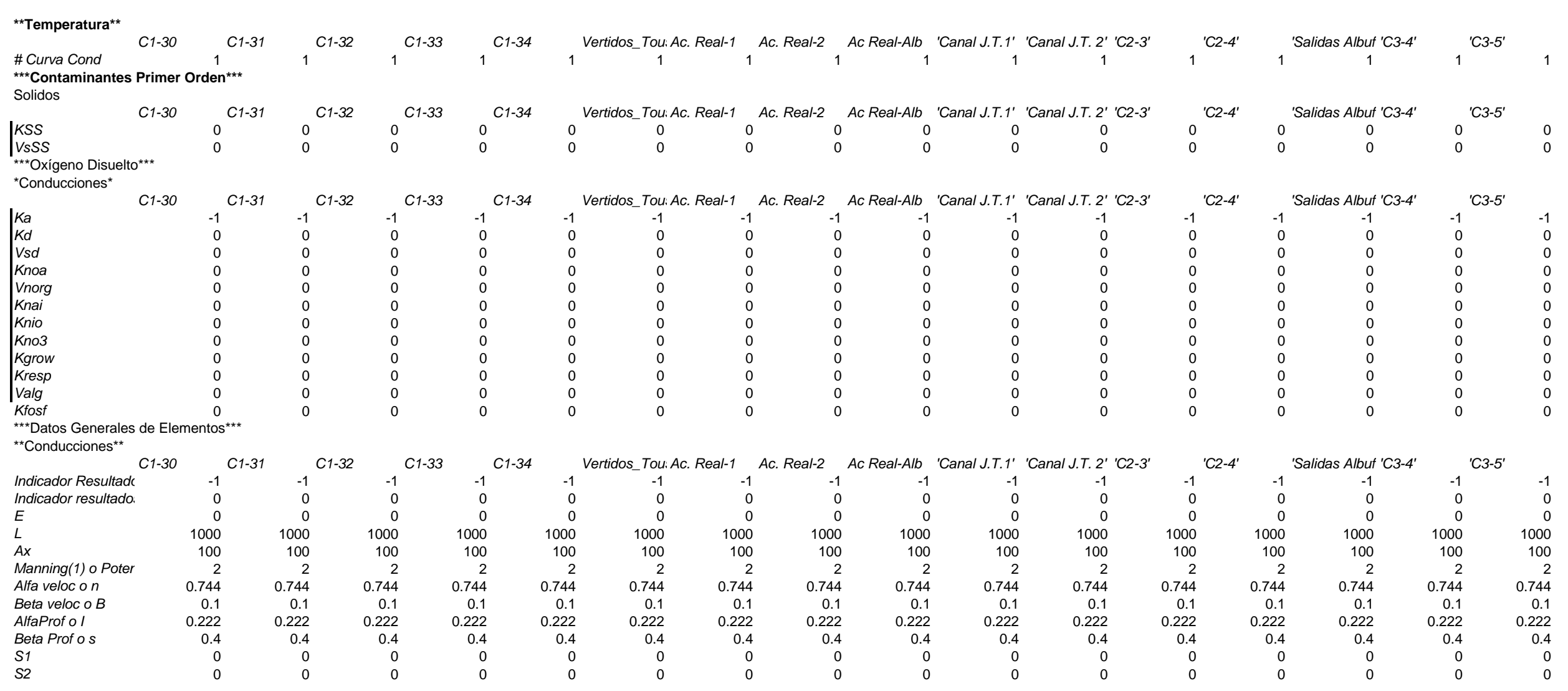




\section{VERTIDOS}

${ }^{\star \star \star}$ Datos Vertidos ${ }^{\star \star \star}$

$14 \quad 8$

**Datos Vertidos Puntuales ${ }^{\star \star}$

Numero Nudo Nuero Curva

$Q$

$\begin{array}{cc}\text { Eq Alarcon } & 1 \\ \text { Eq Contreras } & 8 \\ \text { Alarcón } & 2 \\ \text { Frailes } & 4 \\ \text { Alcalá } & 5 \\ \text { Reconque } & 7 \\ \text { Contreras } & 9 \\ \text { Cortes } & 12 \\ \text { Villatoya } & 10 \\ \text { Antella-Vill } & 16 \\ \text { Albaida Ag Ak } & 35 \\ \text { Alzira } & 36 \\ \text { Algemesi } & 38 \\ \text { Sueca } & 17\end{array}$

**Datos Vertidos Difusos** Numero Condu

$\begin{array}{cc}\text { Jucar-1 } & 2 \\ \text { tos Aguas arr } & 4 \\ \text { onductividad } 1 & 8 \\ \text { te SS hasta Al } & 12 \\ \text { dos Sellent-All } & 14 \\ \text { entre Albaida } & 15\end{array}$

Cond
177071
0
64800000
0
0
0

$\begin{array}{ccc}0.01 & 0.00 & 56329.00 \\ 0.01 & 0.00 & 20956.00 \\ 0.05 & 1300.00 & 220.00 \\ 0.02 & 1300.00 & 220.00 \\ 0.03 & 1300.00 & 220.00 \\ 1.11 & 1503.62 & 15.69 \\ 0.02 & 973.79 & 14.27 \\ 0.02 & 1300.00 & 176.00 \\ 0.01 & 1300.00 & 220.00 \\ 0.01 & 1300.00 & 220.00 \\ 0.05 & 1300.00 & 220.00 \\ 1.74 & 1300.00 & 220.00 \\ 0.36 & 1300.00 & 44.00 \\ 0.02 & 1300.00 & 380.00 \\ & & \\ S S & D B O 5 & O D \\ & & \\ 29966 & 29966 & 272 \\ 0 & 0 & 0 \\ 0 & 0 & 0 \\ 1319523 & 0 & 0 \\ 425097 & 425097 & 3864 \\ 0 & 0 & 0\end{array}$

$D B O 5$
200.00
2.00
220.00
220.00
220.00
2.00
2.17
176.00
220.00
220.00
220.00
220.00
44.00
900.00

$N h 4$

3405
0
0
0
62103
0

$O D$
0.00
0.00
2.00
2.00
2.00
9.67
9.83
2.00
2.00
2.00
2.00
2.00
2.00
2.00

$N o 2$
0
0
0
0
0
0

$\begin{array}{cc}\text { Nh4 } & \text { No2 } \\ & \\ 90.00 & 80.00 \\ 102.41 & 54.29 \\ 32.14 & 0.00 \\ 32.14 & 0.00 \\ 32.14 & 0.00 \\ 0.16 & 0.13 \\ 0.08 & 0.05 \\ 32.14 & 0.00 \\ 25.00 & 0.00 \\ 32.14 & 0.00 \\ 32.14 & 0.00 \\ 19.00 & 0.00 \\ 32.14 & 0.00 \\ 32.14 & 0.00 \\ & \\ \text { No3 } & P \\ 0 & 1090 \\ 2500000 & 0 \\ 0 & 0 \\ 0 & 0 \\ 0 & 15458 \\ 4000000 & 0\end{array}$

$\begin{array}{cc}\text { No3 } & P \\ 5000.00 & 170.00 \\ 6454.34 & 42.00 \\ 0.00 & 8.00 \\ 0.00 & 8.00 \\ 0.00 & 8.00 \\ 6.96 & 0.15 \\ 0.02 & 0.06 \\ 0.00 & 8.00 \\ 0.00 & 8.00 \\ 0.00 & 8.00 \\ 0.00 & 8.00 \\ 0.00 & 4.00 \\ 0.00 & 8.00 \\ 0.00 & 8.00\end{array}$




\section{ACUÍFEROS}

${ }^{* \star A}$ Acuíferos ${ }^{* *}$

${ }^{\star \star *}$ Datos Condiciones Iniciales ${ }^{\star \star \star}$

$\begin{array}{ccccccccc} & \text { Conduct } & S S & D B O 5 & O D & N H 4 & \text { No2 } & \text { No3 } & P \\ \text { Filtraciones Contreras } & 828.000 & 7.300 & 2.000 & 9.500 & 0.079 & 0.019 & 2.000 & 0.040 \\ \text { Ret Esc Carcag } & 941.461 & 3.399 & 5.000 & 10.097 & 0.050 & 0.041 & 11.451 & 0.095 \\ \text { Mancha Oriental } & 759.783 & 5.065 & 2.000 & 10.422 & 0.030 & 0.021 & 8.555 & 0.014 \\ \text { Acu Ret Real } & 1073.500 & 14.417 & 11.917 & 2.850 & 1.093 & 0.500 & 24.000 & 0.095 \\ \text { Albufera } & 500.000 & 5.000 & 2.000 & 10.000 & 0.010 & 0.010 & 0.010 & 0.010\end{array}$

\section{RETORNOS}

**Elementos de Retorno**

$\begin{array}{ccccccccc} & \text { Conduct } & \text { SS } & \text { DBO5 } & \text { OD } & \text { NH4 } & \text { No2 } & \text { No3 } & P \\ \text { CNCofrentes } & 1500 & 6.76 & 2 & 10.33 & 0.0239 & 0.0259 & 0.01 & 0.018 \\ \text { Antella } & 1000.0000 & 23.2560 & 3.6250 & 9.0917 & 0.0526 & 0.0883 & 8.8600 & 0.0950 \\ \text { Escal-Carcag } & 1073.5 & 14.4166667 & 11.9166667 & 2.85 & 1.093 & 0.500 & 24.000 \\ \text { Ret 4 Pueblos } & -1 & -1 & -1 & -1 & -1 & -1 & -1 & -1\end{array}$




\section{TEMPERATURA}

Oct Nov Dic Ene Feb Mar Abr May Jun Jul Ago Sep

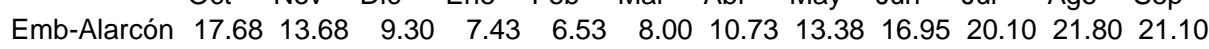

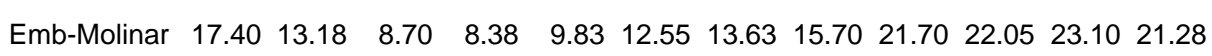

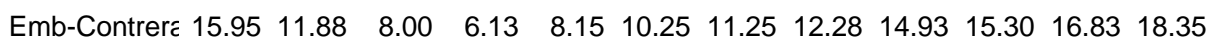

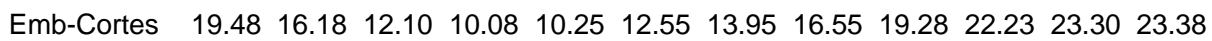
$\begin{array}{llllllllllll}\text { Jucar-1 } \quad 17.48 & 13.21 & 8.72 & 6.81 & 7.03 & 9.29 & 11.35 & 13.58 & 17.91 & 21.09 & 21.90 & 21.08\end{array}$ $\begin{array}{llllllllllll}\text { Jucar-2 } \quad 17.31 & 13.06 & 9.07 & 8.15 & 9.45 & 12.61 & 12.96 & 13.94 & 19.18 & 22.31 & 22.29 & 21.24\end{array}$ $\begin{array}{lllllllllllll}\text { Jucar-3 } & 17.23 & 13.49 & 9.43 & 9.71 & 11.48 & 13.83 & 13.98 & 14.61 & 20.01 & 22.56 & 22.51 & 21.76\end{array}$

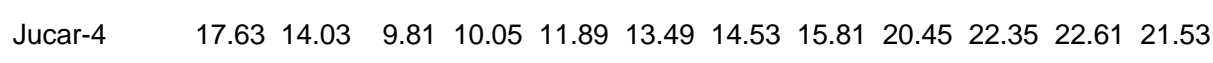

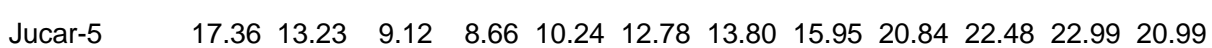

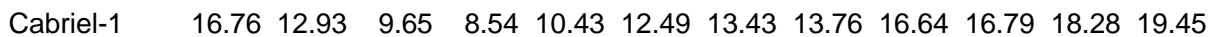

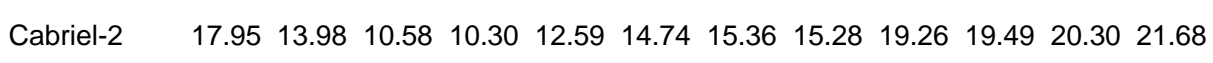

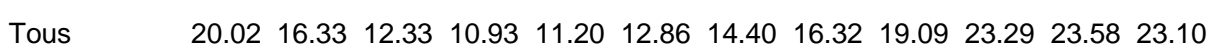

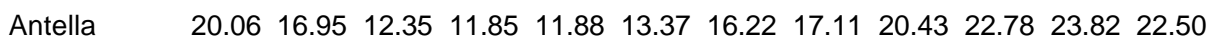

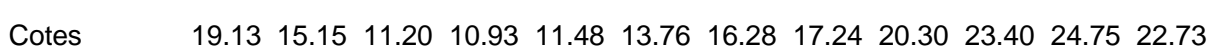

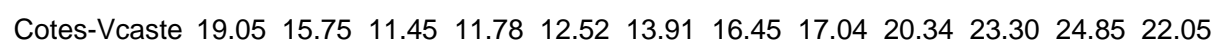

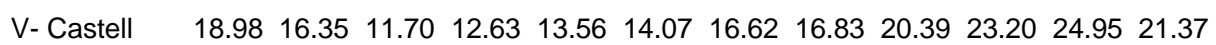

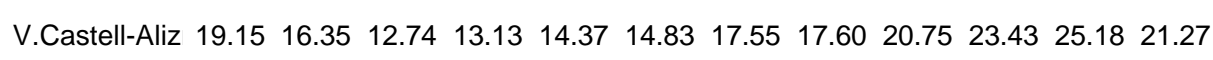

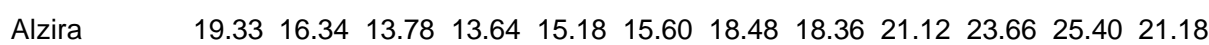

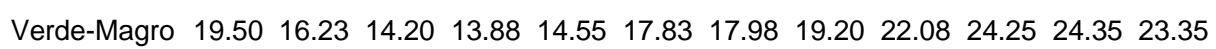

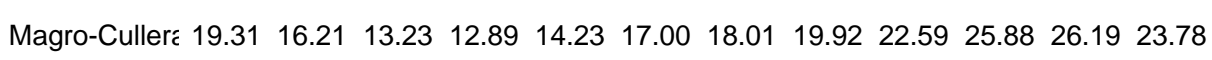

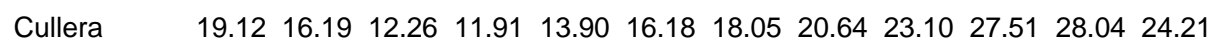





\section{ANEJO B. CALIBRACIÓN Y ANÁLISIS DE SENSIBILIDAD.}



GRÁFICOS DE CALIBRACIÓN.

Figuras calibración Embalse Alarcón

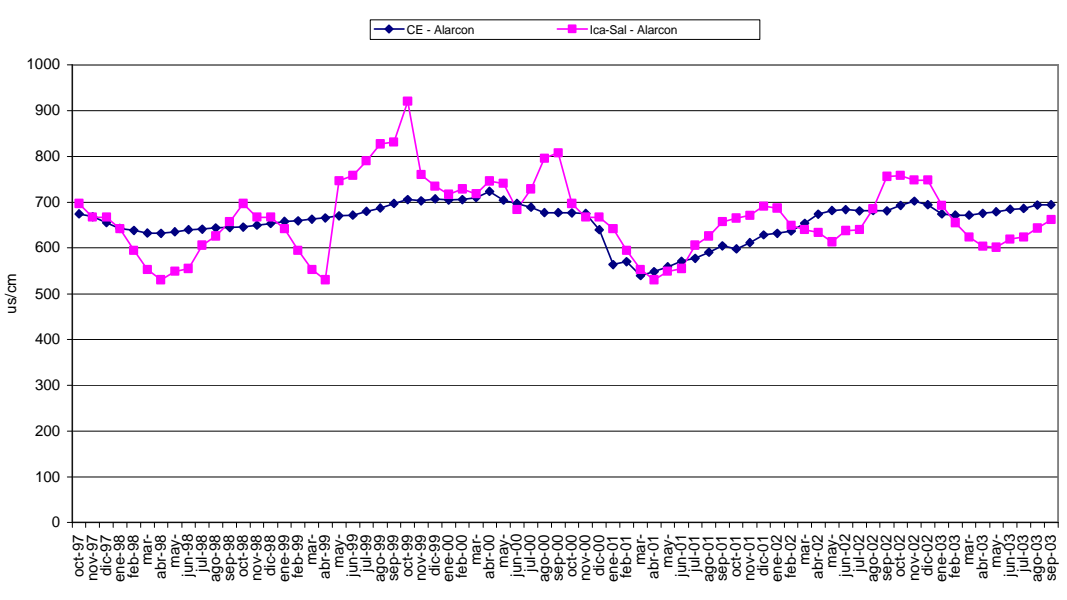

Calibración embalse de Alarcón. Sólidos suspendidos

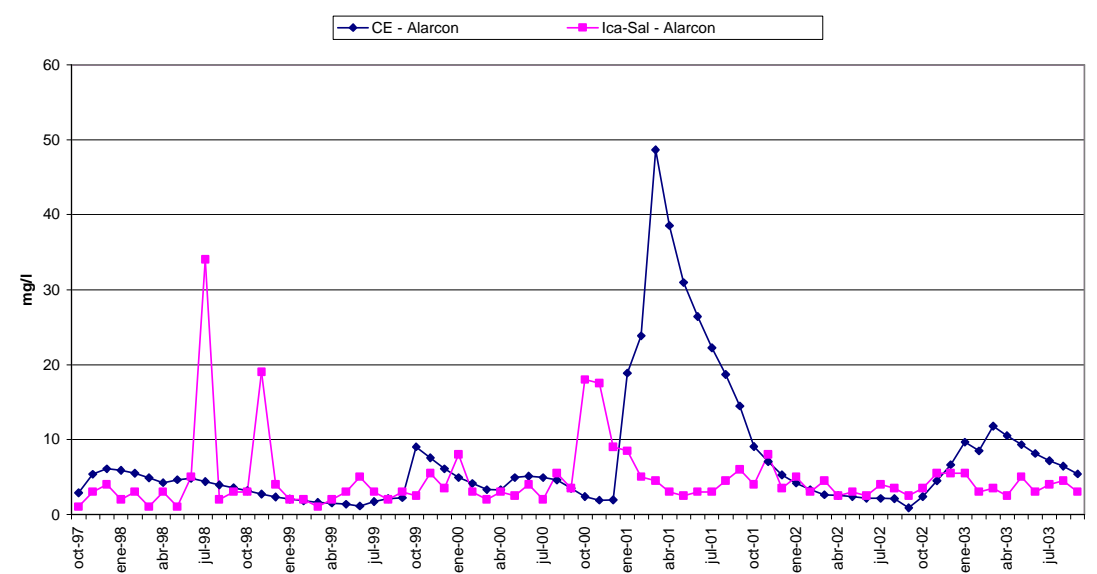

Calibración embalse de Alarcón. Oxígeno disuelto

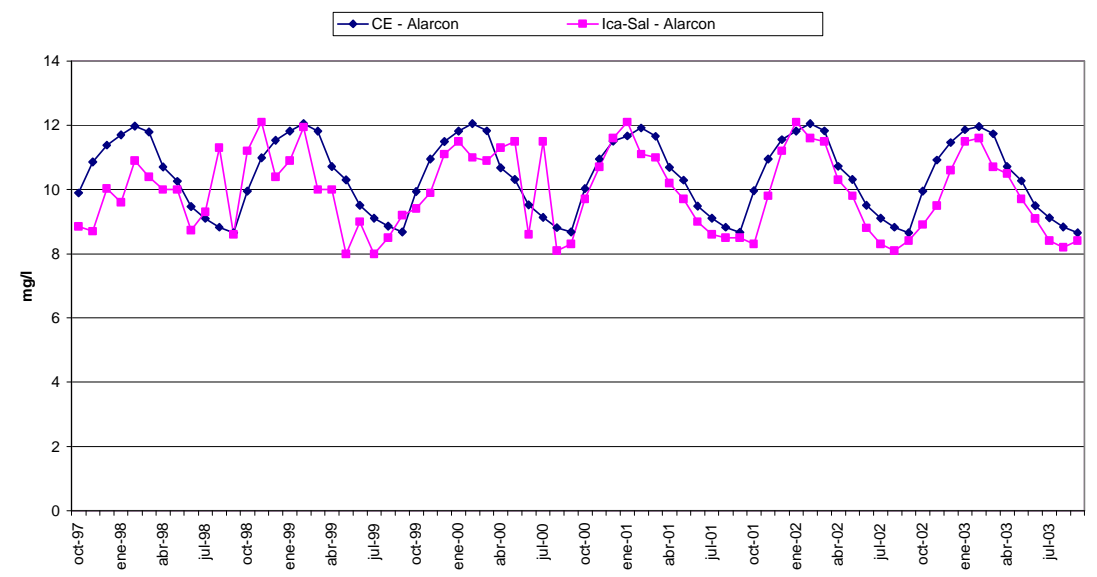


Integración de la modelación de la calidad del agua en un sistema de ayuda a la decisión para la gestión de recursos hídricos.

Calibración embalse de Alarcón. NH4
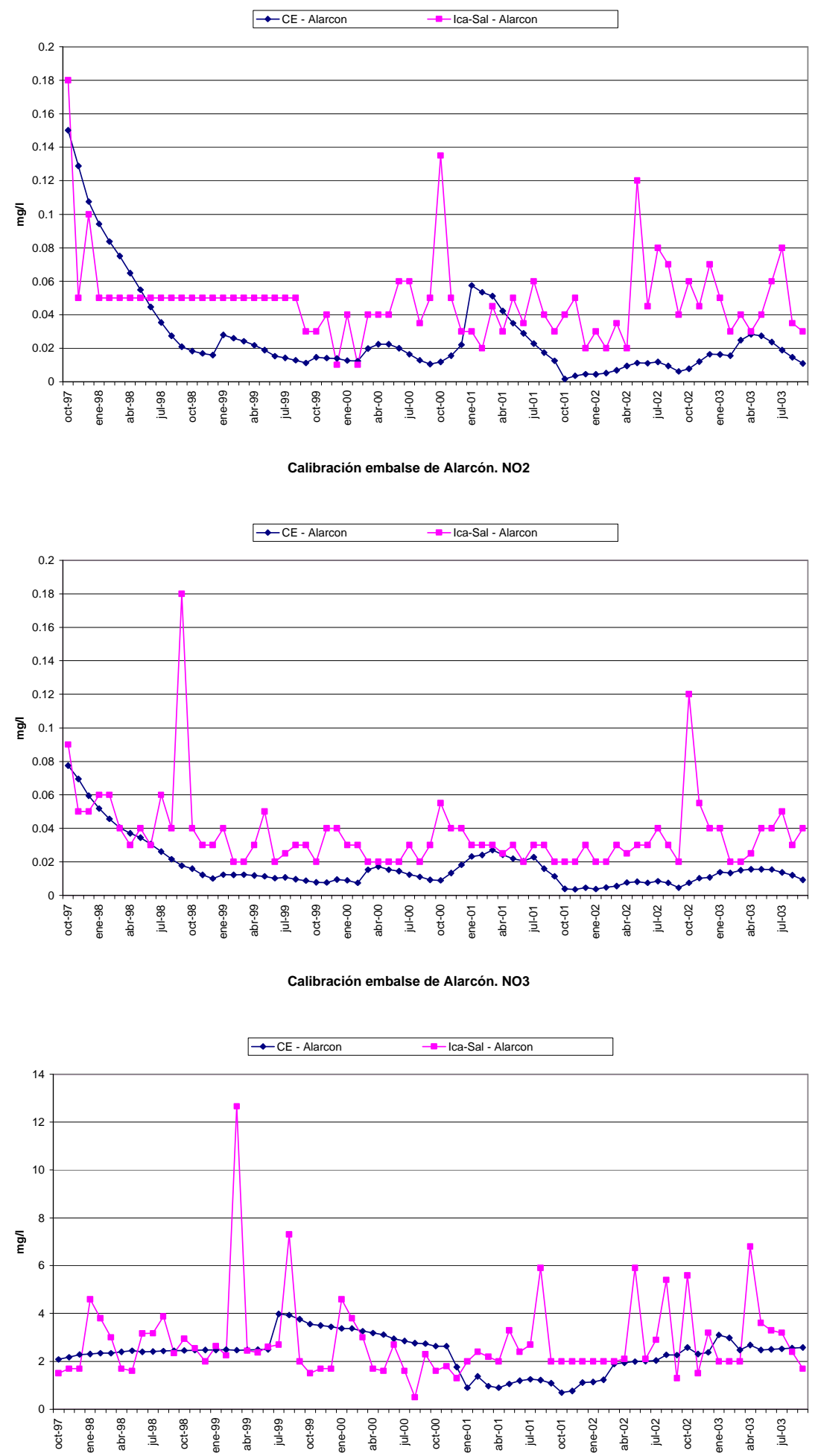


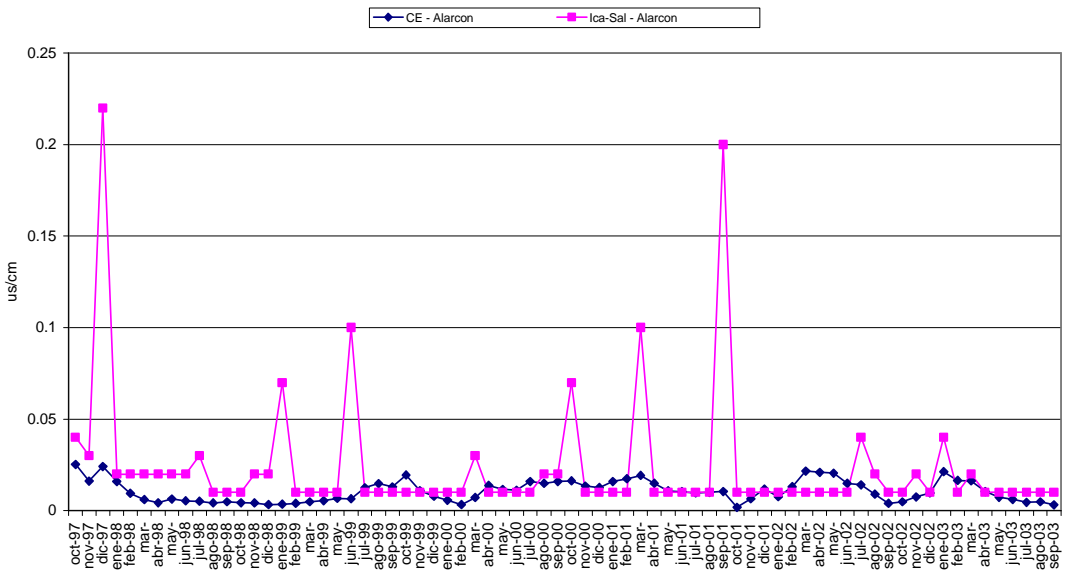

Figuras calibración embalse de Molinar

Calibración embalse de Molinar. Conductividad

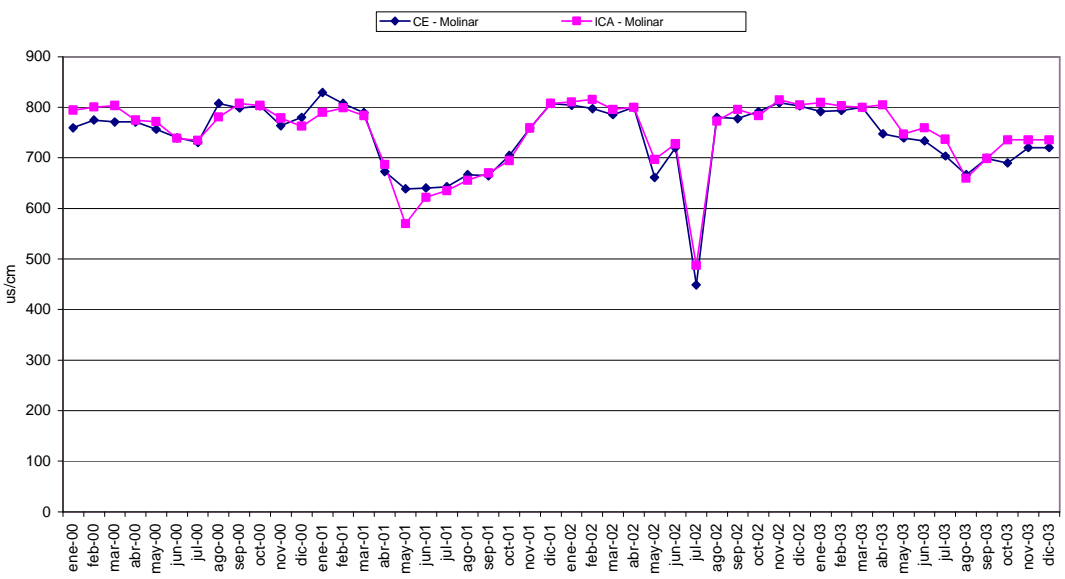

Calibración embalse de Molinar. Sólidos suspendidos

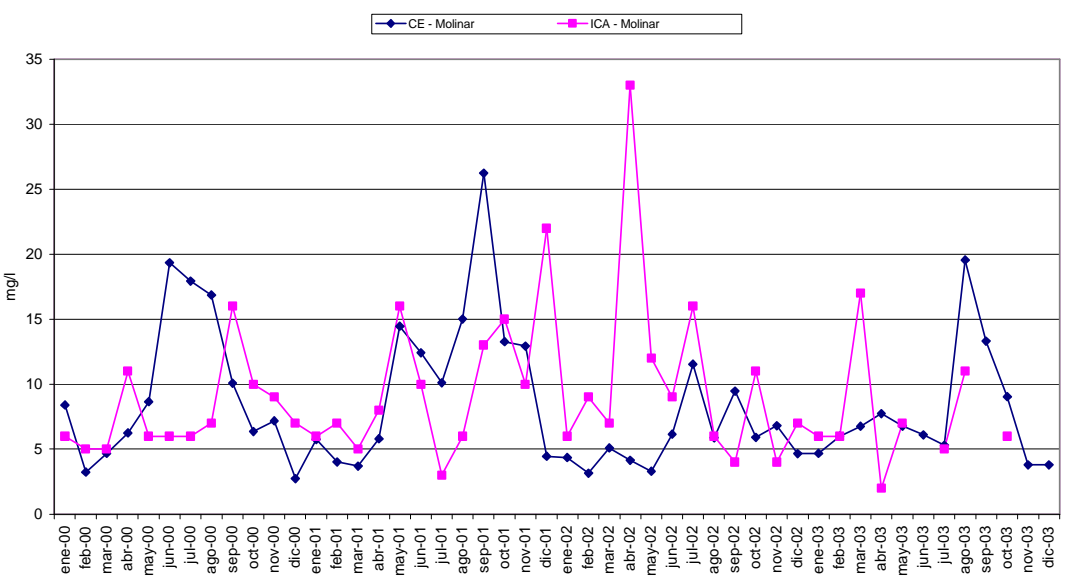


Calibración embalse de Molinar. Oxigeno Disuelto

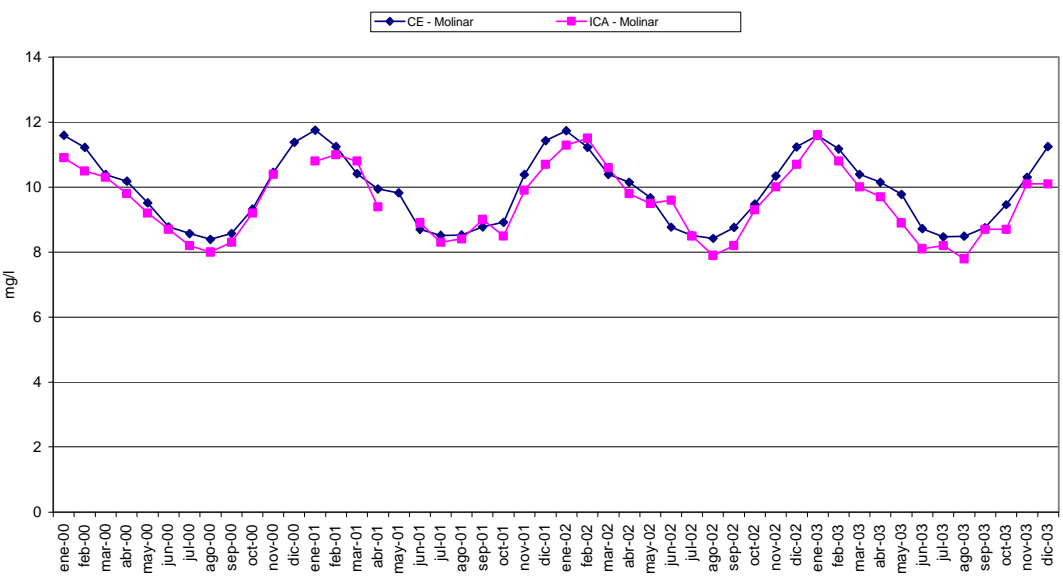

Calibración embalse de Molinar. NH4

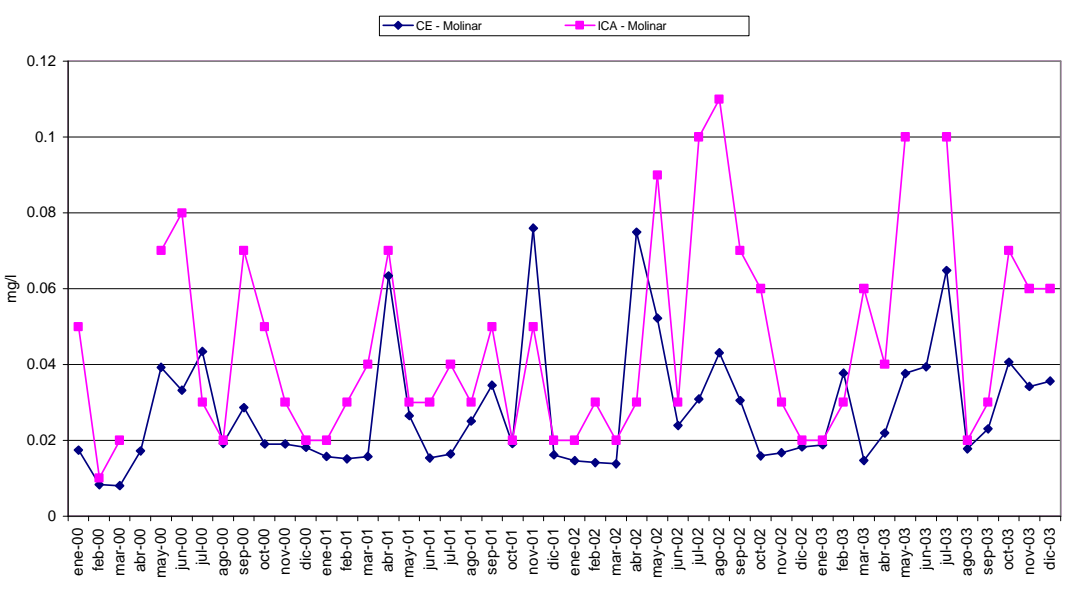

Calibración embalse de Molinar. NO2

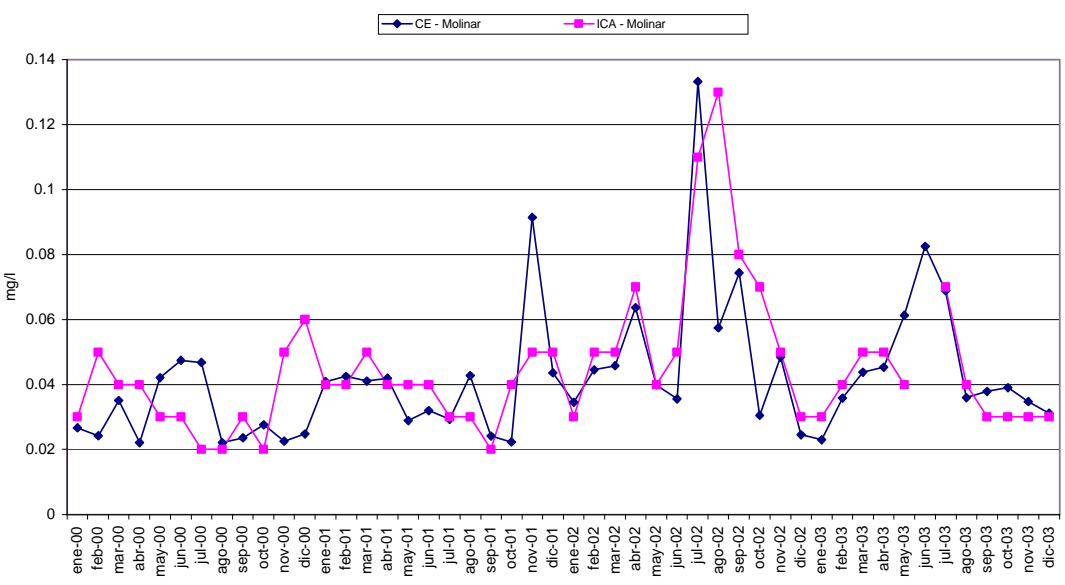


Calibración embalse de Molinar. NO3

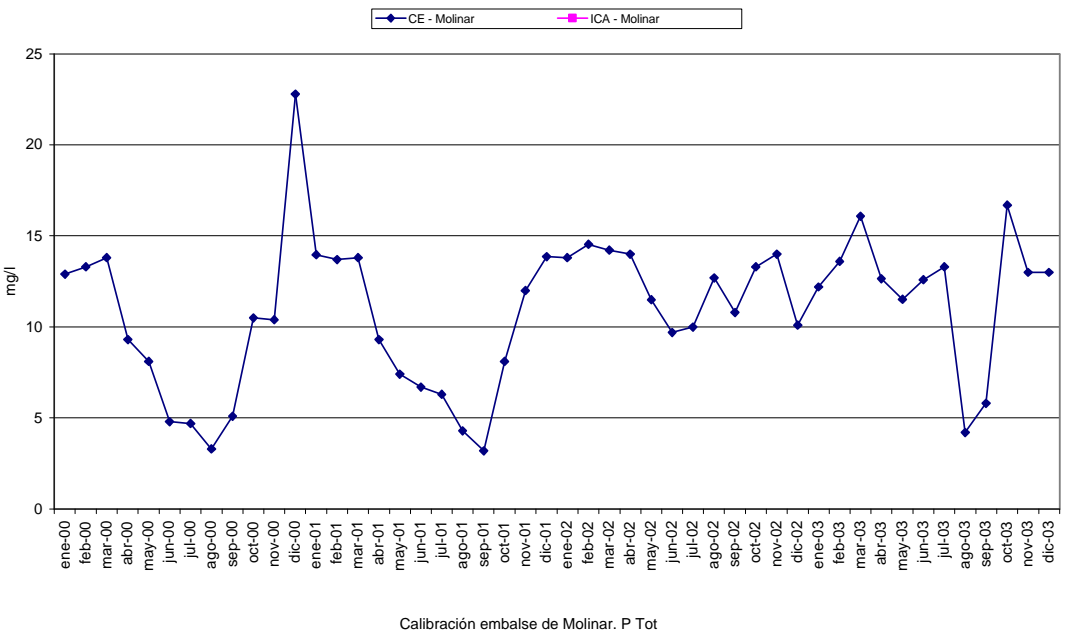

$\rightarrow-$ CE-Molinar $\rightarrow$-ICA-Molinar

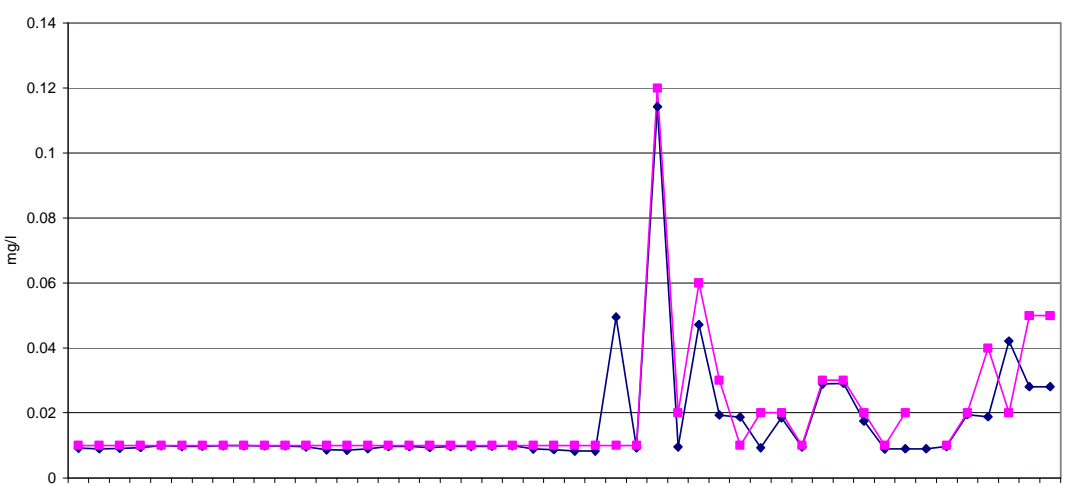

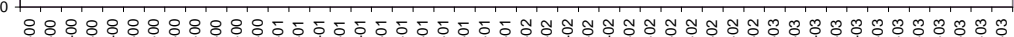

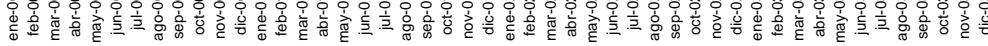


Integración de la modelación de la calidad del agua en un sistema de ayuda a la decisión para la gestión de recursos hídricos.

Figuras calibración Embalse de Contreras

Calibración embalse de Contreras. Conductividad

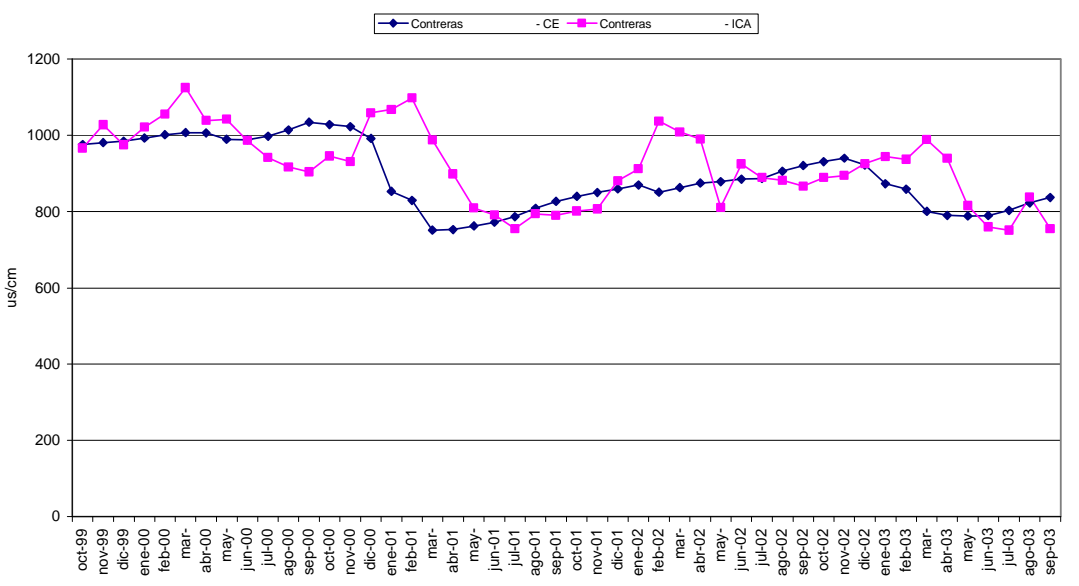

Calibración embalse de Contreras. Sólidos suspendidos

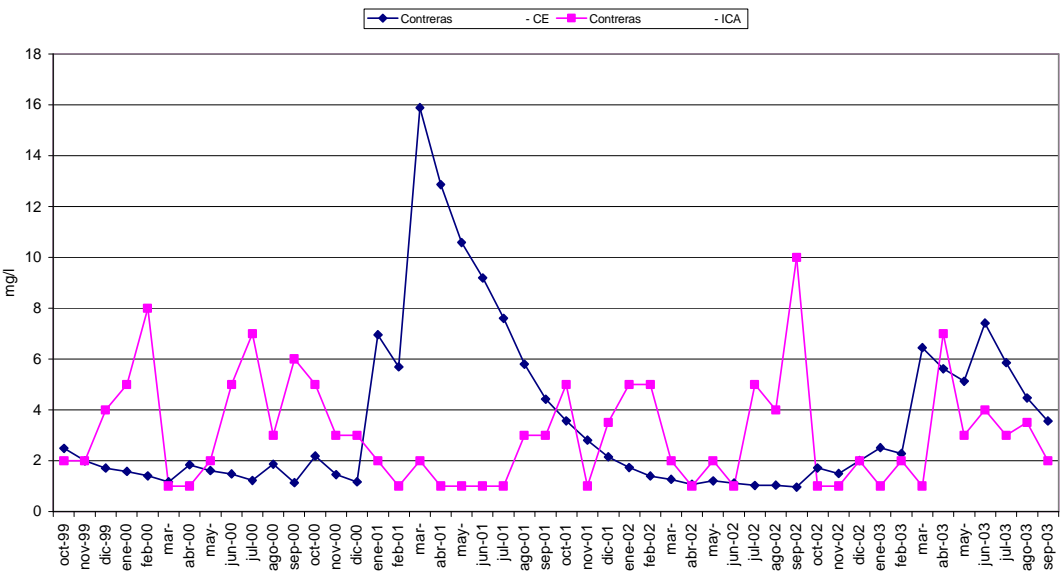

Calibración embalse de Contreras. Oxigeno Disuelto

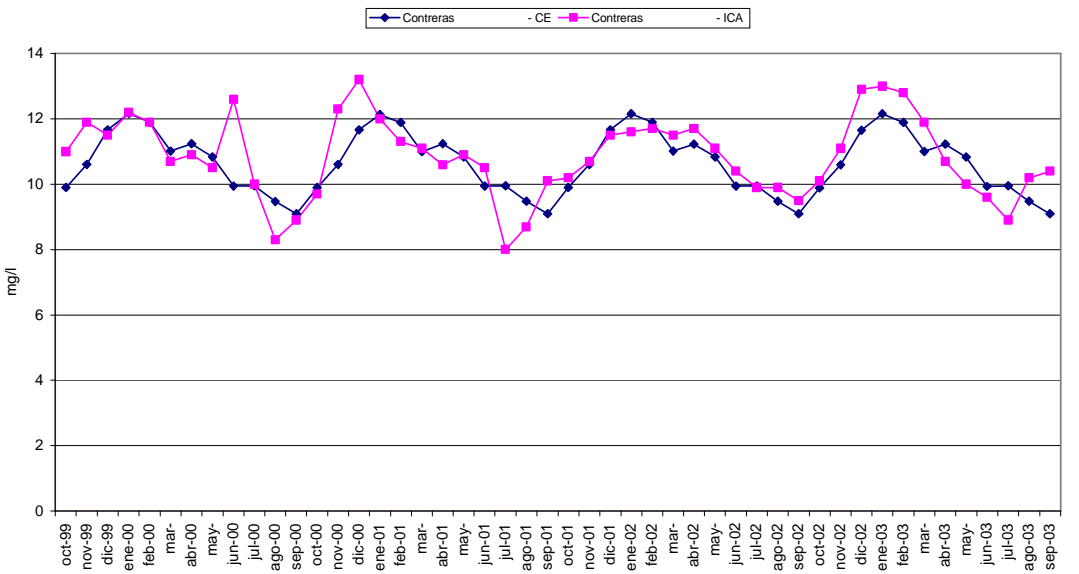


Anejo B. Calibración y análisis de sensibilidad.

Calibración embalse de Contreras. NH4

$\rightarrow-$ Contreras $\quad$ - CE $\rightarrow$ - Contreras $\quad$ ICA

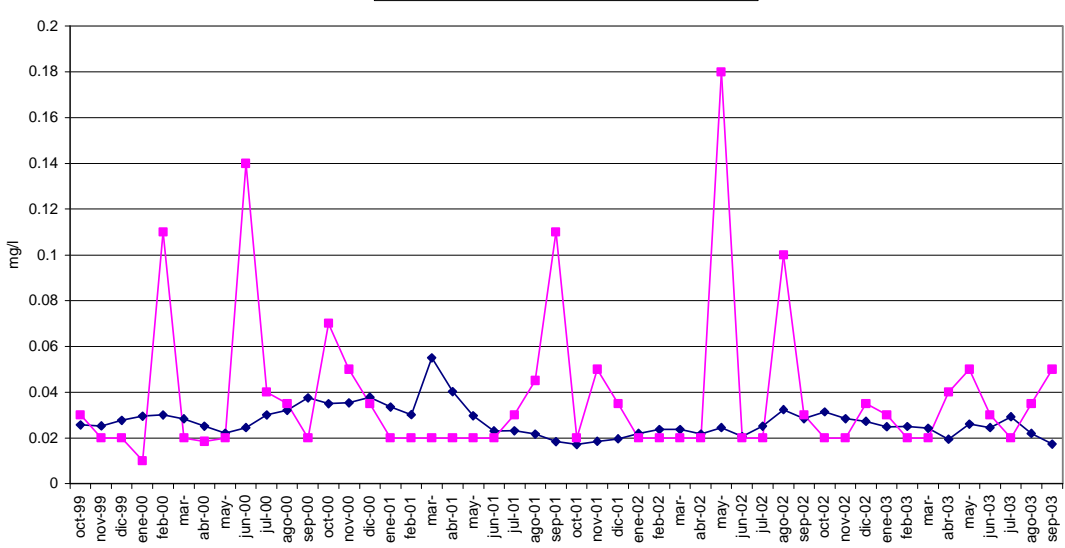

Calbracín embalse de Controras NO2

$\rightarrow-$ Contreras $\quad$-CE $\rightarrow$ - Contreras $\quad$-ICA

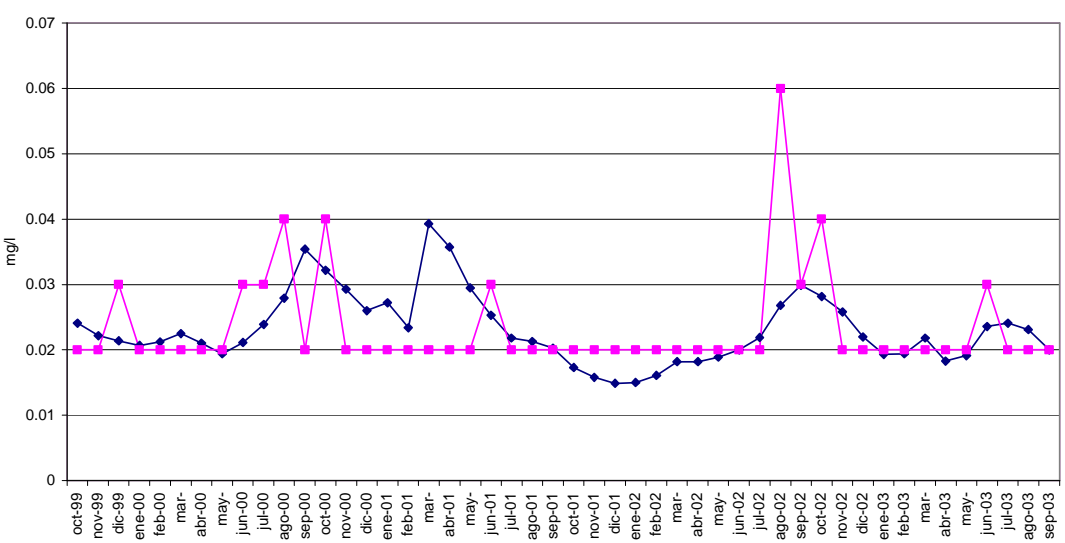

Calibración embalse de Contreras. P To

- - Contreras $\quad$ - CE $\rightarrow$ - Contreras $\quad$ - ICA

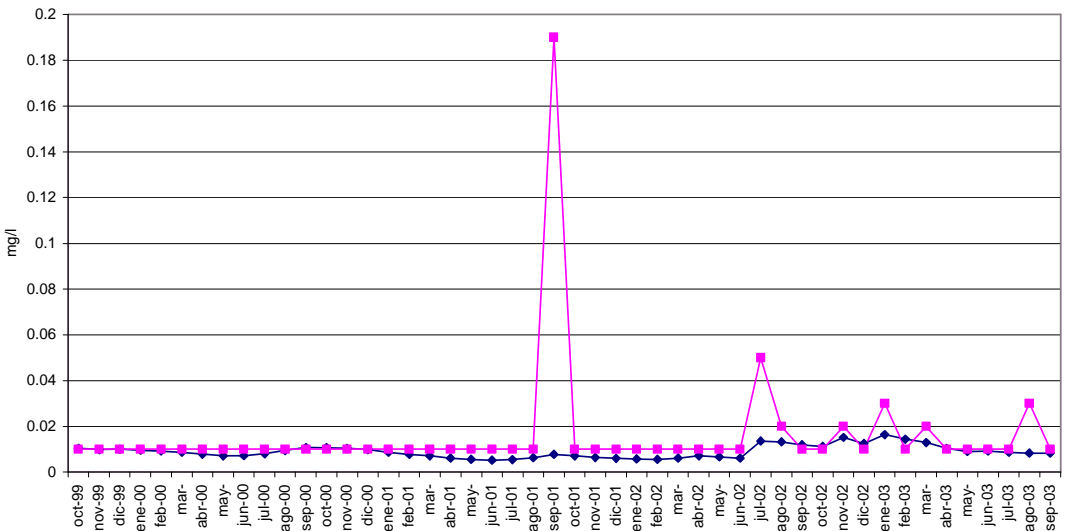


Integración de la modelación de la calidad del agua en un sistema de ayuda a la decisión para la gestión de recursos hídricos.

Figuras calibración embalses de CortesII y Naranjero

Calibración embalses Cortes II y Naranjero. Conductividad

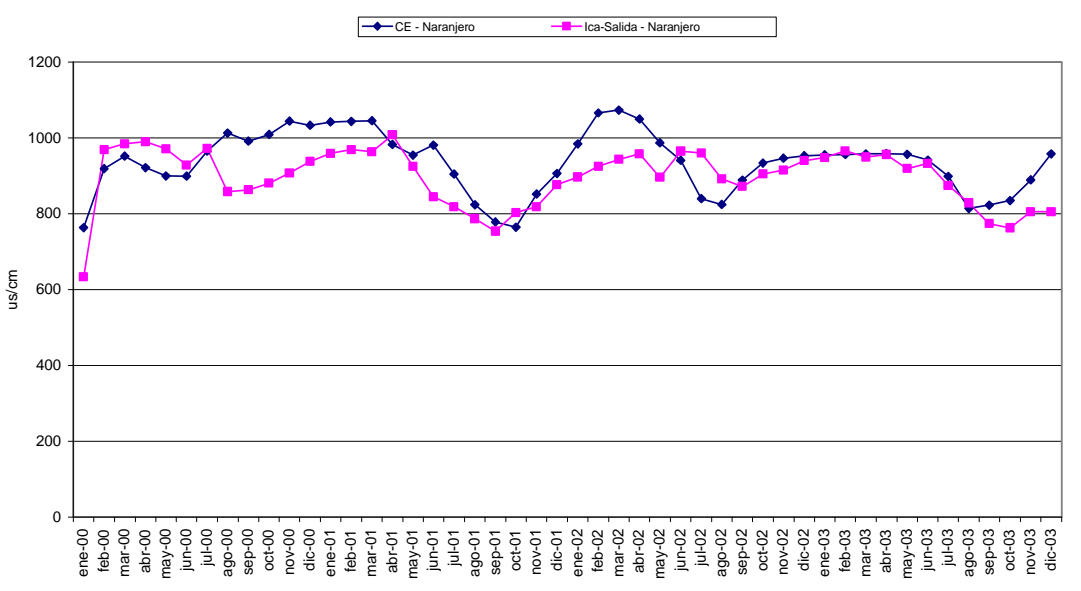

Calibración embalses Cortes II y Naranjero. Sólidos suspendidos

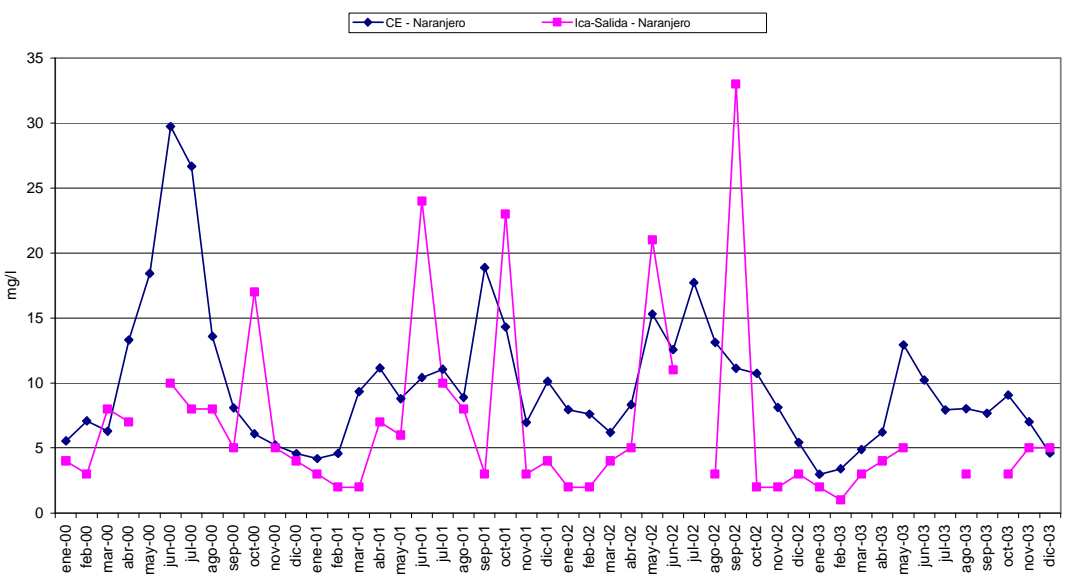

Calibración embalses Cortes II y Naranjero. Oxigeno disuelto

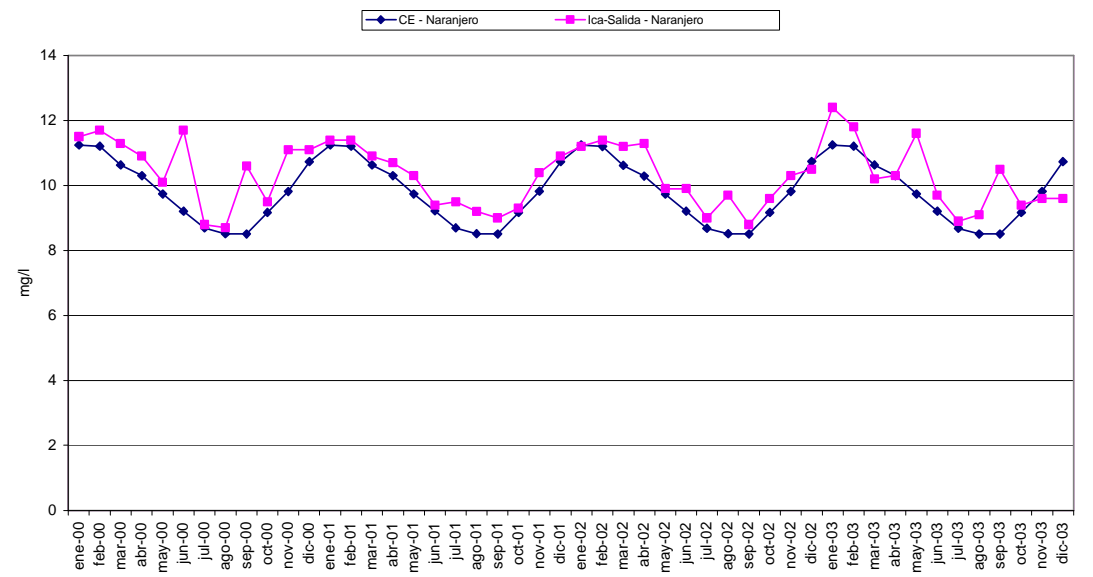


Anejo B. Calibración y análisis de sensibilidad.

Calibración embalses Cortes II y Naranjero. NH4

$\rightarrow-$ CE- Naranjero $\rightarrow$-ICa-Salida - Naranjero

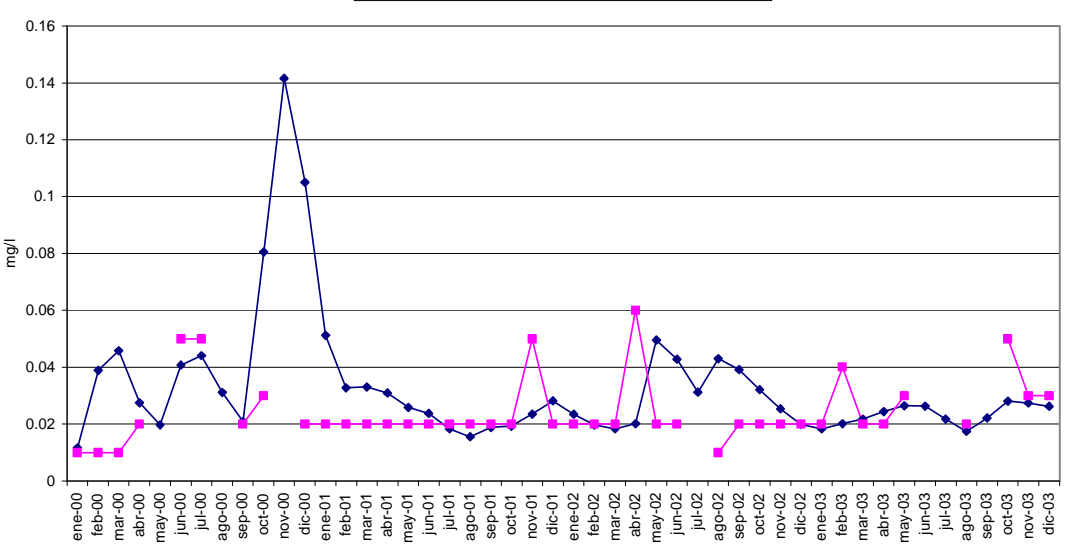

Calibración embalses Cortes II y Naraniero. NO2

$\rightarrow$ - CE-Naranjero $\rightarrow-$-ICa-Salida-Naranjero

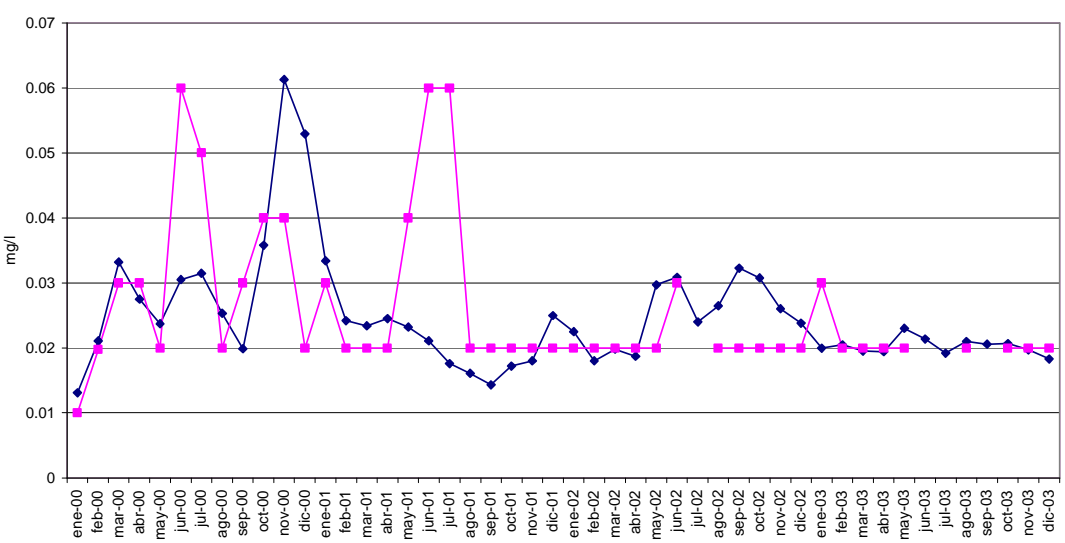

Calibración embalses Cortes II y Naranjero. P T

$\rightarrow-$ CE - Naranjero $\rightarrow-$ Ica-Salida - Naranjero

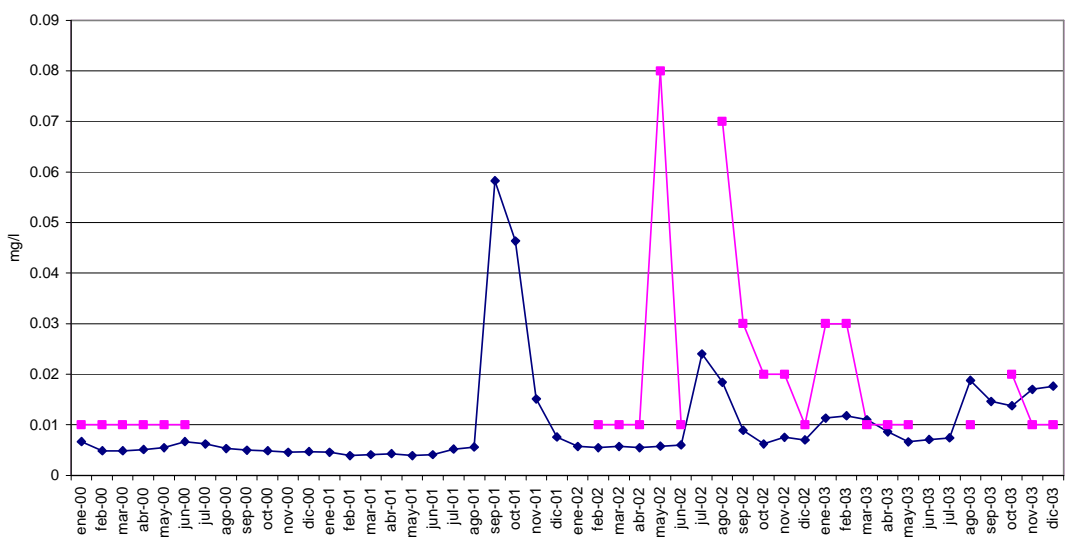


Integración de la modelación de la calidad del agua en un sistema de ayuda a la decisión para la gestión de recursos hídricos.

Figuras calibración embalse de Tous

Calibración embalse de Tous. Conductividad

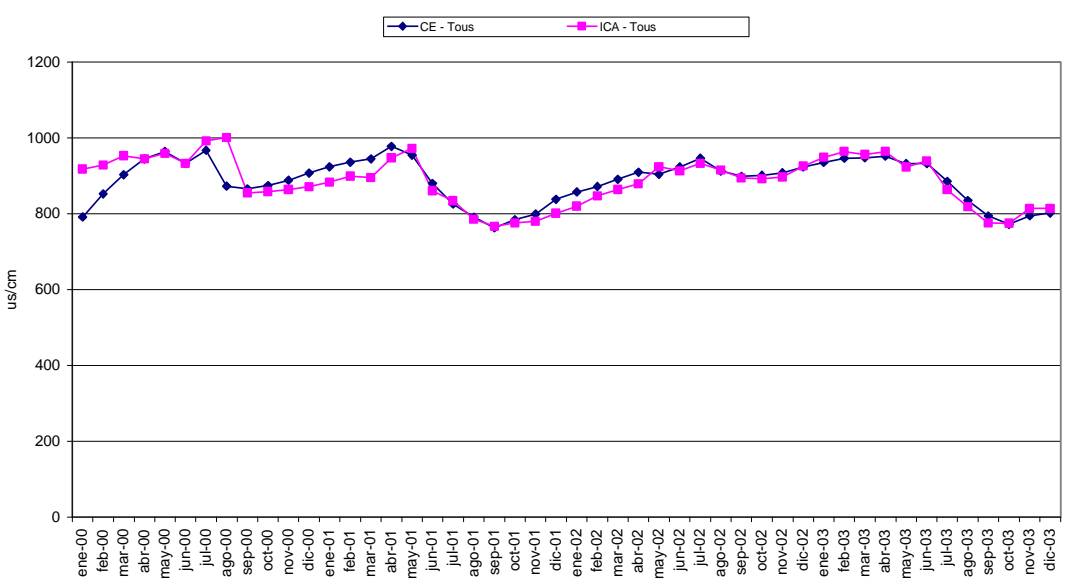

Calibración embalse de Tous. Sólidos suspendidos

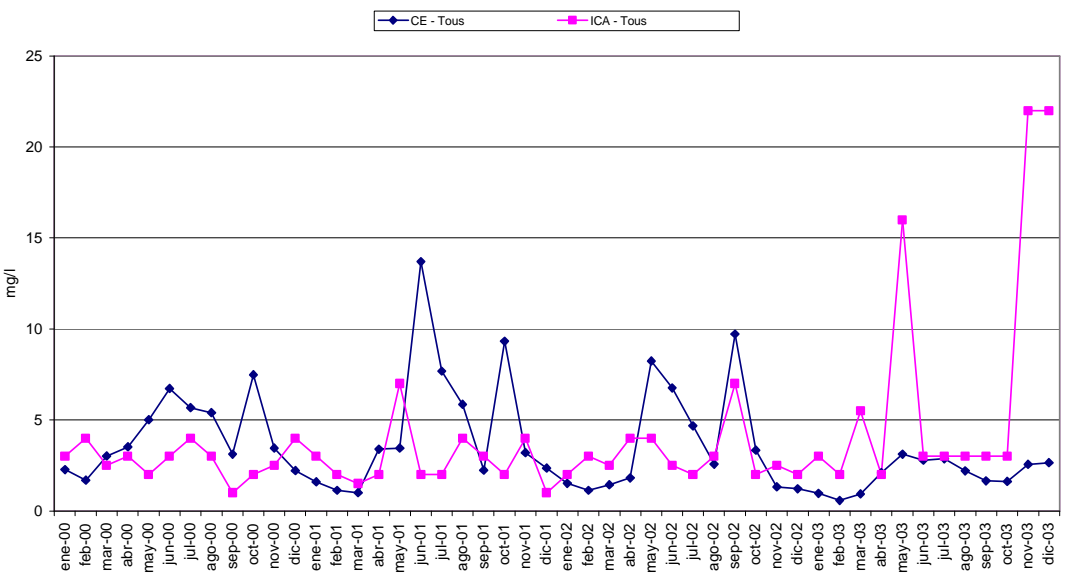

Calibración embalse de Tous. Oxigeno Disuelto

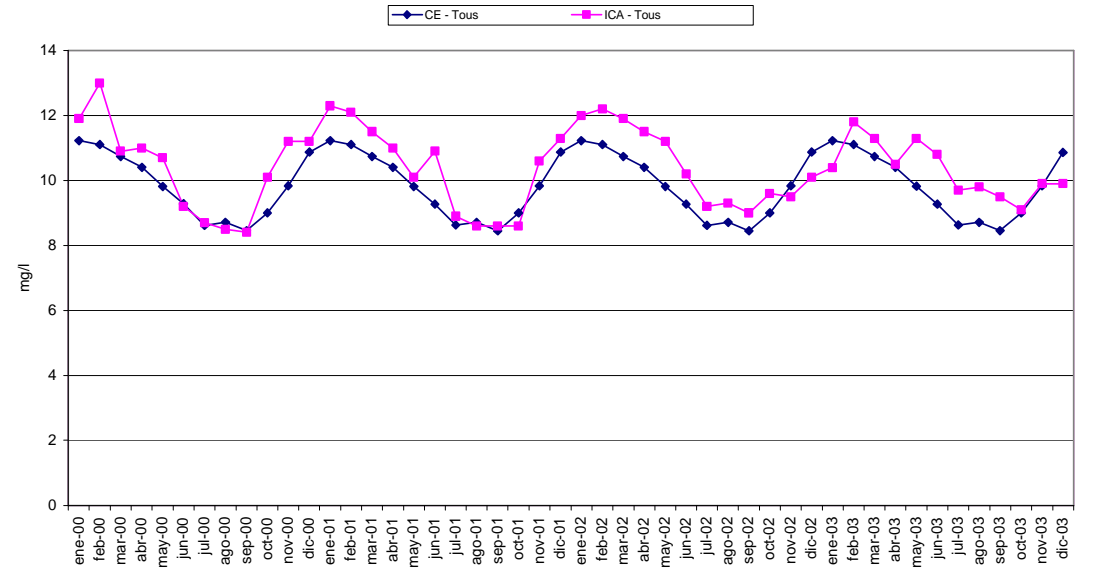


Anejo B. Calibración y análisis de sensibilidad.

Calibración embalse de Tous. NH4

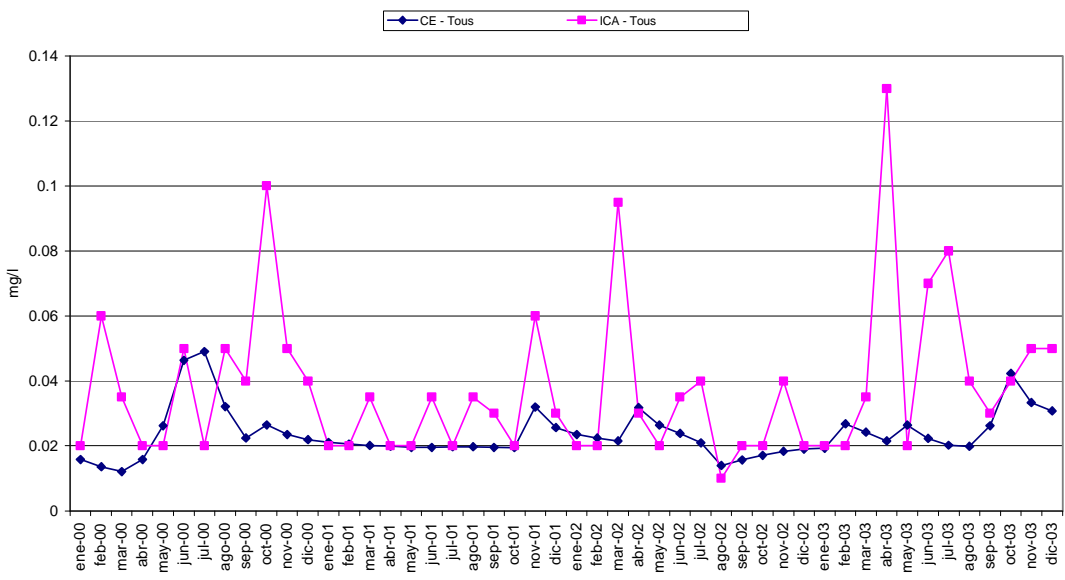

Calibración embalse de Tous. NO2

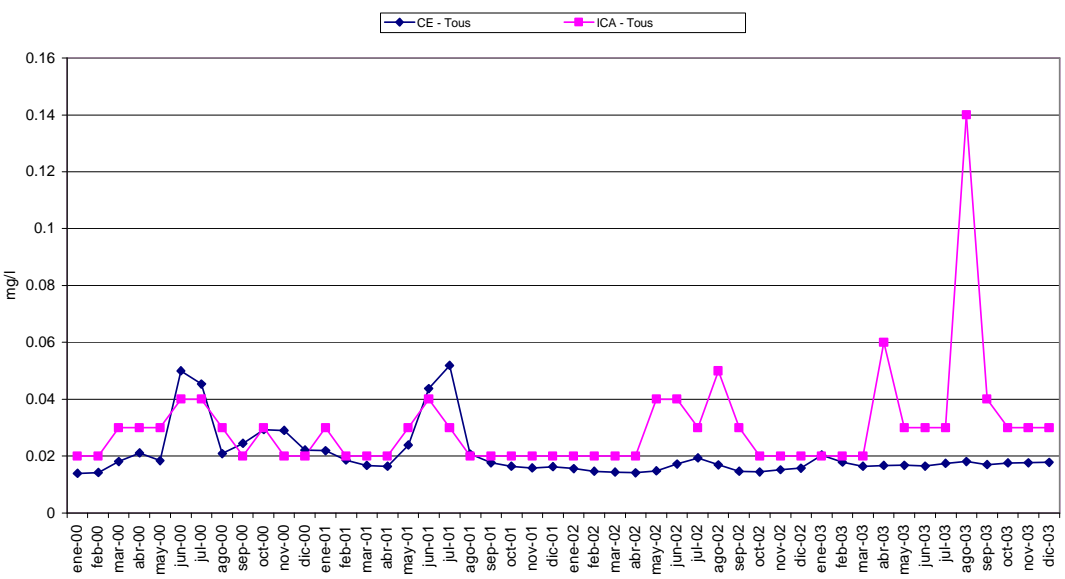

Calibración embalse de Tous. P To

$\rightarrow-$ CE-Tous $\quad \rightarrow-$ ICA- Tous

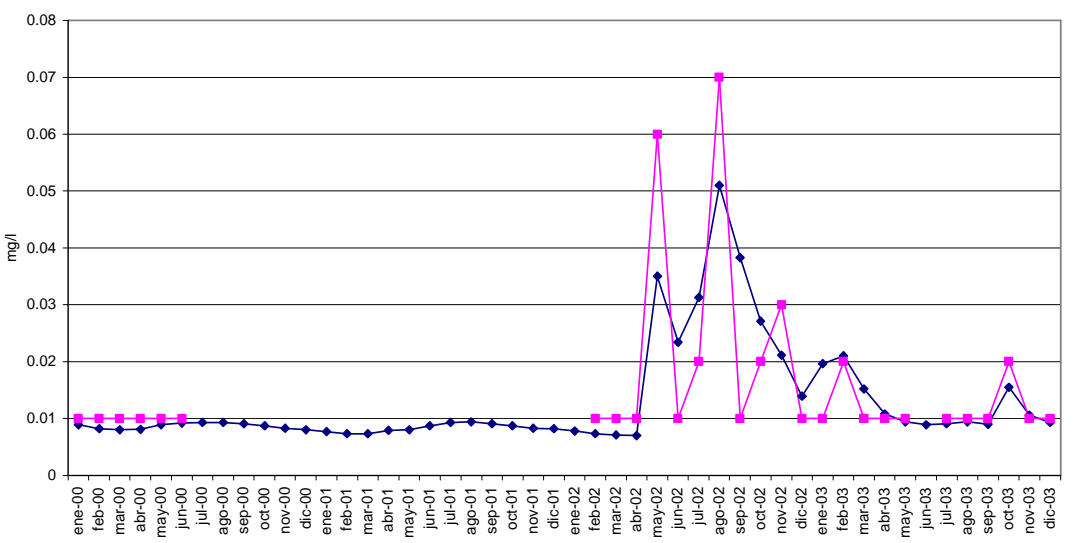


Integración de la modelación de la calidad del agua en un sistema de ayuda a la decisión para la gestión de recursos hídricos.

Figuras calibración Júcar-1

Calibración Júcar-1. Conductividad
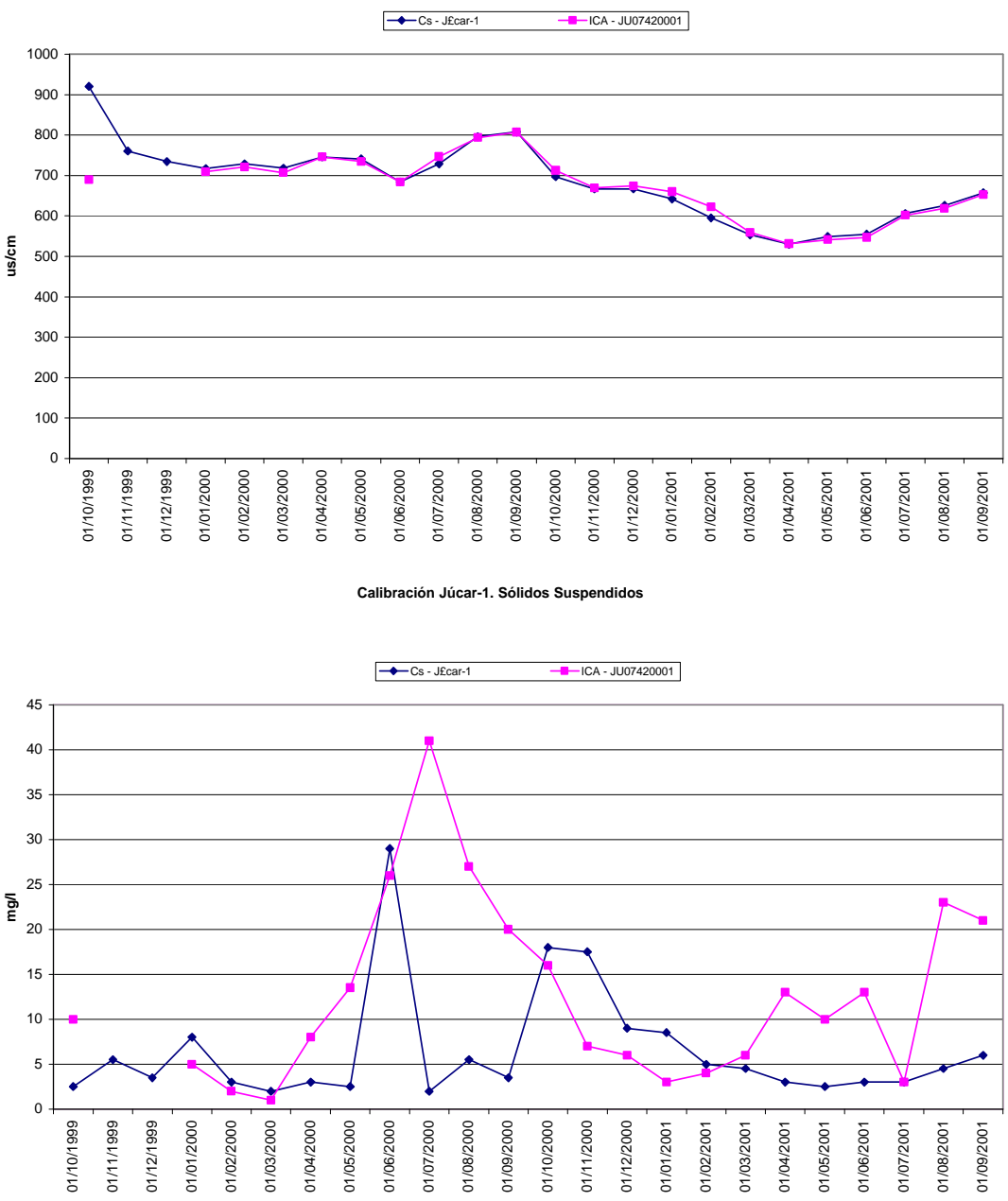

Calibración Júcar-1. Oxigeno Disuelto

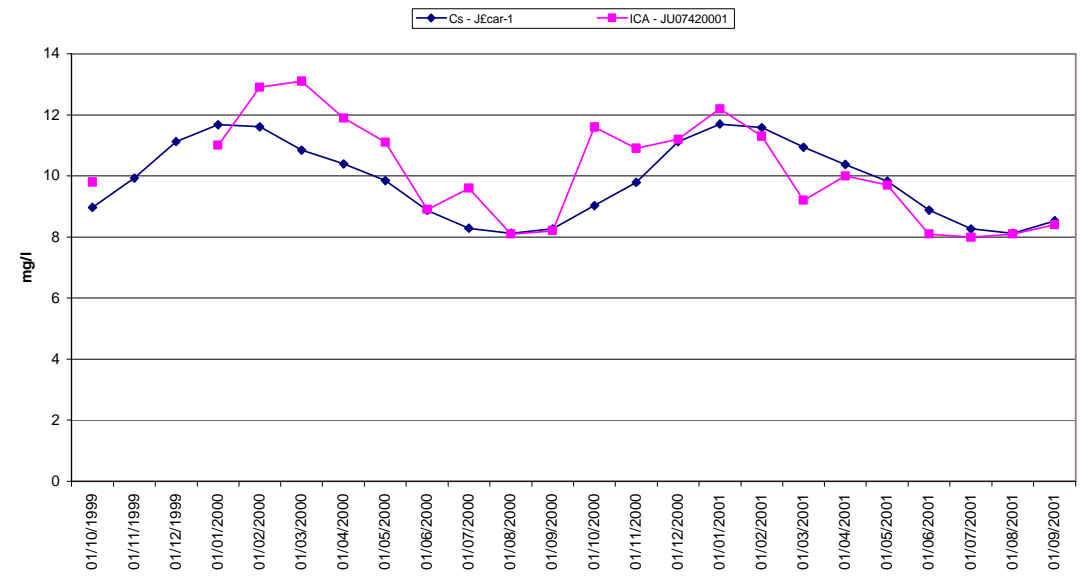



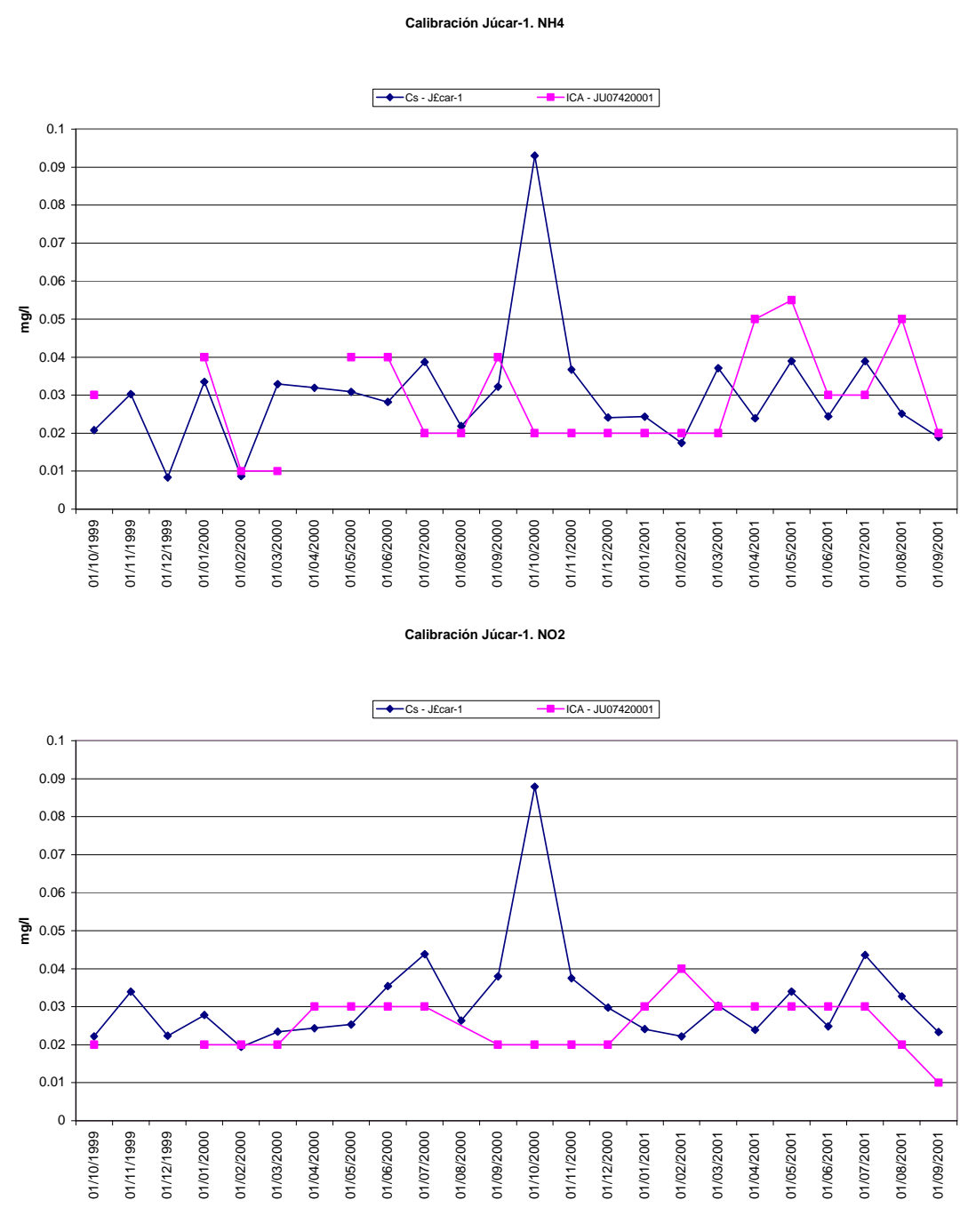

Calibración Júcar-1. P Tot

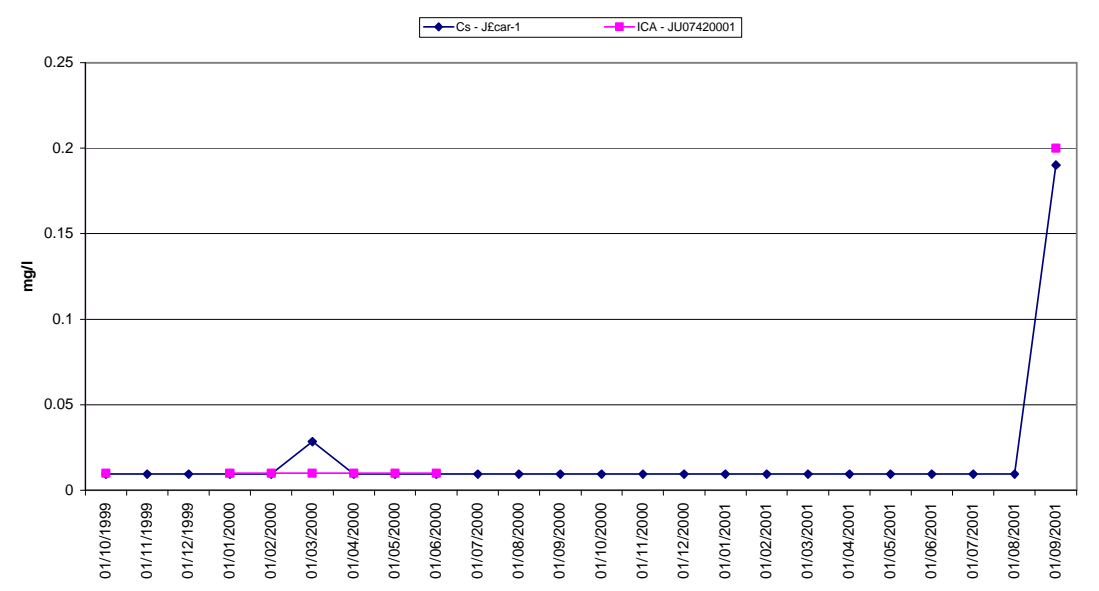


Integración de la modelación de la calidad del agua en un sistema de ayuda a la decisión para la gestión de recursos hídricos.

Figuras calibración Conexión Júcar-Macha

Calibración Conexión Júcar-Macha. Conductividad

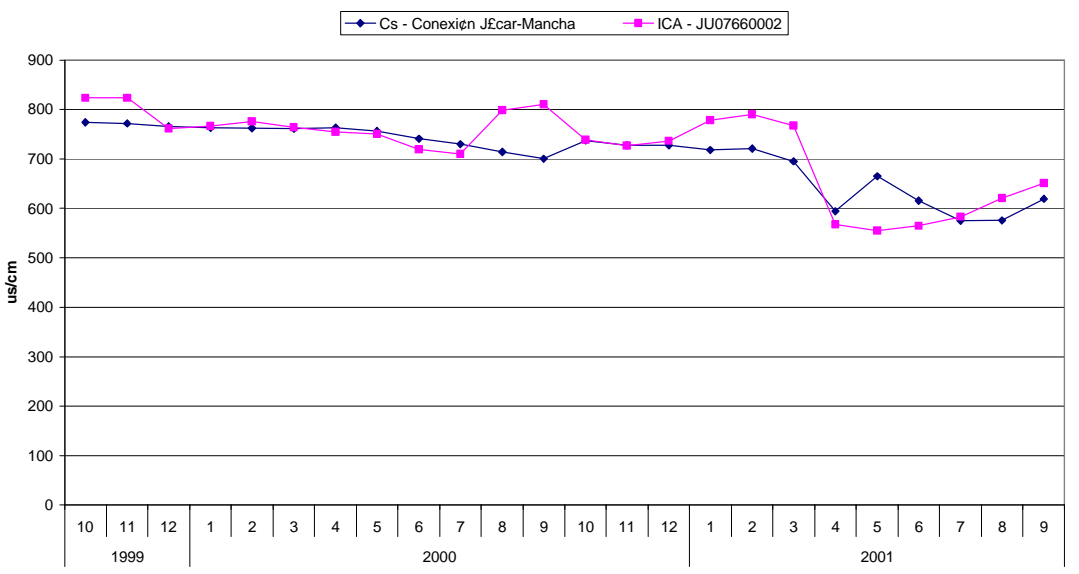

Calibración Conexión Júcar-Macha. Sólidos Suspendidos

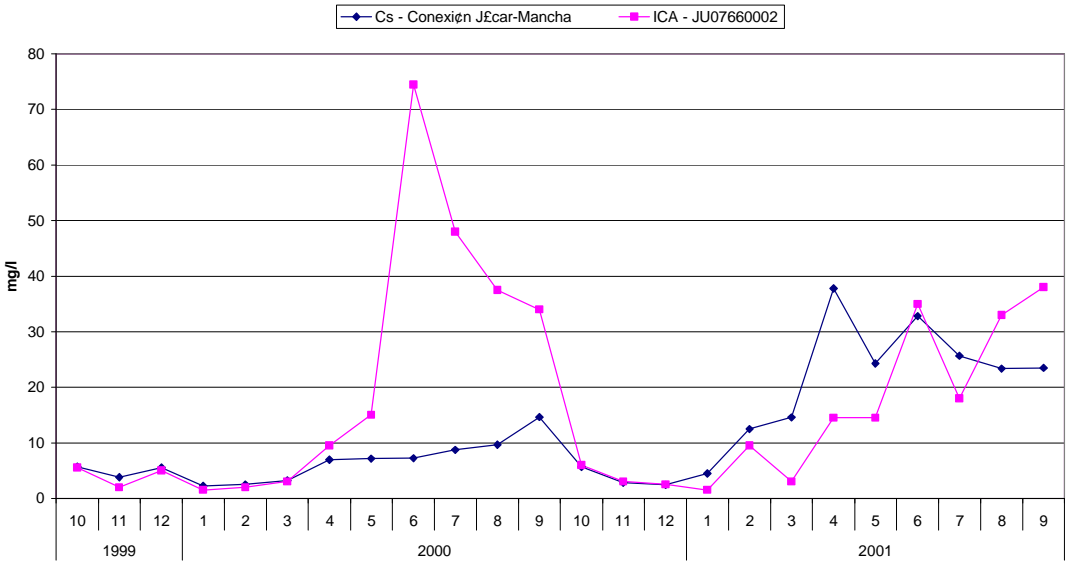

Calibración Conexión Júcar-Macha. Oxígeno Disuelto

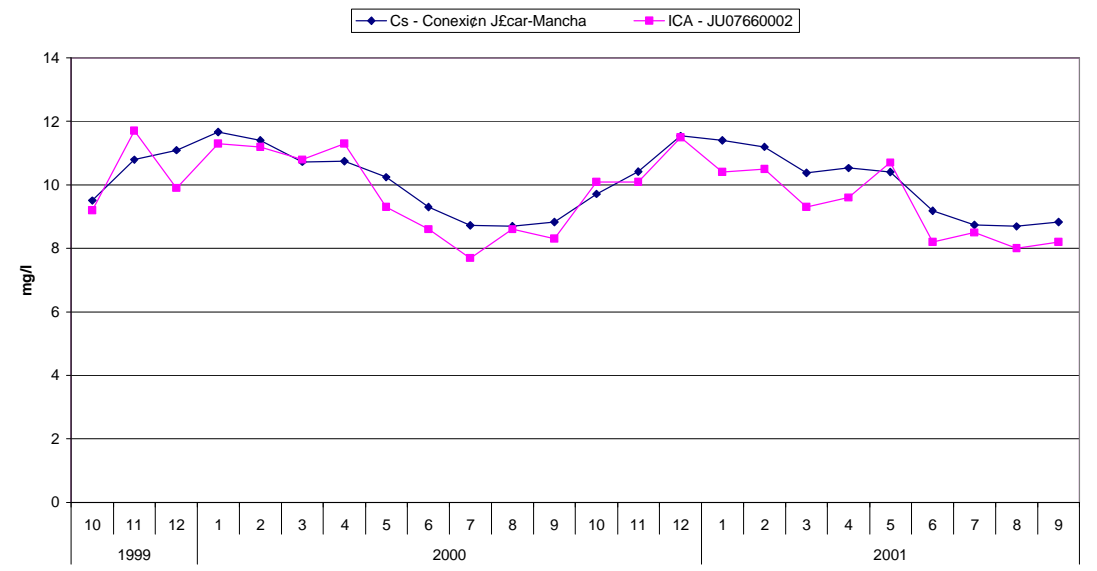


Anejo B. Calibración y análisis de sensibilidad.

Calibración Conexión Júcar-Macha. NH4

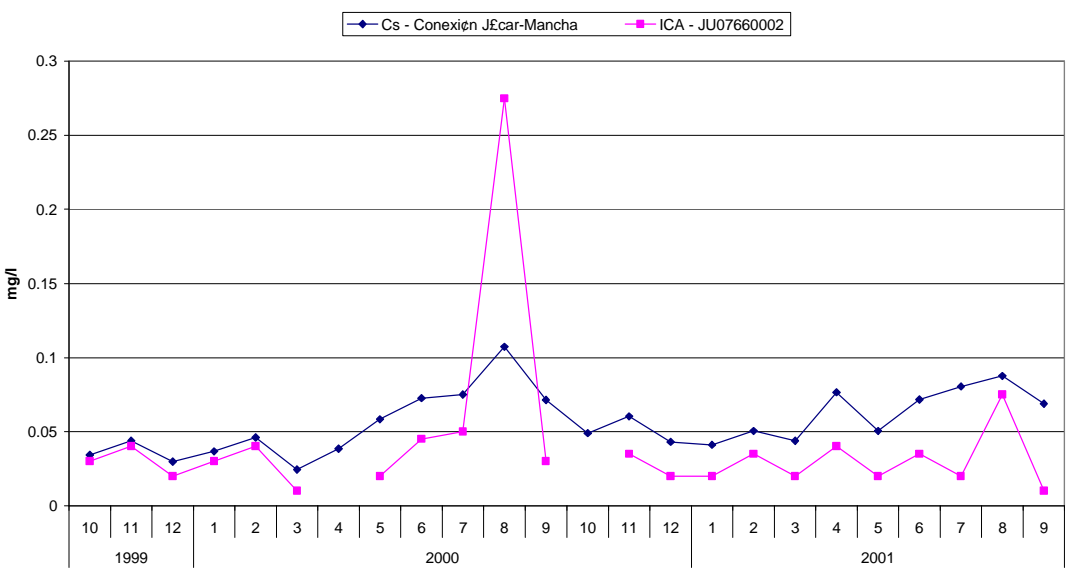

Calibración Conexión Júcar-Macha. NO2

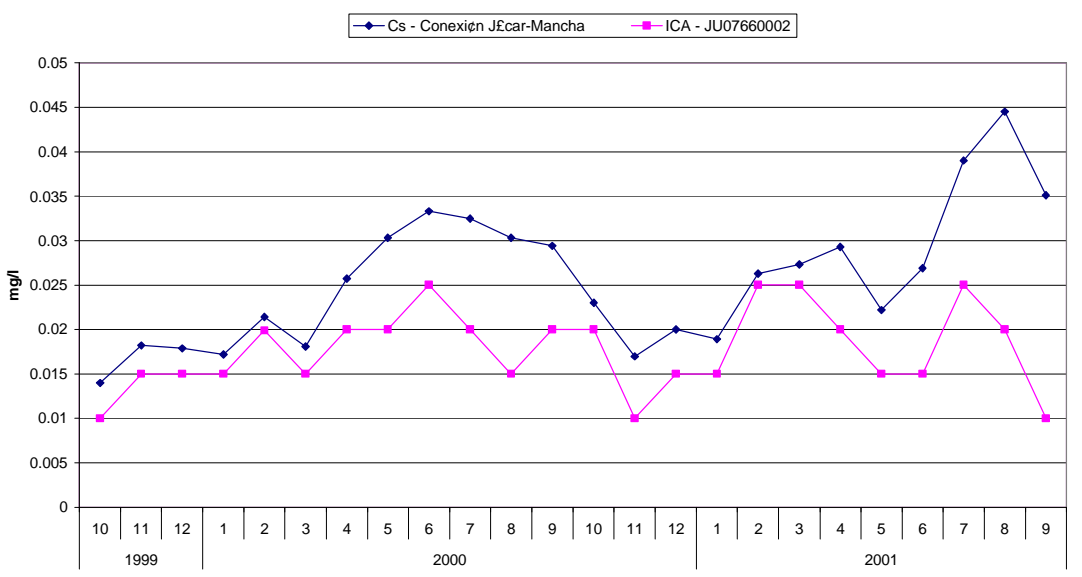

Calibración Conexión Júcar-Macha. NO3

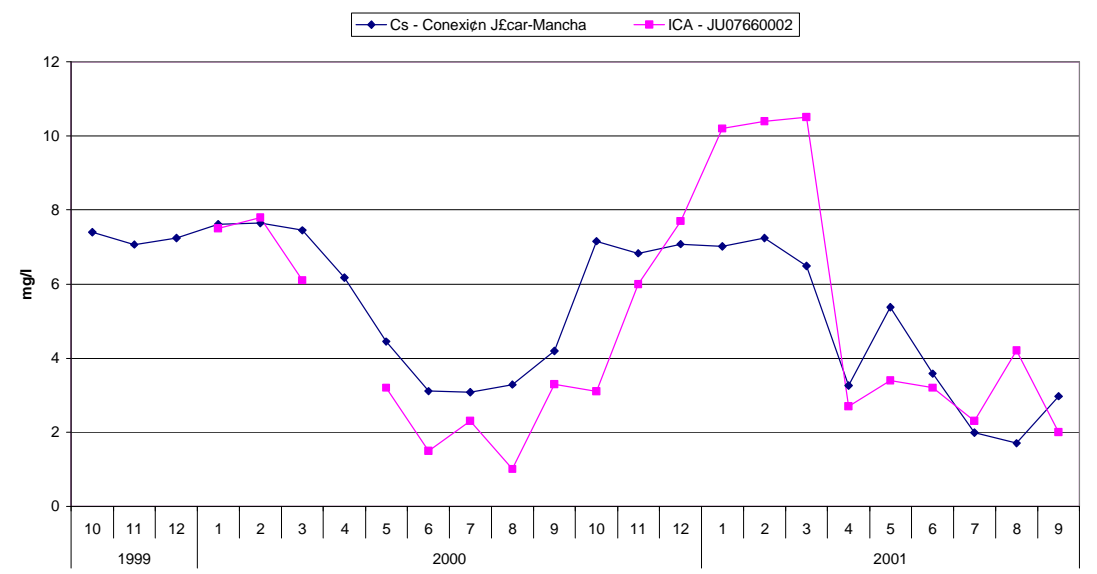


Integración de la modelación de la calidad del agua en un sistema de ayuda a la decisión para la gestión de recursos hídricos.

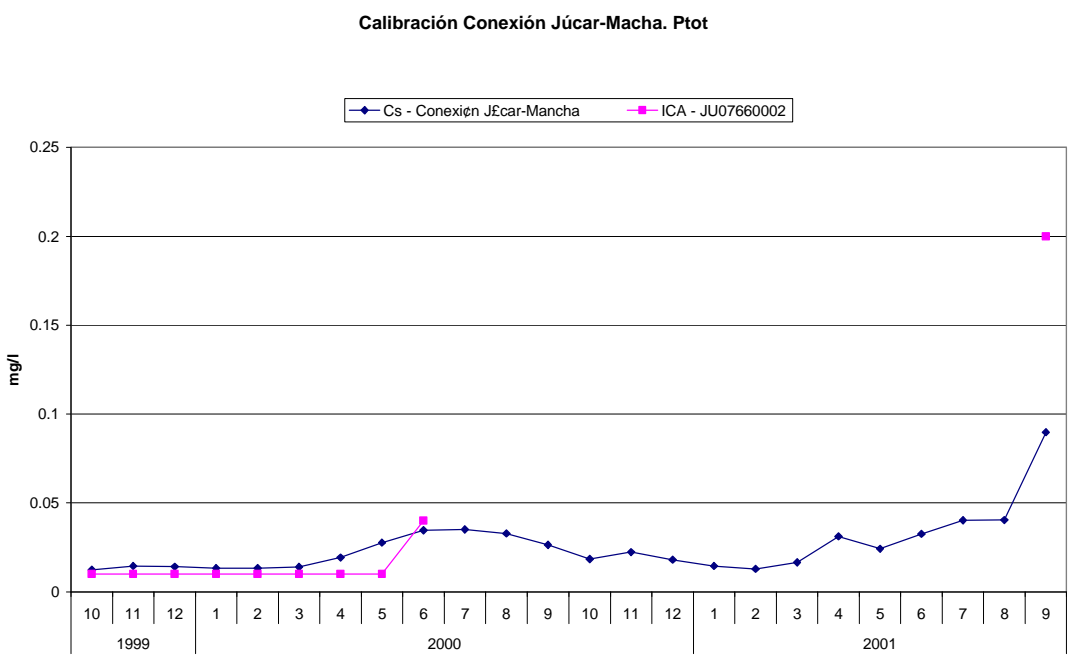

Figuras calibración Júcar-3

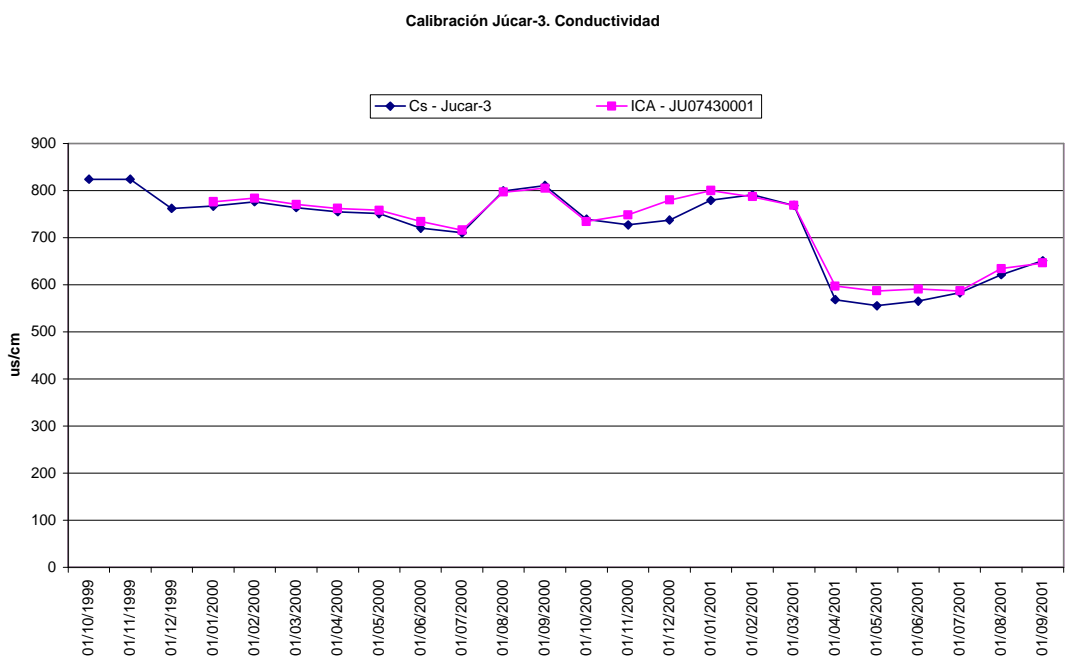

Calibración Júcar-3. Sólidos Suspendidos

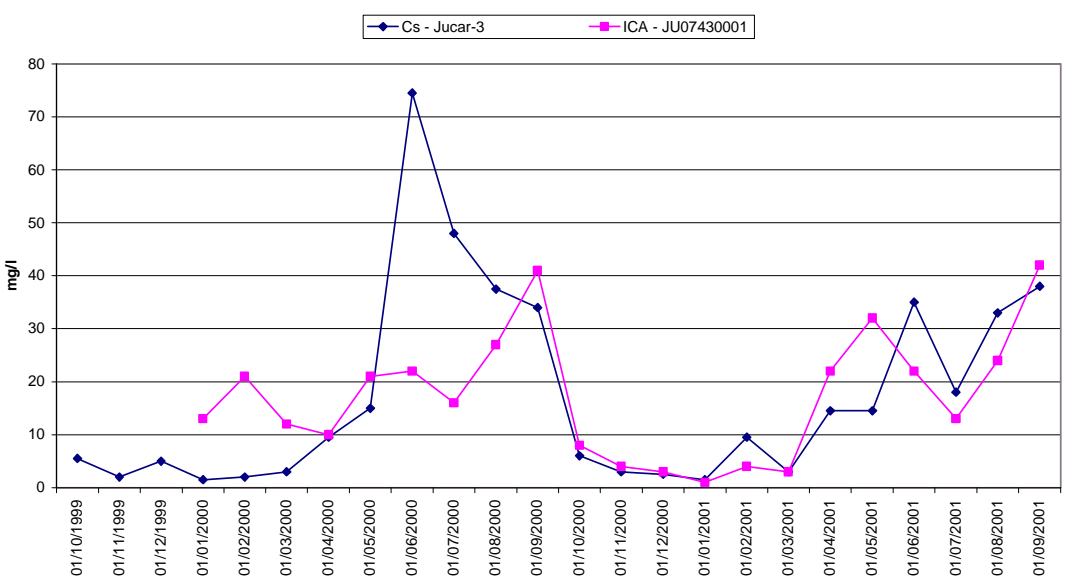



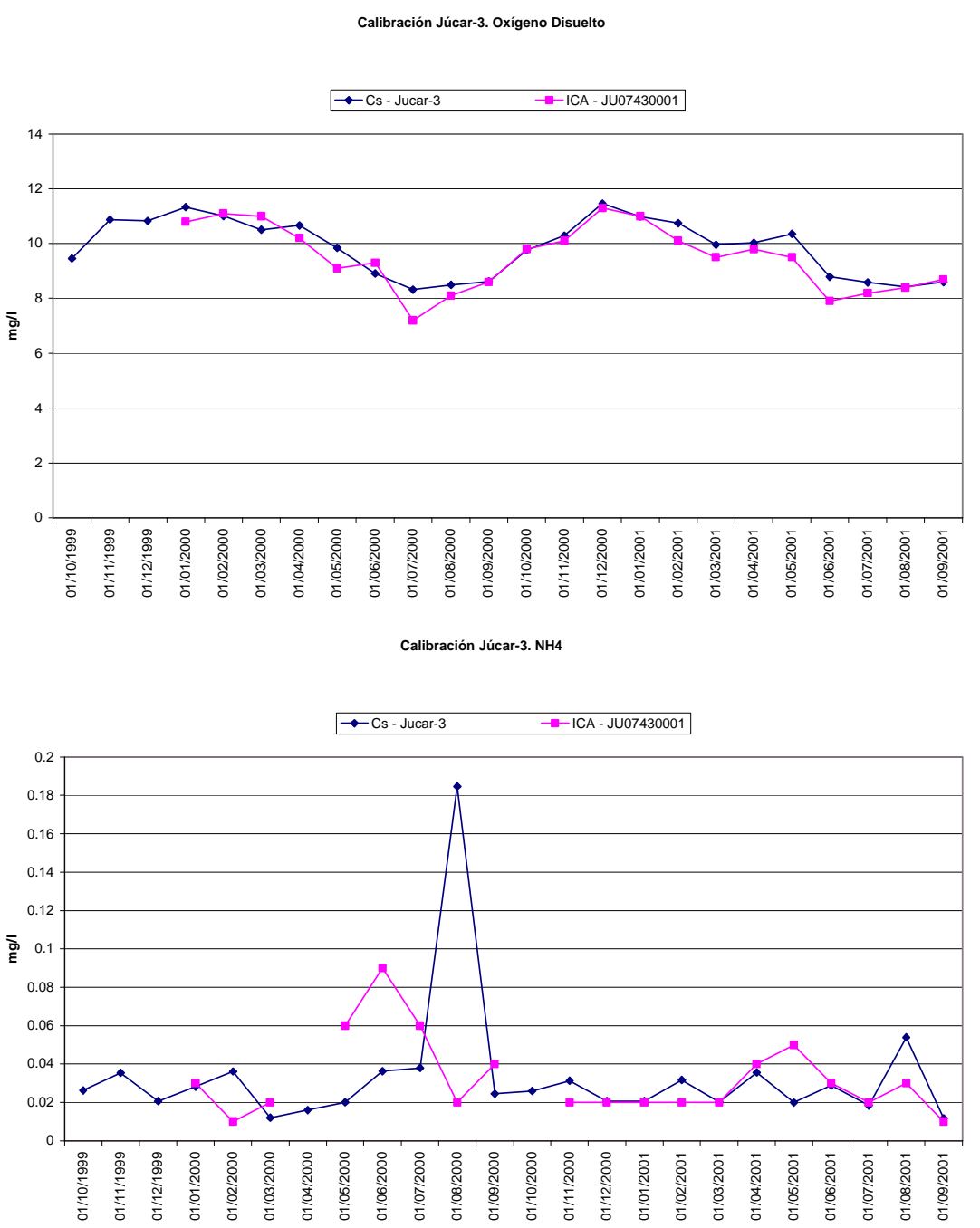
Integración de la modelación de la calidad del agua en un sistema de ayuda a la decisión para la gestión de recursos hídricos.

Calibración Júcar-3. NO2
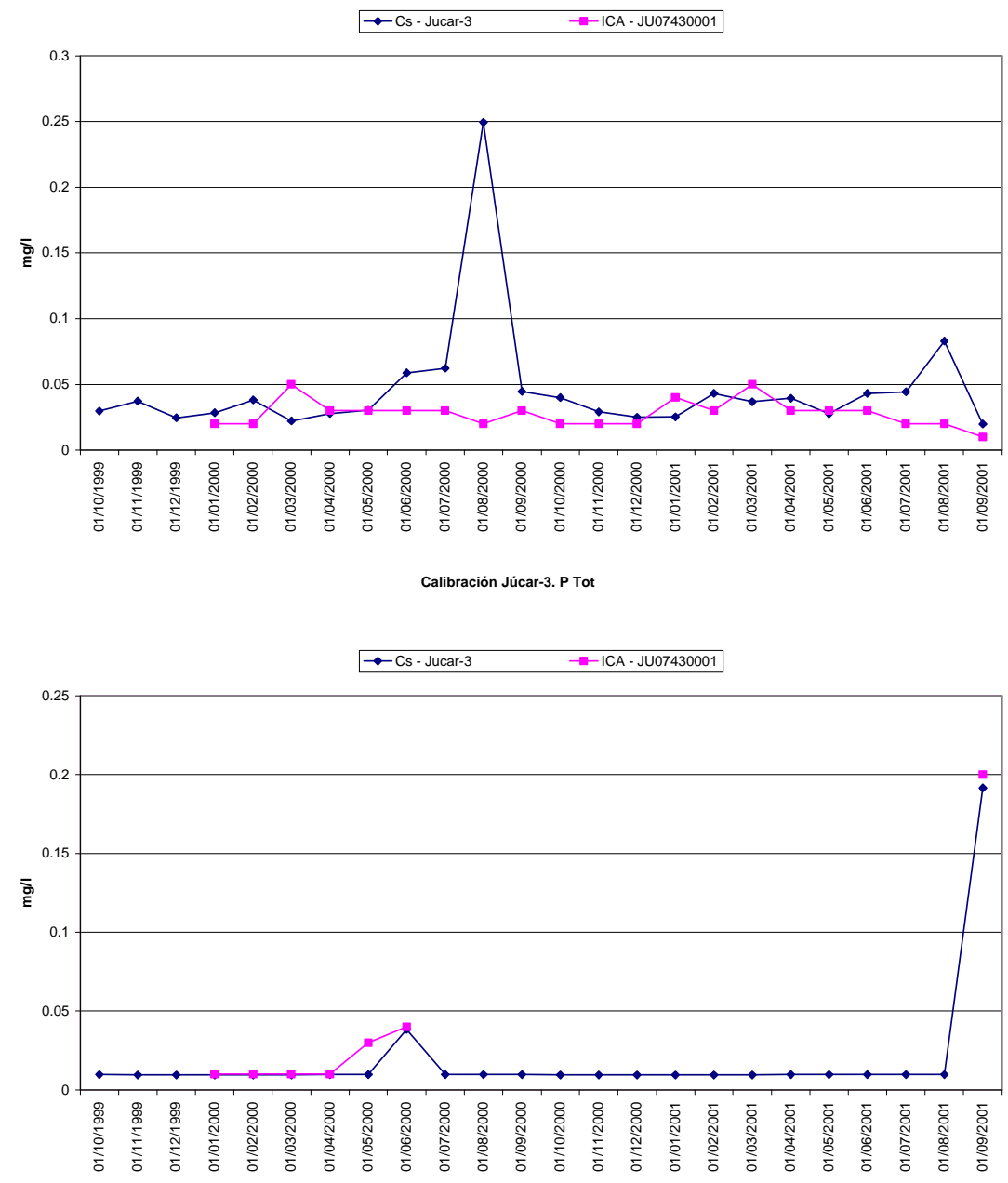
Figuras calibración Júcar-4. Aguas arriba Molinar

Nitritos

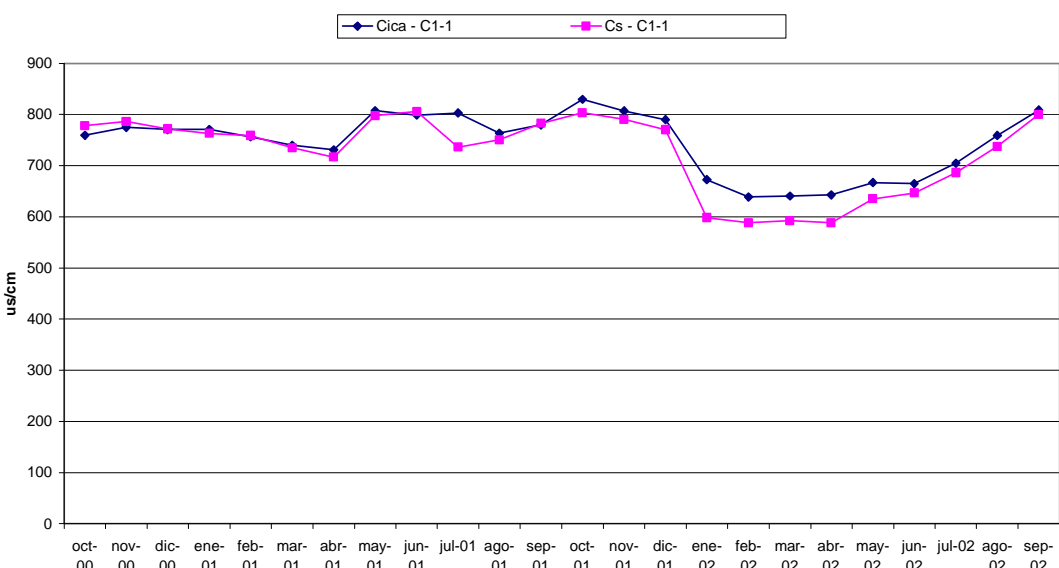

Sólidos Suspendidos

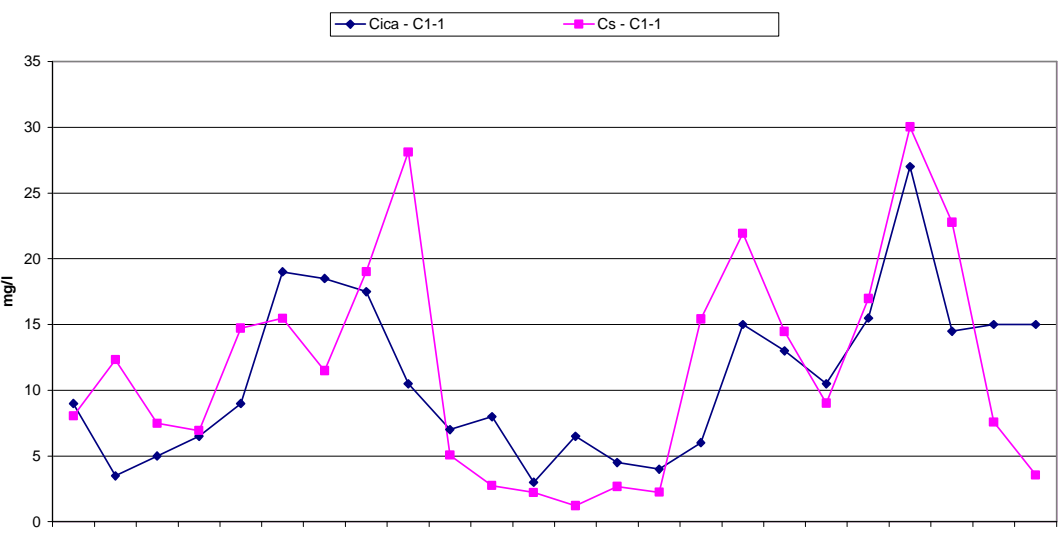

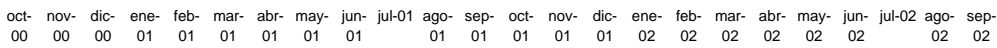

Oxigeno Disuelto

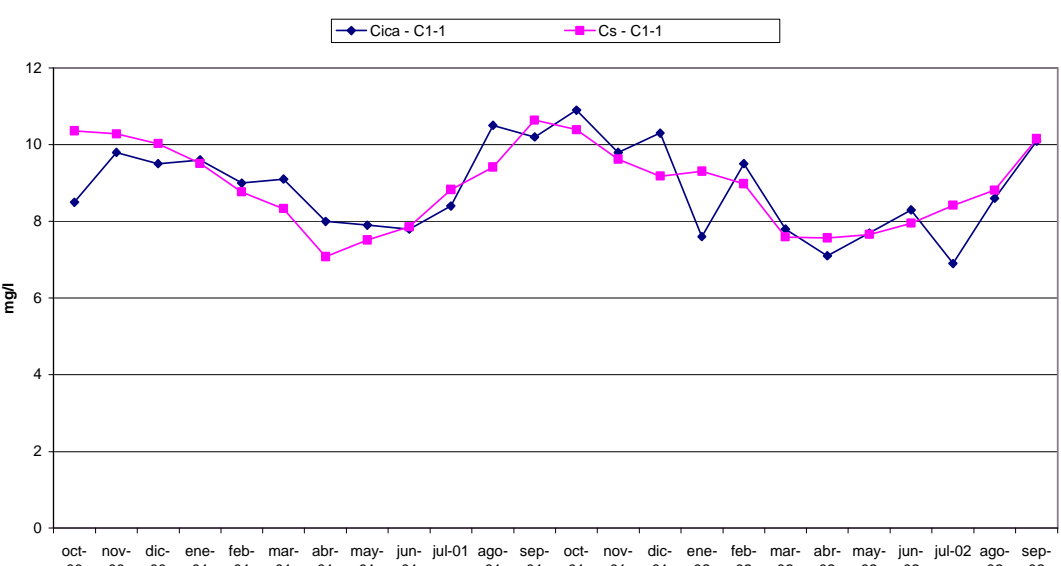

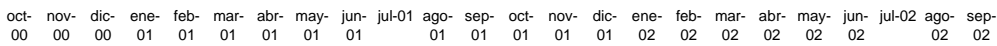




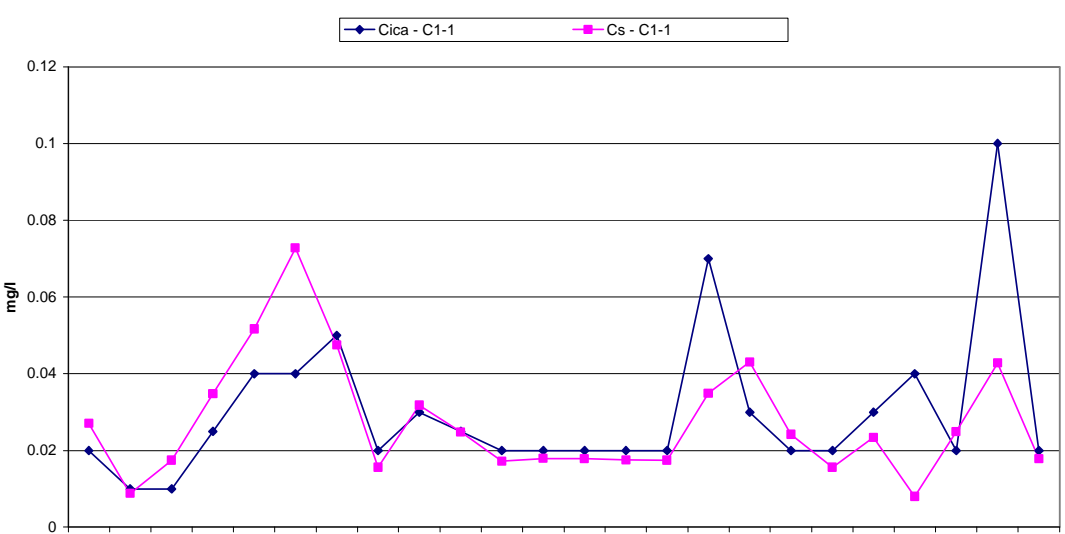

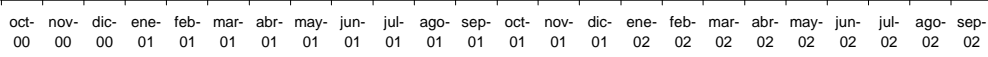

Nitritos

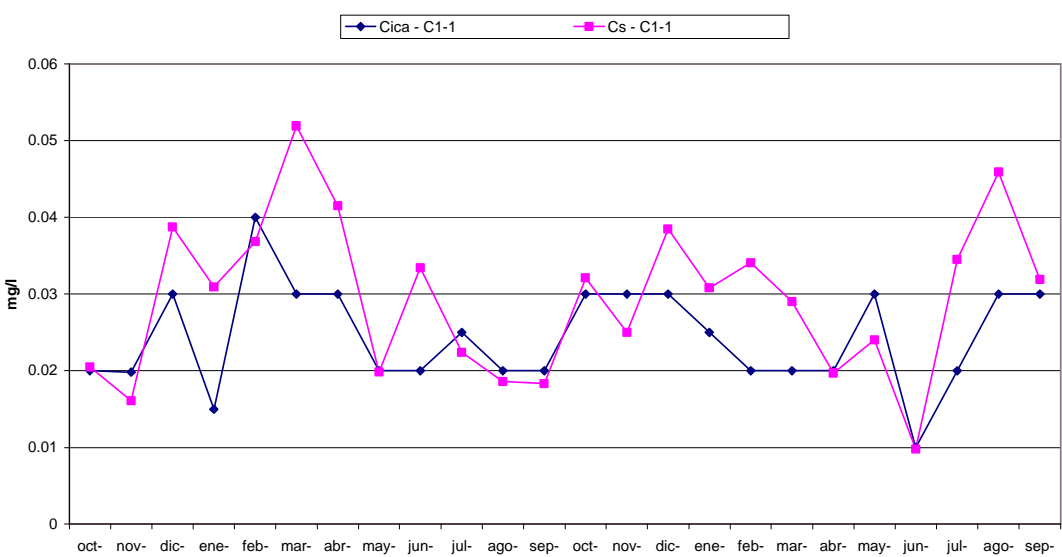

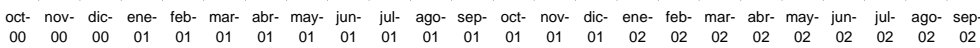

Nitratos

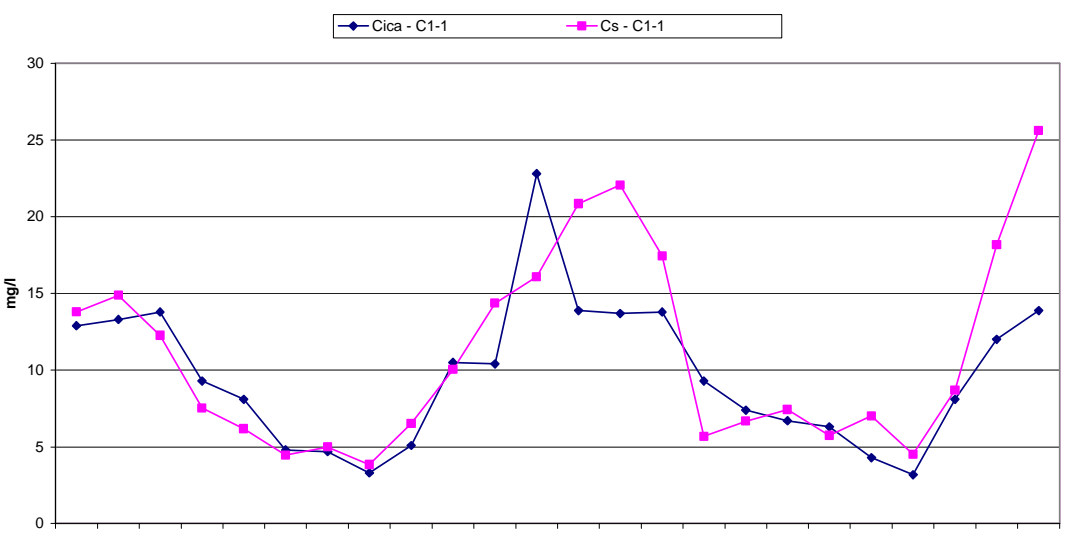

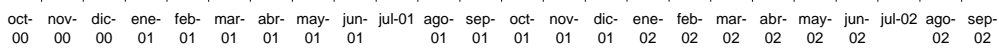


Fósforo total

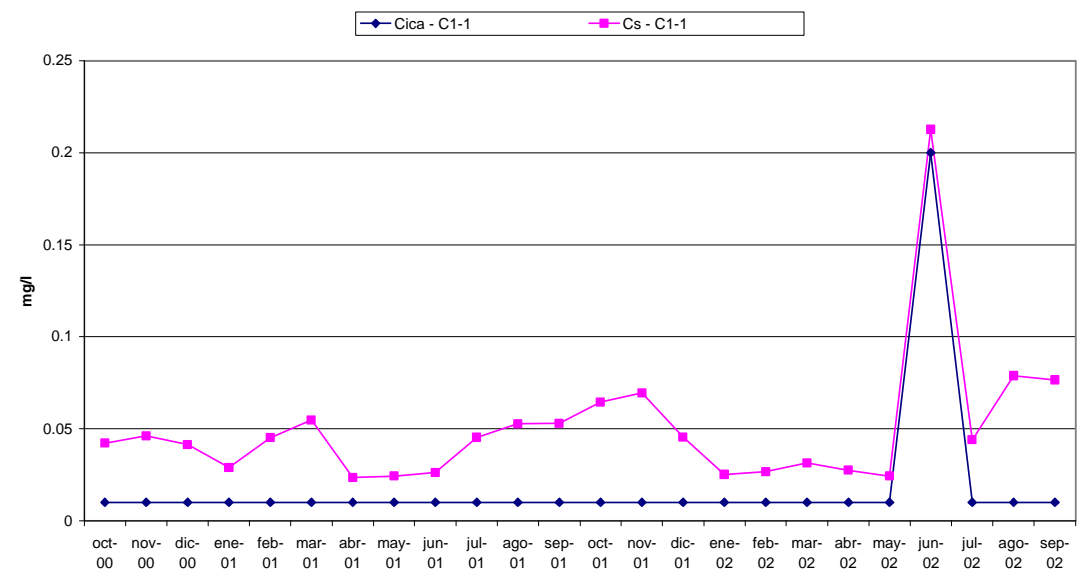

Figuras calibración Júcar-5

Calibración Júcar-5. Conductividad

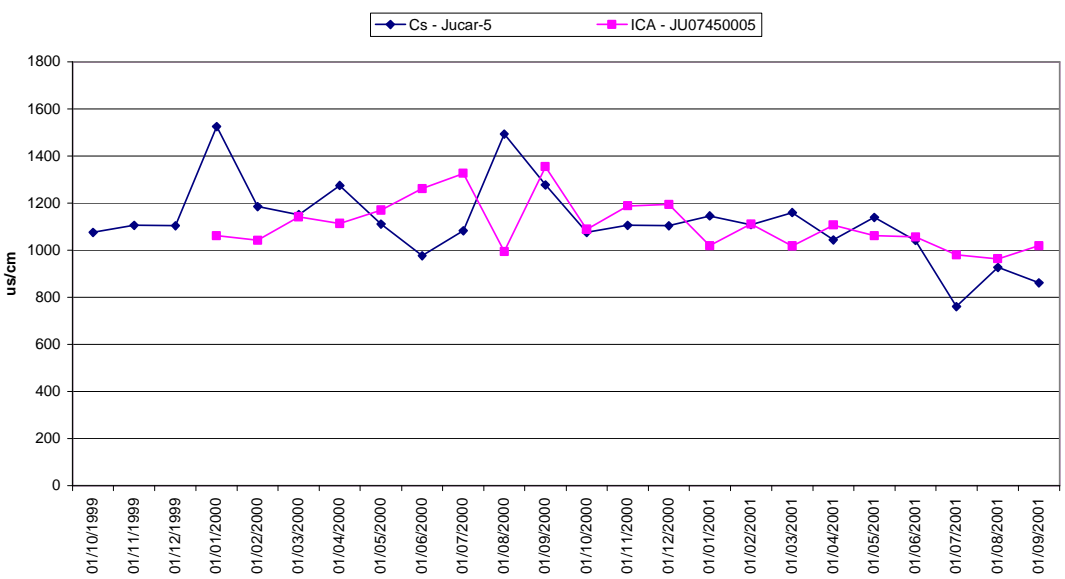

Calibración Júcar-5. Sólidos Suspendidos

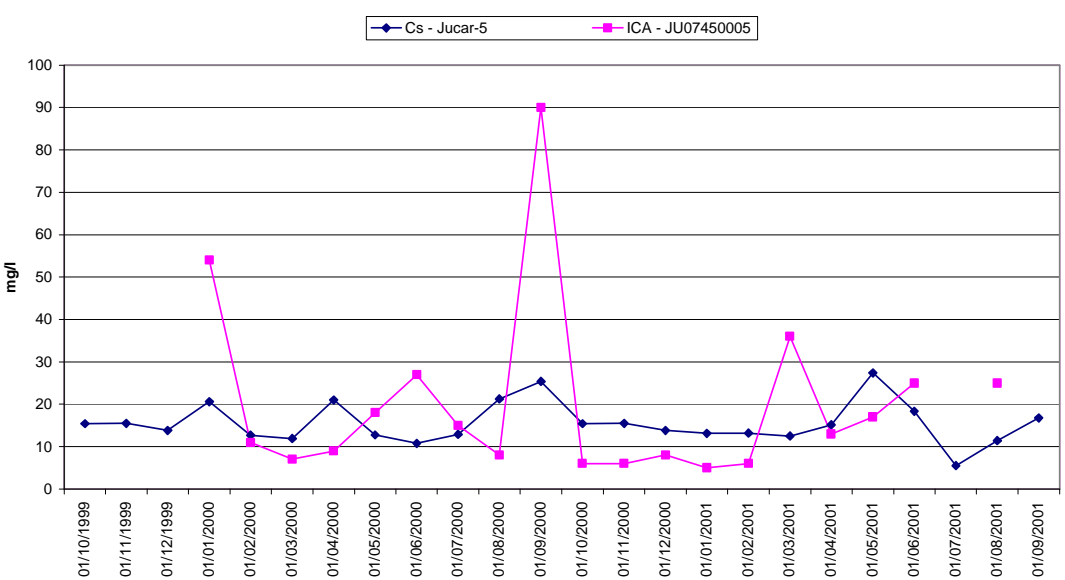


Integración de la modelación de la calidad del agua en un sistema de ayuda a la decisión para la gestión de recursos hídricos.

Calibración Júcar-5. Oxigeno Disuelto
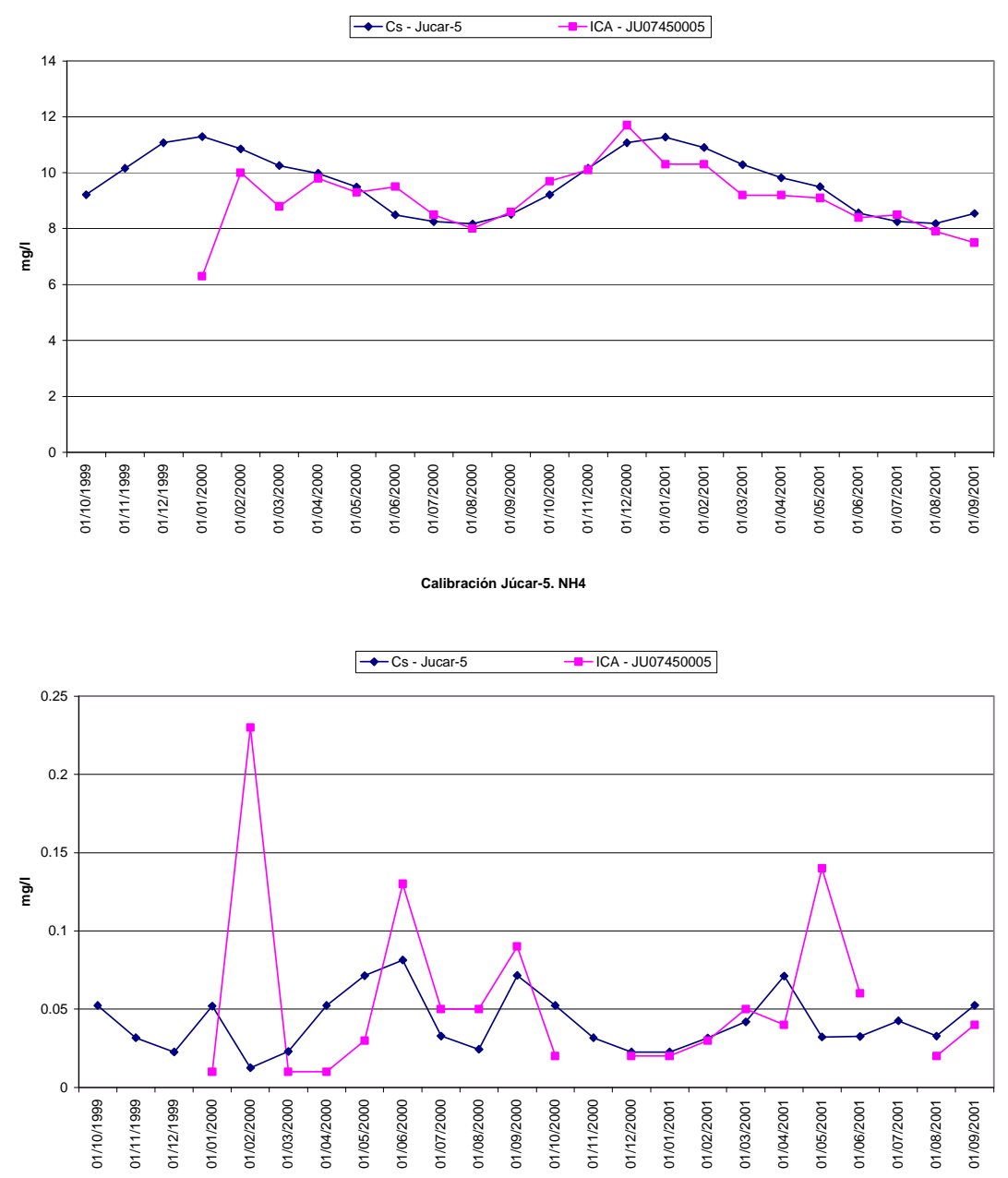

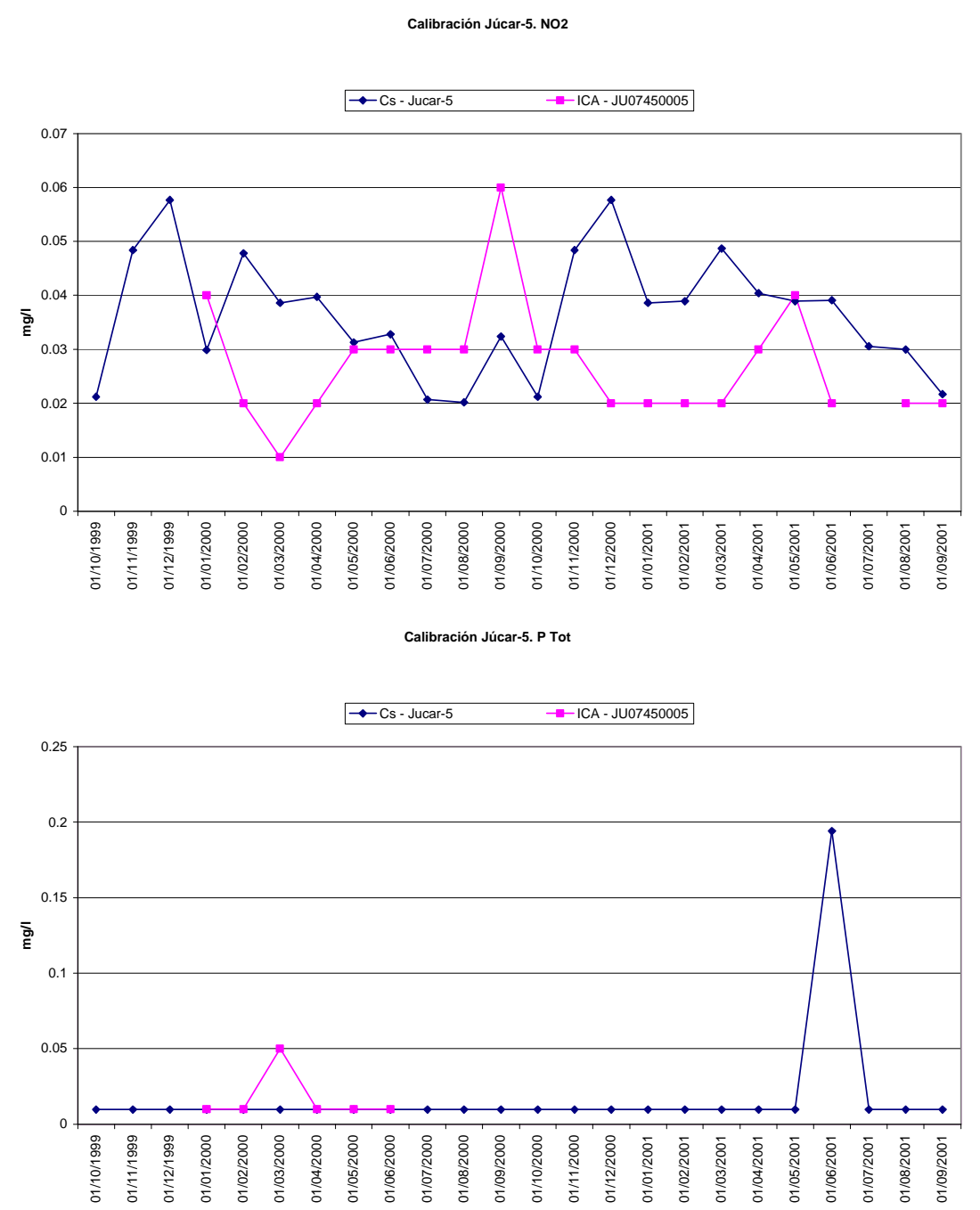
Integración de la modelación de la calidad del agua en un sistema de ayuda a la decisión para la gestión de recursos hídricos.

Figuras calibración Contreras-1.

Calibración Contreras-1. Conductividad
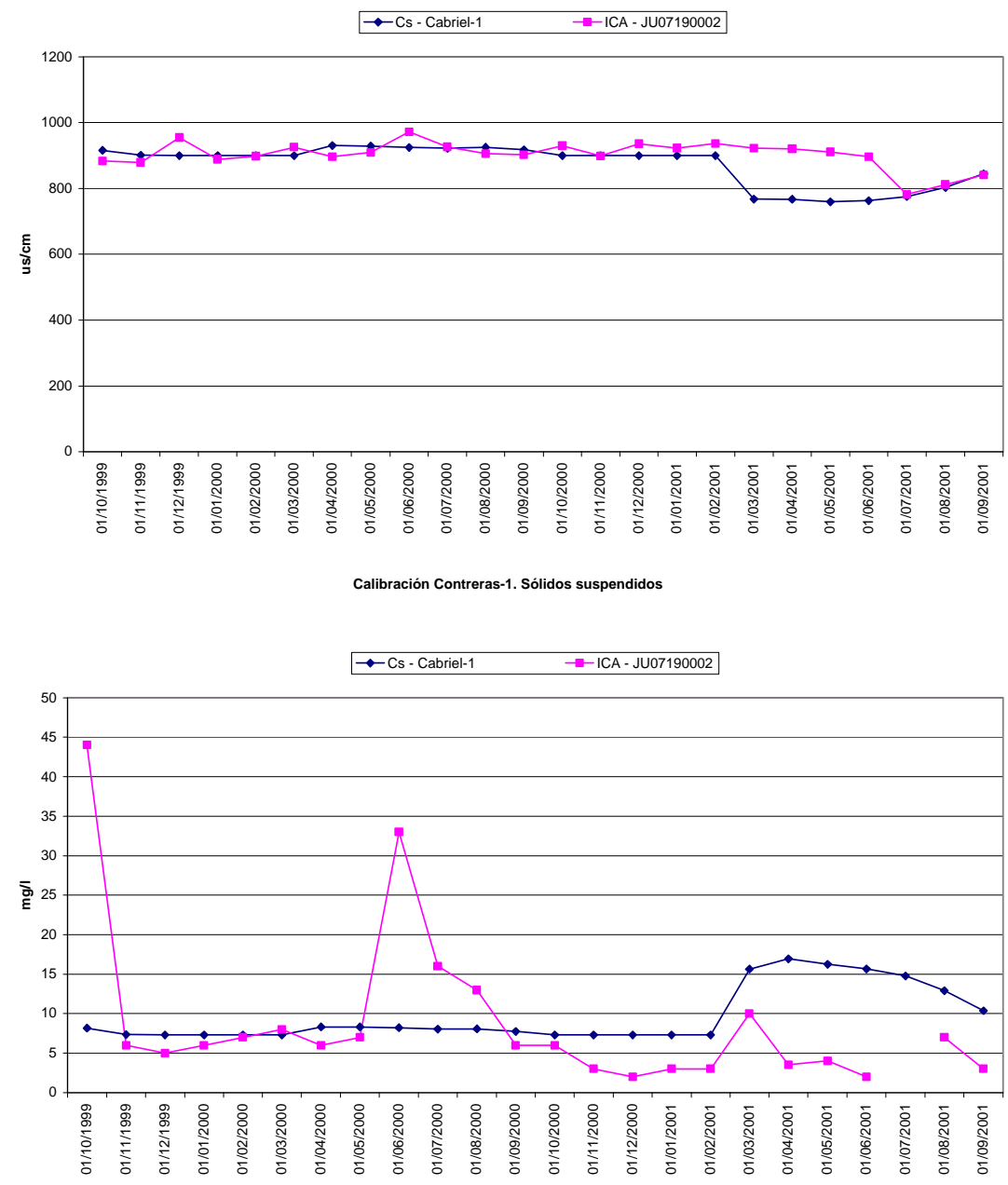

Calibración Contreras-1. Oxigeno Disuelto

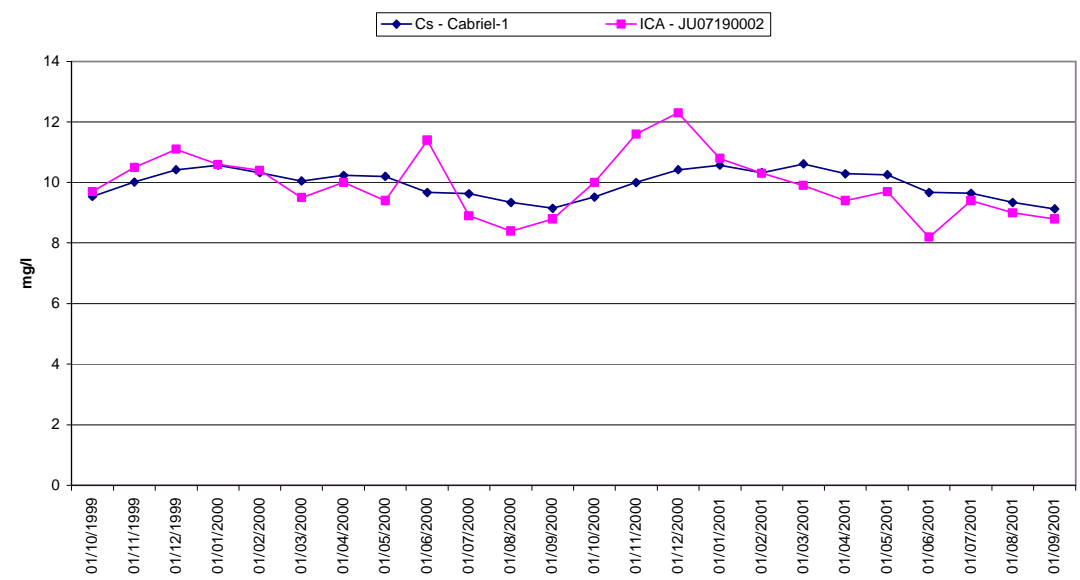


Calibración Contreras-1. NH4
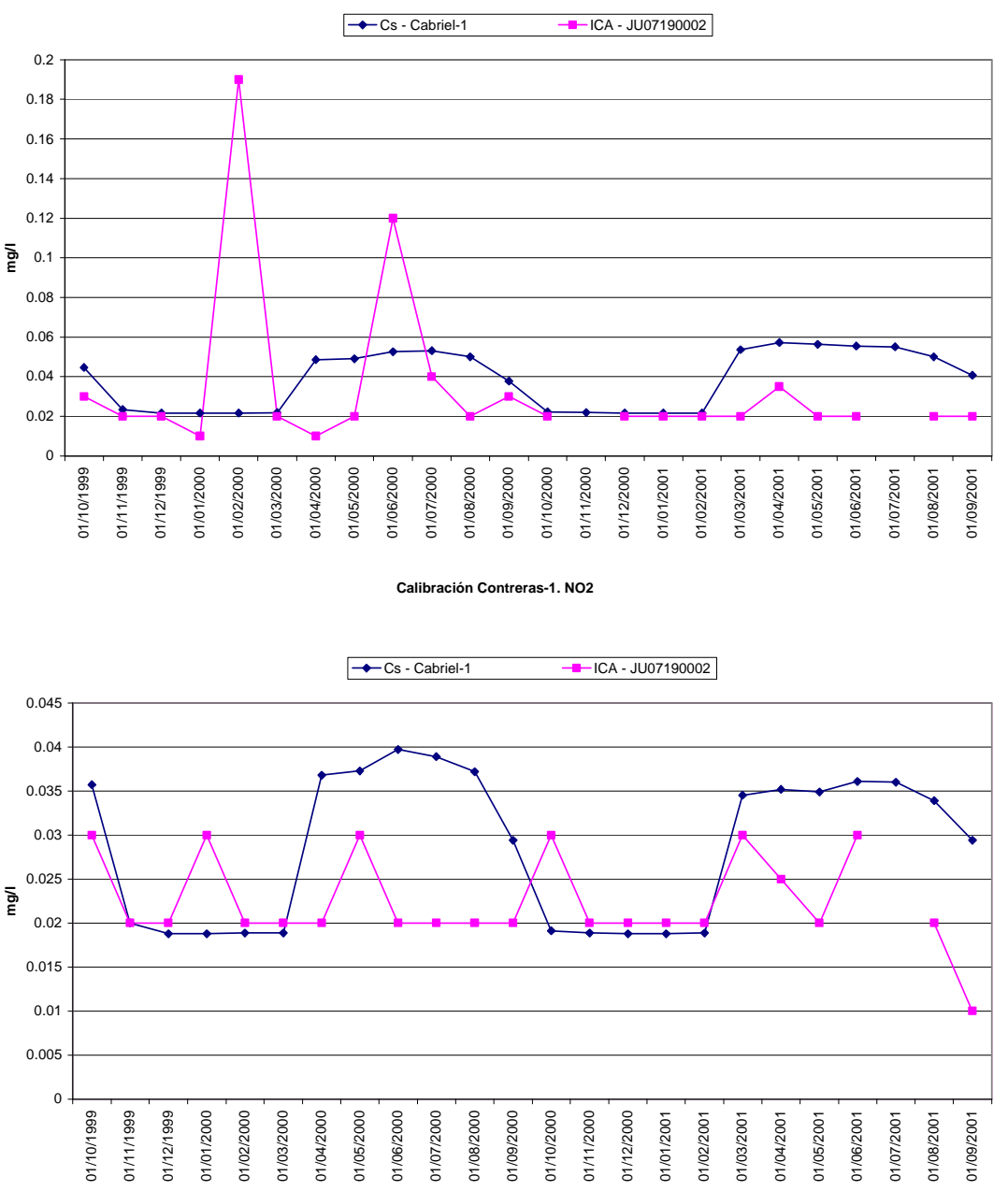

Calibración Contreras-1. NO3

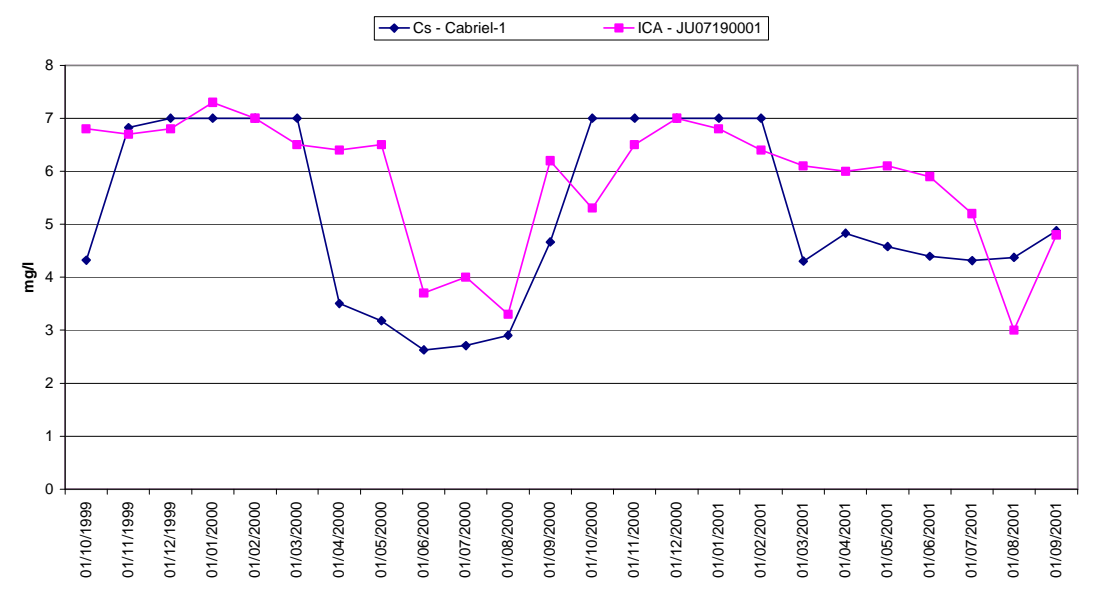


Integración de la modelación de la calidad del agua en un sistema de ayuda a la decisión para la gestión de recursos hídricos.

ibración Contreras-1. P Tot

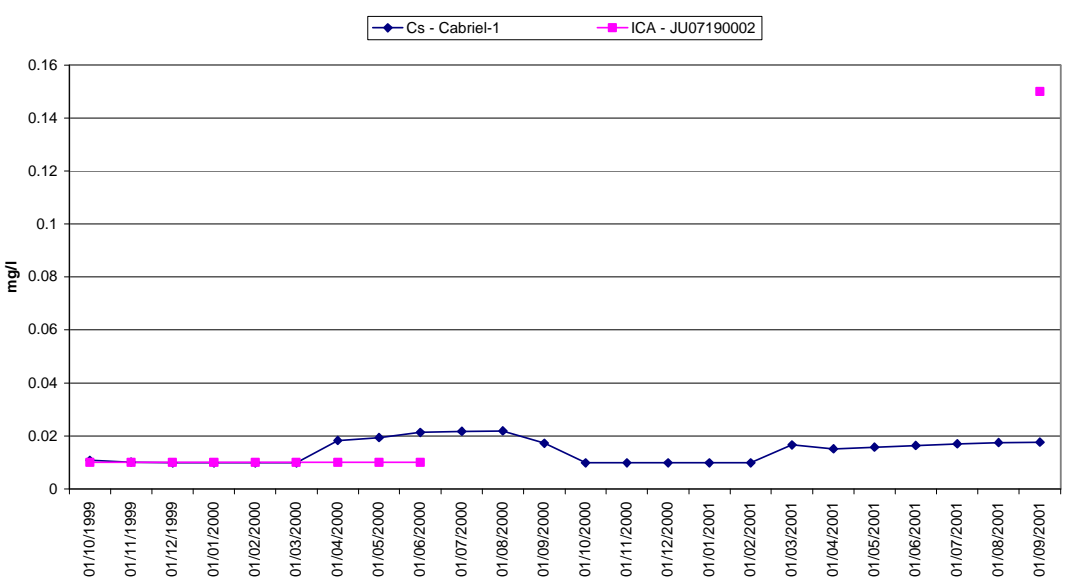

Figuras calibración Contreras-2

Calibración Cabriel-2. Conductividad

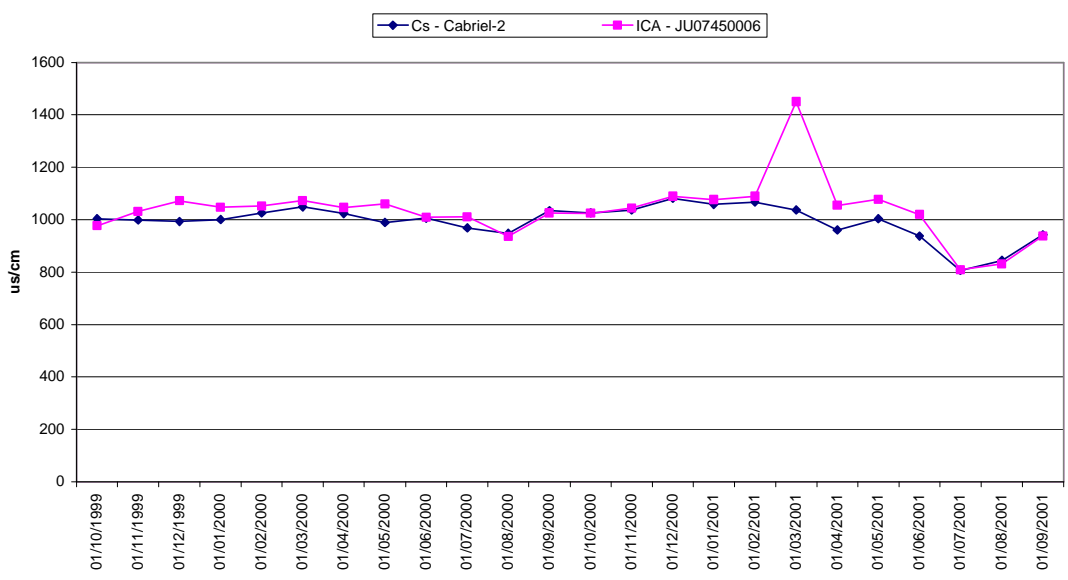

Calibración Cabriel-2. Sólidos Suspendidos

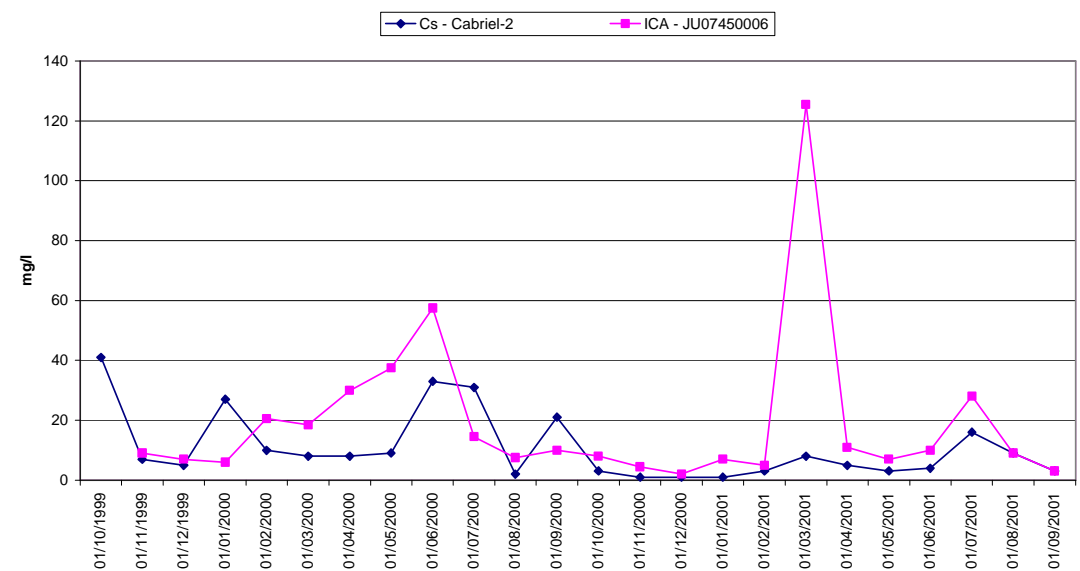


Calibración Cabriel-2. Oxigeno Disuelto
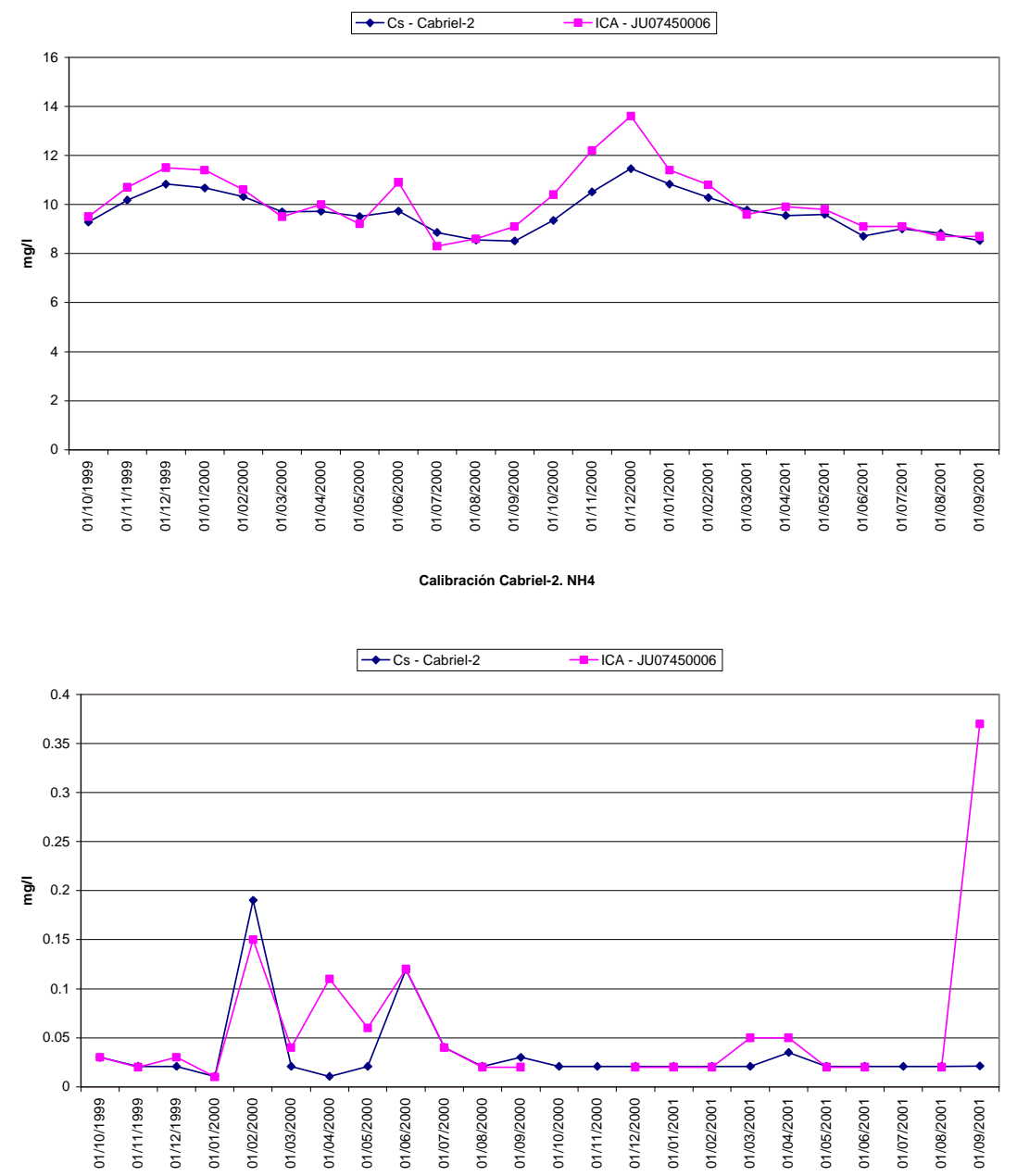

Calibración Cabriel-2. NO2

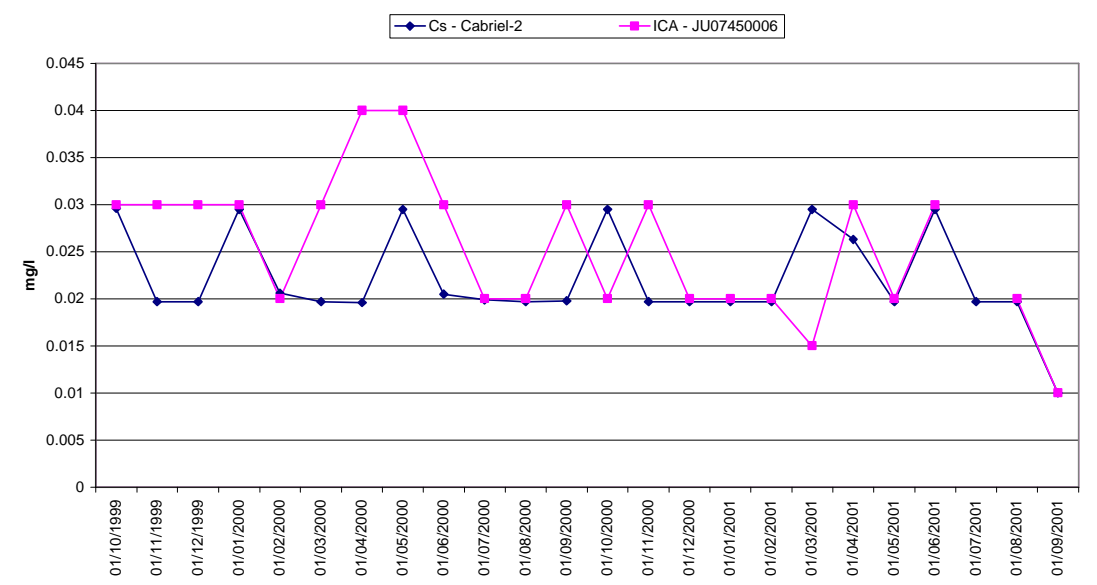


Integración de la modelación de la calidad del agua en un sistema de ayuda a la decisión para la gestión de recursos hídricos.

Calibración Cabriel-2. NO3
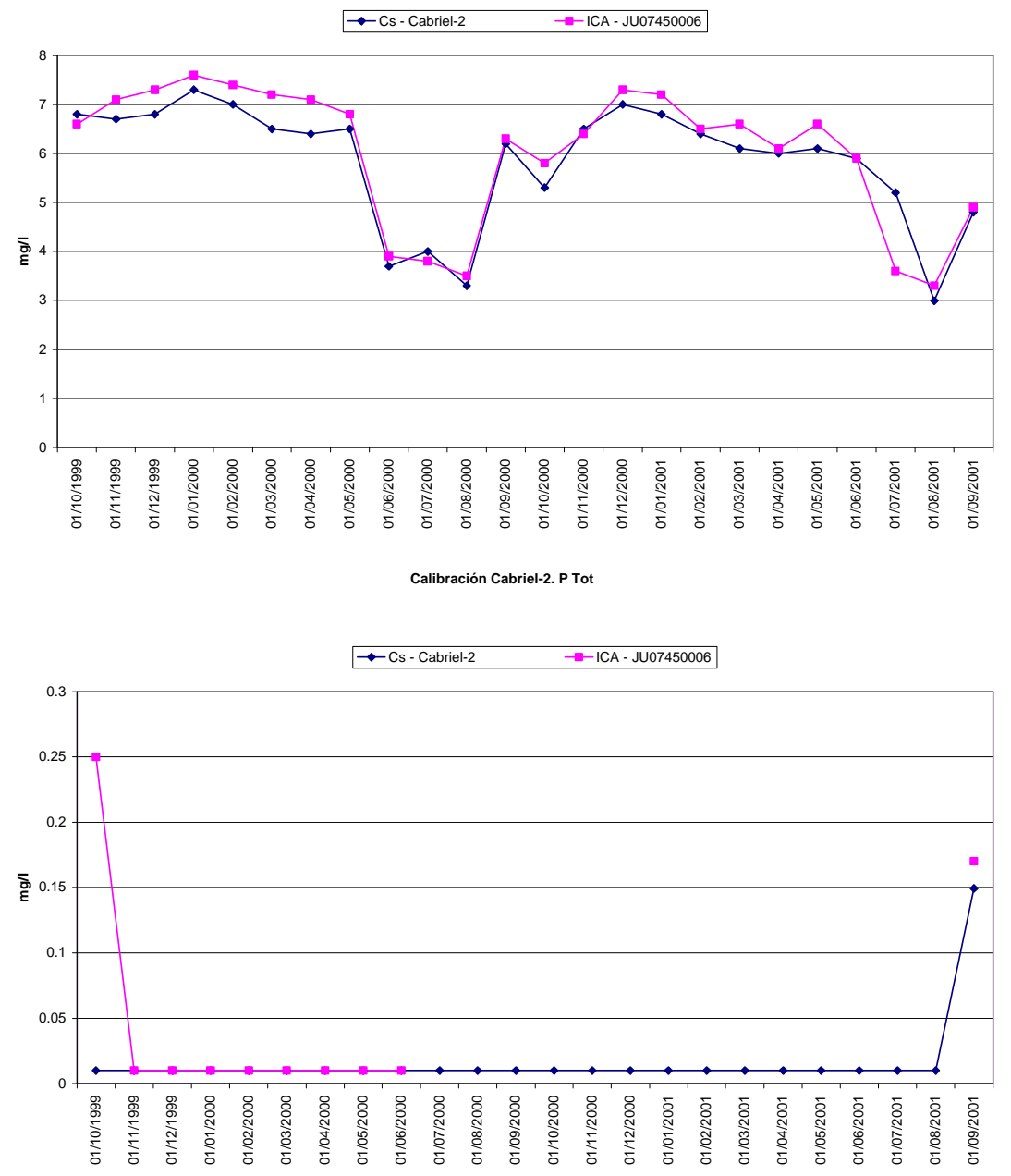


\section{CALIBRACIÓN AGUAS ABAJO DE TOUS}

Figuras calibración tramo Salida de Tous a Río; Estación JU7690002 (Cotes)

Calibración Tous hasta Cotes. Conductividad

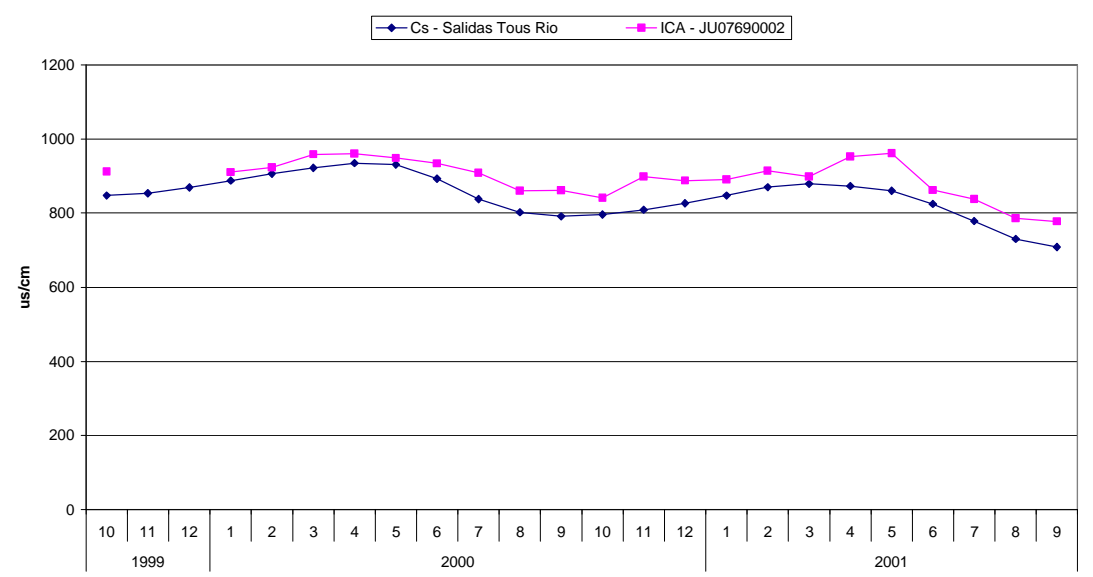

Calibración Tous hasta Cotes. Sólidos Suspendidos

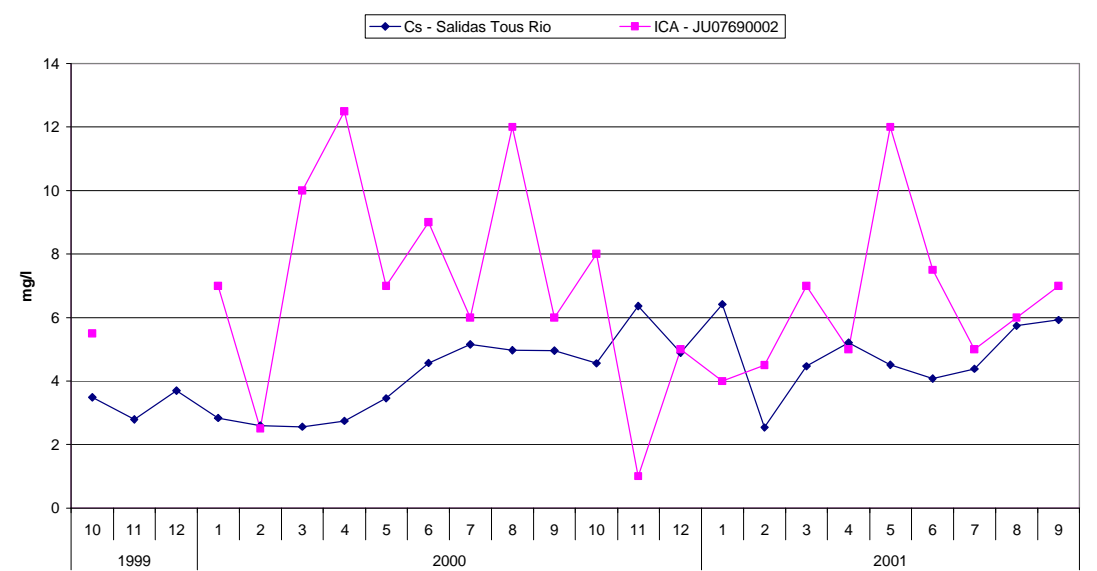


Integración de la modelación de la calidad del agua en un sistema de ayuda a la decisión para la gestión de recursos hídricos.

Calibración Tous hasta Cotes. Oxígeno disuelto

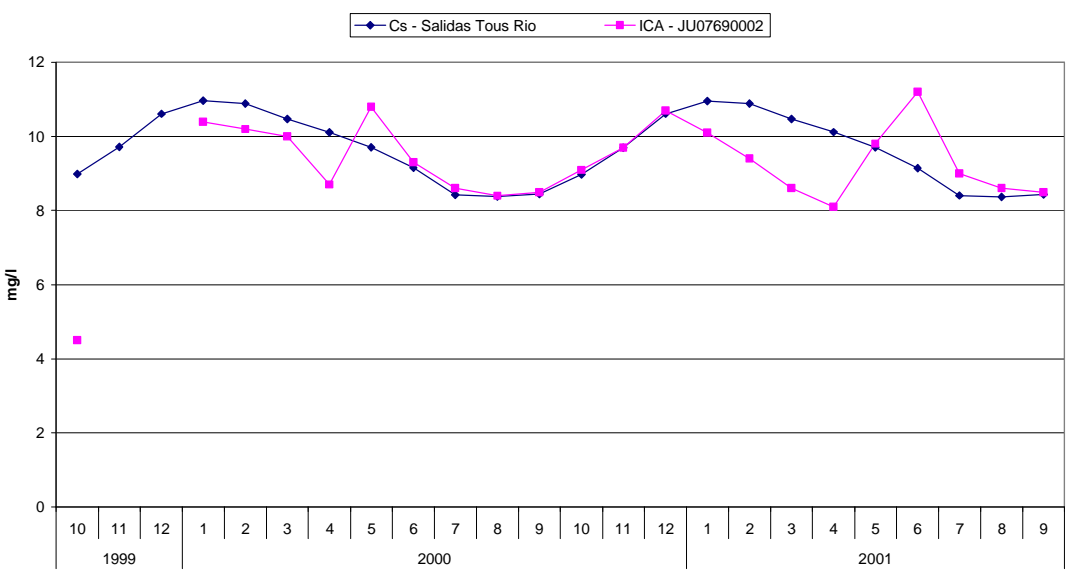

Calibración Tous hasta Cotes. DBO5

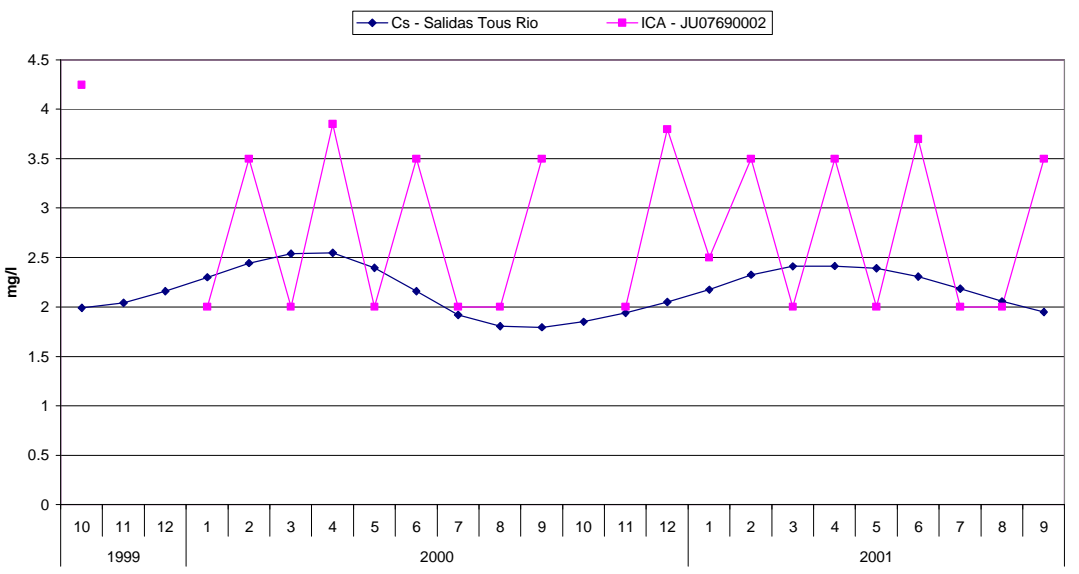

Calibración Tous hasta Cotes. NH4

$\rightarrow$ Cs - Salidas Tous Rio $\quad-$ ICA - JU07690002

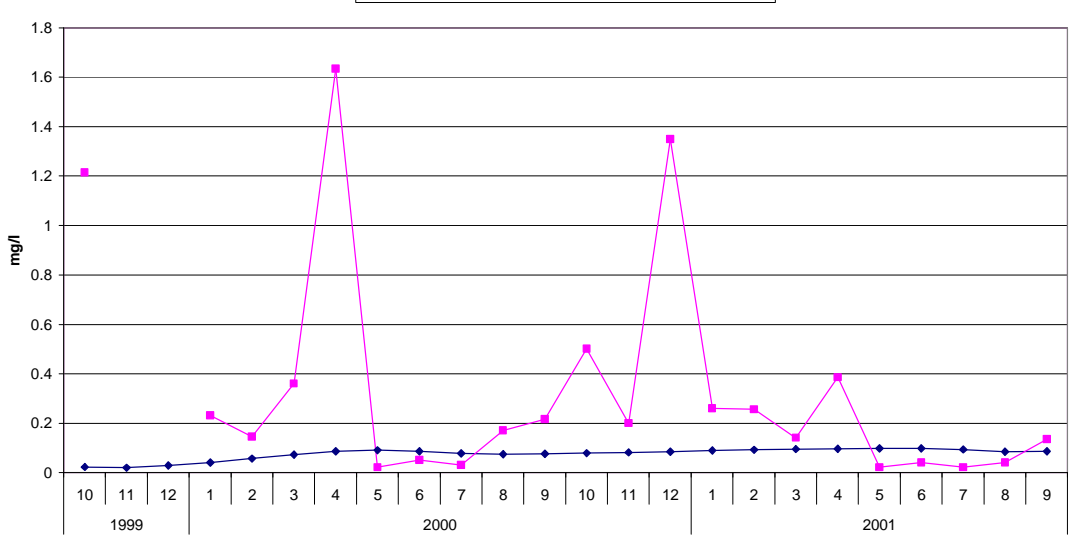


Anejo B. Calibración y análisis de sensibilidad.

Calibración Tous hasta Cotes. NO2

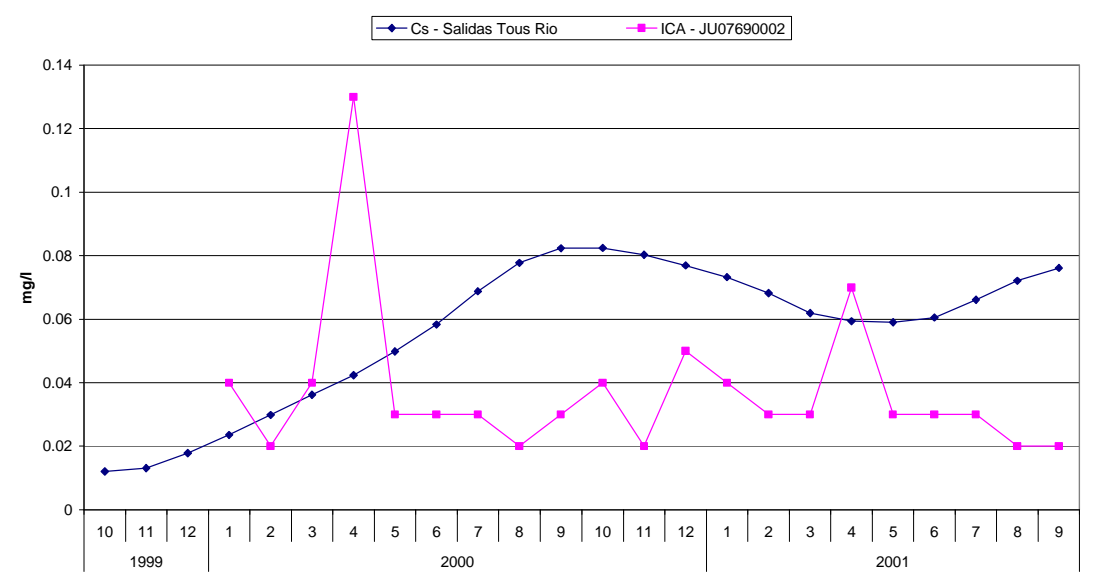

Calibración Tous hasta Cotes. NO3

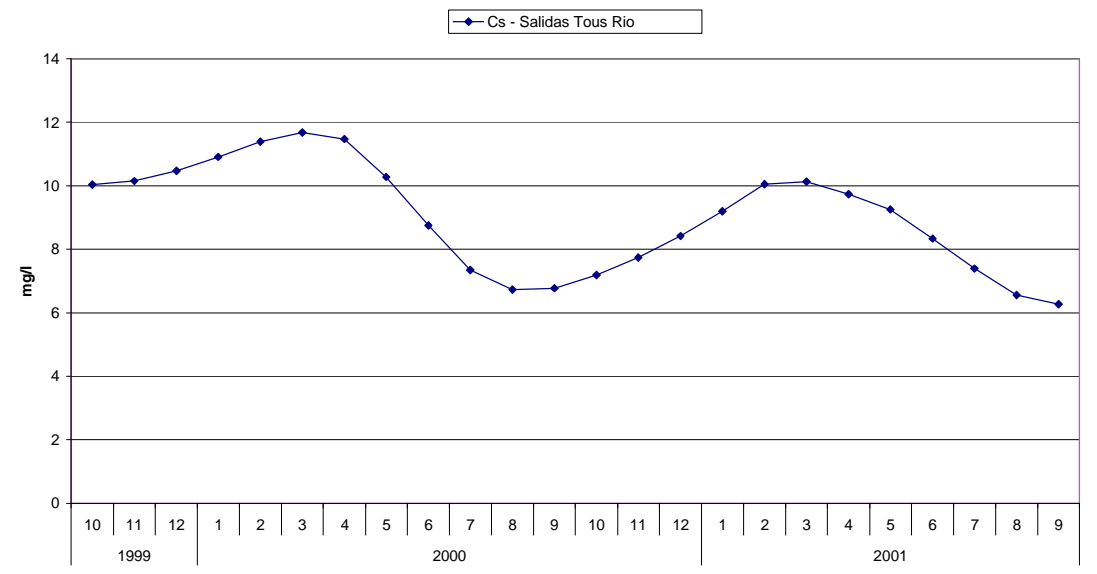

Calibración Tous hasta Cotes. PTot

$\rightarrow-$ Cs - Salidas Tous Rio $\rightarrow-$ ICA - JU07690002

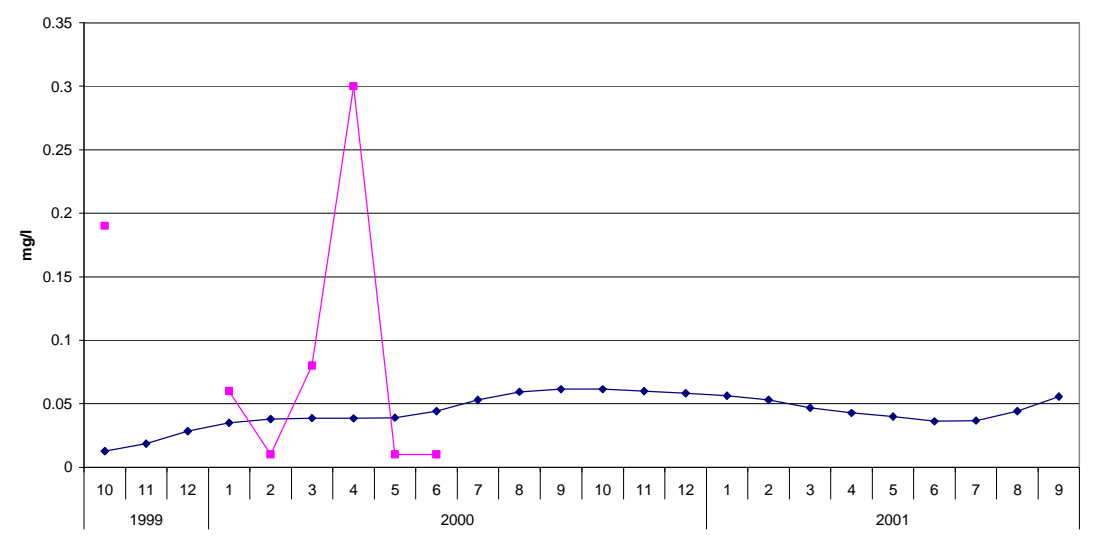


Integración de la modelación de la calidad del agua en un sistema de ayuda a la decisión para la gestión de recursos hídricos.

Figuras calibración tramo Sellent-Albaida; Estación Vill. De Castellón JU07690001.

Calibración Sellent-Albaida. Conductividad

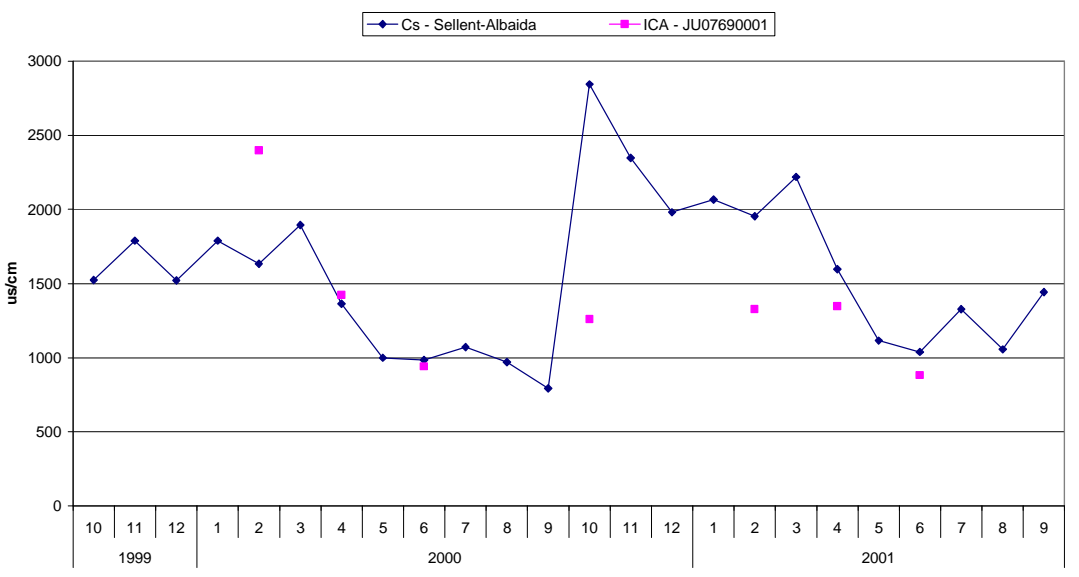

Calibración Sellent-Albaida. Sólidos Suspendidos

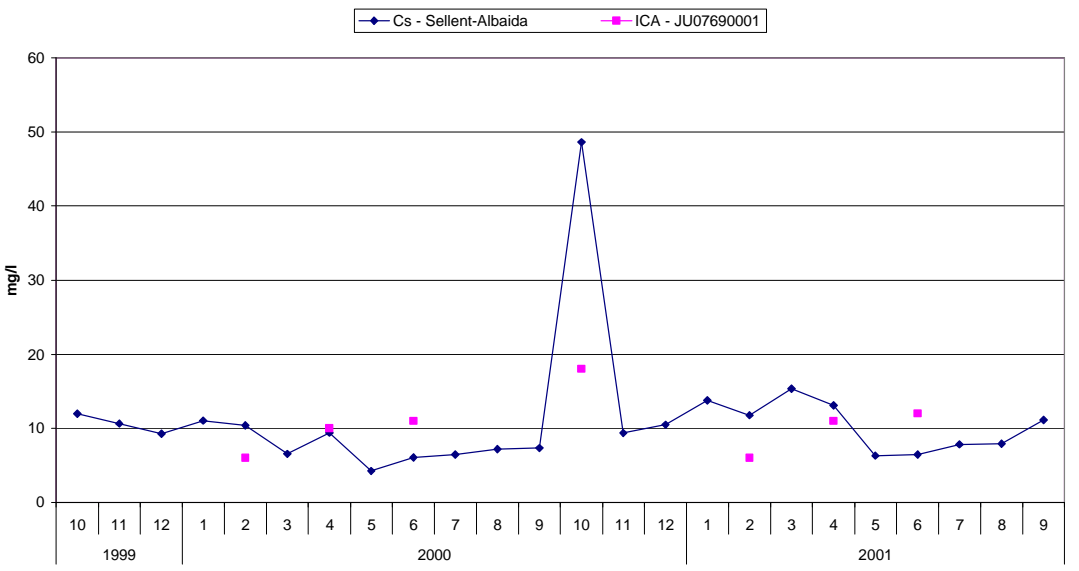

Calibración Sellent-Albaida. Oxígeno Disuelto

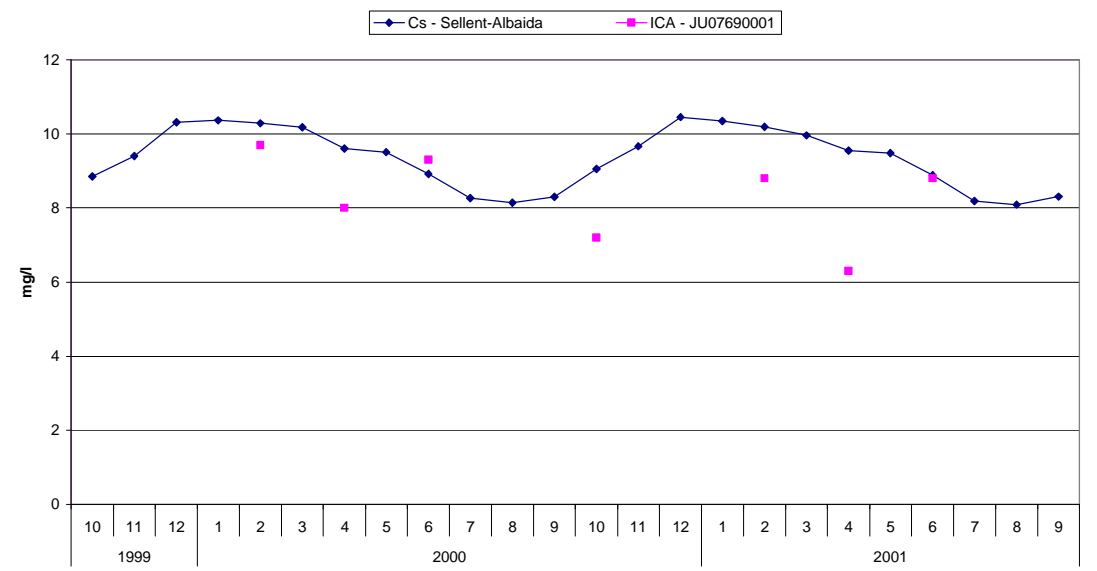


Anejo B. Calibración y análisis de sensibilidad.

Calibración Sellent-Albaida. DBO5

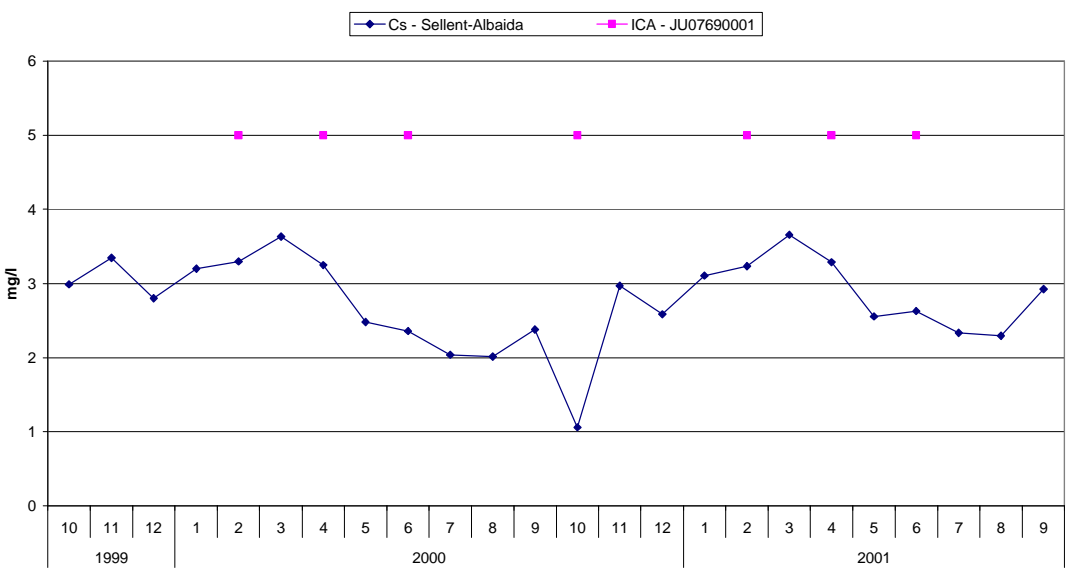

Calibración Sellent-Albaida. NH4

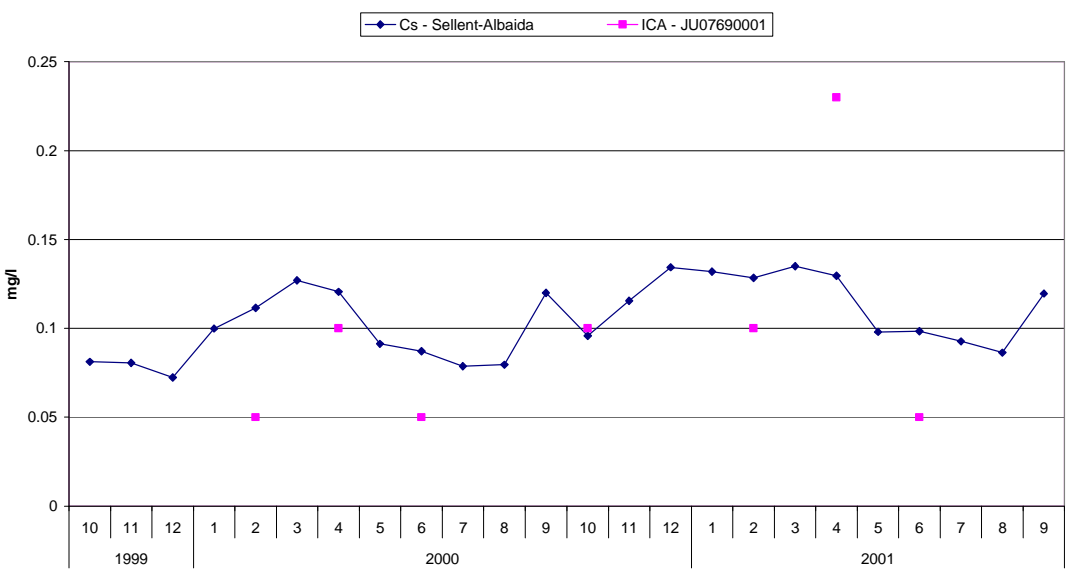

Calibración Sellent-Albaida. NO2

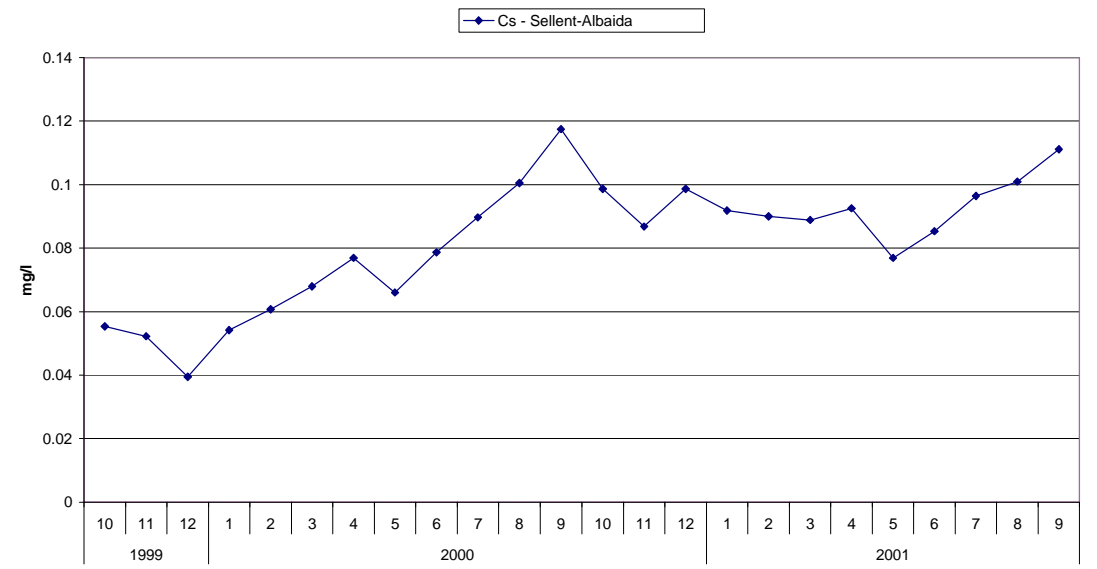


Integración de la modelación de la calidad del agua en un sistema de ayuda a la decisión para la gestión de recursos hídricos.

Calibración Sellent-Albaida. NO3

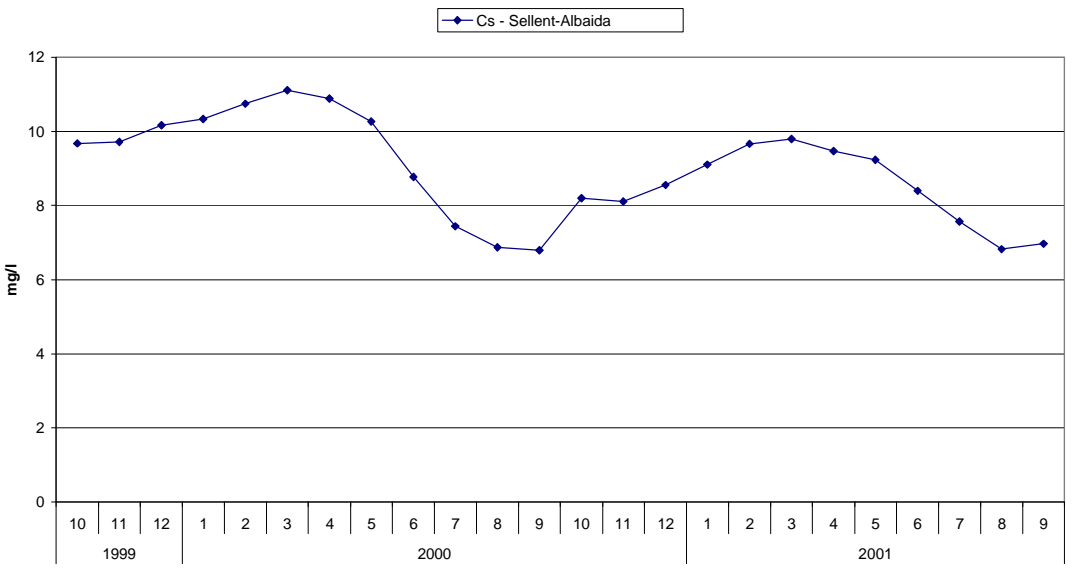

Calibración Sellent-Albaida. PTot

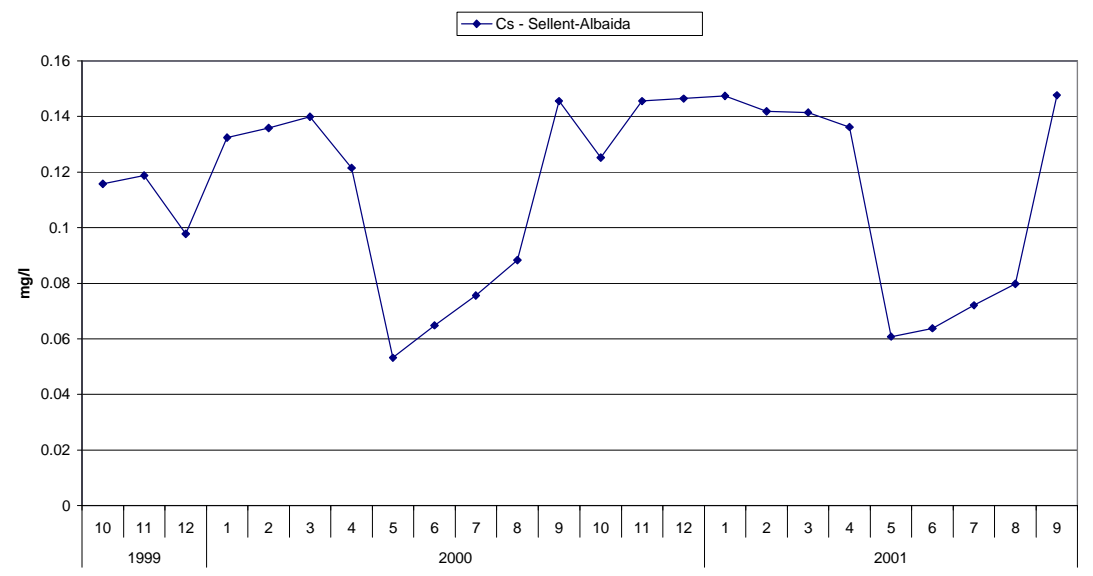


Anejo B. Calibración y análisis de sensibilidad.

Figuras calibración tramo Albaida-Alcira. Estación Alcira JU07700001.

Calibración Albaida-Alcira. Conductividad

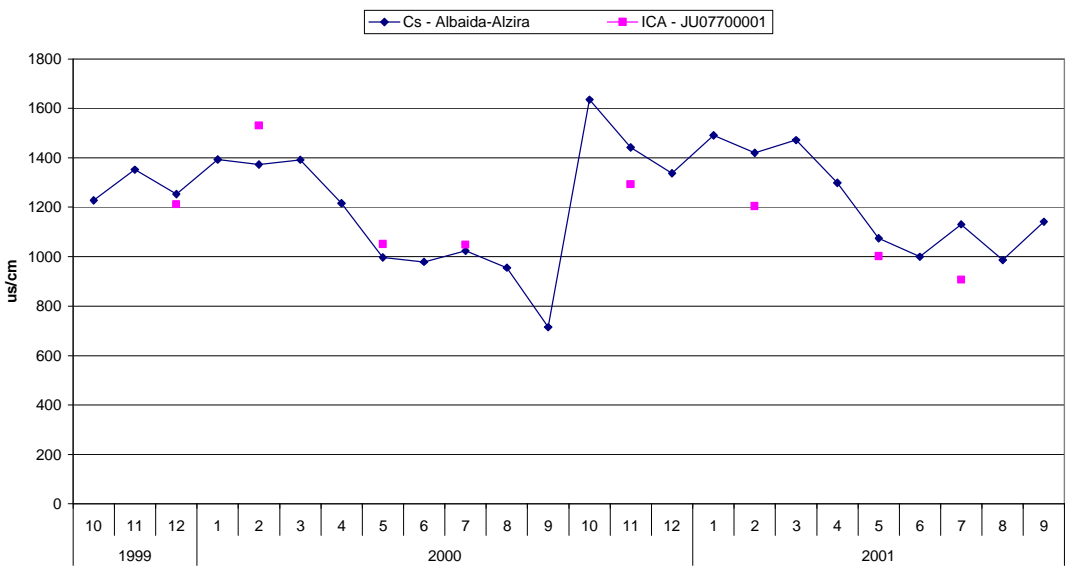

Calibración Albaida-Alcira. Sólidos Suspendidos

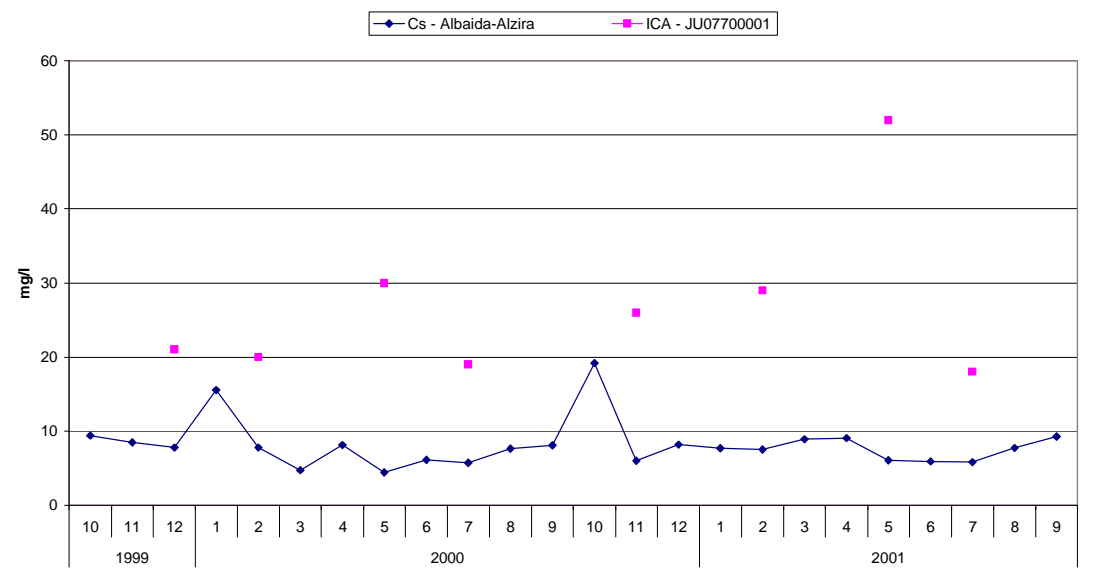

Calibración Albaida-Alcira. Oxígeno Disuelto

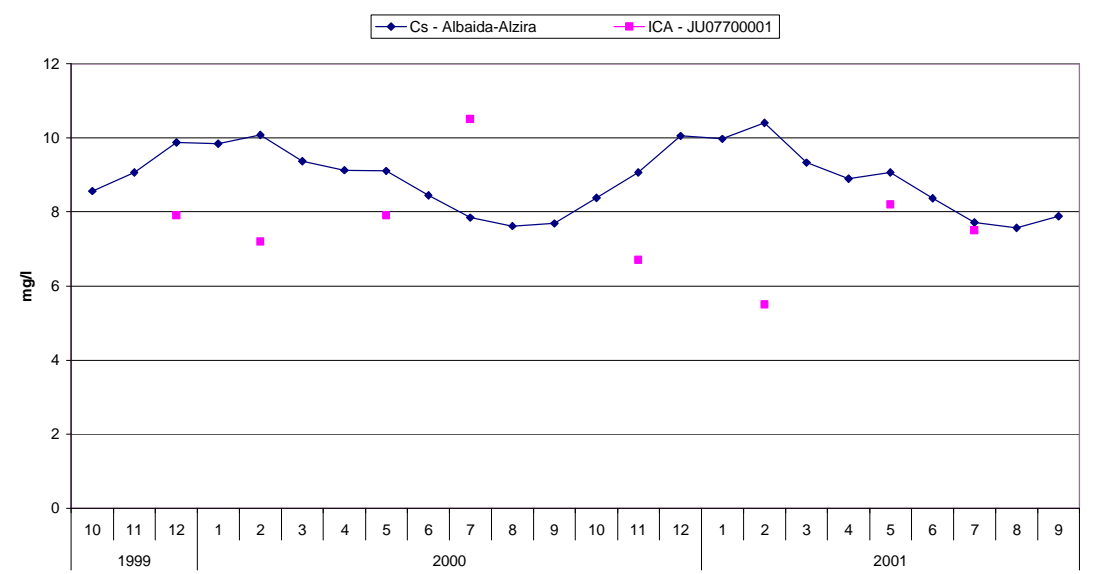


Integración de la modelación de la calidad del agua en un sistema de ayuda a la decisión para la gestión de recursos hídricos.

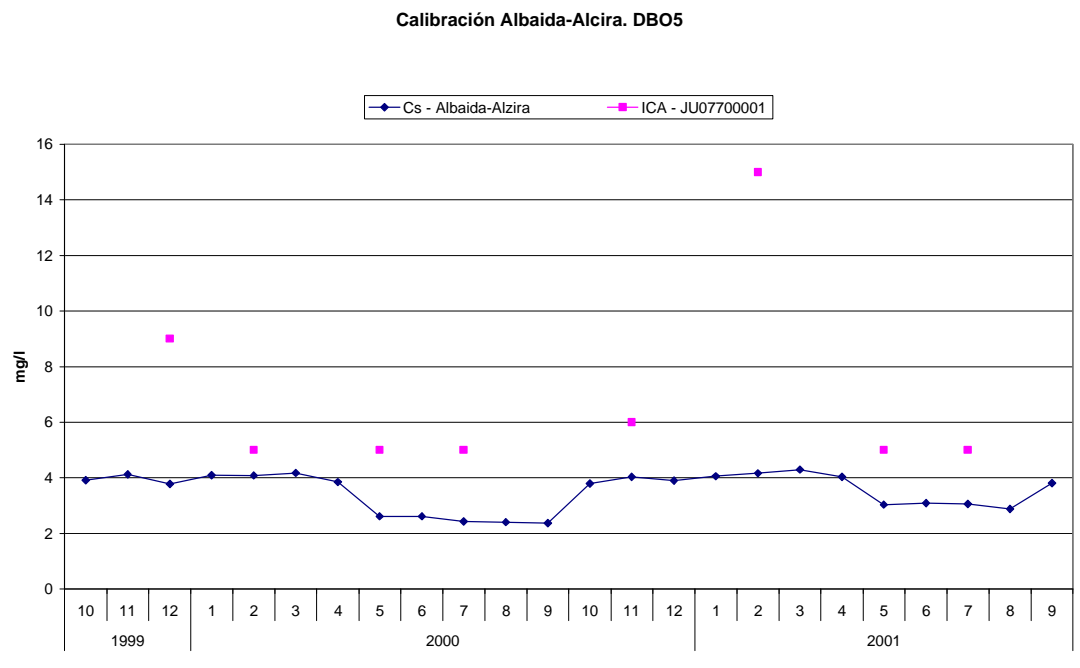

Calibración Albaida-Alcira. NH4

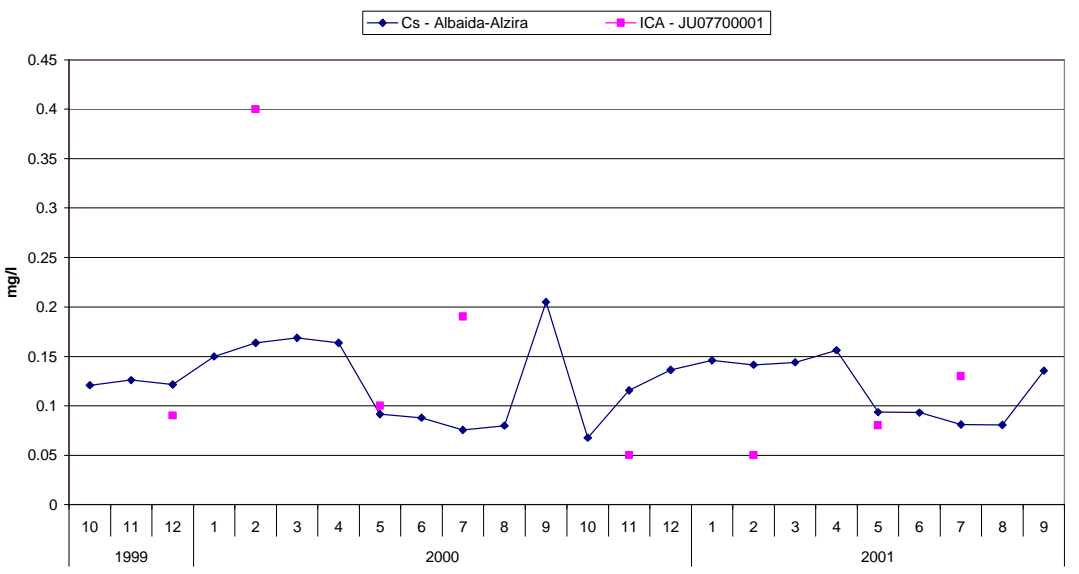

Calibración Albaida-Alcira. NO2

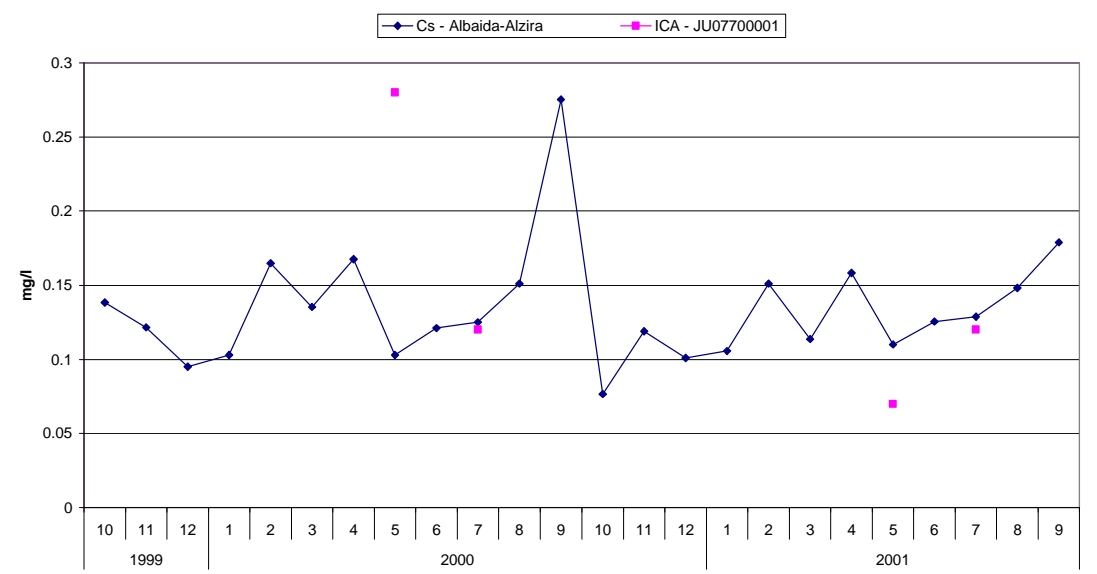


Anejo B. Calibración y análisis de sensibilidad.

Calibración Albaida-Alcira. NO3

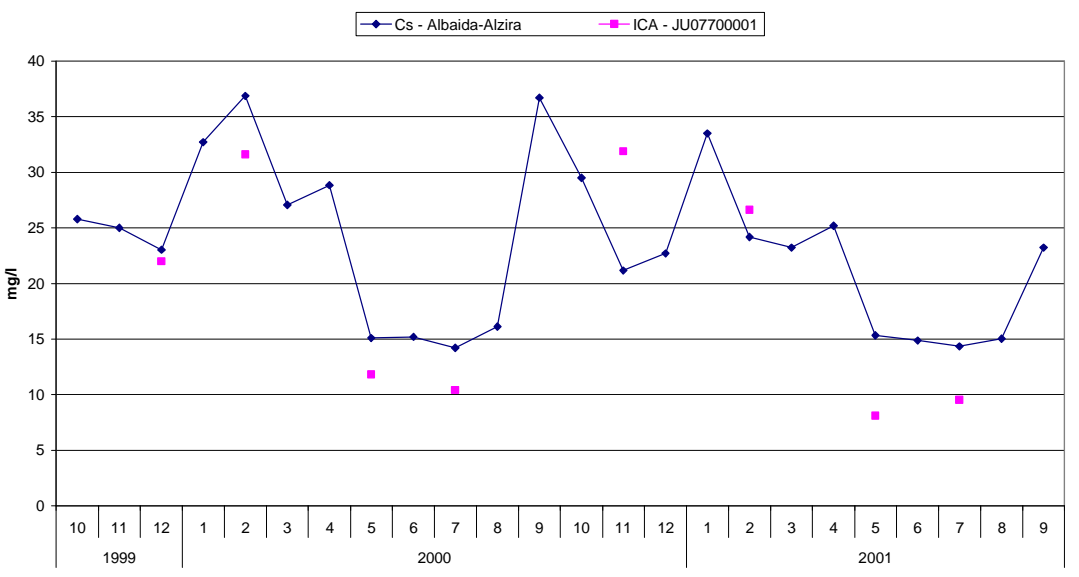

Calibración tramo Albaida-Alcira. Fósforo Tota

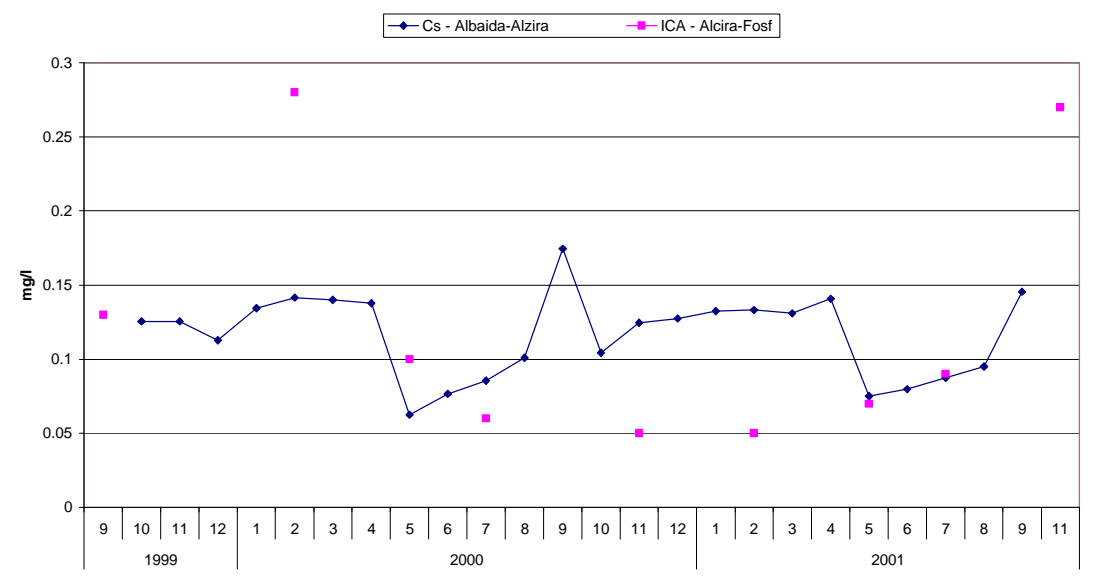


Integración de la modelación de la calidad del agua en un sistema de ayuda a la decisión para la gestión de recursos hídricos.

Figuras calibración tramo Verde -Magro. Estación Aguas Arriba del Magro JU07470004.

Calibración Verde-Magro. Conductividad

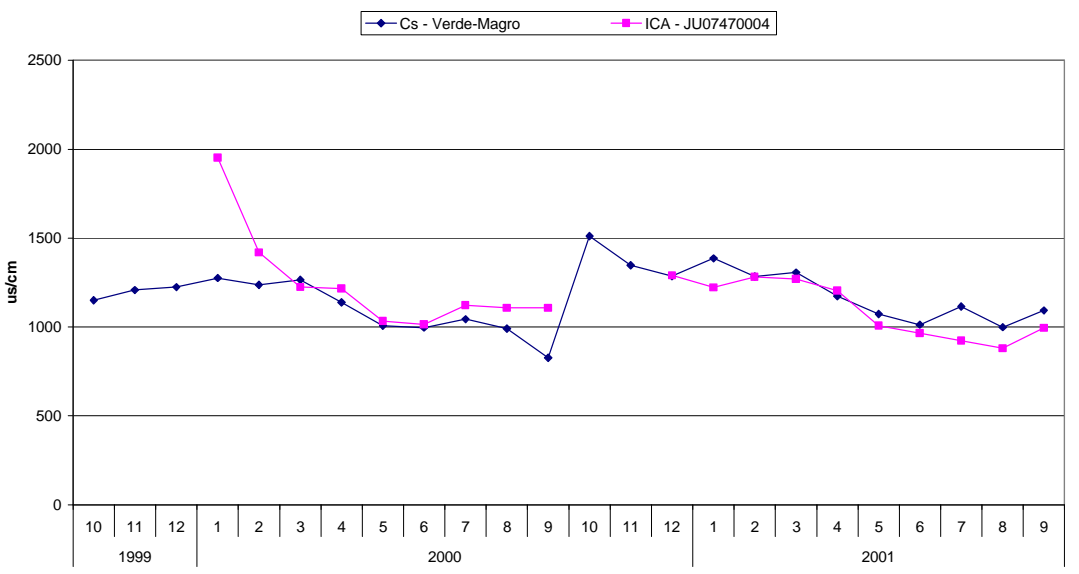

Calibración Verde-Magro. Sólidos Suspendidos

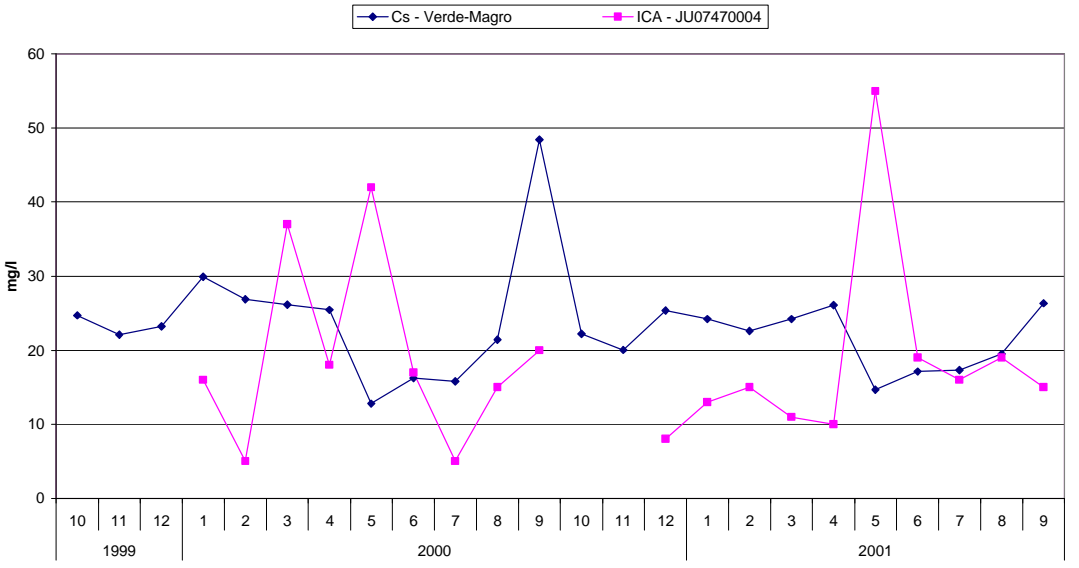

Calibración Verde-Magro. Oxígeno Disuelto

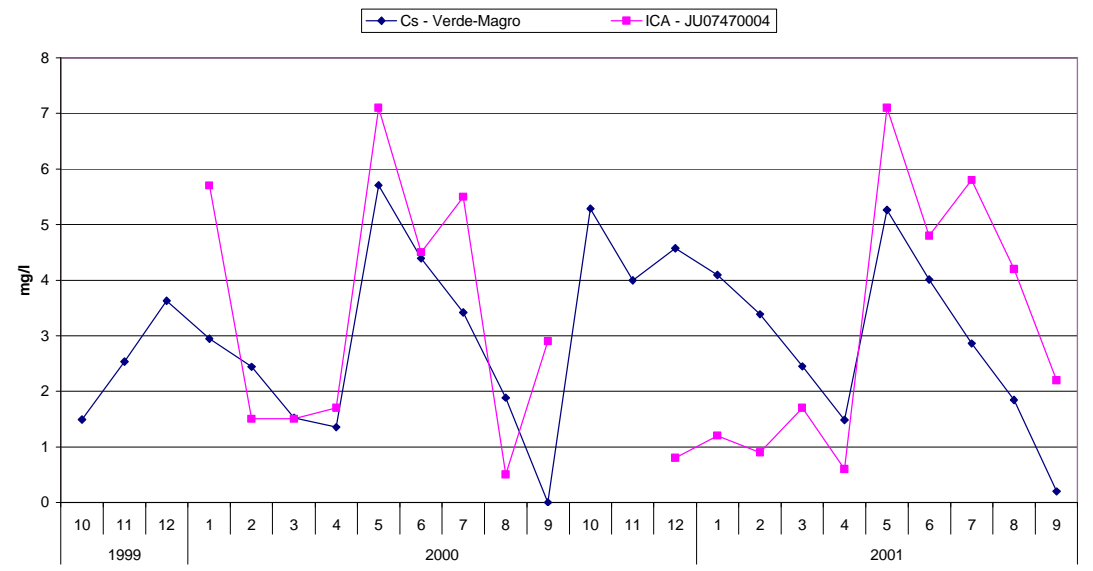


Calibración Verde-Magro. DBO5

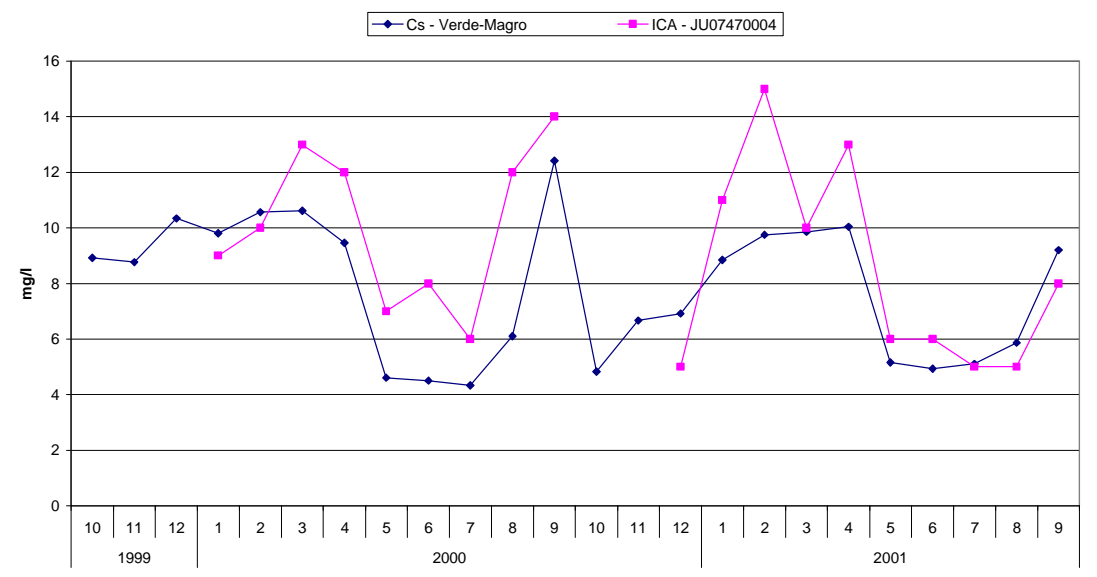

Calibración Verde-Magro. NH4

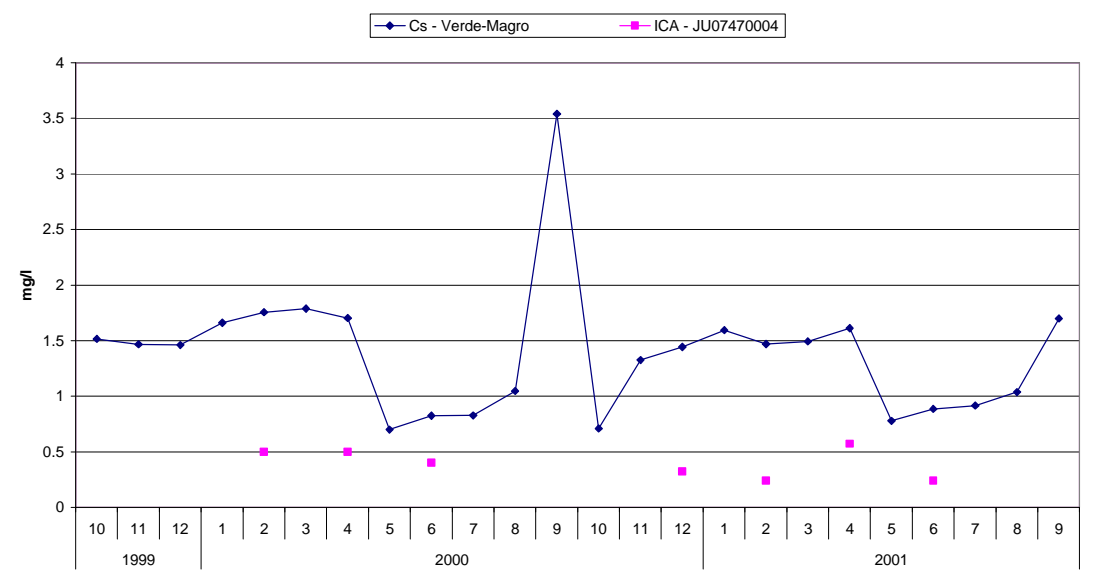

Calibración Verde-Magro. NO2

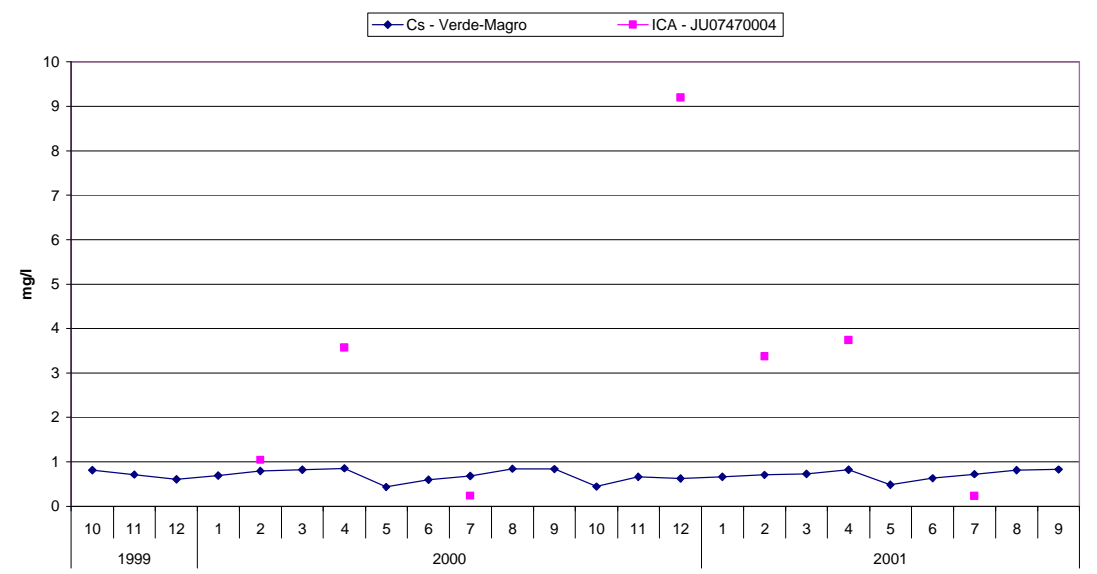


Integración de la modelación de la calidad del agua en un sistema de ayuda a la decisión para la gestión de recursos hídricos.

Calibración Verde-Magro. NO3

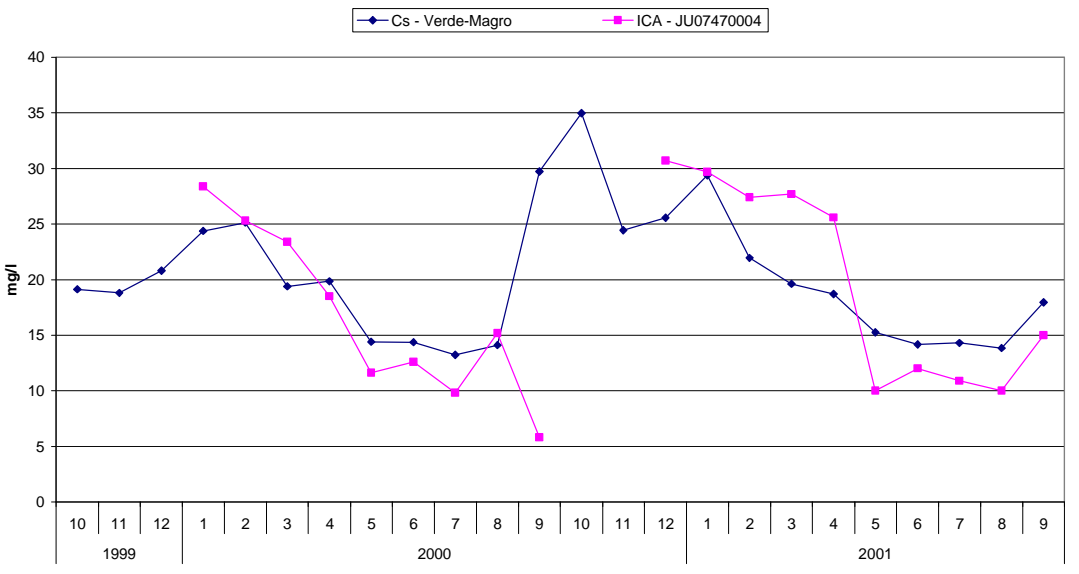

Calibración tramo Verde-Magro. Fósforo Total

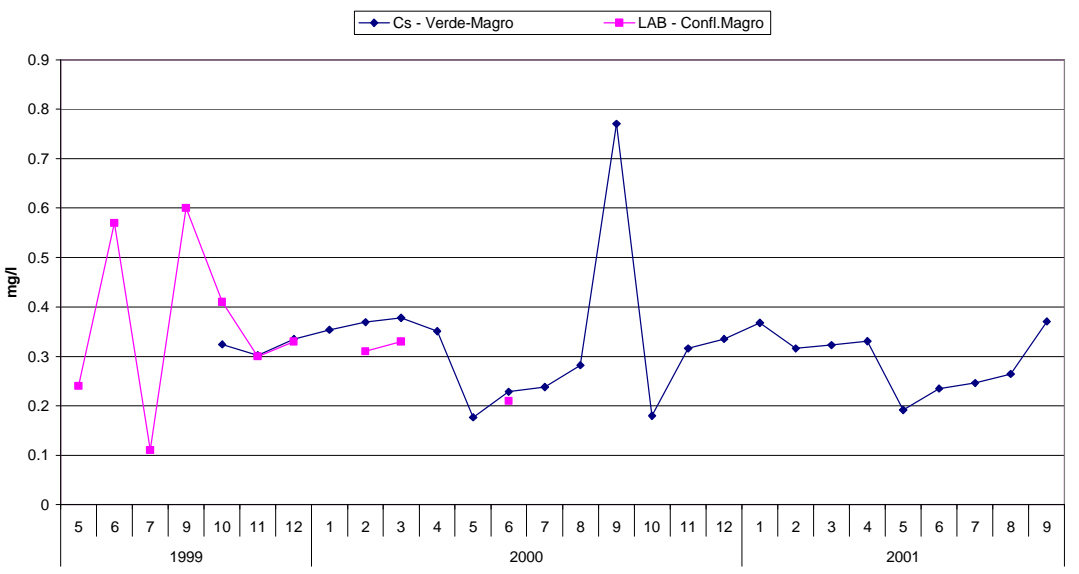


Anejo B. Calibración y análisis de sensibilidad.

Figuras calibración tramo: Magro-Azud de Sueca; Estación Azud de Sueca Laboratorio.

Calibración Magro- Azud Sueca. Conductividad

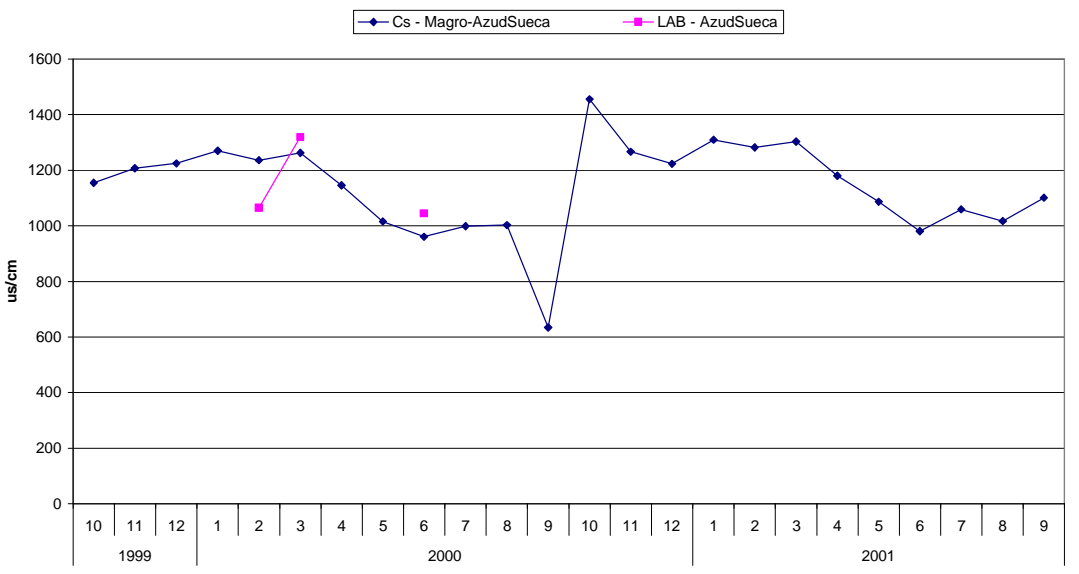

Calibración Magro- Azud Sueca. Sólidos Suspendidos

$\rightarrow-$ Cs - Magro-AzudSueca $\quad-\quad-$ LAB - AzudSueca

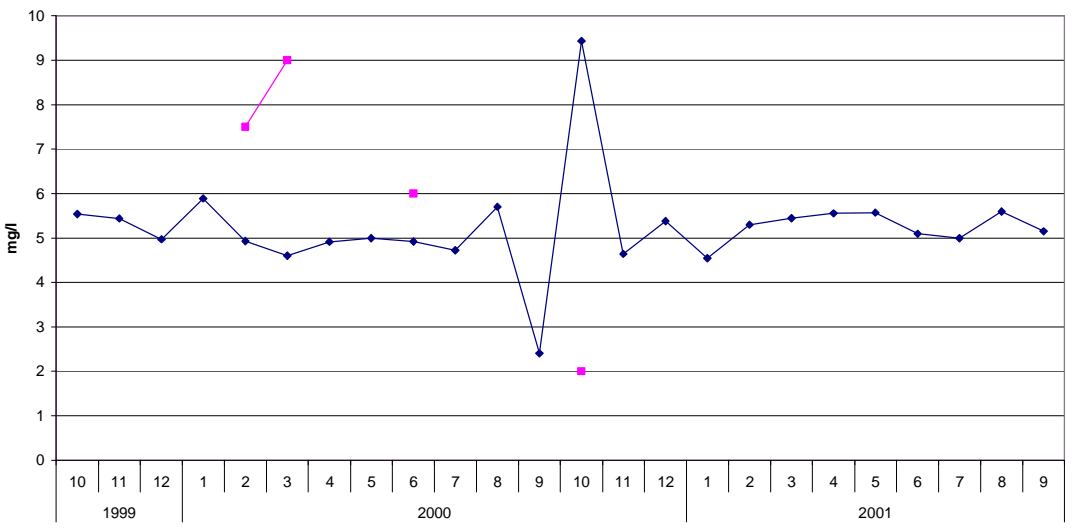

Calibración Magro- Azud Sueca. Oxígeno Disuelto

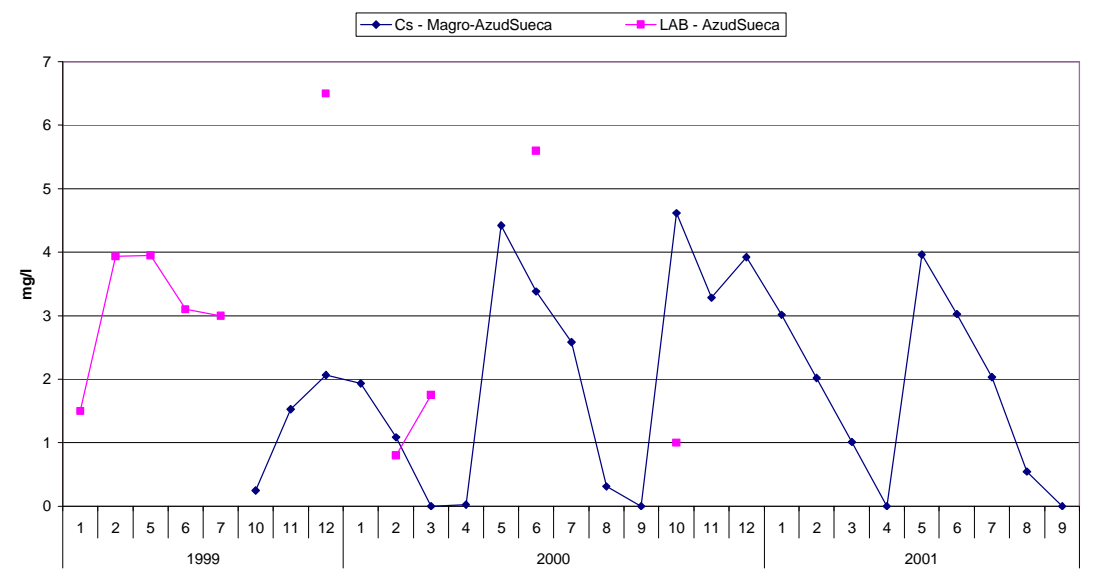


Integración de la modelación de la calidad del agua en un sistema de ayuda a la decisión para la gestión de recursos hídricos.

Calibración Magro- Azud Sueca. DBO5

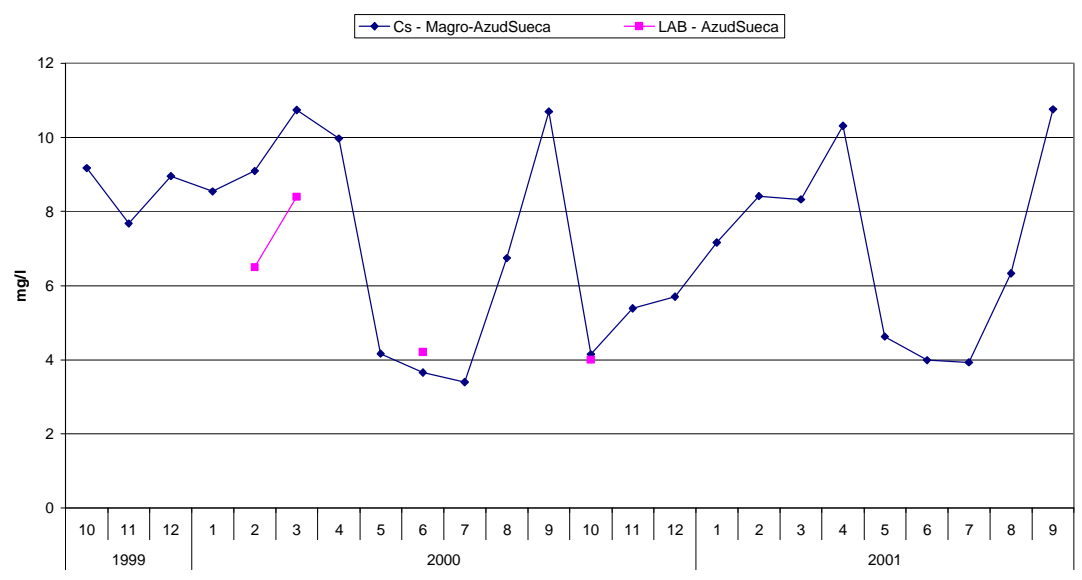

Calibración Magro- Azud Sueca. NH4

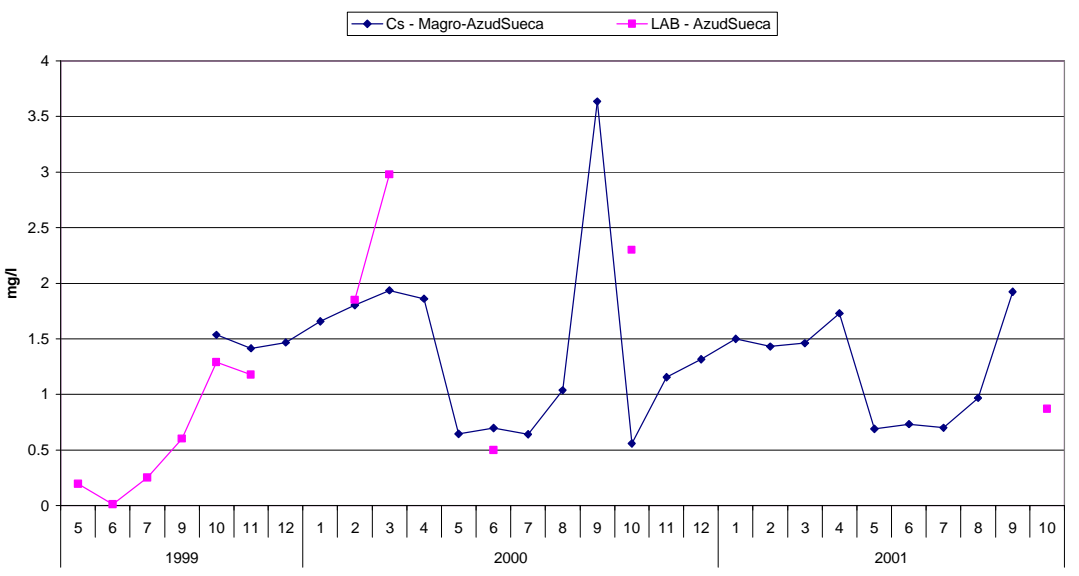

Calibración Magro- Azud Sueca. NO2

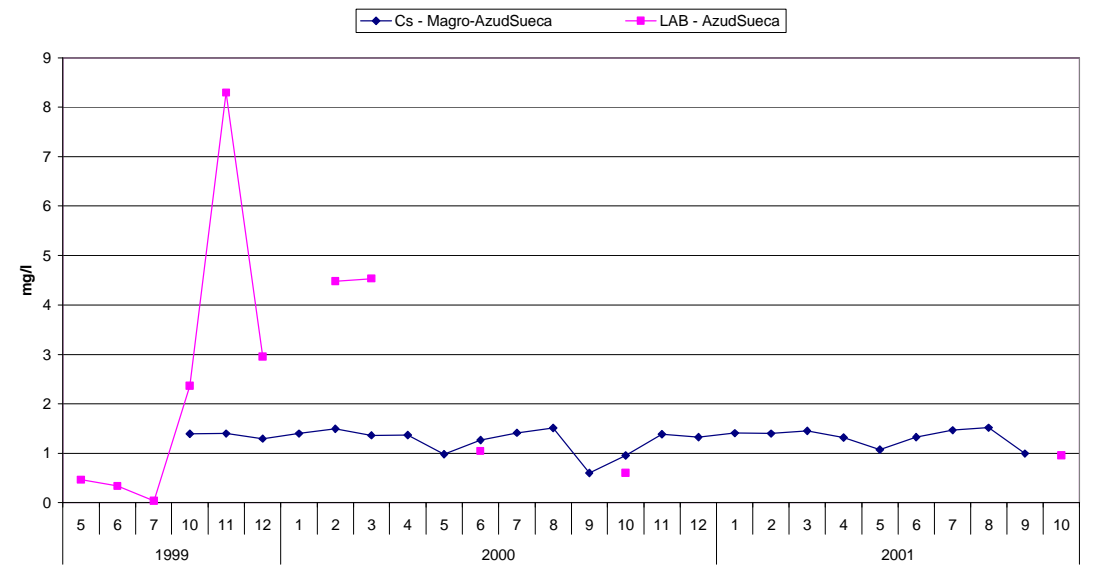


Anejo B. Calibración y análisis de sensibilidad.

Calibración Magro- Azud Sueca. NO3

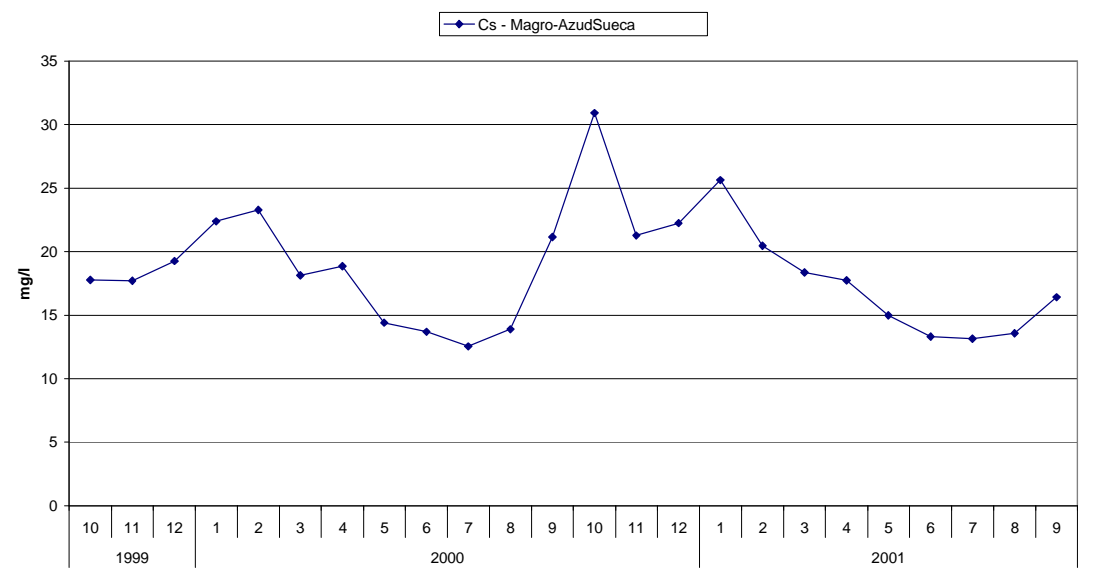

Calibración Magro- Azud Sueca. PTot

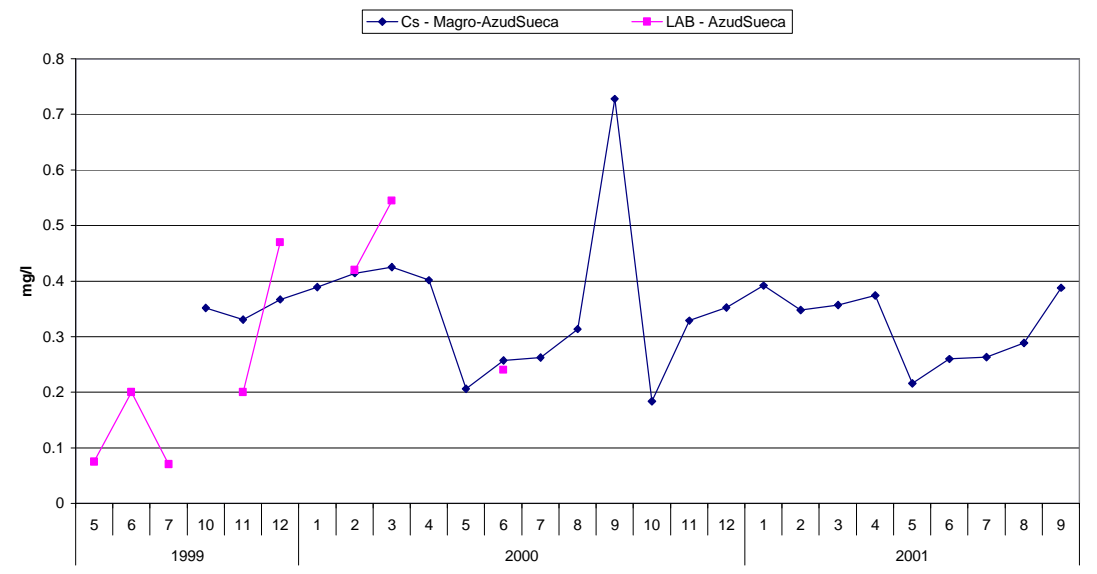


Integración de la modelación de la calidad del agua en un sistema de ayuda a la decisión para la gestión de recursos hídricos.

Figuras calibración tramo Azud de Sueca -Azud de Cullera. Estación Azud de Cullera Laboratorio.

Calibración Az. Sueca - Az. Cullera. Conductividad

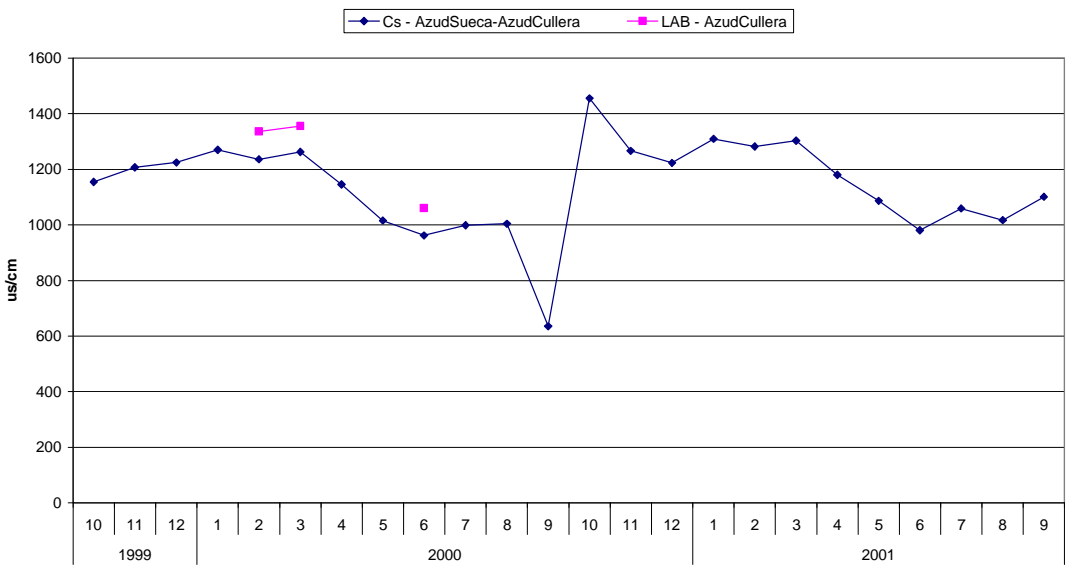

Calibración Az. Sueca - Az. Cullera. Sólidos Suspendidos

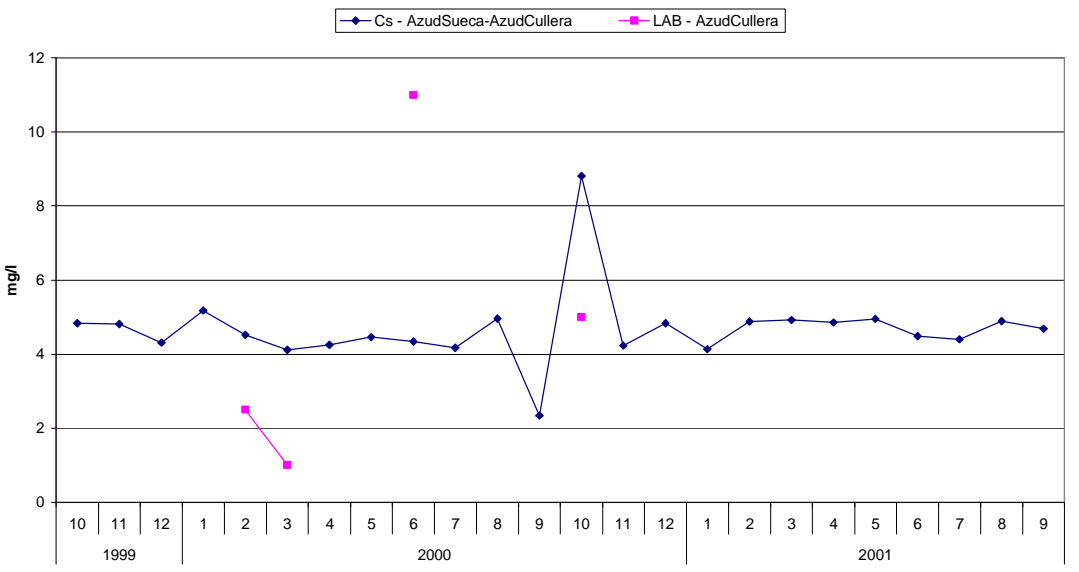

Calibración Az. Sueca - Az. Cullera. Oxígeno Disuelto

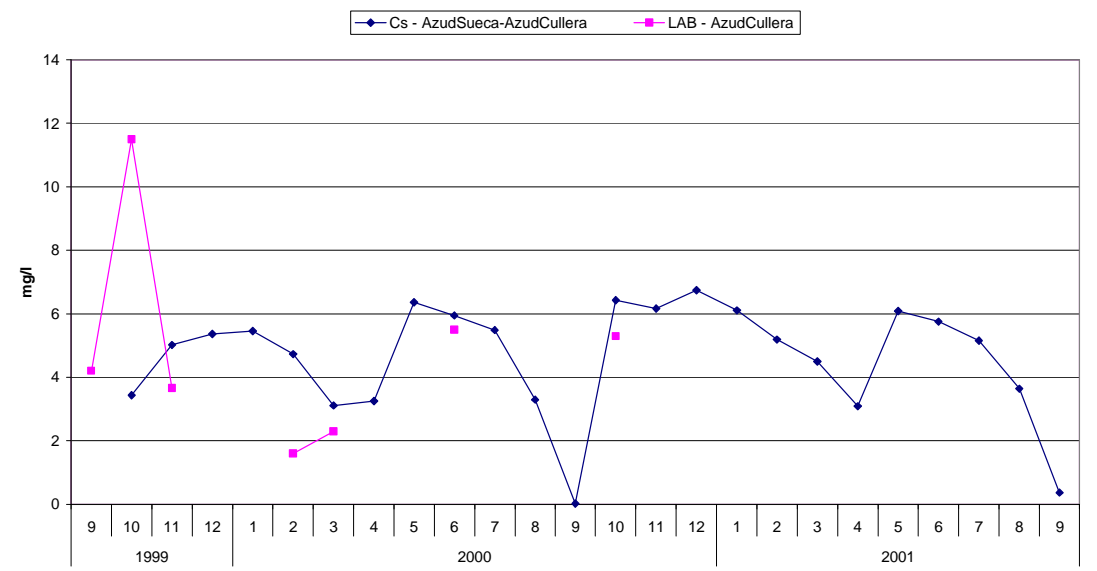


Anejo B. Calibración y análisis de sensibilidad.

Calibración Az. Sueca - Az. Cullera. DBO5

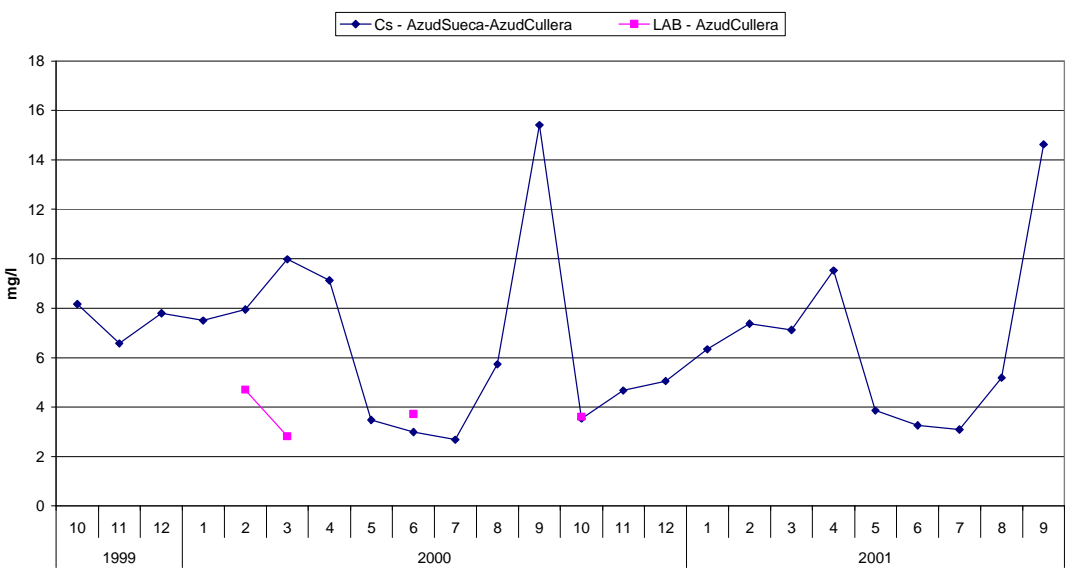

Calibración Az. Sueca - Az. Cullera. NH4

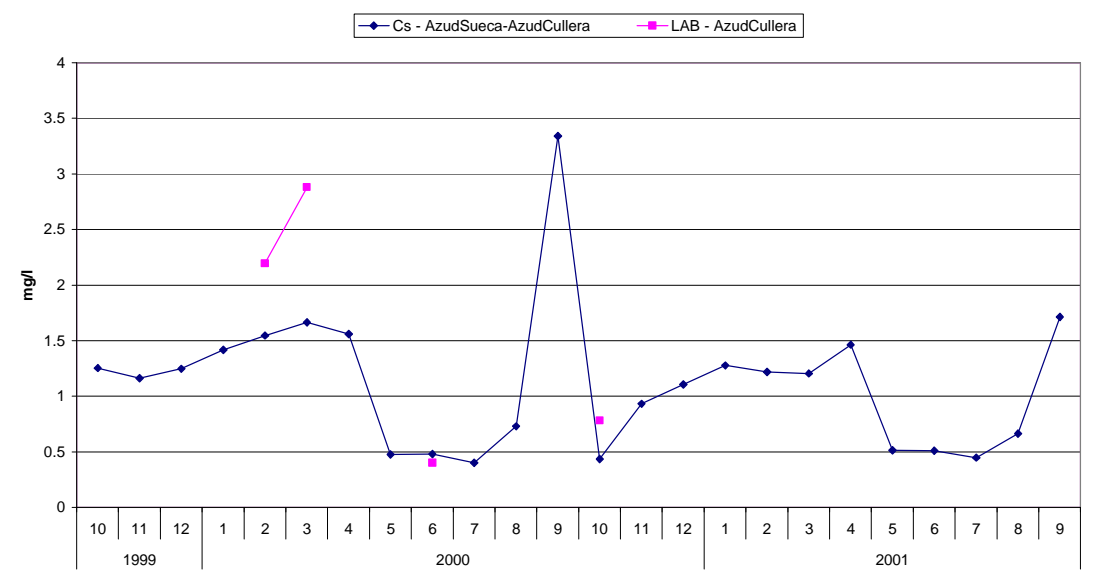

Calibración Az. Sueca - Az. Cullera. NO2

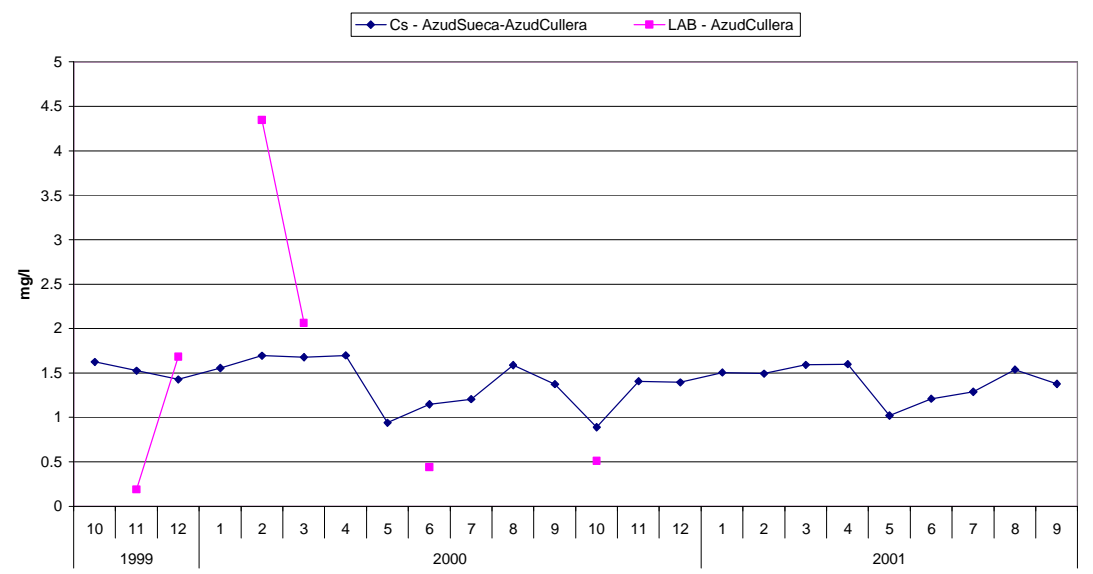


Integración de la modelación de la calidad del agua en un sistema de ayuda a la decisión para la gestión de recursos hídricos.

Calibración Az. Sueca - Az. Cullera. NO3

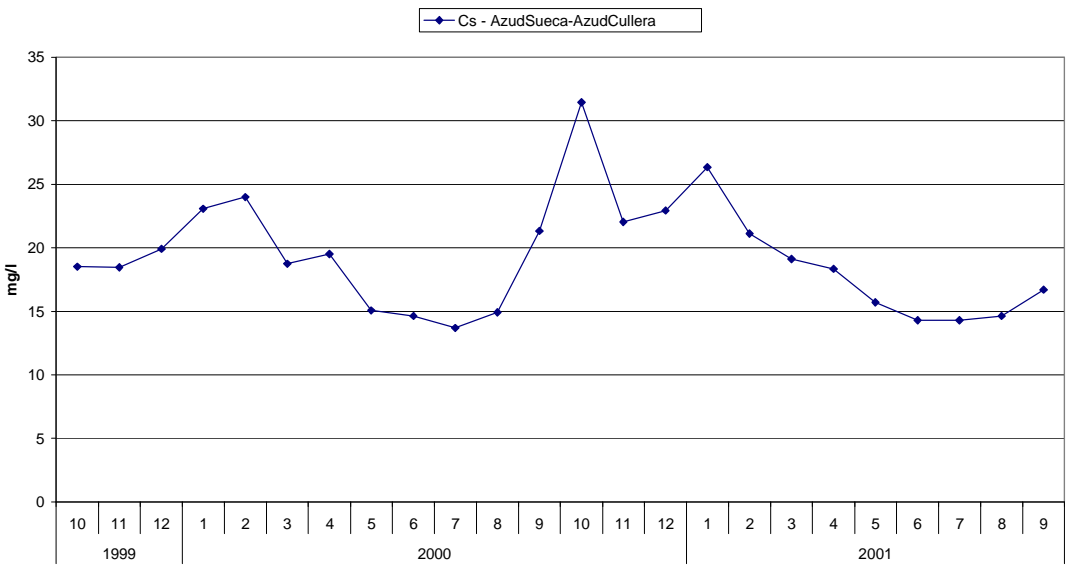

Calibración Az. Sueca - Az. Cullera. PTot

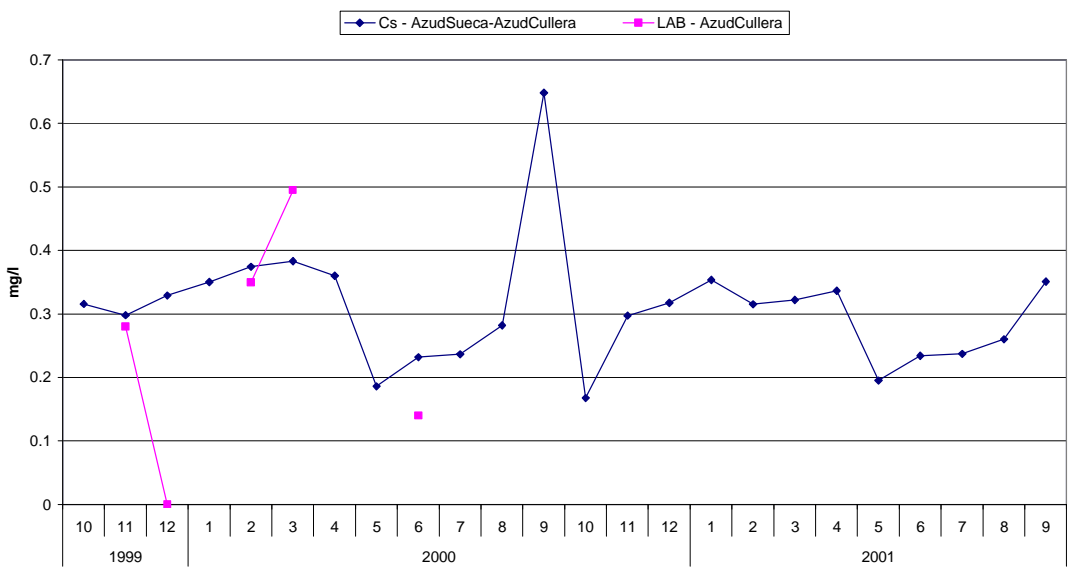


Figuras calibración tramo Azud de Cullera - Azud de la Marquesa. Estación Cullera JU07470001 Calibración Az. Cullera - Az. Marquesa. Condcutividad

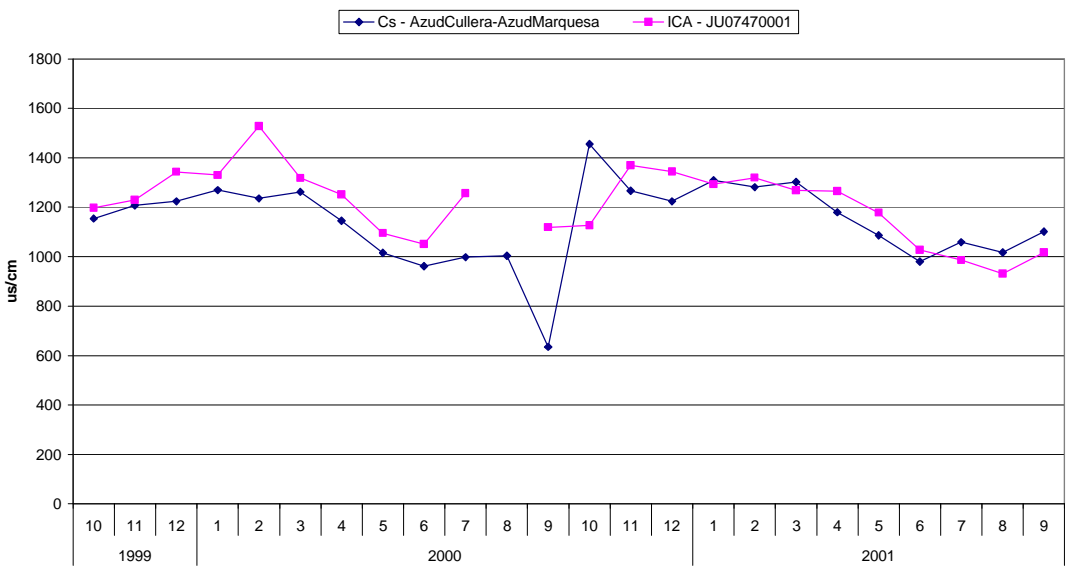

Calibración Az. Cullera - Az. Marquesa. Sólidos Suspendidos

$\rightarrow$ - Cs - AzudCullera-AzudMarquesa $\rightarrow$-ICA - JU07470001

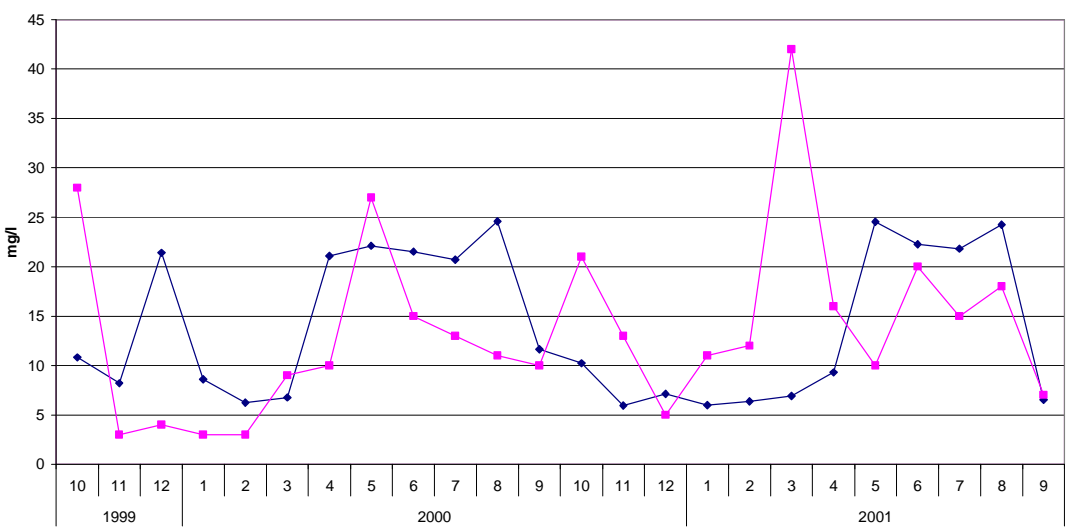

Calibración Az. Cullera - Az. Marquesa. Oxígeno Disuelto

$\rightarrow$ - Cs - AzudCullera-AzudMarquesa $\rightarrow-$ ICA - JU07470001

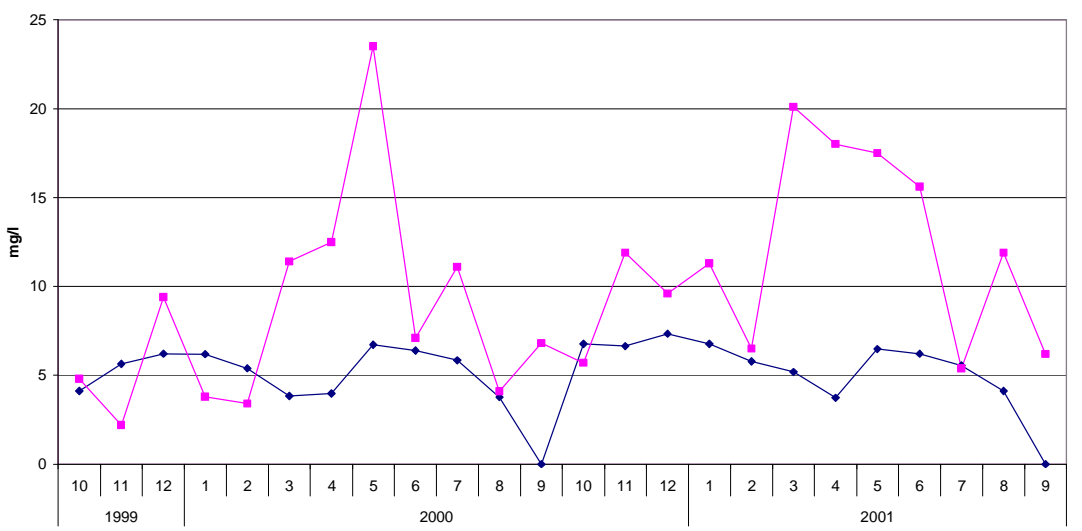


Integración de la modelación de la calidad del agua en un sistema de ayuda a la decisión para la gestión de recursos hídricos.

Calibración Az. Cullera - Az. Marquesa. DBO5

$\rightarrow-$ Cs - AzudCullera-AzudMarquesa $\rightarrow-$ ICA - JU07470001

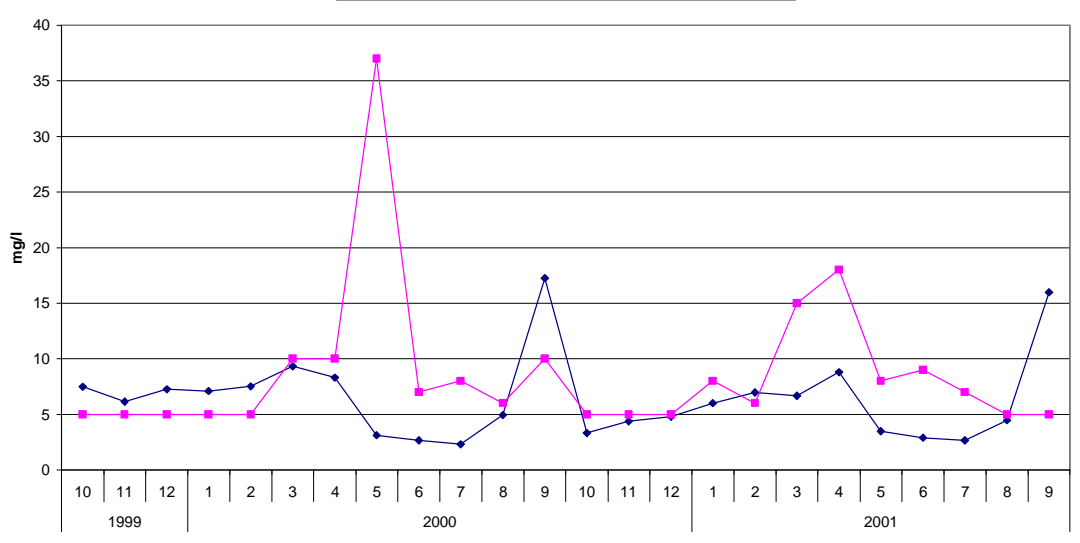

Calibración Az. Cullera - Az. Marquesa. NH4

- - Cs - AzudCullera-AzudMarquesa $\rightarrow$-ICA - JU07470001

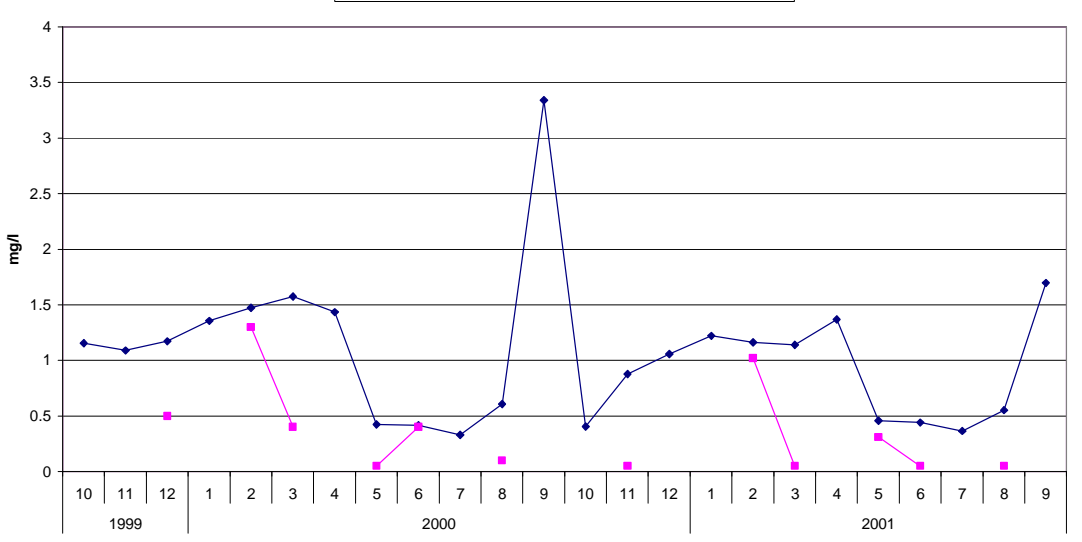

Calibración Az. Cullera - Az. Marquesa. NO2

$\rightarrow$ - Cs - AzudCullera-AzudMarquesa $\rightarrow-$ ICA - JU07470001

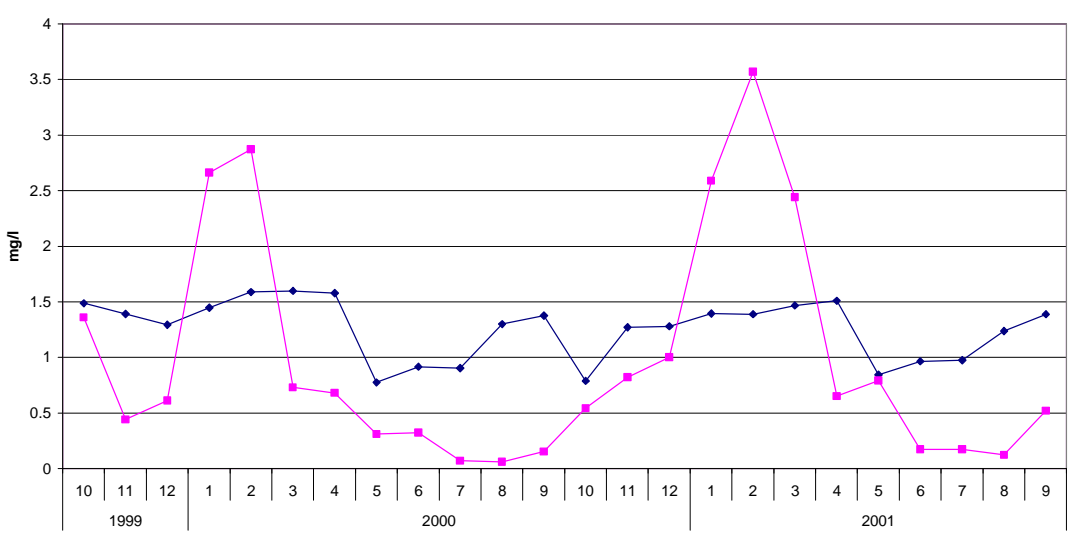


Anejo B. Calibración y análisis de sensibilidad.

Calibración Az. Cullera - Az. Marquesa. NO3

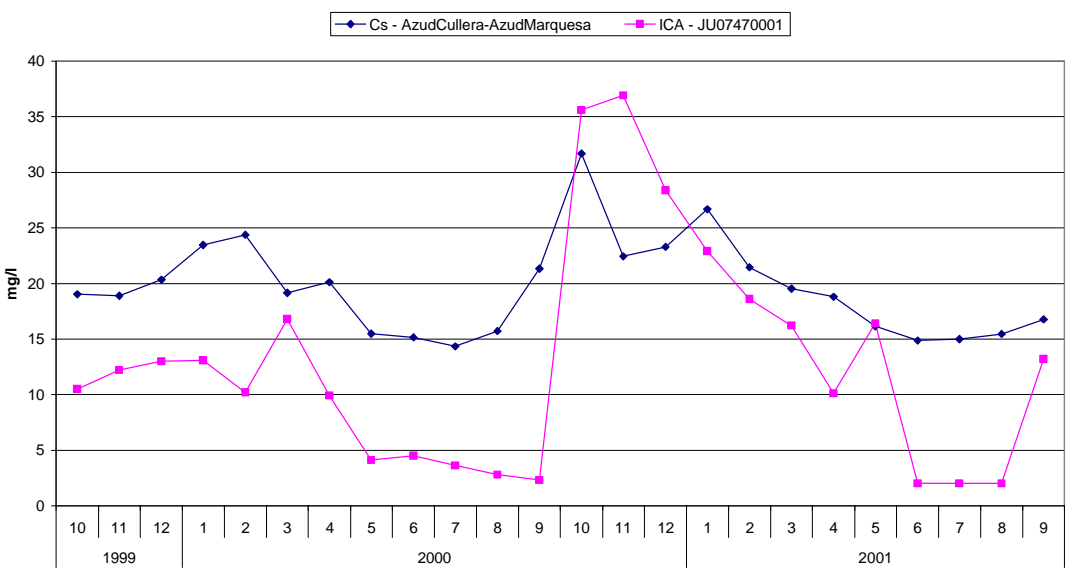

Calibración Az. Cullera - Az. Marquesa. PTot

$-\bullet$ Cs - AzudCullera-AzudMarquesa

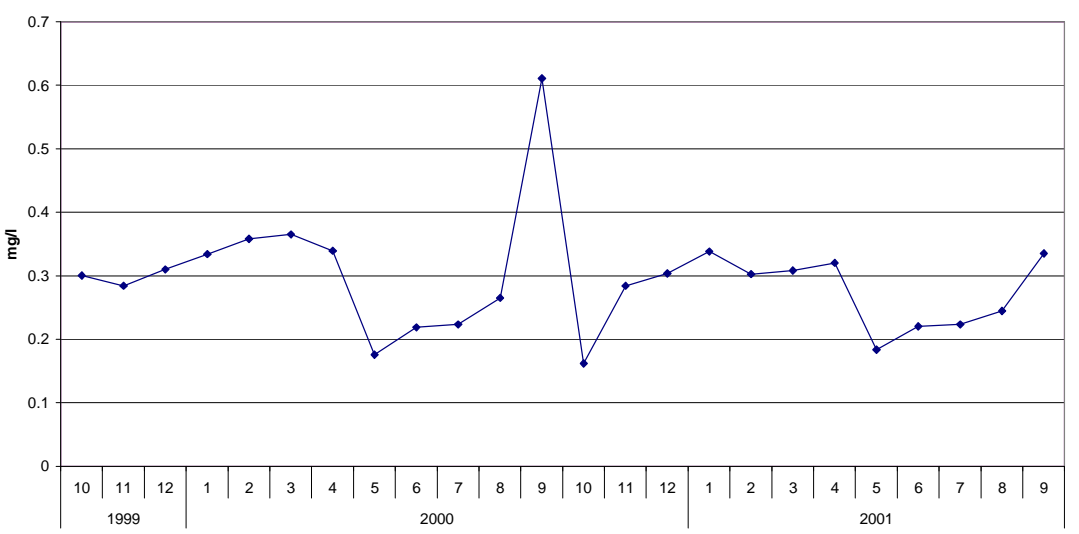




\section{ANÁLISIS DE SENSIBILIDAD DEL SISTEMA}

Análisis Sensibilidad Sólidos Supendidos. $\mathrm{Sx}=(\mathrm{Ax} / \mathrm{x} / \mathrm{Ap} / \mathrm{p})$

\begin{tabular}{|c|c|c|c|c|c|c|}
\hline & Alarcón & Contreras & Cortes & Naranjero & Tous & Molinar \\
\hline Medio & -0.54740518 & -0.95279891 & -0.46964651 & -0.225883359 & 2.41400431 & 2.52103466 \\
\hline Max & -0.20314942 & -0.39617559 & -0.24191773 & -0.240426675 & 2.38815037 & -0.01502398 \\
\hline & Júcar-4 & \multicolumn{5}{|c|}{ Magro-Azud $\leqslant A z$. Sueca-Az Az. Cullera-Az. Marquesa } \\
\hline Medio & -0.69639101 & -1.2702125 & -0.20370818 & $\begin{array}{r}-8.345091667 \\
\end{array}$ & & \\
\hline Max & -0.4690926 & -0.95181983 & -0.0964053 & 1.643228561 & & \\
\hline
\end{tabular}

Análisis Sensibilidad Fósforo Total. Sx=(Ax/x/Ap/p)

\begin{tabular}{|lrrrrrr|}
\multicolumn{1}{l}{ Alarcón } & \multicolumn{1}{c}{ Molinar } & Contreras & Cortes & Naranjero & \multicolumn{1}{l}{ Tous } \\
\hline Medio & 0.00034 & 0.83876846 & 0.000056 & 0.00003 & 0.0000256 & 0.24243173 \\
Max & 0 & 0 & 0 & 0 & 0 & 0.8375 \\
\hline
\end{tabular}

\begin{tabular}{|llllllr|}
\multicolumn{1}{ll}{ Júcar-1 } & Júcar-3 & Júcar-4 & \multicolumn{1}{l}{ Júcar-5 } & \multicolumn{1}{l}{ Júcar-7 } & \multicolumn{1}{c|}{ Cabriel-2 } \\
\hline Medio & -0.06811989 & -0.05769231 & -0.00259002 & -0.03917762 & -0.03352391 & -0.0051006 \\
Max & -0.08602151 & -0.05436014 & -0.00313808 & -0.03464203 & -0.03325416 & -0.00547695 \\
\hline
\end{tabular}

Salida Tous F Antella-Sellen Sellent-Alabid Albaida-Alzira Alzira-Verde Verde-Magro Magro-Azud 〔Az. Sueca-Az Az. Cullera-Az. Marquesa

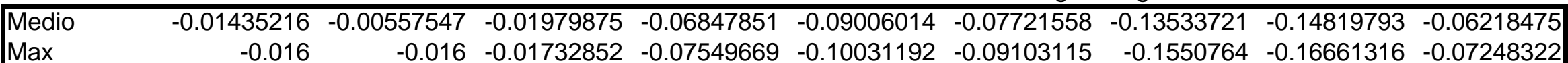


Analisis Sensibilidad.Sx $=(\mathbf{A x} / \mathbf{x} / \mathbf{A p} / \mathbf{p})$

\begin{tabular}{|c|c|c|c|c|c|c|c|c|c|c|c|}
\hline Alarcón & & $\mathrm{Ka}$ & $\mathrm{Kd}$ & Knai & Knio & Contreras & & $\mathrm{Ka}$ & $\mathrm{Kd}$ & Knai & Knio \\
\hline \multirow{5}{*}{ Medio } & OD & 0.002103 & $\overline{0}$ & 0 & 0 & \multirow{5}{*}{ Medio } & OD & 0.000952609 & $\overline{0}$ & 0 & 0 \\
\hline & DBO5 & 0 & 0.000123 & 0 & 0 & & DBO5 & 0 & 0.00012472 & 0 & 0 \\
\hline & $\mathrm{NH} 4$ & 0 & 0 & 0.000972 & 0 & & $\mathrm{NH} 4$ & 0 & 0 & 0.00089165 & 0 \\
\hline & NO2 & 0 & 0 & 0 & $9.63 \mathrm{E}-05$ & & NO2 & 0 & 0 & 0 & $1.17878 \mathrm{E}-05$ \\
\hline & NO3 & 0 & 0 & 0 & 0 & & NO3 & 0 & 0 & 0 & $8.45322 \mathrm{E}-06$ \\
\hline \multirow{5}{*}{ Máximo } & OD & 0.009517 & $\overline{0}$ & 0 & 0 & \multirow{5}{*}{ Máximo } & $\mathrm{OD}$ & -0.000225585 & 0 & $\overline{0}$ & 0 \\
\hline & DBO5 & 0 & 0 & 0 & 0 & & DBO5 & 0 & 0 & 0 & 0 \\
\hline & $\mathrm{NH} 4$ & 0 & 0 & 0 & 0 & & $\mathrm{NH} 4$ & 0 & 0 & 0 & 0 \\
\hline & $\mathrm{NO} 2$ & 0 & 0 & 0 & 0 & & NO2 & 0 & 0 & 0 & 0 \\
\hline & NO3 & 0 & 0 & 0 & 0 & & NO3 & 0 & 0 & 0 & 0 \\
\hline \multirow[t]{2}{*}{ Molinar } & \multicolumn{2}{|r|}{$\mathrm{Ka}$} & \multicolumn{3}{|r|}{ Knio } & Tous & \multicolumn{2}{|r|}{$\mathrm{Ka}$} & \multicolumn{2}{|r|}{ Knai } & Knio \\
\hline & OD & 0.081219 & 0 & 0 & 0 & & OD & -0.003109371 & 0 & 0 & 0 \\
\hline \multirow{4}{*}{ Medio } & DBO5 & 0.189995 & $8.95 \mathrm{E}-05$ & 0 & 0 & \multirow{4}{*}{ Medio } & DBO5 & 0 & 0.000116115 & 0 & 0 \\
\hline & $\mathrm{NH} 4$ & -0.14942 & 0 & 0.00018 & 0 & & $\mathrm{NH} 4$ & 0 & 0 & 0.00029151 & 0 \\
\hline & NO2 & -0.34856 & 0 & 0 & 0.000142 & & NO2 & 0 & 0 & 0 & 0.000761958 \\
\hline & NO3 & 0.205799 & 0 & 0 & $9.84 \mathrm{E}-05$ & & NO3 & 0 & 0 & 0 & 0 \\
\hline \multirow{5}{*}{ Máximo } & OD & 0.013682 & $\overline{0}$ & 0 & 0 & \multirow{5}{*}{ Máximo } & $\mathrm{OD}$ & $-7.83813 \mathrm{E}-05$ & 0 & $\overline{0}$ & $\overline{0}$ \\
\hline & DBO5 & 0 & 0 & 0 & 0 & & DBO5 & 0 & 0.000603027 & 0 & 0 \\
\hline & $\mathrm{NH} 4$ & 0 & 0 & 0 & 0 & & $\mathrm{NH} 4$ & 0 & 0 & 0 & 0 \\
\hline & $\mathrm{NO} 2$ & 0 & 0 & 0 & 0 & & $\mathrm{NO} 2$ & 0 & 0 & 0 & 0 \\
\hline & NO3 & 0 & 0 & 0 & 0 & & NO3 & 0 & 0 & 0 & 0 \\
\hline \multirow[t]{2}{*}{ Cortes } & & $\mathrm{Ka}$ & $\mathrm{Kd}$ & Knai & Knio & Naranjero & \multicolumn{2}{|r|}{$\mathrm{Ka}$} & $\mathrm{Kd}$ & Knai & Knio \\
\hline & OD & $1.36 \mathrm{E}-05$ & 0 & 0 & 0 & & OD & $1.6955 \mathrm{E}-06$ & $\overline{0}$ & 0 & 0 \\
\hline \multirow{4}{*}{ Medio } & DBO5 & 0 & 7.57E-05 & 0 & 0 & \multirow{4}{*}{ Medio } & DBO5 & 0 & 8.88434E-05 & 0 & 0 \\
\hline & $\mathrm{NH} 4$ & 0 & 0 & 0.000411 & 0 & & $\mathrm{NH} 4$ & 0 & 0 & 0.00016349 & 0 \\
\hline & $\mathrm{NO} 2$ & 0 & 0 & 0 & 0.000765 & & $\mathrm{NO} 2$ & 0 & 0 & 0 & $6.7121 \mathrm{E}-05$ \\
\hline & NO3 & 0 & 0 & 0 & & & NO3 & 0 & 0 & 0 & \\
\hline \multirow{5}{*}{ Máximo } & OD & 0 & $\overline{0}$ & 0 & $\overline{0}$ & & OD & 0 & 0 & $\overline{0}$ & 0 \\
\hline & DBO5 & 0 & 0 & 0 & 0 & \multirow{4}{*}{ Máximo } & DBO5 & 0 & 0 & 0 & 0 \\
\hline & $\mathrm{NH} 4$ & 0 & 0 & 0 & 0 & & $\mathrm{NH} 4$ & 0 & 0 & 0 & 0 \\
\hline & $\mathrm{NO} 2$ & 0 & 0 & 0 & 0 & & $\mathrm{NO} 2$ & 0 & 0 & 0 & 0 \\
\hline & NO3 & 0 & 0 & 0 & 0 & & NO3 & 0 & 0 & 0 & 0 \\
\hline
\end{tabular}


Analisis Sensibilidad.Sx $=(\mathbf{A x} / \mathbf{x} / \mathbf{A p} / \mathbf{p})$

\begin{tabular}{|lcrrrr|}
\hline \multirow{4}{*}{ Júcar-1 } & \multicolumn{1}{c}{ Ka } & \multicolumn{1}{c}{ Kd } & \multicolumn{1}{c|}{ Knai } & \multicolumn{1}{c|}{ Knio } \\
\hline \multirow{4}{*}{ Medio } & OD & $-4.6 \mathrm{E}-05$ & -0.0001 & $-2.4 \mathrm{E}-06$ & $-4.8 \mathrm{E}-06$ \\
& $\mathrm{DBO5}$ & 0 & -0.00058 & 0 & 0 \\
& $\mathrm{NH} 4$ & 0 & 0 & -0.00084 & 0 \\
& $\mathrm{NO} 2$ & 0 & 0 & 0.003696 & -0.02302 \\
& $\mathrm{NO3}$ & 0 & 0 & 0 & 0.000531 \\
\hline \multirow{4}{*}{ Máximo } & $\mathrm{OD}$ & 0.001641 & $-4.9 \mathrm{E}-05$ & 0 & 0 \\
& $\mathrm{DBO5}$ & 0 & -0.00055 & 0 & 0 \\
& $\mathrm{NH} 4$ & 0 & 0 & 0 & 0 \\
& $\mathrm{NO} 2$ & 0 & 0 & 0.012793 & -0.02575 \\
& $\mathrm{NO3}$ & 0 & 0 & 0 & 0.000352 \\
\hline
\end{tabular}

\begin{tabular}{|lcrrrr|} 
Júcar-4 & & \multicolumn{1}{c}{ Ka } & \multicolumn{1}{c}{ Kd } & \multicolumn{1}{c}{ Knai } & \multicolumn{1}{c|}{ Knio } \\
\hline \multirow{4}{*}{ Medio } & OD & 0.005691 & -0.17407 & -0.0078 & -0.00112 \\
& DBO5 & 0 & -0.13742 & 0 & 0 \\
& NH4 & -0.00021 & 0.002986 & -0.19269 & 0 \\
& NO2 & 0.00031 & -0.0031 & 0.521493 & -0.33801 \\
& NO3 & 0 & $-5.7 \mathrm{E}-05$ & 0.012655 & 0.014169 \\
\hline \multirow{4}{*}{ Máximo } & OD & 0.004255 & -0.14497 & -0.00581 & -0.00065 \\
& DBO5 & 0 & -0.1109 & 0 & 0 \\
& NH4 & 0 & 0 & -0.18762 & 0 \\
& NO2 & 0 & -0.00481 & 0.55814 & -0.39453 \\
& NO3 & 0 & $-3.1 \mathrm{E}-05$ & 0.000648 & 0.013367 \\
\hline
\end{tabular}

\begin{tabular}{|rcrrrr|}
\multicolumn{1}{c}{ Júcar-7 } & Ka & \multicolumn{1}{c}{ Kd } & Knai & \multicolumn{1}{c|}{ Knio } \\
\hline \multirow{4}{*}{ Medio } & OD & 0 & -0.00017 & 0 & 0 \\
& DBO5 & 0 & -0.00018 & 0 & 0 \\
& NH4 & 0 & 0 & 0 & 0 \\
& NO2 & 0 & 0 & 0.001126 & -0.00282 \\
& NO3 & 0 & 0 & 0 & $1.44 \mathrm{E}-05$ \\
\hline \multirow{3}{*}{ Máximo } & OD & 0 & -0.00016 & 0 & 0 \\
& DBO5 & 0 & -0.00023 & 0 & 0 \\
& NH4 & 0 & 0 & 0 & 0 \\
& NO2 & 0 & 0 & 0 & -0.00908 \\
& NO3 & 0 & 0 & 0 & 0 \\
\hline
\end{tabular}

\begin{tabular}{|lcrrrr|} 
Júcar-3 & & \multicolumn{1}{c}{ Ka } & \multicolumn{1}{c}{ Kd } & \multicolumn{1}{c|}{ Knai } \\
\hline \multirow{4}{*}{ Medio } & OD & -0.1008954 & -0.103218202 & -0.00272704 & -0.000400068 \\
& DBO5 & 0 & -0.238109266 & 0 & 0 \\
& NH4 & 0.00293255 & 0.004031519 & -0.35668955 & 0 \\
& NO2 & -0.00135095 & -0.002251914 & 0.65673238 & -0.489368609 \\
& NO3 & $-8.7543 E-05$ & -0.000147443 & 0.00440611 & 0.00625502 \\
\hline \multirow{4}{*}{ Máximo } & OD & -0.08158742 & -0.093625979 & -0.00188313 & -0.000228195 \\
& DBO5 & 0 & -0.186135747 & 0 & 0 \\
& NH4 & 0 & 0 & -0.31509847 & 0 \\
& NO2 & 0 & 0 & 0.6615215 & -0.516823688 \\
& NO3 & 0 & $-7.83249 E-05$ & 0.00203573 & 0.00313132 \\
\hline
\end{tabular}

\begin{tabular}{|lcrrrr|}
\multicolumn{1}{c}{ Júcar-5 } & \multicolumn{1}{c}{ Ka } & \multicolumn{1}{c}{ Kd } & \multicolumn{1}{c|}{ Knai } & \multicolumn{1}{c|}{ Knio } \\
\hline \multirow{4}{*}{ Medio } & OD & 0.00075872 & -0.003128564 & -0.00067232 & -0.000147693 \\
& DBO5 & 0 & -0.003088201 & 0 & 0 \\
& NH4 & 0 & 0 & -0.02163355 & 0 \\
& NO2 & 0 & 0 & 0.07477763 & -0.052669405 \\
& NO3 & 0 & 0 & $1.4275 \mathrm{E}-05$ & 0.000413952 \\
\hline \multirow{4}{*}{ Máximo } & OD & 0.00026019 & -0.002446897 & -0.0004684 & -0.000104083 \\
& DBO5 & 0 & -0.002423263 & 0 & 0 \\
& NH4 & 0 & 0 & -0.01943005 & 0 \\
& NO2 & 0 & 0 & 0.10084034 & -0.062176166 \\
& NO3 & 0 & 0 & 0 & 0.000218708 \\
\hline
\end{tabular}

\begin{tabular}{|c|c|c|c|c|c|}
\hline Cabriel-2 & & $\mathrm{Ka}$ & $\mathrm{Kd}$ & Knai & Knio \\
\hline \multirow{5}{*}{ Medio } & OD & -0.0008568 & -0.155603425 & $-5.245 E-05$ & $-5.24503 E-05$ \\
\hline & DBO5 & 0 & -0.637973664 & 0 & 0 \\
\hline & $\mathrm{NH} 4$ & 0 & 0.734576758 & -0.00368073 & -0.003680731 \\
\hline & NO2 & 0 & 0.205992509 & 0.01836636 & 0.018366361 \\
\hline & NO3 & 0 & -1.741240108 & 0 & 0 \\
\hline \multirow{5}{*}{ Máximo } & OD & -0.00569062 & -0.019869124 & $-4.7377 \mathrm{E}-05$ & $-4.73773 \mathrm{E}-05$ \\
\hline & DBO5 & 0 & -0.024729135 & 0 & 0 \\
\hline & $\mathrm{NH} 4$ & 0 & 0 & -0.00294262 & -0.002942619 \\
\hline & NO2 & 0 & 0 & 0.01769912 & 0.017699115 \\
\hline & $\mathrm{NO} 3$ & 0 & 0 & 0 & 0 \\
\hline
\end{tabular}


Analisis Sensibilidad.Sx $=(\mathrm{Ax} / \mathrm{x} / \mathrm{Ap} / \mathrm{p})$

\begin{tabular}{|lcrrrr|} 
Salida Tous Río & \multicolumn{2}{c}{ Ka } & Kd & \multicolumn{1}{c|}{ Knai } & \multicolumn{1}{c|}{ Knio } \\
\hline \multirow{4}{*}{ Medio } & OD & 0.011544 & -0.01347 & -0.00093 & -0.00021 \\
& DBO5 & 0 & -0.01332 & 0 & 0 \\
& $\mathrm{NH} 4$ & 0 & 0 & -0.05151 & 0 \\
& $\mathrm{NO} 2$ & 0 & 0 & 0.168813 & -0.1262 \\
& $\mathrm{NO3}$ & 0.860278 & $-3.6 \mathrm{E}-06$ & $9.3 \mathrm{E}-05$ & 0.001105 \\
\hline \multirow{4}{*}{ Máximo } & $\mathrm{OD}$ & 0.007223 & -0.01004 & -0.00033 & -0.00011 \\
& $\mathrm{DBO} 5$ & 0 & -0.01156 & 0 & 0 \\
& $\mathrm{NH} 4$ & 0 & 0 & -0.03659 & 0 \\
& $\mathrm{NO} 2$ & 0 & 0 & 0.150888 & -0.1493 \\
& $\mathrm{NO3}$ & 0.801841 & 0.00366 & 0.00372 & 0.00408 \\
\hline
\end{tabular}

\begin{tabular}{|lcrrrr|} 
Sellent - Albaida & & Ka & \multicolumn{1}{c}{ Kd } & \multicolumn{1}{c}{ Knai } & \multicolumn{1}{c|}{ Knio } \\
\hline \multirow{4}{*}{ Medio } & OD & 0 & -0.03169 & -0.00527 & -0.00054 \\
& DBO5 & 0 & -0.02063 & 0 & 0 \\
& $\mathrm{NH} 4$ & 0.000934 & 0.001495 & -0.13317 & 0.000934 \\
& $\mathrm{NO} 2$ & -0.00232 & -0.00258 & 0.395888 & -0.15264 \\
& $\mathrm{NO3}$ & $-2.5 \mathrm{E}-05$ & $-3.2 \mathrm{E}-05$ & 0.000559 & 0.002377 \\
\hline \multirow{4}{*}{ Máximo } & $\mathrm{OD}$ & 0 & -0.01769 & -0.00284 & -0.00035 \\
& $\mathrm{DBO5}$ & 0 & -0.02005 & 0 & 0 \\
& $\mathrm{NH} 4$ & 0 & 0 & -0.12809 & 0 \\
& $\mathrm{NO} 2$ & 0 & 0 & 0.482721 & -0.17402 \\
& $\mathrm{NO3}$ & 0 & 0 & 0.000467 & 0.002021 \\
\hline
\end{tabular}

\begin{tabular}{|lcrrrr|} 
Alzira-Verde & & \multicolumn{1}{l}{ Ka } & \multicolumn{1}{c}{ Kd } & \multicolumn{1}{c|}{ Knai } & \multicolumn{1}{c|}{ Knio } \\
\hline \multirow{4}{*}{ Medio } & OD & 0.01919 & -1.80826 & -0.13115 & -0.00075 \\
& DBO5 & -0.00034 & -0.10918 & 0.0029 & 0 \\
& $\mathrm{NH} 4$ & -0.00036 & 0.034832 & -0.09818 & $1.5 \mathrm{E}-05$ \\
& $\mathrm{NO} 2$ & 0.002768 & -0.29613 & 0.698043 & -0.01442 \\
& $\mathrm{NO3}$ & $1.26 \mathrm{E}-06$ & -0.00025 & 0.00025 & 0.000496 \\
\hline \multirow{4}{*}{ Máximo } & $\mathrm{OD}$ & 0.004544 & -0.47052 & -0.03328 & -0.00029 \\
& $\mathrm{DBO5}$ & 0.001646 & -0.00459 & 0.008518 & 0 \\
& $\mathrm{NH} 4$ & -0.00051 & 0.056165 & -0.06516 & 0 \\
& $\mathrm{NO2}$ & 0.006918 & -0.72832 & 0.66507 & -0.00925 \\
& $\mathrm{NO3}$ & 0 & -0.00015 & 0.000188 & 0.000394 \\
\hline
\end{tabular}

\begin{tabular}{|c|c|c|c|c|c|}
\hline Antella-Sellent & & $\mathrm{Ka}$ & $\mathrm{Kd}$ & Knai & Knio \\
\hline \multirow{5}{*}{ Medio } & OD & $8.8253 \mathrm{E}-05$ & -0.013288311 & -0.00091124 & -0.000199877 \\
\hline & DBO5 & 0 & -0.013338363 & 0 & 0 \\
\hline & $\mathrm{NH} 4$ & 0 & 0 & -0.05159512 & 0 \\
\hline & NO2 & 0 & -0.000543626 & 0.1675033 & -0.127116292 \\
\hline & NO3 & 0 & 0 & $9.2997 \mathrm{E}-05$ & 0.001101477 \\
\hline \multirow{5}{*}{ Máximo } & OD & $5.4812 \mathrm{E}-05$ & -0.009882418 & -0.00032889 & -0.000109626 \\
\hline & DBO5 & 0 & -0.011563877 & 0 & 0 \\
\hline & $\mathrm{NH} 4$ & 0 & 0 & -0.03663004 & 0 \\
\hline & NO2 & 0 & 0 & 0.15088757 & -0.149300156 \\
\hline & NO3 & 0 & 0 & 0 & 0.000359996 \\
\hline Albaida-Alzira & & $\mathrm{Ka}$ & $\mathrm{Kd}$ & Knai & Knio \\
\hline \multirow{5}{*}{ Medio } & OD & 0.00606759 & -0.125803133 & -0.0203939 & -0.002804104 \\
\hline & DBO5 & 0 & -0.060669293 & 0 & 0 \\
\hline & $\mathrm{NH} 4$ & -0.00033789 & 0.004726536 & -0.42842921 & 0.000168933 \\
\hline & NO2 & 0 & -0.00308634 & 0.60457698 & -0.454633445 \\
\hline & NO3 & 5.6719E-06 & $-8.1676 \mathrm{E}-05$ & 0.00257506 & 0.004181787 \\
\hline \multirow{5}{*}{ Máximo } & OD & -0.00561104 & -0.100427472 & -0.01539931 & -0.002467566 \\
\hline & DBO5 & 0 & -0.057639691 & 0 & 0 \\
\hline & $\mathrm{NH} 4$ & -0.00253378 & 0.002531646 & -0.4375 & 0 \\
\hline & NO2 & 0 & -0.004397215 & 0.60098847 & -0.497224425 \\
\hline & NO3 & 0 & $-4.94022 E-05$ & 0.00169565 & 0.003423239 \\
\hline Verde-Magro & & $\mathrm{Ka}$ & $\mathrm{Kd}$ & Knai & Knio \\
\hline \multirow{5}{*}{ Medio } & $\overline{O D}$ & 0.02689598 & -0.53095548 & -0.08574662 & -0.001072506 \\
\hline & DBO5 & 0.00015253 & -0.042710233 & 0.00026959 & 0 \\
\hline & $\mathrm{NH} 4$ & -0.00042845 & 0.008031816 & -0.07195057 & 0 \\
\hline & NO2 & 0.00177017 & -0.038484628 & 0.32959286 & -0.014161186 \\
\hline & NO3 & 2.6622E-06 & $-8.51901 \mathrm{E}-05$ & 0.00011181 & 0.000665465 \\
\hline \multirow{5}{*}{ Máximo } & $\overline{O D}$ & 0.00741198 & -0.15899445 & -0.02929688 & -0.000424096 \\
\hline & DBO5 & 0.00307192 & 0 & 0 & 0 \\
\hline & $\mathrm{NH} 4$ & 0 & 0 & 0 & 0 \\
\hline & NO2 & 0 & 0 & 0.20202726 & 0 \\
\hline & $\mathrm{NO} 3$ & 0 & $-1.73398 E-05$ & 5.2019E-05 & 0.000260086 \\
\hline
\end{tabular}


Analisis Sensibilidad.Sx $=(\mathbf{A x} / \mathbf{x} / \mathbf{A p} / \mathrm{p})$

\begin{tabular}{|c|c|c|c|c|c|}
\hline \multicolumn{2}{|c|}{ Magro-Azud Sueca } & $\mathrm{Ka}$ & $\mathrm{Kd}$ & Knai & Knio \\
\hline \multirow{5}{*}{ Medio } & OD & 0.296327 & -2.60364 & -0.57746 & -0.04561 \\
\hline & DBO5 & -0.00168 & -0.01706 & 0.016599 & 0.000459 \\
\hline & $\mathrm{NH} 4$ & -0.0119 & 0.116867 & -0.14991 & 0.00177 \\
\hline & NO2 & 0.025403 & -0.26997 & 0.391942 & -0.12297 \\
\hline & NO3 & 0.000881 & -0.00843 & 0.001264 & 0.010241 \\
\hline \multirow{5}{*}{ Máximo } & OD & 0.090814 & -1.14735 & -0.22102 & -0.01937 \\
\hline & DBO5 & 0.016657 & 0 & 0 & 0 \\
\hline & $\mathrm{NH} 4$ & 0 & 0 & -0.00033 & 0 \\
\hline & NO2 & 0.030576 & -0.30848 & 0.369931 & -0.10008 \\
\hline & NO3 & 0.000137 & -0.00167 & 0.002118 & 0.007741 \\
\hline
\end{tabular}

\begin{tabular}{|c|c|c|c|c|c|}
\hline \multicolumn{2}{|c|}{ Az Sueca-Az Cullera } & $\mathrm{Ka}$ & $\mathrm{Kd}$ & Knai & Knio \\
\hline \multirow{5}{*}{ Medio } & $\mathrm{OD}$ & -1.03578862 & -0.408159471 & -0.05841378 & -0.015947019 \\
\hline & DBO5 & -0.03451518 & -0.202731752 & 0 & 0 \\
\hline & $\mathrm{NH} 4$ & 0.1581552 & 0.11353834 & -0.27970918 & 0.00141751 \\
\hline & NO2 & -0.1242 & -0.122868735 & 0.3500542 & -0.452475209 \\
\hline & NO3 & -0.01590623 & -0.007642052 & 0.0102909 & 0.043416099 \\
\hline \multirow{5}{*}{ Máximo } & OD & -0.60930916 & -0.296587886 & -0.05222385 & -0.012837276 \\
\hline & DBO5 & -0.34641833 & 0 & 0 & \\
\hline & $\mathrm{NH} 4$ & 0.56965323 & 0.532564747 & -0.06436169 & 0.002517306 \\
\hline & NO2 & 0.02342573 & 0.012739565 & 0.36743061 & -0.463626493 \\
\hline & $\mathrm{NO} 3$ & -0.00179174 & -0.00077051 & 0.00321474 & 0.016556546 \\
\hline
\end{tabular}

Az. Cullera-Az. Marquesa
\begin{tabular}{|lcrrrr|}
\hline \multirow{4}{*}{ Ka } & \multicolumn{1}{c}{ Kd } & \multicolumn{1}{c}{ Knai } & \multicolumn{1}{c|}{ Knio } \\
\hline \multirow{4}{*}{ OD } & -0.38646 & -0.22373 & -0.02301 & -0.01318 \\
& DBO5 & -0.01864 & -0.0847 & 0 & 0 \\
& $\mathrm{NH} 4$ & 0.004329 & 0.002667 & -0.08222 & 0.000287 \\
& $\mathrm{NO} 2$ & 0.008251 & 0.005029 & 0.128586 & -0.29858 \\
& $\mathrm{NO3}$ & -0.00074 & -0.00018 & 0.002444 & 0.025345 \\
\hline \multirow{4}{*}{ Máximo } & $\mathrm{OD}$ & -0.27925 & -0.15036 & -0.01695 & -0.00941 \\
& $\mathrm{DBO5}$ & -0.13044 & 0 & 0 & 0 \\
& $\mathrm{NH} 4$ & 0.00018 & 0.00018 & -0.00018 & 0 \\
& $\mathrm{NO} 2$ & 0.015689 & 0.009959 & 0.140136 & -0.28198 \\
& $\mathrm{NO3}$ & $-9.6 \mathrm{E}-05$ & $-1.9 \mathrm{E}-05$ & 0.000421 & 0.007885 \\
\hline
\end{tabular}



